\title{
Temporary expansion to shelf depths rather than an onshore-offshore trend: the shallow-water rise and demise of the modern deep-sea brittle star family Ophiacanthidae (Echinodermata: Ophiuroidea)
}

\author{
Ben THUY \\ Musée national d'histoire naturelle du Luxembourg, section Paléontologie, \\ 24 rue Münster, L-2160 Luxembourg \\ Email:nebyuht@yahoo.com \\ urn:1sid:zoobank.org:author:04186A8C-3F0D-485E-834A-08414A217ACA
}

\begin{abstract}
Hypotheses on the age and possible antiquity of the modern deep-sea fauna put forward to date almost all agree on the assumption that the deep-sea fauna is largely the result of colonisation from shallow-water environments. Here, the fossil record of the Ophiacanthidae, a modern deep-sea brittle star family with extensive fossil occurrences at shelf depths, is systematically traced against a calibrated phylogeny. Several lines of evidence suggest that the Ophiacanthidae originated and greatly diversified in the deep sea, with most extant clades having diverged by the end of the Triassic at the latest. During the Jurassic, the family temporarily invaded shelf environments, attaining relative abundances and diversities comparable to those found in coeval and modern deep-sea settings, and gradually declined in abundance subsequently, to become largely restricted to the deep-sea again. The pattern of temporary expansion to shelf environments suggested here underpins the potential of deep-sea environments to contribute significantly to shallow-water biodiversity; an aspect that has mostly been neglected so far. It is speculated that the large-scale ophiacanthid invasion of shelf environments around the TriassicJurassic boundary was initiated by a change from thermohaline to halothermal circulation, attenuating the thermal stratification of the water column and thus providing opportunities for enhanced vertical migration of marine taxa.
\end{abstract}

Keywords. Ophiacanthidae, fossil record, bathymetric trends, onshore-offshore trends, evolution.

Thuy B. 2013. Temporary expansion to shelf depths rather than an onshore-offshore trend: the shallow-water rise and demise of the modern deep-sea brittle star family Ophiacanthidae (Echinodermata: Ophiuroidea). European Journal of Taxonomy 48: 1-242. http://dx.doi.org/10.5852/ejt.2013.48

\section{Introduction}

The deep sea is by far the most widespread environment on Earth, yet our knowledge of the composition, biodiversity and origin of deep-sea biota remains remarkably poor (e.g. Gage \& Tyler 1991). Since the discovery of unexpectedly high species richnesses in the deep sea, attempts have been made to explain the origin of modern bathyal and abyssal communities (Menzies et al. 1973). Debates have largely centred on two competing hypotheses: deep-sea biota are either relatively recent, resulting from multiple turnovers linked to large disruptions of the deep-sea environment (Menzies et al. 1973; Jacobs \& Lindberg 1998; 
Rex \& Etter 2010), or they are ancient and presumably resilient to such changes (Zenkevitch \& Birstein 1960; Wilson 1999). Recently, more sophisticated concepts have been articulated; these acknowledge that the modern deep-sea fauna, rather than of single origin, is most probably the result of multiple colonisation events (McClain \& Minks Hardy 2010). However differentiated, all attempts at explanation share the same potential pitfall: they almost invariably imply that the deep-sea fauna originated from shallow-water ancestors (Menzies et al. 1973; Jacobs \& Lindberg 1998; Smith \& Stockley 2005; Strugnell et al. 2008).

It has been noted that evolutionary innovations, indeed, follow a shallow (onshore) to deep (offshore) pattern (e.g. Jablonski et al. 1983; Bottjer \& Jablonski 1988; Jablonski 2005). Regrettably, however, this pattern has been commonly mistaken for a general rule, although, originally, it was explicitly stressed that it held true only for orders and that families and genera commonly diverted from the onshoreoffshore expansion concept. As a result, it has become widely accepted practice to ignore the possibility of deep (offshore) to shallow (onshore) patterns of groups and to simply eclipse the role of the deep sea in most macroevolutionary processes.

Yet, there is solid evidence for a reversed pattern implying deep origination with subsequent shallow expansion in some groups. For example, using a worldwide phylogeny of stylasterid corals, Lindner et al. (2008) showed that the group first appeared in a deep-water setting, extensively diversified in the deep sea and expanded to shallow-water habitats several times. Moura et al. (2012) stressed the importance of the deep sea in generating and accumulating lineages of plumulariid hydrozoans that may occasionally invade coastal waters in the northeast Atlantic. Clearly, the potential of the deep sea to contribute to shallow-marine biodiversity is a yet largely unexplored aspect of macroevolutionary processes (Miglietta et al. 2011).

Promising pieces of evidence in this respect are furnished by modern deep-sea groups with an extensive shallow-water fossil record, such as isocrinid sea lilies (Hess et al. 1999) and glypheid crustaceans (Forest 2006), because of their potential to provide valuable insights into the controls and modalities of bathymetric shifts on macroevolutionary time scales. Key questions revolve around the significance of the shallow-water fossil record, in particular whether it reflects the shallow origin of the group followed by retreat or migration into the deep sea, as commonly suggested, or, alternatively, documents a temporary shallow expansion of an originally deep group.

One of these groups is brittle star family Ophiacanthidae (Echinodermata: Ophiuroidea). Recent members of the family are found almost exclusively in bathyal (200-2000 m) and, to a slightly lesser extent, abyssal (2000-6000 m) depths (Tyler 1980; Stöhr et al. 2012) and constitute a common and diverse component of present-day deep-sea invertebrate communities (e.g. Metaxas \& Giffin 2004; O'Hara \& Stöhr 2006). The family has a well-documented, fairly extensive and diverse fossil record at shelf depths in the Mesozoic, and has recently been shown to extend as far back as the early Late Triassic (Carnian) (Thuy et al. 2012).

In the present study, the global fossil record of the Ophiacanthidae is systematically explored in order to assess the macroevolutionary significance of the extensive fossil occurrences at shelf depths. As a first step, the fossil record of individual ophiacanthid lineages is traced in time and along a coarse depth gradient to test whether they first occur at shelf depths or in the deep sea. Secondly, the observed first occurrence dates at shelf depths and the timing of relative abundance and diversity trends are compared with a revised phylogeny of the family calibrated using a number of key fossil occurrences to bracket minimum divergence times. The results strongly suggest that most of the early evolution of the Ophiacanthidae took place in the deep sea, and that the shelf fossil record documents a temporary expansion of the bathymetric distribution to shallower depths rather than an onshore (shallow) origination followed by an offshore (deep) migration or retreat. 


\section{Material and methods}

\section{Sample selection and treatment}

A total of 93 previously published and new ophiuroid assemblages from shallow-water (Table 1) and seven from deep-sea settings (Table 2) ranging in age from the Early Triassic to the Miocene were assessed, yielding the data base of the present study. In order to cover the ophiacanthid fossil record as exhaustively as possible, care was taken to include assemblages from various types of habitats that were as broadly distributed geographically and stratigraphically as possible. Almost all assemblages studied herein comprise dissociated lateral arm plates, for several reasons:

1) dissociated lateral arm plates generally occur in great numbers in sediment bulk samples, even in deep-sea sediment cores, whereas (semi-) articulated ophiuroid skeletons are preserved only under exceptional conditions (e.g. Kerr \& Twitchett 2004) and thus are extremely rare;

2) dissociated lateral arm plates have recently been shown to be identifiable to species level and to yield insights into phylogenetic relationships (Thuy \& Stöhr 2011);

3) as previously shown, diagnostic fragmentary or disarticulated remains yield a much more accurate picture of spatial and temporal echinoderm diversities and distributions than the patchy occurrences of articulated specimens (Nebelsick 1992, 1996; Gordon \& Donovan 1992; Donovan 2001, 2003; Kroh 2007); and finally

4) their generally high abundance in micropalaeontological samples and ease of extraction from the matrix make dissociated lateral arm plates suitable for quantitative analysis.

More than two-thirds $(n=64)$ of the ophiuroid assemblages studied were previously unpublished. They were retrieved from bulk sediment samples which were dried, processed (using $\mathrm{H}_{2} \mathrm{O}_{2}$ whenever needed) over a $100 \mu \mathrm{m}$ sieve, graded and picked under a dissecting microscope. The lateral arm plates were cleaned in an ultrasonic bath and sorted into individual species. Selected specimens from both the new assemblages and, if available, the previously published non-type material were mounted on aluminium stubs and gold-coated for scanning electron microscopy (SEM). After the first scanning session, the plates were flipped, remounted and coated for another SEM examination, in line with the recommendation made by Thuy \& Stöhr (2011) to document both sides of the selected lateral arm plates. All previously unpublished fossil specimens were deposited in the collections of a publicly accessible institute (see below).

\section{Institutional abbreviations}

MnhnL $=$ Natural History Museum Luxembourg
MHI $=$ Muschelkalk Museum Hagdorn Ingelfingen, Germany
NHM $=$ Natural History Museum London, United Kingdom
NHMB $=$ Natural History Museum Basel, Switzerland
NHMM $=$ Natural History Museum Maastricht, the Netherlands
NHMW $=$ Natural History Museum Wien, Vienna, Austria
GZG.INV $=$ Geoscientific Museum of the Georg-August-University Göttingen, Germany

\section{Palaeo-depth classification of assemblages}

In order to assess depth-related trends in the ophiacanthid fossil record, the assemblages studied are assigned to different bathymetric categories. The boundary between "shallow water" and "deep sea" is here defined at a depth of $200 \mathrm{~m}$, as commonly adopted in deep-sea biological studies (e.g. Menzies et al. 1973; Gage \& Tyler 1991). This level is in line with a conservative interpretation of the average continental shelf break depth at $130 \mathrm{~m}$ (Davis 1977), and approximates the base of the photic zone in clear waters at low latitudes (Gill et al. 2004). Assemblages classified as "shallow" are subdivided as follows: 
1) shallow shelf, 0 to approximately $50 \mathrm{~m}$, corresponding to the zone of frequent storm wave disturbance, reflected in the sedimentary record by well-developed tempestites; this zone commonly includes organisms that are dependent of high illumination levels such as the vast majority of zooxanthellate corals and green algae;

2) middle shelf, approximately from 50 to $100 \mathrm{~m}$, corresponding to the zone of occasional storm wave influence, reflected in the sedimentary record by thin distal tempestites; $100 \mathrm{~m}$ is generally considered as the maximum depth of storm wave action (Bottjer \& Jablonski 1988; Lindner et al. 2008);

3) deep shelf, approximately from 100 to $200 \mathrm{~m}$, corresponding to the zone below maximum storm disturbance, reflected by the complete lack of tempestites and other wave-induced sedimentary features; often this zone still is within the photic zone, especially at low latitudes.

All assemblages classified as "shallow" are listed in Table 1, together with the literature items consulted to determine palaeo-depth. If possible, the depositional setting of the shallow-water assemblages is additionally interpreted in terms of substrate and possible organismal build-ups such as reefs and mounds, thus allowing for the detection of potential patterns in the shallow-water fossil occurrences of ophiacanthids in relation to habitat type.

A total of seven samples are interpreted here as deep-sea assemblages (Table 2). All of them reflect deposition at bathyal (200-2000 m) depths. Further subdivisions used here are shallow (200-500 m), middle (500-1000 m) and deep bathyal (1000-2000 m) (Gage \& Tyler 1991).

Of particular importance for the purpose of the present study is the Glasenbach Gorge assemblage. This is the oldest deep-sea assemblage documented to date and, being dated as late Sinemurian to early Pliensbachian, it bears witness to the late phase in the major early radiation predicted for ophiuroids in general (Smith et al. 1995) and ophiacanthids in particular (Thuy et al. 2012). In view of the enormous potential for the present study and in acknowledgement of the difficulties and pitfalls of palaeobathymetries, particular care is given to a sound palaeo-depth estimate for the Glasenbach Gorge assemblage.

The assemblage in question was retrieved from poorly lithified sediments referred to as the "Hauptknollenbrekzie" within the Adnet Formation, interpreted as a huge slumping mass of semiconsolidated upper Sinemurian to lower Pliensbachian pelagic red marls and limestones transported downslope in the late Pliensbachian as debris flows into deeper parts of the basin (Böhm et al. 1995). The Adnet Formation, inclusive of the "Hauptknollenbrekzie", is generally considered to be a deep-sea deposit (e.g. Böhm 1992; Böhm \& Brachert 1993; Bernoulli \& Jenkyns 2009), mainly on account of the lack of light-dependent organisms, the close lateral and vertical association with radiolarian cherts, and the striking lithological analogies with the slightly younger sediments directly overlying oceanic crust and deeply submerged continental crust in the North Atlantic Ocean. Microendolithic ichnofossils in shell fragments and belemnite coleoids that co-occur with the ophiuroid remains described herein consistently indicate aphotic conditions (M. Wisshak pers. comm. May 2012), which, in combination with the very low sedimentation rates (low turbidity) and the low palaeo-latitude (Scotese 1991), implies an original palaeo-depth for the transported sediments of at least $250 \mathrm{~m}$. Seeing that the source of the transported sediments was at the slope rather than the top of submarine highs, and that the top of the latter also lack evidence of photic conditions, palaeo-depths were most probably in excess of $250 \mathrm{~m}$.

\section{Phylogenetic analysis}

In order to place the ophiacanthid fossil record into a solid evolutionary context, the phylogeny of the family as previously presented by Thuy et al. (2012) is revised. In addition to the species included in the original phylogeny, four recently described or reassessed fossil ophiacanthids [Ophiosternle crinitum (Quenstedt, 1876), Dermocoma wrighti Hess, 1964, Hanshessia trochitophila Thuy \& Meyer, 2013 
Table 1. Locality details of previously published and new shallow-water ophiuroid assemblages (as studied herein), including reference-supported details on the age and, whenever available, the stratigraphic unit, as well as palaeodepth classification (see section Material and methods) and substrate interpretation. References for previously published ophiuroid assemblages are given. Country and state acronyms: $\mathrm{A}=$ Austria; $\mathrm{B}=$ Belgium; $\mathrm{CH}=$ Switzerland; $\mathrm{CN}=$ China; $\mathrm{CZ}=$ Czech Republic; $\mathrm{D}=$ Germany; $\mathrm{E}=$ Spain; $\mathrm{F}=$ France; $\mathrm{GB}=$ Great Britain; $\mathrm{H}=$ Hungary $\mathrm{I}=\mathrm{Italy}$; IND = India; JP = Japan; $\mathrm{MO}=$ Morocco $; \mathrm{NL}=$ Netherlands $; \mathrm{P}=$ Portugal $; \mathrm{PL}=$ Poland; $\mathrm{S}=$ Sweden; $\mathrm{TX}=$ Texas. Age acronyms: $\mathrm{E}=$ early; $\mathrm{L}=$ late; $\mathrm{M}=$ middle; Cret. $=$ Cretaceous; Jur. $=$ Jurassic; Mioc. $=$ Miocene; Tr. $=$ Triassic.

\begin{tabular}{|c|c|c|c|}
\hline Locality & Age & Palaeohabitat & References \\
\hline Baden, A & $\begin{array}{l}\text { Middle Langhian, M. Mioc. (Rögl et al. } \\
\text { 2008) }\end{array}$ & $\begin{array}{l}\text { Deep shelf, muddy bottom (Rögl et al. } \\
\text { 2008) }\end{array}$ & This paper \\
\hline Rauchstallbrunngraben, A & Langhian, M. Mioc. (Kühn 1952) & $\begin{array}{l}\text { Shallow to middle shelf, bryozoan } \\
\text { thickets (Kühn 1952) }\end{array}$ & This paper \\
\hline Mannersdorf, A & Langhian, M. Mioc. (Kroh 2007) & $\begin{array}{l}\text { Shallow shelf, detrital sand bottom } \\
\text { (Kroh, pers. comm., 2012) }\end{array}$ & This paper \\
\hline Wiesfleck, A & Langhian, M. Mioc. (Kroh 2007) & $\begin{array}{l}\text { Shallow shelf, coral patch reef (Kroh } \\
\text { 2007) }\end{array}$ & This paper \\
\hline Stotzing, A & Langhian, M. Mioc. (Kroh 2007) & $\begin{array}{l}\text { Shallow shelf, detrital sand bottom } \\
\text { (Kroh, pers. comm., 2012) }\end{array}$ & This paper \\
\hline Obernalb, A & $\begin{array}{l}\text { Early Burdigalian, E. Mioc. (Kroh \& } \\
\text { Harzhauser 1999) }\end{array}$ & $\begin{array}{l}\text { Shallow shelf, sandy bottom (Kroh \& } \\
\text { Harzhauser 1999) }\end{array}$ & This paper \\
\hline Seymour Island, Antarctica & Late Eocene (Blake \& Aronson 1998) & $\begin{array}{l}\text { Shallow to middle shelf (Feldmann \& } \\
\text { Woodburne 1988) }\end{array}$ & Blake \& Aronson (1998) \\
\hline Barton Cliff, GB & $\begin{array}{l}\text { Bartonian, M. Eocene (Murray \& Wright } \\
\text { 1974) }\end{array}$ & $\begin{array}{l}\text { Middle shelf, mud bottom (Murray \& } \\
\text { Wright 1974) }\end{array}$ & Rasmussen (1972) \\
\hline Grignon, F & $\begin{array}{l}\text { Middle Lutetian, M. Eocene (Merle } \\
\text { 2008) }\end{array}$ & $\begin{array}{l}\text { Shallow shelf, calcareous sands (Merle } \\
\text { 2008) }\end{array}$ & This paper \\
\hline Eben Emael, B & $\begin{array}{l}\text { Latest Maastrichtian, Lanaye Member } \\
\text { and lower Maastricht Formation, L. Cret. } \\
\text { (Jagt 1999b) }\end{array}$ & $\begin{array}{l}\text { Shallow shelf, calcareous muds and } \\
\text { sands, seagrass meadows (Jagt 1999b) }\end{array}$ & Jagt (1999a, 2000) \\
\hline Maastricht, NL & $\begin{array}{l}\text { Late Maastrichtian, Gronsveld Member, } \\
\text { L. Cret. (Jagt 1999b) }\end{array}$ & $\begin{array}{l}\text { Shallow shelf, carbonate sands, seagrass } \\
\text { meadows (Jagt 1999b) }\end{array}$ & Jagt (1999a, 2000) \\
\hline Rügen, D & $\begin{array}{l}\text { Early Maastrichtian, L. Cret. (Herrig } \\
\text { 1996) }\end{array}$ & $\begin{array}{l}\text { Deep shelf, mud bottom (Reich \& } \\
\text { Frenzel 2002) }\end{array}$ & Kutscher \& Jagt (2000) \\
\hline Lägerdorf-Kronsmoor, D & $\begin{array}{l}\text { Early Maastrichtian, L. Cret. (Schönfeld } \\
\text { 1990) }\end{array}$ & $\begin{array}{l}\text { Middle to deep shelf, muddy bottom } \\
\text { (Hofmann 1996) }\end{array}$ & This paper \\
\hline Haccourt, B & $\begin{array}{l}\text { Early late Maastrichtian, Vijlen Member, } \\
\text { L. Cret. (Jagt 1999b) }\end{array}$ & Middle shelf, mud bottom (Jagt 1999b) & Jagt (1999a, 2000) \\
\hline Aachen, D & $\begin{array}{l}\text { Early to early late Maastrichtian, Vijlen } \\
\text { Member, L. Cret. (Jagt \& Jagt-Yazykova } \\
\text { 2012) }\end{array}$ & $\begin{array}{l}\text { Shallow to middle shelf, muddy bottom } \\
\text { (Jagt \& Jagt-Yazykova 2012) }\end{array}$ & Jagt (2000) \\
\hline Haccourt, B & $\begin{array}{l}\text { Late Campanian, Zeven Wegen Member, } \\
\text { L. Cret. (Jagt 1999b) }\end{array}$ & Middle shelf, mud bottom (Jagt 1999b) & Jagt (1999a, 2000) \\
\hline Lägerdorf-Alsen, D & $\begin{array}{l}\text { Galerites vulgaris Zone, Late } \\
\text { Campanian, L. Cret. (Schulz et al. 1984) }\end{array}$ & $\begin{array}{l}\text { Middle to deep shelf, muddy bottom } \\
\text { (Hofmann 1996) }\end{array}$ & This paper \\
\hline Ivö Klack, S & $\begin{array}{l}\text { Early Campanian, Belemnellocamax } \\
\text { mammillatus Zone, L. Cret. (Surlyk \& } \\
\text { Sørensen 2010) }\end{array}$ & $\begin{array}{l}\text { Shallow shelf, rocky shore (Surlyk \& } \\
\text { Sørensen 2010) }\end{array}$ & This paper \\
\hline
\end{tabular}




\begin{tabular}{|c|c|c|c|}
\hline Locality & Age & Palaeohabitat & References \\
\hline Piesting, A & $\begin{array}{l}\text { Late Santonian, L. Cret. (Summesberger } \\
\text { 1997) }\end{array}$ & $\begin{array}{l}\text { Shallow shelf, coral reef (Zágoršek \& } \\
\text { Kroh 2003) }\end{array}$ & This paper \\
\hline Upohlávy, CZ & $\begin{array}{l}\text { Late Turonian, Teplice Formation, L. } \\
\text { Cret. (Štorc \& Žítt 2008) }\end{array}$ & $\begin{array}{l}\text { Middle shelf, muddy bottom (Wiese } \\
\text { et al. 2004) }\end{array}$ & Štorc \& Žítt (2008) \\
\hline Waco, TX & $\begin{array}{l}\text { Early Cenomanian, L. Cret. (Blake \& } \\
\text { Reid 1998) }\end{array}$ & $\begin{array}{l}\text { Shallow to middle shelf, muddy bottom } \\
\text { (Blake \& Reid 1998) }\end{array}$ & This paper \\
\hline Saginaw, TX & $\begin{array}{l}\text { Late Albian, Rostratum Zone, E. Cret. } \\
\text { (Blake \& Reid 1998) }\end{array}$ & $\begin{array}{l}\text { Shallow to middle shelf, muddy bottom } \\
\text { (Blake \& Reid 1998) }\end{array}$ & This paper \\
\hline Folkestone, GB & $\begin{array}{l}\text { Middle Albian, Lautus (sample A) and } \\
\text { Loricatus (sample B) zones, "Gault } \\
\text { clay", E. Cret. (Young et al. 2010) }\end{array}$ & $\begin{array}{l}\text { Shallow to middle shelf, muddy bottom } \\
\text { (Young et al. 2010) }\end{array}$ & This paper \\
\hline Leighton Buzzard, GB & $\begin{array}{l}\text { Early Albian, Tardefurcata Zone, E. Cret. } \\
\text { (Hess \& Gale 2010) }\end{array}$ & $\begin{array}{l}\text { Shallow shelf, hardground with } \\
\text { carbonate muds (Hess \& Gale 2010) }\end{array}$ & This paper \\
\hline Wizard Way, TX & $\begin{array}{l}\text { Latest Aptian, Echinoid marker bed, E. } \\
\text { Cret. (Smith \& Rader 2009) }\end{array}$ & $\begin{array}{l}\text { Shallow to middle shelf, carbonate } \\
\text { muds (Smith a Rader 2009) }\end{array}$ & This paper \\
\hline Cuchía, E & $\begin{array}{l}\text { Early Aptian, Marl Member, Caranceja } \\
\text { Formation (Wilmsen 2005) }\end{array}$ & $\begin{array}{l}\text { Middle shelf, muddy bottom (Wilmsen } \\
\text { 2005) }\end{array}$ & This paper \\
\hline Serre de Bleyton, F & $\begin{array}{l}\text { Late Barremian, E. Cret. (Lukeneder } \\
\text { 2011) }\end{array}$ & $\begin{array}{l}\text { Shallow to middle shelf-derived debris } \\
\text { in turbidites (Adatte et al. 2005) }\end{array}$ & Thuy \& Kroh (2011) \\
\hline Sarstedt, D & $\begin{array}{l}\text { Latest Hauterivian, E. Cret. (Mutterlose } \\
\text { 1997) }\end{array}$ & Middle shelf (Mutterlose 1997) & This paper \\
\hline Neuchâtel, CH & Late Hauterivian, E. Cret. (Hess 1970b) & $\begin{array}{l}\text { Shallow shelf, hardground with } \\
\text { carbonate muds (Hess 1970b) }\end{array}$ & Hess (1970b) \\
\hline Trancoso, $\mathrm{P}$ & $\begin{array}{l}\text { Late Kimmeridgian, Amaral Formation, } \\
\text { L. Jur. (Schneider et al. 2009) }\end{array}$ & $\begin{array}{l}\text { Shallow shelf, coral biostromes (Schmid } \\
\text { et al. 2001) }\end{array}$ & This paper \\
\hline Geisingen, D & $\begin{array}{l}\text { Early Kimmeridgian, Lacunosa Marls, L. } \\
\text { Jur. (M. Jäger, pers. comm.) }\end{array}$ & $\begin{array}{l}\text { Middle shelf, muddy bottom with } \\
\text { scattered sponges (A.S. Gale, pers. } \\
\text { comm.) }\end{array}$ & This paper \\
\hline Pointe du Chay, F & $\begin{array}{l}\text { Early Kimmeridgian, Cymodoce Zone, L. } \\
\text { Jur. (Olivier et al. 2003) }\end{array}$ & $\begin{array}{l}\text { Shallow to middle shelf, muddy bottom } \\
\text { in part within in situ coral heads } \\
\text { (Olivier } \text { et al. } 2003 \text { ) }\end{array}$ & This paper \\
\hline Plettenberg, D & $\begin{array}{l}\text { Late Oxfordian, Bimammatum Zone, L. } \\
\text { Jur. (Olivier et al. 2004) }\end{array}$ & $\begin{array}{l}\text { Deep shelf, sponge reefs (Olivier et al. } \\
\text { 2004) }\end{array}$ & This paper \\
\hline Guldental, $\mathrm{CH}$ & $\begin{array}{l}\text { Late Oxfordian, Günsberg Member, L. } \\
\text { Jur. (Allenbach 2001) }\end{array}$ & $\begin{array}{l}\text { Shallow shelf, muddy bottom } \\
\text { (Allenbach 2001) }\end{array}$ & Hess (1975a) \\
\hline Raedersdorf, F & $\begin{array}{l}\text { Late Oxfordian, Humeralis Member, L. } \\
\text { Jur. (Allenbach 2001) }\end{array}$ & $\begin{array}{l}\text { Shallow to middle shelf, muddy bottom } \\
\text { (Allenbach 2001) }\end{array}$ & Hess (1975b) \\
\hline Savigna, F & $\begin{array}{l}\text { Late Oxfordian, Bifurcatus Zone, L. Jur. } \\
\text { (Gale 2011) (samples 1, 2a and 2b) }\end{array}$ & $\begin{array}{l}\text { Middle shelf, muddy bottom (Gale } \\
\text { 2011) }\end{array}$ & Hess (1966); this paper \\
\hline Guldental, $\mathrm{CH}$ & $\begin{array}{l}\text { Late Oxfordian, Bifurcatus Zone, L. Jur. } \\
\text { (Allenbach 2001) }\end{array}$ & $\begin{array}{l}\text { Middle shelf, muddy bottom (Allenbach } \\
\text { 2001) }\end{array}$ & Hess (1966) \\
\hline Foug, F & $\begin{array}{l}\text { Middle Oxfordian, Transversarium Zone, } \\
\text { L. Jur. (Geister \& Lathuilière 1991) }\end{array}$ & $\begin{array}{l}\text { Shallow shelf, microsolenid coral reef } \\
\text { (Insalaco et al. 1997) }\end{array}$ & This paper \\
\hline $\begin{array}{l}\text { Chapois and Longecombe, } \\
\text { F }\end{array}$ & $\begin{array}{l}\text { Early Oxfordian, Renggeri Member, } \\
\text { Bärschwil Formation, L. Jur. (Allenbach } \\
\text { 2001) }\end{array}$ & $\begin{array}{l}\text { Middle shelf, muddy bottom (Allenbach } \\
\text { 2001) }\end{array}$ & Hess (1965a) \\
\hline Jumara, Kachchh, IND & $\begin{array}{l}\text { Callovian, upper Chari Formation, M. } \\
\text { Jur. (Fürsich et al. 2001) (samples 117, } \\
119 \text { and 121) }\end{array}$ & $\begin{array}{l}\text { Middle shelf, muddy bottom (Fürsich } \\
\text { et al. 2004) }\end{array}$ & This paper \\
\hline
\end{tabular}


THUY B., Fossil record of ophiacanthid brittle stars

\begin{tabular}{|c|c|c|c|}
\hline Locality & Age & Palaeohabitat & References \\
\hline Jumara, Kachchh, IND & $\begin{array}{l}\text { Callovian, lower Chari Formation, M. } \\
\text { Jur. (Fürsich et al. 2001) (samples } 31 \\
\text { and 95) }\end{array}$ & $\begin{array}{l}\text { Middle shelf, muddy bottom (Fürsich } \\
\text { et al. 2004) }\end{array}$ & This paper \\
\hline $\begin{array}{l}\text { B a u e r - W e h r } 1 \text { a } \mathrm{n} \mathrm{d} \text {, } \\
\text { Hohensaaten and } \\
\text { Althüttendorf, D }\end{array}$ & Callovian, M. Jur. (Kutscher 1987) & $\begin{array}{l}\text { Shallow to middle shelf (Pieńkowski } \\
\text { et al. 2008) }\end{array}$ & Kutscher (1987) \\
\hline Liesberg, $\mathrm{CH}$ & $\begin{array}{l}\text { Early Callovian, Koenigi Zone, M. Jur. } \\
\text { (Hess 1963) }\end{array}$ & $\begin{array}{l}\text { Middle shelf, muddy bottom (Dimter \& } \\
\text { Smelror 1990) }\end{array}$ & Hess (1963) \\
\hline Jumara, Kachchh, IND & $\begin{array}{l}\text { Late Bathonian, Patcham Formation, M. } \\
\text { Jur. (Fürsich et al. 2001a) (sample 24) }\end{array}$ & $\begin{array}{l}\text { Middle shelf, muddy bottom with } \\
\text { sponge meadows (Fürsich et al. 2004) }\end{array}$ & This paper \\
\hline Jumara, Kachchh, IND & $\begin{array}{l}\text { Middle Bathonian, Jhurio Formation, M. } \\
\text { Jur. (Fürsich et al. 2001a) (samples } 15 \\
\text { and 89) }\end{array}$ & $\begin{array}{l}\text { Middle shelf, muddy bottom with } \\
\text { microsolenid corals (Fürsich et al. } \\
\text { 2004) }\end{array}$ & This paper \\
\hline La Pouza, F & $\begin{array}{l}\text { Early Bathonian, Zigzag Zone, M. Jur. } \\
\text { (Hess 2012) }\end{array}$ & $\begin{array}{l}\text { Debris flows from middle shelf } \\
\text { hardground into deep shelf muddy } \\
\text { bottom (Hess 2012) }\end{array}$ & This paper \\
\hline Delkhofen, D & $\begin{array}{l}\text { Early Bajocian, Humphriesianum Zone, } \\
\text { M. Jur. (Geyer \& Gwinner 1986) }\end{array}$ & $\begin{array}{l}\text { Middle shelf, muddy bottom } \\
\text { (Pieńkowski et al. 2008) }\end{array}$ & This paper \\
\hline Cirey-lès-Nolay, F & $\begin{array}{l}\text { Early Bajocian, Humphriesianum Zone, } \\
\text { M. Jur. (Lathuilière 2000) }\end{array}$ & $\begin{array}{l}\text { Shallow shelf, coral reef (Lathuilière } \\
\text { 2000) }\end{array}$ & This paper \\
\hline Longwy, F & $\begin{array}{l}\text { Early Bajocian, Laeviuscula Zone } \\
\text { (Delsate 1993) }\end{array}$ & $\begin{array}{l}\text { Shallow shelf, shell debris between } \\
\text { patch reefs (Delsate 1993) }\end{array}$ & This paper \\
\hline Seewen, $\mathrm{CH}$ & $\begin{array}{l}\text { Late Toarcian, Thouarsense Zone, E. Jur. } \\
\text { (Reisdorf et al. 2011) }\end{array}$ & $\begin{array}{l}\text { Middle shelf, muddy bottom (Reisdorf } \\
\text { et al. 2011) }\end{array}$ & Hess (1962) \\
\hline Le Clapier, F & $\begin{array}{l}\text { Middle Toarcian, E. Jur. (Fürsich et al. } \\
\text { 2001) (2 samples) }\end{array}$ & $\begin{array}{l}\text { Debris flows from middle shelf muddy } \\
\text { bottoms (Fürsich et al. 2001) }\end{array}$ & This paper \\
\hline Aix-sur-Cloie, B & $\begin{array}{l}\text { Earliest Toarcian, Tenuicostatum Zone, } \\
\text { E. Jur. (Boulvain et al. 2001) }\end{array}$ & $\begin{array}{l}\text { Shallow to middle shelf, muddy bottom } \\
\text { (Pieńkowski et al. 2008) }\end{array}$ & This paper \\
\hline Seewen, $\mathrm{CH}$ & $\begin{array}{l}\text { Late Pliensbachian, Margaritatus Zone, } \\
\text { E. Jur. (Reisdorf et al. 2011) }\end{array}$ & $\begin{array}{l}\text { Middle shelf, muddy bottom (Reisdorf } \\
\text { et al. 2011) }\end{array}$ & Hess (1962) \\
\hline Amellago, MO & Late Pliensbachian, E. Jur. (Smith 2011) & $\begin{array}{l}\text { Debris flows from middle shelf sponge/ } \\
\text { coral reefs (Smith 2011) }\end{array}$ & This paper \\
\hline Feuguerolles, F & $\begin{array}{l}\text { Late Pliensbachian, E. Jur. (A.S. Gale, } \\
\text { pers. comm.) }\end{array}$ & $\begin{array}{l}\text { Shallow shelf, rocky shore (A.S. Gale, } \\
\text { pers. comm.) }\end{array}$ & This paper \\
\hline Blockley, GB & $\begin{array}{l}\text { Early Pliensbachian, Davoei Zone, E. } \\
\text { Jur. (Simms et al. 2004) }\end{array}$ & $\begin{array}{l}\text { Middle shelf, muddy bottom } \\
\text { (Pieńkowski et al. 2008) }\end{array}$ & This paper \\
\hline Sedan, F & $\begin{array}{l}\text { Early Pliensbachian, Davoei Zone, E. } \\
\text { Jur. (Thuy 2011) }\end{array}$ & $\begin{array}{l}\text { Shallow shelf, muddy bottom with } \\
\text { bivalve aggregations (Thuy 2011) }\end{array}$ & This paper \\
\hline Bishop's Cleeve, GB & $\begin{array}{l}\text { Late Sinemurian, Obtusum Zone, E. Jur. } \\
\text { (Simms et al. 2004) }\end{array}$ & $\begin{array}{l}\text { Middle shelf, muddy bottom } \\
\text { (Pieńkowski et al. 2008) }\end{array}$ & This paper \\
\hline Remerschen, L & $\begin{array}{l}\text { Early Sinemurian, Bucklandi Zone, E. } \\
\text { Jur. (Lucius 1948) }\end{array}$ & $\begin{array}{l}\text { Shallow to middle shelf, muddy bottom } \\
\text { (Pieńkowski et al. 2008) }\end{array}$ & This paper \\
\hline Fontenoille, B & $\begin{array}{l}\text { Hettangian, Liasicus Zone, E. Jur. } \\
\text { (Delsate et al. 2002) }\end{array}$ & $\begin{array}{l}\text { Shallow shelf, muddy bottom with } \\
\text { biogenic sands (Delsate et al. 2002) }\end{array}$ & This paper \\
\hline Vance, B & $\begin{array}{l}\text { Hettangian, Planorbis Zone, E. Jur. } \\
\text { (Delsate \& Thuy 2005) (samples Van1 } \\
\text { and Van2) }\end{array}$ & $\begin{array}{l}\text { Shallow to middle shelf, muddy bottom } \\
\text { (Delsate \& Thuy 2005) }\end{array}$ & Thuy (2005) \\
\hline Fischerwiese, A & $\begin{array}{l}\text { Rhaetian, Zlambach Marls, L. Tr. (Zapfe } \\
\text { 1967) }\end{array}$ & $\begin{array}{l}\text { Debris flows from shallow shelf coral } \\
\text { reefs (Zapfe 1967) }\end{array}$ & This paper \\
\hline
\end{tabular}




\begin{tabular}{|c|c|c|c|}
\hline Locality & Age & Palaeohabitat & References \\
\hline Jushui, Sichuan, CN & $\begin{array}{l}\text { Late Carnian, upper Hanwang Formation, } \\
\text { L. Triassic (Wendt et al. 1989) (samples } \\
\text { C30, C33 and C36) }\end{array}$ & $\begin{array}{l}\text { Deep shelf, hexactinellid sponge mounds } \\
\text { (Wendt et al. 1989) }\end{array}$ & This paper \\
\hline Alpe di Specie, I & $\begin{array}{l}\text { Middle Carnian, Austriacum Zone, L. Tr. } \\
\text { (Russo 2005) }\end{array}$ & Shallow shelf, patch reefs (Russo 2005) & This paper \\
\hline Romerlo, I & $\begin{array}{l}\text { Early Carnian, Aonoides Zone, L. Tr. } \\
\text { (Feist-Burkhardt et al. 2008) }\end{array}$ & $\begin{array}{l}\text { Shallow shelf, detrital sands (Feist- } \\
\text { Burkhardt et al. 2008) }\end{array}$ & This paper \\
\hline Milieres, I & $\begin{array}{l}\text { Early Carnian, Cassian Formation, L. Tr. } \\
\text { (Russo 2005) }\end{array}$ & $\begin{array}{l}\text { Debris flows from shallow to middle } \\
\text { shelf reefs (Russo 2005) }\end{array}$ & This paper \\
\hline Oberscheffach, D & $\begin{array}{l}\text { Latest Anisian, Trochitenkalk Formation, } \\
\text { M. Tr. (Geyer \& Gwinner 1986) }\end{array}$ & $\begin{array}{l}\text { Shallow to middle shelf, muddy bottom } \\
\text { (Geyer \& Gwinner 1986) }\end{array}$ & This paper \\
\hline Schillingstadt, D & $\begin{array}{l}\text { Late Anisian, Trochitenkalk Formation } \\
\text { (Feist-Burkhardt et al. 2008) }\end{array}$ & $\begin{array}{l}\text { Shallow to middle shelf, muddy bottom } \\
\text { (Geyer \& Gwinner 1986) }\end{array}$ & This paper \\
\hline Górazdze, PL & $\begin{array}{l}\text { Late Anisian, Karchowice Formation, M. } \\
\text { Tr. (Feist-Burkhardt et al. 2008) }\end{array}$ & $\begin{array}{l}\text { Shallow to middle shelf, detrital sands } \\
\text { (Feist-Burkhardt et al. 2008) }\end{array}$ & This paper \\
\hline Strzelce Opolski, PL & $\begin{array}{l}\text { Late Anisian, Karchowice Formation, M. } \\
\text { Tr. (Hagdorn 2011) }\end{array}$ & $\begin{array}{l}\text { Shallow to middle shelf, detrital } \\
\text { sands with hexactinellid sponges and } \\
\text { hermatypic corals (Hagdorn 2011) }\end{array}$ & This paper \\
\hline Felsöörs, H & $\begin{array}{l}\text { Late Anisian, Felsöörs Formation, M. Tr. } \\
\text { (Vörös 2003) }\end{array}$ & Deep shelf, muddy bottom (Vörös 2003) & This paper \\
\hline Recoaro, I & $\begin{array}{l}\text { Early Anisian, Gracilis Formation, M. Tr. } \\
\text { (Feist-Burkhardt et al. 2008) }\end{array}$ & $\begin{array}{l}\text { Shallow to middle shelf, mud bottom } \\
\text { (Feist-Burkhardt et al. 2008) }\end{array}$ & This paper \\
\hline Sóly, H & $\begin{array}{l}\text { Olenekian, E. Tr. (Feist-Burkhardt et al. } \\
\text { 2008) }\end{array}$ & $\begin{array}{l}\text { Middle shelf, muddy bottom (Feist- } \\
\text { Burkhardt et al. 2008) }\end{array}$ & This paper \\
\hline Dolomites, I. & $\begin{array}{l}\text { Olenekian, E. Tr. (Broglio Loriga \& Berti } \\
\text { Cavicchi 1972) }\end{array}$ & $\begin{array}{l}\text { Shallow to middle shelf, muddy bottom } \\
\text { (Broglio Loriga \& Berti Cavicchi 1972) }\end{array}$ & $\begin{array}{l}\text { Broglio Loriga \& Berti } \\
\text { Cavicchi (1972) }\end{array}$ \\
\hline Kitakami Mountains, JP & $\begin{array}{l}\text { Early Olenekian, Hiraiso Formation, E. } \\
\text { Tr. (Kashiyama \& Oji 2004) }\end{array}$ & $\begin{array}{l}\text { Shallow shelf, sandy bottom } \\
\text { (Kashiyama \& Oji 2004) }\end{array}$ & Twitchett \& Oji (2005) \\
\hline
\end{tabular}

and Alternacantha occulta Thuy \& Meyer, 2013] known from well-preserved articulated skeletons, are included in order to bracket divergence times. Two new characters are added to the set of characters proposed by Thuy et al. (2012); these appear as characters 59-60 in the matrix, in continuation of the original character numbering (Thuy et al. 2012):

59. Tentacle scales perpendicular to the axis of the arm and pointing towards midline of arm.

60. Position of the dorsalmost arm spine alternating between the arm segments.

The phylogenetic analysis was carried out using PAUP* 4.0b10 (PPC) (Swofford 2005), treating all characters as unordered and of equal weight. Characters were then reweighted by their rescaled consistency index and the parsimony analysis repeated under the new weighting scheme. The tree resulting from the analysis of the reweighed dataset is here used as a working hypothesis. Bootstrap percentages are based on 10000 fast (simple addition without branch swapping) heuristic searches in PAUP*. Bremer support (Bremer 1994) was not calculated due to computing time limitations. Illustrated trees were constructed using TreeGraph 2 (Stöver \& Müller 2010).

\section{Interpretation of assemblages}

The taxonomic interpretation of dissociated ophiacanthid lateral arm plates follows Thuy \& Stöhr (2011) and, if possible, is performed using Recent material for comparison. For this purpose, lateral arm 
Table 2. Locality details of previously published and new deep-sea ophiuroid assemblages (as studied herein), including reference-supported details on the age and, whenever available, the stratigraphic unit, as well as palaeodepth classification (see section Material and methods) and substrate interpretation. References for previously published ophiuroid assemblages are given. Country acronyms: A = Austria; $\mathrm{D}=$ Germany; $\mathrm{F}=$ France; NE Atlantic $=$ northeast Atlantic; JP = Japan. Age acronyms: $\mathrm{E}=$ early; $\mathrm{M}=$ middle; Cret. $=$ Cretaceous; Jur. $=$ Jurassic; Mioc. $=$ Miocene; Oligoc. $=$ Oligocene; Paleoc. $=$ Paleocene .

\begin{tabular}{|c|c|c|c|}
\hline Locality & Age & Palaeohabitat & References \\
\hline Azumino City, JP & $\begin{array}{l}\text { Bessho Formation, M. Mioc. (Ishida et al. } \\
\text { 2009) }\end{array}$ & Bathyal, muddy bottom (Ishida et al. 2009) & Ishida et al. (2009) \\
\hline Bad Freienwalde, D & $\begin{array}{l}\text { Rupelian, "Septarienton”, Oligoc. (Brückner } \\
\text { et al. 2003) }\end{array}$ & $\begin{array}{l}\text { Shallow bathyal (Fechner 1996; Brückner } \\
\text { et al. 2003) }\end{array}$ & This paper \\
\hline Fakse, DK & $\begin{array}{l}\text { Middle Danian, Faxe Formation, Tylocidaris } \\
\text { bruennichi Zone, Paleoc. (Donovan \& } \\
\text { Jakobsen 2004) }\end{array}$ & $\begin{array}{l}\text { Shallow to middle bathyal, azooxanthellate } \\
\text { coral reefs (Bernecker \& Weidlich 2005) }\end{array}$ & $\begin{array}{l}\text { Lauridsen } \text { et al. } \\
\text { 2010; this paper }\end{array}$ \\
\hline Blake Nose, NE Atlantic & $\begin{array}{l}\text { Latest Aptian to earliest Albian, Hedbergella } \\
\text { trochoidea to Microhedbergella rischi } \\
\text { planktonic foraminifer zones, E. Cret. } \\
\text { (Huber \& Leckie 2011) }\end{array}$ & Deep bathyal (Norris et al. 1998) & This paper \\
\hline Carniol-Oppedette, F & $\begin{array}{l}\text { Middle Aptian, Gargasian, E. Cret. (Ropolo } \\
\text { et al. 2006) }\end{array}$ & Shallow bathyal (Friès \& Parize 2003) & This paper \\
\hline Ternberg, A & $\begin{array}{l}\text { Late Valanginian, Verrucosum Zone, E. Cret. } \\
\text { (Lukeneder 2004) }\end{array}$ & Shallow bathyal (Lukeneder 2004) & This paper \\
\hline Touert near Chaudon, F & $\begin{array}{l}\text { Bajocian-Bathonian boundary, M. Jur. } \\
\text { (Fernández-López et al. 2009) }\end{array}$ & $\begin{array}{l}\text { Middle bathyal (Fernández-López et al. } \\
\text { 2009) }\end{array}$ & This paper \\
\hline Glasenbach Gorge, A & $\begin{array}{l}\text { Late Sinemurian to Early Pliensbachian, E. } \\
\text { Jur. (Vortisch 1970) }\end{array}$ & $\begin{array}{l}\text { Bathyal, probably middle bathyal (Böhm } \\
\text { 1992; Böhm \& Brachert 1993; Bernoulli \& } \\
\text { Jenkyns 2009; microendolithic ichnofossil } \\
\text { evidence provided by M. Wisshak) }\end{array}$ & This paper \\
\hline
\end{tabular}

plates were extracted from a number of modern representatives of ophiacanthid taxa not illustrated by Thuy \& Stöhr (2011), using conventional household bleach for maceration. Inconsistency of taxonomic data - one of the major biases in large-scale palaeobiodiversity studies - was overcome by taxonomic standardisation. In order to track depth distribution patterns through time, attempts were made to identify evolutionary lineages on the basis of similarities in lateral arm plate morphology, in line with the observation by Thuy \& Stöhr (2011) that the most closely similar lateral arm plates are generally found in the most closely related species.

In addition to the age and palaeo-depth of first occurrences (FOs) of lineages, trends in relative abundance and diversity through time and across the depth gradient are central themes in ophiacanthid evolution considered in the present study. Spatial and temporal patterns in the relative abundance of members of this family are explored using the ratio of the number of ophiacanthid lateral arm plates to the number of those of non-ophiacanthids. Possible biases related to preservation potential of ophiacanthid lateral arm plates are overcome using the lateral arm plates of other ophiuroids as a taphonomic control group. Whenever possible, at least 300 ophiuroid lateral arm plates per assemblage are counted so as to assess the relative abundance of the Ophiacanthidae, in line with standard procedures employed in other micropalaeontological census approaches, in particular using foraminifera (e.g. Pflaumann et al. 1996; Fatela \& Taborda 2002; Kucera 2007). Some samples, however, yielded fewer than 300 plates even after intense sampling efforts. A particularly striking example is the Bathonian sample from La Pouza, France, which yielded only 113 lateral arm plates, yet in excess of 100000 crinoid ossicles (Hess 2012). In addition, it must be borne in mind that the number of arm segments, and thus of lateral arm plates, per individual can vary between species. Relative abundance data from counts of fossil lateral arm plates should therefore not be over-interpreted. They are here used as a tool to assess the general abundance trends, which they can be assumed to reflect fairly accurately in spite of the above-mentioned issues. 
Trends in ophiacanthid diversity through time are used as an additional source of data to explore the evolution of the family. Due to the heterogeneity of the ophiacanthid fossil record, the relatively low species richness values per assemblage and the strong differences in the number of ophiacanthid specimens per assemblage (between 1 and 1343 specimens), however, insights are limited and often should not be taken at face value. A major bias in comparing the diversities of assemblages are differences in sampling effort (number of samples, individuals, habitat types, etc.), as in almost all palaeobiodiversity studies (e.g. Kroh 2007).

The main approach employed in the present study to explore the effect of sampling bias is to lump the assemblages studied in intervals of $5 \mathrm{Ma}$ in order to reduce the effect of differences in habitat type, and to plot the species richness values along with the number of samples and lateral arm plates counted for each individual. Straightforward interpretations on the basis of these plots are found to be both expedient to explore the general, large-scale trends, and less prone to the pitfalls of method abuse (e.g. Tipper 1979) due the above-mentioned peculiarities of the data set at hand. In contrast, rarefaction - one of the most commonly employed, well-established techniques to compare samples of different sizes (e.g. Adrain et al. 2000; Kroh 2007) - was of limited use only in the present study. The requirement that samples are to be taken from a similar "habitat" (Sanders 1968; Tipper 1979), and the extremely low ophiacanthid abundances in most Triassic records preclude a meaningful application to the complete data set. Rarefaction analysis is used only to compare selected assemblages in order to test large-scale trends suggested by the $5 \mathrm{Ma}$ interval diversity plot. Computing of the rarefaction values is done using the PAST software (Hammer et al. 2001) based on the algorithm of Krebs (1989).

\section{Results}

\section{Ophiacanthid lineages: palaeo-depths and dating first occurrences}

A total of 122 ophiacanthid species were identified from the samples studied herein (see Appendix 1); 55 of these are here formally described as new, while another 21 species are most probably new as well, but were not named here due to insufficient material. The remaining 19 species, all previously named, are reinterpreted. Based on a careful comparison with lateral arm plates (LAPs) of Recent ophiacanthid species, and on the observation by Thuy \& Stöhr (2011) that LAP morphology generally reflects phylogenetic relationships in ophiuroids, it is possible to identify a number of ophiacanthid lineages (Fig. 1), based on similarities in LAP morphology. These lineages represent groups of species which share a number of distinctive features and thus are more closely related to each other than to any other species. The generic assignment of the species in question is not always fully consistent, because many extant ophiacanthid genera are ill defined (O'Hara \& Stöhr 2006), and because most of the species considered are known exclusively from dissociated lateral arm plates. Thus, the term lineage is used here to designate those groups of species that share similar LAP morphologies and thus almost certainly represent true clades. Once identified, the individual lineages are systematically traced in time and in connection to palaeo-depth estimates.

The vast majority of the lineages are found in the Jurassic, in stark contrast with the very restricted ophiacanthid faunal spectrum in the Triassic. Only a third (33 per cent) of the lineages have a fossil record at shelf depths in the Cretaceous. Approximately half of the lineages have fossil records in both shallow and deep settings at some point of their evolutionary history. In eight lineages, including extant ones, fossil occurrences are restricted to shallow-water deposits, and a single lineage is known exclusively from deep-sea settings. The most intriguing observation, however, is that more than onethird of the lineages identified first occur in deep-sea settings prior to being found in shelf sediments. This is surprising given the overwhelming sampling bias that can be expected from the number of shelf assemblages studied which exceeds that of deep-sea assemblages by an order of magnitude. Conversely, the much greater completeness of the fossil record at shelf depths strongly suggests that the deep origin of the lineages in question is a true signal rather than a sampling artefact. 


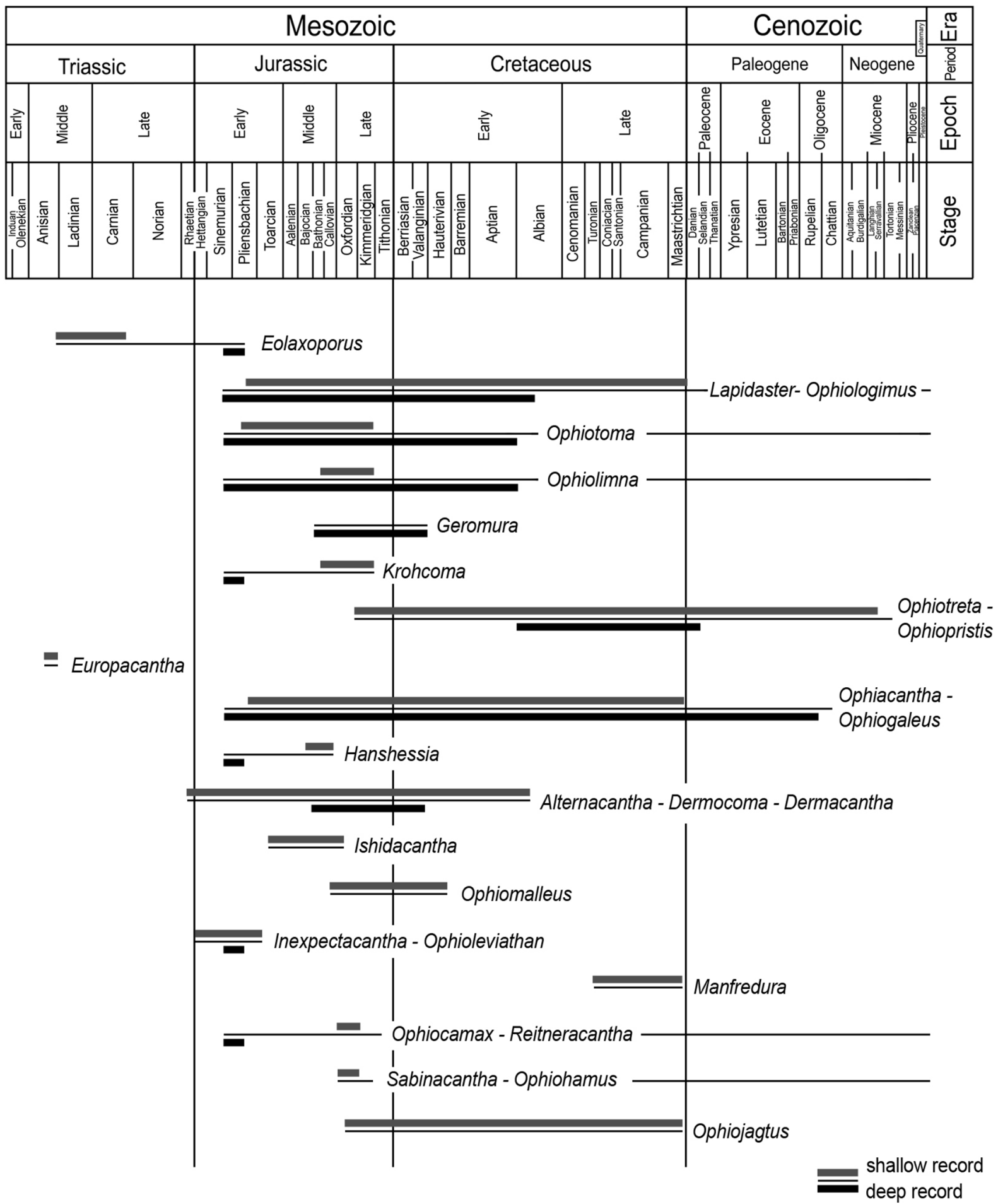

Fig. 1. Ophiacanthid brittle star lineages and their fossil record in shallow $(<200 \mathrm{~m}$ palaeodepth, thick grey lines) and deep ( $>200 \mathrm{~m}$ palaeodepth, thick black lines) environments through time. Extant lineages are indicated by the thin median line extending to the Holocene. 


\section{Calibrated phylogeny versus observed fossil record}

In order to test whether the lineages which first occur at shelf depths are proof of a shallow origin, in line with the assumption of onshore origination, the ophiacanthid phylogeny by Thuy et al. (2012) is revised, inclusive of a number of well-known fossil ophiacanthids to determine the minimum ages of the key nodes. Tree topology (Fig. 2) is basically similar to that of the initial analysis by Thuy et al. (2012), with a slightly lower resolution including three trichotomies rather a single one. Most importantly, however, the new tree corroborates the size of the tentacle pore as one of the major characters of phylogenetic relevance in the Ophiacanthidae, separating the family into a large clade of small-pored taxa and a number of large-pored, basal sister taxa. This is a crucial observation in view of the fact that tentacle pore size can be inferred from the morphology of dissociated LAPs, which can thus be used to bracket the minimum divergence date of the small-pored clade. In addition, the new tree topology agrees with
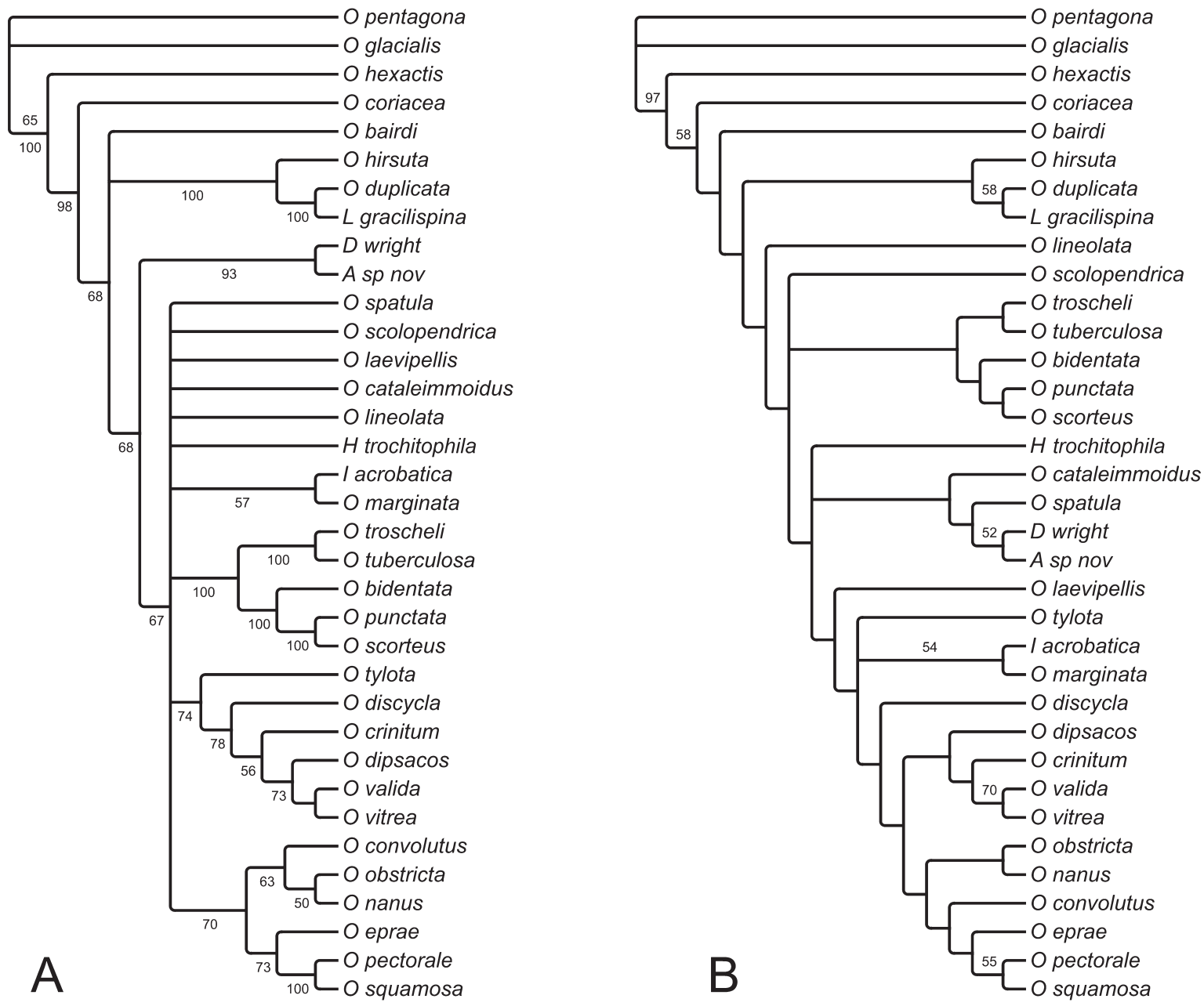

Fig. 2. Phylogeny of the Ophiacanthidae. A. Majority rule consensus of 2572 most parsimonious trees (182 steps length) resulting from the phylogenetic analysis of the full data set. B. Strict consensus of nine most parsimonious trees (47.91375 steps length) resulting from the analysis of the reweighed dataset (characters reweighed by their maximum rescaled consistency index). Numbers above branches represent bootstrap support for the respective nodes (10000 replicates); numbers below branches are node frequencies of the majority rule consensus tree. 
the original one in showing a clade of ophiacanthids with thick disc plates (i.e. composed of the former Ophioplinthacinae Paterson, 1985 and some former hemieuryalids) within the small-pored clade.

Differences between the original tree and the revised one pertain mainly to the position of a few genera. Among the most notable is the position of Ophiocopa spatula Lyman, 1883, sister to the clade formed by the Middle Jurassic Dermocoma wrighti Hess, 1964 and Alternacantha occulta Thuy \& Meyer, 2013, rather than sister to the Early Jurassic Inexpectacantha acrobatica Thuy, 2011 as suggested by the original tree. The new position of Ophiocopa Lyman, 1883 is corroborated by similarities in LAP morphology (see below), in line with observations by Thuy \& Stöhr (2011) on the correlation between LAP morphology and phylogenetic relationship. The Middle Jurassic Hanshessia trochitophila Thuy \& Meyer, 2013 and the Ophiophthalmus-Ophiocopa-Alternacantha-Dermocoma clade are unresolved sister taxa to the large clade that comprises all remaining small-pored ophiacanthids with thick disc plates. As predicted by Thuy \& Schulz (in press), the Late Jurassic Ophiosternle crinitum (Quenstedt, 1876) is a member of the Ophioplinthaca-Ophiocamax-Ophiomitra clade. Finally, the Late Triassic Leadagmara gracilispina Thuy, Ishida, Doi \& Kroh, 2012, holds an even less basal position within the large-pored ophiacanthids than suggested by the original tree. In fact, together with the extant Ophiomedea duplicata Koehler, 1906 and Ophiopristis hirsuta (Lyman, 1875), it forms the direct sister clade to the small-pored ophiacanthids.

In order to place the ophiacanthid fossil record into an evolutionary context, the tree chosen as working hypothesis was transformed into an evolutionary tree using two key fossil occurrences as main calibration points (Fig. 3A). First, the oldest occurrence of an ophiacanthid which unquestionably displays small tentacle pores are dissociated LAPs from Anisian (Middle Triassic) shelf deposits in Hungary, described below as Europacantha paciphila gen. et sp. nov., which astonishingly represent the oldest fossil ophiacanthid remains known to date. This important discovery implies that the small-pored ophiacanthids had already diverged by the Anisian at the latest, and that the large-pored taxa must be even older. Secondly, dissociated LAPs from Pliensbachian deep-sea strata in Austria which display a combination of characters exclusively found in members of the extant Ophiocamax-Ophiomitra clade, imply that even the more derived members of the small-pored ophiacanthids with thick disc plates must have diverged prior to the Pliensbachian. All other divergence times are estimated conservatively on the basis of the oldest fossil occurrences of the respective genera and lineages. The resultant evolutionary tree strongly suggests that almost the entire early cladogenesis in the Ophiacanthidae occurred in preJurassic times.

Next, the fossil record of the ophiacanthids other than those used as calibration points is compared with the evolutionary tree in order to test whether the predicted origination times match the observed first occurrence dates of the respective taxa in shelf deposits, in line with the hypothesis of onshore origination, or not. Almost all taxa with a fossil record at shelf depths first occur in the Jurassic, i.e. much later than predicted by the phylogeny. The pattern is particularly striking in large-pored taxa such as Ophiologimus H.L. Clark, 1911, Ophiotoma Verrill, 1899 and Ophiolimna Verrill, 1899 whose first occurrence dates at shelf depths post-date even the most conservative divergence date estimates by more than $60 \mathrm{Ma}$. The long ghost lineages that result from the discrepancy between the predicted origination and the first occurrence observed at shelf depths challenges the hypothesis of onshore origination.

\section{Relative abundance patterns in the fossil record of ophiacanthids}

While the Ophiacanthidae are here shown to have occurrences at shelf depths extending back to the Middle Triassic, their fossil record is far from homogeneous in terms of relative abundance (Fig. 3). LAP counts clearly show that ophiacanthids were extremely rare in the Triassic, accounting for less than 4 percent in all brittle star assemblages studied. Intriguingly, the highest relative abundances in the pre-Rhaetian Triassic are attained in deep-shelf assemblages (1.6 per cent at Felsöörs and 3.4 per cent 


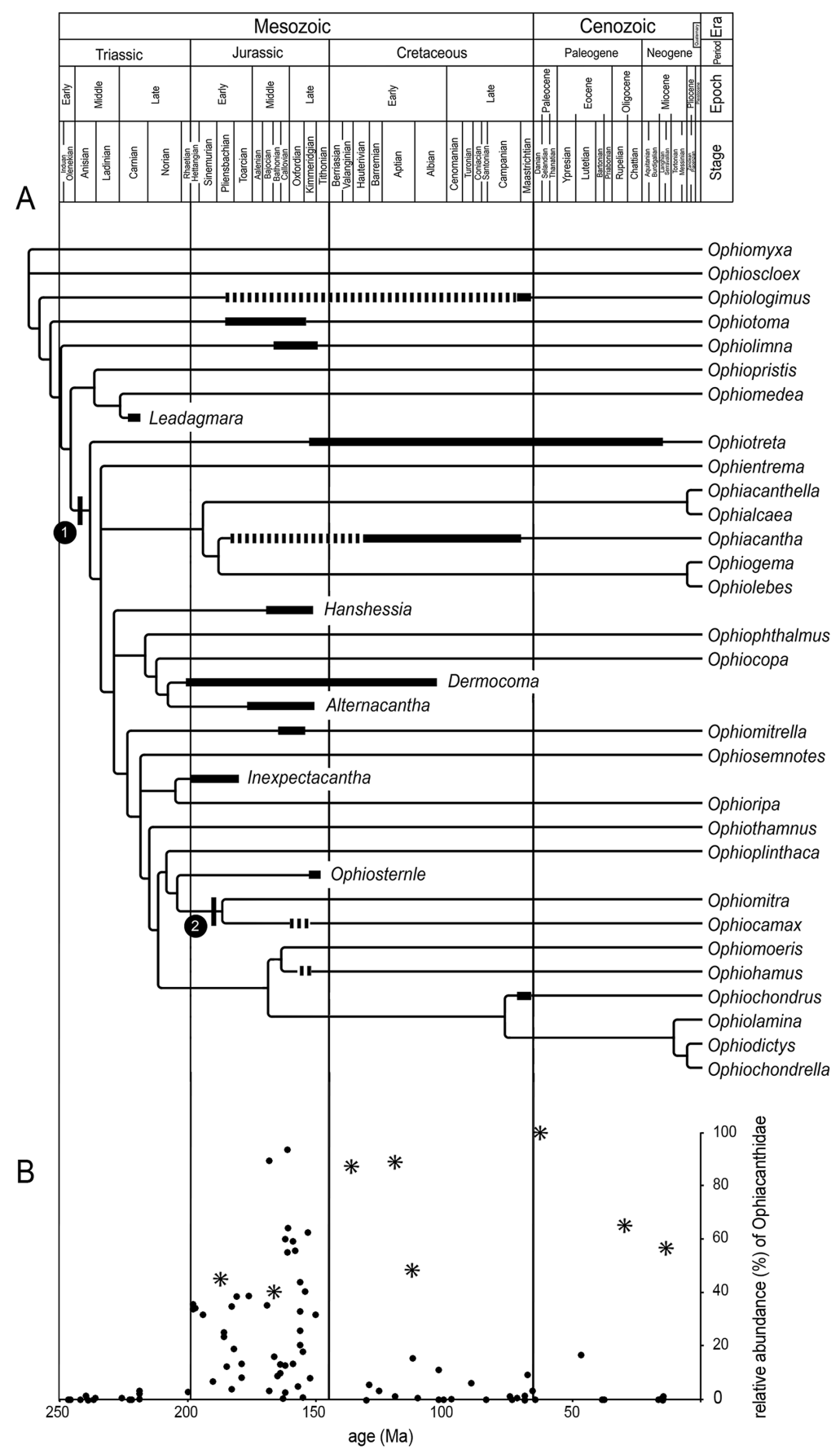

Fig. 3. A. Evolutionary tree of the Ophiacanthidae based on the reweighed dataset tree of Fig. 2B. Calibration is based on nodes marked as 1 (oldest occurrence of small tentacle pores, Europacantha paciphila sp. nov. from the Anisian of Hungary) and 2 (oldest occurrence of lateral arm plate morphology exclusively found in the Ophiomitra-Ophiocamax clade, Reitneracantha dissidens sp. nov. from the late Sinemurian to early Pliensbachian of Austria), and on the first occurrences of a number of extinct genera (Leadagmara Thuy et al., 2012, Dermocoma Hess, 1964, Inexpectacantha Thuy, 2011). Thick lines indicate the observed fossil record of the actual genus, doted lines denote the fossil record of a genus within the same lineage (e.g. Lapidaster sp. nov. in Ophiologimus H.L. Clark, 1911), and thin lines are the expected ranges. B. Relative abundances of the Ophiacanthidae in shallow $(<200 \mathrm{~m}$ palaeodepth, small dots) and deep ( $>200 \mathrm{~m}$ palaeodepth, asterisks) environments through time. 
at Jushui; see Table 1 for locality details). In the Hettangian, abundance abruptly increased to more than 30 per cent and remained high throughout the Jurassic. Peak values ( $>85$ per cent) were reached in a Bajocian shallow-shelf coral reef assemblage from France and a Callovian middle-shelf, muddy bottom assemblage from India. Relative abundance values rapidly dropped again at the end of the Jurassic and remained well below 20 per cent, up to the youngest (middle Miocene) assemblage studied in the present paper. Clearly, the Jurassic was the time when the Ophiacanthidae were most abundant at shelf depths, attaining relative abundances comparable to those observed in present-day bathyal settings (e.g. Clark 1911; Koehler 1922; Metaxas \& Giffin 2004). Interestingly, this trend seems to be independent of habitat type. In fact, shallow-water coral reefs, sponge reefs, mud bottoms and hardgrounds/rocky shores all show highest ophiacanthid abundances in the Jurassic, preceded in all cases by extremely low values in the Triassic, and followed again by low values in the Cretaceous and Cenozoic. In contrast, in all deepsea assemblages studied, inclusive of the Pliensbachian one from Austria, the family accounts for at least 40 per cent of ophiuroid deep-sea communities throughout, in line with present-day relative abundance of the family at bathyal depths (see above).

The main bias in relative abundance patterns is sampling completeness. Incompleteness of the fossil record is inherent to palaeontology. Yet, attempts should be made to keep the data set used for studies of relative abundance patterns as representative as possible in order to make certain that the patterns observed are, indeed, due to shifts in depth distribution of taxa over time rather than the result of regional migrations between shelf habitats. The Triassic record studied herein includes assemblages from the Germanic Basin, the western margin of the Tethys Ocean, the South China terrane and the northwestern margin of Panthalassa (Fig. 4). All yielded very low numbers of ophiacanthid LAPs, if any at all. In addition to these new assemblages, a number of previously published Triassic ophiuroid occurrences from various parts of the Triassic world oceans, including the northeastern margin of Panthalassa in present-day North America, provide useful data (see caption of Fig. 4 for full list of references). In fact, except for the Rhaetian assemblage from the Wombat Plateau (Kristan-Tollmann \& Gramann 1992), none of these previously published Triassic ophiuroid record includes ophiacanthids, not even the extraordinarily thoroughly sampled Central European Muschelkalk Basin (e.g. Hess 1965a; Zatoń et al. 2008). Thus, the extremely low numbers of ophiacanthids at shelf depths during the Triassic appears to be a real phenomenon that begs for an explanation.

The Jurassic record studied herein is strongly biased towards the Peri-Tethys, yet it also includes a number of assemblages from the Malagasy Gulf in the Southern Hemisphere, situated in present-day northwestern India (Scotese 1991). The ophiacanthid abundance patterns of the Malagasy assemblages perfectly match those observed in the Peri-Tethyan area, suggesting that the Jurassic abundance maximum, similar to the Triassic abundance minimum, is a real, global phenomenon. Similarly, Cretaceous and younger abundance values also follow comparable trends in more than one palaeogeographical region.

Very low relative abundance values of ophiacanthids at shelf depths in the Triassic are at odds with the prediction that most of the early cladogenesis of the family occurred at that time. The sudden, habitat type-independent increase in abundance at shelf depths in the Jurassic, paralleled by similarly high abundance values in coeval deep-sea assemblages, is intriguing. It can only be reconciled with the hypothesis of onshore origination when assuming a sudden, massive proliferation of the family at shelf depths long after the initial radiation and almost immediately followed by a similarly massive migration into the deep sea. A much more likely scenario is a sudden large-scale invasion of shelf habitats in the Jurassic as offshoots of previously diversified deep-sea ophiacanthid communities.

\section{Ophiacanthid diversity through time}

Among the 122 ophiacanthid species identified in the present study, 26 species are found in deep-sea settings and the remaining 96 at shelf depths. No species occurs in both shallow and deep sediments. 
More than two-thirds (34) of the shallow-water species are Jurassic in age, whereas only six are known from the Triassic. At the same time, however, the Jurassic yielded more than 29000 specimens from 45 assemblages, compared to only 6051 specimens from 16 assemblages of Triassic age, although both time intervals are of largely comparable duration (Ogg et al. 2008).

A more differentiated picture emerges when species richness values of assemblages lumped in $5 \mathrm{Ma}$ intervals is plotted together with the corresponding numbers of samples and specimens (Fig. 5). The mid-Jurassic and uppermost Cretaceous peaks in species richness coincide with peaks in sample and/ or specimen numbers. Thus, chances are high that these are at least to a considerable extent the result of sampling artefacts. In contrast, the terminal Triassic and lower Jurassic increase in species richness is only weakly paralleled, if at all, by sample and specimen numbers. Most importantly, the OxfordianKimmeridgian species richness maximum, the highest in the entire ophiacanthid shallow-water fossil record, coincides with comparatively low numbers of samples and specimens, not significantly exceeding those of the more completely sampled Triassic intervals.

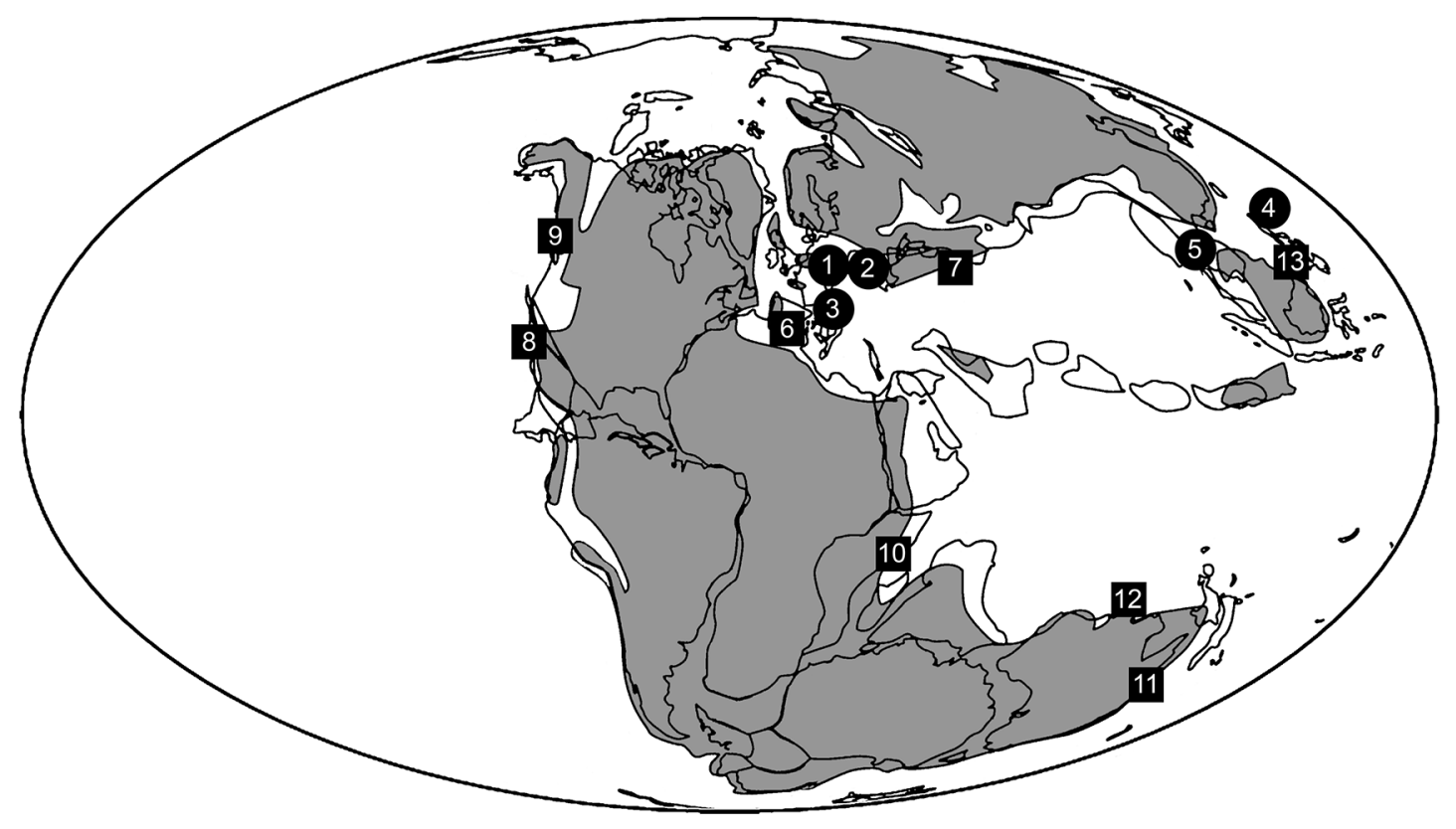

Fig. 4. Palaeogeographic reconstruction for the Middle Triassic [after Smith et al. (1994)] with positions of currently known Triassic ophiuroid occurrences (grey areas indicate emerged land). Round dots indicate assemblages quantitatively assessed in this study (see Table 1 for details). 1. Fischerwiese, Oberscheffach, Schillingstadt. 2. Górazdze, Strzelce Opolski, Felsöörs, Sóly. 3. Alpe di Specie, Romerlo, Milieres, Recoaro. 4. Kitakami Mountains. 5. Jushui. Squares indicate previously published Triassic records. At the same positions as round dots 1-3: Bachmayer \& Kollmann (1968), Broglio Loriga \& Berti Cavicchi (1972), Hess (1970a), Kutscher (1987b, 2000), Radwański (2002), Salamon (2004) and ophiuroid records revised by Hess (1965b). Squares: 6. Calzada \& Gutiérrez (1988). 7. Hess (1972b), Kristan-Tollmann et al. (1979). 8. Twitchett et al. (2005). 9. Zonneveld (2001). 10. Kummel \& Teichert (1970). 11. Runnegar (1969). 12. Kristan-Tollmann \& Gramann (1992). At the same position as round dot 5: Yang (1960), Feng (1985), Chen et al. (2004). Square 13. Ishida et al. (2011). 
In order to test whether the Oxfordian-Kimmeridgian diversity peak is indeed a real phenomenon worth explaining or not, rarefaction analysis was performed to allow for pairwise comparison of OxfordianKimmeridgian and Triassic assemblages from similar habitats. In all cases, Oxfordian-Kimmeridgian species richness values exceed those of the Triassic samples when scaled down to the same sample size. The greatest deviations are found for deep-shelf sponge reefs (3.70 at the Plettenberg, Germany versus 1 at Jushui, China; see Table 1 for locality details), followed by mid-shelf mud bottoms (2.93 in Savigna, France versus 1 at Felsöörs, Hungary; see Table 1 for locality details). These results lend support to the initial observation that ophiacanthid diversity at shelf depths was much higher in the Jurassic than in the Triassic, which strongly suggests that the early diversification of the family in the Triassic, as predicted by the phylogeny (see above), did not occur at shelf depths. Considering the extremely small sample sizes of most Triassic assemblages (e.g. only eight specimens for the mud-bottom assemblage), however, caution must be exercised when interpreting the results.

Interestingly, the highest species richness values per assemblage were found in the lower Maastrichtian deep shelf of Rügen, Germany (eight species), and the two deep-sea assemblages from Blake Nose (eight

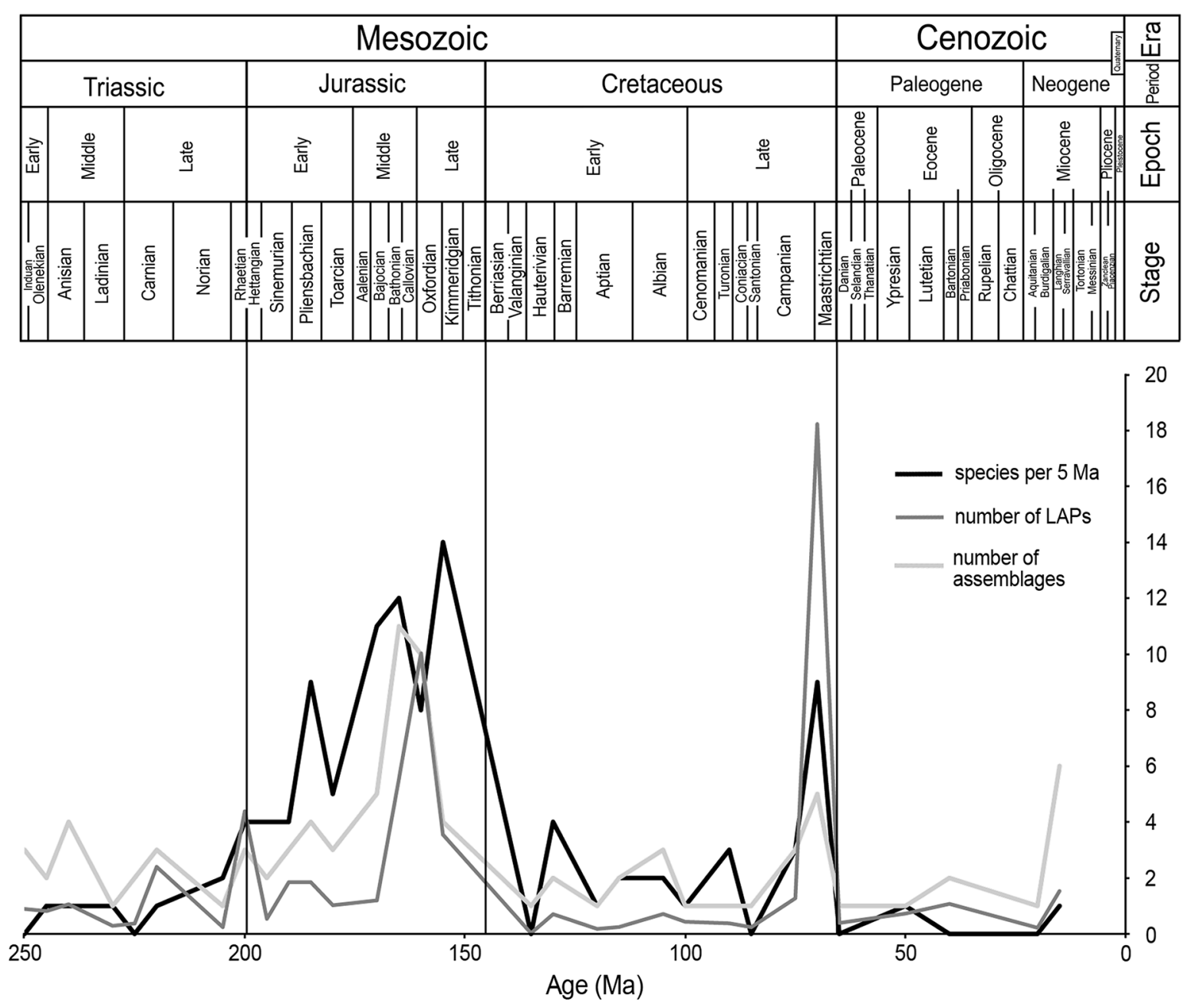

Fig. 5. Diversity of ophiacanthid brittle stars, given as species richness per $5 \mathrm{Ma}$ intervals, in shallowwater $(<200 \mathrm{~m}$ palaeodepth) environments through time, together with corresponding numbers of samples and of lateral arm plates (LAPs) counted (both ophiacanthids and non-ophiacanthids) per interval. Note that the scale for specimen numbers is increased by factor $10^{3}$. 
species) and the Glasenbach Gorge (ten species), although in the last-named some of the ophiacanthid diversity might be the result of faunal mixing in view of its slumping mass nature. When scaled to the sample size of the Glasenbach Gorge assemblage employing rarefaction analysis, Rügen (7.40) and Blake Nose (6.24) still show extraordinarily high species richness unmatched by any other of the assemblages studied. These values are comparable with ophiacanthid diversities of present-day brittle star communities in the deep sea (e.g. Clark 1911). Since Rügen is probably the deepest shelf assemblage considered herein, the above observations suggest that deep environments yield the highest ophiacanthid diversities throughout most of the ophiacanthid evolutionary history, at least since the Early Jurassic, which is hardly reconcilable with the hypothesis of a shallow-water origin (Ricklefs \& Schluter 1993).

\section{Discussion}

The present study documents several lines of evidence which strongly suggest that the Ophiacanthidae originated in the deep sea, temporarily expanded to shelf depths and eventually became largely restricted to the deep sea again:

1) more than one-third of the ophiacanthid lineages identified first occurred in the deep sea, in spite of the much higher completeness of the fossil record at shelf depths;

2) the observed first occurrence dates at shelf depths in the basal large-pored ophiacanthid lineages post-date the predicted originations by more than $60 \mathrm{Ma}$;

3) almost the entire early evolution of the Ophiacanthidae took place in the Early to Middle Triassic, yet ophiacanthids were extremely rare at shelf depths until the Early Jurassic when relative abundances suddenly increased to values typically observed at present-day bathyal depths;

4) fossil deep-sea assemblages, in contrast, displayed very high ophiacanthid relative abundances throughout, at least since the Early Jurassic;

5) the diversity of the family was very low throughout most of the Triassic, and most probably increased in the latest Triassic and Early Jurassic, reaching acme in the Late Jurassic. These observations are hardly reconcilable with the hypothesis of onshore origination of the family, which is thus rejected here.

The conclusion is substantiated by extensive sampling of the Triassic shallow-water fossil record. In combination with numerous previously published occurrences of articulated Triassic ophiuroids, the samples based on dissociated lateral arm plates provide a fairly accurate picture of the Triassic ophiacanthid fossil record at shelf depths. It seems unlikely that the representatives of the numerous originally Triassic lineages which do not appear in shelf environments until the Jurassic were missed out, all the more so in view of the fact that modern ophiuroid distributions at family level are in general anything but patchy (Stöhr et al. 2012). The Triassic record of the Ophiacanthidae is comparable to the present-day distribution of the family at shelf depths consisting of very rare and patchy occurrences of single species (e.g. Baker \& Devaney 1981; O’Hara \& Stöhr 2006; Stöhr 2011). In order to provide the ultimate test of the conclusions reached here, however, Triassic deep-sea ophiuroid assemblages need to be discovered and screened for ophiacanthids. Although unaltered, fossiliferous deep-sea sediments of Triassic age are very rare; however, a few promising outcrops have been described (Guaiumi et al. 2007; Peckmann et al. 2011), suggesting that the search for Triassic deep-sea ophiuroids is not an inconceivable task.

Previously, the extensive fossil occurrences at shelf depths of a number of modern deep-sea groups have commonly been considered as evidence for the long-proposed onshore-offshore trend in the evolution of marine biodiversity (e.g. Moseley 1880; Wolf 1960; Madsen 1961; Clarke 1962; Hessler \& Sanders 1967). The realisation that an originally deep-sea group temporarily invaded shelf environments radically breaks with this paradigm. One of the very few authors to cast a comparably critical light on the shallow-water fossil record of an extant deep-sea group was Vörös (2005), who speculated that 
post-Palaeozoic smooth brachiopods invaded shallow environments as offshoots of stable deep-sea communities in times of suitable palaeoceanographic conditions. The potential of deep-sea groups to contribute to shallow-water diversity has recently been demonstrated by Lindner et al. (2008), who showed that Recent shallow-water stylasterid corals evolved from deep-sea ancestors at least three times. Similar trends may thus be expected in other groups with both shallow and deep representatives. The evidence presented herein, however, is unprecedented in departing from the usual unidirectional assumptions invoking either onshore to offshore shifts or vice versa, but rarely a combination of both. For the first time, a group is shown to originate in the deep-sea, expand to shallow environments and gradually retreat again from the latter.

The model of temporary, large-scale shelf invasion by deep-sea groups provides new, potentially insightful perspectives for a number of key aspects in marine (palaeo)biodiversity. It stresses the necessity of taking into account the possibility of vertical shifts in distribution on macroevolutionary time scales when exploring shallow-marine diversity. Studies of biogeographic patterns of species distributions, for example, almost invariably ignore the possibility of shelf invasion by deep-sea groups (e.g. Goldberg et al. 2005). The present study adds to the growing body of evidence that modern shallow-water environments are not exclusively the result of in situ evolution but received considerable input from deep-sea invaders (Lindner et al. 2008). Although, admittedly, adding the vertical migration component presents the risk of making palaeobiodiversity analyses exceedingly complex, straightforward exclusion of the potential contribution of deep-sea environments to shallow-water diversity is an oversimplification that is no longer tenable.

The model of temporary expansions of deep-sea groups to shelf environments also calls for a fundamental reappraisal of the role of the deep sea in macroevolutionary processes, away from the classic concept of a sink basically accumulating species and lineages from shallow environments, as implicitly stated by the onshore-offshore hypothesis (Jablonski et al. 1983). The conclusions drawn herein significantly add to the growing body of evidence that deep-sea environments provided opportunities for the evolution and diversification of groups that have subsequently invaded other environments (Lindner et al. 2008; Moura et al. 2012). The deep-sea assemblages described herein also suggest that the deep sea provided sufficient resilience against large-scale perturbations to sustain ophiacanthid diversities unmatched by any shallow-water assemblage at least since the Early Jurassic. Clearly, the concept of the deepsea as a refuge for taxa retreating from shelf environments that is episodically swept by large-scale palaeoceanographic perturbations such as Oceanic Anoxic Events (OAEs) (Jacobs \& Lindberg 1998) is untenable.

Finally, the evolutionary history of the Ophiacanthidae as reconstructed in the present study raises the question as to what factors control macroevolutionary shifts in bathymetric distribution. So far, debates have almost exclusively focused on the offshore retreat of groups, arguing for an increase in predation pressure or the evolution of superior competitors (Vermeij 1977, 1987, 1995; Oji 1996; McClintock et al. 1999). In this respect, the data presented here contribute little to the ongoing debates other than to add yet another group to the list of organisms which gradually retreated from shallow depths in the course of the Late Mesozoic.

Much more intriguing is the large-scale, habitat-unspecific invasion of shelf environments around the Triassic-Jurassic boundary. While the present study provides little insight into the actual factors that controlled this deep- to shallow-water pattern, it is among the first to constrain the timing of such a pattern using fossil evidence. The Rhaetian LAP assemblage described herein, in combination with the array of previously published latest Triassic ophiuroid records (see caption of Fig. 4 for a full list of references), suggest that the large-scale invasion of shelf environments started at the very end of the Triassic. It can be speculated that the mass extinction at the Triassic-Jurassic boundary (Benton 
1995) vacated a niche in shelf environments which the ophiacanthids then temporarily filled. Modern ophiacanthids are slow-moving suspension feeders (e.g. McClintock 1994; Metaxas \& Giffin 2004), catching prey using their long spines and tube feet, and often clinging to coral or sponge hosts (Stöhr et al. 2012). Triassic ophiuroids, however, do not include any other long-spined forms which could have occupied the same niche as the Ophiacanthidae, unlike, for instance, members of the modern Ophiothricidae which are the dominant long-spined, suspension-feeding ophiuroids in most present-day tropical to temperate shelf habitats (Jangoux \& Lawrence 1982).

An alternative explanation for the end-Triassic invasion of shelf environments might be sought in globalscale changes in ocean circulation mode. Many modern deep-sea groups are restricted to a particular, comparatively narrow depth range (Menzies et al. 1973), and limits in larval dispersal are among the key factors which constrain the bathymetric range of organisms (Tyler \& Young 1998; Young et al. 1997; AquinoSouza et al. 2008). It has recently been shown that larvae of deep-sea corals generally are retained within water masses rather than migrating among them (Miller et al. 2011), which implies that vertical migration of organisms is most likely to occur when water masses are homogeneous along the depth gradient. Indeed, the thermohaline circulation which connects shallow-water Antarctic environments with the deep Indian, Atlantic and Pacific oceans through an isothermal water column (Rogers 2000), has recently been shown to have played an essential role in the invasion of the deep sea by Antarctic shallow-water octopuses (Strugnell et al. 2008). The cold isothermal water column is assumed to be among the key factors controlling the enhanced eurybathy found among Southern Ocean invertebrates (e.g. Brey et al. 1996; Brandt et al. 2007), involving both the submergence of shallow taxa and the emergence of deep ones. Conversely, in the warm, nearisothermal water column of the present-day Mediterranean, many taxa have a wider bathymetric distribution than e.g. in the thermally more strongly stratified Atlantic (Emig \& Geistdoerfer 2004). Furthermore, Young et al. (1997) documented that the larvae of northeast Atlantic and Mediterranean echinoids were more likely to survive deep-sea pressures at high temperatures than at low temperatures.

During much of the mid- and Late Mesozoic, the prevailing mechanism of deep-water formation was halothermal circulation, the sinking of warm, high-salinity surface waters at low latitudes (Horne 1999). As a consequence, deep water masses were relatively warm $\left(>10^{\circ} \mathrm{C}\right)$ during most of the later Mesozoic (e.g. Huber et al. 2002), and world oceans generally were much less strongly thermally stratified than the present-day major ocean basins due to the cold $\left(\sim 4^{\circ} \mathrm{C}\right)$ deep-water masses that result from surface water sinking at high latitudes. Interestingly, it has been suggested on the basis of ostracod evidence (Kozur 1972) and circulation modelling (Kutzbach \& Guetter 1990) that deep-water masses were cold during most of the Triassic. Based on these observations, it may be speculated that ophiacanthids originated in the pre-Jurassic, presumably cold deep sea, and were only capable of very limited shallow-water invasion until a hypothetical major change in ocean circulation mode around the Triassic-Jurassic boundary led to increased deep-water temperatures. As a consequence, thermal stratification of the water column was attenuated, providing opportunities for enhanced vertical migration of taxa and possibly allowing the Ophiacanthidae to invade shelf environments on a much larger scale than during the Triassic. The ophiacanthid shallow-water fossil record suggests multiple independent invasions of shelf environments by ophiacanthid lineages throughout the Jurassic, rather than a single colonisation event followed by in situ diversification. This pattern is in line with the scenario of enhanced vertical migration potential over a prolonged period, as would be expected from a global-scale change in deep-water circulation mode.

Whatever the causes, the temporary invasion of shelf environments by an originally deep-sea group, as shown here for the Ophiacanthidae, involves processes which are very unlikely to have affected the evolutionary history of a single group without affecting many more. I thus predict that future studies, which should systematically trace the fossil record of modern deep-sea groups and compare it with calibrated phylogenies, will show that temporary expansion to shelf environments was a widespread phenomenon among modern deep-sea groups. 


\title{
Systematic palaeontology
}

\author{
Class Ophiuroidea Gray, 1840 \\ Order Ophiurida Müller \& Troschel, 1840 \\ Family Ophiacanthidae Ljungman, 1867 \\ Genus Eolaxoporus gen. nov. \\ urn:Isid:zoobank.org:act:6C93137E-586A-405A-B553-2359C7534CCE
}

\section{Type species}

Eolaxoporus hagdorni sp. nov. by present designation.

\section{Other species included}

Eolaxoporus imminens sp. nov.

\section{Diagnosis}

Ophiacanthid with lateral arm plates of rectangular outline displaying large tentacle notches; welldeveloped constriction, outer surface without conspicuous ornamentation; two spurs on the outer proximal and inner distal edges; spine articulations with near-parallel, proximally widely separated dorsal and ventral lobes connected distally by sigmoidal fold; tongue-shaped, dorso-proximalwards bent ridge devoid of kinks and widened parts on the inner side.

\section{Etymology}

Name composed of Eos, the Greek goddess of the dawn, laxus, Latin for "wide", and porus, Latin for "pore", in allusion to the fact that this genus represents one of the oldest members of the large-pored ophiacanthid lineages; gender masculine.

\section{Remarks}

Small dissociated lateral arm plates with conspicuously large tentacle notches, a well-developed constriction resulting in an elevated distal part, and spine articulations composed of proximally widely separated dorsal and ventral lobes connected distally by a sigmoidal fold are the commonest and stratigraphically most widely distributed ophiacanthid remains in Triassic shallow-water deposits. The peculiar structure of the spine articulations seems misleading at first, but the presence of a sigmoidal fold (as defined by Martynov 2010) undoubtedly places the present LAP type in the Ophiacanthidae. The size of the tentacle notches implies that the corresponding tentacle pores were large as defined by Thuy et al. (2012). This refers the present LAP type among the basal, large-pored ophiacanthid lineages formerly united as the subfamily Ophiotominae Paterson, 1985 (Paterson 1985).

Indeed, there is a certain resemblance to the LAPs of extant Ophiologimus and, on account of the presence of spurs on the outer proximal and inner distal edges, even a closer match with the LAPs of extinct Lapidaster gen. nov. The structure of the spine articulations, however, differs fundamentally. A new genus, Eolaxoporus gen. nov., is thus erected here to accommodate the LAP type in question. Phylogenetic relations with other large-pored ophiacanthid lineages, however, remain elusive until articulated specimens of this new genus are discovered.

The LAPs described as Ophiacantha? binitorulosa Kristan-Tollmann, Tollmann and Hamedani, 1979 from the Rhaetian of Iran, are probably assignable to Eolaxoporus gen. nov., in particular in view of the nearparallel dorsal and ventral lobes of the spine articulations. In the absence of SEM-supported re-examination of the type material, however, assignment to Eolaxoporus gen. nov. must be treated as questionable. On the basis of the drawings in Kristan-Tollmann et al. (1979), it cannot be decided whether the LAPs of O.? binitorulosa 
display a sigmoidal fold or not; this means that that species cannot even be considered as an unquestionable ophiacanthid record. The LAPs figured by Kristan-Tollmann \& Gramann(1992) as Ophiacantha? binitorulosa from the Rhaetian of the Exmouth Plateau are too poorly preserved to be identifiable.

\section{Eolaxoporus sp.}

Fig. 6: 1

\section{Material examined}

MHI 2083/1 (dissociated LAP) from the uppermost Anisian (middle Triassic) Trochitenkalk of Oberscheffach, Germany.

\section{Description}

MHI 2083/1 is a dissociated, very small, median LAP of near-rectangular outline; approximately 1.5 times wider than high; dorsal edge concave as a result of a well-developed constriction; distal edge slightly convex; ventro-distal tip of LAP slightly protruding; proximal edge concave, too poorly preserved for spurs to be discernible; no conspicuous ornamentation seen on outer surface; mesh size of stereom on outer surface unknown. Four large, ear-shaped spine articulations on slightly elevated distal part of LAP; dorsal and ventral lobes of spine articulations proximally widely separated, horizontally elongate, nearly parallel and slightly arched concentrically; slight dorsalward increase in the size of the spine articulations. Ventral edge of LAP with large, slightly concave tentacle notch.

Inner side of LAP with large, well-defined, bent ridge; dorsal tip of ridge rounded, not widened, pointing dorso-proximalwards; ventral tip of ridge separated from ventral edge of LAP; inner side of distal edge of LAP with two large, poorly defined, slightly prominent spurs, one near the dorso-distal tip and the second near the ventro-distal tip of the LAP.

\section{Remarks}

The single LAP described above is poorly preserved. Yet, it is an important specimen since it is unambiguously assignable to Eolaxoporus gen. nov. on account of the general shape of the LAP, the constriction, the highly distinctive shape of the spine articulations and of the ridge on the inner side, and the very large tentacle notch, and thus documents the presence of the genus in strata as old as Anisian. The specimen shows closest similarities to E. hagdorni sp. nov. but its poor preservation precludes any more detailed comparison on the species level.

Eolaxoporus hagdorni sp. nov. urn:1sid:zoobank.org:act:B382D3C8-B7DC-442C-AA06-CF761442D0DC

Fig. 6: 2-4

\section{Diagnosis}

Species of Eolaxoporus gen. nov. with small LAPs displaying a low height/width ratio; two moderately well-defined spurs on outer proximal and inner distal edges, close to dorsal and ventral edges, respectively; up to four near-horizontal spine articulations; ridge on inner side relatively short and wide.

\section{Etymology}

Named in honour of Hans Hagdorn, who generously provided most of the Triassic samples used in the present study, including those that yielded the type material of the present species.

\section{Type material}

\section{Holotype}

MHI 2084/1. 


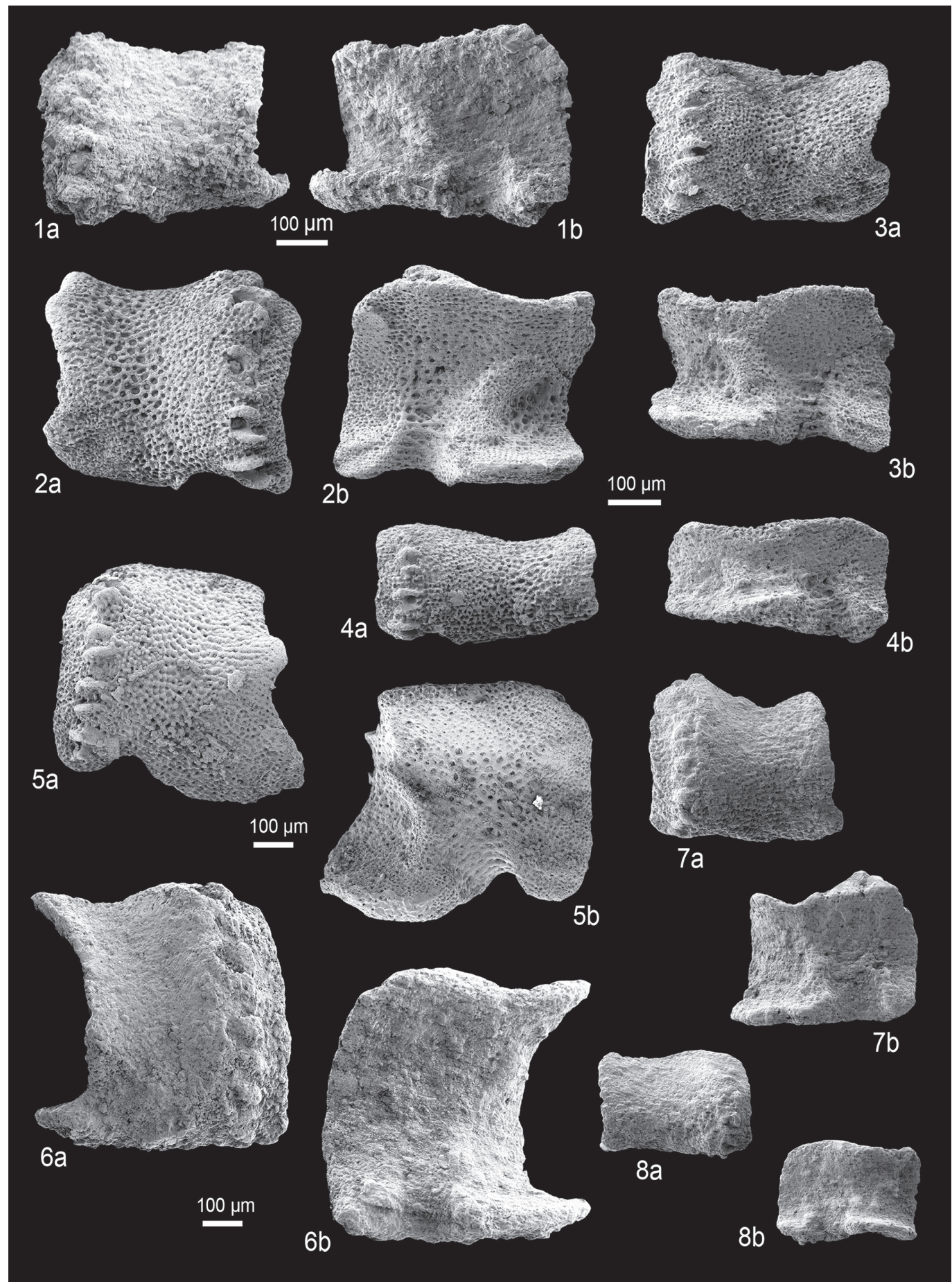

Fig. 6. Fossil lateral arm plates (LAPs) of ophiacanthid brittle stars in external (a) and internal (b) views. 1. Eolaxoporus sp. from the latest Anisian (Middle Triassic) of Oberscheffach, Germany, MHI 2083/1, median LAP. 2-4. Eolaxoporus hagdorni gen. et sp. nov. from the late Carnian (Late Triassic) of Jushui, China. 2. MHI 2084/1 (holotype), proximal LAP. 3. MHI 2085/1 (paratype), median LAP. 4. MHI 2086/1 (paratype), distal LAP. 5. Eolaxoporus sp. nov. innom. from the early Carnian (Late Triassic) of Milieres, Italy; GZG.INV.78500, proximal to median LAP. 6-8. Eolaxoporus imminens gen. et sp. nov. from the late Sinemurian to early Pliensbachian (Early Jurassic) of the Glasenbach Gorge, Austria. 6. NHMW 2012/0137/0001 (holotype), proximal LAP. 7. NHMW 2012/0137/0002 (paratype), median LAP. 8. NHMW 2012/0137/0003 (paratype), distal LAP. One common scale bar per species is given. 
Paratypes

MHI 2085/1 and MHI 2086/1.

\section{Type locality and horizon}

Jushui, Sichuan, China; marly beds in the upper Hanwang Formation, late Carnian, Late Triassic.

\section{Additional material}

MHI 2087/1-35 (35 dissociated LAPs from sample C30); MHI 2088/1-11 (11 dissociated LAPs from sample C36); MHI 2089/1 (1 dissociated LAP from sample C33).

\section{Description}

\section{Holotype}

MHI 2084/1 is a dissociated, small, proximal LAP of rectangular outline; slightly wider than high; dorsal edge strongly concave as a result of a well-developed constriction; ventral fifth of LAP very weakly protruding ventro-proximalwards; ventro-distal tip of LAP protruding; distal edge straight to slightly concave; proximal edge with central notch and two large, moderately well-defined, slightly prominent yet strongly protruding spurs, one in the middle of the dorsal half of the proximal edge, the second in the middle of the ventral half; outer surface lacking conspicuous ornamentation; stereom of outer surface coarsely meshed in a vertical band along the midline of the LAP, becoming more finely meshed towards the proximal edge and towards the spine articulations. Four ear-shaped spine articulations on elevated distal part of LAP; slight dorsalward increase in size of spine articulations and in size of gaps separating them; dorsal and ventral lobes of spine articulations nearly parallel, horizontally elongate, separated proximally by small knobs, connected distally by sigmoidal fold. Ventral edge of LAP with large, concave tentacle notch.

Inner side of LAP with large, prominent, sharply defined, relatively short, tongue shaped, arched ridge; dorsal tip of ridge round, not widened, pointing dorso-proximalwards; ventral tip of ridge widest, sharply defined rather than merged with ventral edge of LAP; inner side of distal edge with two large, well-defined, prominent but not protruding spurs composed of slightly denser stereom, one near dorsodistal tip of LAP, the second near ventro-distal tip. Inner side of tentacle notch with coarsely meshed, slightly horizontally stretched stereom. No perforations discernible.

\section{Paratype supplements and variation}

MHI 2085/1 is a median dissociated LAP of rectangular outline; approximately 1.5 times wider than high; morphologically matching the holotype; spurs on proximal edge less well defined. Four nearly equal-sized spine articulations.

Inner side well in agreement with that of holotype; spurs on distal edge less well defined.

MHI 2086/1 is a dissociated distal LAP; twice wider than high; constriction less well developed than in holotype, thus distal part of LAP less strongly elevated; spurs on proximal edge almost indiscernible. Three nearly equal-sized spine articulations. Ventral edge of LAP with relatively large, gently concave tentacle notch.

Inner side with small, prominent, sharply defined, tongue-shaped knob; two large, poorly defined spurs composed of denser stereom on inner distal edge.

\section{Remarks}

These LAPs can be easily distinguished from the other LAP types assignable to Eolaxoporus n. gen. on account of the vertical spine articulations, in combination with a wide ridge on the inner side and two weakly protruding spurs, the dorsal one of which is close to the dorso-proximal tip of the LAP. It 
displays the highly distinctive combination of characters of Eolaxoporus gen. nov. best and is thus here described as its type species.

\section{Occurrence}

Late Carnian of Sichuan, China.

Eolaxoporus sp. nov. innom.

Fig. 6: 5

\section{Material examined}

GZG.INV.78500 (dissociated LAP) from the Cassian Formation, early Carnian of Milieres, Italy.

\section{Description}

GZG.INV.78500 is a dissociated, small, proximal to median LAP; slightly wider than high; dorsal and distal edges nearly straight; proximal edge gently concave except for very large, conspicuous, strongly protruding, moderately well-defined, prominent and slightly angular spur almost in the middle of the proximal edge and composed of slightly more densely meshed stereom; second much smaller and much less well defined, weakly prominent and non-protruding spur close to ventro-proximal edge of LAP; ventral fifth of LAP strongly protruding ventro-proximalwards; ventro-distal tip of LAP strongly protruding ventralwards, tongue-shaped; outer surface with moderately coarsely meshed stereom. Four moderately large, nearly equal-sized and equidistant spine articulations freestanding on slightly elevated distal portion of LAP; dorsal and ventral lobes of near-equal size, parallel, horizontal, widely separated proximally; gap between spine articulations and distal edge of LAP relatively narrow. Ventral edge of LAP with large, deeply incised, concave tentacle notch.

Inner side of LAP with very small, conspicuously slender, sharply defined, prominent, dorsoproximalwards bent ridge; two rather poorly defined, weakly prominent, round spurs on inner side of distal edge of LAP; inner side of tentacle notch very large. No perforations and furrow discernible.

\section{Remarks}

This single LAP displays all diagnostic characters of Eolaxoporus gen. nov. Within this genus, it is unique in having a strongly protruding, slightly angular dorsal spur almost in the centre of the proximal edge, and a very small, slender ridge on the inner side. The LAP in question certainly belongs to a new species which, in the absence of more material, cannot be described formally for now.

Eolaxoporus imminens sp. nov. urn:1sid:zoobank.org:act:698BEA08-2562-4B83-9062-C09DC982E9A3

Fig. 6: 6-8

\section{Diagnosis}

Species of Eolaxoporus gen. nov. with moderately small LAPs displaying a relatively high height/width ratio; very poorly defined spurs on outer proximal edge; up to five, strongly oblique spine articulations; ridge on inner side of LAP relatively long and slender.

\section{Etymology}

Species name formed after imminere, Latin for "reaching" or "hanging over", in reference of the species being the only known Jurassic species of the otherwise exclusively Triassic Eolaxoporus gen. nov. 


\title{
Type material
}

Holotype

NHMW 2012/0137/0001.

\author{
Paratypes \\ NHMW 2012/0137/0002 and NHMW 2012/0137/0003.
}

\section{Type locality and horizon}

Glasenbach Gorge, Austria; Hauptknollenbrekzie, late Sinemurian to early Pliensbachian, Early Jurassic.

\section{Additional material}

NHMW 2012/0137/0004 (6 dissociated LAPs).

\section{Description}

\section{Holotype}

NHMW 2012/0137/0001 is a dissociated, small, proximal LAP; slightly higher than wide; ventro-distal tip of LAP not protruding; dorsal edge strongly concave as a result of a well-developed constriction; distal edge gently convex; proximal edge strongly concave, with two small, very poorly defined, slightly prominent spurs, one in the middle of the proximal edge, protruding, the second one near the ventroproximal tip of the LAP, not protruding; outer surface without conspicuous ornamentation; finely meshed stereom, becoming slightly more finely meshed towards proximal edge and towards spine articulations. Five large, ear-shaped spine articulations on elevated distal part of LAP; dorsalward increase in size of spine articulations and, a little less strongly, in gaps separating them; spine articulations composed of near-parallel, concentrically arched dorsal and ventral lobes, tilted and therefore dorso-proximally rather than proximally widely separated, connected distally by sigmoidal fold. Ventral edge straight to slightly convex, tentacle notch not visible in external view.

Inner side of LAP with rather narrow, well-defined, finger-shaped, arched ridge, best defined and slightly widened at dorsal and ventral tips; dorsal tip of ridge rounded, pointing dorso-proximalwards; ventral tip sharply separated from thickened ventral edge of LAP; small, moderately well-defined, slightly prominent spur on inner side of ventro-distal tip of LAP; no other spur discernible on inner side of distal edge. Tentacle notch very large. No perforations discernible.

\section{Paratype supplements and variation}

NHMW 2012/0137/0002 is a dissociated median LAP of rectangular outline; dorsal edge strongly concave; ventro-distal tip of LAP slightly protruding; proximal edge of LAP slightly concave with moderately large, poorly defined, prominent spurs, one in the middle of the proximal edge, bluntly protruding, the second one close to the ventro-proximal tip of the LAP. Five spine articulations, similar to those of holotype. Ventral edge of LAP with large, but weakly concave tentacle notch.

Inner side similar to that of holotype.

NHMW 2012/0137/0003 is a dissociated distal LAP of rectangular outline; almost twice wider than high; dorsal edge slightly less concave than in holotype; ventral spur on proximal edge moderately well defined, prominent; no spur discernible in centre of proximal edge. Four spine articulations, similar to those of holotype. Ventral edge of LAP slightly concave; tentacle notch not visible in external view.

Inner side with narrow, bent, well-defined ridge; dorsal and ventral tips best defined and widest; dorsal tip pointing dorso-proximalwards; inner side of ventro-distal tip with large, prominent, well-defined, horizontally elongate spur; no other spur discernible on inner side of distal edge. Tentacle notch very large. No perforations visible. 


\section{Remarks}

These LAPs display the highly distinctive combination of characters typically found in Eolaxoporus gen. nov., although the oblique spine articulations are unusual. Nevertheless, this LAP type appears best placed in Eolaxoporus gen. nov. and can be easily differentiated from its congeners on account of the oblique spine articulations and the very poorly developed spurs on the outer proximal and inner distal edges.

\section{Occurrence}

Late Sinemurian to early Pliensbachian of Austria.

Genus Lapidaster gen. nov.

urn:1sid:zoobank.org:act:C21FF4FC-5361-44D5-ACC9-6AD5907BAC90

\section{Type species}

Lapidaster hystricarboris sp. nov., by present designation.

\section{Other species included}

Lapidaster caeloscopus sp. nov., Lapidaster coreytaylori sp. nov., Lapidaster etteri sp. nov., Sinosura fasciata Kutscher \& Villier, 2003, Lapidaster lukenederi sp. nov., Lapidaster mastodon sp. nov., Lapidaster mathcore sp. nov., Lapidaster wolfi sp. nov. and Lapidaster varuna sp. nov.

\section{Diagnosis}

Ophiacanthid with lateral arm plates displaying large tentacle notches; spine articulations not positioned on elevated ridge and not sunken into depressions or notches; ventral portion of lateral arm plate protruding ventro-proximally; generally single, poorly to moderately defined, spur on outer proximal and inner distal edge of lateral arm plate; inner side with single, well-defined ridge generally separated by rounded kink into dorsal and ventral halves.

\section{Etymology}

Name composed of lapis, Latin for "rock", and aster, Greek for "star", in reference to three species of the genus being named after rockstars; gender masculine.

\section{Remarks}

Lateral arm plates with a conspicuous, large tentacle notch combined with a strongly protruding ventroproximal portion of the plate and spine articulations which are neither on an elevated vertical ridge nor sunken in depressions of the distal plate edge are a common and morphologically diverse component of many Jurassic and Cretaceous ophiuroid assemblages (see below for details of distribution). The large ventral notches of the LAPs imply that the forms they belong to had large tentacle pores as defined by Thuy et al. (2012), which places them among the basal, large-pored ophiacanthid lineages formerly united as the subfamily Ophiotominae (Paterson 1985). Indeed, there are striking morphological similarities between the LAPs of the fossils considered here and those of extant Ophiologimus H.L. Clark, 1911 (Fig. 11: 1), in particular with regard to the development of the tentacle notch and the ventro-proximal portion of the plate, and the position and arrangement of the spine articulations. There are superficial similarities to the LAPs of extant Ophiotoma Verrill, 1899. In that genus, however, the spine articulations generally are slightly sunken into depressions of the distal plate edge, and the ridge on the inner side of the plate displays two kinks instead of one.

As clearly shown by Thuy \& Stöhr (2011), the greater the similarity between LAP morphologies, the more closely related the species in question are. In the present case, the above-mentioned fossil LAPs 
are so similar to the LAPs of Ophiologimus that they, indeed, belong to Ophiologimus or at least to a very closely related genus. The latter possibility is preferred here since the fossil LAPs differ, albeit only slightly, from those of Ophiologimus in generally displaying a spur on the outer proximal and inner distal plate edges. Thus, Lapidaster gen. nov. is erected here to accommodate dissociated fossil LAPs which are most closely similar to those of Ophiologimus. The great similarities in LAP morphology, however, strongly suggest that Ophiologimus and Lapidaster gen. nov. are sister taxa, although definite proof for the existence of an Ophiologimus-Lapidaster lineage can solely be gleaned from articulated specimens of Lapidaster gen. nov.

\section{Lapidaster caeloscopus sp. nov. urn:Isid:zoobank.org:act:C670AEE6-65DA-49F5-B098-A8E1E372063A}

Fig. 7: 1-3

\section{Diagnosis}

Species of Lapidaster with small, elongate LAPs of trapezoid outline, well-developed constriction and strongly enlarged dorsalmost spine articulation pointing dorsally.

\section{Etymology}

Name composed of caelum, Latin for "sky", and scopus, Latin for "target", in reference to the large, dorsally pointing, or "skygazing", dorsalmost arm spine articulation in this species.

\section{Type material}

\section{Holotype}

NHMW 2012/0137/0005.

\section{Paratypes}

NHMW 2012/0137/0006 and NHMW 2012/0137/0007.

\section{Type locality and horizon}

Glasenbach Gorge, Austria; Hauptknollenbrekzie, late Sinemurian to early Pliensbachian, Early Jurassic.

\section{Additional material}

NHMW 2012/0137/0008 (12 dissociated LAPs).

\section{Description}

\section{Holotype}

NHMW 2012/0137/0005 is a dissociated, very small, proximal LAP, somewhat wider than high, of irregularly rectangular to trapezoid outline, with slightly concave dorsal edge as a result of a weak constriction; slightly concave distal edge; ventral fifth of LAP protruding ventro-proximalwards; ventrodistal tip of LAP very large, tongue shaped, strongly protruding ventro-distalwards; proximal edge of LAP almost straight to slightly concave, except for sharp kink in ventral quarter; the latter ventrally bordered by well-defined, elongate, lens-shaped and strongly prominent spur; outer surface with finely to moderately coarsely meshed stereom, with trabeculae not merged into vertical striation. Three earshaped spine articulations; conspicuously wide gap between spine articulations and distal edge of LAP; very strong dorsalward increase in size of spine articulations; dorsalmost spine articulation more than twice larger than ventralmost one, conspicuously pointing dorsalwards; dorsal and ventral lobes of spine articulations forming continuous volute; dorsal gap between spine articulations slightly larger than ventral one. Ventral edge of LAP with very large, concave tentacle notch. 


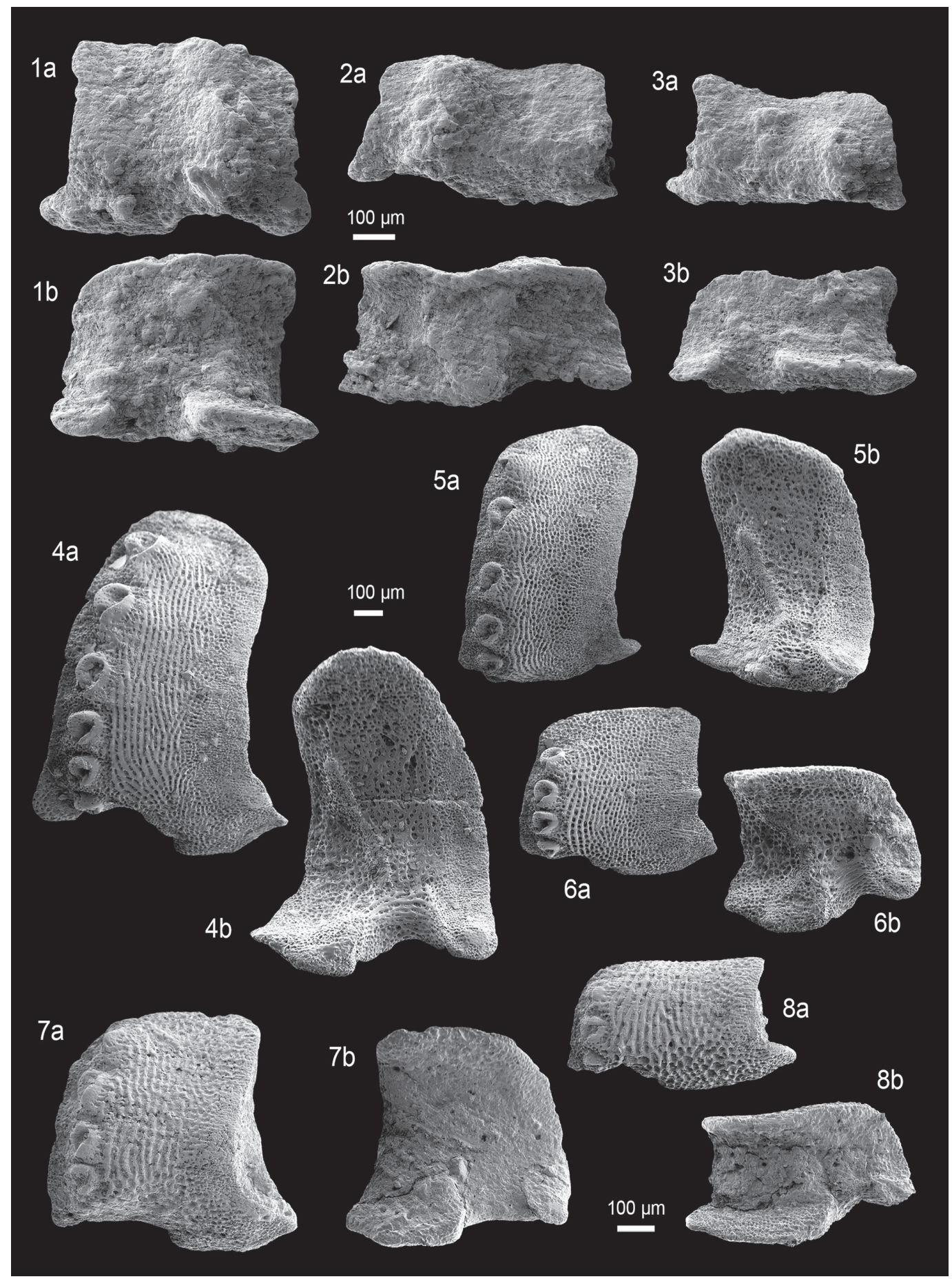

Fig. 7. Fossil lateral arm plates (LAPs) of ophiacanthid brittle stars in external (a) and internal (b) views. 1-3. Lapidaster caeloscopus gen. et sp. nov. from the late Sinemurian to early Pliensbachian (Early Jurassic) of the Glasenbach Gorge, Austria. 1. NHMW 2012/0137/0005 (holotype), proximal LAP. 2. NHMW 2012/0137/0006 (paratype), median LAP. 3. NHMW 2012/0137/0007 (paratype), distal LAP. 4-6. Lapidaster hystricarboris gen. et sp. nov. from the early Pliensbachian (Early Jurassic) of Blockley, Great Britain. 4. GZG.INV.78501 (holotype), proximal LAP. 5. GZG.INV.78502 (paratype), median LAP. 6. GZG.INV.78503 (paratype), distal LAP. 7-8. Lapidaster fasciatus (Kutscher \& Villier, 2003) comb. nov. from the middle Toarcian (Early Jurassic) of Le Clapier, France. 7. GZG.INV.78505, proximal LAP. 8. GZG.INV.78506, distal LAP. One common scale bar per species is given. 
Inner side of LAP unfortunately partially obscured by sediment; ridge discernible, well defined, prominent, nearly straight to slightly bent, narrow, small and conspicuously short, hardly reaching horizontal midline of LAP, ventral tip of ridge well defined, not merged with slightly thickened ventral part of LAP; inner side of ventro-distal tip of LAP thickened into large, prominent, elongate and slightly protruding spur composed of dense stereom. Inner side of large tentacle notch obscured by sediment; presence of possible perforations on inner side indeterminable.

\section{Paratype supplements and variation}

NHMW 2012/0137/0006 is a dissociated median LAP, approximately twice wider than high, of trapezoid outline; ventro-distal tip of LAP very large and strongly protruding; dorsal edge clearly concave as a result of the constricted outer surface; distal edge oblique, straight to slightly convex; dorsal four-fifths of proximal edge evenly convex; ventral fifth of proximal edge separated from the latter by sharp kink, ventrally bordered by moderately well-defined, prominent, elongate spur. Three spine articulations; dorsalward increase in size much weaker than in holotype; dorsalmost spine articulation slightly larger than remaining two, pointing dorsalwards; conspicuously wide gap between row of spine articulations and distal edge of LAP, as in holotype. Ventral edge of LAP with very large, gently concave tentacle notch. Inner side of LAP largely obscured by sediment; ridge similarly short as in holotype; inner side of ventro-distal tip of LAP with large, oval, strongly prominent spur composed of dense stereom.

NHMW 2012/0137/0007 is a dissociated distal LAP, more than twice wider than high, with strongly concave dorsal edge indicating a strong constriction; proximal edge undulose, with central convex part and ventral quarter sharply separated by kink; the latter bordered by relatively large, yet poorly defined, elongate, prominent spur. Two spine articulations, one near the ventral edge of the LAP, the second in the middle of the LAP, slightly larger than the ventral one. Ventral edge of LAP almost straight, except for large, yet only weakly concave tentacle notch.

Inner side with very small, short, knob-like, prominent and well-defined ridge, widest ventrally and not merged with ventral part of LAP.

\section{Remarks}

The very small, dissociated LAPs of Lapidaster caeloscopus sp. nov. are unique in displaying a strongly enlarged dorsalmost spine articulation which points dorsally. The irregular trapezoid outline of the LAPs, as well as the very short ridge on the inner side, are further characters which clearly set the LAPs of L. caeloscopus sp. nov. apart from any other known type of LAPs. Greatest similarities are shared with the LAPs of Lapidaster lukenederi sp. nov. (see below) from the Valanginian of Austria, especially on account of the constriction, the rather thin plate architecture, the small size, and the height/width ratio of the proximal LAPs, which is indicative of elongated arm segments, a typically paedomorphic character (Stöhr 2005). In contrast, similarities to the distal LAPs of Reitneracantha dissidens sp. nov., which occur in the same samples, are merely superficial and limited to the enlarged dorsally pointing spine articulations found in both species. Almost all other characters, in particular the development of the tentacle notch, the outer surface ornamentation and the morphology of the spine articulations clearly differ in both species.

Assignment to Lapidaster gen. nov. is suggested here on account of the general Ophiologimus-like LAP morphology (very large tentacle notch, ventro-proximalwards protruding ventral portion of LAP, strongly protruding ventro-distal tip of LAP, spine articulations neither sunken in depressions nor positioned on strongly elevated ridge), combined with the presence of a well-developed spur on the outer proximal and inner distal edges of the LAP.

\section{Occurrence}

Late Sinemurian to early Pliensbachian of Austria. 


\section{Lapidaster hystricarboris sp. nov. urn:1sid:zoobank.org:act:FBF92066-FE54-4400-867E-FE2E3845307A}

Fig. 7: 4-6

\section{Diagnosis}

Species of Lapidaster gen. nov. with relatively large LAPs displaying a very finely striated outer surface and up to six spine articulations increasing in size dorsalwards.

\section{Etymology}

Name derived from Hystrix, a genus of porcupine, and arbor, Latin for "tree", in honour of Steven Wilson, Richard Barbieri, Gavin Harrison and Colin Edwin of Porcupine Tree whose music was a fertile source of inspiration whenever the creative process of the present study threatened to come to a halt.

\section{Type material}

\section{Holotype}

GZG.INV.78501.

\section{Paratypes}

GZG.INV.78502 and GZG.INV.78503.

\section{Type locality and horizon}

Blockley, near Cheltenham, Great Britain; shell lenses in clay matrix, Davoei Zone, early Pliensbachian, Early Jurassic.

\section{Additional material}

GZG.INV.78504 (41 dissociated LAPs).

\section{Description}

\section{Holotype}

GZG.INV.78501 is a dissociated, medium-sized, proximal lateral arm plate, almost twice higher than wide, with rounded outline, ventral quarter of plate protruding ventro-proximalwards; conspicuous, tongue-like ventro-distal protrusion; dorsal edge of LAP strongly convex; proximal edge gently concave, with single poorly defined, slightly protruding spur close to ventro-proximal tip of the LAP, no other spurs discernible on outer proximal edge; distal edge gently convex; no constriction. Outer surface with irregular vertical striation consisting of very fine ridges separated by narrow bands of fenestrate stereom; ridges irregularly converging on ventral half of outer surface; striation rapidly grading into fine granulation followed by finely meshed stereom towards the proximal edge of the LAP; striation sharply separated from three ventralmost spine articulations, and confluent with the proximal edges of the three dorsal spine articulations, with conspicuous overlap of the striation onto the proximal edge of the dorsalmost spine articulation. Six large, ear-shaped spine articulations freestanding in continuous vertical row close to distal edge of LAP; dorsal and ventral lobes forming continuous volute; dorsalward increase in size of spine articulations and gaps separating them. Ventral edge of LAP with large, conspicuous, evenly concave tentacle notch.

Inner side of LAP with single thin, well-defined, prominent, oblique ridge, slightly widening towards its rounded dorsal tip; dorsal half of ridge nearly straight, not reaching dorsal or proximal edges of LAP, ventral half gently bent, poorly defined and confluent with thickened ventral quarter of LAP; irregular set of perforations on inner side of LAP, hardly discernible as vertical row corresponding to spine articulations; distal edge of LAP thinning distalwards; inner side of ventro-distal protrusion with well- 
defined, prominent knob, corresponding to poorly developed spur on outer proximal edge of the LAP. Inner side of tentacle notch with coarsely reticulate stereom reminiscent of horizontally stretched glue.

\section{Paratype supplements and variation}

GZG.INV.78502 is a dissociated median lateral arm plate, slightly higher than wide; overall morphology agreeing well with holotype. Dorsal edge nearly straight, ventro-distal tip of LAP hardly protruding; proximal edge of LAP strongly concave, with large, poorly defined and barely prominent and protruding spur near ventro-proximal tip of plate, and small, sharply defined, prominent and slightly protruding dorsal spur. Vertical striation on outer surface separated from three ventral spine articulations, confluent with proximal edge of two dorsal spine articulations. A total of five large spine articulations with clear dorsalward increase in size and gaps separating them. Dorsalmost spine articulation, as in holotype, with clear onlap of striation onto proximal edge.

Inner side of LAP in agreement with morphology of holotype; no perforations discernible. Very poorly defined, barely prominent spur in the centre of the inner distal edge of the LAP; spur on inner side of ventro-distal tip of LAP poorly developed, slightly prominent.

GZG.INV.78503 is a dissociated distal lateral arm plate, approximately 1.5 times wider than high. Dorsal edge oblique and straight to very gently convex; ventro-distal tip of LAP slightly protruding; proximal edge of LAP with very well-defined, prominent and clearly protruding spur in centre and second, poorly defined and slightly prominent spur close to ventro-proximal tip of LAP. Vertical striation on outer surface separated from three ventral spine articulations, slightly confluent with single dorsalmost spine articulation. A total of four, near-equal sized spine articulations, the dorsalmost separated from the remainder by a slightly larger gap. Inner side well in agreement with holotype. Two well-defined, prominent spurs on inner distal edge of LAP, corresponding to spurs on outer proximal edge. Single irregular perforation on inner side. Tentacle notch conspicuously large, very similar to notch observed in holotype.

\section{Remarks}

The large size of the LAPs of Lapidaster hystricarboris sp. nov. and their high number of spine articulations differentiaties them from almost all other LAP types assigned to this new genus. Greatest similarities are shared with the LAPs of Lapidaster wolfii sp. nov. In the latter, however, the spine articulations lack the dorsalward increase in size, and the vertical striation of the outer surface is very coarse, yet faint, in contrast to the well-developed, fine striation observed in L. hystricarboris sp. nov. There is a certain resemblance with the LAPs described as Ophiacantha? rugosa Kutscher \& Jagt, 2000 by Kutscher \& Jagt (2000) from the early Maastrichtian of Germany and Denmark, and here re-assigned to Ophiologimus (see below). The LAPs of L. hystricarboris sp. nov., however, differ in displaying a spur on the outer proximal and inner distal edges, and in having a continuous ridge on the inner side rather than two separate knob-like structures. Lapidaster hystricarboris sp. nov. best exemplifies the great similarities, along with slight yet diagnostic differences, between Lapidaster gen. nov. and Ophiologimus, and is therefore chosen as the type species of the former.

\section{Occurrence}

Early Pliensbachian of Great Britain.

Lapidaster fasciatus (Kutscher \& Villier, 2003) comb. nov.

Fig. 7: 7-8

Sinosura fasciata Kutscher \& Villier, 2003: 185, pl. 3 fig. 9, pl. 4 figs 1-2.

Sinosura schneideri - Kutscher 1996: p. 9, pl. 2 figs 6-8 (material incorrectly assigned to Sinosura schneideri Kutscher, 1987). 


\section{Diagnosis}

Species of Lapidaster gen. nov. with small- to medium-sized LAPs displaying an irregular, coarse vertical striation, a relatively short ridge on the inner side, and up to four spine articulations composed of confluent dorsal and ventral lobes.

\section{Material examined}

GZG.INV.78505, GZG.INV.78506 and GZG.INV.78507-1 (16 dissociated LAPs) from the Middle Toarcian of Le Clapier, France; GZG.INV.78507-2 (8 dissociated LAPs) from the Causses, France; type material of Kutscher \& Villier (2003) from the late Toarcian of Sainte-Verge, France; original material of Kutscher (1996) from the Toarcian/Aalenian of Quedlinburg, Germany.

\section{Description}

Relatively small LAPs, proximal ones slightly higher than wide, median ones slightly wider than high and distal ones nearly twice wider than high, with gently convex distal edge; dorsal edge slightly convex (proximal LAPs) to slightly concave (distal LAPs); ventral fifth to quarter of LAP protruding ventroproximalwards; ventro-distal tip of LAP pointed, protruding; proximal edge irregularly concave, with poorly (in proximal LAPs) to well-defined (in distal LAPs), obliquely elongate, slightly prominent spur near ventro-proximal tip, composed of slightly denser stereom; outer surface with coarsely meshed stereom, with trabeculae merging into irregular but well-developed vertical striation. Three (distal LAPs) to four (proximal LAPs) moderately large, ear-shaped spine articulations, with dorsal and ventral lobes forming continuous volute; dorsalward increase in size of spine articulations, with dorsalmost one, however, smaller than second dorsalmost; dorsalward increase in size of gaps separating spine articulations; two to three ventral spine articulations separated from striated outer surface by irregular, confluent areoles of slightly more finely meshed stereom; dorsalmost spine articulation embedded in striated outer surface. Ventral edge of LAP with large, deeply concave tentacle notch.

Inner side of LAP with sharply defined, rather narrow ridge, dorsal portion of which oblique and slightly bent, not widened dorsally and not approaching dorsal or proximal edges of LAP; ventral portion of ridge separated from dorsal one by slightly rounded kink, very short, rapidly merging into thickened ventral part of LAP; inner side of ventro-distal tip of LAP with small, moderately well-defined, slightly prominent spur. Inner side of large tentacle notch with coarsely reticulate, horizontally stretched stereom.

\section{Remarks}

These LAPs seem to be identical with those described and illustrated by Kutscher (1996) from the Toarcian and Aalenian of Germany and assigned to Sinosura schneideri Kutscher, 1987. Similar LAPs from the Toarcian of France have subsequently been described by Kutscher \& Villier (2003), who reassigned them to their new species Sinosura fasciata Kutscher \& Villier, 2003. The genus Sinosura Hess, 1964 was introduced by Hess (1964) to accommodate fossil ophiuroid species with fragile LAPs displaying a vertical striation, a wide gap between the spine articulations and the distal edge of the LAP and well-developed spine articulations. Superficially, the LAPs described by Kutscher (1996) and Kutscher \& Villier (2003) fit this diagnosis. However, an examination of the type material of Sinosura brodiei (Wright, 1866), the type species of the genus, from the Pliensbachian of Great Britain, as well as of additional, exceptionally well-preserved material from the Pliensbachian of France (Thuy et al. 2011) has revealed a fundamental difference in spine articulation morphology. While the spine articulations in S. brodiei are of the ophioleucinid type as described by Martynov (2010), those of Sinosura fasciata are ear-shaped with a sigmoidal fold, as typically found in the Ophiacanthidae (Martynov 2010). On the basis of the clearly ophiacanthid spine articulation structure in combination with the generally Ophiologimus-like morphology and the presence of a spur on the outer proximal and inner distal edges, Sinosura fasciata is here transferred to Lapidaster gen. nov. 
Lapidaster fasciatus comb. nov. differs from $L$. hystricarboris sp. nov. and $L$. wolfii sp. nov. in displaying a much lower number of spine articulations. Lapidaster lukenederi sp. nov. and L. etteri sp. nov. both have constricted LAPs in contrast to L. fasciatus comb. nov., and in L. coreytaylori sp. nov. the trabeculae of the outer surface stereom are very thick and not merged into vertical stripes. Greatest similarities are shared with $L$. mastodon sp. nov. and L. varuna sp. nov. In the former, however, the LAPs have a much less strongly protruding ventro-distal tip, generally no more than three spine articulations, separated ventral and dorsal lobes of the spine articulations, and a more rounded overall aspect. In L. varuna sp. nov., the ridge on the inner side of the LAP is longer, and the vertical striation on the outer surface is much less developed.

\section{Occurrence}

Middle and Late Toarcian of France; Toarcian/Aalenian of Germany.

Lapidaster sp. nov. innom. 1

Fig. 8: 1

p.p. Ophiacantha? toarcensis - Hess 1962: 649 (Schicht C) (original specimen incorrectly assigned to Ophiacantha? toarcensis Hess, 1962).

\section{Material examined}

NHMB M11208 (dissociated LAP) from the late Toarcian of Seewen, Switzerland, the original material of Hess (1962).

\section{Description}

Single dissociated, median to proximal LAP, slightly wider than high, dorsal edge nearly straight, distal edge strongly convex; ventral fifth protruding ventro-proximalwards; ventro-distal tip of LAP large, rounded, protruding; proximal edge concave, with large, strongly protruding, sharply defined, horizontally elongate, lens-shaped, prominent spur in the middle, and with second horizontally elongated, lens-shaped but slightly smaller, less well-defined, less prominent and protruding spur close to ventroproximal tip of LAP; outer surface with very slight constriction, and with coarsely meshed stereom; trabeculae of outer surface stereom showing weak tendency to merge into short, irregular vertical stripes close to row of spine articulations. Four small spine articulations, ventralmost slightly smaller than other three; dorsal and ventral lobes separated by small, round knob; strong dorsal increase in size of gaps separating spine articulations; two ventral spine articulations separated from coarsely meshed outer surface stereom by faint, irregular, confluent areoles; two dorsal spine articulations embedded in outer surface stereom. Ventral edge of LAP with large, moderately deep tentacle notch.

Inner side of LAP with sharply defined, dorsal portion of which straight to slightly bent, not widened dorsally and not approaching ventral or dorsal edges of LAP; ventral portion of LAP separated from dorsal one by rounded kink, very short and sharply defined, not merging with ventral part of LAP; inner distal edge with two large, well-defined, horizontally elongate, prominent spurs composed of dense stereom, ventral one of which slightly protruding. Inner side of tentacle notch moderately large and with coarsely meshed, slightly horizontally stretched stereom. No perforations discernible on inner side.

\section{Remarks}

Among the original material of Ophiacantha? toarcensis Hess, 1962 from the Toarcian of Switzerland, here reassigned to Dermocoma Hess, 1964 (see below), is a single LAP which obviously does not belong to that species. A detailed re-examination of that plate has revealed that it is a species of Lapidaster gen. nov., on account of its Ophiologimus-like morphology and the presence of spurs on the outer proximal and inner distal edges. The unusually small spine articulations composed of separated dorsal and ventral 


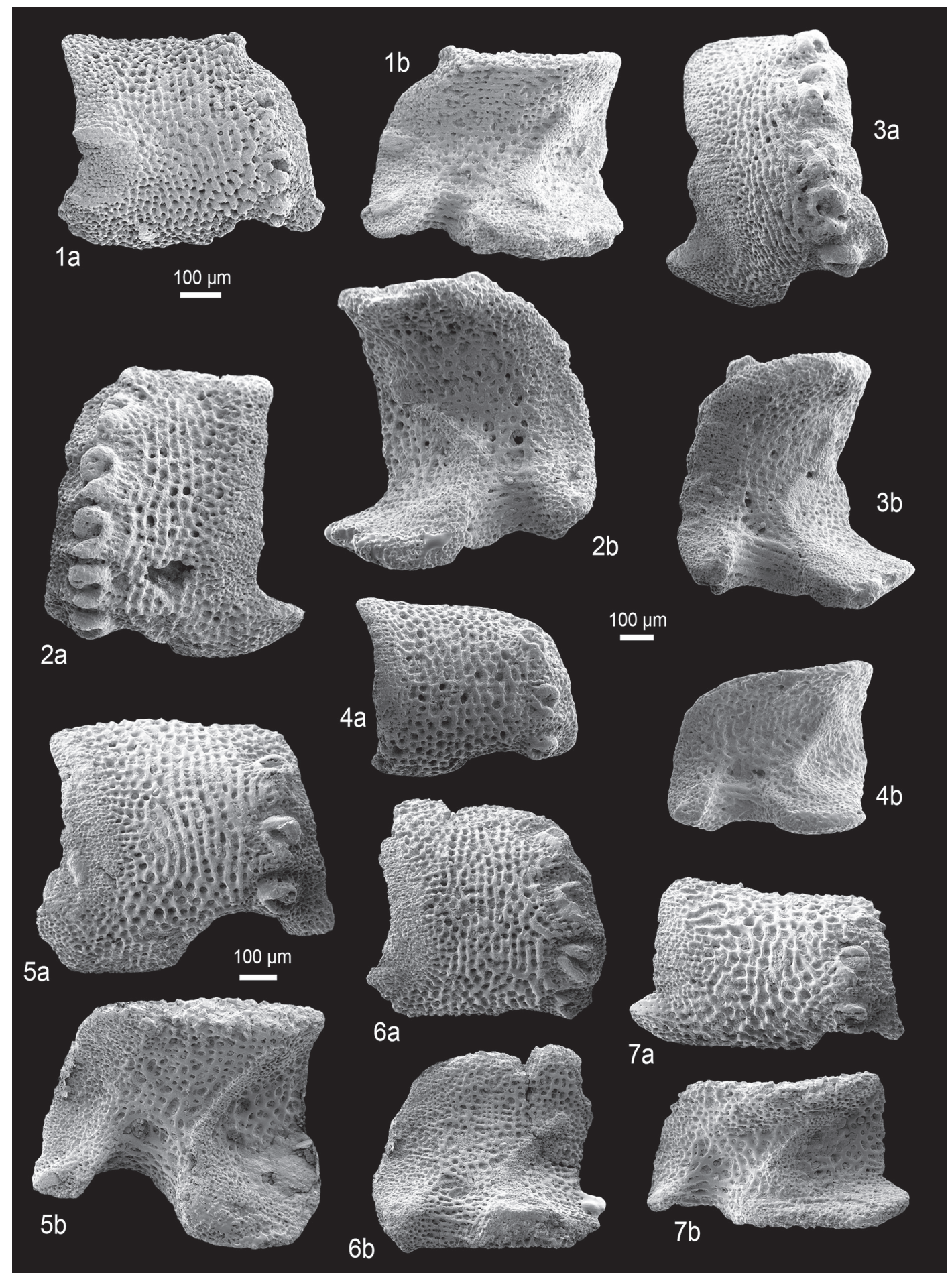

Fig. 8. Fossil lateral arm plates (LAPs) of ophiacanthid brittle stars in external (a) and internal (b) views. 1. Lapidaster sp. nov. innom. 1 from the late Toarcian (Early Jurassic) of Seewen, Switzerland; NHMB M11208, proximal to median LAP. 2-4. Lapidaster wolfii gen. et sp. nov. from the Bajocian-Bathonian boundary (Middle Jurassic) of Touert, France. 2. GZG.INV.78508 (holotype), proximal LAP. 3. GZG. INV.78509 (paratype), median LAP. 4. GZG.INV.78510 (paratype), distal LAP. 5-7. Lapidaster varuna gen. et sp. nov. from the Callovian of Jumara, India. 5. GZG.INV.78511 (holotype), proximal LAP. 6. GZG.INV.78512 (paratype), median LAP. 7. GZG.INV.78513 (paratype), distal LAP. One common scale bar per species is given. 
lobes, as well as the presence of a second, strongly developed spur in the centre of the outer proximal and inner distal edges sets the LAP in question quite apart from other LAP types assigned to Lapidaster gen. nov. It unquestionably represents a distinct, undescribed species. Unfortunately, only a single LAP is currently known, which precludes the formal description of a new species.

Lapidaster wolfii sp. nov.

urn:1sid:zoobank.org:act:ECF21B65-FAD1-488C-8343-0C5C3E192B74

Fig. 8: 2-4

\section{Diagnosis}

Species of Lapidaster gen. nov. with moderately large LAPs showing coarsely meshed stereom with trabecular merging into a very weak vertical striation; up to six large, equal-sized spine articulations.

\section{Etymology}

Species named in honour of my friend and former band-mate Wolfgang ("Wolfi") Prebeck, for cheering up moments of frustration, in particular during the course of the present study.

\section{Type material}

\section{Holotype}

GZG.INV.78508.

Paratypes

GZG.INV.78509 and GZG.INV.78510.

\section{Type locality and horizon}

Touert near Chaudon, France; marl bed at the Bajocian-Bathonian boundary, Middle Jurassic.

\section{Description}

\section{Holotype}

GZG.INV.78508 is a dissociated, small, proximal lateral arm plate, slightly higher than wide, of irregularly angular aspect; ventral quarter of LAP protruding ventro-proximalwards; ventro-distal tip of LAP slightly protruding; dorsal and distal edges of LAP nearly straight; proximal edge slightly undulose, with very faint, almost indiscernible spur close to ventro-proximal tip. Outer surface with coarsely reticulate stereom with trabeculae tending to merge into a very faint, irregular vertical ridges, rapidly grading into finely meshed stereom close to distal edge of LAP; reticulate stereom separated from three ventral spine articulations, and slightly confluent with proximal edge of three dorsalmost spine articulations. Six, large, ear-shaped spine articulations with dorsal and ventral lobes forming a continuous volute, freestanding in continuous vertical row close to distal edge of LAP, equal in size but with slight dorsalward increase in size of gaps separating them. Ventral edge of LAP with large, concave tentacle notch.

Inner side of LAP with single relatively thin, sharply defined, prominent, oblique ridge, of nearly constant width and with rounded dorsal tip: dorsal half of ridge slightly bent dorsalwards; ventral half separated from dorsal one by rounded kink and confluent with thickened ventro-proximal edge of LAP. No perforations discernible. Inner distal edge thinning distalwards; ventro-distal tip thickened into an irregular, oblique, poorly defined, prominent spur. Inner side of tentacle notch with coarsely reticulate stereom, slightly stretched horizontally. 


\title{
Paratype supplements and variation
}

GZG.INV.78509 is a dissociated median lateral arm plate, slightly higher than wide. Overall morphology well in agreement with that of holotype. Proximal edge of LAP strongly undulose, with large, relatively well-defined, slightly prominent spur on ventro-proximal tip, composed of denser stereom. Striation on outer surface slightly better developed than in holotype. A total of five spine articulations of equal size, poorly preserved, with slight increase in size of the gaps separating them.

Morphology of inner side of LAP as in holotype. Ventro-distal spur more clearly defined and slightly more prominent than in holotype.

GZG.INV.78510 is a dissociated distal lateral arm plate, wider than long, of rounded triangular aspect, with slightly convex dorsal and distal edges, and slightly undulose proximal edge; ventral quarter slightly protruding ventro-proximalwards; outer surface with coarsely reticulate stereom, with trabeculae showing hardly any tendency to develop into vertical striation; ventro-proximal tip of LAP poorly preserved. Three spine articulations of equal size, gap between dorsal and median spine articulation slightly larger than gap between median and ventral ones.

Morphology of inner side well in agreement with holotype and other paratype. Oblique ventro-distal spur large, sharply defined and strongly prominent, suggesting equally well-developed counterpart on outer ventro-proximal edge not observable due to insufficient preservation of the LAP. Tentacle notch large and conspicuous.

\section{Remarks}

The present species most closely resembles Lapidaster hystricarboris sp. nov. from which it differs, however, in displaying a much coarser and less well-developed vertical striation on the outer surface of the LAPs, as well as a slightly smaller dorsalward increase in the size of the gaps separating the spine articulations. It is thus described here as a new species. Assignment to Lapidaster gen. nov. is based on the strikingly Ophiologimus-like LAP morphology and the presence of a spur, albeit weakly developed, on the outer proximal and inner distal edges of the LAPs.

\section{Occurrence}

Bajocian-Bathonian boundary beds of France.

Lapidaster varuna sp. nov. urn:1sid:zoobank.org:act:6E723392-8565-4F6C-84C5-B6FEBE1A69CB

\author{
Fig. 8: 5-7
}

\section{Diagnosis}

Species of Lapidaster gen. nov. with relatively large LAPs displaying a weakly to moderately welldeveloped vertical striation, a long ridge on the inner side reaching the dorsal edge of the LAP, and up to four spine articulations composed of confluent dorsal and ventral lobes.

\section{Etymology}

Species named after Varuna, the god of the oceans in Hindu mythology, in reference to the cultural background prevailing in the area of the type locality in Kachchh, India.

\section{Type material}

\section{Holotype}

GZG.INV.78511. 


\section{Paratypes}

GZG.INV.78512 and GZG.INV.78513.

\section{Type locality and horizon}

Jumara, Kachchh, India; sample 117, upper Chari Formation, Callovian, Middle Jurassic.

\section{Additional material}

GZG.INV.78514 (78 dissociated LAPs) from sample 117; GZG.INV.78515 (14 dissociated LAPs) from sample 119; GZG.INV.78516 (12 dissociated LAPs) from sample 121.

\section{Description}

\section{Holotype}

GZG.INV.78511 is a dissociated, medium-sized, median to proximal LAP, slightly wider than high; dorsal and distal edges straight to slightly convex; ventral quarter of LAP protruding ventroproximalwards; ventro-distal tip of LAP strongly protruding, tongue shaped; proximal edge evenly concave, with small, rather poorly defined and slightly prominent spur near ventro-proximal tip of LAP; outer surface consisting of coarsely meshed stereom with trabeculae merging into irregular vertical striation, especially near spine articulations; coarsely meshed stereom rapidly grading into much more finely meshed stereom near proximal edge of LAP. Three equal-sized spine articulations near distal edge of LAP, ventral and dorsal lobes forming continuous volute; two ventral spine articulations surrounded by irregular areole of finely meshed stereom; dorsalmost spine articulation embedded in striated to coarsely meshed stereom, separated from two ventral spine articulations by slightly larger gap. Ventral edge of LAP with large, very deep and concave tentacle notch.

Inner side of LAP with sharply defined, prominent and relatively narrow ridge, dorsal portion of which oblique, nearly straight, with slightly widened, round tip, almost reaching dorso-proximal corner of LAP; ventral portion of ridge separated from dorsal one by slightly round kink, much less sharply defined and rapidly merging into thickened ventral part of LAP. Inner distal edge of LAP thinning out distalwards, with small, sharply defined, lens-shaped spur composed of compact stereom on inner ventro-distal tip of LAP. Inner side of tentacle notch with coarsely meshed and slightly horizontally stretched stereom, dorsally bordered by large, irregular perforation.

\section{Paratype supplements and variation}

GZG.INV.78512 is a dissociated proximal LAP, nearly as wide as high; dorsal and distal edges gently convex; ventral quarter of LAP and ventro-distal tip largely missing; spur on outer proximal edge slightly protruding, otherwise well in agreement with corresponding spur observed on holotype; outer surface with coarsely meshed stereom merged into faint vertical striation. Four spine articulations, ventralmost smaller than remaining three; dorsalward increase in size of gaps separating spine articulations; three ventral spine articulations surrounded by irregular areole.

Inner side of LAP well in agreement with that of holotype; dorsal portion of ridge slightly shorter, not approximating dorso-proximal corner of LAP.

GZG.INV.78513 is a dissociated distal LAP, approximately twice wider than high; dorsal edge slightly concave; distal edge straight; ventral fifth of LAP protruding ventro-proximalwards; ventro-distal tip of LAP strongly protruding, tongue shaped; proximal edge nearly straight, with sharp kink in ventral quarter, marked by well-defined, elongate, slightly prominent and protruding spur composed of very dense stereom; outer surface with coarsely meshed stereom with trabeculae showing only very faint tendency to merge into vertical striation. Three spine articulations, middle one slightly larger than ventral and dorsal ones. Tentacle notch large and moderately deep. 
Inner side well in agreement with than of holotype; dorsal portion of ridge not reaching dorso-proximal corner of LAP, not widened at dorsal tip.

\section{Remarks}

These LAPs display a striking similarity to those of extant Ophiologimus hexactis H.L. Clark, 1911, but differ in having a spur on the outer proximal and inner distal edges. Although this spur is rather poorly developed, the present LAPs are assigned to Lapidaster gen. nov. Within this genus, closest similarities are shared with Lapidaster fasciatus comb. nov., in which, however, the LAPs have a much better-developed vertical striation and a slightly shorter ridge on the inner side. These differences, even if seemingly small, are considered sufficient for distinction at the species level, in accordance with the observations of Thuy \& Stöhr (2011) on the spectrum of possible differences in LAP morphology between congeneric species. The present LAPs are therefore described as a new species.

\section{Occurrence}

Callovian of India.

Lapidaster etteri sp. nov. urn:1sid:zoobank.org:act:DFBC69CF-37F1-4D39-A8F3-D8DA46708D05

Fig. 9: 1-5

p.p. Ophiopholis? trispinosa Hess, 1965a: 1067, 1075, figs 16, 38-40 (non figs 36-37, referable to Ishidacantha trispinosa (Hess, 1965) comb. nov.)

\section{Diagnosis}

Species of Lapidaster gen. nov. with relatively large LAPs showing a weak constriction, a widened dorsal tip of the ridge on the inner side and a thickened ventral part.

\section{Etymology}

Species named in honour of Walter Etter (Naturhistorisches Museum Basel, Switzerland), who generously provided access to the original material of Hans Hess's pioneering studies on ophiuroid micropalaeontology, inclusive of the type material of the new species.

\section{Type material}

\section{Holotype}

NHMB M11209.

\section{Paratypes}

NHMB M11210, NHMB M11211, NHMB M11212 and NHMB M11213.

\section{Type locality and horizon}

Longecombe, France; Renggeri Member, Bärschwil Formation, early Oxfordian, Late Jurassic.

\section{Additional material}

304 dissociated LAPs from Longecombe, France, the original material of Hess (1965a); 7 dissociated LAPs from Chapois, France, the original material of Hess (1965a). 


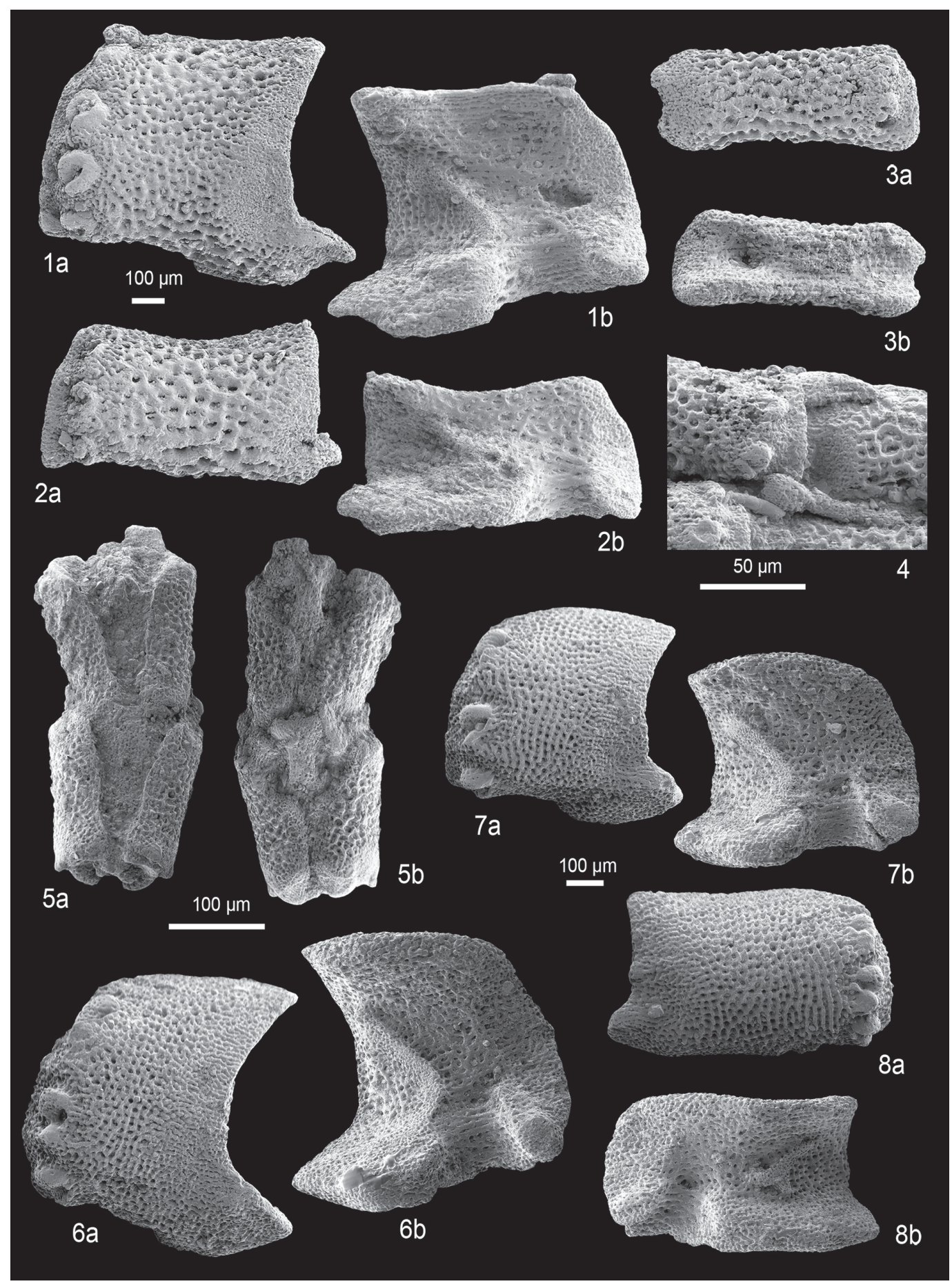

Fig. 9. Fossil lateral arm plates (LAPs) of ophiacanthid brittle stars in external (a) and internal (b) views and articulated arm fragments. 1-5. Lapidaster etteri gen. et sp. nov. from the early Oxfordian (Late Jurassic) of Longecombe, France. 1. NHMB M11209 (holotype), proximal LAP. 2. NHMB 11210 (paratype), median LAP. 3. NHMB M11211 (paratype), distal LAP. 4. NHMB M11212 (paratype), distal arm fragment in lateral view. 5. NHMB M11213 (paratype), distal arm fragment in dorsal (a) and ventral (b) views. 6-8. Lapidaster mastodon gen. et sp. nov. from the late Oxfordian (Late Jurassic) of the Plettenberg, Germany. 6. GZG.INV.78517 (holotype), proximal LAP. 7. GZG.INV.78518 (paratype), median LAP. 8. GZG.INV.78519 (paratype), distal LAP. One common scale bar per species is given, except for 4 and 5 . 


\section{Description}

\section{Holotype}

NHMB M11209 is a dissociated, medium-sized proximal lateral arm plate, slightly wider than long, with strongly concave proximal edge and strongly convex distal edge; ventro-proximal quarter of LAP protruding ventro-proximalwards; slight constriction, resulting in slightly concave dorsal edge; horizontal, elongate, moderately well-defined and prominent spur close to ventro-proximal tip of LAP. Outer surface with coarsely reticulate stereom with thickened trabeculae; trabeculae without tendency to develop into vertical striation; coarsely reticulate stereom evenly surrounding all spine articulations, grading into finely meshed stereom close to proximal edge. Four large, ear-shaped spine articulations, freestanding in continuous row close to distal edge of LAP, dorsal and ventral lobes forming continuous volute in all spine articulations; proximal edge of dorsalmost spine articulation overlapped by finely reticulate stereom; ventralmost and dorsalmost spine articulations smaller than two median ones; dorsalward increase in size of gaps separating spine articulations. Ventral edge of LAP with large, conspicuous and gently concave tentacle notch.

Inner side of LAP with sharply defined, narrow, prominent ridge; dorsal half of ridge oblique and nearly straight, with rounded tip nearly twice wider than remaining dorsal half of ridge and not reaching dorsal or proximal edges of LAP; ventral half of ridge slightly wider than dorsal half, separated from the latter by rounded kink, less sharply defined and prominent than dorsal half but not confluent with thickened ventral edge of LAP. Single irregular perforation discernible on inner side of LAP near tentacle notch. Small, moderately well-defined, prominent and slightly oblique ridge on inner side of ventro-distal tip of LAP. Inner side of tentacle notch with coarsely reticulate and horizontally stretched stereom.

\section{Paratype supplements and variation}

NHMB M11210 is a dissociated median lateral arm plate, wider than high. Overall morphology well in agreement with that of holotype. Constriction stronger than in holotype, resulting in clearly concave dorsal edge of LAP. Spur near ventro-proximal edge of LAP poorly defined, hardly discernible. Three spine articulations in continuous row; median spine articulation slightly larger than others. Ventral edge of LAP with large, conspicuous tentacle notch.

Inner side with well-defined, narrow, prominent ridge; dorsal half of ridge strongly oblique, straight, with slightly widened dorsal tip; ventral half of ridge wider than dorsal one but less well-defined, not confluent with thickened ventral edge of LAP. Small, very poorly defined and barely prominent spur on inner side of ventro-distal edge.

NHMB M11211 is a dissociated distal LAP, almost three times wider than high, of rectangular to barlike outline; distal edge gently convex, proximal edge concave; slight constriction, resulting in very gently concave dorsal edge and clearly concave ventral edge of LAP; no spurs discernible on outer proximal edge. Two spine articulations, nearly equal in size. Large tentacle perforation near ventral spine articulation.

Inner side with two very small, irregular, diffuse, slightly prominent and widely separate knobs. Large tentacle perforation in centre of distal half of LAP.

NHMB M11212 is a median arm fragment composed of two articulated segments. LAPs well in agreement with type specimens; ventral arm plates $T$ shaped, with narrow proximal half, concave lateral edges, distal half almost three times wider than proximal half, distal edge straight to slightly concave. Tentacle openings clearly larger than half the width of the ventral arm plates. Dorsal arm plates very thin, wedge shaped, with strongly acute proximal angle, outline of distal edge not clearly discernible. Single arm spine preserved, attached to ventral spine articulation, conical, with coarse outer surface, broken tip but probably not much longer than half the width of a LAP. 
NHMB M11213 are two distal arm fragments composed of five intact arm segments. One LAP preserving two arm spines in place, ventral one broken, dorsal one intact, shorter than half the width of a LAP, conspicuously claw shaped with point facing ventralwards.

\section{Remarks}

When Hess (1965a) described a new species, Ophiopholis? trispinosa, on the basis of dissociated LAPs and articulated arm fragments from the Oxfordian of France, he lumped two entirely different LAP types under a single species. A re-examination of the original material has now revealed that one type, figured in the original description (Hess 1965a: figs 16, 38-40) along with the second type, bears a striking similarity to the LAPs of extant Ophiologimus. The presence of a spur on the outer proximal and inner distal edges places this type of LAPs in Lapidaster gen. nov. In view of the fact that the holotype of O.? trispinosa is a LAP of the second type (see below for a detailed reassessment), however, the species name cannot be used for the LAPs assigned to Lapidaster gen. nov. The latter are therefore here described as a new species. Greatest similarities are shared with the LAPs of Lapidaster lukenederi sp. nov., especially on account of the slight constriction. The LAPs of Lapidaster etteri sp. nov., however, differ in being more markedly thickened near their ventral edge and in having a better-developed spur on the outer proximal and inner distal edges and a dorsally widened tip of the ridge on the inner side.

Lapidaster etteri sp. nov. is the sole species of the genus of which arm spines and ventral and dorsal arm plates are available. Hook-shaped spines on distal arm segments, as observed in the articulated arm fragments of L. etteri sp. nov. described above are commonly found in extant species of Ophiologimus (e.g. O'Hara \& Stöhr 2006; Martynov 2010). In addition, tentacle pores of the distalmost arm segments developed as within-plate perforations rather than between-plate openings, as observed in L. etteri sp. nov., are regularly seen in extant species of Ophiologimus. The hook-shaped arm spines and within-plate tentacle openings in distalmost arm segments provide additional evidence for the close ties between both genera.

\section{Occurrence}

Early Oxfordian of France.

Lapidaster mastodon sp. nov. urn:lsid:zoobank.org:act:6040E02F-5B0D-4F78-8772-BC23B55BEBD9

Fig. 9: 6-8

\section{Diagnosis}

Species of Lapidaster gen. nov. with moderately large LAPs displaying a round, sickle-shaped outline; up to three spine articulations in proximal LAPs.

\section{Etymology}

Species named in honour of Brent Hinds, Brann Dailor, Bill Kelliher and Troy Sanders of the rockgroup Mastodon, whose music was indispensable during lengthy nightly sessions at the scanning electron microscope.

\section{Type material}

\section{Holotype}

GZG.INV.78517.

\section{Paratypes}

GZG.INV.78518 and GZG.INV.78519. 


\section{Type locality and horizon}

Plettenberg near Balingen, southern Germany; clay pockets between sponge associations in the lowest bed exposed at the quarry, Bimammatum Zone, Late Oxfordian, Late Jurassic.

\section{Additional material}

GZG.INV.78520 (194 dissociated LAPs) from the Late Oxfordian of Plettenberg near Balingen; GZG. INV.78521 (2 dissociated LAPs) from the Early Kimmeridgian of Geisingen, southern Germany.

\section{Description}

\section{Holotype}

GZG.INV.78517 is an isolated, small proximal LAP, of equal height and width, with sickle-shaped outline; ventral third of LAP protruding; ventro-distal tip of LAP only slightly so; proximal edge strongly concave, distal and dorsal edges convex; dorso-proximal and ventro-proximal tips of LAP pointed; no constriction; poorly defined but slightly prominent and protruding spur in ventral third of proximal edge, composed of slightly denser stereom than remaining edge. Outer surface with finely reticulate stereom; trabeculae showing tendency to merge into irregular vertical stripes, especially in ventral half of outer surface; reticulate stereom grading into finely meshed stereom towards proximal edge; dorsalmost spine articulation directly surrounded by reticulate stereom; two ventral spine articulations surrounded by slightly sunken areole of more finely meshed stereom, encompassed by reticulate stereom of outer surface. Three large, ear-shaped spine articulations freestanding in continuous row near distal edge, of equal size, dorsal gap larger than ventral one; dorsal and ventral lobes separated in all three spine articulations by irregularly crenulate central proximal knob. Ventral edge of LAP with large, gently concave tentacle notch.

Inner side of LAP with moderately large, well-defined and prominent ridge; dorsal half of ridge oblique and nearly straight, not reaching dorsal or proximal edges of LAP, with slightly widened dorsal tip; ventral half of ridge confluent with thickened ventral edge of LAP, less prominent than dorsal one, separated from the latter by a rounded kink; no perforations discernible on inner side; inner side of ventro-distal tip of LAP with large, well-defined, round, prominent spur. Inner side of tentacle notch with horizontally stretched stereom.

\section{Paratype supplements and variation}

GZG.INV.78518 is a dissociated median LAP, slightly wider than high, differing from holotype in having a slightly better-defined spur on the ventral third of the outer proximal edge, and in addition a very poorly defined, almost indiscernible spur in the middle of the outer proximal edge. Inner side well in agreement with holotype morphology.

GZG.INV.78519 is a dissociated distal LAP, approximately twice wider than high; dorsal edge straight to very slightly concave; only very small ventral portion of LAP protruding ventro-proximalwards. Proximal edge with well-defined, prominent and slightly protruding spur near ventro-proximal tip of LAP; second, smaller, less well-defined but clearly protruding spur in the middle of the proximal edge. Three spine articulations; dorsal gap between spine articulations only slightly larger than ventral one. Tentacle notch large but shallow.

Inner side with sharply defined, prominent, oblique and nearly straight ridge, widest ventrally, with short ventro-proximalwards pointing protrusion. Inner side of ventro-distal tip of LAP with large, welldefined and prominent spur. Tentacle notch wide, with slightly horizontally stretched stereom, dorsally bordered by single irregular perforation. 


\section{Remarks}

The round, sickle-shaped outline, the unusually weakly protruding ventro-distal tip of the LAPs, and the low number of spine articulations (three in proximal segments) are a combination of characters which is unique among the LAP types assignable to Lapidaster gen. nov. It is therefore here described as a new species within this genus. At least in terms of LAP morphology, however, Lapidaster mastodon sp. nov., L. fasciatus comb. nov. and L. varuna sp. nov. appear to be very closely related.

From a palaeoecological perspective, both known occurrences of Lapidaster mastodon sp. nov. are from clayey crevasse infills within sponge reefs and from clay levels interbedded with sponge reefs. It thus seems to be the sole species known of the genus which is exclusively found associated with sponge build-ups rather than on muddy bottoms.

\section{Occurrence}

Late Oxfordian to early Kimmeridgian of Germany.

Lapidaster sp. nov. innom. 2

Fig. 10: 4

\section{Material examined}

GZG.INV.78522 (dissociated LAP) from the Lacunosa Marls, early Kimmeridgian, Late Jurassic, of Geisingen, southern Germany.

\section{Description}

GZG.INV.78522 is a dissociated, small, proximal to median LAP; approximately 1.5 times wider than high; dorsal edge strongly concave as a result of a well-developed constriction; distal edge convex; proximal edge concave, with two well-defined, prominent spurs; ventral spur slender, strongly horizontally elongate, proximally pointed, non protruding; dorsal spur round, smaller, more strongly prominent, protruding; coarsely meshed stereom with thickened trabeculae on distal two-thirds of outer surface, replaced by finely meshed stereom on proximal third of outer surface. Three moderately large, equidistant, very poorly preserved spine articulations. Ventral edge of LAP with very large, but rather shallowly concave, tentacle notch.

Inner side of LAP with large, sharply defined, conspicuous, prominent ridge composed of straight, oblique dorsal half with non-thickened dorsal tip, and ventro-proximally bent, slightly broader ventral part; both parts of ridge connected by angular kink; one moderately large, well-defined, weakly prominent spur composed of densely meshed stereom on inner side of distal edge of LAP; second less well-defined, but larger and more prominent spur on inner side of ventro-distal tip of LAP; inner side of tentacle notch with coarsely meshed, horizontally elongate stereom. Single, moderately large perforation dorsally bordering tentacle notch.

\section{Remarks}

This LAP is strikingly similar to those of Lapidaster coreytaylori sp. nov. and L. mathcore sp. nov. with respect to general morphology, the outer surface stereom and the shape of the ridge on the inner side. It clearly belongs to the same group within Lapidaster gen. nov. as the two last-named species. The welldeveloped second spur on the outer proximal and inner distal edges sets the present LAP apart from those of Lapidaster coreytaylori sp. nov. and L. mathcore sp. nov. The LAP in question most probably represents a new species, the formal description and naming of which, however, cannot be based on a single, imperfectly preserved specimen. 


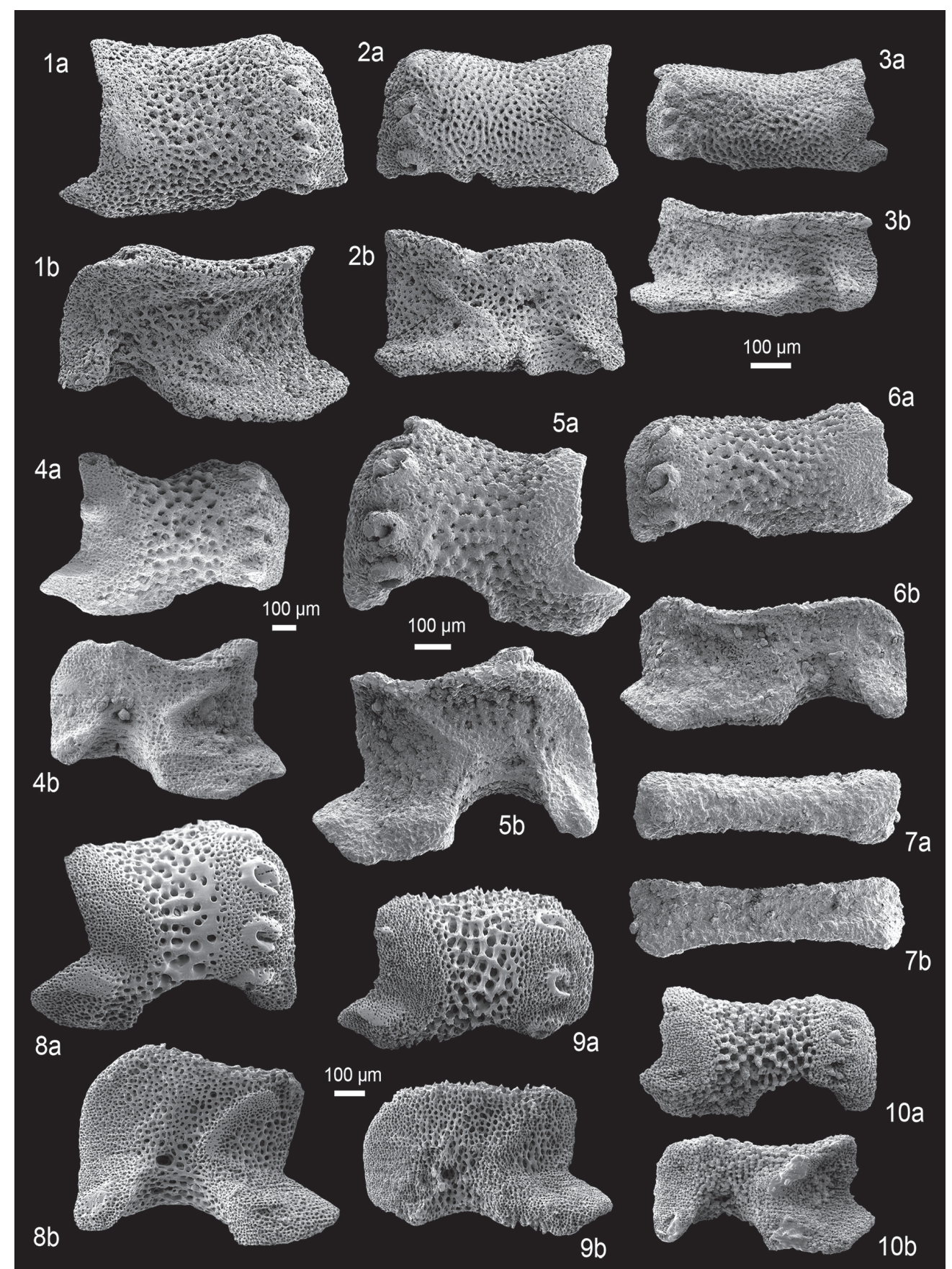

Fig. 10. Fossil lateral arm plates (LAPs) of ophiacanthid brittle stars in external (a) and internal (b) views. 1-3. Lapidaster lukenederi gen. et sp. nov. from the late Valanginian (Early Cretaceous) of the Ternberg Nappe, Austria. 1. NHMW 2012/0138/0001 (holotype), proximal LAP. 2. NHMW 2012/0138/0002 (paratype), median LAP. 3. NHMW 2012/0138/0003 (paratype), distal LAP. 4. Lapidaster sp. nov. innom. 2 from the early Kimmeridgian (Late Jurassic) of Geisingen, Germany; GZG.INV.78522, proximal to median LAP. 5-7. Lapidaster coreytaylori gen. et sp. nov. from the middle Aptian (Early Cretaceous) of Carniol, France. 5. GZG.INV.78523 (holotype), proximal LAP. 6. GZG.INV.78524 (paratype), median LAP. 7. GZG.INV.78525 (paratype), distal LAP. 8-10. Lapidaster mathcore gen. et sp. nov. from the middle Albian (Early Cretaceous) of Folkestone, Great Britain. 8. GZG.INV.78528 (holotype), proximal LAP. 9. GZG.INV.78529 (paratype), median LAP. 10. GZG.INV.78530 (paratype), distal LAP. One common scale bar per species is given. 
Lapidaster lukenederi sp. nov. urn:1sid:zoobank.org:act:7E64C5B3-CAFF-4342-AD67-DDB05F3050EB

Fig. 10: 1-3

\section{Diagnosis}

Species of Lapidaster gen. nov. with small LAPs displaying a low height/width ratio and a welldeveloped constriction; ventral portion of LAP not thickened; spur on the outer proximal and inner distal edges very poorly defined; dorsal part of ridge on inner side not widened.

\section{Etymology}

Named in honour of Alexander Lukeneder (Naturhistorisches Museum Wien, Vienna), who collected and generously provided the residues yielding the type material of the new species.

\section{Type material}

\section{Holotype}

NHMW 2012/0138/0001.

\section{Paratypes}

NHMW 2012/0138/0002 and NHMW 2012/0138/0003.

\section{Type locality and horizon}

KB1-A section of Lukeneder (2004) in the Ternberg Nappe, Austria; Verrucosum Zone, late Valanginian, Early Cretaceous.

\section{Additional material}

NHMW 2012/0138/0004 (88 dissociated LAPs).

\section{Description}

\section{Holotype}

NHMW 2012/0138/0001 is a dissociated, small, proximal to median LAP, approximately 1.5 times wider than high, with gently convex distal edge; dorsal edge clearly concave, indicating a slight constriction of the outer surface; ventral fifth of LAP protruding ventro-proximalwards; ventro-distal tip of LAP not conspicuously large, slightly protruding ventro-distalwards; proximal edge of LAP angular, with small very faint, hardly discernible, spur-like structure near ventro-proximal tip of LAP; outer surface with coarsely meshed stereom; trabeculae of outer surface stereom showing no tendency to merge into vertical striation. Four relatively small spine articulations, ventralmost slightly smaller than remaining three; very small dorsalward increase in size of gaps separating spine articulations; dorsal and ventral lobes composing volute connected by very short, markedly narrow ridge proximally; dorsalmost spine articulation pointing dorsalwards; all spine articulations embedded in outer surface stereom. Ventral edge of LAP with moderately large, gently concave tentacle notch.

Inner side of LAP with relatively narrow, well-defined ridge, dorsal portion of which nearly straight, widest in middle part, with narrow tip not reaching dorsal and distal edges of LAP; ventral portion of ridge separated from dorsal one by kink, shorter, wider, less well defined but not confluent with ventral part of LAP; ventral part of LAP not thickened; ventro-distal tip of LAP with barely discernible spur composed of slightly denser stereom; inner side of tentacle notch with coarsely meshed stereom, hardly stretched horizontally. No perforations visible on inner side. 


\section{Paratype supplements and variation}

NHMW 2012/0138/0002 is a dissociated median LAP, approximately twice wider than high; ventrodistal tip of LAP slightly larger than in holotype; dorsal edge strongly concave, indicating well-developed constriction; proximal edge gently concave with small, very poorly defined, barely visible spur close to ventro-proximal tip of LAP; outer surface with coarsely meshed stereom with very weak tendency of trabeculae to merge into irregular vertical striation. Three equal-sized spine articulations, separated by equal-sized gaps.

Inner side of LAP generally well in agreement with that of holotype; dorsal portion of ridge straight, slightly widened dorsally; ventral portion of ridge wider, very short, poorly defined but not confluent with ventral part of LAP; no spur discernible on inner side of ventro-distal tip of LAP.

NHMW 2012/0138/0003 is a dissociated distal plate, more than twice wider than high; both dorsal and ventral edges concave as a result of the constriction; no spur discernible on proximal edge of LAP. Three equal-sized spine articulations near distal edge of LAP, separated by equal-sized gaps. Ventral edge of LAP with large, gently concave tentacle notch.

Inner side with moderately well-defined ridge, oblique and slightly bent, relatively wide, short; no kink separating ridge into dorsal and ventral portions; ventral tip of ridge widest, best defined; no spur discernible on inner side of ventro-distal tip of LAP.

\section{Remarks}

These LAPs share greatest similarities with those of Lapidaster etteri sp. nov., especially with regard to the constriction and the height/width ratio of the proximal LAPs. In the latter, however, the the ventral part is more strongly thickened, the dorsal tip of the ridge on the inner side is widened, and the spur on the outer proximal and inner distal edges is slightly better defined.

\section{Occurrence}

Late Valanginian of Austria.

Lapidaster coreytaylori $\mathrm{sp}$. nov. urn:lsid:zoobank.org:act:EC3622FF-FE17-43EF-8626-8270BA1F7C38

Fig. 10: 5-7

\section{Diagnosis}

Species of Lapidaster gen. nov. with moderately large LAPs with coarsely meshed stereom in a broad band of the outer surface displaying conspicuously thick trabeculae; ventral portion moderately narrow and strongly protruding ventro-proximalwards; spur on outer proximal edge slender, horizontally elongate and proximally pointed, paralleled by a well-defined spur on the inner distal edge; dorsal part of the ridge on the inner side straight.

\section{Etymology}

Species named in honour of Corey Taylor, lead vocalist of the rockgroup Slipknot and Stone Sour, for lending a powerful voice during moments of despair in the course of the present study.

\section{Type material}

\section{Holotype}

GZG.INV.78523.

\section{Paratypes}

GZG.INV.78524, GZG.INV.78525 and GZG.INV.78526. 


\section{Type locality and horizon}

Carniol, France; Furcatus Zone, middle Aptian, Early Cretaceous.

\section{Additional material}

GZG.INV.78527 (51 dissociated LAPs).

\section{Description}

\section{Holotype}

GZG.INV.78523 is a dissociated medium-sized, proximal LAP; approximately 1.5 times wider than high; distal edge convex; dorsal edge clearly concave as a result of a constriction of the outer surface; ventral quarter of LAP relatively narrow, strongly protruding ventro-proximalwards; ventro-distal tip of LAP very large, tongue shaped and conspicuously protruding; proximal edge separated by sharp kink into dorsal and ventral portion; kink bordered by large, conspicuous, sharply defined, prominent, horizontally strongly elongate and proximally pointed spur composed of dense stereom; coarsely meshed stereom on distal two-thirds of outer surface; trabeculae of outer surface stereom thick but with no tendency to merge into vertical striation; coarsely meshed stereom of outer surface replaced by more finely meshed stereom in proximal third of outer surface. Four ear-shaped spine articulations freestanding on very weakly elevated distal portion of LAP with slight dorsalward increase in size of gaps separating them; second dorsalmost spine articulation slightly larger than remaining three; dorsal and ventral lobes forming continuous volute; all four spine articulations surrounded by irregular, confluent areoles of finely meshed stereom. Ventral edge of LAP with extremely large, deeply concave tentacle notch.

Inner side of LAP with large, sharply defined ridge separated by angular kink into dorsal and ventral portions; dorsal portion oblique, straight, with clearly widened dorsal tip in contact with dorsal edge of LAP; ventral portion straight, forming an almost right angle with dorsal portion and approximately as long as the latter, with thickened, horizontally elongate ventral tip; inner side of ventro-distal tip of LAP thickened with moderately well-defined, round, slightly prominent spur composed of dense stereom. Inner side of large tentacle notch with coarsely meshed and slightly horizontally stretched stereom dorsally bordered by large, irregular perforation.

\section{Paratype supplements and variation}

GZG.INV.78524 is a dissociated median LAP, twice wider than high; proximal edge with sharp kink similar to that observed in holotype, bordered by moderately well-defined, elongated and prominent spur; second spur in dorsal half of proximal edge, slightly smaller than ventral spur and protruding, but similarly well defined, prominent and elongate. Outer surface with coarsely meshed stereom, with thick trabeculae showing no tendency to merge into a vertical striation. Three spine articulations separated by equal-sized gaps; middle spine articulation slightly larger than remaining two. Ventral edge of LAP with extremely large, gently concave tentacle notch.

Inner side of LAP with thin, moderately well-defined ridge composed of two portions separated by kink; dorsal portion narrow, with slightly wider dorsal tip; ventral portion of ridge forming acute angle with dorsal one, nearly as long as the latter but wider and less well defined, confluent with ventral edge of LAP.

GZG.INV.78525 is a dissociated distal LAP, approximately 2.5 times wider than high; ventro-distal tip conspicuously protruding; proximal edge concave, with poorly defined, elongate and slightly prominent spur in ventral half; second spur in dorsal half smaller, similarly poorly defined, prominent and slightly protruding. Three spine articulations, ventralmost of which slightly smaller than remaining two. Ventral edge of LAP concave as a result of a clear constriction of the outer surface, and with large, concave tentacle notch. 
Inner side of LAP with two moderately well-defined, prominent and slightly elongated spurs on dorsodistal and ventro-distal tips, respectively, dorsal one of which slightly protrudes; ridge on inner side of LAP hardly discernible as a result of insufficient preservation.

GZG.INV.78526 is a dissociated distalmost LAP, rod-like in outline, more than three times wider than high, with concave dorsal and ventral edges. Two small equal-sized spine articulations. No tentacle notch on ventral edge of LAP; tentacle perforation distally bordering ventral spine articulation. Inner side of LAP insufficiently preserved.

\title{
Remarks
}

These LAPs reveal striking similarities to those of Lapidaster mathcore sp. nov. and with the single unnamed LAP from the Kimmeridgian of Germany described above. It differs from the former in displaying a slightly wider ventral portion of the LAPs, coarsely meshed stereom on two-thirds rather than half of the outer surface, a slender, horizontally strongly elongate and proximally pointed spur, and a straight dorsal half of the ridge on the inner side with a more markedly widened dorsal tip. These LAPs, L. mathcore sp. nov. and the unnamed Jurassic specimen form one of the groups of similar species in terms of LAP morphology within Lapidaster gen. nov. . Another example of such a group of morphologically similar LAPs includes L. fasciatus comb. nov., L. mastodon sp. nov. and L. varuna sp. nov. Whether these groups are all assignable to Lapidaster gen. nov. or, in contrast, represent different closely related genera remains to be tested.

\section{Occurrence}

Middle Aptian of France.

Lapidaster mathcore sp. nov. urn:1sid:zoobank.org:act:134870A5-8900-4C8F-97E4-8D098266865D

Fig. 10: 8-10

\section{Diagnosis}

Species of Lapidaster gen. nov. with moderately large LAPs with coarsely meshed stereom in a narrow band of the outer surface displaying conspicuously thick trabeculae; ventral portion very narrow and strongly protruding ventro-proximalwards; spur on outer proximal edge oval, slightly horizontally elongate, not pointed proximally, paralleled by a well-defined spur on the inner distal edge; dorsal part of ridge on the inner side bent proximally.

\section{Etymology}

Species named after "Mathcore", a music genre that has been among my most influential sources of inspiration in understanding and expressing complexity.

\section{Type material}

\author{
Holotype \\ GZG.INV.78528. \\ Paratypes \\ GZG.INV.78529 and GZG.INV.78530.
}

\section{Type locality and horizon}

Folkestone, Great Britain; level 2 of Young et al. (2010), Loricatus Zone, middle Albian, Early Cretaceous. 


\section{Additional material}

GZG.INV.78531 (5 dissociated LAPs).

\section{Description}

\section{Holotype}

GZG.INV.78528 is a dissociated, moderately large, proximal LAP; nearly 1.5 times wider than high; distal edge convex; dorsal edge slightly concave as a result of a weakly developed constriction; ventral quarter of LAP very narrow, strongly protruding ventro-proximalwards; ventro-distal tip of LAP very large, tongue shaped and conspicuously protruding; proximal edge separated by sharp kink into dorsal and ventral portion; large, conspicuous, sharply defined, prominent and slightly elongated, oval spur composed of more densely meshed stereom at some distance from kink separating proximal edge; coarsely meshed stereom in distal half of outer surface; trabeculae of outer surface stereom thick, no tendency to merge into vertical striation; coarsely meshed stereom of outer surface replaced by more finely meshed stereom in proximal half of outer surface. Four ear-shaped spine articulations, with slight dorsalward increase in size of gaps separating them; second dorsalmost spine articulation slightly larger than remaining three; dorsal and ventral lobes forming continuous volute; all four spine articulations surrounded by irregular, confluent areoles of finely meshed stereom. Ventral edge of LAP with extremely large, deeply concave tentacle notch.

Inner side of LAP with large ridge separated by kink into sharply defined dorsal and less well-defined ventral portions; dorsal portion oblique, bent proximally, with weakly widened dorsal tip; ventral portion straight, forming a slightly obtuse angle with dorsal portion and approximately as long as the latter, with slightly thickened ventral tip not confluent with ventral portion of LAP; inner side of ventro-distal tip of LAP thickened with moderately well-defined, round, slightly prominent spur composed of dense stereom. Inner side of large tentacle notch with coarsely meshed and slightly horizontally stretched stereom dorsally bordered by large, irregular perforation.

\section{Paratype supplements and variation}

GZG.INV.78529 is a dissociated median LAP; well in agreement with holotype but slightly less well preserved; ventral portion of LAP smaller, slightly less strongly protruding ventro-proximalwards; proximal edge with spur on ventral portion similar to that observed on holotype; second much smaller, but similarly well-defined, spur in dorsal half of proximal edge. Three spine articulations similar to those observed on holotype. Tentacle notch very large but not as deeply concave as in holotype.

Ridge on inner side poorly preserved but superficially similar to that of holotype.

GZG.INV.78530 is a dissociated distal LAP; less well preserved than holotype; large spur in the middle of the ventral portion of the LAP probably similar to that of holotype; second small, slightly protruding, very poorly preserved spur in dorsal half of proximal edge; coarsely meshed stereom on distal twothirds of outer surface, replaced by finely meshed stereom on proximal third of outer surface. Three very poorly preserved spine articulations. Tentacle notch very large and almost as deeply incised as in holotype.

Ridge on inner side similar to that of holotype but with straight dorsal half and very poorly defined ventral half.

\section{Remarks}

These LAPs are remarkably similar to those of Lapidaster coreytaylori sp. nov. from slightly older deep-sea sediments in France. They can be unambiguously distinguished from the latter on account of the size of the ventral LAP portion, the extent of the coarsely meshed stereom on the outer surface, the shape and position of the spur on the ventral portion of the outer proximal edge, and the shape of the ridge on the inner side. 


\section{Occurrence}

Middle Albian of Great Britain.

Genus Ophiologimus H.L. Clark, 1911

\section{Type species}

Ophiologimus hexactis H.L. Clark, 1911, by original designation.

\section{Diagnosis}

LAPs with large, conspicuous tentacle notches; spine articulations not on elevated ridge and not sunken into depressions or notches; ventral portion of lateral arm plate strongly protruding ventroproximalwards; generally no spurs on outer proximal and inner distal edges of LAP.

\section{Remarks}

The LAPs of extant species of Ophiologimus are characterised by very large, generally deeply incised tentacle notches, the absence of a strong constriction or a strongly elevated distal portion, the moderately large, freestanding spine articulations and the relatively simple ridge on the inner side devoid of strongly widened parts. Closest similarities are shared with the LAPs of extinct Lapidaster gen. nov., which differ mainly in the possession of at least one spur on the outer proximal and inner distal edges. As discussed above, it seems highly probable that Ophiologimus and Lapidaster gen. nov. come from a single lineage, in view of the striking similarities in LAP morphology displayed by both genera.

Ophiologimus martynovi sp. nov. urn:1sid:zoobank.org:act:F05FA7AB-4BE9-43BE-B1D1-693D08CAE2D2

Fig. 11: 2-4

\section{Diagnosis}

Species of Ophiologimus with large LAPs; well-developed vertical striation composed of overlapping lamellae at least in proximal LAPs; up to three large, ear-shaped spine articulations; ventral lobe more slender than dorsal one and projecting ventro-distalwards beyond latter; inner side of LAP with moderately wide, straight, oblique ridge ventrally not merged with ventral portion of LAP; tentacle notch very deeply incised.

\section{Etymology}

Species named in honour of Alexander Martynov, who generously provided SEM pictures of lateral arm plates of Recent species of Ophiologimus for comparison.

\section{Type material}

\section{Holotype}

GZG.INV.78532.

\section{Paratypes}

GZG.INV.78533 and GZG.INV.78534.

\section{Type locality and horizon}

Blake Nose, borehole ODP 171B 1049C 12x6, tropical northeast Atlantic; latest Aptian to earliest Albian, Hedbergella trochoidea to Microhedbergella rischi planktonic foraminifer zones, Early Cretaceous. 


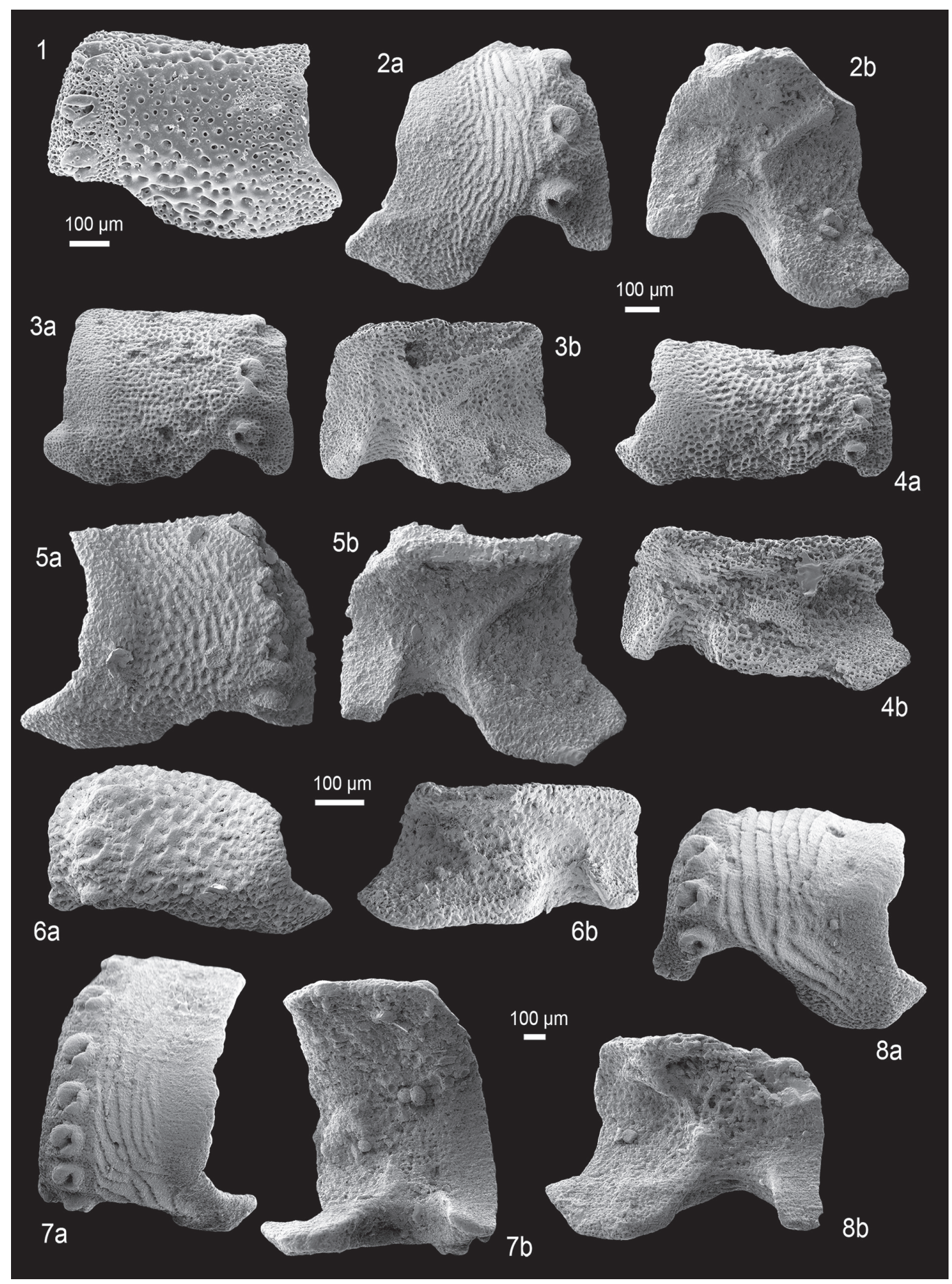

Fig. 11. Lateral arm plates (LAPs) of fossil and Recent ophiacanthid brittle stars in external (a) and internal (b) views. 1. Ophiologimus hexactis H.L. Clark, 1911, Recent, median LAP in external view. 2-4. Ophiologimus martynovi sp. nov. from the latest Aptian to earliest Albian (Early Cretaceous) of Blake Nose, NE Atlantic. 2. GZG.INV.78532 (holotype), proximal LAP. 3. GZG.INV.78533 (paratype), median LAP. 4. GZG.INV.78534 (paratype), distal LAP. 5-6. Ophiologimus aiodipius sp. nov. from the latest Aptian to earliest Albian (Early Cretaceous) of Blake Nose, NE Atlantic. 5. GZG.INV.78536 (holotype), proximal LAP. 6. GZG.INV.78537 (paratype), median LAP. 7-8. Ophiologimus rugosus (Kutscher \& Jagt, 2000) comb. nov. from the early Maastrichtian (Late Cretaceous) of Rügen, Germany. 7. GZG. INV.78539, proximal LAP. 8. GZG.INV.78540, median LAP. One common scale bar per species is given. 


\section{Additional material}

GZG.INV.78535 (45 dissociated LAPs).

\section{Description of holotype}

\section{Holotype}

GZG.INV.78532 is a dissociated, large proximal LAP; nearly as high as wide; dorso-proximal tip fragmentary; outline of dorsal edge not determinable; distal edge gently convex; proximal edge irregularly concave, devoid of spurs; ventral third of LAP strongly protruding ventro-proximalwards; ventro-distal tip of LAP strongly protruding ventralwards, tongue shaped; outer surface with well-developed, rather irregular, coarse vertical striation composed of overlapping lamellae with proximalward decrease in size and replaced by moderately coarsely to finely meshed stereom in proximal half of outer surface. Three large, equal-sized and equidistant, ear-shaped, nearly round spine articulations freestanding on non-elevated distal portion of LAP; dorsal and ventral lobes merged into continuous volute; ventral lobe more slender and smaller than dorsal one, ventro-distalwards projecting beyond dorsal lobe; gap between spine articulations and distal edge of LAP increasing in width ventralwards. Ventral edge of LAP with very large, deeply incised, concave tentacle notch.

Inner side of LAP with large, sharply defined, prominent, oblique, straight ridge with very weakly widened, round dorsal and ventral tips; no kinks, knobs or extensions; no spurs on inner side of distal edge of LAP; inner side of tentacle notch very large, with coarsely meshed, horizontally elongate stereom. No perforations or furrow discernible.

\section{Paratype supplements and variation}

GZG.INV.78533 is a dissociated median LAP; approximately 1.5 times higher than wide; closely similar to holotype; outer surface with coarsely meshed stereom, trabeculae not merged into vertical striation; coarsely meshed stereom replaced by more finely meshed stereom near proximal edge of LAP. Three spine articulations similar to those observed on holotype. Tentacle notch large and conspicuous but not as deep as in holotype. Ridge on inner side similar to that of holotype.

GZG.INV.78534 is a dissociated distal LAP; almost twice wider than high; dorsal edge slightly concave as a result of a weak constriction; outer surface with coarsely meshed stereom; few trabeculae merged into very weak, almost indiscernible vertical striation in distal half of outer surface; coarsely meshed stereom replaced by more finely meshed one towards proximal edge of LAP. Three spine articulations similar to those observed on holotype; ventral spine articulation slightly smaller than remaining two. Tentacle notch not as deep as in holotype but large, conspicuous, concave.

Ridge on inner side of LAP with strongly widened ventral tip; dorsal part of ridge straight, slender and oblique.

\section{Remarks}

These LAPs display the distinctive combination of characters typically found in LAPs of Ophiologimus, thus warranting assignment to this genus. Closest similarities are shared with the LAPs of Ophiologimus rugosus (Kutscher \& Jagt, 2000) comb. nov. (see below) in particular with respect to the outer surface vertical striation and the deeply incised tentacle notch. The LAPs of $O$. rugosus comb. nov., however, display up to seven, rather than three, spine articulations as well as two widely separate knobs or short ridges rather than a single large one on the inner side.

\section{Occurrence}

Latest Aptian to earliest Albian of the tropical northeast Atlantic. 


\section{Ophiologimus aiodipius sp. nov. urn:lsid:zoobank.org:act:C014CC2C-60E3-43F6-B1D6-20F6410E6A97}

Fig. 11: 5-6

\section{Diagnosis}

Species of Ophiologimus with large LAPs displaying coarsely meshed stereom on outer surface; trabeculae of coarsely meshed stereom merged into short, irregular vertical stripes close to spine articulations; up to four lenticular, oblique spine articulations; ridge on inner side of LAPs very slender; ventral part of ridge merged with ventral portion of LAP and connected with dorsal part of ridge by gently rounded kink; tentacle notch rather shallow.

\section{Etymology}

Species name derived from IODP, Integrated Ocean Drilling Program, under which the samples yielding the type material were recovered.

\section{Type material}

\section{Holotype}

GZG.INV.78536.

\section{Paratypes}

GZG.INV.78537.

\section{Type locality and horizon}

Blake Nose, borehole ODP 171B 1049C 12x5, tropical northeast Atlantic; latest Aptian to earliest Albian, Hedbergella trochoidea to Microhedbergella rischi planktonic foraminifer zones, Early Cretaceous.

\section{Additional material}

GZG.INV.78538 (33 dissociated LAPs).

\section{Description}

\section{Holotype}

GZG.INV.78536 is a dissociated, large, proximal LAP; slightly wider than high; dorsal edge straight; distal edge convex; proximal edge concave, devoid of spurs; ventral fifth of LAP strongly protruding ventro-proximalwards; ventro-distal tip of LAP slightly protruding; outer surface with coarsely meshed stereom; trabeculae merging into short, irregular, vertical stripes close to spine articulations; coarsely meshed stereom replaced by finely meshed stereom in narrow band along proximal edge of LAP. Four large, lenticular, oblique, slightly elongate, nearly equal-sized and equidistant spine articulations freestanding on non-elevated distal portion of LAP; dorsal and ventral lobes merged by sharp, acute kink proximally into continuous volute; gap between spine articulations and distal edge of LAP narrow, slightly increasing in width ventralwards. Ventral edge of LAP with very large, moderately deeply incised, concave tentacle notch.

Inner side of LAP with large, very slender ridge; dorsal part of ridge straight, oblique; ventral part almost vertical, merged with ventral portion of LAP and connected with dorsal part by gently rounded kink; no spurs on inner side of distal edge of LAP; inner side of tentacle notch very large. No perforations or furrow discernible.

\section{Paratype supplements and variation}

GZG.INV.78537 is a dissociated distal LAP; approximately twice wider than high; well in agreement with holotype; outer surface with very coarsely meshed stereom; trabeculae merged into shorter and 
even less regular vertical stripes than in holotype. Three spine articulations similar to those observed in holotype but with dorsalward increase in size. Ventral edge of LAP with very large, but shallow tentacle notch.

Ridge on inner side of LAP straight, oblique, slender, merged ventrally with ventral portion of LAP.

\section{Remarks}

These LAPs are unambiguously assignable to Ophiologimus on account of the very large tentacle notch combined with the spine articulations freestanding on the non-elevated distal portion of the LAP and the simple ridge on the inner side devoid of conspicuously thickened parts. Among the fossil LAP types assigned to this genus, the above is unique in combining a coarsely meshed outer surface stereom with lenticular, oblique spine articulations and a continuous ridge on the inner side with the ventral part merged with the ventral portion of the LAP.

\section{Occurrence}

Latest Aptian to earliest Albian of the tropical northeast Atlantic.

Ophiologimus rugosus (Kutscher \& Jagt, 2000) comb. nov. Fig. 11: 7-8

Ophiacantha? rugosa Kutscher \& Jagt, 2000 in Jagt 2000: 11, pl. 13 fig. 1.

Ophiacantha? rugosa Kutscher \& Jagt, 2000: 63, pl. 25 fig. 7.

Ophiacantha? n. sp. - Jagt 1999a: 200, pl. 2 fig. 5.

\section{Diagnosis}

Species of Ophiologimus with large LAPs displaying well-developed vertical constriction on outer surface composed of coarse, strongly overlapping lamellae; up to seven large, ear-shaped spine articulations; ventral portion of LAP relatively narrow; inner side of LAP with two widely separate short ridges or knobs; tentacle notch deeply incised.

\section{Material examined}

GZG.INV.78539 and GZG.INV.78540 (leg. Manfred Kutscher) 50 dissociated LAPs, original material listed by Kutscher \& Jagt (2000); dissociated LAP (NHMM JJ 10600/12e) from the upper Campanian Zeven Wegen Member (Gulpen Formation) of Haccourt, northeast Belgium, the original material of Jagt (2000).

\section{Description}

Relatively large LAPs, proximal ones nearly 1.5 times higher than wide, distal ones slightly wider than high; ventral fifth (proximal LAPs) to third (distal LAPs) strongly protruding ventro-proximalwards; ventro-distal tip of LAPs tongue shaped, conspicuously protruding; dorsal edge straight to slightly concave as a result of a very weak constriction; distal edge evenly convex; proximal edge undulose, with convex central part and protruding ventral fifth to quarter, separated by kink; no spurs on proximal edge; outer surface with conspicuous irregular striation composed of broad, flattened, distalwards slightly overlapping stripes loosely following outline of proximal edge of LAP; striation restricted to central band, proximally bordered by band of very finely meshed stereom and distally bordered by confluent areoles of finely meshed stereom surrounding all spine articulations. Four (distal LAPs) to seven (proximal LAPs) relatively large, ear-shaped, equal-sized spine articulations; dorsalward increase in size of gaps separating spine articulations; dorsal and ventral lobes forming continuous 
volute in all spine articulations. Ventral edge of LAPs with extremely large, deeply concave tentacle notch.

Inner side of LAPs with two separate ridges or knobs; ventral ridge consisting of a short, prominent dorsalward protrusion of the slightly thickened ventral portion of the LAP, with well-defined, widened, rounded dorsal tip; second ridge near centre of inner proximal edge of the LAP, consisting of a welldefined, prominent, reversed V-shaped knob with a ventro-proximally pointing branch and slightly shorter and narrower ventro-distalward pointing branch; in distal LAPs poorly defined and only slightly prominent connection between both ridge-like structures; inner side of ventro-distal tip of LAP strongly protruding but not thickened and devoid of spurs. Inner side of tentacle notch with coarsely meshed, horizontally stretched stereom. Very faint, irregular vertical row of small perforations on inner side of proximal LAPs.

\section{Remarks}

This species was originally described by Kutscher \& Jagt (in Jagt 2000) on the basis of dissociated LAPs from the early Maastrichtian of Germany and Denmark and tentatively assigned to the genus Ophiacantha. Reassessment of the type specimens has revealed that the species is assignable to Ophiologimus. Within this genus, it is unambiguously recognisable on account of the high number of spine articulations.

\section{Occurrence}

Late Campanian of northeast Belgium and early Maastrichtian of northeast Germany and Denmark.

Genus Ophiotoma Verrill, 1899

\section{Type species}

Ophiotoma coriacea Lyman, 1883, by monotypy.

\section{Diagnosis}

LAPs devoid of constriction or strongly elevated or bulging distal portion; spine articulations free standing or in shallow notches of the slightly elevated distal edge; ventral portion of LAP very large, protruding ventro-proximalwards; tentacle notch large, inner side of tentacle notch in proximal LAPs at least as wide as one-third of the total ventral LAP edge width; outer surface commonly with vertical striation; no conspicuous spurs on outer proximal and inner distal edges; ridge on inner side of LAP generally with widened dorsal tip.

\section{Remarks}

The LAPs of extant species of Ophiotoma (Fig. 12: 1-3) are characterised by the lack of a constriction and of a bulging or strongly elevated distal portion, as well as a large, strongly protruding ventral portion bordering a large tentacle notch. The spine articulations are generally in shallow notches or depressions of the slightly elevated distal LAP edge, which differentiates them from the LAPs of Ophiologimus (see above). Superficial similarities exist to the LAPs of extant species of Ophiolimna Verrill, 1899 (see below). In these, however, the spine articulations are proximally slightly overlain by the coarse vertical striation of the outer surface and merged with the latter by a connecting ridge.

The ophiacanthid fossil record includes only very few dissociated LAP types which convincingly match the diagnosis of Ophiotoma. Given their scarcity and limited currently known diversity, these fossil LAP types are here assigned to the extant genus Ophiotoma. The discovery of articulated specimens with the LAP types in question, however, are very likely to reveal differences in general skeletal morphology which imply distinction at the generic level. Irrespective of generic placement 
issues, the striking morphological similarities shared by the fossil LAPs and those of Ophiotoma strongly suggest close phylogenetic ties, which is the relevant aspect for the scope of the present study.

The LAPs of Ophiotoma, especially the fossil ones, share an intriguing similarity with those assigned to extinct Dermocoma Hess, 1964 (see below), in particular on account of the strongly protruding ventral portion of the LAPs, the absence of a constriction and a bulging distal portion, the position of the spine articulations and the shape of the ridge on the inner side of the LAPs. The LAPs of Dermocoma tend to differ from those of Ophiotoma in displaying large and strongly protruding spurs on their outer proximal and inner distal edges. However, since both genera include species which deviate from this pattern, the latter cannot be taken as a rule. The only unambiguous character to distinguish the LAPs of Ophiotoma and Dermocoma is the size of the tentacle notch.

Ophiotoma sp. nov. innom.

Fig. 12: 4

\section{Material examined}

NHMW 2012/0137/0009 (dissociated LAP) from the late Sinemurian to early Pliensbachian of the Glasenbach Gorge, Austria.

\section{Description}

NHMW 2012/0137/0009 is a dissociated, small, proximal to median LAP, slightly wider than high; dorsal edge nearly straight; distal edge oblique, nearly straight to slightly convex; proximal edge strongly concave, devoid of spurs; ventral third of LAP strongly protruding ventro-proximalwards; distal portion of LAP not bulging and not elevated; outer surface almost entirely covered by fine, regular, vertical striation composed of thin distally slightly overlapping lamellae. Four ear-shaped, equi-distant spine articulations in tight, shallow notches of the the distal edge only very slightly interrupting the vertical striation; ventralmost spine articulation slightly smaller than remaining three; moderately large and ventrally increasing gap between spine articulations and distal edge of LAP; dorsal and ventral lobes of spine articulations forming continuous volute. Ventral edge of LAP with very large, concave tentacle notch.

Inner side of LAP: ridge very narrow, well defined, prominent, evenly bent, with widened dorsal tip reaching dorso-proximal corner of LAP; ventral tip pointing ventro-proximalwards, merging with ventral portion of LAP; no spurs discernible on inner side of distal edge of LAP; inner side of tentacle notch slightly wider than one-third of the ventral edge width of the LAP. Presence of perforations on the inner side not determinable on account of insufficient preservation.

\section{Remarks}

The single known LAP is characterised by the very large tentacle notch, the absence of a constriction or strongly elevated distal portion, and the spine articulations in shallow notches and devoid of connecting ridges with the outer surface ornament. This combination of characters strongly suggests assignment to Ophiotoma or at least to the fossil LAP types placed in Ophiotoma for the reasons discussed above. The LAP in question shows closest similarities to those of Ophiotoma charlottae sp. nov. (see below), but differs in having its outer surface almost entirely covered by vertical striation. In Ophiotoma vadosa sp. nov. the spine articulations show a strong dorsalward increase in size and in the gaps separating them. The LAP from the Glasenbach Gorge belongs to an undescribed species, but in view of the fact that a single specimen is available, any formal description is premature. 


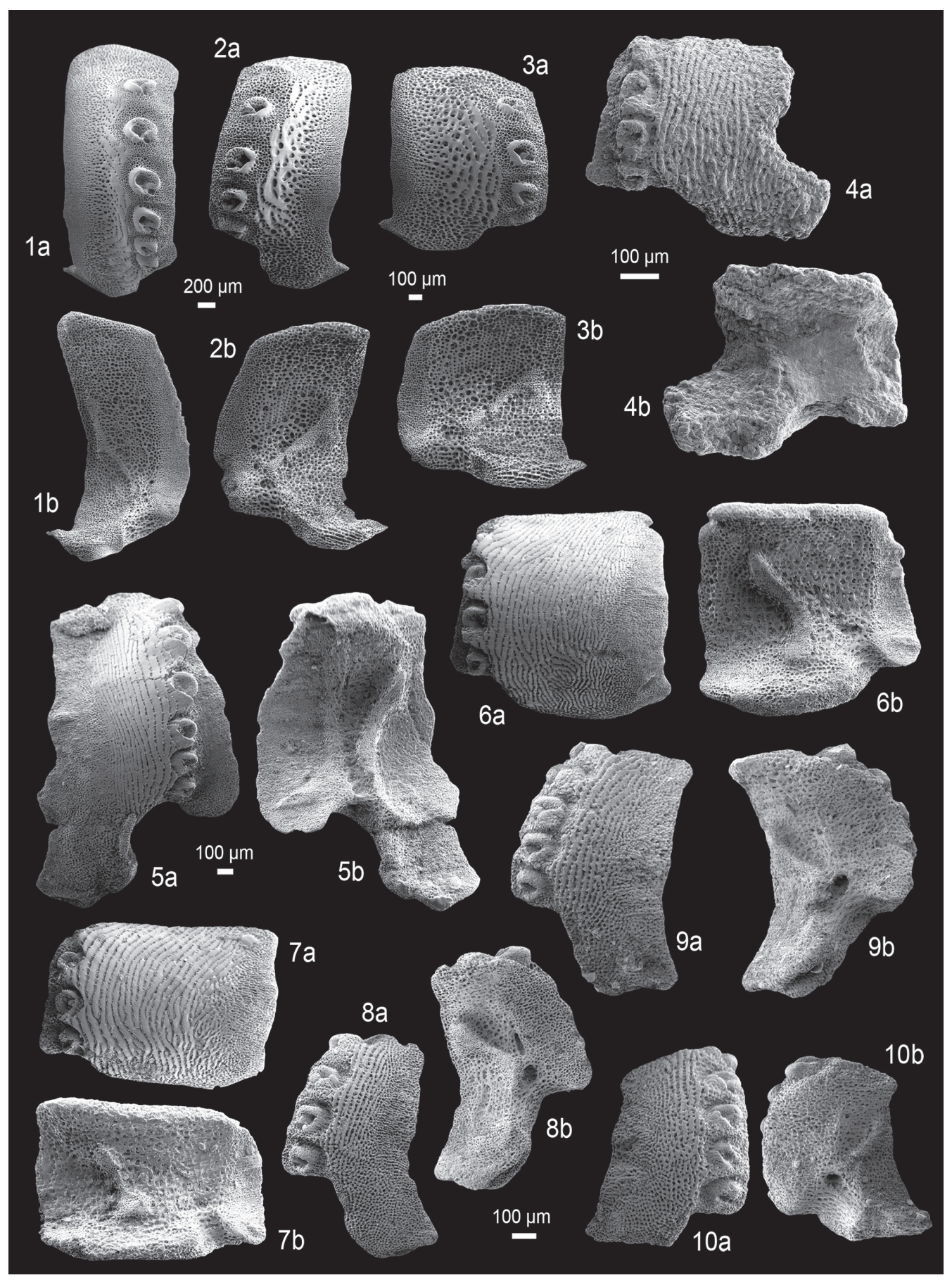

Fig. 12. Lateral arm plates (LAPs) of fossil and Recent ophiacanthid brittle stars in external (a) and internal (b) views. 1. Ophiotoma assimilis Koehler, 1904, Recent, proximal LAP. 2-3. Ophiotoma megatreta (H.L. Clark, 1911), Recent. 2. Proximal LAP. 3. Median LAP. 4. Ophiotoma sp. nov. innom. from the late Sinemurian to early Pliensbachian (Early Jurassic) of the Glasenbach Gorge, Austria; NHMW 2012/0137/0009, median LAP. 5-7. Ophiotoma vadosa sp. nov. from the early Pliensbachian (Early Jurassic) of Blockley, Great Britain. 5. GZG.INV.78541 (holotype), proximal LAP. 6. GZG.INV.78542 (paratype), median LAP. 7. GZG.INV.78543 (paratype), distal LAP. 8-10. Ophiotoma charlottae sp. nov. from the early Kimmeridgian of the Pointe du Chay, France. 8. GZG.INV.78545 (holotype), proximal LAP. 9. GZG.INV.78546 (paratype), proximal to median LAP. 10. GZG.INV.78547 (paratype), distal LAP. One common scale bar per species is given. 


\section{Ophiotoma vadosa sp. nov. urn:Isid:zoobank.org:act:698A06E5-BC2D-4729-8C41-15F2EBBFEB3E}

Fig. 12: 5-7

\section{Diagnosis}

Species of Ophiotoma with relatively large LAPs displaying large, conspicuous, tongue-shaped and strongly protruding ventro-distal tip; two small, but comparatively well-developed spurs on the outer proximal and inner distal edges; up to six spine articulations displaying strong dorsalward increase in size and in the size of the gaps separating them; dorsal tip of the ridge on the inner side of the proximal LAPs only slightly enlarged.

\section{Etymology}

From vadosus, Latin for "shallow", in reference to the relatively shallow (mid-shelf) water depth assumed for the palaeohabitat of the species.

\section{Type material}

\section{Holotype}

GZG.INV.78541.

\section{Paratypes}

GZG.INV.78542 and GZG.INV.78543.

\section{Type locality and horizon}

Blockley, near Cheltenham, Great Britain; shell lenses in clayey matrix, Davoei Zone, early Pliensbachian, Early Jurassic.

\section{Additional material}

GZG.INV.78544 (20 dissociated LAPs) from Blockley, Great Britain; 175 dissociated LAPs from the late Pliensbachian of Seewen, Switzerland, the original material of Hess (1962).

\section{Description}

\section{Holotype}

GZG.INV.78541 is a dissociated, large, proximal LAP; dorsal and distal edges slightly convex; proximal edge undulose, with small, well-defined, oval, prominent spur positioned in the centre of protruding part of proximal LAP edge; second slightly larger but much less well-defined spur in the middle of the ventral half of the proximal edge; ventral third to quarter of LAP strongly protruding ventro-proximalwards; ventro-distal tip of LAP large, strongly protruding, tongue shaped; distal portion of LAP neither bulging nor elevated; outer surface with well-developed, regular vertical striation composed of thin, distalwards slightly overlapping lamellae, replaced by finely meshed stereom on ventral portion of LAP and near proximal edge. Six ear-shaped spine articulations in notches of distal edge; strong dorsalward increase in size of spine articulations and of gaps separating them; no connecting ridge with striation of outer surface; dorsal and ventral lobes of spine articulations separated by very small incision proximally; large and ventrally strongly increasing gap between spine articulations and distal edge. Ventral edge with very large, deeply concave, conspicuous tentacle notch, exacerbated by strongly protruding ventro-distal tip of LAP.

Inner side of LAP with large, sharply defined, prominent, bent ridge; dorsal tip of ridge only very slightly widened, pointing dorsalwards; ventral tip of ridge merged with ventral portion of LAP; inner side of distal edge of LAP with two spurs, dorsal one of which small, round, poorly defined, very slightly prominent but not protruding; ventral spur much larger, better defined, prominent, lenticular; inner side of tentacle notch slightly wider than one-third of the total ventral LAP edge width. Irregular vertical row 
of perforations, ventralmost of which dorsally bordering tentacle notch, moderately large; remaining perforations minute; row of perforations distally bordered by poorly defined, slightly prominent ridge.

\section{Paratype supplements and variation}

GZG.INV.78542 is a dissociated median LAP, nearly as high as wide; of rectangular to trapezoid outline; dorsal and distal edges oblique, straight; proximal edge slightly undulose, with two small, poorly defined, slightly prominent and very slightly protruding spurs; ventral fifth of LAP protruding; outer surface with vertical striation becoming slightly irregular in ventral half of LAP; striation replaced by finely meshed stereom close to proximal edge of LAP. Four spine articulations in moderately deep notches of distal edge; very weak dorsalward increase in size of spine articulations and of gaps separating them; narrow but ventrally increasing gap between spine articulations and distal edge of LAP. Ventral edge of LAP convex with moderately large, weakly concave tentacle notch.

Inner side with large, sharply defined ridge; dorsal tip of ridge slightly widened, ventral tip separated from ventral portion of LAP; inner side of distal edge of LAP with two small, moderately well-defined, slightly prominent spurs; inner side of tentacle notch slightly smaller than one-quarter of the total ventral edge of the LAP. Poorly defined, irregular perforation halfway between ridge and distal edge of LAP.

GZG.INV.78543 is a dissociated distal LAP, approximately 1.5 times wider than high, of rectangular outline; well in agreement with other paratype; ventral portion of LAP hardly protruding.

Inner side of LAP with sharply defined, prominent, bone-shaped ridge; dorsal and ventral tips of ridge strongly widened.

\section{Remarks}

These LAPs show a certain resemblance with LAPs assigned to Dermocoma (see below), in particular on account of the relatively deep notches holding the spine articulations and the spurs on the outer proximal and inner distal edges. These similarities, however, are superficial at most. In fact, the very large tentacle notches clearly preclude assignment to Dermocoma. Among the large-pored ophiacanthid lineages, greatest similarities are shared with the LAPs of extant Ophiotoma and the fossil LAP types assigned to that genus. Thus, in spite of the rather atypically well-developed spurs on the outer proximal and inner distal edges, the above-described LAPs are assigned to Ophiotoma. Within this genus, the LAPs in question are highly distinctive on account of the spurs and their very large, conspicuous, tongue-shaped ventro-distal tip, which is why they are described as a new species.

\section{Occurrence}

Early Pliensbachian of Great Britain and Late Pliensbachian of Switzerland.

\section{Ophiotoma charlottae sp. nov. urn:1sid:zoobank.org:act:BFA9592E-7CEA-4B12-B2F0-45E1E27B7EF6}

Fig. 12: 8-10

\section{Diagnosis}

Species of Ophiotoma with comparatively small LAPs displaying a large, nearly rectangular and strongly protruding ventral portion (third of a proximal LAP); four to five equal-sized spine articulations; outer surface with striation restricted to relatively narrow band close to spine articulations and composed of thin lamellae separated by single rows of small stereom pores; inner side with main, central bone-shaped ridge and second ridge on ventral portion of LAP; very large, single perforation bordering ventral tip of main ridge, occasionally dorsally accompanied by second vertically elongate ridge. 


\section{Etymology}

Species named in honour of Charlotte Bruneau for introducing me to Alexandre Jardin's wonderful L'île des gauchers.

\section{Type material}

\section{Holotype}

GZG.INV.78545.

\section{Paratypes}

GZG.INV.78546 and GZG.INV.78547.

\section{Type locality and horizon}

Pointe du Chay near La Rochelle, France; Achilles Subzone, Cymodoce Zone, early Kimmeridgian, Late Jurassic.

\section{Additional material}

GZG.INV.78548 (3 dissociated LAPs).

\section{Description}

\section{Holotype}

GZG.INV.78545 is a dissociated, small, proximal LAP; approximately 1.5 times higher than wide; slightly convex dorsal and distal edges; proximal edge gently concave with very slight central protrusion; no spurs discernible on proximal edge; small, poorly defined, shallow depression in the middle of the proximal edge; ventral third nearly rectangular, strongly protruding ventro-proximalwards; no constriction; distal portion of LAP neither bulging nor elevated; outer surface with fine, regular vertical striation composed of thin lamellae separated by single rows of small stereom pores; striation replaced by finely meshed stereom in proximal third of outer surface and on most of the ventral portion of the LAP. Four ear-shaped, equal-sized spine articulations in shallow notches of the distal edge, moderately deeply incising the vertical striation of the outer surface; slight dorsalward increase in size of gaps separating the spine articulations; dorsal and ventral lobes separated by a small knob; almost no gap between spine articulations and distal edge of LAP. Ventral edge of LAP with very large, slightly angular tentacle notch.

Inner side of LAP with large but comparatively short, sharply defined, prominent, bone-shaped main ridge; dorsal portion of ridge oblique, with strongly widened dorsal tip; ventral portion with similarly widened ventral tip, well defined but not as sharply and prominently as dorsal tip; second less welldefined, less prominent but slightly wider, proximally bent ridge proximally bordering the inner side of the tentacle notch, in direct continuation of the ventral portion of the main ridge but separated from the latter; no spurs on the inner side of the distal edge of the LAP; inner side of the tentacle notch with coarsely meshed, horizontally stretched stereom, almost as wide as half of the total ventral LAP edge width. Single very large perforation distally bordering the tip of the ventral portion of the main ridge; second smaller, vertically elongate perforation above large one. Ventro-distal edge of ventral LAP portion with prominent ridge.

\section{Paratype supplements and variation}

GZG.INV.78546 is a proximal LAP; well in agreement with holotype. Vertical striation on outer surface extending to a slightly larger area close to spine articulations and on dorsal edge of ventral portion of LAP. Five spine articulations, of equal size and nearly equi-distant.

Inner side very well in agreement with that of holotype. Vertically elongate perforation lacking. 
GZG.INV.78547 is a median LAP; nearly as high as wide; well in agreement with holotype; ventral quarter of LAP strongly protruding ventro-proximalwards; shallow, poorly defined depression in the centre of the proximal edge slightly larger. Five equal-sized, nearly equi-distant spine articulations shallowly incising the vertical striation of the outer surface.

Inner side with well-defined, bone-shaped main ridge well in agreement with that of holotype; no second ridge on inner side of ventral portion of LAP discernible; inner side of tentacle notch with coarsely meshed, horizontally stretched stereom, nearly as wide as half of the total ventral LAP edge width. Single large perforation bordering ventral tip of main ridge; no second, elongate perforation. Ventrodistal edge of ventral LAP portion with poorly defined, slightly prominent knob.

\title{
Remarks
}

These LAPs display the highly distinctive characters of the LAPs of extant species of Ophiotoma, in particular the very large tentacle notches, the spine articulations in shallow depressions or notches of the non-bulging, non-elevated distal edge, the large and strongly protruding ventral portion, and the widened dorsal tip of the ridge on the inner side. The LAPs in question thus seem best accommodated in Ophiotoma, acknowledging, however, that the discovery of articulated specimens might reveal substantial differences in general skeleton morphology warranting separation at the generic level. The shape of the large, ventral portion of the LAPs, the large perforation and the distinctly bone-shaped ridge on the inner side, and the development and spatial extent of the vertical striation on the outer surface unmistakably characterise the above-described LAPs, which is why they are here described as a new species of Ophiotoma.

\section{Occurrence}

Early Kimmeridgian of France.

$$
\begin{aligned}
& \text { Ophiotoma incredibilis sp. nov. } \\
& \text { urn:1sid:zoobank.org:act:768EE8E5-D636-4D23-9640-6D22A392265B }
\end{aligned}
$$

Fig. 13: 1-3

\section{Diagnosis}

Species of Ophiotoma with large LAPs displaying a low height/width ratio; outer surface with welldeveloped vertical striation; up to four relatively small spine articulations in shallow notches of the non-elevated distal portion of the LAP; ridge on inner side devoid of thickened parts, composed of two separated parts: a long, oblique, nearly straight, dorso-proximally pointing dorsal one and a shorter ventro-proximally pointing ventral one.

\section{Etymology}

From incredibilis, Latin for "unbelievable", referring to the surprisingly emotional reactions some colleagues showed when confronted with the discovery of the Blake Nose deep-sea ophiuroid assemblage.

\section{Type material}

\author{
Holotype \\ GZG.INV.78549. \\ Paratypes \\ GZG.INV.78550 and GZG.INV.78551.
}

\section{Type locality and horizon}

Blake Nose, borehole ODP 171B 1049A 20x5, tropical northeast Atlantic; latest Aptian to earliest Albian, Hedbergella trochoidea to Microhedbergella rischi planktonic foraminiferal zones, Early Cretaceous. 


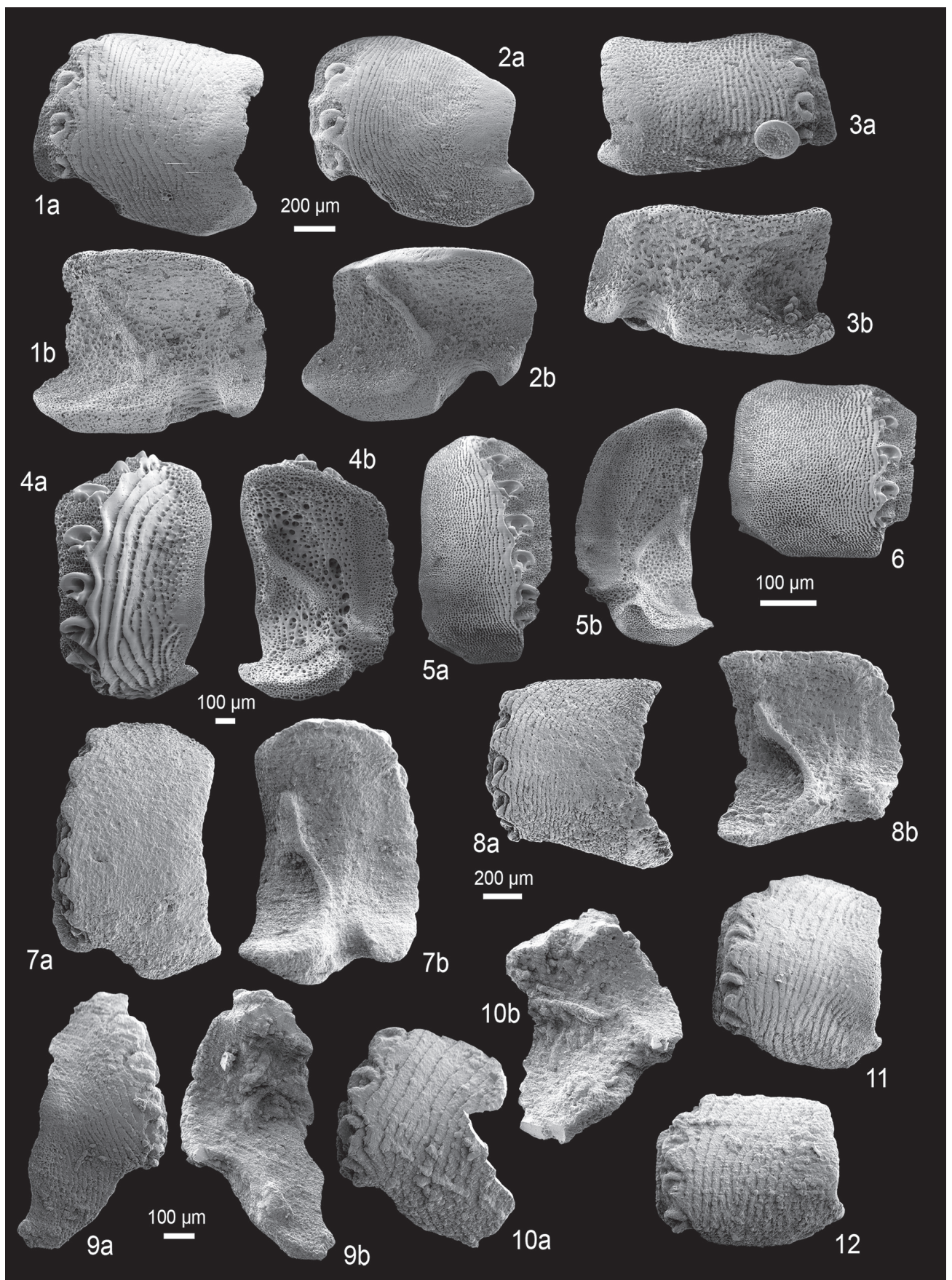

Fig. 13. Lateral arm plates (LAPs) of fossil and Recent ophiacanthid brittle stars in external (a) and internal (b) views. 1-3. Ophiotoma incredibilis sp. nov. from the latest Aptian to earliest Albian (Early Cretaceous) of Blake Nose, NE Atlantic. 1. GZG.INV.78549 (holotype), proximal LAP. 2. GZG. INV.78550 (paratype), median LAP. 3. GZG.INV.78551 (paratype), distal LAP. 4. Ophiolimna antarctica (Lyman, 1879), Recent, proximal LAP. 5-6. Ophiolimna perfida (Koehler, 1904), Recent. 5. Proximal LAP. 6. distal LAP. 7-8. Ophiolimna tiamatia sp. nov. from the late Sinemurian to early Pliensbachian (Early Jurassic) of the Glasenbach Gorge, Austria. 7. NHMW 2012/0137/0010 (holotype), proximal LAP. 8. NHMW 2012/0137/0011 (paratype), median LAP. 9-12. Ophiolimna malagasica sp. nov. from the Bathonian (Middle Jurassic) of Jumara, India. 9. GZG.INV.78553 (holotype), proximal LAP. 10. GZG.INV.78554 (paratype), median LAP. 11. GZG.INV.78555 (paratype), median LAP. 12. GZG. INV.78556 (paratype), distal LAP. One common scale bar per species is given. 


\section{Additional material}

GZG.INV.78552 (26 dissociated LAPs).

\section{Description}

\section{Holotype}

GZG.INV.78549 is a dissociated, very large, proximal LAP; slightly wider than high; dorsal edge straight; distal edge convex; proximal edge irregularly concave, devoid of spurs; ventral third to quarter strongly protruding ventro-proximalwards; ventro-distal tip of LAP weakly protruding, tongue shaped; outer surface with well-developed, rather regular vertical striation composed of coarse, overlapping lamellae replaced by finely meshed stereom in very narrow band along the proximal edge of the LAP. Four relatively small, ear-shaped spine articulations in shallow notches of the non-elevated distal edge of LAP; very weak dorsalward increase in size of spine articulations and of gaps separating them; notches of spine articulations deeply incising vertical striation of outer surface; dorsal and ventral lobes of spine articulations proximally separated by very small notch; gap between spine articulations and distal edge of LAP narrow, with ventralward increase in width. Ventral edge of LAP with large, deeply concave tentacle notch.

Inner side of LAP with two sharply defined, prominent, very slender ridges separated by poorly defined, very weakly prominent connection; dorsal ridge oblique, nearly straight except for ventrally pointing ventral tip; ventral ridge much shorter, nearly straight, ventro-proximally pointing; inner side of distal edge of LAP devoid of spurs; inner side of tentacle notch large, well defined, with coarsely meshed, horizontally elongate stereom, slightly narrower than one-third of the total ventral LAP edge width. No perforations or furrow discernible.

\section{Paratype supplements and variation}

GZG.INV.78550 is a dissociated median to proximal LAP; almost 1.5 times wider than high; dorsoproximal tip fragmentary; very well in agreement with holotype; vertical striation on outer surface slightly finer and slightly less regular. Three spine articulations similar to those observed on holotype but of equal size.

Inner side well in agreement with holotype; ridges slightly better preserved, completely separate. Single small perforation dorsally bordering tentacle notch.

GZG.INV.78551 is a dissociated distal LAP; twice higher than wide; dorsal edge slightly concave as a result of a very weak constriction; vertical striation on outer surface less well developed than in holotype. Three spine articulations similar to those observed on the holotype.

Inner side of LAP with small, slender ridge composed of slightly bent, oblique, dorso-proximally pointing dorsal part and shorter ventro-proximally pointing ventral part separated from the dorsal one by a gently rounded kink; sharply defined, prominent, round knob distally bordering the ridge.

\section{Remarks}

These LAPs are characterised by a well-developed outer surface vertical striation, a strongly ventroproximally protruding ventral portion, and the absence of a strongly elevated or bulging distal portion. The genera Ophiologimus and Lapidaster gen. nov. can be excluded since the spine articulations are in shallow notches rather than freestanding. The LAPs of Dermocoma display a continuous spine articulation volute rather than dorsal and ventral lobes separated proximally by a small notch.

Among the genera with LAPs displaying strongly protruding, generally large ventral portions, closets affinities are shared with Ophiotoma and Dermacantha gen. nov. The LAPs of the latter, although with similarly low height/width ratio, generally display spurs on the outer proximal and inner distal edges and a smaller tentacle notch. The above-described LAPs are thus assigned to Ophiotoma, acknowledging, 
however, that the height/width ration is atypically low and the tentacle notch unusually small. Nevertheless, assignment to Ophiotoma is favoured for now.

\section{Occurrence}

Latest Aptian to earliest Albian of the tropical northeast Atlantic.

\section{Genus Ophiolimna Verrill, 1899}

\section{Type species}

Ophiolimna bairdi Lyman, 1883, by original designation.

\section{Diagnosis}

LAPs with at least part of their outer surface covered by a well-developed, coarse vertical striation composed of broad, overlapping lamellae; spine articulations sunken into notches of the distal edge and partly overlapped by the strongly undulose distalmost lamella and connected with the latter by the large, tongue-shaped ventral lobe of the spine articulations; inner side with central ridge, commonly with widened or bifurcated dorsal tip, and ventral ridge, in direct continuation of central ridge or connected with the latter.

\section{Remarks}

The LAPs of extant Ophiolimna (Fig. 13: 4-6) are among the most distinctive of the currently known ophiacanthids. The well-developed, coarse vertical striation of the outer surface consisting of broadly overlapping lamellae, and the spine articulations overlapped by the undulose distalmost lamella and connected with the latter by the large, tongue-like ventral lobes of the spine articulations are found in no other type of ophiacanthid LAP morphology. There is, however, a superficial resemblance with the LAPs of extant Ophioconis Lütken, 1869, currently assigned to the Ophiodermatidae Ljungman, 1867 (Stöhr \& O'Hara 2007), as already pointed out by Martynov (2010). However, the LAPs of the two genera can easily be told apart on the basis of the ridges on the inner side of the proximal LAPs: while in Ophiolimna there is one large, central ridge with a second ventral one indirect continuation of the former, Ophioconis displays three round knobs instead of true ridges. Ophiolimna and Ophiotoma share a very similar development of the ridges on the inner side of the LAPs, which underpins their close phylogenetic ties.

The ophiacanthid fossil record includes a number of rare occurrences, from both shallow- and deepwater settings, of dissociated LAP types which closely recall the LAPs of extant Ophiolimna. In fact, they fit the LAP-morphological diagnosis of Ophiolimna so well that they almost certainly belong to Ophiolimna or at least to a very closely related genus.

Ophiolimna tiamatia sp. nov. urn:1sid:zoobank.org:act:89A5AD8F-A02B-47C1-8238-E21F29F1F526

Fig. 13: 7-8

\section{Diagnosis}

Species of Ophiolimna with moderately large LAPs of rectangular outline; outer surface with relatively fine vertical striation; comparatively small spine articulations deeply sunken into notches of distal edge; inner side of proximal LAPs with large central ridge displaying slightly widened dorsally pointing dorsal tip. 


\section{Etymology}

Species named after Tiamat, primordial goddess of the ocean and chaos monster in Babylonian mythology, in reference to the fact that this species is the oldest currently known occurrence of the Ophiolimna lineage and, on account of its deep-water origin, thus challenges the widely accepted concepts of the macroevolutionary significance of deep-water habitats.

\section{Type material}

\section{Holotype}

NHMW 2012/0137/0010.

\section{Paratypes}

NHMW 2012/0137/0011.

\section{Type locality and horizon}

Glasenbach Gorge, Austria; Hauptknollenbrekzie, late Sinemurian to early Pliensbachian, Early Jurassic.

\section{Additional material}

NHMW 2012/0137/0012 (54 dissociated LAPs).

\section{Description}

\section{Holotype}

NHMW 2012/0137/0010 is a dissociated, medium-sized, proximal LAP of rectangular outline; approximately 1.5 times higher than wide; dorsal edge pointed, with strongly obtuse angle; distal edge convex; proximal edge unevenly concave, devoid of spurs; ventral portion of LAP slightly protruding ventro-proximalwards, accounting for less than a seventh of total LAP height; ventro-distal tip of LAP very slightly protruding, rounded; outer surface with very regular vertical striation composed of broadly overlapping lamellae, with strong proximalward decrease in size; lamellae replaced by finely meshed stereom in proximalmost third of outer surface and on ventral portion of LAP. Seven small, ear-shaped and nearly equal-sized spine articulations in deep notches of the distal edge and partly overlapped by the undulose distalmost lamella; ventral lobes of spine articulations strongly increasing in size dorsalwards, conspicuously tongue shaped and connected with the distalmost lamella in all but the two ventralmost spine articulations; dorsalward increase in size of the gaps separating spine articulations; narrow gap between the four ventral spine articulations and the distal edge of the LAP. Ventral edge of LAP with large, concave tentacle notch.

Inner side of LAP with large, sharply defined and prominent central ridge composed of an oblique, relatively narrow median part, a widened, dorsally pointing dorsal part, and a ventro-proximally bent, slightly less well-defined and relatively narrow ventral part; second small, inconspicuous, poorly defined and weakly prominent, proximally pointing ridge near ventro-proximal tip of LAP; inner side of distal edge of LAP devoid of spurs; inner side of tentacle notch distally bordered by slightly thickened ventrodistal edge of LAP. Very shallow vertical furrow dorsally bordering tentacle notch with single, very small perforation near ventralmost tip of furrow; no other perforations discernible.

\section{Paratype supplements and variation}

NHMW 2012/0137/0011 is a dissociated median LAP of trapezoid outline; nearly as high as wide; dorsal edge straight. Five equal-sized spine articulations; ventral lobe large, conspicuously tongue shaped and connected with distalmost lamella in all spine articulations; slight dorsalward increase in size of ventral lobes; strong dorsalward increase in size of gaps separating spine articulations. Ventral edge of LAP oblique, tentacle notch not discernible, possibly on account of insufficient preservation. 
Inner side of LAP with central ridge well in agreement with that of holotype; dorsal tip only very slightly widened; no second, ventral ridge discernible; inner side of tentacle notch large but poorly defined. Vertical furrow dorsally bordering tentacle notch very faint, almost indiscernible.

\section{Remarks}

Although at first sight these LAPs appear rather atypical of the Ophiacanthidae, their spine articulations are overlapped by the distalmost lamella of the outer surface striation, and the ventral lobes of the spine articulations are large, tongue like and connected with the distalmost lamella, which, together with the well-developed ridges on their inner side, unambiguously places them in the Ophiolimna lineage. There is a superficial resemblance with the similarly rectangular LAPs of the extinct ophioleucinid Eirenura Thuy, 2011. In the latter, however, the outer surface is only faintly striated, the dorsal tip of the ridge is not widened, and, most importantly, the spine articulations are rhombic rather than ear-shaped and lack the tongue-shaped ventral lobe.

The comparatively small and deeply sunken spine articulations and the slightly widened dorsal tip of the central ridge on the inner side are highly distinctive features of the above-described LAPs, precluding confusion with any other LAP type assigned to Ophiolimna. Thus, the LAP type in question is described here as a new species.

\section{Occurrence}

Late Sinemurian to early Pliensbachian of Austria.

Ophiolimna malagasica sp. nov. urn:1sid:zoobank.org:act:158198F0-5105-4FD2-94F3-F79984D38A0E

Fig. 13: 9-12

\section{Diagnosis}

Species of Ophiolimna with tiny LAPs displaying pointed, strongly ventro-proximalwards protruding ventral portion (accounting for at least one-third of the total height of proximal LAPs); outer surface almost entirely covered by relatively coarse vertical striation; up to six relatively large spine articulations separated from distal edge of LAP by very narrow gap; inner side with spoon-shaped central ridge with strongly widened, round dorsal tip, and second ventral, triangular ridge.

\section{Etymology}

Name formed after the Malagasy Gulf which formed a southerly extension of the Tethys between Africa and India in Jurassic times, in reference to the origin of the type material.

\section{Type material}

\section{Holotype}

GZG.INV.78553.

\section{Paratypes}

GZG.INV.78554, GZG.INV.78555 and GZG.INV.78556.

\section{Type locality and horizon}

Jumara, Kachchh, India; sample 24, Patcham Formation, late Bathonian, Middle Jurassic. 


\section{Additional material}

GZG.INV.78557 (5 dissociated LAPs) from sample 24; GZG.INV.78558 (13 dissociated LAPs) from sample 15; GZG.INV.78559 (6 dissociated LAPs) from sample 31; GZG.INV.78560 (8 dissociated LAPs) from sample 89.

\section{Description}

\section{Holotype}

GZG.INV.78553 is a dissociated, minute, very fragile, proximal LAP; considerably higher than wide; dorsal edge fragmentary; distal edge slightly convex; preserved portion of proximal edge undulose, devoid of spurs; ventral portion of LAP pointed, strongly protruding ventro-proximalwards, accounting for at least one-third of the total LAP height; outer surface almost entirely covered by coarse, regular, vertical striation composed of broad, overlapping lamellae decreasing in size distalwards and replaced by finely meshed stereom only at the very proximal edge of the LAP. Six relatively large, ear-shaped, equi-distant spine articulations in notches of the distal edge, overlapped by the undulose distalmost lamella; ventral lobe large, conspicuously tongue shaped and connected with the distalmost lamella in all spine articulations; strong dorsalward increase in size of spine articulations; very narrow gap between spine articulations and distal edge of LAP. Ventral edge of LAP strongly oblique on account of the pointed ventral portion, with large, concave tentacle notch.

Inner side of LAP with conspicuous, sharply defined, prominent, spoon-shaped central ridge displaying strongly widened, round and proximally pointing dorsal tip and very slightly widened ventro-distally pointing ventral tip; second sharply defined, strongly prominent, triangular ridge close to the centre of the ventro-distal edge of the LAP; no spurs discernible on inner side of distal edge of LAP. No perforations discernible.

\section{Paratype supplements and variation}

GZG.INV.78554 is a dissociated median LAP; nearly as wide as high, dorso-proximal edge strongly fragmentary; ventral third to quarter strongly protruding ventro-proximalwards; lamellae of outer surface vertical striation very coarse. Four equidistant spine articulations with slight dorsalward increase in size. Inner side well in agreement with that of holotype; dorsal tip of central ridge less strongly widened.

GZG.INV.78555 is a dissociated distal LAP of rounded rectangular outline, slightly wider than high; dorsal edge straight; proximal edge intact, slightly undulose, devoid of spurs; ventral portion of LAP hardly protruding ventro-proximalwards. Four equidistant and nearly equal-sized spine articulations in notches of distal edge. Ventral edge of LAP convex with small, concave tentacle notch next to ventralmost spine articulation.

Inner side of LAP largely obscured by sediment; dorsal tip of central ridge discernible, only slightly widened, proximalwards pointing; no ventral ridge discernible.

GZG.INV.78556 is a dissociated median LAP; proximal edge completely intact, slightly undulose with narrow band of finely meshed stereom, otherwise well in agreement with other type specimens.

\section{Remarks}

The tiny LAPs described above are so strikingly similar to those of extant species of Ophiolimna, showing all the diagnostic LAP-morphological characters of the genus, that assignment to Ophiolimna seems unquestionable. Among the species assigned to Ophiolimna, the closest similarities are shared with Ophiolimna kucerai sp. nov. (see below). In the latter, however, the LAPs are larger and display a larger gap between the spine articulations and the distal edge. 


\section{Occurrence}

Middle Bathonian to Callovian of India.

Ophiolimna lisae sp. nov. urn:1sid:zoobank.org:act:53A4D340-3462-4B83-B996-14E4D2A3F071

Fig. 14: 1-3

\section{Diagnosis}

Species of Ophiolimna with large LAPs displaying a large, conspicuous, straight, oblique, golf clubshaped central ridge with strongly widened, ventro-proximally pointing dorsal tip; second ventral, short ridge almost directly bordering ventral tip of central ridge.

\section{Etymology}

Species named in honour of my friend Lisa Walz, who would always find encouraging words to cheer up moments of despair, including those accompanying the terminal phase of this study.

\section{Type material}

Holotype

GZG.INV.78561.

\section{Paratypes}

GZG.INV.78562, GZG.INV.78563 and GZG.INV.78564 from the upper Kimmeridgian Amaral Formation of Trancoso, Portugal

\section{Type locality and horizon}

Pointe du Chay near La Rochelle, France; Achilles Subzone, Cymodoce Zone, early Kimmeridgian, Late Jurassic.

\section{Additional material}

GZG.INV.78565 (78 dissociated LAPs) from the upper Kimmeridgian Amaral Formation of Trancoso, Portugal.

\section{Description}

\section{Holotype}

GZG.INV.78561 is a dissociated, large, proximal one; higher than wide; dorsal and distal edges convex; proximal edge concave and slightly angular, devoid of spurs but with narrow band of very finely meshed stereom; ventral seventh of LAP only weakly protruding ventro-proximalwards; outer surface almost entirely covered by coarse, regular vertical striation composed of broad, overlapping lamellae decreasing in size proximalwards and replaced by densely meshed stereom in narrow area bordering the central part of the finely meshed band at the proximal edge of the LAP. Six large, ear-shaped spine articulations in relatively deep notches of the distal edge, overlapped by the strongly undulose distalmost lamella and connected with the latter by the large, conspicuously tongue-shaped ventral lobes of the spine articulations; dorsalward increase in the size of the spine articulations and of the gaps separating them; no gap between spine articulations and distal edge of LAP. Tentacle notch almost indiscernible in external view.

Inner side of LAP with large, conspicuous, sharply defined, prominent, oblique, straight, golf clubshaped central ridge; dorsal tip of ridge strongly widened, pointing ventro-proximalwards; second ventral, well-defined and prominent but short ridge almost directly bordering ventral tip of central ridge but nevertheless sharply separated from the latter; no spurs on inner side of distal edge of LAP; inner 


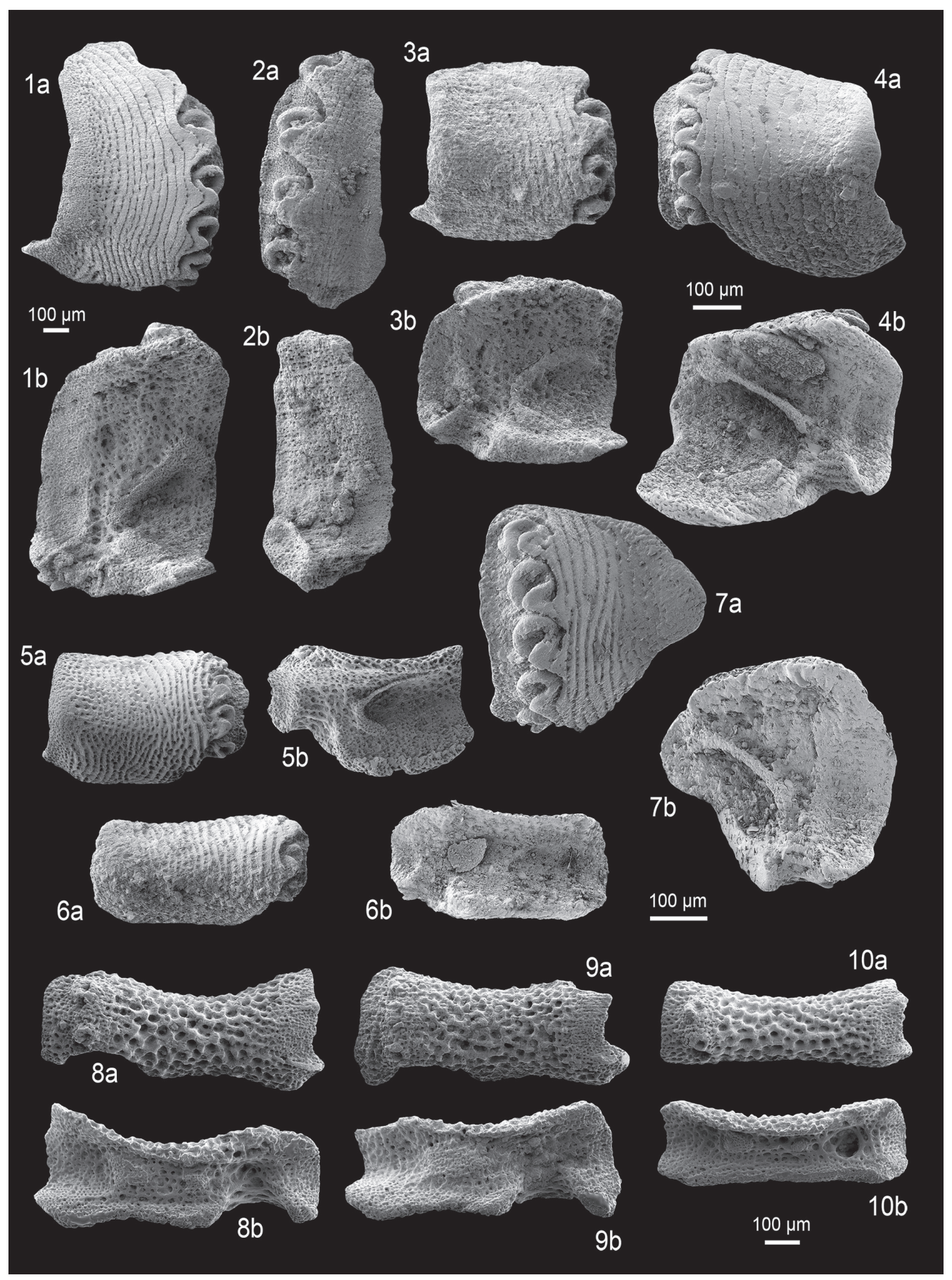

Fig. 14. Fossil lateral arm plates (LAPs) of ophiacanthid brittle stars in external (a) and internal (b) views. 1-3. Ophiolimna lisae sp. nov. from the early Kimmeridgian of the Pointe du Chay (1), France, and the late Kimmeridgian of Trancoso, Portugal (2-3). 1. GZG.INV.78561 (holotype), proximal LAP. 2. GZG. INV.78562 (paratype), proximal LAP. 3. GZG.INV.78563 (paratype), median LAP. 4-7. Ophiolimna kucerai sp. nov. from the latest Aptian to earliest Albian (Early Cretaceous) of Blake Nose, NE Atlantic. 4. GZG.INV.78566 (holotype), proximal LAP. 5. GZG.INV.78567 (paratype), median LAP. 6. GZG. INV.78568 (paratype), distal LAP. 7. GZG.INV.78569 (paratype), proximal LAP. 8-10. Geromura touertensis gen. et sp. nov. from the Bajocian-Bathonian boundary of Touert, France. 8. GZG.INV.78571 (holotype) median to proximal LAP. 9. GZG.INV.78572 (paratype), proximal LAP. 10. GZG.INV.78573 (paratype), distal LAP. One common scale bar per species is given. 
side of tentacle notch large, obscured by sediment. Broad, shallow vertical furrow dorsally bordering tentacle notch with series of irregular, medium-sized perforations, with dorsalward increase in gaps separating perforations.

\section{Paratype supplements and variation}

GZG.INV.78562 is a dissociated proximal LAP, fragmentary, ventral portion of LAP missing; originally larger and higher than holotype; otherwise well in agreement with holotype.

GZG.INV.78563 is a dissociated median LAP; nearly as high as wide, of rounded aspect; generally well in agreement with holotype. Four large, ear-shaped spine articulations with dorsalward increase in size of gaps separating them.

Inner side of LAP with large, conspicuous central ridge, similar to that of holotype but slightly bent rather than straight; ventral ridge similar to that of holotype; inner side of tentacle notch large, bordered distally by thin, moderately well-defined ridge. Broad, shallow vertical furrow dorsally bordering tentacle notch with series of irregular, medium-sized perforations, distally bordered by poorly defined and dorsally fading ridge.

GZG.INV.78564 is a dissociated distal LAP; slightly wider than high; well in agreement with holotype. Four spine articulations, dorsalmost of which invisible in external view.

Inner side of LAP with large, conspicuous central ridge, similar to that of holotype but slightly bent and merged with ventral ridge; inner side of tentacle notch large and distally bordered by prominent, welldefined ridge. Broad, shallow, poorly defined vertical furrow dorsally bordering tentacle notch with series of irregular, medium-sized perforations, distally bordered by poorly defined and dorsally fading ridge.

\section{Remarks}

The highly distinctive outer surface striation and spine articulation morphology leave no doubt as to the assignment of these LAPs to the genus Ophiolimna. On account of its large size and the shape and arrangement of the ridges on its inner side, the LAPs in question are incompatible with any currently known species of Ophiolimna.

\section{Occurrence}

Early Kimmeridgian of France and late Kimmeridgian of Portugal.

$$
\begin{gathered}
\text { Ophiolimna kucerai sp. nov. } \\
\text { urn:Isid:zoobank.org:act:736B12D4-3C48-4CE3-A6B4-FA0B1CE9BDCE }
\end{gathered}
$$

Fig. 14: 4-7

\section{Diagnosis}

Species of Ophiolimna with small LAPs; ventral third to quarter strongly protruding ventroproximalwards; up to five moderately large spine articulations; relatively wide gap between spine articulations and distal edge of LAP; inner side with nearly straight, oblique, spoon-shaped dorsal ridge displaying strongly widened, round dorsal tip, and second, ventral, much shorter, nearly straight, ventroproximally pointing ridge.

\section{Etymology}

Species named in honour of Michal Kucera for generously providing the samples yielding the type material of the species, and for the very fruitful and encouraging discussions on the potential of ophiuroids as a model to explore the evolutionary history of modern deep-sea benthos. 


\section{Type material}

Holotype

GZG.INV.78566.

Paratypes

GZG.INV.78567, GZG.INV.78568 and GZG.INV.78569.

\section{Type locality and horizon}

Blake Nose, borehole ODP 171B 1049A 20x5, tropical northeast Atlantic; latest Aptian to earliest Albian, Hedbergella trochoidea to Microhedbergella rischi planktonic foraminifer zones, Early Cretaceous.

\section{Additional material}

GZG.INV.78568 (752 dissociated LAPs).

\section{Description}

\section{Holotype}

GZG.INV.78566 is a dissociated, small, proximal LAP; dorsal edge oblique, very weakly concave; distal edge irregularly undulose; proximal edge devoid of spurs, with large, slightly thickened, very poorly defined central part; ventral quarter strongly protruding ventro-proximalwards; outer surface with well-developed, coarse, regular vertical striation composed of broad, overlapping lamellae replaced by finely meshed stereom in very narrow band along proximal edge. Five moderately large, nearly equi-distant, ear-shaped spine articulations in relatively deep notches of weakly elevated distal edge of LAP; overlapped by the undulose distalmost lamella and connected with the latter by the moderately large, tongue-shaped ventral lobes of the spine articulations; dorsalward increase in the size of the spine articulations; gap between spine articulations and distal edge of LAP relatively wide. Ventral edge of LAP with moderately large, concave tentacle notch.

Inner side of LAP with sharply defined, prominent, very slender, relatively long, oblique, nearly straight, spoon-shaped dorsal ridge with strongly widened, round dorsal tip; second much shorter, slightly wider, ventro-proximalwards pointing ridge on ventral portion of LAP; inner side of distal edge of LAP devoid of spurs; inner side of tentacle notch moderately large. No perforations or furrow discernible.

\section{Paratype supplements and variation}

GZG.INV.78567 is a dissociated proximal LAP, ventro-proximal part strongly fragmentary; very well in agreement with holotype. Five spine articulations similar to those observed on holotype but slightly larger, with stronger dorsal increase in size, and with larger and thicker lip-shaped ventral lobe connected with the distalmost lamella.

GZG.INV.78568 is a dissociated median LAP; approximately 1.5 times wider than high; dorsal edge very weakly concave as a result of a slight constriction; vertical striation on outer surface less regular than in holotype and composed of finer lamellae. Four spine articulations similar to thos observed on holotype; dorsalmost and ventralmost spine articulations slightly smaller than remaining two.

Inner side of LAP with single ridge composed of oblique, near-straight dorsal part with very weakly widened dorsal tip, and much shorter, slightly wider ventral part; both parts of ridge connected by rounded kink.

GZG.INV.78569 is a dissociated distal LAP; more than twice wider than high. Three spine articulations similar to those observed on holotype.

Inner side largely obscured by sediment; slender, oblique, near-straight dorsal part of ridge discernible. 


\section{Remarks}

These LAPs are unambiguously assignable to Ophiolimna on account of the highly distinctive spine articulation morphology and the outer surface striation. Within this genus, greatest similarities are shared with the LAPs of Ophiolimna malagasica sp. nov. (see above), which, however, are smaller and display six rather than five spine articulations separated by a much narrower gap from the distal edge of the LAP.

\section{Occurrence}

Latest Aptian to earliest Albian of the tropical northeast Atlantic.

Genus Geromura gen. nov. urn:1sid:zoobank.org:act:10BE3FAB-5984-4759-8DF1-172F60DE98CA

\section{Type species}

Geromura teckliformis sp. nov., by present designation.

\section{Other species included}

Geromura touertensis sp. nov.

\section{Diagnosis}

Ophiacanthid genus with relatively small and extremely elongate LAPs, proximal ones at least twice wider than high; well-developed constriction; relatively small spine articulations of rugged appearance, freestanding on slightly elevated distal part of LAP; very large tentacle notch; two separate knobs on inner side at least in median to distal LAPs.

\section{Etymology}

Genus named in honour of Gero Moosleitner, who introduced me to the spectacular site at the Glasenbach Gorge near Salzburg, Austria, and who generously provided a major part of the samples used in this study, including those yielding the original material of the type species of the genus; from oura, Greek for "tail", a commonly used suffix for ophiuroid names, gender feminine.

\section{Remarks}

The Mesozoic ophiuroid fossil record includes a highly peculiar type of dissociated LAPs which is characterised by its extraordinary width. In fact, even proximal LAPs of the type in question are more than twice wider than high, a ratio which, in most other ophiuroid lineages, is only found in the very distalmost LAPs. Other distinctive characters of such LAP type are the relatively small, freestanding, ear-shaped spine articulations composed of irregular, rough dorsal and ventral lobes, a very large tentacle notch implying a large tentacle pore as defined by Thuy et al. (2012), a strong constriction, and two separate knobs on the inner side at least of the median to distal LAPs. The last-named character precludes confusion with the LAPs of Lapidaster gen. nov. and Ophiologimus, which share the greatest similarities with the LAP type in question. A new genus, Geromura gen. nov., is therefore introduced here to accommodate the peculiar type of LAPs in question. In spite of their rugged and rather atypical appearance, the spine articulations of Geromura gen. nov. display a sigmoidal fold, which unambiguously places them in the Ophiacanthidae.

The phylogenetic position of Geromura gen. nov. remains elusive as long as no articulated specimens are known on the basis of which a complete character analysis could be performed. It is very likely, however, that it shares greatest phylogenetic ties with the other large-pores lineages, in particular the Lapidaster-Ophiologimus lineage (see above) as suggested by the close similarities in LAP morphology. Interestingly, Geromura gen. nov. is currently known exclusively from deep-water deposits. 


\section{Geromura touertensis sp. nov. urn:1sid:zoobank.org:act:83E97048-1F4F-447A-927A-EA58AE3B4973}

Fig. 14: 8-10

\section{Diagnosis}

Species of Geromura gen. nov. with moderately large LAPs, at least twice wider than high; displaying two conspicuous, well-defined and strongly protruding spurs on the outer proximal edge paralleled by two poorly defined areas of densely meshed stereom on the inner distal edge; up to three spine articulations; single large knob in proximal LAPs, divided into two widely separate, smaller knobs in median and distal LAPs.

\section{Etymology}

Species named after its type locality Le Touert near Chaudon-Norante, Alpes-de-Haute-Provence, France.

\section{Type material}

\section{Holotype}

GZG.INV.78571.

\section{Paratypes}

GZG.INV.78572 and GZG.INV.78573.

\section{Type locality and horizon}

Le Touert near Chaudon, France; marl bed at the Bajocian-Bathonian boundary, Middle Jurassic.

\section{Description}

\section{Holotype}

GZG.INV.78571 is a dissociated, moderately large median to proximal LAP; slightly more than twice wider than high; dorsal edge strongly concave as a result of a well-developed constriction; distal edge nearly straight; ventro-distal tip of LAP strongly protruding; proximal edge wavy, with two moderately large, well-defined, prominent, horizontally elongate and conspicuously protruding spurs composed of densely meshed stereom; ventral spur larger and more strongly protruding than dorsal one; outer surface with very coarsely meshed stereom, replaced by finely meshed stereom in a narrow band along the proximal edge of the LAP; intersections of trabeculae thickened into granules. Two relatively small, rugged, ear-shaped spine articulations, freestanding on slightly elevated distal edge, not in notches or depressions; ventral and dorsal lobes forming nearly circular volute; nerve opening large, ventrodistally bordering sigmoidal fold; dorsal spine articulation slightly larger than ventral one; very large gap separating spine articulations and distal edge of LAP. Ventral edge of LAP concave, with very large, concave tentacle notch.

Inner side of LAP with two widely separate, sharply defined and prominent knobs; the proximal knob three times larger than distal one, nearly triangular; distal knob rounded; inner side of distal edge of LAP with poorly defined, slightly prominent knobs composed of densely meshed stereom, one knob in the dorso-distal corner, the other in the ventro-distal corner. Inner side of tentacle notch with very coarsely meshed and horizontally stretched stereom. No perforations discernible on inner side.

\section{Paratype supplements and variation}

GZG.INV.78572 is a dissociated proximal LAP; twice wider than high; generally well in agreement with holotype; dorso-proximal tip fragmentary. Three spine articulations, with very slight dorsalward increase in size; ventral gap larger than dorsal gap. 
Inner side with single, large, sharply defined, prominent, nearly wedge-shaped knob.

GZG.INV.78573 is a dissociated distal LAP; rod shaped; almost three times as wide as high; spurs on proximal edge strongly protruding, nearly equal sized. Two spine articulations, ventral one slightly smaller than dorsal one. Ventral edge of LAP evenly concave, tentacle opening developed as perforation ventrally bordering the ventral spine articulation.

Inner side with two sharply defined, rounded, prominent and widely separated knobs; proximal knob approximately three times larger than distal one. Very large tentacle notch in the middle of the distal third of the inner side.

\section{Remarks}

These LAPs can be unmistakably distinguished from those of its congener Geromura teckliformis sp. nov. (see below) on account of the two well-developed and strongly protruding spurs on the outer proximal edge paralleled by less well-defined, slightly prominent spurs on the inner distal edge, as well as the lower number of spine articulations. The transformation of two separate knobs into a single larger one from median to proximal LAPs is remarkable. In fact, it suggests that the development of the knobs on the inner side is primarily controlled by biomechanical constraints imposed by the height/ width ration of the LAPs. This is corroborated by G. teckliformis sp. nov. in which all LAPs, including the proximal ones, have a significantly lower height/width ratio than those of G. touertensis sp. nov., and at the same time invariably display two widely separated knobs. Supportive evidence furthermore comes from the distalmost LAPs of Lapidaster etteri sp. nov. (see above). With a height/width ratio of 1:3 and thus comparable to that of most LAPs of species of Geromura gen. nov., the distalmost LAPs of Lapidaster etteri sp. nov. display two widely separate knobs rather than a single knob or ridge.

Because elongate arm segments are a typically juvenile character (Stöhr 2005), it appears probable that Geromura gen. nov. developed from an ancestor of the Lapidaster-Ophiologimus lineage via paedogenesis. The strong elongation of the arm segments entailed the transformation of a single knob or ridge on the inner side of the LAPs into two widely separate knobs. It cannot be ruled out that this process occurred more than once, which would imply that Geromura gen. nov. is an artificial grouping of superficially similar but independently evolved LAP morphologies. The strong similarities in spine articulation morphology, however, endorse the concept of Geromura gen. nov. as a single lineage, since there is no evidence that a decrease in height/width ratio entails any changes in the structure of the spine articulations.

\section{Occurrence}

Bajocian-Bathonian of France.

\section{Geromura teckliformis sp. nov. urn:1sid:zoobank.org:act:FFC94D1F-2BB4-4CAF-AF61-7E7C0D60F1CA}

Fig. 15: 1-3

\section{Diagnosis}

Species of Geromura with moderately large LAPs, at least 3.5 times wider than high; two poorly defined and non-protruding spurs on the outer proximal edge paralleled by very weakly developed spurs composed of slightly more densely meshed stereom on the inner distal edge; up to five spine articulations; two widely separate knobs on inner side of all LAPs. 


\section{Etymology}

Name derived from "Teckel", the German sausage dog, in reference to the extremely elongate LAPs of the species.

\section{Type material}

\section{Holotype}

NHMW 2012/0138/0005.

\section{Paratypes}

NHMW 2012/0138/0006 and NHMW 2012/0138/0007.

\section{Type locality and horizon}

KB1-A section of Lukeneder (2004) in the Ternberg Nappe, Austria; Verrucosum Zone, late Valanginian, Early Cretaceous.

\section{Additional material}

NHMW 2012/0138/0008 (123 dissociated LAPs).

\section{Description}

\section{Holotype}

NHMW 2012/0138/0005 is a dissociated, medium-sized, proximal LAP; rod shaped, approximately 3.5 times wider than high; dorsal edge concave as a result of a well-developed constriction; distal edge nearly straight; ventro-distal tip of LAP strongly protruding, tongue shaped; proximal edge irregularly concave, with two small, poorly defined, horizontally elongate, slightly prominent but not protruding spurs composed of slightly more densely meshed stereom; outer surface with very coarsely meshed stereom, replaced by finely meshed stereom in a narrow band along the proximal edge of the LAP; intersections of trabeculae not thickened into granules. Five small, round to slightly ear-shaped, equidistant spine articulations of rugged appearance, freestanding on elevated distal portion of LAP; ventralmost spine articulation slightly smaller than remaining four; dorsalmost spine articulation on dorsal edge of LAP, hardly discernible in external view; ventral and dorsal lobes of spine articulations forming nearly circular volute with very small sigmoidal fold and very small nerve opening; gap between spine articulations and distal edge of LAP very wide, almost twice wider than spine articulations. Ventral edge of LAP gently convex except for very large, concave tentacle notch.

Inner side of LAP with two very small, sharply defined, prominent, round and widely separate knobs composed of finely meshed stereom; inner side of distal edge of LAP with two very weakly defined, non-prominent and non-protruding spurs composed of slightly more densely meshed stereom. No perforations discernible.

\section{Paratype supplements and variation}

NHMW 2012/0138/0006 is a dissociated median LAP; four times wider than high; spurs on proximal edge very small, hardly discernible. Four spine articulations, ventralmost slightly smaller than remaining three; gap separating spine articulations and distal edge of LAP more than twice wider than spine articulations. Ventral edge of LAP nearly straight, with very large concave tentacle notch.

Inner side of LAP well in agreement with that of holotype.

NHMW 2012/0138/0007 is a dissociated distal LAP; five times wider than high; spurs on proximal edge very small, hardly discernible. Three poorly preserved spine articulations; row of spine articulations strongly protruding dorsalwards; gap between spine articulations and distal edge of LAP wider than 


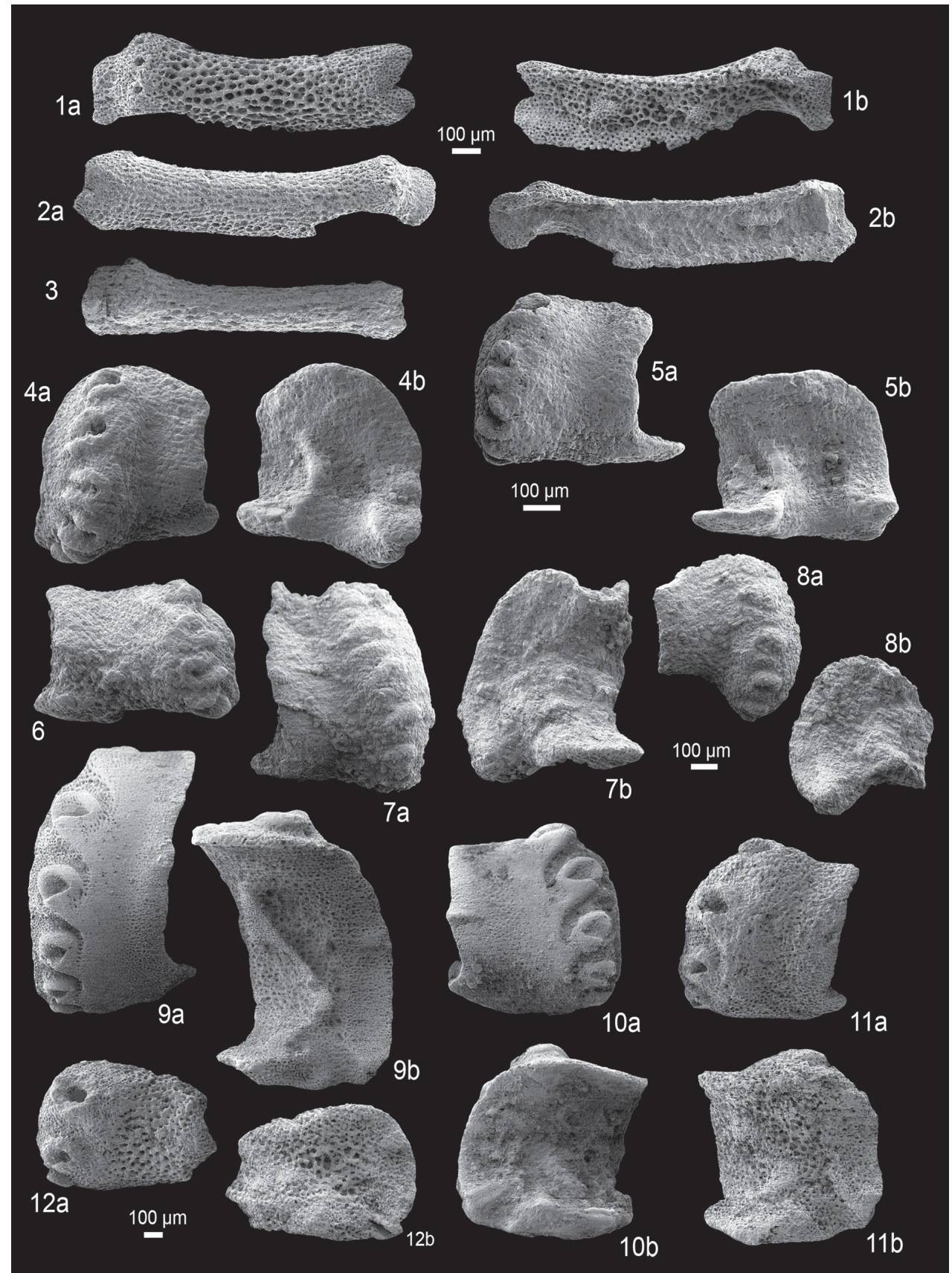

Fig. 15. Fossil lateral arm plates (LAPs) of ophiacanthid brittle stars in external (a) and internal (b) views. 1-3. Geromura teckliformis gen. et sp. nov. from the late Valanginian (Early Cretaceous) of the Ternberg Nappe, Austria. 1. NHMW 2012/0138/0005 (holotype), proximal LAP. 2. NHMW 2012/0138/0006 (paratype), median LAP. 3. NHMW 2012/0138/0007 (paratype), distal LAP. 4-6. Krohcoma mira gen. et sp. nov. from the late Sinemurian to early Pliensbachian (Early Jurassic) of the Glasenbach Gorge, Austria. 4. NHMW 2012/0137/0013 (holotype), proximal LAP. 5. NHMW 2012/0137/0014 (paratype), median LAP. 6. NHMW 2012/0137/0015 (paratype), distal LAP. 7-8. Krohcoma sp. nov. innom from the late Bathonian (Middle Jurassic) of Jumara, India. 7. GZG.INV.78574, proximal LAP. 8. GZG.INV.78575, median to distal LAP. 9-12. Krohcoma ampla gen. et sp. nov. from the early Kimmeridgian of the Pointe du Chay (9-10), France, and the late Kimmeridgian of Trancoso, Portugal (11-12). 9. GZG.INV.78577 (holotype), proximal LAP. 10. GZG.INV.78578 (paratype), median LAP. 11. GZG.INV.78579 (paratype), median LAP. 12. GZG.INV.78580 (paratype), distal LAP. One common scale bar per species is given. 
one spine articulation. Ventral edge of LAP very gently concave, no tentacle notch; hardly discernible tentacle opening near ventro-distal edge of ventralmost spine articulation.

Inner side of LAP obscured by sediment.

\section{Remarks}

Differences between the present LAPs and Geromura touertensis sp. nov. are discussed above. The present LAPs are so highly distinctive that there is hardly any chance to confuse them with any other ophiuroid species.

\section{Occurrence}

Late Valanginian of Austria.

$$
\begin{aligned}
& \text { Genus Krohcoma gen. nov. } \\
& \text { urn:1sid:zoobank.org:act:0A950939-8454-48E0-853A-A431FB153F6F }
\end{aligned}
$$

\section{Type species}

Krohcoma mira sp. nov., by present designation.

\section{Other species included}

Krohcoma ampla sp. nov.

\section{Diagnosis}

Ophiacanthid genus with relatively stout LAPs devoid of conspicuous outer surface ornament; spine articulations very large, with thick dorsal and ventral lobes and very large muscle opening, freestanding on strongly elevated ridge, arranged in conspicuously dorso-proximally receding row; spine articulations not sharply separated from remaining outer surface; tentacle notch large to very large.

\section{Etymology}

Genus named in honour of my friend and colleague Andreas Kroh for his valuable support in the cladistic phylogenetic anaylsis of the Ophiacanthidae and in sampling the spectacular Glasenbach Gorge section, which produced the type species of the genus; from coma, Latin for "hair", a commonly used suffix in ophiuroid names, gender feminine.

\section{Remarks}

Most fossil LAP types assignable to the Ophiacanthidae can be related to an extant lineage on the basis of strong morphological similarities. Among the more challenging fossil ophiacanthid LAP types is one which is characterised by very large, ear-shaped spine articulations arranged in a conspicuously dorso-proximalwards obliquely receding and ventrally protruding row, and displaying a large muscle opening. These relatively stout LAPs, unambiguously assignable to the Ophiacanthidae on account of the sigmoidal fold and the absence of a single large perforation on the inner side, furthermore display a very large tentacle notch. Although articulated specimens have yet to be discovered, it seems highly probable that the large tentacle notches, indeed, reflect large tentacle pores as defined by Thuy et al. (2012), which would place the LAP type in question among the basal, large-pored ophiacanthids formerly united as the Ophiotominae.

Among the currently known large-pored ophiacanthid lineages, Ophiotoma and the LapidasterOphiologimus lineage clearly differ in having a non-bulging or elevated distal portion of their LAPs. The LAPs of Ophiolimna and Ophiopristis Verrill, 1899 display a conspicuous vertical striation on the outer surface and fundamentally different ridge structures on their inner side, and in Geromura gen. nov. 
the LAPs are extremely elongate. There is a superficial similarity to the LAPs of Eolaxoporus gen. nov., which, however, fundamentally differ in having proximally widely separate dorsal and ventral lobes of the spine articulations. Closest similarities are shared with the LAPs of Ophiomedea Koehler, 1906 and Leadagmara Thuy et al., 2012. Neither of these, however, display a dorso-proximalwards receding row of spine articulations. Krohcoma gen. nov. is thus introduced here to accommodate the above-mentioned LAPs. Its exact phylogenetic position remains elusive. On the basis of LAP morphology, however, Krohcoma gen. nov. seems closest to Eolaxoporus gen. nov. and to the Ophiomedea-Leadagmara clade.

\section{Krohcoma mira sp. nov. urn:Isid:zoobank.org:act:79C26A85-E693-4AF7-8A41-36FB956BE7ED}

Fig. 15: 4-6

\section{Diagnosis}

Species of Krohcoma gen. nov. with relatively small LAPs, displaying very poorly defined, large spur in the middle of the proximal edge; up to five very large, equal-sized spine articulations; row of spine articulations protruding ventrally; tentacle notch very large, equalling half of the total ventral LAP edge width; ridge on inner side of LAPs merged with ventral LAP edge.

\section{Etymology}

Name derived from mirus, Latin for "astonishing", in reference to the palaeohabitat of the species suggesting a deep-water origin of the genus and thus challenging widely accepted concepts on the role of the deep sea in macroevolutionary patterns.

\section{Type material}

\section{Holotype}

NHMW 2012/0137/0013.

\section{Paratypes}

NHMW 2012/0137/0014 and NHMW 2012/0137/0015.

\section{Type locality and horizon}

Glasenbach Gorge, Austria; Hauptknollenbrekzie, late Sinemurian to early Pliensbachian, Early Jurassic.

\section{Additional material}

NHMW 2012/0137/0015 (10 dissociated LAPs).

\section{Description}

\section{Holotype}

NHMW 2012/0137/0013 is a dissociated, small, proximal LAP; nearly as high as wide; dorsal edge slightly convex; distal edge oblique, convex; proximal edge irregularly undulose, with very poorly defined, prominent and slightly protruding central spur composed of slightly more densely meshed stereom; ventro-proximal tip of LAP thickened into very poorly defined, prominent spur composed of slightly more densely meshed stereom; outer surface with moderately finely meshed stereom, devoid of conspicuous ornament elements. Five very large, ear- to horseshoe-shaped spine articulations, freestanding in dorso-proximally receding row on strongly bulging distal portion of LAP; dorsal and ventral lobes of spine articulations very thick, proximally merged by relatively thin connection into continuous lobe encompassing conspicuously large muscle opening; spine articulations nearly equal sized and equi-distant; row of spine articulations protruding ventrally. Ventral edge of LAP straight except for protruding ventral tip of spine articulation row; tentacle notch not visible in external view. 
Inner side of LAP with relatively small, narrow, sharply defined, prominent and slightly bent ridge; dorsal tip of ridge pointing dorso-proximalwards, not widened; ventral portion of ridge merged with thickened ventral edge of LAP; inner side of distal edge of LAP with poorly defined, slightly prominent but not protruding spur composed of slightly more densely meshed stereom; inner side of tentacle notch very large, accounting for approximately half of the total ventral LAP edge width. No perforations discernible.

\section{Paratype supplements and variation}

NHMW 2012/0137/0014 is a dissociated median LAP; slightly wider than high; dorsal edge straight to slightly concave. Four very large, nearly equal-sized spine articulations similar to those observed on holotype; very weak dorsalward increase in size of gaps separating spine articulations; row of spine articulations only slightly protruding ventrally. Ventral edge of LAP nearly straight.

Inner side of LAP well in agreement with that of holotype; no spur discernible on inner side of distal edge of LAP.

NHMW 2012/0137/0015 is a dissociated distal LAP; almost twice wider than high; dorsal edge clearly concave as a result of a well-developed constriction; proximal edge with rather poorly defined, prominent and very slightly protruding central spur composed of slightly more densely meshed stereom; ventral sixth of LAP slightly protruding ventro-proximalwards. Four very large, equal-sized, ear- to horseshoeshaped spine articulations on elevated distal portion of LAP, arranged in dorso-proximally receding row; very slight dorsalward increase in size of gaps separating spine articulations. Ventral edge with very large, weakly concave tentacle notch.

Inner side of LAP obscured by sediment.

\section{Remarks}

These LAPs can be easily differentiated from almost every other type of LAPs on account of the distinctive dorso-proximally receding row of very large spine articulations. Within the group of LAPs that display the latter character, here assigned to Krohcoma gen. nov., the above-described ones are unique in having equal-sized spine articulations and very large tentacle notches accounting for nearly half of the total ventral LAP edge width.

\section{Occurrence}

Late Sinemurian to early Pliensbachian of Austria.

Krohcoma sp. nov. innom.

Fig. 15: 7-8

\section{Material examined}

GZG.INV.78574, GZG.INV.78575 and GZG.INV.78576 (dissociated LAP) from the Patcham Formation, late Bathonian, of Jumara, India.

\section{Description of proximal LAP}

GZG.INV.78574 is a dissociated relatively small, proximal LAP; slightly higher than wide; dorsal edge strongly concave as a result of a well-developed constriction; distal edge obliquely convex; proximal edge irregularly concave, devoid of spurs or thickened parts; outer surface with moderately finely meshed stereom, no conspicuous ornament elements discernible; six very large, ear-shaped to horseshoeshaped spine articulations in continuous, dorso-proximalwards conspicuously receding row on strongly elevated distal portion of LAP; dorsal and ventral lobes of spine articulations thick, proximally merged by relatively thin connection into continuous, horizontally slightly elongate volute; dorsalward increase 
in size of spine articulations and of gaps separating them; row of spine articulations protruding ventrally. Ventral edge of LAP slightly concave, tentacle notch not visible in external view.

Inner side of LAP largely obscured by sediment; ridge not clearly discernible; inner side of distal edge of LAP devoid of spurs; inner side of tentacle notch large, accounting for slightly less than one-third of the total ventral LAP edge width. No perforations dicernible.

\section{Description of median to distal LAP}

GZG.INV.78575 is a dissociated, small, median to distal LAP, with slightly fragmentary dorsoproximal tip; nearly as wide as high; proximal edge devoid of spurs or thickened parts; outer surface with moderately finely meshed stereom. Five very large spine articulations, similar to those observed of holotype but muscle opening not obscured by sediment, very large; spine articulations arranged in dorso-proximally strongly receding row on elevated distal portion of LAP; row of spine articulations very strongly protruding ventrally. Ventral edge of LAP strongly concave as a result of the strongly protruding row of spine articulations.

Inner side of LAP with large, moderately well-defined, wide, bent, prominent ridge; dorsal tip of ridge pointing dorso-proximalwards; ventral tip of ridge merged with ventral LAP edge; inner side of distal edge of LAP devoid of spurs; inner side of tentacle notch very large, accounting for at least one-third of the total ventral LAP edge width. No perforations discernible.

\section{Remarks}

These LAPs unquestionably belong to Krohcoma gen. nov. on account of the position and morphology of the spine articulations. The combination of up to six large spine articulations with slight dorsalward increase in size, moderately large tentacle notches, the absence of spurs on the outer proximal and inner distal edges, and the strongly protruding ventral tip of the row of spine articulations distinguishes these two LAPs from the two other species here assigned to Krohcoma gen. nov. These two LAPs clearly represent a new species, the formal description of which, however, requires better-preserved material.

\section{Krohcoma ampla sp. nov. urn:1sid:zoobank.org:act:CE375CEA-89F3-4641-9C52-71B0F7E80517}

Fig. 15: 9-12

\section{Diagnosis}

Species of Krohcoma gen. nov. with large LAPs, displaying small, poorly defined, protruding spur in dorsal half of outer proximal edge, paralleled by more clearly defined, round spur in dorsal half of inner distal edges; up to six very large spine articulations; very strong dorsalward increase in size of spine articulations and of gaps separating them; ventral lobe of spine articulations connected with outer surface; row of spine articulations not protruding ventrally; tentacle notch relatively small, accounting for slightly more than one-quarter of the total ventral LAP edge width; ridge on inner side of LAP with widened, triangular dorsal tip.

\section{Etymology}

Name formed from amplus, Latin for "large", "magnificent", in reference to the large size of the LAPs of the species in comparison to those of its congeners.

\section{Type material}

\section{Holotype}

GZG.INV.78577. 
Paratypes

GZG.INV.78578, same locality as holotype; GZG.INV.78579 and GZG.INV.78580 from the upper Kimmeridgian Amaral Formation of Trancoso, Portugal.

\section{Type locality and horizon}

Pointe du Chay near La Rochelle, France; Achilles Subzone, Cymodoce Zone, early Kimmeridgian, Late Jurassic.

\section{Additional material}

GZG.INV.78581 (dissociated LAP) from the Kimmeridgian of Pointe du Chay, France; GZG.INV.78582 (12 dissociated LAPs) from the upper Kimmeridgian Amaral Formation of Trancoso, Portugal.

\section{Description}

\section{Holotype}

GZG.INV.78577 is a very large, dissociated proximal LAP; at least twice higher than wide; dorsal edge nearly straight; distal edge obliquely convex; proximal edge irregularly concave, with small, poorly defined and weakly prominent, yet protruding spur; outer surface with finely meshed stereom, devoid of conspicuous ornament elements. Six very large, ear-shaped spine articulations arranged in dorsoproximally strongly receding row on elevated distal portion of LAP; very strong dorsalward increase in size of spine articulations and of gaps separating them; dorsal and ventral lobes of spine articulations thick, merged into continuous volute encompassing conspicuously large muscle opening; ventral lobe of spine articulations connected with finely meshed outer surface; row of spine articulations not protruding ventrally. Ventral edge of LAP irregularly convex, tentacle notch not discernible in external view.

Inner side of LAP with large, well-defined, prominent ridge; dorsal half nearly straight, oblique, with widened triangular dorsal tip, separated from ventral half by rounded kink; ventral half short, less welldefined than dorsal one, not connected with ventral edge of LAP; inner side of distal edge of LAP with small, moderately well-defined, slightly prominent spur composed of slightly more densely meshed stereom; inner side of tentacle notch large, accounting for slightly more than a quarter of the total ventral LAP edge width. Vertical row of small perforations distally bordering kink between dorsal and ventral portions of the ridge, with dorsalward increase in size of perforations and of gaps separating them.

\section{Paratype supplements and variation}

GZG.INV.78578 is a dissociated median LAP; slightly higher than wide; well matching holotype; spur on proximal edge slighty better defined and more prominent. Five very large spine articulations similar to those observed on holotype; connection between ventral lobe of spine articulations and finely meshed stereom of outer surface slightly more prominent.

Inner side of LAP largely obscured by sediment, only ventral portion of ridge discernible, separated from ventral edge of LAP; inner side of distal edge of LAP with small, poorly defined, round and weakly prominent spur composed of slightly more densely meshed stereom. Inner side of tentacle notch moderately large, distally bordered by moderately well-defined, oblique, prominent ridge. No perforations discernible.

GZG.INV.78579 is a dissociated median LAP; slightly higher than wide; dorsal edge concave; outer surface with slightly more coarsely meshed stereom than in holotype, probably as a result of poorer preservation. Four very large spine articulations similar to those observed in holotype but with less welldeveloped connection between outer surface and ventral lobe of spine articulations, again probably due to slightly poorer preservation.

Inner side of LAP with well-defined ridge separated by round kink into dorsal portion with slightly widened dorsal tip, and much shorter ventral portion not connected with ventral edge of LAP; inner 
side of tentacle notch large, distally bordered by poorly defined, short, oblique ridge-like knob. No perforations discernible.

GZG.INV.78580 is a dissociated distal LAP; slightly wider than high; proximal edge slightly fragmentary. Three very large spine articulations, with very strong dorsalward increase in size; dorsal gap between spine articulations larger than ventral one.

Inner side of LAP with very poorly defined, oblique, weakly prominent ridge composed of more finely meshed stereom; dorsal half of inner side of distal LAP edge with small, round, well-defined, prominent spur.

\section{Remarks}

Although, at first sight, these LAPs seem to differ significantly from those assigned to Krohcoma gen. nov., similarities in spine articulation morphology and arrangement are striking. In fact, large spine articulations with thick dorsal and ventral lobes encompassing a conspicuously large muscle opening, arranged in a dorso-proximalwards receding row on the elevated distal portion of the LAPs are a highly distinctive feature which is not found in any other ophiacanthid LAP type. There are admittedly strong differences between these LAPs and those of its congeners in terms of size of tentacle notch, connection between outer surface and ventral lobe of spine articulations and size and shape of the ridge on the inner side. These differences might, in fact, warrant separation at the generic level. On the basis of the striking similarities in spine articulation morphology and arrangement, however, the present LAPs are here considered as a new species of Krohcoma gen. nov.

\section{Occurrence}

Early Kimmeridgian of France and late Kimmeridgian of Portugal.

Genus Ophiotreta Verrill, 1899

\section{Type species}

Ophiacantha lineolata Lyman, 1883, by original designation.

\section{Diagnosis}

LAPs with nearly equal-sized spine articulations freestanding in continuous vertical row on elevated distal portion; outer surface commonly with vertical striation composed of thin overlapping lamellae, distalmost of which largest and undulose, sharply bordering spine articulations; commonly thin and poorly to moderately and well-defined connecting ridge between ventral of spine articulations and distalmost lamella; inner side of LAPs with very large conspicuous ridge composed of short, oblique ventral portion and very long, near-vertical dorsal portion paralleling proximal edge of LAP; kink between dorsal and ventral portions of ridge commonly with ventro-proximally pointing angle.

\section{Remarks}

The LAPs of extant species of Ophiotreta (Fig. 16: 1-4) almost invariably combine numerous near-equally sized spine articulations on an elevated distal portion, proximally bordered by the distalmost lamella of the outer surface striation, and a ridge on the inner side which displays a distinctively long, narrow, near-vertical dorsal portion very close to the proximal edge separated from the shorter, oblique ventral portion by a kink with a ventro-proximally pointing angle. While this highly distinctive combination of characters clearly sets the LAPs of Ophiotreta apart from those of almost all other ophiacanthid lineages, the LAPs of extant Ophiopristis Verrill, 1899 (Fig. 16: 5-6) are almost identical to those of Ophiotreta. At first sight, this appears puzzling considering that the two genera were formerly assigned into separate ophiacanthid subfamilies (e.g. Paterson 1985; Stöhr \& O'Hara 2007). Ophiotreta has been 
generally considered to be closely related to Ophiacantha Müller \& Troschel, 1842, while Ophiopristis has been interpreted as a member of the more basal, large-pored lineages (e.g. Martynov 2010).

The strong similarities in general skeletal morphology between both genera, especially considering the long jaws, the number, shape and arrangement of the oral papillae and the size of the tentacle pores, however, were mentioned, although briefly, by Paterson (1985). These imply that the two genera in question are either much more closely related than previously thought, or that they independently evolved similarly shaped jaws and tentacle pores. The above-mentioned, striking similarities in LAP morphology favour the former interpretation, in line with the observations by Thuy \& Stöhr (2011) concerning similarities in LAP morphology and close phylogenetic relationships.

The size of the tentacle pore needs more detailed consideration here since it was identified as one of the major characters separating ophiacanthid genera into the basal, large-pored lineages and the large clade of the small-pored genera in the phylogenetic analysis of Thuy et al. (2012). In the revised phylogenetic analysis presented here, Ophiotreta is basalmost among the large-pored genera and thus close to Ophiopristis. As already pointed out by Paterson (1985), tentacle pores in Ophiopristis are rather small in comparison with other former ophiotominids, and in Ophiotreta they are rather large for a former ophiacanthinid. The definition of the tentacle pore size as proposed by Thuy et al. (2012) might not be suited to reflect the close relationship between Ophiotreta and Ophiopristis adequately, which obviously seem to hold an intermediate position between the basal large-pored lineages and the more derived small-pored ones. Whether Ophiotreta and Ophiopristis represent an unusually small-pored group within the large-pored lineages or vice versa requires a careful reassessment of the definition of the tentacle pore size with respect to its application in cladistic phylogenetic analyses.

The fossil Ophiotreta- and Ophiopristis-like LAPs described herein mostly display connecting ridges between the distalmost lamella of the outer surface ornament and the ventral lobe of the spine articulation, a feature shared by both Ophiopristis and Ophiotreta but more commonly observed in the latter, especially when in proximal LAPs. Thus, the fossil LAPs in question are here assigned to Ophiotreta, stressing, however, that Ophiotreta and Ophiopristis share barely distinguishable LAP morphologies, and that at least some of the fossil LAPs most probably belong to undescribed genera close to the two extant taxa and best erected on the basis of articulated finds. Ophiotreta and Ophiopristis most probably represent a single lineage, of which the fossil LAPs described herein, although assigned to Ophiotreta, constitute the fossil record.

Ophiotreta stefaniae sp. nov. urn:lsid:zoobank.org:act:91A11ADF-3122-45D4-856B-A42B1C989127

Fig. 16: 7-10

\section{Diagnosis}

Species of Ophiotreta with large LAPs displaying a relatively small, protruding, pointed spur on the outer proximal edge, paralleled by a large, round, slightly prominent but not protruding spur on the inner distal edge composed of densely meshed stereom; up to six nearly equal-sized spine articulations, all with well-developed connecting ridge between ventral lobe and strongly undulose distalmost lamella of outer surface striation; ridge on inner side composed of three parts, the ventralmost of which relatively short, straight, oblique, pointing ventro-proximalwards; no knob on the ventral portion of the inner side.

\section{Etymology}

Species named in honour of my friend Steffi Lutz, in memory of the superb years spent together in Tübingen, not far from the type locality of the species. 


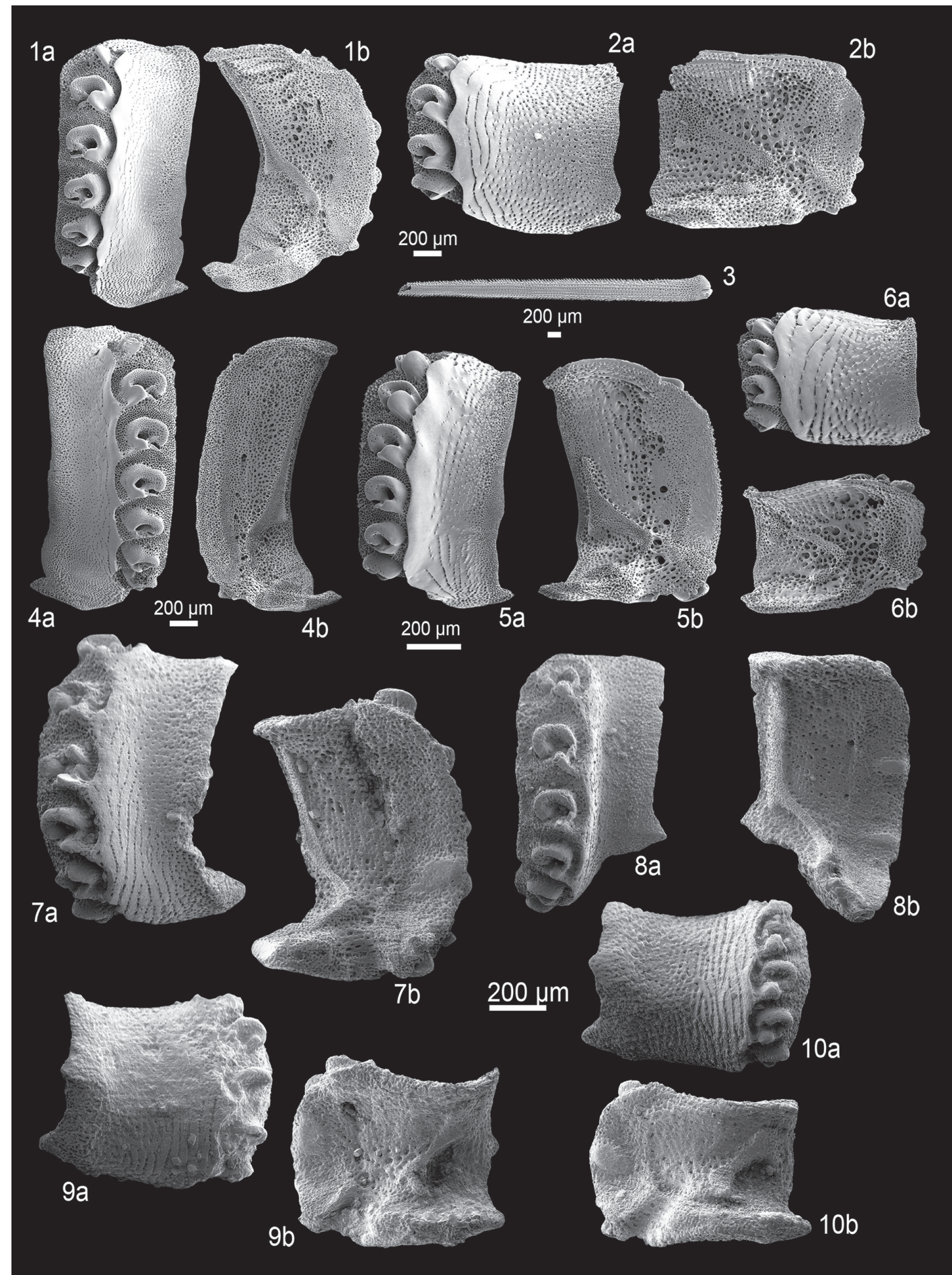

Fig. 16. Skeletal plates of fossil and Recent ophiacanthid brittle stars; lateral arm plates (LAPs) in external (a) and internal (b) views. 1-3. Ophiotreta durbanensis (Mortensen, 1933), Recent. 1. Proximal LAP. 2. Distal LAP. 3. Arm spine. 4. Ophiotreta valenciennesi (Lyman, 1879), Recent; proximal to median LAP. 5-6. Ophiopristis procera (Koehler, 1904), Recent. 5. Proximal LAP. 6. Distal LAP. 7-10. Ophiotreta stefaniae sp. nov. from the late Oxfordian (Late Jurassic) of the Plettenberg, Germany. 7. GZG.INV.78583 (holotype), proximal LAP. 8. GZG.INV.78584 (paratype), proximal LAP. 9. GZG. INV.78585 (paratype), median LAP. 10. GZG.INV.78586 (paratype), distal LAP. One common scale bar per species is given, except for 3 . 


\section{Type material}

Holotype

GZG.INV.78583.

Paratypes

GZG.INV.78584, GZG.INV.78585 and GZG.INV.78586.

\section{Type locality and horizon}

Plettenberg near Balingen, southern Germany; clay pockets between sponge associations in the lowest bed exposed in the quarry, Bimammatum Zone, late Oxfordian, Late Jurassic.

\section{Additional material}

GZG.INV.78587 (53 dissociated LAPs).

\section{Description}

\section{Holotype}

GZG.INV.78583 is a dissociated, large, proximal LAP; more than twice higher than wide; dorsal edge slightly concave as a result of a well-developed constriction; distal edge evenly convex; proximal edge concave, with small, poorly defined, slightly prominent and protruding spur in the middle; ventral half of proximal edge slightly fragmentary; outer surface with rather irregular vertical striation composed of broad lamellae separated by single very thin lines of stereom pores and covering the proximal edge of the strongly elevated distal portion of the LAP and the ventral portion of the outer surface; vertical striation replaced by densely to finely meshed stereom in other parts of the outer surface. Six large, earshaped spine articulations freestanding on strongly elevated distal portion of LAP, proximally sharply bordered by undulose distalmost lamella; dorsal lobe of spine articulations very large, separated from smaller ventral lobe by very small, shallow notch; short but well-developed and prominent connecting ridge between distalmost lamella and ventral lobe in every spine articulation; very weak dorsalward increase in size of spine articulations and of gaps separating them. Ventral edge of LAP irregularly convex, tentacle notch not visible in external view.

Inner side of LAP with large, sharply defined, prominent and relatively narrow ridge separated by two angular kinks into long, straight and near-vertical dorsal part close to the proximal edge of the LAP, a much shorter, oblique, straight central part, and a similarly short slightly bent, oblique ventral part; inner side of distal edge of LAP with large, oval, moderately well-defined, prominent spur composed of densely meshed stereom; inner side of tentacle notch moderately large, with coarsely meshed stereom. Vertical row of small, irregular perforations in shallow, poorly defined furrow dorsally bordering tentacle notch.

\section{Paratype supplements and variation}

GZG.INV.78584 is a dissociated proximal LAP; ventro-proximal portion missing; generally very well in agreement with holotype; spur on proximal edge better preserved, strongly protruding, pointed. Six spine articulations similar to those observed in holotype.

Inner side of LAP with dorsal and central parts of ridge very well preserved, similar to those observed in holotype except for ventro-proximally pointing angle in kink separating them; inner side of distal edge of LAP with two moderately large, well-defined, prominent spurs composed of densely meshed stereom.

GZG.INV.78585 is a dissociated median LAP; nearly as high as wide; dorsal edge strongly concave as a result of a strong constriction; proximal edge with moderately large; rather poorly defined, weakly prominent but protruding and pointed spur. Five spine articulations similar to those observed in holotype; 
weak dorsalward increase in size of spine articulations and of gaps separating them but dorsalmost spine articulation as small as ventralmost one. Ventral edge irregularly convex with relatively small, concave tentacle notch near ventralmost spine articulation.

Inner side of LAP with well-defined ridge separated by kink into long, straight, oblique dorsal part with widened, poorly defined dorsal tip, and much shorter oblique ventral part with well-defined ventral tip; inner side of distal edge of LAP with large, round, moderately well-defined and weakly prominent spur composed of densely meshed stereom. Three irregular perforations in vertical row dorsally bordering inner side of tentacle notch.

GZG.INV.78586 is a dissociated distal LAP; approximately 1.5 times wider than high; dorsal edge clearly concave as a result of a strong constriction; proximal edge with moderately large; rather poorly defined, weakly prominent, protruding and pointed spur. Five spine articulations; ventral lobe of spine articulations thickened into small, round knob, connected with the distalmost lamella of the outer surface striation by a very short, moderately prominent connecting ridge; weak dorsalward increase in size of spine articulations and of gaps separating them but dorsalmost spine articulation as small as ventralmost one.

Inner side of LAP with sharply defined, straight, oblique ridge with widened, rounded and well-defined dorsal tip, and slightly widened, ventrally pointing ventral tip. Single moderately large perforation dorsally bordering inner side of tentacle notch.

\section{Remarks}

These LAPs display the highly distinctive combination of spine articulations with a well-developed connecting ridge with the undulose distalmost lamella, and the ridge on the inner side composed of a long, near-vertical dorsal part and a shorter oblique ventral part separated from the dorsal one by a kink with a ventro-proximally pointing angle, exclusively found in the LAPs of Ophiotreta and Ophiopristis. In contrast to the LAPs of most extant species of these two genera, however, these fossil ones display a third part of the ridge in addition to the usual dorsal and ventral ones, pointing ventro-proximally. Whether this difference in ridge morphology warrants separation at the generic level is questionable. It seems highly probably, however, that the third, ventralmost part of the ridge in the present fossil LAP is the equivalent of the knob observed on the ventral portion of the LAPs in other species of Ophiotreta and Ophiopristis.

Awaiting the discovery of articulated specimens that can supply additional grounds for separation at the generic level, the present specimens are assigned to Ophiotreta (see above for a detailed discussion on a morphological analysis of LAPs of Ophiotreta and Ophiopristis). Confusion with other fossil LAPs assigned to this genus can be ruled out on account of the protruding, pointed spur on the outer proximal edge of these LAPs.

\section{Occurrence}

Late Oxfordian of Germany.

Ophiotreta sp. nov. innom. 1

“Ophiacanthid A" - Thuy \& Kroh 2011: 781, pl. 1 figs 1-2.

\section{Remarks}

A re-examination of the four LAPs described and illustrated by Thuy \& Kroh (2011) as an indeterminate record of an ophiacanthid ("Ophiacanthid A") from the Barremian of France has revealed that those LAPs are assignable to Ophiotreta mainly on account of the highly distinctive shape of the ridge on their inner side and the moderately well-developed connecting ridge between the spine articulations 
and the outer surface. Greatest similarities are shared with the LAPs of Ophiacantha jaegeri sp. nov. (see below), especially with respect to the ventral part of the ridge, missing or reduced to a knob on the ventral portion of the inner side of the LAP and widely separated from the remaining ridge in all other fossil species of Ophiotreta. The LAPs described by Thuy \& Kroh (2011) differ from those of Ophiacantha jaegeri sp. nov. in lacking the spur on the outer proximal and inner distal edges. They most probably represent a new species, the formal description of which, however, requires additional, less fragmentary specimens. It is remarkable that this Barremian species of Ophiotreta is morphologically closer to Ophiacantha jaegeri sp. nov., its Jurassic congener and oldest currently known species of the genus, than to O. striata (Kutscher \& Jagt, 2000) comb. nov. from the early Maastrichtian and all other, younger records. This supports the observation by Thuy \& Kroh (2011) that the Barremian ophiuroid assemblage they described was closer to Jurassic equivalents than to Late Cretaceous ones in terms of faunal spectrum.

Ophiotreta striata (Kutscher \& Jagt, 2000) comb. nov.

Fig. 17: 1-2

Ophiacantha? striata Kutscher \& Jagt, 2000: 64, pl. 25 figs 8-10.

non Ophiacantha? aff. striata - Štorc \& Žítt 2008: 128, fig. 4L-M.

\section{Diagnosis}

Species of Ophiotreta with large LAPs, displaying up to ten nearly equal-sized spine articulations; very weak connecting ridge between ventral lobe of spine articulations and distalmost lamella of outer surface striation in all LAPs, including the median and distal ones; no spurs on outer proximal and inner distal LAPs.

\section{Material examined}

GZG.INV.78588, GZG.INV.78589 and 216 dissociated LAPs from the Manfred Kutscher Collection in Sassnitz,Germany, the type material of Kutscher \& Jagt (2000); 2 dissociated LAPs from the early Maastrichtian of Lägerdorf-Kronsmoor, Germany.

\section{Description}

Dissociated moderately large LAPs, more than twice higher than wide (proximal ones) to slightly wider than high (distal LAPs); dorsal edge mostly straight to slightly concave as a result of a weak constriction; distal edge convex; proximal edge irregularly undulose, devoid of spurs; outer surface with vertical striation composed of broad, slightly overlapping lamellae restricted to the proximal edge of the strongly elevated distal portion of proximal LAPs, extending into middle of outer surface in median to distal LAPs; lamellae becoming finer proximally and replaced by moderately finely meshed stereom towards proximal edge of LAP. Ten (proximal LAPs) to five (distal LAPs) large, ear-shaped spine articulations on strongly elevated distal portion of LAPs; dorsal lobe of spine articulations very large, separated from smaller ventral lobe by small, moderately deep notch; spine articulations proximally sharply delimited by thin, slightly undulose distalmost lamella; very weakly defined, slightly prominent connecting ridge between ventral lobes of spine articulations and distalmost lamella; very weak dorsalward increase in size of spine articulations and of gaps separating them. Ventral edge of LAP straight to slightly convex; tentacle notch generally invisible in external view.

Inner side of LAPs with large, conspicuous, sharply defined yet narrow ridge composed of very long, straight, near-vertical dorsal portion very close to the proximal edge of the lap; and shorter and slightly wider, straight, oblique ventral portion with slightly more prominent rounded ventral tip; ventral and dorsal portions of ridge separated by sharp kink with ventro-proximally pointing angle; small, round, sharply defined, prominent knob on ventral portion of inner side, widely separated from ridge; inner 


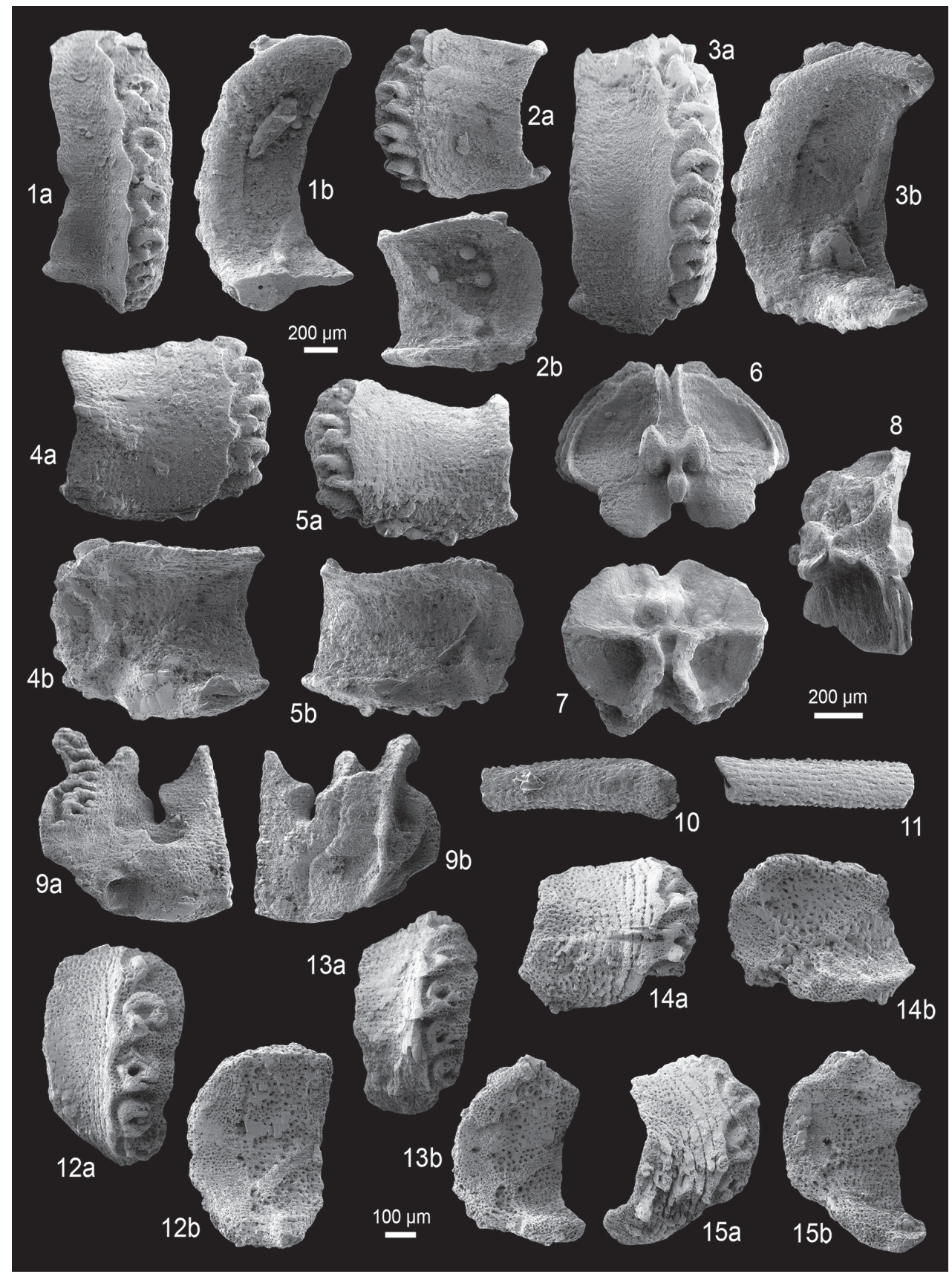

Fig. 17. Fossil skeletal plates of ophiacanthid brittle stars; lateral arm plates (LAPs) in external (a) and internal (b) views. 1-2. Ophiotreta striata (Kutscher \& Jagt, 2000) comb. nov. from the early Maastrichtian of Rügen, Germany. 1. GZG.INV.78588, proximal LAP. 2. GZG.INV.78589, distal LAP. 3-11. Ophiotreta dendrophyllicola sp. nov. from the middle Danian (Paleocene) of Fakse, Denmark. 3. MGUH 30236 (holotype), proximal LAP. 4. NHMM 2012050 (paratype), median LAP. 5. NHMM 2012051 (paratype), distal LAP. 6. NHMM 2012052 (paratype), vertebra in distal view. 7. NHMM 2012053 (paratype), vertebra in proximal view. 8. NHMM 2012054 (paratype), vertebra in dorsal view. 9. NHMM 2012055 (paratype), oral plate in adradial (a) and abradial (b) view. 10. NHMM 2012056 (paratype), arm spine fragment. 11. NHMM 2012057 (paratype), arm spine fragment. 12-15. Ophiotreta hedone sp. nov. from the middle Lutetian (Eocene) of Grignon, France. 12. GZG.INV.78590 (holotype), proximal LAP. 13. GZG.INV.78591 (paratype), median LAP. 14. GZG.INV.78592 (paratype), distal LAP. 15. GZG.INV.78593 (paratype), median LAP. One common scale bar per species. 
side of distal edge of LAP devoid of spurs; inner side of tentacle notch moderately large. Vertical row of very small, seemingly irregularly spaced perforations in very shallow, poorly defined furrow dorsally bordering inner side of tentacle notch.

\section{Remarks}

The dissociated LAPs from the early Maastrichtian of Germany and Denmark, on the basis of which Kutscher \& Jagt (2000) described the new species, Ophiacantha? striata, are unequivocally assignable to the Ophiotreta-Ophiopristis group mainly on account of the highly distinctive shape of the ridge on the inner side. The connecting ridges between the ventral lobe of the spine articulations and the distalmost lamella of the outer surface striation are weakly developed in this species, which makes assignment to Ophiopristis equally probable. It is of prime importance here to recall that the LAP morphologies of Ophiopristis and Ophiotreta are almost indistinguishable. In view of the fact that a species can only be assigned to a single genus, Ophiotreta is preferred here, for reasons outlined above in the discussion of the genus. This generic placement is likely to change as soon as more will be known of the general skeletal morphology of Ophiotreta striata comb. nov., but also following a systematic reappraisal of extant species of Ophiotreta and Ophiopristis.

Among the fossil LAPs assigned to Ophiotreta, O. striata comb. nov. is unambiguously characterised by the lack of spurs on the outer proximal edge and the high number of spine articulations. The closest resemblance is with Ophiotreta dendrophyllicola sp. nov. in which, however, the median and distal LAPs display a small, protruding spur on the outer proximal edge, and better-developed connecting ridges between the spine articulations and the outer surface. The LAPs from the Turonian of the Czech Republic described as Ophiacantha? aff. striata by Štorc \& Žítt (2008) are most probably assignable to Ophiotreta. Their slightly better-developed connecting ridge suggests that they belong to an undescribed species close to O. striata comb. nov.

\section{Occurrence}

Early Maastrichtian of Germany and Denmark.

Ophiotreta dendrophyllicola sp. nov. urn:1sid:zoobank.org:act:87010E71-C329-48FF-ADEB-F2A939732039

Fig. 17: 3-11

\section{Diagnosis}

Species of Ophiotreta with large LAPs displaying a poorly developed vertical striation on the outer surface; poorly defined, thickened area in the middle of the proximal edge of the LAP; up to seven large spine articulations with a very well-developed connecting ridge with the distalmost lamella of the outer surface stereom.

\section{Etymology}

The species name is composed of Dendrophyllia Blainville, 1830, the prevailing deep-water scleractinian genus at the type locality of this ophiuroid species, and the Latin suffix -cola, translating to "residing on", "inhabitant of".

\section{Type material}

\section{Holotype}

MGUH 30236. 


\section{Paratypes \\ NHMM 2012 050-2012 057.}

\section{Type locality and horizon}

Fakse, Denmark; pockets of unconsolidated sediment within azooxanthellate coral bioherms, Tylocidaris bruennichi Zone, middle Danian, Paleocene.

\section{Additional material}

NHMM 2012058 (114 dissociated LAPs), NHMM 2012059 (22 dissociated vertebrae, 17 arm spine fragments, 1 oral plate and 2 ventral arm plates).

\section{Description}

\section{Holotype}

MGUH 30236 is a dissociated, large, proximal LAP; slightly more than twice higher than wide; ventral portion of LAP slightly protruding ventro-proximalwards; dorsal edge concave as a result of a welldeveloped constriction; distal edge gently convex; proximal edge irregularly undulose to nearly straight, with very poorly defined, slightly thickened, weakly prominent and protruding central area; outer surface almost entirely covered by finely meshed stereom; very few broad vertical lamellae on proximal edge of strongly elevated distal portion of LAP. Seven large, ear-shaped, nearly equal-sized spine articulations freestanding on strongly elevated distal portion of LAP, proximally bordered by strongly undulose distalmost lamella of outer surface striation; large dorsal lobe and smaller ventral separated by small, sharp, moderately deep notch; ventral lobe slightly thickened into small knob, with moderately welldeveloped, short connecting ridge with distalmost lamella; very weak dorsalward increase in size of gaps separating spine articulations. Ventral edge of LAP with almost indiscernible, moderately large tentacle notch.

Inner side of LAP with large, sharply defined, prominent, conspicuous ridge composed of long, straight, near-vertical dorsal portion very close to proximal edge of LAP, and shorter, near-straight, oblique ventral portion with rounded, sharply defined and slightly more prominent ventral tip; dorsal and ventral parts of ridge separated by broad kink with ventro-proximally pointing angle; round, sharply defined, prominent knob on ventral portion of inner side of LAP, widely separated from ventral tip of ridge; inner side of tentacle scale moderately large, not sharply defined. Shallow, moderately well-defined vertical furrow with small perforations dorsally bordering inner side of tentacle notch.

\section{Paratype supplements and variation}

NHMM 2012050 is a dissociated median LAP; slightly wider than high; proximal edge concave with a small, moderately well-defined, prominent and protruding spur composed of densely meshed stereom; outer surface with poorly developed vertical striation composed of broad lamellae replaced by finely meshed stereom in the proximal half of the outer surface. Five nearly equal-sized spine articulations similar to those observed on the holotype. Ventral edge of LAP convex with relatively small, shallowly concave tentacle notch.

Inner side of LAP with well-defined ridge with straight, oblique dorsal part with widened dorsal tip with ventro-proximally pointing angle strongly reminiscent of kink between dorsal and ventral parts of ridge in holotype; inner side of distal edge of LAP with small, moderately well-defined, weakly prominent spur composed of densely meshed stereom; ventral part of ridge shorter, ventro-proximally pointing; no knob on ventral portion of inner side. Poorly defined, shallow furrow with single perforation near its ventral tip dorsally bordering inner side of tentacle notch.

NHMM 2012051 is a dissociated distal LAP; nearly 1.5 times wider than high; proximal edge with small, moderately well-defined, prominent and protruding, pointed spur; distal half of outer surface with 
weakly developed vertical striation. Five spine articulations similar to those observed on holotype, on strongly elevated distal portion of LAP, proximally sharply bordered by undulose distalmost lamella; well-developed connecting ridge between ventral lobe of spine articulations and distalmost lamella; ventral lobe of spine articulations slightly thickened; dorsalmost spine articulation smaller than remaining four. Ventral edge of LAP convex; tentacle notch obscured by syntaxial calcite crystals. Inner side of LAP well in agreement with that of paratype. No perforations discernible.

\section{Additional material}

Vertebrae of rounded aspect, with nearly equal-sized proximal muscular fossae, large dorso-distal and smaller ventro-distal muscular fossae; large and strongly protruding distal articular knobs, zygospondyline articulation.

Oral plate short, approximately as high as wide; deeply incised notch for ring nerve; adradial articular area with conspicuous dorso-distalwards projection.

Spines flattened, hollow, with slight kink near base; coarse longitudinal ribs with short thorns.

\section{Remarks}

These LAPs are unambiguously assignable to the Ophiotreta-Ophiopristis group on account of the highly distinctive spine articulation morphology and the shape of the ridge on the inner side. For reasons outlined above, Ophiotreta is preferred here. Closest similarities are shared with the LAPs of Ophiotreta striata comb. nov., which, however, differ in completely lacking spurs on the outer proximal and inner distal edges, and in displaying a better-developed vertical striation and more poorly developed connecting ridges between the spine articulations and the outer surface throughout.

Since the present LAPs were the only ones found in the original sample, all other ophiuroid skeletal parts can be assumed to have belonged to the same species. The flattened arm spines found in the sample substantiate assignment to the Ophiotreta-Ophiopristis group, modern species of which commonly display similarly flattened arm spines.

\section{Occurrence}

Early Paleocene of Denmark.

Ophiotreta hedone sp. nov. urn:Isid:zoobank.org:act:959BB836-3EA8-4855-B7AC-3FCCADA44A8E

Fig. 17: 12-15

\section{Diagnosis}

Species of Ophiotreta with very small LAPs displaying well-developed vertical striation; ventral sixth to third of LAP protruding ventro-proximalwards; up to five large spine articulations with moderately well-developed connecting ridge between ventral lobes and distalmost lamella of outer surface striation.

\section{Etymology}

Species named after Hedone, Greek for pleasure, as a homage to French "savoir-vivre".

\section{Type material}

Holotype

GZG.INV.78590.

Paratypes

GZG.INV.78591, GZG.INV.78592 and GZG.INV.78593. 


\section{Type locality and horizon}

Grignon, France; base of level 2 of Merle (2008), Campanile giganteum beds, middle Lutetian, Middle Eocene.

\section{Additional material}

GZG.INV.78594 (118 dissociated LAPs).

\section{Description}

Holotype

GZG.INV.78590 is a dissociated, small, proximal LAP; almost twice higher than wide; dorsal edge slightly concave as a result of a weak constriction; distal edge weakly convex to straight; proximal edge irregularly undulose, devoid of spurs; ventro-proximal portion of LAP missing; outer surface with fine, well-developed vertical striation composed of fine, slightly overlapping lamellae restricted to narrow band close to spine articulations, replaced by finely meshed stereom in all other parts of the outer surface. Five, large, ear-shaped spine articulations freestanding on strongly elevated distal portion of LAP and proximally bordered by undulose distalmost lamella; dorsal lobe large, separated from much smaller ventral lobe by small, shallow notch; short, weakly developed connecting ridge between ventral lobe of spine articulations and distalmost lamella; second dorsalmost spine articulation slightly larger than remaining four; very weak dorsalward increase in size of gaps separating spine articulations. Ventral edge of LAP fragmentary; tentacle notch not visible in external view.

Inner side of LAP with large, conspicuous, sharply defined ridge composed of near-vertical, straight dorsal part very close to proximal edge of LAP, and straight, oblique and slightly wider ventral part with ventrally pointing ventral tip; dorsal and ventral parts almost of equal length, separated by angular kink with conspicuous ventro-proximally pointing angle; very small, weakly prominent, inconspicuous and hardly discernible knob on ventral portion of LAP, widely separated from ridge; inner side of distal edge of LAP devoid of spurs; inner side of tentacle notch moderately large. Vertical row of moderately large, irregularly spaced perforations in very shallow, poorly defined furrow dorsally bordering inner side of tentacle notch.

\section{Paratype supplements and variation}

GZG.INV.78591 is a dissociated proximal LAP; generally in close agreement with holotype but ventroproximal sixth better preserved, slightly protruding ventro-proximalwards; proximal edge slightly undulose, devoid of spurs.

Inner side of LAP with almost indiscernible, weakly prominent and slightly elongate knob close to ventro-distal edge of ventral LAP portion, in addition to ridge similar to that observed on holotype. Two large, irregular perforations distally bordering ventral tip of ridge, no furrow discernible.

GZG.INV.78592 is a dissociated median LAP; slightly higher than wide; ventral third protruding ventroproximalwards; outer surface mostly covered by well-developed vertical striation composed of rather broad lamellae, replaced by finely meshed stereom in narrow band near proximal edge of LAP. Four spine articulations similar to those observed in holotype. Ventral edge of LAP oblique, tentacle notch invisible in external view.

Inner side of LAP with oblique, straight ridge similar to the ventral part of the ridge observed in the holotype, and with a widened dorsal tip; large, prominent but poorly defined, elongate knob near ventrodistal edge of LAP. Two to three moderately large perforations loosely arranged in vertical row dorsally bordering inner side of tentacle notch; no furrow discernible.

GZG.INV.78593 is a dissociated distal LAP; slightly wider than high; ventral third to quarter of LAP slightly protruding ventro-proximalwards; well-developed striation on outer surface restricted to narrow 
band near spine articulations. Four spine articulations, two median ones larger than ventral and dorsal ones; ventral lobe of spine articulations slightly thickened into small knob, with short, thin, yet welldeveloped connecting ridge with distalmost lamella.

Inner side of LAP with oblique, straight ridge similar to the ventral part of the ridge observed in the holotype, and with a widened dorsal tip; no ventral knob discernible; inner side of tentacle notch relatively small. No perforations discernible.

\section{Remarks}

These LAPs are unambiguously assignable to the Ophiotreta-Ophiopristis group mainly on account of the highly distinctive shape of the ridge on the inner side. On the basis of the moderately well-developed connecting ridge between the ventral lobe of the spine articulations and the distalmost lamella of the outer surface striation, even in proximal LAPs, Ophiotreta is preferred here. Their very small size, low number of spine articulations and unusually long ventral portion make these LAPs incompatible with any other fossil LAP type assigned to Ophiotreta.

\section{Occurrence}

Middle Lutetian of France.

Ophiotreta sp. nov. innom. 2

Fig. 18: 1-2

\section{Material examined}

NHMW 2012/0139/0001 and NHMW 2012/0139/0002 (4 dissociated LAPs) from the Langhian, middle Miocene, of Mannersdorf, Austria; NHMW 2012/0139/0003 (dissociated LAP) from the Langhian of Stotzing, Austria.

\section{Description}

Small dissociated LAPs, proximal ones nearly twice higher than wide, median ones slightly higher than wide; dorsal edge straight to very weakly concave; distal edge convex; proximal edge slightly concave, devoid of spurs; outer surface with very narrow band of fine, regular vertical striation composed of few fine lamellae close to spine articulations, replaced by finely meshed stereom on majority of outer surface. Up to six large, ear-shaped spine articulations freestanding on elevated ridge of distal portion of LAP, proximally bordered by slightly (proximal LAPs) to strongly (median LAPs) undulose distalmost lamella; dorsal lobe of spine articulation much larger than ventral one, separated from the latter by small, shallow notch; ventral notch with short, weakly (proximal LAPs) to moderately well-developed (median LAPs) connecting ridge with distalmost lamella; very weak dorsalward increase in size of spine articulations and of gaps separating them. Tentacle notch not visible in external view.

Inner side of LAPs with large, conspicuous, sharply defined and prominent ridge composed of straight, near-vertical dorsal part very close to proximal edge of LAP, and straight, oblique slightly shorter and wider ventral part with slightly widened, round ventral tip; dorsal and ventral parts of ridge separated by angular kink with ventro-proximally pointing angle; no ventral knob discernible; inner side of tentacle notch moderately large. Shallow, moderately well-defined vertical furrow with medium-sized, irregular perforations dorsally bordering inner side of tentacle notch.

\section{Remarks}

The highly distinctive shape of the ridge on the inner side along with the arrangement of the spine articulations and the moderately well-developed connecting ridge between the spine articulations and the outer surface leave no doubt as to the assignment of these LAPs to Ophiotreta. Closest similarities 


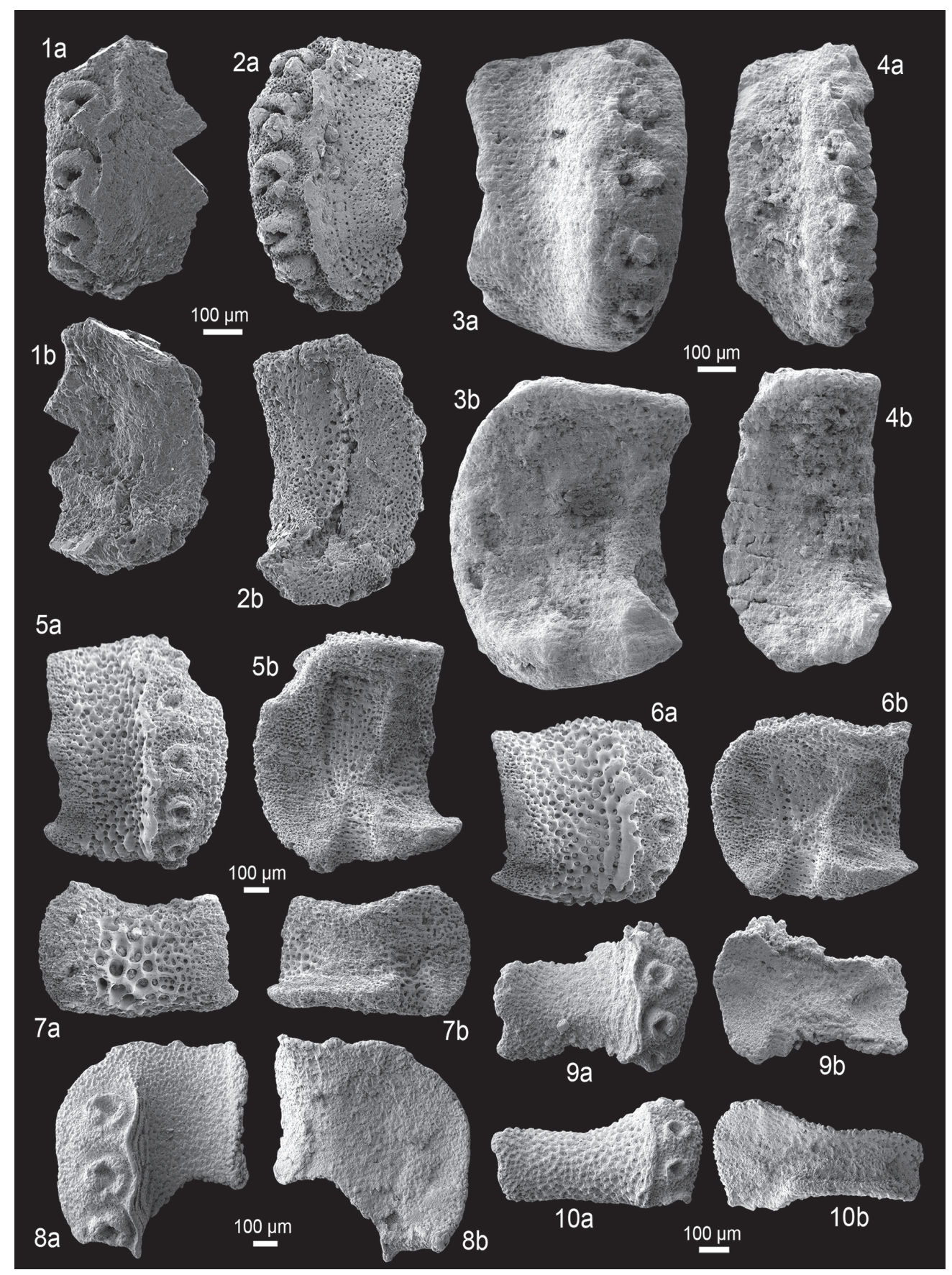

Fig. 18. Fossil lateral arm plates (LAPs) of ophiacanthid brittle stars in external (a) and internal (b) views. 1-2. Ophiotreta sp. nov. innom 2 from the Langhian (middle Miocene) of Stotzing (1) and Mannersdorf (2), Austria. 1. NHMW 2012/0139/0003, proximal LAP. 2. NHMW 2012/0139/0001, proximal LAP. 3-4. Europacantha paciphila gen. et sp. nov. from the late Anisian (Middle Triassic) of Felsöörs, Hungary. 3. MHI 2090/1 (holotype), proximal to median LAP. 4. MHI 2091/1 (paratype), proximal LAP. 5-7. Ophiacantha jaegeri sp. nov. from the latest Hauterivian (Early Cretaceous) of Sarstedt, Germany. 5. GZG.INV.78595 (holotype), proximal LAP. 6. GZG.INV.78596 (paratype), median LAP. 7. GZG. INV.78597 (paratype), distal LAP. 8-9. Ophiacantha sp. nov. innom 1 from the latest Aptian to earliest Albian (Early Cretaceous) of Blake Nose, NE Atlantic. 8. GZG.INV.78599, proximal LAP. 9. GZG. INV.78600, distal LAP. 10. Ophiacantha sp. nov. innom 2 from the latest Aptian to earliest Albian (Early Cretaceous) of Blake Nose, NE Atlantic; GZG.INV.78601, distal LAP. One common scale bar per species. 
are shared with the LAPs of Ophiotreta hedone sp. nov. on account of the small size and the low number of spine articulations. The present specimens, however, differ in having a much shorter ventral portion and up to six, rather than five, spine articulations. All extant species of Ophiotreta have much larger LAPs with numerous spine articulations. Thus, it seems highly probable that the present LAPs represent a new species. I refrain from formally describing this new species here, however, since it is currently represented by a few plates only, most of which are fragmentary. With such limited material available, it cannot be ruled out that the LAPs in question are from juvenile individuals rather than small-sized adults.

Genus Europacantha gen. nov.

urn:Isid:zoobank.org:act:511AAE08-FCA9-4DA9-AFC4-6B2A2C39B2DB

\section{Type and sole known species}

Europacantha paciphila sp. nov.

\section{Diagnosis}

Ophiacanthid with relatively small, stout, trapezoid LAPs devoid of conspicuous outer surface ornament; small, inconspicuous, very weakly protruding spur on outer proximal edge; up to six large, ear-shaped spine articulations on strongly elevated distal portion of LAP, not bordered proximally by a ridge-like structure; relatively broad, gently proximally bent ridge on inner side with widened dorsal tip displaying a ventrally projecting extension; tentacle notch small, invisible in external view.

\section{Etymology}

Name composed of Europa, a Phoenician princess whose name is commonly translated into "perspicacious", honouring the idea of a united Europe, and Acantha, a Greek nymph whose name literally translates into "thorny"; gender feminine.

\section{Remarks}

The oldest known ophiacanthid record is here described in the form of rare dissociated LAPs from the Anisian (early Middle Triassic) of Hungary. The LAPs in question are unambiguously assignable to the Ophiacanthidae on account of the large, ear-shaped spine articulations with a typical sigmoidal fold, combined with several small perforations in a shallow vertical furrow on the inner side. Astonishingly, these Anisian LAPs display small tentacle notches, almost certainly reflecting originally small tentacle pores as defined by Thuy et al. (2012), which places them in the more derived small-pored ophiacanthids rather than the basal large-pored ones.

Indeed, greatest similarities in LAP morphology are shared with the small-pored Ophiacantha, on account of the number, size and position of the spine articulations, the absence of more than a single spur on the outer proximal edge, and the shape of the ridge on the inner side, as well as with Inexpectacantha Thuy, 2011 on account of the stout, trapezoid aspect, the proximally non-bordered spine articulations and the lack of a conspicuous outer surface ornament. Yet, in the LAPs of Ophiacantha, the spine articulations are proximally sharply bordered by a ridge or the distalmost lamella of the outer surface striation, while in Inexpectacantha the ridge on the inner side of the LAPs lacks a ventrally projecting extension, and the spine articulations are more oblique, displaying a coarsely corrugated ventral lobe. On account of these incompatibilities, Europacantha gen. nov. is thus introduced here to accommodate the Anisian LAPs. 
Europacantha paciphila sp. nov. urn:Isid:zoobank.org:act:96307602-8F71-4187-B901-312179D4E69C

Fig. 18: 3-4

\section{Diagnosis}

As for genus.

\section{Etymology}

Name derived from pax, Latin for "peace", and Philia, Greek for "love", in reference to peace prevailing between nations in Europe, against all nationalist odds.

\section{Type material}

\section{Holotype}

MHI 2090/1.

\section{Paratype}

MHI 2091/1.

\section{Type locality and horizon}

Felsöörs, Hungary; Felsöörs Formation, late Anisian, Middle Triassic.

\section{Additional material}

MHI 2092/1-6 (6 dissociated LAPs).

\section{Description}

\section{Holotype}

MHI 2090/1 is a dissociated, small, median to proximal LAP; approximately 1.5 times higher than wide; rather stout, trapezoid aspect; dorsal edge oblique, very weakly concave as a result of a constriction; distal edge gently convex; proximal edge irregularly concave, with small, round, non-prominent central protrusion; outer surface with finely meshed stereom, devoid of vertical striation or other conspicuous elements of ornament elements. Five large, equi-distant, ear-shaped spine articulations freestanding on strongly elevated distal portion of LAP; ventral and dorsal lobes merged into continuous volute; dorsal lobe larger than ventral one, thickened; dorsalward increase in size of spine articulations; gap between spine articulations and distal edge of LAP narrow; spine articulations not bordered proximally by a ridge-like structure. Ventral edge of LAP oblique, very gently convex.

Inner side of LAP with sharply defined, prominent, relatively broad, oblique, gently proximally bent ridge; ventral half of ridge most strongly prominent; not merged with ventral portion fo LAP; dorsal half of ridge widening dorsalwards, with short, ventrally pointing extension; inner side of distal edge of LAP devoid of spurs; inner side of tentacle notch relatively small, shallow, moderately well defined laterally. Very shallow, poorly defined vertical ridge dorsally bordering tentacle notch.

\section{Paratype supplements and variation}

MHI 2091/1 is a dissociated proximal LAP; almost twice higher than wide; ventro-proximal tip fragmentary; slightly less stout than holotype; single small, slightly protruding and very weakly prominent spur in the middle of the proximal edge. Six spine articulations on strongly elevated distal portion of LAP, poorly preserved but apparently similar to those observed on holotype; spine articulations not sharply bordered proximally by a ridge-like structure.

Inner side of LAP poorly preserved and partly obscured by sediment; ridge not clearly discernible, probably gently proximally bent as in holotype, with widened, near-triangular dorsal tip displaying 
a very short ventrally pointing extension; no spurs on inner side of distal edge of LAP; inner side of tentacle notch poorly preserved, small. Very shallow, poorly preserved vertical furrow with two or three small, widely spaced perforations, dorsally bordering tentacle notch.

\section{Remarks}

Since these LAP type is the only one assigned to Europacantha gen. nov., its systematic affinities are discussed above.

\section{Occurrence}

Late Anisian of Hungary.

Genus Ophiacantha Müller \& Troschel, 1842

\section{Type species}

Ophiacantha spinulosa Müller \& Troschel, 1842 [junior synonym of Ophiacantha bidentata (Bruzelius, 1805)], by original designation.

\section{Diagnosis}

LAPs with dorsal and ventral lobes of spine articulations fused into continuous volute; ventral part of LAPs not protruding ventro-proximalwards; generally no more than one spur on the outer proximal and inner distal edges; ridge on inner side composed of long, oblique, straight to slightly bent main part with a pointed dorsal tip and with ventrally pointing, vertical to slightly oblique or bent extension generally at least as long as half of the main part; in many cases, main part and ventrally pointing extension fused into large, irregularly triangular knob; tentacle notch small.

\section{Remarks}

Ophiacantha is one of the most speciose (Stöhr et al. 2012), but also one of the most heterogeneous genera among the extant ophiuroids (O'Hara \& Stöhr 2006). This morphological heterogeneity is also reflected in LAP morphology, as already pointed out by Thuy \& Stöhr (2011), with some species sharing greater similarities in LAP morphology to species of other ophiacanthid genera than with their congeners. Thus, working out a comprehensive and at the same time meaningful LAP morphological diagnosis of Ophiacantha is a major challenge. To make matters worse, most characters observed in the LAPs of Ophiacantha also occur in other genera. The most stringent approach is to focus on the LAP morphology of the type species, Ophiacantha bidentata, on the basis of which the LAP morphologies of the other species are assessed.

The LAPs of $O$. bidentata were described in detail and illustrated by Thuy \& Stöhr (2011). They are characterised by a ridge on their inner side, which consists of a main oblique, straight to slightly proximally bent part with a pointed dorsal tip and fused dorsally to a ventrally pointing, near-vertical to slightly oblique extension close to the proximal edge of the LAP longer than half of the main part of the ridge. In some cases, the main part of the ridge and its ventrally pointing dorsal extension are merged into a single, large, irregularly triangular knob. In combination with the large ear-shaped spine articulations on a strongly elevated distal portion of the LAP, with dorsal and ventral lobes merged into a continuous volute, and proximally sharply bordered by the distalmost lamella of a well-developed vertical striation on part of the outer surface, the shape of this ridge is distinctive. This is important to note since slightly modified versions of ridge shape are also found in other, not necessarily closely related ophiacanthids (e.g. Ophiomitrella Verrill, 1899; Ophioplinthaca Verrill, 1899, "Ophiophthalmus" Matsumoto, 1917). Many species of Ophiacantha share the above-mentioned combination of features, which can be thus considered as the Ophiacantha LAP morphology in its proper sense. Whether the species in question 
also share similar general skeletal morphologies, and thus potentially represent a true clade with the Ophiacanthidae, remains to be investigated.

A number of extant species of Ophiacantha conflict with the type species in terms of LAP morphology. Particularly striking is the occurrence in a number of species of Ophiacantha of a ridge shape otherwise exclusively found in Ophiotreta and Ophiopristis. The species in question include Ophiacantha anomala G.O. Sars, 1872, O. rosea Lyman, 1878, O. spectabilis G.O. Sars, 1872 and O. vivipara Ljungman, 1872. Remarkably, these four species are known to have closely similar general skeletal morphologies in common (Paterson 1985; O'Hara \& Stöhr 2006), thus most probably form a phylogenetically consistent group. A detailed reassessment of the species in question is likely to result in separation at the generic level, which would gain support from evidence of LAP morphology.

Other species currently assigned to Ophiacantha differ from the type species in displaying generally lower LAPs (smaller height/width ratios), proximally separated dorsal and ventral lobes of the spine articulations which thus become slightly horizontally elongate rather than round, a single protruding spur in the middle of the outer proximal and inner distal edges, and a densely meshed or even granulated stereom covering the outer surface rather than a vertical striation. At the same time, they share the highly distinctive shape of the ridge on the inner side with Ophiacantha bidentata. Such taxa include Ophiacantha smitti Ljungman, 1872, O. pentagona Koehler, 1897, O. prionota H.L. Clark, 1911 and $O$. levispina Lyman, 1878. Whether this grouping is artificial or, indeed, reflects general skeletal morphological similarities is in need of further study. Remarkably, the species in question are closer to species of Ophiolebes Lyman, 1878 in terms of LAP morphology than to their congeners.

According to the revised cladistic phylogeny presented here, Ophiacantha is sister taxon to the Ophiolebes-Ophialcaea clade. Unfortunately, LAPs of extant species of Ophialcaea Verrill, 1899 could not be examined using the standards set by Thuy \& Stöhr (2011). Ophiolebes, however, is shown here to share largely similar LAP morphologies with Ophiacantha, in particular with the species mentioned above. Similar to those of the latter, the LAPs of Ophiolebes display a ridge that is superficially comparable to the one seen in Ophiacantha bidentata. The main distinction between the LAPs of Ophiolebes and those of $O$. bidentata and similar congeners are the proximally separated dorsal and ventral lobes of the spine articulations.

To conclude, as currently understood, the genus Ophiacantha obviously unites a number of fundamentally different LAP morphologies, some of which definitely reflect differences at the generic level to be worked out in detail by future studies. It is very difficult to characterise the LAP morphology of the genus convincingly, even if restricted to the type species and species with morphologically similar LAPs. The ridge shape described above for Ophiacantha bidentata, along with spine articulations freestanding on the elevated distal edge of the LAP, with dorsal and ventral lobes fused into a continuous volute, and bordered proximally by a not exceedingly thickened distalmost lamella is a combination which probably comes closest to a diagnosis of the LAP morphology of Ophiacantha in its proper sense. For the purpose of the present, only fossil LAPs displaying this combination of characters are assigned to Ophiacantha.

Ophiacantha jaegeri sp. nov. urn:1sid:zoobank.org:act:A991EFFE-BA53-46CC-B06A-84E27C84A749

Fig. 18: 5-7

\section{Diagnosis}

Species of Ophiacantha with moderately large LAPs displaying a rather knobby general aspect; single poorly defined, protruding spur on outer proximal edge; outer surface devoid of vertical striation, with 
coarsely meshed stereom displaying thickened trabecular intersections; up to six large spine articulations proximally bordered by knobby, undulose ridge; tentacle notch invisible in external view.

\section{Etymology}

Species named in honour of Manfred Jäger, who kindly provided the sample yielding the type material of the species.

\section{Type material}

\section{Holotype}

GZG.INV.78595.

\section{Paratypes}

GZG.INV.78596 and GZG.INV.78597.

\section{Type locality and horizon}

Claypit Gott in Sarstedt, Germany; latest Hauterivian, Early Cretaceous.

\section{Additional material}

GZG.INV.78598 (6 dissociated LAPs).

\section{Description}

\section{Holotype}

GZG.INV.78595 is a dissociated, moderately large LAP; approximately 1.5 times higher than wide; dorsal edge oblique, very weakly concave; distal edge evenly convex; proximal edge irregularly undulose, with small, poorly defined, weakly prominent but conspicuously protruding spur in its centre; outer surface with coarsely meshed stereom with trabeculae thickened into conspicuously large granules in ventral sixth of outer surface and into smaller granules in remaining outer surface; narrow band of finely meshed stereom along proximal edge. Six large, ear-shaped spine articulations freestanding on strongly elevated distal portion of LAP; ventral and dorsal lobes fused into near-round, continuous volute; spine articulations proximally bordered by knobby, wavy vertical ridge; dorsalward increase in size of spine articulations and in of gaps separating them; gap between spine articulations and distal edge of LAP as wide as one spine articulation. Ventral edge of LAP slightly convex, tentacle notch invisible in external view.

Inner side with large, conspicuous, sharply defined and prominent ridge composed of oblique, nearstraight main part with pointed dorsal tip and with ventro-proximally pointing dorsal extension slightly longer than main part and merged with the latter into near-triangular, vertically elongate knob; ventral portion of main ridge part with rounded kink and short ventro-proximally pointing extension; inner side of distal edge of LAP with small, poorly defined and hardly prominent spur composed of slightly more densely meshed stereom; inner side of tentacle notch relatively small, well defined laterally. Shallow but moderately well-defined vertical furrow dorsally bordering tentacle notch with small, irregularly spaced perforations.

\section{Paratype supplements and variation}

GZG.INV.78596 is a dissociated median LAP; nearly as high as wide; generally closely matching holotype; spur on proximal edge very weakly defined, almost indiscernible, not protruding. Five spine articulations similar to those observed on holotype; gap between spine articulations and distal edge of LAP narrower than one spine articulation. Ventral edge with very shallow, poorly developed tentacle notch. 
Inner side of LAP with large, conspicuous, relatively wide, oblique ventralwards bent ridge with widened, nearly triangular dorsal tip; no spur discernible on inner side of distal LAP edge; inner side of tentacle notch relatively small, well defined laterally. Very shallow and weakly defined furrow dorsally bordering tentacle notch, no perforations clearly discernible.

GZG.INV.78597 is a dissociated distal LAP; almost twice wider than high; generally well in agreement with holotype but poorly preserved; dorsal edge strongly concave as a result of a well-developed constriction; no spur discernible on outer proximal edge; outer surface with coarsely meshed stereom replaced by finely meshed stereom in proximal third of outer surface; few trabecular intersections, especially in ventral part of outer surface, thickened into small granules. Four poorly preserved spine articulations on elevated distal portion of LAP, seemingly similar to those observed on holotype. Tentacle notch not visible in external view.

Inner side of LAP with large, moderately well-defined, oblique ridge with narrow, rounded dorsal tip and strongly widened ventral part; inner side of tentacle notch relatively small, moderately well defined laterally. Single, poorly defined perforation dorsally bordering tentacle notch, no furrow discernible.

\section{Remarks}

The shape of the ridge on the inner side in combination with the continuous, round volute of the spine articulations and the single spur on the outer proximal and inner distal edges strongly suggest that these LAPs to belong to the genus Ophiacantha or at least to a very closely related, yet undescribed genus. Morphological similarities are much closer to Ophiacantha than to the allegedly closely related Ophiogaleus gen. nov., which is why the LAPs in question are here assigned to the former genus. Among the fossil LAP types assigned to Ophiacantha, the ones described above are unique in lacking a vertical striation and at the same time in displaying a generally knobby appearance, with trabecular intersections thickened into small granules especially on the ventral portion of the outer surface but also in other parts, and with the conspicuously knobby ridge proximally bordering the spine articulations.

\section{Occurrence}

Latest Hauterivian of Germany.

Ophiacantha sp. nov. innom. 1

Fig. 18: 8-9

\section{Material examined}

GZG.INV.78599 and GZG.INV.78600 from the latest Aptian to earliest Albian of Blake Nose, tropical northeast Atlantic.

\section{Description}

GZG.INV.78599 is a fragment of a dissociated, medium-sized, proximal LAP of which only dorso-distal portion is preserved; LAP fragile; dorsal edge slightly concave; distal edge convex; preserved portion of proximal edge slightly undulose, devoid of spurs; outer surface with very narrow band of welldeveloped, vertical striation composed of a few fine, overlapping lamellae close to spine articulations; remaining outer surface with finely meshed stereom. Three large, ear-shaped spine articulations preserved, freestanding on strongly elevated distal portion of LAP; dorsal and ventral lobes of spine articulations merged into continuous, round volute; spine articulations proximally sharply bordered by strongly undulose distalmost lamella; gap between spine articulations and distal edge of LAP slightly narrower than one spine articulation.

Inner side of LAP with dorsal tip of ridge, sharply defined, prominent, dorsally pointed, with ventroproximally pointing extension; possible large, poorly defined, non-prominent spur on preserved portion 
of inner distal LAP edge and composed of slightly more densely meshed stereom; no perforations discernible.

GZG.INV.78600 is a dissociated distal LAP; very fragile, dorsal and ventral edges fragmentary; very well in agreement with proximal LAP described above; distal edge irregularly convex; proximal edge poorly preserved, irregularly undulose, no spur discernible. Four spine articulations similar to those observed in proximal LAP described above. Ventral edge of LAP poorly preserved.

Inner side of LAP with large, conspicuous, sharply defined and prominent, straight, oblique ridge with strongly widened, near-triangular dorsal tip displaying ventro-proximally pointing extension; ventral tip of ridge strongly widened; inner side of distal edge of LAP with large, poorly defined, weakly prominent spur composed of more densely meshed stereom; inner side of tentacle notch relatively small and moderately well defined laterally. No perforations discernible.

\section{Remarks}

Although this LAP type is represented by very limited material only, it displays sufficient morphological detail to argue in favour of an assignment to Ophiacantha, based mainly on the shape of the ridge in the distal LAP as well as the round, continuous volute of the large, freestanding spine articulations. In the absence of more complete material, however, this generic placement must be treated with caution. The very fragile nature of the LAPs, the very large, near-circular spine articulations, and the narrow band of very fine vertical striation distally bordered by finely meshed stereom are not found in any other fossil LAP type currently assigned to Ophiacantha. This LAP type most probably represents a new species, the description of which, however, should be based on more complete material.

Ophiacantha sp. nov. innom 2

Fig. 18: 10

\section{Material examined}

GZG.INV.78601 from the latest Aptian to earliest Albian of Blake Nose, tropical northeast Atlantic.

\section{Description}

GZG.INV.78601 is a dissociated, moderately large, distal LAP; more than twice wider than high; fragile; dorsal edge strongly concave as a result of a well-developed constriction; distal edge convex; proximal edge irregularly undulose, with large, very poorly defined, weakly prominent but strongly protruding spur in dorsal half; outer surface entirely covered with coarsely meshed stereom, slightly becoming finer close to proximal edge of LAP. Four large, equal-sized, equi-distant, near-circular spine articulations freestanding on strongly elevated distal portion of LAP; dorsal and ventral lobes of spine articulations thin, merged into continuous, near-circular volute; spine articulations proximally sharply bordered by vertical, straight, well-defined and prominent ridge; gap between spine articulations and distal edge of LAP relatively narrow, barely as wide as half a spine articulation. Ventral edge of LAP weakly concave, tentacle notch invisible in external view.

Inner side of LAP with large, moderately well-defined, prominent, straight, near-horizontal ridge; dorsal tip of ridge strongly widened, dorsally pointed, with ventro-proximally pointing extension; inner side of distal edge with moderately large, poorly defined, non-prominent spur composed of slightly more densely meshed stereom; inner side of tentacle notch relatively large. No perforations discernible.

\section{Remarks}

Only a single specimen of this LAP type is currently known. Although it is from distal arm portions, it displays characters strongly pointing to the genus Ophiacantha, in particular with regard to the shape of the ridge on the inner side, as well as the shape and arrangement of the spine articulations. Closest 
similarities are shared with LAPs assigned to Ophiacantha from the Albian of England (see below). These differ, however, in displaying a strongly undulose, rather than straight, ridge proximally bordering the spine articulations. The present LAP most probably represents a new species of Ophiacantha but in the absence of more material it cannot be formally described.

Ophiacantha sp. nov. innom. 3

Fig. 19: 1-2

\section{Material examined}

GZG.INV.78602, GZG.INV.78603 and GZG.INV.78604 (2 dissociated LAPs) from level 2 of Young et al. (2010) in the middle Albian Loricatus Zone of Folkestone, Great Britain.

\section{Description}

GZG.INV.78602 is a dissociated, large, proximal to median LAP; dorsal edge fragmentary; distal edge convex; proximal edge irregularly undulose; small, sharply defined, slightly prominent and protruding, round spur in the dorsal half of the proximal edge, composed of more densely meshed stereom; outer surface with moderately finely meshed stereom; few trabecular intersections, especially in ventral quarter of outer surface, thickened into very small granules; moderately finely meshed stereom of outer surface replaced by much more finely meshed stereom in relatively broad band paralleling proximal edge of LAP. Four large, ear-shaped spine articulations freestanding on strongly elevated distal portion of LAP; dorsal and ventral lobes of spine articulations merged into continuous, round volute; spine articulations proximally bordered by irregularly knobby, undulose and weakly prominent ridge; very weak dorsalward increase in size of spine articulations and of gaps separating them; gap between spine articulations and distal edge of LAP nearly half as wide as one spine articulation. Ventral edge convex, with conspicuous, moderately large, deeply concave tentacle notch.

Inner side of LAP with large, conspicuous ridge composed of a main central, near-straight, oblique part and slightly shorter and wider, oblique, ventro-proximally pointing ventral part separated from the main part by a rounded kink; dorsal tip of main part of ridge fragmentary, but originally widened and with relatively short, pointed ventralward extension; dorsal half of inner side of distal LAP edge with small, moderately well-defined, slightly prominent, dorsally fragmented spur; inner side of tentacle notch deep, relatively short, well-defined laterally. No perforations discernible.

GZG.INV.78603 is a dissociated distal LAP; almost twice wider than high; dorsal edge strongly concave as a result of a well-developed constriction; distal edge nearly straight to slightly convex; spur in dorsal half of proximal edge very weakly defined, almost indiscernible. Four spine articulations similar to those observed on proximal to median LAP described above; ventral edge of LAP slightly concave, tentacle notch invisible in external view.

Inner side of LAP with large, proximally bent, sharply defined ridge; dorsal tip of ridge strongly widened; ventral part of ridge distally bordered by round, prominent, well-defined knob; spur in dorsal half of inner side of distal LAP edge very poorly defined, hardly discernible, slightly prominent; inner side of tentacle notch relatively small, moderately well-defined laterally. No perforations discernible.

\section{Remarks}

The ridge displayed by these LAPs is rather atypical of Ophiacantha in that its ventrally pointing extension is unusually short. Nevertheless, the shape of the ridge is basically compatible with the LAP morphology of Ophiacantha in its proper sense, in particular in combination with the shape and arrangement of the spine articulations and the single spur on the outer proximal and inner distal edges. The LAPs in question are unambiguously recognisable on account of the deeply concave tentacle notch visible even in external view, combined with the irregular, undulose ridge proximally bordering the 


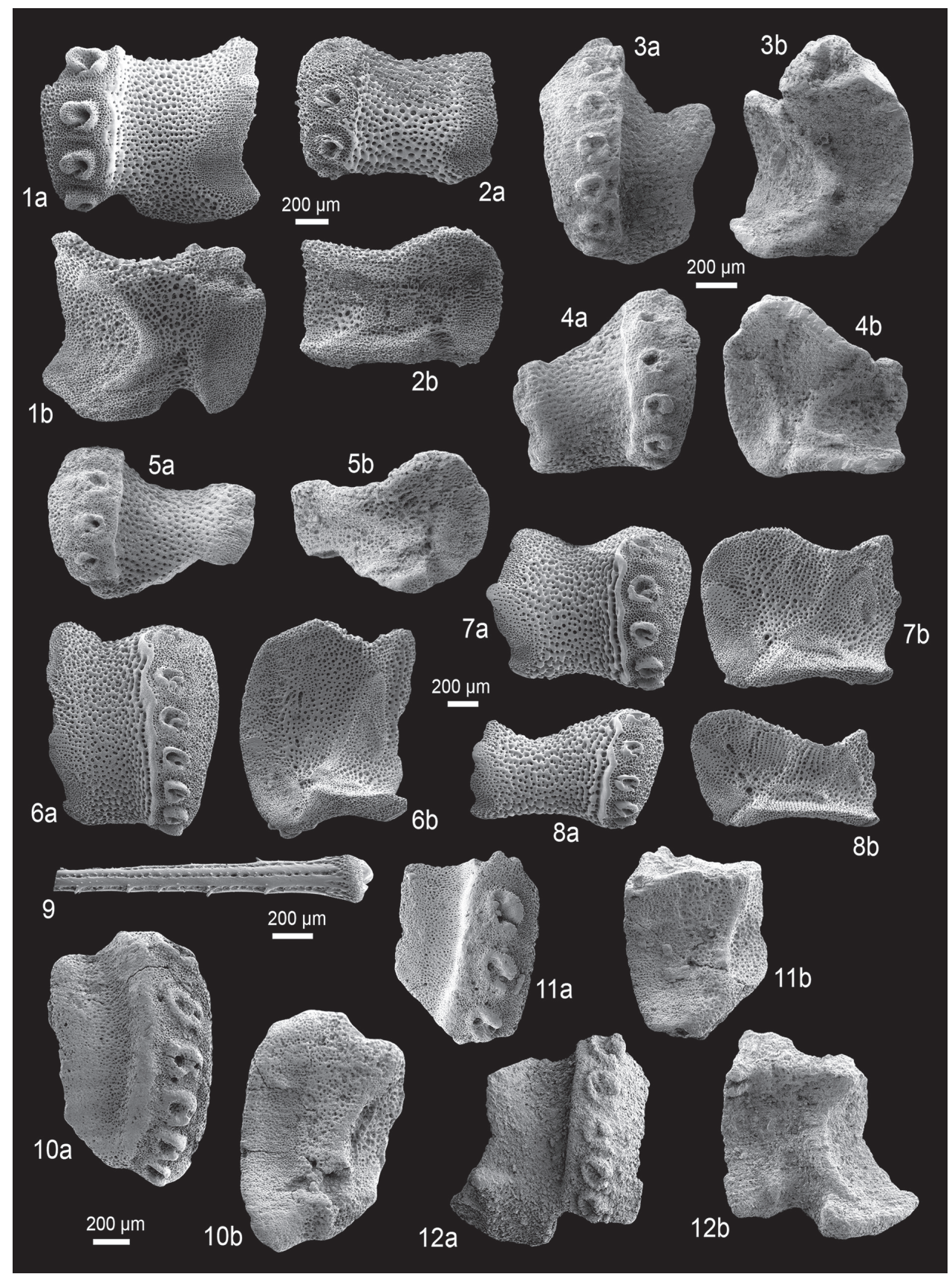

Fig. 19. Fossil skeletal plates of ophiacanthid brittle stars; lateral arm plates (LAPs) in external (a) and internal (b) views. 1-2. Ophiacantha sp. nov. innom 3 from the middle Albian (Early Cretaceous) of Folkestone, Great Britain. 1. GZG.INV.78602, proximal LAP. 2. GZG.INV.78603, distal LAP. 3-5. Ophiacantha reginae sp. nov. from the late Campanian (Late Cretaceous) of Lägerdorf-Alsen, Germany. 3. GZG.INV.78605 (holotype), proximal LAP. 4. GZG.INV.78606 (paratype), median LAP. 5. GZG.INV.78607 (paratype), distal LAP. 6-9. Ophiacantha steffenschneideri sp. nov. from the Rupelian (Oligocene) of Bad Freienwalde, Germany. 6. GZG.INV.78609 (holotype), proximal LAP. 7. GZG.INV.78610 (paratype), median LAP. 8. GZG.INV.78611 (paratype), distal LAP. 9. GZG. INV.78612 (paratype), arm spine. 10-12. Ophiogaleus sp. nov. innom 1 from the late Sinemurian to early Pliensbachian (Early Jurassic) of the Glasenbach Gorge, Austria. 10. NHMW 2012/0137/0017, proximal LAP. 11. NHMW 2012/0137/0018, proximal to median LAP. 12. NHMW 2012/0137/0019, proximal to median LAP. One common scale bar per species except for 9. 
spine articulations, and the short ventrally pointing extension of the ridge on the inner side. Although these LAPs unquestionably represent a new species, the fragmentary condition and limited number of plates currently available precludes a formal description of the species.

Ophiacantha reginae sp. nov. urn:1sid:zoobank.org:act:283B7CEB-644F-4997-A2FE-EFAED468A3BD

Fig. 19: 3-5

\section{Diagnosis}

Species of Ophiacantha with moderately large LAPs; outer surface stereom rather finely meshed, devoid of vertical striation; no spur on outer proximal and inner distal edges; up to seven spine articulations on strongly elevated distal portion of LAP; row of spine articulations strongly protruding dorsalwards.

\section{Etymology}

Species named in honour of Regina Fischer, who generously provided the sample yielding the type material of the species.

\section{Type material}

\section{Holotype}

GZG.INV.78605.

\section{Paratypes}

GZG.INV.78606 and GZG.INV.78607.

\section{Type locality and horizon}

Alsen quarry, Lägerdorf, Germany; Galerites vulgaris Zone, late Campanian, Late Cretaceous.

\section{Additional material}

GZG.INV.78608 (one dissociated LAP).

\section{Description}

\section{Holotype}

GZG.INV.78605 is a dissociated, moderately large, proximal LAP; slightly higher than wide; dorsal edge strongly concave as a result of a well-developed constriction; distal edge weakly convex; proximal edge concave, devoid of spurs; outer surface with moderately finely meshed stereom. Seven large, earshaped, round spine articulations on strongly elevated distal portion of LAP; very weak dorsalward increase in size of spine articulations and of gaps separating them; dorsal and ventral lobes of spine articulations merged into continuous, round volute; spine articulations proximally bordered by sharply defined, straight edge of strongly elevated distal portion of LAP; gap between spine articulations and distal edge of LAP from slightly narrower to clearly wider than one spine articulation, with dorsalward increase in width; row of spine articulations conspicuously protruding dorsalwards. Ventral edge of LAP convex, slightly pointed; tentacle notch invisible in external view.

Inner side of LAP with large, well-defined, prominent ridge; main part of ridge straight, oblique, dorsal tip widened and merged with rather short ventrally projecting extension; ventral part of ridge slightly shorter than main part, gently bent, ventro-proximally bent, not merged with ventral portion of LAP; kink between ventral and main part of ridge rounded, slightly thickened; inner side of distal edge of LAP devoid of spurs; inner side of tentacle notch small, poorly defined, shallow. No perforations or furrow discernible. 


\title{
Paratype supplements and variation
}

GZG.INV.78606 is a dissociated median LAP; nearly as high as wide; dorso-proximal tip slightly fragmentary; very well in agreement with holotype. Six spine articulations similar to those observed on holotype; edge of strongly elevated distal portion of LAP proximally bordering spine articulations slightly undulose. Ventral edge of LAP nearly straight.

Ridge on inner side of LAP similar to that of holotype but with slightly bent main part; very shallow, poorly defined vertical furrow dorsally bordering tentacle notch, with single, small perforation at dorsal end of furrow.

GZG.INV.78607 is a dissociated distal LAP; nearly 1.5 times wider than high; ventro-proximal tip of LAP fragmentary. Five spine articulations similar to those of holotype; edge of strongly elevated distal portion of LAP proximally bordering spine articulations slightly undulose; row of spine articulations less strongly protruding dorsalwards than in holotype.

Ridge on inner side of LAP similar to that of holotype but with smaller, less well-defined ventralward projecting extension of dorsal tip. Irregular perforations loosely arranged in vertical row dorsally bordering tentacle notch.

\section{Remarks}

The structure and position of the spine articulations, the shape of the ridge and the absence of spurs on the outer proximal and inner distal edges strongly suggest that these LAPs are assignable to Ophiacantha. The conspicuously dorsally protruding row of spine articulations clearly differentiates this LAP type from other types assigned to that genus. While, at first sight, this character might seem unusual for Ophiacantha, it is not uncommon among Recent species of the genus such as O. duplex Koehler, 1897 and $O$. serrata Lyman, 1878, which otherwise perfectly match the LAP morphology of Ophiacantha in its proper sense.

\section{Occurrence}

Late Campanian of Germany.

$$
\begin{aligned}
& \text { Ophiacantha steffenschneideri sp. nov. } \\
& \text { urn:1sid:zoobank.org:act:4FB6425F-54A5-4285-88EE-8FD4911F63AB }
\end{aligned}
$$

Fig. 19: 6-9

\section{Diagnosis}

Species of Ophiacantha with relatively large LAPs displaying a well-developed vertical striation confined to a very narrow band close to the spine articulations; up to seven relatively small spine articulations; well-developed spur on the outer proximal and inner distal edges.

\section{Etymology}

Species named in honour of Steffen Schneider, who kindly provided the type material of the species.

\section{Type material}

\author{
Holotype
}

GZG.INV.78609.

Paratypes

GZG.INV.78610, GZG.INV.78611 and GZG.INV.78612. 


\section{Type locality and horizon}

Bad Freienwalde, Germany; “Septarienton”, Rupelian, Oligocene.

\section{Additional material}

GZG.INV.78613 (710 dissociated LAPs); GZG.INV.78614 (11 dissociated arm spines).

\section{Description}

\section{Holotype}

GZG.INV.78609 is a dissociated, large, proximal LAP; approximately 1.5 times higher than wide; dorsal edge strongly concave as a result of a well-developed constriction; distal edge convex; proximal edge irregularly undulose, with small, moderately well-defined, slightly prominent and protruding, angular spur; outer surface with very narrow band of a well-developed, regular, vertical striation composed of very few fine lamellae proximally bordering spine articulations; lamellae replaced by moderately finely meshed stereom on almost entire outer surface; trabecular intersections thickened into small granules on ventral sixth of outer surface. Seven relatively small, $\leqslant$ ear-shaped spine articulations freestanding on strongly elevated distal portion of LAP; dorsal and ventral lobes of spine articulation merged into continuous, round volute; spine articulations proximally sharply bordered by distalmost lamella, becoming increasingly undulose dorsalwards; spine articulations nearly equal-sized but gap separating them with dorsalward increase in size; gap between spine articulations at least as wide as one spine articulation. Ventral edge of LAP nearly straight except for protruding row of spine articulations; tentacle notch invisible in external view.

Inner side of LAP with very large, conspicuous, sharply defined and prominent ridge; main part of ridge nearly straight, oblique, dorsally strongly widened and merged with nearly vertical ventrally pointing extension close to proximal edge and almost as long as main part of ridge; ventral part of ridge with slightly thickened kink and short proximally pointing part; inner side of distal edge of LAP with small, round, well-defined, weakly prominent spur composed of densely meshed stereom; inner side of tentacle notch poorly defined, small, rather inconspicuous. Small perforations, round to vertically elongate, in irregular vertical row dorsally bordering tentacle notch.

\section{Paratype supplements and variation}

GZG.INV.78610 is a dissociated median LAP; slightly wider than high; agreeing well with holotype; spur on proximal edge much better defined and more strongly protruding. Five spine articulations similar to those observed on holotype. Ventral edge of LAP concave; tentacle notch invisible in external view. Inner side of LAP with conspicuous ridge similar to that observed on holotype; spur on inner side of distal edge of LAP better defined. Two small, well-defined perforations dorsally bordering inner side of tentacle notch.

GZG.INV.78611 is a dissociated distal LAP; almost twice wider than high; very well in agreement with holotype; spur on proximal edge better defined and more strongly protruding. Five spine articulations on strongly elevated distal portion of LAP, slightly more horizontally elongate than those of holotype; dorsal and ventral lobes merged into continuous volute but with small, shallow notch proximally. Ventral edge strongly concave; tentacle notch invisible in external view.

Inner side of LAP with large, well-defined, prominent ridge; dorsal part of ridge similar to that observed on holotype; ventral part of ridge distally rather than proximally pointing and longer than dorsal part; inner side of distal edge of LAP with relatively large, poorly defined, oblique spur composed of more densely meshed stereom; inner side of tentacle notch small, oblique, moderately well defined. Three relatively large, irregular perforations in oblique row dorsally bordering inner side of tentacle notch. 
GZG.INV.78612 is a dissociated arm spine; cylindrical, slowly tapering; few coarse, regular longitudinal ribs irregularly beset with minute granules, separated by narrow rows of pores with occasional short thorns pointing towards the apex of the spine; tip of spine broken.

\section{Remarks}

These LAPs fit the LAP morphology diagnosis of Ophiacantha in its proper sense so markedly well that assignment to that genus is unquestionable. The LAPs in question clearly differ from all other fossil LAP types assigned to Ophiacantha in combining a fine vertical striation, which is confined to a very narrow band of the outer surface, with relatively small spine articulations and the well-developed (at least in median and distal LAPs) spur on the outer proximal and inner distal edges. It is thus described here as a new species.

This LAP type bears striking similarities to the LAPs of extant Ophiacantha bidentata and its morphologically closely similar congener O. fraterna Verrill, 1885 (Martynov \& Litvinova 2008). In terms of the shape of the ridge on the inner side, the size of the spine articulations and the presence of a spur on the outer proximal and inner distal edges, the Oligocene species is closer to $O$. fraterna. The slightly better-developed constriction and the more strongly undulose distalmost lamella proximally bordering the spine articulations, in contrast, place the Oligocene species closer to O. bidentata. These striking similarities in LAP morphology suggest that the Oligocene taxon from the North Sea Basin shares close phylogenetic ties with the North Atlantic $O$. bidentata and $O$. fraterna. Interestingly, the latter two are morphologically so similar that they were long considered to be conspecific (Martynov \& Litvinova 2008), implying a recent divergence date and/or very little morphological differentiation following divergence. In this light, Ophiacantha steffenschneideri sp. nov. would be a plausible candidate for an ancestor of $O$. bidentata and $O$. fraterna. However, such a claim cannot, of course, be substantiated on the basis of LAP morphology alone.

\section{Occurrence}

Oligocene of Germany.

Genus Ophiogaleus gen. nov. urn:1sid:zoobank.org:act:25557BA8-022E-49DC-99A2-ACA17793A5EB

\section{Type species}

Ophiacantha? constricta Hess, 1966, by present designation.

\section{Other species included}

Ophiacantha? danica Rasmussen, 1952; Ophiacantha? dorecki Hess, 1962 and Ophiogaleus stans sp. nov.

\section{Diagnosis}

Ophiacanthid genus with numerous (generally at least seven) ear-shaped spine articulations on strongly elevated distal portion of LAP; dorsal and ventral lobes of spine articulations merged into continuous lobe; outer surface with moderately coarsely meshed stereom; ridge on inner side composed of short, narrow, oblique central part with generally strongly widened, triangular dorsal portion with nearvertical distal edge and pointed dorsal and ventro-proximal tips; generally several spurs at least on inner distal edge of LAPs; arm spines forming fan dorsally at least in proximal arm segments; row of spine articulations commonly protruding ventrally.

\section{Etymology}

Genus named in honour of my friend and colleague Andy Scott Gale for his continuous and encouraging support, the delightfully shared delicacies and wines, and for providing some of the most important 
samples used in the present study; from ophis, Greek for "snake", a commonly used prefix for ophiuroid names, gender masculine.

\section{Remarks}

Ophiacanthid fossil occurrences based exclusively on dissociated LAPs were almost invariably assigned tentatively to the genus Ophiacantha using open nomenclature (Thuy et al. 2012, plus references therein) following Hess's (1962) suggestion to use the type taxon of a family in case of uncertain generic placement. Although assignment of the present species to the genus Ophiacantha is shown here to be untenable (see above), some of the other species, including Ophiacantha? constricta and Ophiacantha? danica, display LAP morphologies which are very close to that of Ophiacantha in its proper sense. These similarities pertain mainly to the shape and position of the spine articulations and the shape of the ridge on the inner side of the LAPs. In fact, the relatively short, oblique central part with the strongly widened, triangular dorsal part displaying a near-vertical distal edge and pointed dorsal and ventroproximal tips observed in the fossil LAP types in question can be considered as a variant of the ridge observed in Ophiacantha bidentata and similar extant congeners. In the latter, the ridge is composed of a long main, oblique, straight to slightly bent part displaying a generally relatively long ventrally pointing extension. In some cases, the main part and its ventrally pointing extension are fused into a large, neartriangular knob, which then looks very similar to the ridge observed in the fossil LAP types in question, except that in the latter there is a kink between the non-widened part of the ridge and the large triangular dorsal part.

In spite of the striking similarities, in particular with respect to the shape of the ridge, the fossil LAPs in question differ from the LAPs of Ophiacantha in displaying several spurs on the inner distal and, to a lesser extent, the outer proximal edge. In combination with the above-mentioned kink between the narrow central part of the ridge and its strongly widened, triangular part, this difference warrants separation at the generic level. Ophiogaleus gen. nov. is thus introduced here to accommodate the fossil LAPs in question. It must be stressed, however, that the striking similarities in LAP morphology strongly suggest that Ophiogaleus gen. nov. and Ophiacantha are phylogenetically very close.

Ophiogaleus sp. nov. innom. 1

Fig. 19: 10-12

\section{Material examined}

NHMW 2012/0137/0017, NHMW 2012/0137/0018, NHMW 2012/0137/0019 and NHMW 2012/0137/0020 (12 dissociated LAPs) from the late Sinemurian to early Pliensbachian of the Glasenbach Gorge, Austria.

\section{Description}

Relatively large, dissociated proximal to median, fragmentary LAPs; originally much higher than wide; dorsal edge not preserved; well-developed constriction; distal edge convex; proximal edge irregularly undulose; at least one large, moderately well-defined, prominent and slightly protruding, oval spur in the ventral half of the proximal edge, composed of more densely meshed stereom; outer surface with moderately finely meshed stereom, replaced by more finely meshed stereom in a relatively broad band paralleling proximal edge of LAP; trabecular intersections of outer surface stereom not thickened or developed into granules. At least six large, ear-shaped spine articulations freestanding on strongly elevated distal portion of LAP; dorsal and ventral lobes of spine articulations merged into continuous, conspicuously oblique volute; spine articulations proximally sharply bordered by well-defined but weakly prominent, near-straight ridge; very weak dorsalward increase in size of spine articulations and 
of gaps separating them; relatively narrow gap between spine articulations and distal edge of LAP; row of spine articulations originally most probably slightly protruding ventralwards.

Inner side of LAPs with large, sharply defined and prominent ridge; ventral part long, relatively narrow, strongly bent, ventral tip slightly pointed, sharply separated from ventral portion of LAP; dorsal part of ridge fragmentary in all available LAPs, slightly widened, small, vertically elongate, exact outline not unambiguously determinable; inner side of distal edge of LAP with one to two small, moderately well to poorly defined, horizontally elongate and slightly prominent spurs; inner side of tentacle notch relatively large, well defined laterally. No perforations or furrow discernible.

\section{Remarks}

The limited amount of material available and its fragmentary condition make a sound systematic assessment difficult. While assignment to the Ophiacanthidae is unquestionable on account of the spine articulation structure and the morphology of the inner side, affinities within this family are more problematic. Greatest similarities are shared with the LAPs of Ophiogaleus gen. nov. on account of the number, position and shape of the spine articulations and the number and position of spurs on the outer proximal and inner distal edges. The shape of the ridge on the inner side, however, is rather atypical for Ophiogaleus gen. nov. with respect to the narrow dorsal part of the ridge. In the light of the similarly atypical ridge in Ophiogaleus dorecki (Hess, 1962) comb. nov. (see below), known from more complete material, assignment to Ophiogaleus gen. nov. seems justified after all, especially considering the possibility that the above-described specimens and the slightly younger $O$. dorecki are two stratigraphically closely spaced representatives of the same lineage. Within Ophiogaleus gen. nov., the LAPs described above are unique in displaying oblique spine articulations. The fragmentary nature of the record, however, precludes a formal description of this species in the present study.

Ophiogaleus dorecki (Hess, 1962) comb. nov.

Fig. 20: 1-2

p.p. Ophiacantha? dorecki Hess, 1962: 622, figs 17, 19 (fig. 18 is a different species, probably not even an ophiacanthid).

non Ophiacantha? cf. dorecki - Kutscher 1996: 18, pl. 4, fig. 5 (probably an ophiomycetid close to extant Ophiohelus Lyman, 1880).

\section{Diagnosis}

Species of Ophiogaleus gen. nov. with relatively large LAPs displaying up to eleven spine articulations on the strongly elevated, yet proximally not sharply bordered, distal portion; no spurs discernible on outer proximal edge; up to three small, well-defined, strongly prominent spurs on inner distal edge of the LAP; ridge on the inner side with relatively narrow but vertically extremely elongate dorsal part.

\section{Material examined}

NHMB M1214, NHMB M1215 and 35 dissociated LAPs from the late Pliensbachian of Seewen, Switzerland, the type material of Hess (1962).

\section{Description}

Large LAPs; proximal ones more than twice higher than wide; distal ones nearly as high as wide; dorsal edge slightly concave as a result of a moderately well-developed constriction; distal edge convex; proximal edge irregularly undulose, no spurs discernible; outer surface with moderately finely meshed stereom, replaced by more finely meshed stereom in very narrow band paralleling proximal edge of LAP. Eleven (proximal LAPs) to seven (distal LAPs) large, ear-shaped spine articulations freestanding 


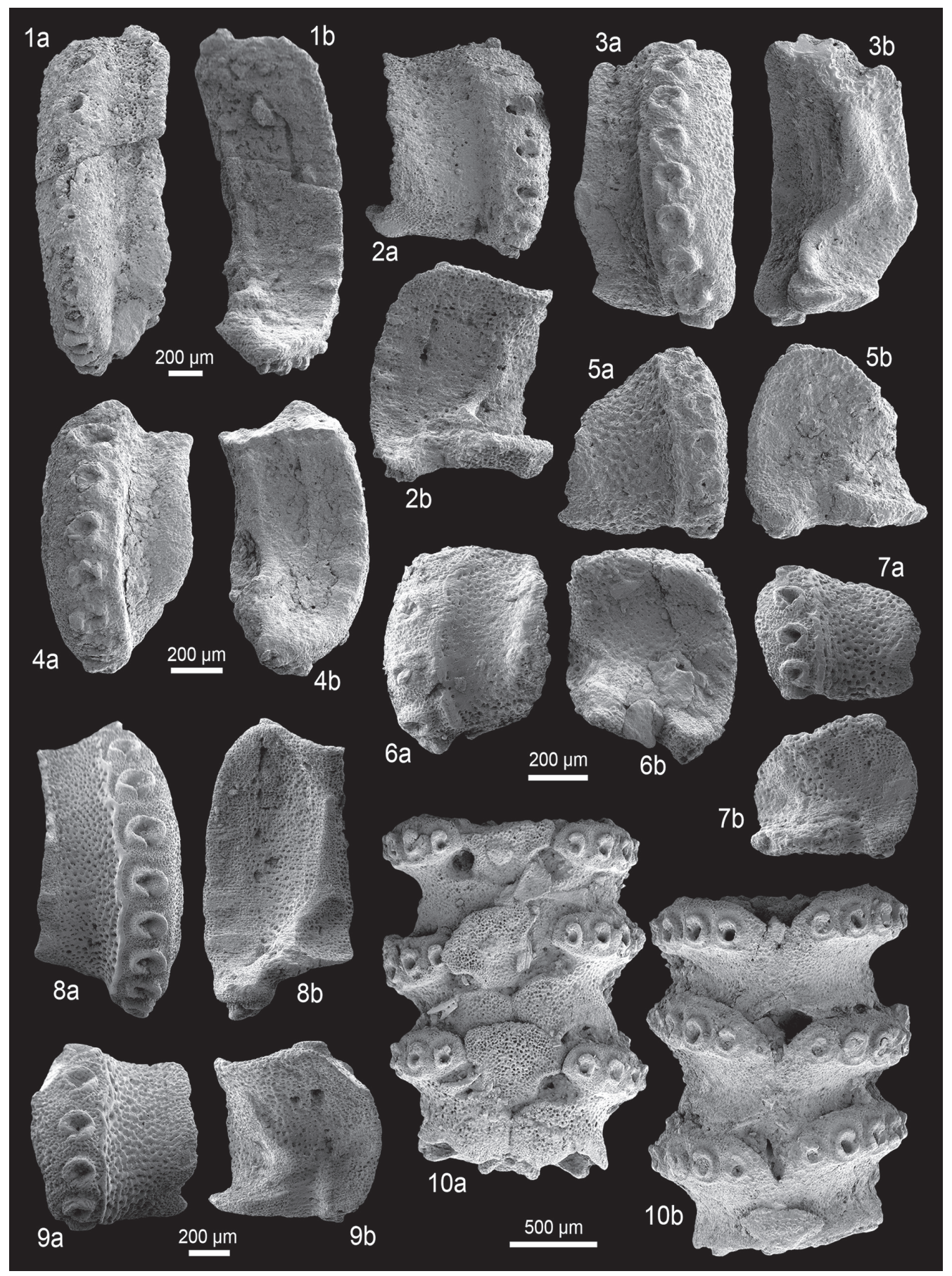

Fig. 20. Fossil lateral arm plates (LAPs) of ophiacanthid brittle stars in external (a) and internal (b) views and articulated arm fragment. 1-2. Ophiogaleus dorecki (Hess, 1962) comb. nov. from the late Pliensbachian (Early Jurassic) of Seewen, Switzerland. 1. NHMB M11214, proximal LAP. 2. NHMB M11215, distal LAP. 3-5. Ophiogaleus stans sp. nov. from the early Bathonian (Middle Jurassic) of La Pouza, France. 3. GZG.INV.78615 (holotype), proximal LAP. 4. GZG.INV.78616 (paratype), median LAP. 5. GZG.INV.78617 (paratype), distal LAP. 6-7. Ophiogaleus sp. nov. innom 2 from the Callovian (Middle Jurassic) of Jumara, India. 6. GZG.INV.78619, proximal LAP. 7. GZG.INV.78620, distal LAP. 8-10. Ophiogaleus constrictus (Hess, 1966) comb. nov. from the late Oxfordian (Late Jurassic) of Savigna, France. 8. GZG.INV.78624, proximal LAP. 9. GZG.INV.78625, distal LAP. 10. GZG.INV.78626, proximal arm fragment in ventral (a) and dorsal (b) views. One common scale bar per species except for 10. 
on strongly elevated distal portion of LAP; dorsal and ventral lobes of spine articulations merged into continuous volute; spine articulations not sharply bordered proximally; relatively narrow gap between spine articulations and distal edge of LAP; moderate (proximal LAPs) to weak (median and distal LAPs) dorsalward increase in size of spine articulations and of gaps separating them; row of spine articulations strongly (proximal LAPs) to weakly (distal ones) protruding ventralwards. Tentacle notch invisible in external view.

Inner side of LAPs with large, conspicuous, sharply defined, prominent ridge; short oblique central part of ridge; dorsal part widened, strongly vertically elongate, nearly triangular, with pointed (in proximal LAPs extremely elongate) dorsal tip, ventro-proximal tip slightly pointed; ventral portion of central part of ridge very short, ventro-proximally pointing, sharply separated from ventral part of LAP; inner side of distal edge of LAP with two to three small, well-defined, strongly prominent spurs composed of slightly more densely meshed stereom; inner side of tentacle notch relatively small, poorly defined laterally; moderately shallow, dorsally well-defined vertical furrow with small, irregular perforations dorsally bordering tentacle notch.

\section{Remarks}

Hess (1962) described the new species Ophiacantha? dorecki on the basis of dissociated lateral arm plates from the Pliensbachian of Switzerland. A re-examination of the type material, however, has revealed that it actually includes two different LAP types, one similar to the holotype (see Hess 1962, fig. 17), the other resembling Hess's (1962) fig. 18, characterised by a slightly oblique row of closely spaced spine articulations widely separated from the distal edge of the LAP. The higher-level taxonomic affinities of the latter type are unclear. Some features point to the Ophiacanthidae but the sigmoidal fold, one of the key diagnostic features of the family, could not be unambiguously observed in the specimens at hand.

In contrast, the LAP type, including the holotype, unquestionably belongs to the Ophiacanthidae. Within this family, strongest affinities are shared with the LAPs of Ophiogaleus constrictus comb. nov. and $O$. danicus comb. nov., on account of the number, shape and position of the spine articulations and the number of spurs on the inner distal edge of the LAP. The shape of the ridge on the inner side of the type specimens of Hess (1962) is admittedly rather unusual for Ophiogaleus gen. nov., but nevertheless compatible with the LAP morphological diagnosis of the genus. Within this genus, the LAPs are unique in displaying up to eleven spine articulations, lacking a ridge sharply bordering the spine articulations proximally and in having a relatively narrow but vertically extremely elongate dorsal part of the ridge on the inner side.

The LAPs described and illustrated by Kutscher (1996) as Ophiacantha? cf. dorecki from the Toarcian/ Aalenian of Germany fundamentally differ from the type material of Hess (1962), in particular with respect to spine articulation morphology. The LAPs in question share greatest similarities with those of the extant ophiomycetid Ophiohelus.

\section{Occurrence}

Late Pliensbachian of Switzerland.

Ophiogaleus stans sp. nov. urn:1sid:zoobank.org:act:1B346B9F-A7E0-489B-B4DC-B87CCE351C95

Fig. 20: 3-5

\section{Diagnosis}

Species of Ophiogaleus gen. nov. with relatively small LAPs; dorsalmost spine articulation enlarged; row of spine articulations slightly oblique; ventral part of the ridge on the inner side strongly bent. 


\title{
Etymology
}

Name formed after stare, Latin for "staunch", in reference to the very few type specimens of the species having been isolated, against all odds, from amongst more than 100000 crinoid ossicles.

\section{Type material}

\author{
Holotype \\ GZG.INV.78615. \\ Paratypes \\ GZG.INV.78616 and GZG.INV.78617.
}

\section{Type locality and horizon}

La Pouza, France; Zigzag Zone, early Bathonian, Middle Jurassic.

\section{Additional material}

GZG.INV.78618 (3 dissociated LAPs).

\section{Description}

\section{Holotype}

GZG.INV.78615 is a dissociated, relatively small, proximal LAP; twice higher than wide; dorsal edge strongly concave as a result of a well-developed constriction; distal edge very weakly convex; proximal edge irregularly undulose, with large, moderately well-defined, prominent and strongly protruding, vertically elongate spur composed of more densely meshed stereom; outer surface with moderately coarsely meshed stereom, except for narrow band of finely meshed stereom paralleling proximal edge of LAP. Nine large, ear-shaped spine articulations freestanding in slightly oblique row on strongly elevated distal portion of LAP; dorsal and ventral lobes of spine articulations merged into continuous, round volute; spine articulations proximally sharply bordered by very weakly prominent, very narrow ridge becoming slightly undulose dorsalwards; large, dorsalwards increasing gap separating spine articulations and distal edge of LAP; spine articulations equi-distant and almost all of equal size; dorsalmost spine articulation much larger than remaining ones; row of spine articulations strongly protruding ventralwards. Ventral edge of LAP slightly convex; tentacle notch invisible in external view.

Inner side of LAP with large, conspicuous, sharply defined and strongly prominent ridge; ventral part of ridge narrow, strongly bent dorso-proximalwards; dorsal part of ridge very large, strongly widened, triangular, with pointed ventro-proximal angle and blunt dorsal tip; inner side of distal edge of LAP with medium-sized, moderately well-defined, round, weakly prominent spur composed of more densely meshed stereom; second smaller, less well-defined, almost indiscernible spur ventrally bordering large spur; inner side of tentacle notch very small. Shallow yet well-defined vertical furrow dorsally bordering centre of ventral ridge part; no perforations discernible in furrow.

\section{Paratype supplements and variation}

GZG.INV.78616 is a dissociated median LAP; ventro-proximal edge slightly fragmentary; slightly less than twice higher than wide; closely agreeing with holotype; distal edge convex; preserved portion of proximal edge slightly undulose, with very poorly defined, almost indiscernible, weakly prominent and non-protruding spur. Seven spine articulations similar to those observed on holotype, arranged in very slightly oblique row; gap separating spine articulations from distal edge narrower than in holotype, with very slight dorsalward increase in width; dorsalmost spine articulation much larger than remaining ones, as in holotype. 
Inner side of LAP with ridge similar to that observed in holotype but with slightly narrower dorsal part; inner side of distal edge of LAP with three poorly defined, weakly prominent spurs, one medium-sized central one bordered dorsally and ventrally by smaller ones.

GZG.INV.78617 is a dissociated distal LAP; dorso-proximal corner slightly fragmentary; slightly higher than wide; distal edge convex. Seven spine articulations similar to those of holotype freestanding in vertical row on strongly elevated distal portion of LAP; ridge proximally sharply bordering spine articulations slightly wider and more strongly prominent than in holotype; gap between spine articulations and distal edge of LAP narrow; all spine articulations including the dorsalmost of equal size; row of spine articulations only slightly protruding ventralwards. Ventral edge of LAP with small concave tentacle notch.

Inner side of LAP with poorly defined ridge; ventral part short, bent, prominent; dorsal part widened, slightly fragmentary but originally nearly triangular, less prominent; no spurs on inner side of distal edge of LAP; inner side of tentacle notch moderately large. No furrow or perforations discernible.

\section{Remarks}

The highly distinctive shape of the ridge in combination with the number, position and arrangement of the spine articulations and the number of spurs on the inner distal edge unambiguously place these LAPs in Ophiogaleus gen. nov. The LAPs in question differ markedly from other types assigned to this genus on account of the enlarged dorsalmost spine articulation, the slightly oblique row of spine articulations in proximal LAPs, the strongly bent ventral part of the ridge on the inner side, and the lack of spurs in the distal LAP. Therefore, in spite of the limited amount of material available and its slightly fragmentary nature, this LAP type is here formally described as a new species.

\section{Occurrence}

Early Bathonian of France.

Ophiogaleus sp. nov. innom. 2

Fig. 20: 6-7

\section{Material examined}

GZG.INV.78619, GZG.INV.78620, GZG.INV.78621 (20 dissociated LAPs) from sample 95, lower Chari Formation, Callovian of Jumara, India; GZG.INV.78622 (dissociated LAP) from sample 31, lower Chari Formation, Callovian, Jumara, India; GZG.INV.78623 (dissociated LAP) from sample 121, upper Chari Formation, Callovian of Jumara, India.

\section{Description}

GZG.INV.78619 is a dissociated, moderately large, proximal LAP; ventral edge fragmentary, originally probably 1.5 times higher than wide; dorsal edge nearly straight; distal edge convex; proximal edge irregularly undulose with three moderately large, poorly defined, round to vertically slightly elongate, prominent and weakly protruding spurs, two closely spaced ones in the middle of the proximal edge, and one in the dorsal half of the proximal edge; outer surface with moderately coarsely meshed stereom; trabeculae of outer surface stereom merging into very weakly developed vertical striation close to ventral edge of LAP. At least five large, ear-shaped spine articulations; ventral and dorsal lobes merged into continuous volute; very weak dorsalward increase in size of spine articulations and slightly stronger increase in size of gaps separating them; spine articulations proximally sharply bordered by slightly undulose, well-defined, prominent, relatively broad ridge; gap between spine articulations and distal edge of LAP narrow. 
Inner side of LAP with relatively small, well-defined, prominent, oblique ridge with widened, triangular ventral part and widened, vertically elongate, triangular dorsal part with dorsalwards and ventroproximally pointing angles; inner side of distal edge of LAP with at least two relatively large, poorly defined, round, weakly prominent spurs composed of more densely meshed stereom; inner side of tentacle notch relatively small, deeply incised, partly obscured by sediment; laterally well defined. No perforations or furrow discernible.

GZG.INV.78620 is a dissociated distal LAP; slightly wider than high; well in agreement with abovedescribed LAP; dorsal edge weakly concave as a result of a constriction; single, large, poorly defined, round, prominent and weakly protruding spur on proximal edge. Five spine articulations similar to those observed in other specimen. Ventral edge slightly convex, with very small, gently concave tentacle notch.

Inner side of LAP with relatively small, inconspicuous oblique ridge displaying strongly widened, triangular ventral part and slightly widened dorsal tip; single large, moderately well-defined, round, very weakly prominent spur composed of densely meshed stereom on inner side of distal edge of LAP.

\section{Remarks}

In spite of the rather poor preservation, these specimens are assignable to Ophiogaleus gen. nov. on account of the highly distinctive shape of the ridge on the inner side, the shape and position of the spine articulations and the presence of more than one spur on the outer proximal and inner distal edges, at least in proximal LAPs. Admittedly, the number of spine articulations is atypically low for Ophiogaleus gen. nov., although it appears likely that this is an artefact of the fragmentary condition of the proximal LAPs. There is a certain resemblance with the LAPs assigned herein to Ophiomitrella, especially on account of the conspicuous ridge proximally bordering the spine articulations. However, the shape of the ridge on the inner side of the LAPs differs fundamentally.

The low number of spine articulations and the poorly developed vertical striation near the ventral edge of the outer surface suggest that the above-described LAPs belong to a new species. In the absence of more complete and better-preserved material, however, the LAPs in question cannot be formally described.

Ophiogaleus constrictus (Hess, 1966) comb. nov.

Figs 20: 8-10; 21: 1

p.p. Ophiacantha? suprajurassica Hess, 1965: 1065, 1077, figs 12, 14, 43.

Ophiacantha? constricta Hess, 1966: 1031, 1054, figs 8, 11, 74-75, 78 [figs 76-77 show a different species which is here reinterpreted as Ophiocamax dorotheae sp. nov. (see below)].

non Ophiacantha? oder Ophiothrix? sp. - Hess 1960: 417, figs 39-40.

non Ophiacantha? cf. constricta - Hess \& Holenweg 1985: 164, fig. 17 [material re-described by Thuy \& Meyer (2013) as Hanshessia trochitophila Thuy \& Meyer, 2013].

non Ophiacantha? constricta - Kutscher 1987a: 61, pl. 3 figs 1-2 [material here redescribed as Ophiomalleus beneficarum gen. et sp. nov. (see below)].

\section{Diagnosis}

Species of Ophiogaleus gen. nov. with relatively small LAPs displaying moderately coarsely meshed stereom on outer surface; up to ten spine articulations on strongly elevated distal edge proximally sharply bordered by undulose ridge; three poorly defined spurs on outer proximal edge paralleled by up to four well-defined spurs on inner distal edge in proximal LAPs; single large, well-defined spur on outer proximal and inner distal edges in median to distal LAPs; ridge on inner side of LAPs with strongly widened dorsal part with conspicuously pointed dorsal and ventro-proximal angles. 


\section{Material examined}

GZG.INV.78624, GZG.INV.78625, GZG.INV.78626, GZG.INV.78627, GZG.INV.78628 (7 dissociated LAPs) from sample S1 of Gale (2011); GZG.INV.78629 (14 dissociated LAPs) from sample S2a of Gale (2011); GZG.INV.78630 (72 dissociated LAPs) from sample S2b of Gale (2011), and GZG.INV.78631 (4 articulated arm fragments) from sample S2b of Gale (2011), all from the upper Oxfordian Bifurcatus Zone of Savigna, France; 22 dissociated LAPs from the upper Oxfordian Bifurcatus Zone of Guldenthal, Switzerland, the original material of Hess (1966); 4 dissociated LAPs from the lower Oxfordian Renggeri Member of Chapois, France, the original material of Hess (1965a).

\section{Description}

Relatively small LAPs; at least twice higher than wide (proximal LAPs) to nearly as high as wide (distal LAPs); dorsal edge concave as a result of a well-developed constriction; distal edge convex; proximal edge concave in proximal LAPs, with three to four poorly defined, weakly prominent and very slightly protruding spurs, ventral one of which largest and best defined; proximal edge in median and distal LAPs irregularly undulose, with single large, moderately well-defined, prominent and strongly protruding spur probably corresponding to large, ventralmost spur in proximal LAPs; outer surface with moderately coarsely meshed stereom replaced by finely meshed stereom in very narrow band paralleling proximal edge of LAP; trabeculae of moderately coarsely meshed stereom proximally bordering spine articulations merged into very poorly developed vertical striation in a few LAPs; trabecular intersections slightly thickened into granules in ventral portion of distal LAPs. Ten (proximal LAPs) to six (distal ones) large, ear-shaped spine articulations freestanding on strongly elevated ridge; dorsal and ventral lobes of spine articulations merged into continuous volute; spine articulations proximally bordered by narrow, welldefined, undulose ridge; dorsalmost and ventralmost spine articulations slightly smaller than remaining, nearly equal-sized ones; gap separating spine articulations and distal edge very narrow in proximal LAPs, slightly wider and dorsally widening in median to distal LAPs; row of spine articulations strongly protruding ventralwards in proximal LAPs, slightly protruding in median ones and not protruding in distal ones. Ventral edge of LAPs nearly straight; tentacle opening generally invisible in external view. Inner side of LAP with very large, conspicuous, sharply defined, prominent ridge; relatively short, slender, oblique, straight central part of ridge, merged dorsally with very large, vertically elongate (in proximal to median LAPs), near-triangular dorsal part of ridge with concave edges and pointed dorsal and ventroproximal angles; central part of ridge merged ventrally with short, slender, ventro-proximally pointing part not merged with ventral portion of LAP; inner side of distal edge with three to four well-defined, weakly prominent, oval spurs generally with dorsalward increase in size and composed of more densely meshed stereom in proximal LAPs; single spur in median to distal LAPs similar to the ventralmost spur observed in proximal LAPs; inner side of tentacle notch relatively small, nearly vertical, moderately well defined laterally. Very shallow, narrow, moderately well-defined vertical furrow with small, irregularly spaced perforations dorsally bordering tentacle notch in proximal to median LAPs; no furrow in distal LAPs.

Articulated arm fragments: LAPs broadly in contact dorsally and ventrally in proximal to distal arm segments; dorsal arm plates relatively small, bell shaped, with slightly convex distal edge, pointed proximal angle with slightly concave edges; spine articulations meeting mid-radially forming continuous band at least in proximal segments, arm spines thus originally forming fan; ventral arm plates nearly T-shaped, weakly convex distal edge, deeply concave latero-proximal edges and obtuse proximal angle; proximal and latero-proximal edges of ventral arm plates slightly prominent; round, slightly swollen area of coarsely meshed stereom in centre of ventral arm plates; tentacle pores small, covered by single, spatulate, distally widening tentacle scale; arm spines slightly flattened, with coarsely reticulate stereom displaying small thorns, irregular longitudinal row of much larger thorns along both margins of the spines. 


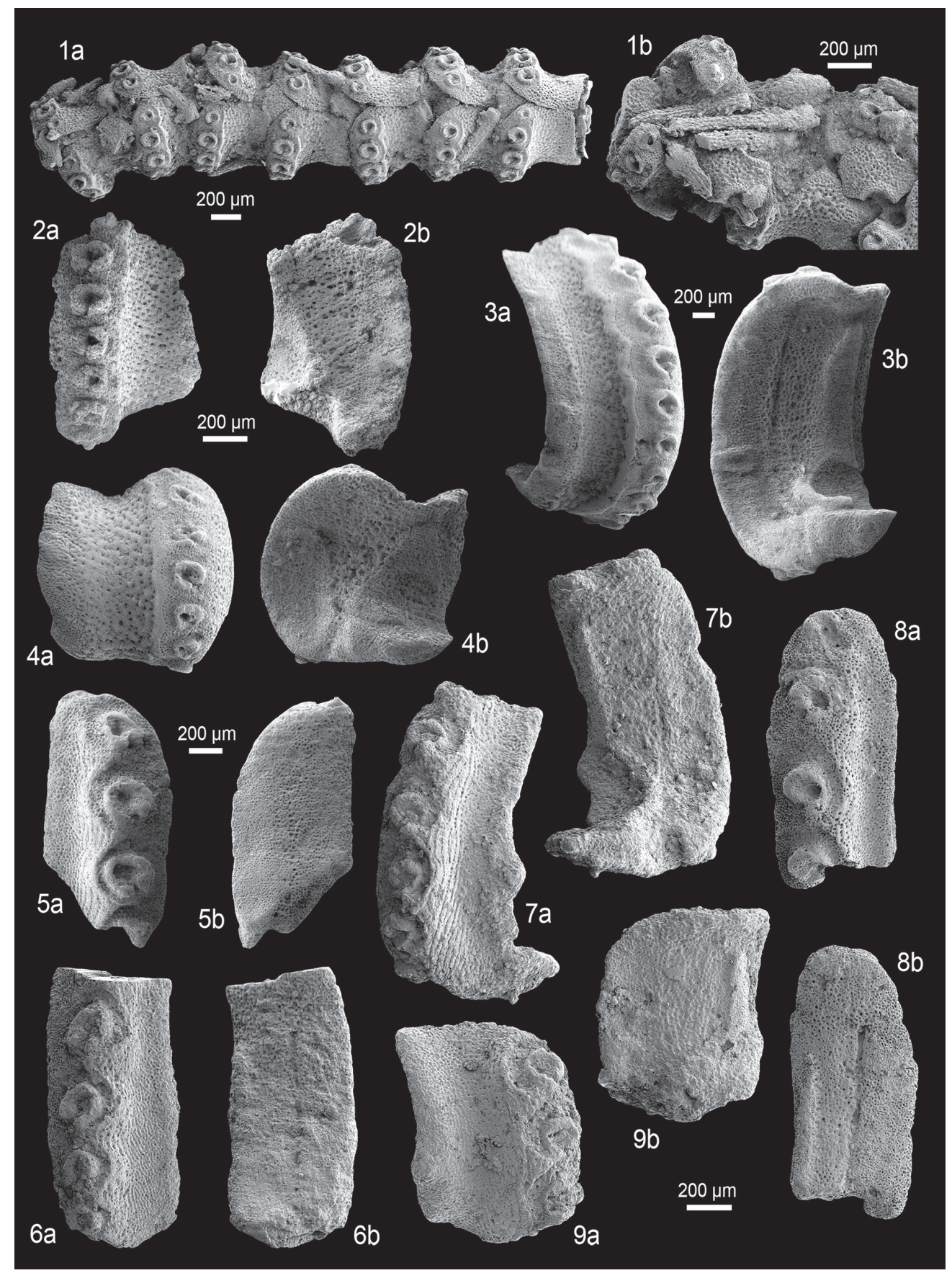

Fig. 21. Fossil lateral arm plates (LAPs) of ophiacanthid brittle stars in external (a) and internal (b) views and articulated arm fragment in ventral (a) and dorsal (b) views. 1. Ophiogaleus constrictus (Hess, 1966) comb. nov. from the late Oxfordian (Late Jurassic) of Savigna, France; GZG.INV.78627 distal arm fragment. 2. Ophiogaleus sp. from the early Kimmeridgian (Late Jurassic) of Geisingen, Germany; GZG.INV.78632, proximal LAP. 3-4. Ophiogaleus danicus (Rasmussen, 1952) comb. nov. from the early Maastrichtian (Late Cretaceous) of Rügen, Germany. 3. GZG.INV.78635, proximal LAP. 4. GZG. INV.78636, distal LAP. 5-6. Hanshessia sp. nov. innom. 1 from the late Sinemurian to early Pliensbachian (Early Jurassic) of the Glasenbach Gorge, Austria. 5. NHMW 2012/0137/0021, proximal LAP. 6. NHMW 2012/0137/0022, proximal LAP. 7-9. Hanshessia sp. nov. innom. 2 from the early Bathonian (Middle Jurassic) of La Pouza, France. 7. GZG.INV.78637, proximal LAP. 8. GZG.INV.78638, proximal LAP. 9. GZG.INV.78639, distal to median LAP. One common scale bar per species except for 1. 


\section{Remarks}

The concept of Ophiogaleus constrictus comb. nov. has repeatedly caused confusion in the past. This form was originally described by Hess (1966) as Ophiacantha? constricta when he noted that the type material from the Oxfordian of Switzerland and France previously described as Ophiacantha? suprajurassica Hess, 1965 included more than one type of LAP. Hess (1966) based the distinction on the higher number of spine articulations and the lack of a vertical striation on the outer surface in $O$. constrictus comb. nov. These are, indeed, valid differences, yet the concept of $O$. constrictus comb. nov. was still not sufficiently specific because Hess (1966) also included LAPs which are here reinterpreted as Ophiocamax dorotheae sp. nov. (see Hess 1960, figs 39-40; Hess 1966, figs 76-77). Following this confusion, Kutscher (1987a) described dissociated LAPs from the Callovian of Germany as Ophiacantha? constricta; these markedly differ from the holotype of the species but do have clear features in common with some of the LAPs erroneously included in that species by Hess (1966).

A re-examination of the type specimens, complemented by new, partially articulated, equivalent finds from the Oxfordian of France, has enabled a consistent reinterpretation of Ophiacantha? constricta. Thanks to Hess's (1966) careful choice of the holotype (a single well-preserved proximal LAP, rather than a less distinctive median LAP or a series of LAPs), the species in question is now unambiguously identifiable. It is chosen as the type species of Ophiogaleus gen. nov., an assumedly close relative of extant Ophiacantha (see above), since it is known from numerous well-preserved specimens, including articulated arm fragments, and most typically displays the distinctive features of the genus.

\section{Occurrence}

Early to Late Oxfordian of France and Switzerland.

\section{Ophiogaleus sp.}

Fig. 21: 2

\section{Material examined}

GZG.INV.78632 and GZG.INV.78633 (2 dissociated LAPs) from the lower Kimmeridgian Lacunosa Marls of Geisingen, Germany; GZG.INV.78634 (3 dissociated LAPs) from the upper Oxfordian Bimammatum Zone of the Plettenberg, Germany.

\section{Description}

Small, fragmentary proximal to distal LAPs; edges poorly preserved, outline and presence of spurs cannot be assessed; outer surface with moderately finely meshed stereom. Five (distal LAPs) to at least seven (proximal LAPs) large, ear-shaped spine articulations freestanding on strongly elevated distal portion of LAP; dorsal and ventral lobes merged into continuous volute; spine articulations proximally sharply delimited by very narrow, weakly prominent dorsally very slightly undulose ridge; gap between spine articulations and distal edge of LAP narrower than one spine articulation; very weak dorsalward increase in size of spine articulations; row of spine articulations strongly protruding ventralwards.

Inner side of LAPs with large, conspicuous, sharply defined, prominent ridge composed of narrow ventral part and strongly widened, vertically elongate, triangular dorsal part with pointed dorsal and ventro-proximal angles; very short ventro-proximalward extension of ventralpart of ridge; inner side of distal edge of LAP with up to three moderately large, weakly defined, non-prominent spurs composed of slightly more densely meshed stereom; inner side of tentacle notch relatively small. No perforations or furrow discernible. 


\section{Remarks}

This material unambiguously belongs to Ophiogaleus gen. nov. Its fragmentary nature, however, precludes a detailed identification at the specific level. Closest similarities are shared with the LAPs of Ophiogaleus constrictus comb. nov. and it is more than likely that the above-described material, indeed, belongs to that species. In the absence of more complete specimens, however, this assignment remains elusive.

Ophiogaleus danicus (Rasmussen, 1952) comb. nov.

Fig. 21: 3-4

Ophiacantha? danica Rasmussen, 1952: 52, fig. 6.

Ophiacantha? danica - Jagt 1999a: 199, pl. 1 fig. 8. - Kutscher \& Jagt 2000: 61, pl. 24 figs 7-9, pl. 25 figs 1-2 [non pl. 24 fig. 10, which most probably is an LAP of Ophiotreta striata (see above)]. - Jagt \& Odin 2001: 416, pl. 1 fig. 1.

p.p. Ophiacantha? danica - Jagt 2000: 10, pl. 2 fig. 10 [non pl. 2 figs 5-7, Ophiomitrella sp. nov. (see below)]

\section{Diagnosis}

Species of Ophiogaleus gen. nov. with very large LAPs displaying coarsely meshed stereom on the outer surface with strongly thickened trabecular intersections, especially in ventral part of the LAPs developed into large granules; up to four variably developed spurs on outer proximal and inner distal edges of proximal to distal LAPs; up to eleven spine articulations sharply separated proximally by thick, well-defined, prominent ridge.

\section{Material examined}

GZG.INV.78635, GZG.INV.78636, and 328 dissociated LAPs from the early Maastrichtian of Rügen, the original material of Kutscher \& Jagt (2000); 16 dissociated LAPs from the early Maastrichtian of Lägerdorf-Kronsmoor, Germany.

\section{Description}

Very large LAPs; more than twice wider than high (proximal LAPs) to slightly wider than high (distal ones); dorsal edge strongly concave as a result of a well-developed constriction; distal edge convex; proximal edge irregularly convex, with one to four moderately well-defined, prominent, rarely protruding, oval spurs of variable size and position in proximal to distal LAPs; outer surface with coarsely meshed stereom, trabecular intersections strongly thickened, in ventral part of LAP developed into large, conspicuous granules; more finely meshed stereom in narrow band paralleling proximal edge of LAP. Eleven (proximal LAPs) to five (distal ones) large, ear-shaped spine articulations freestanding on strongly elevated distal portion of LAP; dorsal and ventral lobes of spine articulations merged into continuous volute; spine articulations proximally sharply bordered by thick, well-defined, prominent, slightly knobby and wavy ridge; gap between spine articulations and distal edge of LAP slightly narrower than one spine articulation; very weak dorsalward increase in size of spine articulations and of gaps separating them; row of spine articulations slightly protruding in proximal to median LAPs. Ventral edge of LAP slightly concave; tentacle notch not visible in external view.

Inner side of LAPs with large, broad, conspicuous, sharply defined and prominent ridge; ventral part of ridge relatively short, moderately wide, strongly bent; dorsal part of ridge conspicuously large, triangular, vertically elongate, dorsal and ventro-proximal tips pointed, proximal and ventral edges slightly concave, distal edge slightly convex; inner side of distal edge of LAP with one to four variably well-defined, slightly prominent, non-protruding, oval spurs of variable size and position; inner side of 
tentacle notch very small, slightly oblique, poorly defined. Well- to moderately well-defined, narrow, vertical furrow with very small perforations dorsally bordering tentacle notch in proximal and median LAPs.

\section{Remarks}

Ophiogaleus danicus comb. nov. was originally described by Rasmussen (1952) from the late Maastrichtian of Denmark. The brief description and single illustration was beautifully complemented by Kutscher \& Jagt (2000) on the basis of new material from the Maastrichtian of Germany and Denmark. Those authors retained the species in the genus Ophiacantha, albeit in open nomenclature, although they speculated about close similarities with the LAPs of extant Ophiomitra Lyman, 1869. In that genus, however, the shape of the ridge on the inner side differs fundamentally. In contrast, striking similarities are shared with the LAPs of Ophiogaleus constrictus comb. nov. from the Oxfordian of France and Switzerland (see above), in particular with regard to the shape of the ridge, the number, shape and position of the spine articulations, and the outer surface ornament. Thus, the present species is here transferred to Ophiogaleus gen. nov., which is in line with Rasmussen's (1952) initial tentative assignment to Ophiacantha considering that both genera share highly similar LAP morphologies and thus most probably are also phylogenetically close.

One of the specimens illustrated by Kutscher \& Jagt (2000, pl. 24, fig. 10) does not belong to Ophiogaleus danicus comb. nov. but most probably to Ophiotreta striata comb. nov. (see above). The specimens illustrated by Jagt (2000, pl. 2, figs 5-7) almost all belong to a yet undescribed species of Ophiomitrella (see below).

\section{Occurrence}

Late Campanian of Belgium and France, Maastrichtian of Germany and Denmark.

Genus Hanshessia Thuy \& Meyer, 2013

\section{Type species}

Hanshessia trochitophila Thuy \& Meyer, 2013, by original designation.

\section{Diagnosis}

Ophiacanthid with relatively large LAPs, proximal ones generally at least twice higher than wide; dorsal edge of proximal LAPs round, tongue shaped; ventral part of LAPs protruding ventro-proximalwards; numerous very large, ear-shaped spine articulations on strongly elevated distal portion of LAP; ridge on inner side composed of strongly bent ventral part and straight, near-vertical dorsal part closely paralleling proximal edge of LAP; tip of dorsal ridge part widely separated from dorsal edge of LAP; kink between dorsal and ventral parts of ridge devoid of ventro-proximalwards protruding angle.

\section{Remarks}

Hanshessia is an extinct genus described on the basis of articulated specimens from the Bajocian of Switzerland (Thuy \& Meyer 2013) and thus one of the very few fossil ophiacanthid genera for which detailed data on general skeletal morphology are available. The LAPs of the type specimens are well preserved and well known, at least as far as external structures are concerned. The morphology of the inner side, in contrast, could not be directly assessed on the basis of the type specimens. Upon careful re-examination of the latter, however, a few dissociated vertebrae exposing the vertical groove on the lateral side could be observed, allowing for conclusions on the shape of the ridge on the inner side of the LAPs. In fact, the lateral groove on the vertebrae and the ridge on the inner side of the 
LAPs serve as articulation interface between both skeletal components thus sharing complementary morphologies.

Judging from observations on the type specimens, the ridge on the inner side of Hanshessia trochitophila is composed of an oblique, strongly bent ventral part and a slightly longer, straight, near-vertical part sharply interrupted well below the dorsal edge of the LAP and separated from the ventral part by an angular, but not ventro-proximalwards extended, kink. In combination with the numerous, very large spine articulations, the tongue-shaped dorsal edge of the LAPs, and the ventro-proximally protruding ventral portion of the LAPs, the above-described ridge shape is highly distinctive. Closest similarities in LAP morphology are shared with the Ophiotreta-Ophiopristis group. In the latter, however, the ridge on the inner side, although superficially almost identical, generally displays a straight ventral part, a kink with a conspicuous ventro-proximally pointing angle, and a dorsal part which almost reaches the dorsal edge of the LAP. In addition, the LAPs of species of Ophiotreta and Ophiopristis are characterised by a strongly prominent, conspicuous distalmost lamella proximally bordering the spine articulations and commonly displaying a connecting ridge with the ventral lobe of the latter.

Hanshessia sp. nov. innom. 1

Fig. 21: 5-6

\section{Material examined}

NHMW 2012/0137/0021, NHMW 2012/0137/0022 and NHMW 2012/0137/0023 (4 dissociated LAPs) from the late Sinemurian to early Pliensbachian of the Glasenbach Gorge, Austria.

\section{Description}

Very large, dissociated proximal LAPs, with ventral portion missing; originally more than twice higher than wide; dorsal edge convex, tongue shaped; distal edge convex; preserved portion of poximal edge nearly straight to slightly concave, devoid of spurs; outer surface with fine, well-developed, slightly undulose, vertical striation confined to a narrow band close to spine articulations and composed of fine lamellae, replaced on most of outer surface by finely meshed stereom. At least four very large, earshaped spine articulations in shallow notches on strongly elevated distal portion of LAP; notches of spine articulations deeply incising vertical striation; ventral and dorsal lobes of spine articulations merged into continuous, near-circular volute; spine articulations proximally bordered by moderately well-defined, weakly prominent, strongly undulose ridge; dorsalward increase in size of spine articulations and of gaps separating them, but dorsalmost spine articulation smaller than second dorsalmost; gap between spine articulations and distal edge of LAP relatively narrow.

Inner side of LAPs with conspicuous, sharply defined, prominent, very narrow dorsal part of ridge, paralleling proximal edge of LAP, not reaching dorsal edge of LAP but abruptly interrupted well below the latter; angular kink at ventral tip of dorsal part of ridge, devoid of ventro-proximally pointing angle; ventral part of ridge not preserved; inner side of distal edge of LAP devoid of spurs; tentacle notch not preserved. Well-defined, narrow, vertical furrow with scattered, very small perforations.

\section{Remarks}

Despite its fragmentary nature, the above-described material is unambiguously assignable to Hanshessia on account of the shape of the ridge, the shape and arrangement of the spine articulations and the shape of the dorsal LAP edge. The present specimens differ from the other types of LAPs assigned to Hanshessia in displaying a fine vertical striation and lacking spurs on the outer proximal and inner distal edges. Unfortunately, the incompleteness of the material available precludes a formal description. 
Hanshessia sp. nov. innom. 2

Fig. 21: 7-9

\section{Material examined}

GZG.INV.78637, GZG.INV.78638, GZG.INV.78639 and GZG.INV.78640 (2 dissociated LAPs) from the lower Bathonian Zigzag Zone of La Pouza, France.

\section{Description}

GZG.INV.78637 is a dissociated, moderately large, proximal LAP; dorsal edge fragmentary; LAP originally more than twice higher than wide; ventral portion of LAP protruding ventro-proximalwards; distal edge convex; proximal edge irregularly undulose, with large, poorly defined, prominent and very strongly protruding spur; outer surface with well-developed, fine, slightly undulose vertical striation near spine articulations, composed by fine lamellae and replaced by finely meshed stereom on the proximal half of the outer surface. At least six very large, ear-shaped spine articulations in shallow notches on the strongly elevated distal portion of the LAP; notches of spine articulations deeply incising vertical striation; ventral and dorsal lobes of spine articulations merged into continuous, near-circular volute; spine articulations proximally bordered by very poorly defined, weakly prominent, strongly undulose ridge; narrow gap between spine articulations and distal edge of LAP; weak dorsalward increase in size of spine articulations and gaps separating them. Ventral edge convex, with small, concave tentacle notch. Inner side of LAP with large, conspicuous, sharply defined, prominent ridge composed of strongly bent ventral part not merged with thickened ventral portion of LAP, and straight, near-vertical dorsal part closely paralleling proximal edge of LAP and abruptly interrupted well below dorsal edge of LAP; dorsal and ventral parts of ridge separated by angular kink devoid of conspicuous ventro-proximally protruding angle; inner side of distal edge of LAP with large, very weakly defined, almost indiscernible depression; inner side of tentacle notch small, moderately well defined laterally. Narrow, poorly defined, shallow vertical furrow with minute irragularly spaced perforations dorsally bordering tentacle notch.

GZG.INV.78638 is a dissociated, moderately large, proximal LAP fragment; ventral half missing; dorsal edge completely preserved, convex, tongue shaped; preserved portion of proximal edge devoid of spur; outer surface almost entirely with finely meshed stereom, only few weakly developed vertical lamellae between notches of spine articulations. Four very large spine articulations preserved, similar to those observed on above-described specimen; dorsalmost spine articulation slightly smaller than remaining three.

Inner side of LAP with narrow, sharply defined, prominent dorsal part of ridge abruptly interrupted well below dorsal edge of LAP. Well-defined, moderately wide and deep vertical furrow halfway between dorsal part of ridge and distal edge of LAP.

GZG.INV.78639 is a dissociated, small, distal LAP; ventral portion of LAP missing; LAP originally at least 1.5 times higher than wide; dorsal edge slightly convex; proximal edge with large, moderately well-defined, prominent and strongly protruding spur; outer surface almost entirely with finely meshed stereom in dorsal half of preserved LAP portion, and with narrow area of well-defined, fine vertical striation. Three spine articulations similar to those of above-described specimens preserved.

Inner side of LAP with large ridge similar to that of above-described specimen but with half of ventral part missing; inner side of distal edge of LAP with moderately large, very poorly defined, almost indiscernible depression. No perforations or furrows discernible.

\section{Remarks}

The shape of the ridge on the inner side, the structure and arrangement of the spine articulations and the outline of the dorsal tip of the LAPs unambiguously place the present material in the genus Hanshessia. 
In contrast to the LAPs of the nearly coeval type species, H. trochitophila, however, these LAPs display a well-developed vertical striation on their outer surface. The large, conspicuously protruding spur on the proximal edge of the LAPs clearly differentiates them from the ones (unnamed) from the Pliensbachian of Austria assigned to the same genus. The material described above represents a new species but in the absence of more complete specimens it cannot be described formally.

\section{Hanshessia sp.}

Fig. 22: 1-2

\section{Material examined}

GZG.INV.78641, GZG.INV.78642 and GZG.INV.78643 (dissociated LAPs) from the Callovian lower Chari Formation of Jumara (sample 95), India; GZG.INV.78644 (dissociated LAP) from the Callovian of Bauer-Wehrland, Germany.

\section{Description}

Moderately large, dissociated proximal to median LAPs; dorsally and ventrally fragmentary; originally at least twice higher than wide; distal edge convex; preserved portion of proximal edge nearly straight to slightly concave, with small, round, poorly defined, prominent and slightly protruding spur; outer surface with finely meshed stereom, no vertical striation. At least five very large, ear-shaped spine articulations in very shallow notches of strongly elevated distal portion of LAP; dorsal and ventral lobes of spine articulations merged into continuous, round volute; spine articulations proximally bordered by poorly defined, weakly prominent, undulose ridge; relatively large gap separating spine articulations and distal edge of LAP; dorsalward increase in size of spine articulations and of gaps separating them. Inner side of LAPs largely obscured by sediment; large, sharply defined, prominent ridge composed of bent ventral part and straight, near-vertical dorsal part abruptly interrupted at some distance from dorsal edge of LAP; dorsal and ventral parts of ridge separated by kink devoid of conspicuous, ventroproximally pointing angle; inner side of distal edge of LAP with well-defined, round, slightly prominent spur composed of densely meshed stereom.

\section{Remarks}

Although, unfortunately, the limited available material is highly fragmentary, the specimens display sufficient morphological detail to allow them to be firmly assigned to Hanshessia on the basis of the shape of the ridge on the inner side and the shape and arrangement of the spine articulations. Similarities are closest with the LAPs of the type species, $H$. trochitophila. On the basis of the currently available material, however, it is impossible to decide whether the present specimens are conspecific with $H$. trochitophila or, instead, represent a new species.

Genus Alternacantha Thuy \& Meyer, 2013

\section{Type species}

Alternacantha occulta Thuy \& Meyer, 2013, by original designation.

\section{Diagnosis}

Ophiacanthid with large LAPs displaying a relatively large, ventro-proximalwards protruding ventral portion; small tentacle notch; large, ear-shaped spine articulations with the position of the dorsalmost spine articulation alternating between close to the remaining ones and widely separated from the latter. 


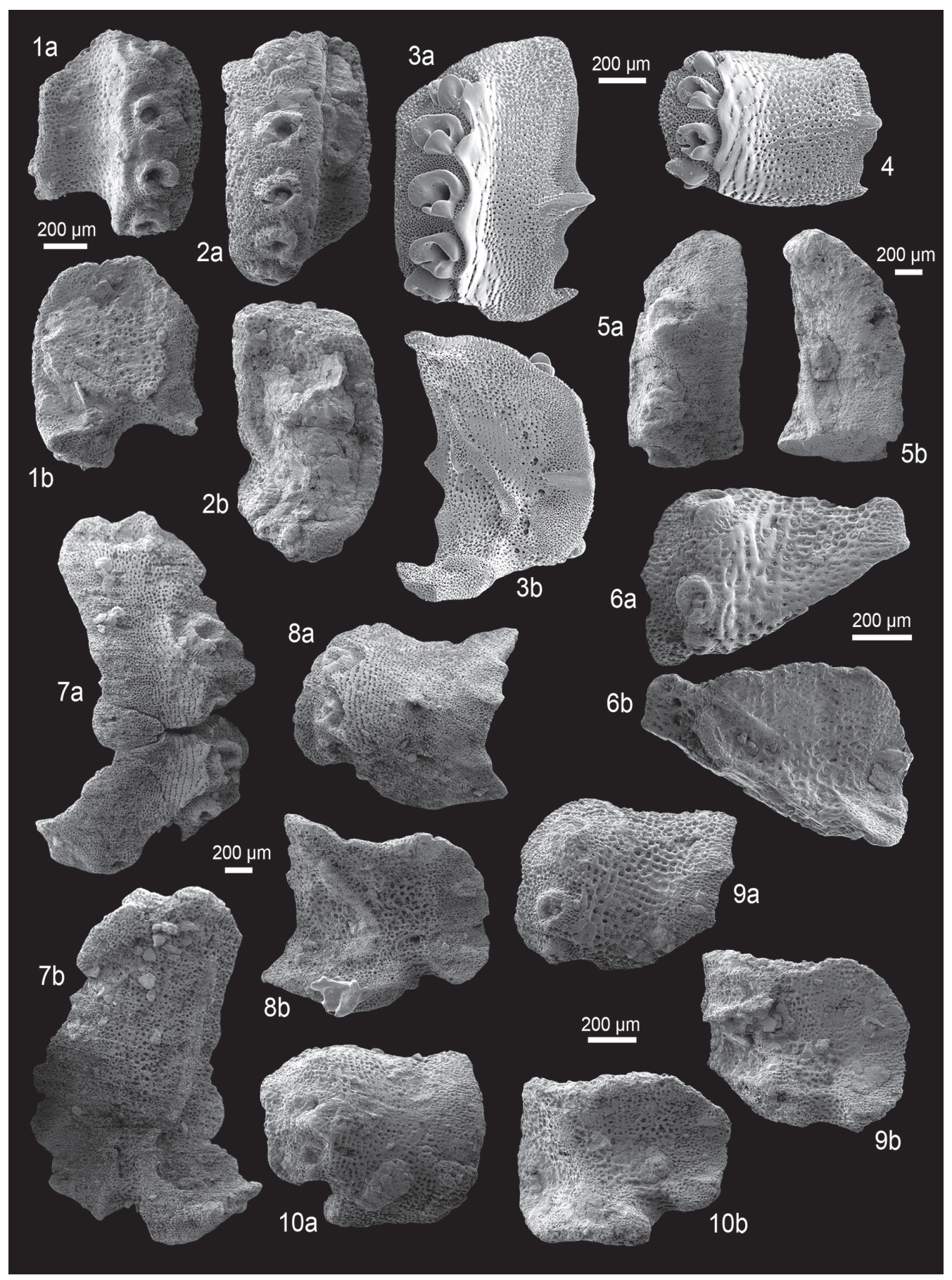

Fig. 22. Lateral arm plates (LAPs) of fossil and Recent ophiacanthid brittle stars in external (a) and internal (b) views. 1-2. Hanshessia sp. from the Callovian (Middle Jurassic) of Jumara, India. 1. GZG. INV.78641, proximal to median LAP. 2. GZG.INV.78642, proximal LAP. 3-4. Ophiocopa spatula Lyman, 1883, Recent. 3. Proximal LAP. 4. Distal LAP. 5. Alternacantha? sp. from the late Pliensbachian (Early Jurassic) of Amellago, Morocco; GZG.INV.78645, proximal LAP. 6. Alternacantha sp. nov. innom. 1 from the middle Toarcian (Early Jurassic) of Le Clapier, France; GZG.INV.78647, proximal to median LAP. 7-8. Alternacantha occulta Thuy \& Meyer, 2013, from the early Bajocian (Middle Jurassic) of Longwy, France. 7. GZG.INV.78648, proximal LAP. 8. GZG.INV.78649, distal LAP. 9-10. Alternacantha sp. nov. innom. 2 from the Callovian (Middle Jurassic) of Jumara, India. 9. GZG.INV.78652, proximal to median LAP. 10. GZG.INV.78653, median LAP. One common scale bar per species. 


\section{Remarks}

In terms of LAP morphology, Alternacantha is probably among the most distinctive and unambiguously identifiable ophiacanthids. In fact, the alternating position of the dorsalmost spine articulation, varying from close to the remaining spine articulations to widely separated from the latter, is a feature not found in any other LAP type. Since Alternacantha is known from well-preserved, articulated specimens (Thuy \& Meyer 2013), its phylogenetic position is well understood. Together with its extinct sister taxon Dermocoma, it holds a basal position within the large-pored ophiacanthids displaying well-developed disc plates rather than translucent scales obscured by skin.

Indeed, the close phylogenetic relationship with Dermocoma is reflected by LAP morphology. Both genera share ear-shaped spine articulations sunken in shallow notches of the gently elevated distal edge, a strongly ventro-proximally protruding ventral portion of the LAPs, strongly protruding spurs on the outer proximal edge, and a relatively simple ridge on the inner side devoid of sharp kinks or an exceedingly widened dorsal part. While proximal LAPs of the two genera can be readily differentiated, median and, in particular, distal LAPs can be so closely similar that distinction is very difficult, if possible at all. Thus, it is crucial for records based exclusively on dissociated LAPs to focus on well-preserved proximal LAPs in these genera. It should be stressed that it is strongly advisable in general to choose adult proximal LAPs as holotypes of new ophiuroid species known solely from dissociated LAPs, as clearly stressed by Thuy \& Stöhr (2011). Unfortunately, the holotype of Ophiacantha? suprajurassica Hess, 1965 is a median LAP from strata which have yielded both Dermocoma and Alternacantha. In view of the near-identical morphologies of median and distal LAPs in these two genera, the holotype in question cannot be unambiguously assigned. Ophiacantha? suprajurassica should therefore be considered as a nomen dubium, even though non-type specimens assigned to Ophiacantha? suprajurassica by Hess (1965a, 1966) can be assigned beyond doubt.

The closest extant relative of Alternacantha is Ophiocopa Lyman, 1883, which is sister to the clade formed by Alternacantha and Dermocoma. Again, the close phylogenetic ties are reflected by LAP morphology. In fact, the LAPs of extant Ophiocopa spatula Lyman, 1883 (Fig. 22: 3-4) closely resemble those of the two fossil genera, in particular on account of the ventro-proximalwards protruding ventral portion of the LAP, the shape, number and position of the spine articulations, the outer surface ornament and the conspicuous, strongly protruding spur on the outer proximal edge. Differences pertain mainly to the shape of the ridge on the inner side of the LAPs, which in Ophiocopa is composed of a slightly bent, oblique dorsal part with a triangular tip, widely separated from a short knob-like part on the ventral portion of the inner side.

All currently known species of Alternacantha share strongly similar, near-identical LAP morphologies, making a distinction on the basis of dissociated LAPs a major challenge. Similarly indistinguishable LAP morphologies have been reported from closely related extant taxa (Thuy \& Stöhr 2011). Fortunately, most species of Alternacantha are known from articulated arm fragments, in addition to the dissociated LAPs, providing additional features for species-level distinction.

Alternacantha? sp.

Fig. 22: 5

\section{Material examined}

GZG.INV.78645, GZG.INV.78646 (2 dissociated LAPs) from the late Pliensbachian of Amellago, Morocco. 


\section{Description}

Dorsal tips of moderately large, dissociated proximal LAPs; originally more than twice higher than wide; dorsal tip rounded, tongue shaped; distal edge convex; preserved part of proximal edge gently concave, devoid of spurs; outer surface with finely meshed stereom. Two large, widely separated, earshaped spine articulations in shallow notches of the moderately elevated distal portion of the LAP, not sharply bordered proximally by a ridge; remains of a third spine articulation suggests much smaller gap between the fragmentary third and the middle spine articulations than between the dorsalmost and the middle ones.

Inner side of LAP with dorsal tip of a narrow, sharply defined, prominent and originally oblique ridge. No perforations or furrow discernible.

\section{Remarks}

Assignment of the present record has posed problems due to its highly fragmentary condition. The unusually wide gap between the two dorsalmost spine articulations, the size and position of the latter, and the shape of the ridge on the inner side are strongly suggestive of Alternacantha, in particular $A$. occulta, because of the rounded, tongue-shaped dorsal tip of the LAPs. Superficial similarities are also shared with the LAPs of Hanshessia. Assignment to the latter genus is less likely, however, on account of the oblique, rather than near-vertical, dorsal part of the ridge on the inner side and the large gap between the two dorsalmost spine articulations. The present specimens are thus described here as a questionable record of Alternacantha, indeterminate at the specific level.

Alternacantha sp. nov. innom. 1

Fig. 22: 6

\section{Material examined}

GZG.INV.78647 (dissociated LAP) from the middle Toarcian of Le Clapier, France.

\section{Description}

The sole known specimen is a dissociated, moderately large, median LAP; ventro-proximal portion missing; LAP originally slightly wider than high; dorsal edge concave as a result of a well-developed constriction; distal edge convex; proximal edge largely missing; ventro-distal tip of LAP protruding, tongue shaped; outer surface with coarsely meshed stereom displaying thickened trabeculae merged into irregular vertical striation close to spine articulations. Three large, ear-shaped spine articulations freestanding in very shallow notches of the slightly elevated distal portion of the LAP; ventral and dorsal lobes composed of densely meshed stereom and merged into continuous, near-circular volute; spine articulations not sharply bordered proximally by a well-defined ridge; strong dorsalward increase in size of spine articulations; dorsalmost spine articulations widely separated from ventral two.

Inner side of LAP with dorsal tip of ridge preserved, narrow, sharply defined, prominent, oblique and not reaching dorsal edge of LAP; inner side of distal edge of LAP with two moderately large, well-defined, prominent, oval spurs composed of densely meshed stereom. No perforations or furrow discernible.

\section{Remarks}

In spite of its fragmentary condition, this LAP is unambiguously assignable to Alternacantha on account of the highly distinctive gap separating the dorsalmost spine articulation from the remaining ones. All other characters preserved are in agreement with this assignment. It is very unfortunate that the present specimen is the only one of this type available at the time. In fact, the outer surface ornament, the unusually low height/width ratio of the LAP (or, alternatively, the occurrence of an alternating position of the dorsalmost spine articulation even in elongated distal LAPs) and the spine articulations composed 
of densely rather than finely meshed stereom is a unique combination of characters. The specimen in question clearly belongs to a new species, but its formal description requires more complete material.

Alternacantha occulta Thuy \& Meyer, 2013

Fig. 22: 7-8

\section{Synonymy}

Reference is made to Thuy \& Meyer (2013) for a complete synonymy of the species.

\section{Diagnosis}

[complementary to that provided by Thuy \& Meyer (2013)]

Species of Alternacantha with large LAPs displaying a pointed to tongue-shaped, relatively narrow dorsal edge; outer surface with a well-developed vertical striation; up to four moderately well-developed spurs on the outer proximal and inner distal edges; up to five spine articulations; distal edge of ventral arm plates evenly convex; distal edge of dorsal arm plates parabolic.

\section{Material studied}

GZG.INV.78648, GZG.INV.78649 and GZG.INV.78650 (48 dissociated LAPs) from the early Bajocian of Longwy, France; GZG.INV.78651 (23 dissociated LAPs) from the early Bajocian of Cirey-lès-Nolay, France.

\section{Description}

Large, dissociated LAPs; more than twice wider than high (proximal LAPs) to 1.5 times wider than high (distal LAPs); dorsal edge convex, pointed to round and tongue like in proximal LAPs, concave as a result of a well-developed constriction in median to distal LAPs; distal edge convex; ventral quarter to fifth of LAP strongly protruding ventro-proximalwards; ventro-distal tip of LAP slightly protruding ventralwards, tongue shaped; proximal edge concave with up to four, medium-sized to large, moderately well-developed, prominent, horizontally elongate, pointedly to bluntly protruding spurs of variable position; outer surface with well-developed, fine, regular vertical striation composed of narrow, slightly overlapping lamellae; striation replaced by finely meshed stereom in distal half of outer surface in all LAPs and additionally in dorsal fifth of proximal LAPs. Five (proximal LAPs) to three (distal LAPs) large to very large, ear-shaped spine articulations in moderately shallow notches of elevated distal portion of LAP; dorsal and ventral lobes of spine articulations merged into continuous lobe, with small, very shallow notch at proximal point of contact; spine articulations sharply bordered by edge of notches rather than a well-defined ridge of distalmost lamella; notches deeply incising outer surface striation; strong dorsalward increase in size of spine articulations and of gaps separating them in all LAPs; position of dorsalmost spine articulation varying in position between close to the remaining spine articulations to widely separated from the latter by a gap equalling up to twice the height of the dorsalmost spine articulation in proximal to median LAPs. Ventral edge of LAP with relatively small but deeply incised, concave tentacle notch in all LAPs.

Inner side with large, relatively narrow (proximal and median LAPs) to moderately broad (distal LAPs), sharply defined, prominent ridge devoid of kink or thickened part; ventral tip of ridge pointing ventroproximally, not merged with ventral portion of LAP; dorsal half of ridge straight and oblique, not reaching dorsal edge of LAP; inner side of distal edge of LAP with up to four variably well-defined, oval to lenticular, slightly prominent spurs composed of more densely meshed stereom; inner side of tentacle notch relatively small, with coarsely meshed and slightly horizontally stretched stereom. Small, irregular perforations densely grouped in short vertical row dorsally bordering the tentacle notch in proximal to median LAPs; single small perforation dorsally bordering tentacle notch in distal ones. 


\section{Remark}

The original description of Alternacantha occulta on the basis of several articulated specimens (Thuy \& Meyer 2013) is here complemented by a detailed description of the LAP morphology of the species, including the inner side of the LAPs which is not exposed on the articulated type specimens. As noted above, species of Alternacantha share nearly indistinguishable LAP morphologies, which makes a distinction of $A$. occulta from species known exclusively from arm fragments and dissociated LAPs a major challenge. In terms of the shape of the ventral and dorsal arm plates, $A$. occulta is closest to A. dilionessa sp. nov. (see below). In the former, however, the proximal LAPs are smaller, the dorsal edge is pointed to tongue shaped, rather than broad and oblique, and the outer proximal and inner distal edges display up to four, rather than six, spurs. In A. schwermannorum sp. nov., the ventral arm plates have a truncated rather than evenly convex distal edge, and the LAPs are dorsally broad rather than tongue like and display very thin, horizontally elongate rather than oval spurs on the inner distal edge. Alternacantha arges sp. nov. is a much larger species with LAPs devoid of vertical striation, truncated rather than evenly convex distal edges of the ventral plates and distinctively Gauss-curve-shaped rather than parabolic distal edges of the dorsal arm plates.

Alternacantha sp. nov. innom. 2

Fig. 22: 9-10

\section{Material examined}

GZG.INV.78652 and GZG.INV.78653 from sample 95, lower Chari Formation, Callovian of Jumara, India.

\section{Description}

GZG.INV.78652 is a dissociated, large, median LAP; slightly longer than wide; dorsal edge concave as a result of a well-developed constriction; distal edge nearly straight; proximal edge gently convex, with two very poorly defined, almost indiscernible, weakly prominent, non-protruding spurs; outer surface with weakly developed, irregular vertical striation close to spine articulations composed of slender, widely separate, vertically merged trabeculae of outer surface stereom; moderately finely to finely meshed stereom on proximal three-quarters of outer surface. Three large, ear-shaped spine articulations in shallow notches of strongly elevated distal portion of LAP; dorsalward increase in size of spine articulations and of gaps separating them; gap between spine articulations and distal edge of LAP almost as wide as one spine articulation. Ventral edge of LAP nearly straight, deeply incised but small tentacle notch.

Inner side of LAP with small, sharply defined, very slender, oblique ridge with slightly widened ventral tip merged with ventral portion of LAP; inner side of distal edge of LAP with two small, horizontally elongate, moderately well-defined spurs composed of slightly more densely meshed stereom; inner side of tentacle notch deeply incised, laterally sharply defined. No perforations or furrow discernible.

GZG.INV.78653 is a dissociated proximal to median LAP; ventro-proximal portion missing; dorsal spur on proximal edge similarly poorly defined and weakly prominent as in the LAP described above but protruding; vertical striation less regular and restricted to a smaller area of outer surface. Three spine articulations, better preserved than in the previous specimen; dorsal and ventral lobes composed of finely meshed stereom and merged into continuous volute; spine articulations not sharply bordered proximally; dorsal gap between spine articulations more than twice larger than ventral one.

Inner side partly obscured by sediment but visible part well in agreement with the previous specimen. 


\section{Remarks}

These specimens are unambiguously assignable to Alternacantha on account of the unusually large gap which separates the dorsalmost spine articulation from the remaining ones. Superficial similarities are shared with the median and distal LAPs of Ophiomalleus gen. nov., which, however, are much more robust, display freestanding spine articulations and a broader ridge on the inner side. Within Alternacantha, greatest similarities are shared with the single, fragmentary LAP from the Toarcian of France described above, with respect to the outer surface ornament and the height/width ratio of the LAPs displaying the alternating position of the dorsalmost spine articulation. In the Toarcian specimen, however, the lobes of the spine articulation are composed of densely rather than finely meshed stereom. The Callovian material described above most probably represents a new species, the formal description of which, however, requires more complete material.

\section{Alternacantha schwermannorum sp. nov. urn:1sid:zoobank.org:act:08DCE3FA-60AD-4415-80D3-127E2FD02F76}

Fig. 23

p.p. Ophiacantha? suprajurassica - Hess 1966: 1030, 1054, figs 10, 70, 72 (material incorrectly referred to Ophiacantha? suprajurassica Hess, 1965).

\section{Diagnosis}

Species of Alternacantha with large LAPs displaying well-developed, regular vertical striation on outer surface; up to five poorly to moderately well-defined spurs on outer proximal edge; up to six welldefined, horizontally strongly elongate, ridge-like spurs on inner side of distal edge of LAP; up to five spine articulations; distal edge of ventral arm plates truncated.

\section{Etymology}

Species named in honour of my friends Leonie and Achim Schwermann.

\section{Type material}

Holotype

GZG.INV.78654.

Paratypes

GZG.INV.78655, GZG.INV.78656, GZG.INV.78657 and GZG.INV.78658.

\section{Type locality and horizon}

Savigna, France; sample S2a of Gale (2011), Bimammatum Zone, late Oxfordian, Late Jurassic.

\section{Additional material}

GZG.INV.78659 (102 dissociated LAPs) from sample S2a of Gale (2011); GZG.INV.78660 (47 dissociated LAPs) from sample S1 of Gale (2011); GZG.INV.78661 (166 dissociated LAPs) from sample S2b of Gale (2011).

\section{Description}

\section{Holotype}

GZG.INV.78654 is a dissociated, large, proximal LAP; dorsal edge slightly fragmentary distally, originally slightly convex, broad; distal edge irregularly undulose; ventral seventh of LAP protruding ventro-proximalwards, slightly fragmentary; proximal edge nearly straight, with five small, poorly defined, prominent and protruding spurs, three of which are grouped centrally and the fourth one in 


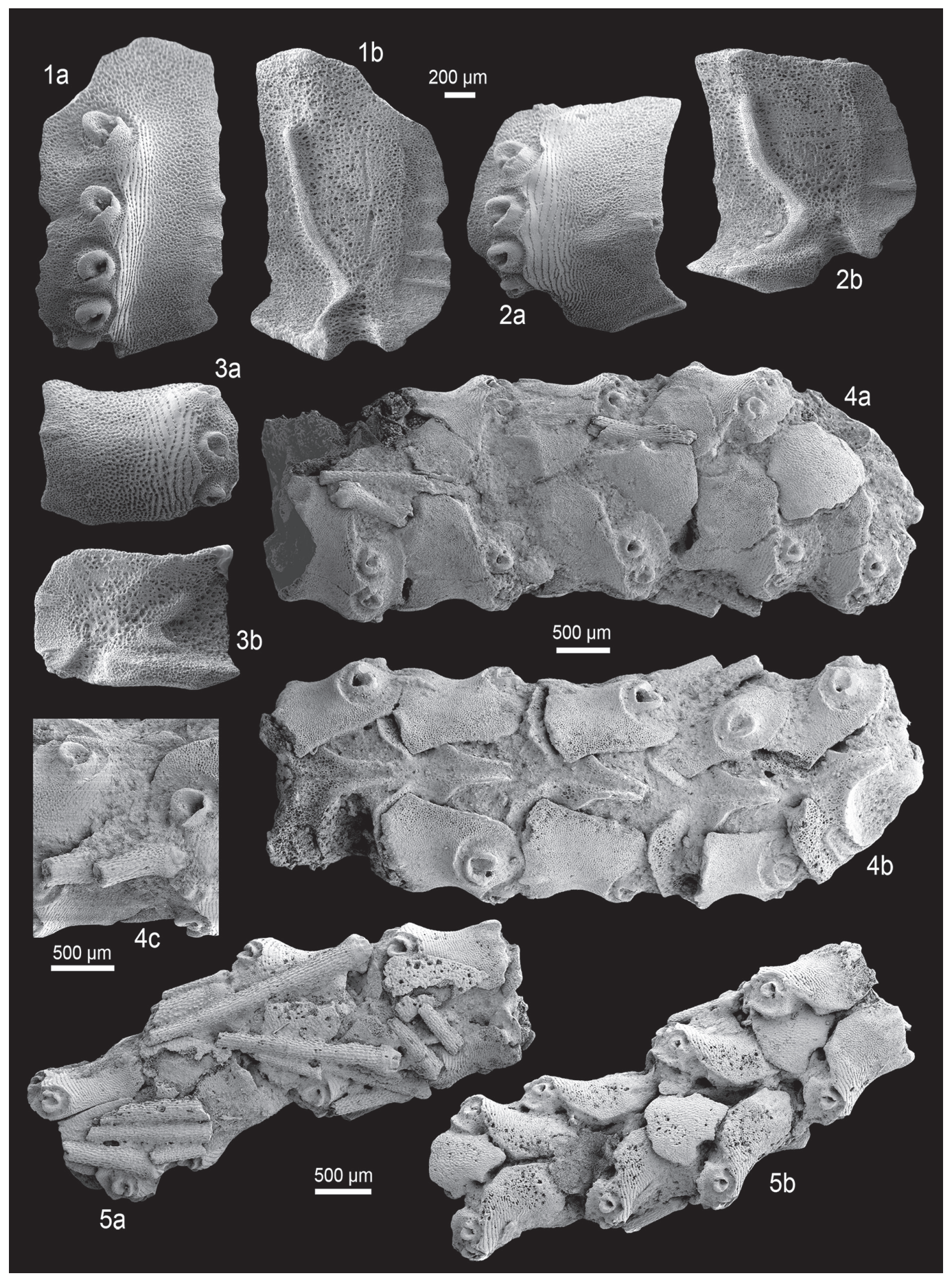

Fig. 23. Fossil lateral arm plates in external (a) and internal (b) views and articulated arm fragments of Alternacantha schwermannorum sp. nov. from the late Oxfordian (Late Jurassic) of Savigna, France. 1. GZG.INV.78654 (holotype), proximal LAP. 2. GZG.INV.78655 (paratype), median LAP. 3. GZG. INV.78656 (paratype), distal LAP. 4. GZG.INV.78657 (paratype), proximal arm fragment in ventral (a) and dorsal (b) views and with detail in dorso-lateral (c) view. 5. GZG.INV.78658 (paratype), distal arm fragment in dorsal (a) and ventral (b) view. One common scale bar for 1-3. 
middle of dorsal half of proximal edge; outer surface with very well-developed, fine, regular to very slightly undulose, vertical striation composed of fine and very slightly overlapping lamellae, restricted to distal third of outer surface near spine articulations, replaced by very finely meshed stereom on remaining outer surface. Five large, ear-shaped spine articulations in shallow notches of elevated distal edge; ventral and dorsal lobes of spine articulations merged into continuous volute; wide gap between spine articulations and distal edge of LAP, nearly as wide as one spine articulation; spine articulations proximally sharply delimited by edge of notches rather than single distalmost lamella or well-defined, prominent ridge; dorsalward increase in size of spine articulations and in gaps separating them; dorsalmost spine articulations separated from remaining four by larger gap. Ventral edge of LAP with small, concave tentacle notch.

Inner side of LAP with large, conspicuous, sharply defined, very narrow ridge; ventral part of ridge slightly bent, pointing ventro-proximalwards; central part of ridge straight, oblique and dorsal part straight and very slightly oblique, not reaching dorsal edge of LAP; all parts connected by very gently rounded kinks; no thickened parts or sharp kinks; inner side of distal edge of LAP with six large, conspicuous, well-defined, slightly prominent, horizontally strongly elongate, ridge-like spurs, becoming smaller and less well-defined dorsalwards; inner side of tentacle notch small, well defined laterally. Very shallow, moderately well-defined, slightly irregular, vertical furrow with single small perforation dorsally bordering tentacle notch.

\section{Paratype supplements and variation}

GZG.INV.78655 is a dissociated median LAP; well in agreement with holotype; dorsal edge straight, broad; distal edge convex; proximal edge concave, with single, large, moderately well-defined, prominent and slightly protruding spur. Five spine articulations similar to those observed on holotype; dorsalmost spine articulation smallest, widely separated from remaining four.

Inner side of LAP with ridge similar to that of holotype; inner side of distal edge of LAP with one large ventral, well-defined, prominent, horizontally strongly elongate, lenticular spur, and second dorsal, much smaller, less well-defined spurs. Very shallow and weakly defined, irregular vertical furrow dorsally bordering tentacle notch.

GZG.INV.78656 is a dissociated distal LAP; dorsal edge concave as a result of a well-defined constriction; distal edge convex; proximal edge irregularly wavy, with single moderately well-defined, prominent, lenticular, slightly protruding spur. Three spine articulations similar to those observed in holotype; ventral spine articulation smaller than remaining two; dorsal gap slightly larger than ventral one. Ventral edge of LAP with very small, almost indiscernible tentacle notch.

Inner side of LAP with sharply defined, prominent ridge displaying oblique, near-straight, narrow dorsal part and shorter, strongly widened ventral part with ventro-proximalwards pointing tip; inner side of tentacle notch small, sharply defined laterally. No perforations or furrow discernible.

GZG.INV.78657 is an articulated arm fragment preserving five median to proximal segments; LAPs well in agreement with holotype; position of dorsalmost spine articulation alternating between close to the remaining ones, close to the dorsal edge of the LAP, and intermediate between the latter two positions; a few arm spine fragments preserved, broken near base, exposing lumen filled with coarsely meshed stereom; arm spines cylindrical, with finely meshed and slightly longitudinally elongate stereom; dorsal arm plates missing; LAPs not in contact dorsally; ventral arm plates large, nearly as long as wide, widest distally, not separating LAPs; distal edge of ventral arm plates convex but with slightly truncated, straight tip; lateral edges moderately strongly concave; proximal angle acute; no tentacle scales discernible.

GZG.INV.78658 is an articulated arm fragment preserving four distal segments; several arm spine fragments preserved; most complete arm spine very large, nearly as long as two arm segments, cylindrical, straight, slowly tapering, with finely meshed, slightly longitudinally elongate stereom beset 
with numerous minute thorns pointing towards the spine tip; dorsal arm plates leaf shaped, longer than wide, with very acute proximal angle, slightly convex lateral edges and convex distal edge; outer surface of dorsal arm plates with very fine, regular transverse striation; ventral arm plates similar to those observed on other paratype arm fragment, slightly longer than wide; tentacle pores very small, single small, leaf-like tentacle scale preserved.

\section{Remarks}

This material is unequivocally assignable to the genus Alternacantha on account of the alternating position of the dorsalmost spine articulation. It differs from its congeners in combining five arm spines, a well-developed vertical striation on the outer surface, a slightly truncated distal edge of the ventral arm plates, a parabolic distal edge of the dorsal arm plates, and, most importantly, large, well-defined, thin, horizontally strongly elongate spurs on the inner side of the distal edge of the LAPs. The arm fragments described and illustrated by de Loriol (1872) as a new species, Ophiurella royeri de Loriol, 1872, from near-coeval strata of Haute-Marne, France, could well be conspecific with the present material. Since, however, Ophiurella royeri is based on arm fragments which do not expose the inner side of the LAPs and in particular the highly diagnostic shape of the spurs on the inner distal edge, it cannot be ruled out that they are rather conspecific with the specimens described below as Alternacantha dilionessa sp. nov. Ophiurella royeri should therefore be considered as a nomen dubium.

\section{Occurrence}

Late Oxfordian of France.

$$
\begin{aligned}
& \text { Alternacantha arges sp. nov. } \\
& \text { urn:1sid:zoobank.org:act:B1D9DEC0-8F10-4D8D-AAB0-15949F6DB8CA }
\end{aligned}
$$

Fig. 24: 1-2

Ophiothrix? royeri - Hess 1960: 396, figs 7-8 [specimen incorrectly assigned to Ophiothrix? royeri (de Loriol, 1872)].

\section{Diagnosis}

Species of Alternacantha with extremely large LAPs devoid of vertical striation on the outer surface; up to three large, well-defined spurs on the outer proximal edge; up to four spine articulations; distal edge of ventral arm plates truncated; distal edge of dorsal arm plates Gauss-curve-shaped.

\section{Etymology}

Species named after Arges, one of the three giant cyclopes in Greek mythology, in reference to the extremely large size of the species in combination with the large dorsalmost spine articulation resembling the single eye of the cyclopes.

\section{Holotype}

NHMB M 610.

\section{Type locality and horizon}

Raedersdorf, France; Humeralis Member, late Oxfordian, Late Jurassic.

\section{Description of holotype}

M 610 is an extremely large, articulated arm fragment preserving nine proximal segments; LAPs more than twice higher than wide; dorsal edge pointed to tongue shaped; distal edge irregularly undulose; proximal edge concave, with up to three very large, well-defined, strongly prominent, horizontally 


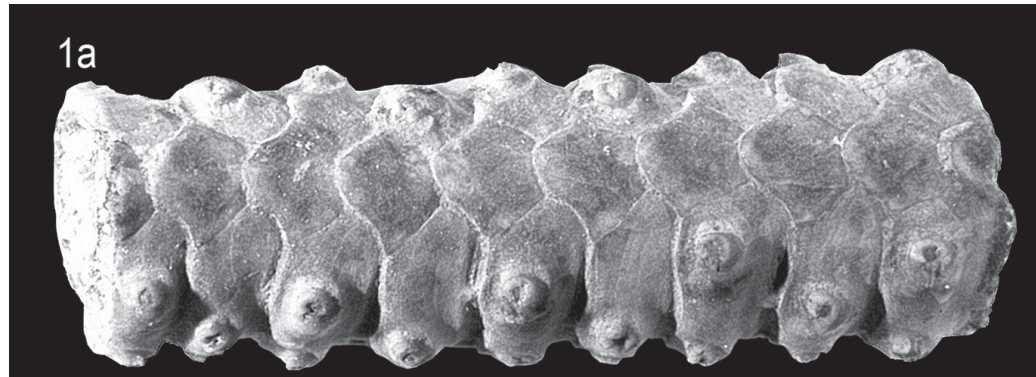

$1 b$

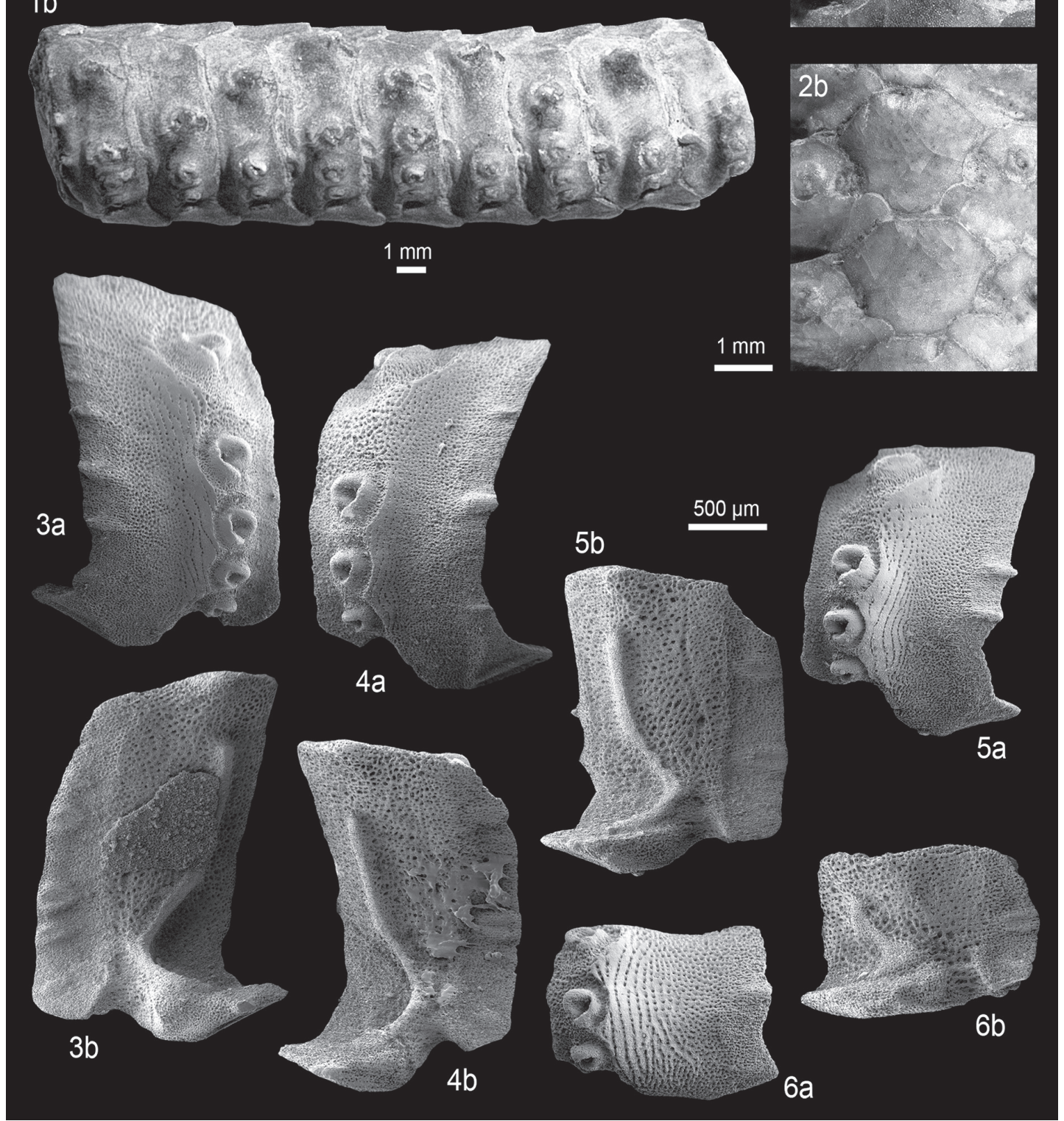

Fig. 24. Fossil lateral arm plates in external (a) and internal (b) views and articulated arm fragment of ophiacanthid brittle stars. 1-2. Alternacantha arges sp. nov. from the late Oxfordian (Late Jurassic) of Raedersdorf, France; M 610 in dorsal (1a) and ventral (1b) views and with details of dorsal (2a) and ventral (2b) arm plating. 3-6. Alternacantha dilionessa sp. nov. from the early Kimmeridgian of the Pointe du Chay, France. 3. GZG.INV.78662 (holotype), proximal LAP. 4. GZG.INV.78663 (paratype), proximal LAP. 5. GZG.INV.78664 (paratype), median LAP. 6. GZG.INV.78665 (paratype), distal LAP. One common scale bar for 1 , for 2 and for 3-6, respectively. 
elongate, protruding spurs; ventral portion of LAP small, protruding ventro-proximalwards; outer surface of LAPs with finely meshed stereom, devoid of vertical striation. Three to four very large, earshaped spine articulations in notches of strongly elevated distal edge; dorsal and ventral lobes of spine articulations merged into continuous volute; strong dorsalward increase in size of spine articulations and of gaps separating them; position of dorsalmost spine articulation alternating between close to the remaining ones and near the dorsal edge of the LAP, separated from the remaining spine articulations by an extremely wide gap; spine articulations proximally sharply bordered by edge of notches; gap between spine articulations and distal edge of LAP relatively large.

Inner side of LAPs not exposed.

Ventral arm plates large, wider than long, distal half widest; distal edge of ventral arm plates convex but with a sharply truncated, straight tip; lateral and latero-proximal edges of ventral arm plates concave; proximal angle of ventral arm plates right to slightly acute; ventral arm plates overlapping but LAP most probably in contact underneath ventral arm plates; tentacle pores small, no tentacle scales preserved; dorsal arm plates large, nearly as wide as long, with straight distalwards diverging lateral edges and conspicuously Gauss-curve-shaped distal edge with tongue-shaped tip; dorsal arm plates broadly overlapping, separating LAPs on all preserved segments.

\section{Remarks}

Hess (1960) already provided a detailed description and excellent figures of the present specimen, which he considered to be conspecific with de Loriol's (1872) Ophiurella royeri which was tentatively transferred to the extant genus Ophiothrix Müller \& Troschel, 1840. It obviously belongs to Alternacantha on account of the alternating position of the dorsalmost spine articulation. A detailed re-examination of Hess's (1960) specimen, however, has now revealed a highly distinctive arm morphology which differentiates it unambiguously from all other species assignable to Alternacantha, including the type material of $O . ?$ royeri. In fact, apart from its extremely large size, the specimen lacks a vertical striation on the outer surface, and displays only up to four spine articulations and a conspicuously Gauss-curveshaped distal edge of the dorsal arm plates. Even if it could be argued that the lack of a vertical striation on the outer surface is related to the larger size and thus greater heigth/width ratio of the LAPs of the specimen, the number of spine articulations and shape of the distal edge of the dorsal arm plate are sizeindependent features. This particular specimen is thus described here as a new species.

\section{Alternacantha dilionessa sp. nov. urn:1sid:zoobank.org:act:FD230CAD-9C1E-4C38-B407-1EAB92E10F70}

Figs 24: 3-6; 25: 1-3

\section{Diagnosis}

Species of Alternacantha with very large LAPs displaying a moderately well-defined vertical striation on the outer surface; up to six large, well-defined spurs on the outer proximal edge, paralleled by large, relatively short, oval spurs on the inner distal edge; distal edge of ventral arm plates evenly convex; distal edge of dorsal arm plates parabolic.

\section{Etymology}

Name composed of diligere, Latin for "to cherish", and "lioness", translating into lea in Latin, as an affectionate declaration of esteem to my beloved wife Lea, without whose support the present study would not have been possible.

\section{Type material}

Holotype

GZG.INV.78662. 
THUY B., Fossil record of ophiacanthid brittle stars

\section{Paratypes}

GZG.INV.78663, GZG.INV.78664, GZG.INV.78665, GZG.INV.78666, GZG.INV.78667 and GZG. INV.78668.

\section{Type locality and horizon}

Pointe du Chay near La Rochelle, France; Achilles Subzone, Cymodoce Zone, early Kimmeridgian, Late Jurassic.

\section{Additional material}

GZG.INV.78669 (512 dissociated LAPs) and GZG.INV.78670 (distal articulated arm fragment).

\section{Description}

\section{Holotype}

GZG.INV.78662 is a dissociated, very large, proximal LAP; approximately twice wider than high; dorsal edge oblique, nearly straight, with pointed dorso-proximal tip; distal edge slightly convex; proximal edge nearly straight, with six small to moderately large, well-defined, prominent, horizontally elongate, proximally pointed and slightly protruding spurs; second and third ventralmost spurs largest; ventral fifth of LAP strongly protruding ventro-proximalwards; ventro-distal edge of LAP round, weakly protruding ventralwards; outer surface with moderately well-developed, rather coarse, slightly undulose, vertical striation restricted to narrow band near spine articulations and composed of slightly overlapping lamellae of variable width; greater part of outer surface with finely meshed stereom. Five very large, ear-shaped spine articulations in shallow notches of elevated distal edge; ventral and dorsal lobes of spine articulations merged into continuous volute; spine articulations proximally sharply bordered by edge of notches rather than well-defined ridge or single distalmost lamella; notches incising outer surface; gap between spine articulations and distal edge of LAP slightly narrower than one spine articulation; dorsalward increase in size of spine articulations and of gaps separating them; dorsalmost spine articulation separated from the remaining four by very large gap with slightly more coarsely meshed stereom. Ventral edge of LAP with relatively small but deeply concave tentacle notch.

Inner side of LAP with very large, conspicuous, sharply defined, prominent, very narrow ridge; ventral part of ridge bent, pointing ventro-proximalwards; central part of ridge straight, oblique, and dorsal part straight and very slightly oblique, not reaching dorsal edge of LAP; all parts connected by rounded kinks; no thickened parts; inner side of distal edge of LAP with three large, moderately well-defined, prominent, relatively short and high oval spurs in the centre and two smaller, poorly defined spurs ventrally and dorsally bordering the three larger ones; inner side of tentacle notch relatively small, well defined laterally. Shallow, poorly defined furrow dorsally bordering tentacle notch, dorsally obscured by shell fragment.

\section{Paratype supplements and variation}

GZG.INV.78663 is a dissociated, very large, proximal LAP; approximately twice wider than high; agreeing closely with holotype; proximal edge with one large, central, well-defined, prominent and protruding spur and two smaller, dorsal and ventral, non-protruding spurs; striation on outer surface limited to a very narrow band near the three ventralmost spine articulations. Four spine articulations similar to those observed on holotype; dorsalmost one even more widely separated from remaining spine articulations.

Inner side similar to that of holotype.

GZG.INV.78664 is a dissociated median LAP; slightly higher than wide; proximal edge with two large, well-defined, prominent, and strongly protruding spurs. Four spine articulations similar to those observed on holotype. 


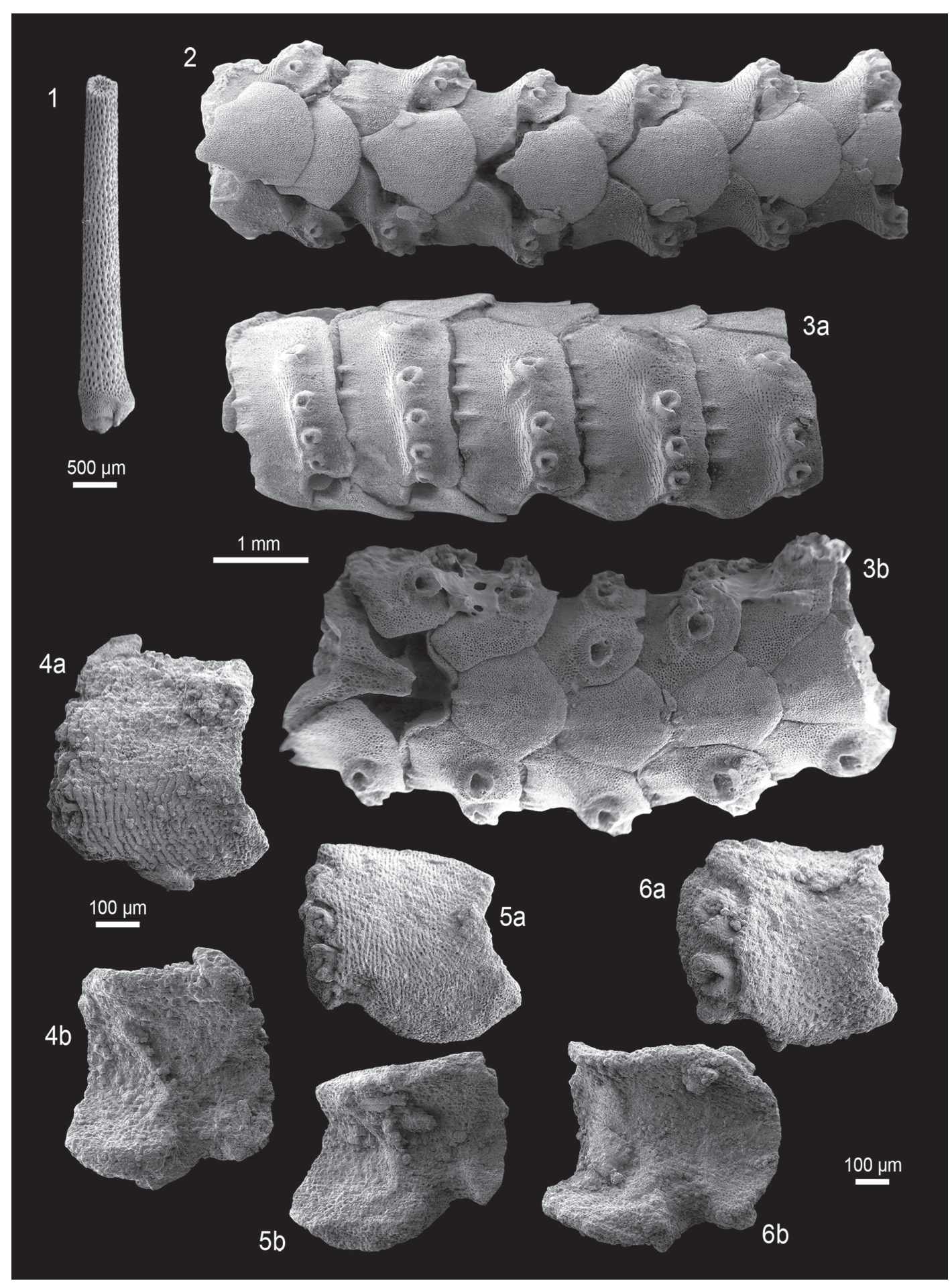

Fig. 25. Fossil skeletal plates and articulated arm fragments of ophiacanthid brittle stars; lateral arm plates (LAPs) in external (a) and internal (b) views. 1-3. Alternacantha dilionessa sp. nov. from the early Kimmeridgian of the Pointe du Chay, France. 1. GZG.INV.78666 (paratype), arm spine. 2. GZG. INV.78667 (paratype), median arm fragment in ventral view. 3. GZG.INV.78668 (paratype), proximal arm fragment in lateral (a) and dorsal (b) views. 4-5. Dermocoma subtilirugosa (Kristan-Tollmann \& Gramann, 1992) comb. nov. from the Rhaetian (Late Triassic) of Fischerwiese, Austria. 4. GZG.INV.78671, proximal LAP. 5. GZG.INV.78672, median LAP. 6. Dermocoma sp. nov. innom. 1 from the Rhaetian (Late Triassic) of Fischerwiese, Austria; GZG.INV.78674, median LAP. One common scale bar per species except for 1. 
Inner side of LAP with ridge similar to that observed on holotype; inner side of distal edge of LAP with two large, moderately well-defined, weakly prominent spurs. Shallow, moderately well-defined, slightly oblique furrow with two very small spine articulations dorsally bordering tentacle notch.

GZG.INV.78665 is a dissociated distal LAP; slightly wider than high; dorsal edge concave as a result of a weakly developed constriction; proximal edge with single, moderately well-defined, prominent and slightly protruding spur; vertical striation well developed on distal two-fifths of the outer surface. Three spine articulations similar to those observed on holotype; dorsal gap between spine articulations slightly wider than ventral one. Ventral edge of LAP with small, weakly concave tentacle notch.

Inner side of LAP with sharply defined, prominent ridge composed of strongly widened ventral part and ventro-proximally pointing orsal part; inner side of distal edge with single well-defined, slightly prominent spur; inner side of tentacle notch small, sharply defined laterally, pointing ventralwards. No perforations or furrows discernible.

GZG.INV.78666 is a dissociated, large arm spine; cylindrical; slowly tapering; straight; with finely meshed, slightly longitudinally elongate stereom beset with scattered, minute granules; tip broken, exposing lumen filled with loosely meshed stereom.

GZG.INV.78667 is an articulated arm fragment counting five proximal segments; LAPs well in agreement with holotype; ventral arm plates very large, approximately bell shaped, slightly wider than high, widest distally, with strongly and evenly convex distal edge, concave lateral and latero-distal edges and pointed proximal angle; ventral arm plates overlapping, covering ventral portions of LAPs, the latter meeting underneath ventral arm plates; tentacle pores small, no tentacles scales preserved; dorsal arm plates large, nearly as wide as long, with nearly straight, short proximal edge; straight, distalwards diverging lateral edges and convex, parabolic distal edge; short, well-defined and prominent longitudinal ridge in proximal third of dorsal arm plate outer surface; dorsal arm plates overlapping, separating LAPs.

GZG.INV.78668 is an articulated arm fragment counting six proximal to median segments; well in agreement with other arm fragment paratype; tentacle pores with two small, leaf-like scales.

\section{Remarks}

D'Orbigny (1850) already mentioned an articulated arm fragment from the Kimmeridgian of Chay peninsula, France, listing it as "Ophiurella bispinosa d'Orbigny, 1850", and it is more than likely that he was referring to the same species as the one described here. However, since Ophiurella bispinosa has never been described, it must be considered as nomen nudum. The present specimens share greatest similarities with Alternacantha occulta which, however, differs in having smaller proximal LAPs with a pointed to tongue-shaped distal edge, as well as fewer and less well-defined spurs on the outer proximal and inner distal edges. In A. schwermannorum sp. nov. (see above), the distal edge of the ventral arm plates is slightly truncated rather than evenly convex, and the spurs on the inner side of the distal edge of the LAPs are very thin, horizontally elongate and pointed rather than high and oval.

\section{Occurrence}

Early Kimmeridgian of France.

Genus Dermocoma Hess, 1964

\section{Type species}

Dermocoma wrighti Hess, 1964, by original designation. 


\section{Diagnosis}

Ophiacanthid with LAPs commonly displaying a fine vertical striation on their outer surface; welldeveloped spurs on the inner distal and, in some cases to a lesser extent, outer proximal edge; ventral portion of LAP strongly protruding ventro-proximalwards; up to six moderately large, ear-shaped spine articulations with continuous volute in notches of elevated distal portion of LAP; ridge on inner side of LAPs simple, continuous, generally slender, devoid of sharp kinks or conspicuously thickened parts; tentacle notch small to moderately large.

\section{Remarks}

Dermocoma was introduced by Hess (1964) on the basis of articulated specimens from the Middle Jurassic of Great Britain which were all assigned to the type, and at that time only known, species $D$. wrighti Hess, 1964. While the higher taxonomic position of Dermocoma was initially left open (Hess 1964), it was later used as type taxon for the introduction of the extinct family Dermocomidae Hess, 1972 (Hess 1972a). Thuy \& Meyer (2013), however, showed it to be unambiguously assignable to the Ophiacanthidae.

Since the original description of Dermocoma wrighti provided only few data on LAP morphology, a reexamination of the type specimens was called for in order to work out a comprehensive LAP morphology including as many characters as possible. Dermocoma and its sister genus Alternacantha share basically similar LAP morphologies, as already noted above. While the median and distal LAPs of both genera may be almost indistinguishable, the proximal LAPs allow for an unambiguous distinction. In fact, in the proximal LAPs of Dermocoma the position of the dorsalmost spine articulation never alternates, the distal portion of the LAPs is less strongly elevated and the notches of the spine articulations are generally deeper. As in Alternacantha, however, distinction of species within Dermocoma on the basis of dissociated LAPs can be a major challenge with differences occasionally found in the finest details only.

The LAPs of Dermocoma can be easily distinguished from those of other ophiacanthids on account of the position of the spine articulations, the ventro-proximally protruding ventral part, and the simple ridge on the inner side devoid of sharp kinks and conspicuously widened parts. The LAPs assignable to Dermacantha gen. nov. (see below) share the greatest similarities with those of Dermocoma, differing only in having generally smaller spine articulations, a discontinuous volute of the spine articulations and a generally smaller height/width ratio. However, the similarities are so striking that Dermocoma and Dermacantha. gen. nov. are most probably closely related.

Many of the previously known Jurassic ophiacanthid records based exclusively on dissociated LAPs have turned out to be assignable to Dermocoma. Together with the new records described in the present study, Dermocoma is among the most speciose and most widely distributed ophiacanthids in Mesozoic shallow-water deposits. Scattered records from a deep-shelf to upper slope setting, however, suggests that the genus was also present in deeper settings. The closest extant relative Ophiocopa spatula, sister to the Dermocoma-Alternacantha clade (see above), inhabits upper to middle bathyal depths (279-965 m) of the Pacific (O’Hara \& Stöhr 2006).

Dermocoma subtilirugosa (Kristan-Tollmann \& Gramann, 1992) comb. nov.

Fig. 25: 4-5

Ophiacantha? subtilirugosa Kristan-Tollmann \& Gramann, 1992: 468, pl. 3 figs 1-6. 


\section{Diagnosis}

Species of Dermocoma with moderately large LAPs displaying a very fine vertical striation on almost entire outer surface; two very poorly defined spurs on the outer proximal and inner distal edges; up to four small spine articulations in tight notches of non-elevated distal edge.

\section{Material examined}

GZG.INV.78671, GZG.INV.78672 and GZG.INV.78673 (3 dissociated LAPs) from the Rhaetian of Fischerwiese, Austria..

\section{Description}

Moderately large LAPs; rounded, crescentic (proximal LAPs) to rectangular (distal LAPs) outline; slightly higher than wide (proximal LAPs) to more than twice wider than high (distalmost LAPs); dorsal edge straight to slightly convex, distal edge gently convex; ventral quarter to fifth large and protruding ventro-proximalwards in proximal to median LAPs; proximal edge evenly concave, with up to two small, very poorly defined, weakly prominent and not protruding, almost indiscernible spurs; outer surface almost entirely covered by very fine vertical striation, composed of thin lamellae, distalwards slightly overlapping, proximalwards decreasing in size and fading into finely meshed stereom close to proximal edge of LAP; striation mostly regularly vertical, with occasional irregularities (slightly oblique and/or branching lamellae) in ventral half of outer surface. Three (distal LAPs) to four (proximal LAPs) small, ear-shaped, nearly equal-sized spine articulations in tight notches of distal edge, interrupting vertical striation; gaps separating spine articulations increasing in size dorsalwards; dorsal and ventral lobes of spine articulations forming continuous volute; very narrow gap between spine articulations and distal edge of LAP. Ventral edge of proximal LAPs with large but weakly concave tentacle notch; tentacle perforation ventro-distally bordering ventralmost spine articulation in distal LAPs.

Inner side of proximal and median LAPs with narrow, well-defined, prominent ridge separated by rounded kink into dorsal and ventral portions; dorsal portion oblique, bent dorso-proximalwards, with widened slightly less prominent and less well-defined dorsal tip; ventral portion much shorter than dorsal one, pointing ventro-proximalwards, sharply separated from thickened ventral edge of LAP; ridge in distal LAPs short, oblique, well-defined, prominent, without kink, bone-shaped to triangular. Very faint vertical row of small, irregular perforations close to distal edge of LAPs, separating inner side into coarsely meshed main portion, and narrow, finely meshed distal portion. Tentacle notch in proximal and median LAPs large, distally bordered by narrow, oblique ridge.

\section{Remarks}

LAPs similar to the ones described here were first recorded from the Rhaetian of rocks dredged from the northern Exmouth Plateau and described as Ophiacantha? subtilirugosa by Kristan-Tollmann \& Gramann (1992). The new material from the Rhaetian of Austria now enables a reassessment of this species in accordance with the most recently set standards in ophiuroid micropalaeontology (Thuy \& Stöhr 2011). The shape, size and position of the spine articulations, the outer surface ornament and the shape of the ridge on the inner side strongly suggest assignment to Dermocoma. Among the LAP types assigned to this genus, the present one differs in combining small spine articulations with a fine vertical striation which covers almost the entire outer surface and two almost indiscernible spurs on the outer proximal and inner edges.

\section{Occurrence}

Rhaetian of Austria and the Wombat Plateau off northern Australia. 
Dermocoma sp. nov. innom. 1

Fig. 25: 6

\section{Material examined}

GZG.INV.78674 from the Rhaetian of Fischerwiese, Austria.

\section{Description}

Single, dissociated, moderately large, median LAP known; nearly as high as wide; dorsal edge slightly concave as a result of a constriction; distal edge convex; ventral sixth of LAP protruding ventroproximalwards; proximal edge irregularly undulose, with two medium-sized, very poorly defined, weakly prominent but protruding spurs, one in the middle of the dorsal half, the other in the middle of the ventral half; outer surface with rather coarse, poorly developed vertical striation composed of broad, slightly overlapping lamellae close to spine articulations, replaced by finely meshed stereom on proximal half of outer surface. Four large, ear-shaped spine articulations in moderately deep notches of elevated distal edge of LAP; ventral and dorsal lobes merged into continuous volute; ventral lobe not connected with outer surface; spine articulations proximally sharply bordered by edge of notches; spine articulations nearly of equal size except for slightly smaller ventralmost one; very weak dorsalward increase in size of gaps separating spine articulations. Ventral edge of LAP with moderately large, concave tentacle notch.

Inner side of LAP with moderately large, well-defined, rather broad, prominent, oblique, bent ridge; dorsal and ventral tips of ridge slightly widened, rounded, dorsal one pointing dorsalwards, ventral one pointing ventro-proximalwards and not merged with thickened ventral portion of LAP; inner side of distal edge with single large, poorly defined, oval, weakly prominent spur composed of more densely meshed stereom; inner side of tentacle notch rather small, deeply incised, sharply defined laterally. Very shallow, poorly defined vertical furrow dorsally bordering tentacle notch; no perforations discernible.

\section{Remarks}

The single specimen available differs markedly from co-occurring LAPs of Dermocoma subtilirugosa comb. nov. with respect to the much larger spine articulations on an elevated distal portion, the protruding spurs and the poorly developed vertical striation restricted to a narrow band near the spine articulations. Assignment to Dermocoma seems warranted on account of the position of the spine articulations in notches of the comparatively weakly elevated distal portion of the LAP, the ventro-proximalwards protruding ventral portion of the LAP and the shape of the ridge on the inner side. Within this genus, similarities are greatest with the LAPs of Dermocoma potti sp. nov. on account of the spine articulations which are not connected with the outer surface stereom, the rather poorly developed outer surface striation and the two poorly defined spurs on the outer proximal and inner distal edges. In view of the fact that many species of Dermocoma share almost indistinguishable LAP morphologies, this single record of an allegedly median LAP cannot be identified in more detail. It is likely that it represents a new species but in the absence of material it can at present only be listed as a new record of Dermocoma which differs markedly from co-occurring $D$. subtilirugosa comb. nov.

Dermocoma faberi sp. nov.

urn:1sid:zoobank.org:act:563DC91F-6457-4DDE-A0EE-A4C9D2A04770

Fig. 26: 1-3

Ophiacantha? toarcensis - Thuy 2005: 40, pl. 5 figs 1-6 (material incorrectly assigned to Ophiacantha? toarcensis Hess, 1962). 


\title{
Diagnosis
}

Species of Dermocoma with large LAPs displaying a fine, vertical striation on almost entire outer surface; up to four spurs on outer proximal and inner distal edges; up to six relatively small spine articulations.

\section{Etymology}

Species named in honour of Alain Faber, who provided valuable support, especially at the very beginning of my palaeontological studies.

\section{Type material}

\author{
Holotype \\ MnhnL HE408.

\section{Paratypes} \\ MnhnL HE409 and MnhnL HE410.
}

\section{Type locality and horizon}

Vance, Belgium; sample Van1 of Thuy (2005), Planorbis Zone, early Hettangian, Early Jurassic.

\section{Additional material}

MnhnL HE411 (385 dissociated LAPs), MnhnL HE256 and HE 257 (7 dissociated LAPs), original material from sample Van1 of Thuy (2005); MnhnL HE412 (239 dissociated LAPs), original material from sample Van2 of Thuy (2005); MnhnL HE413 (457 dissociated LAPs) from level c of Delsate et al. (2002), Liasicus Zone, Hettangian of Fontenoille, Belgium; original material of Thuy (2005) from the Hettangian of Bourglinster, Bereldange and Bridel in Luxembourg.

\section{Description}

\section{Holotype}

MnhnL HE408 is a dissociated, large, proximal LAP; approximately 1.5 times higher than wide, with oblique, slightly concave dorsal edge as a result of a very weak constriction; distal edge weakly convex; ventral quarter of LAP protruding ventro-proximalwards; proximal edge of LAP gently concave, with four horizontally elongate, prominent and strongly protruding, poorly defined but conspicuous spurs; second dorsalmost spur in the centre of the proximal edge, more than twice larger than remaining three spurs of near-equal size; outer surface with fine vertical striation consisting of thin, slightly distalwards overlapping lamellae; striation covering almost entire outer surface, with slight irregularities in ventral half of outer surface, otherwise very regularly vertical; lamellae decreasing in size and fading into finely meshed stereom towards proximal edge of LAP. Six relatively small, ear-shaped spine articulations in notches of distal edge interrupting vertical striation; no connecting ridge between spine articulation and striation; spine articulations of nearly equal size, with very weak dorsalward increase in size; dorsal and ventral lobes forming continuous, round lobe; very strong dorsalward increase in size of gaps separating spine articulations; relatively wide gap between spine articulations and distal edge of LAP. Ventral edge of LAP with moderately large, gently concave tentacle notch.

Inner side of LAP with narrow, sharply defined, prominent ridge separated by gentle kink into ventral and dorsal portions; dorsal portion oblique with dorsal tip widened, less sharply defined and bent dorsalwards; ventral portion bent proximalwards, slightly less prominent and more weakly defined than dorsal portion but not merged with thickened ventral edge of LAP; inner side of distal edge thin and with relatively wide vertical band of finely meshed stereom sharply separated from coarsely meshed stereom of remaining inner side; four relatively small, horizontally elongate, poorly defined, prominent, albeit not protruding, spurs in finely meshed band of distal edge; second dorsalmost spur slightly larger than remaining three. Tentacle notch relatively large, proximally bordered by thickened ventral edge of LAP, 


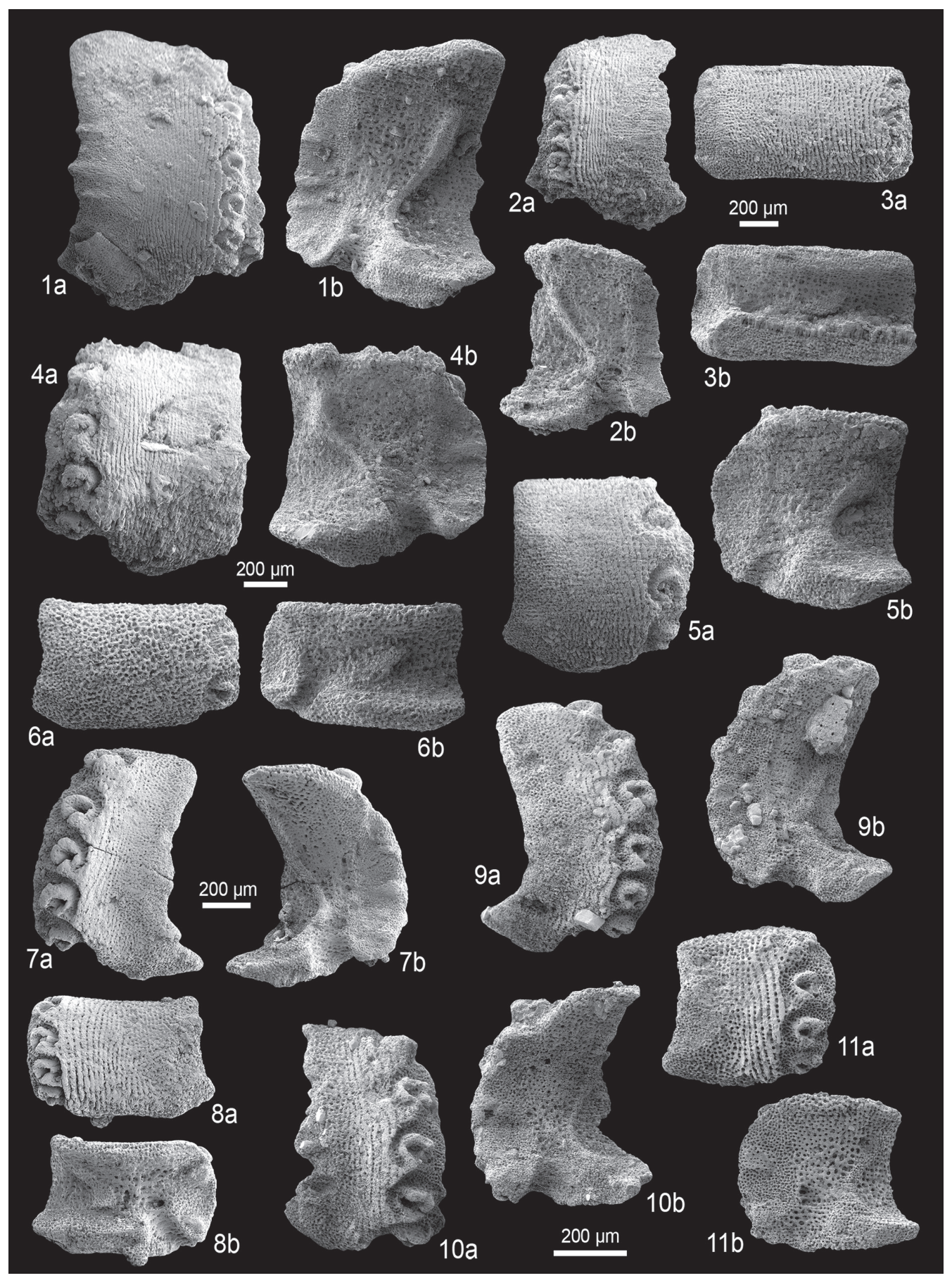

Fig. 26. Fossil lateral arm plates (LAPs) of ophiacanthid brittle stars in external (a) and internal (b) views. 1-3. Dermocoma faberi sp. nov. from the Hettangian (Early Jurassic) of Vance, Belgium. 1. MnhnL HE408 (holotype), proximal LAP. 2. MnhnL HE409 (paratype), median LAP. 3. MnhnL HE410 (paratype), distal LAP. 4-6. Dermocoma potti sp. nov. from the late Pliensbachian (Early Jurassic) of Feuguerolles, France. 4. GZG.INV.78675 (holotype), proximal LAP. 5. GZG.INV.78676 (paratype), median LAP. 6. GZG. INV.78677 (paratype), distal LAP. 7-8. Dermocoma toarcensis (Hess, 1962) comb. nov. from the late Toarcian (Early Jurassic) of Seewen, Switzerland. 7. NHMB M11216, proximal LAP. 8. NHMB M11217, distal LAP. 9-11. Dermocoma longwyensis sp. nov. from the early Bajocian (Middle Jurassic) of Longwy, France. 9. GZG.INV.78679 (holotype), proximal LAP. 10. GZG.INV.78680 (paratype), median LAP. 11. GZG.INV.78681 (paratype), distal LAP. One common scale bar per species. 
and distally by short nearly vertical ridge close to ventro-distal tip of LAP. Hardly discernible, irregular, vertical row of perforations at boundary between finely meshed stereom of distal edge and coarsely meshed stereom of remaining inner surface.

\section{Paratype supplements and variation}

MnhnL HE409 is a dissociated median LAP, slightly higher than wide; dorsal edge oblique, nearly straight to slightly convex; proximal edge slightly broken, with only single poorly defined, slightly prominent and protruding, horizontally elongate spur approximately in centre of proximal edge. Four ear-shaped, nearly equal-sized spine articulations; dorsalward increase in size of gaps separating spine articulations.

Inner side of LAP with ridge similar to that in holotype; inner side of distal edge with two weakly defined, slightly prominent, horizontally elongate ridges, ventral one of which slightly better defined and protruding as a result of the distal edge of the LAP being broken.

MnhnL HE410 is a dissociated distal LAP; twice wider than high, of nearly perfectly rectangular outline; dorsal and ventral edges straight; distal edge slightly convex, proximal straight, bordered by with oblique dorso-proximal and ventro-proximal tips of LAP; no spurs discernible on proximal edge. Three spine articulations sunken into notches of distal edge. Ventralmost spine articulation ventro-distally bordered by tentacle perforation.

Inner side of LAP with sharply defined, short, oblique ridge, slightly pointed dorso-proximally and ventro-distally; distal edge of LAP with two very weakly defined, slightly protruding spurs near dorsoand ventro-distal tips of LAP. Large tentacle perforation in the centre of the distal half of the LAP.

\section{Remarks}

These specimens were originally recorded by Thuy (2005) as Ophiacantha? toarcensis Hess, 1962, who acknowledged that they were not entirely compatible with the diagnosis of the species. The discrepancies in LAP morphology, originally interpreted as within-species variability (Thuy 2005), are here identified as differences of systematic importance warranting separation at the specific level, in line with the observations by Thuy \& Stöhr (2011) on variability patterns in LAP morpologies of extant ophiuroid species.

The size, shape and position of the spine articulations, the outer surface ornament and the shape of the ridge on the inner side strongly suggest that these LAPs are assignable to Dermocoma. Within this genus, greatest similarities are, indeed, shared with Dermocoma toarcensis comb. nov., originally described as Ophiacantha? toarcensis, on account of the higher number of spine articulations and spurs on the outer proximal and inner distal edges. However, the present LAPs differ in displaying up to four, rather than three, spurs, as well as smaller spine articulations on a less strongly elevated distal portion of the LAP.

\section{Occurrence}

Hettangian of Belgium and Luxembourg.

Dermocoma potti sp. nov. urn:1sid:zoobank.org:act:3AD371F8-AFD1-4629-A4FF-448A10F04AB1

Fig. 26: 4-6

\section{Diagnosis}

Species of Dermocoma with large LAPs displaying a well-developed vertical striation; two moderately well-defined spurs on outer proximal and inner distal edge, dorsal one of which slightly larger and better defined; up to four relatively large spine articulations; ridge on inner side with strongly widened and dorsalwards pointing dorsal tip. 


\section{Etymology}

Species named in honour of my friend and colleague Christian Pott, who will always find a moment to share and spread happiness.

\section{Type material}

\section{Holotype}

GZG.INV.78675.

\section{Paratypes}

GZG.INV.78676 and GZG.INV.78677.

\section{Type locality and horizon}

Feuguerolles, France; calcarenitic sediments infilling topography on surface of unconformity, late Pliensbachian, Early Jurassic.

\section{Additional material}

GZG.INV.78678 (63 dissociated LAPs).

\section{Description}

\section{Holotype}

GZG.INV.78675 is a dissociated, large, proximal to median LAP; slightly higher than wide; dorsal edge oblique, nearly straight; distal edge gently convex; ventral fifth of LAP protruding ventro-proximalwards; proximal edge of LAP gently concave, with large, moderately well-defined, prominent and pointedly protruding, horizontally elongate spur in the centre of the proximal edge; second smaller, less prominent and not protruding, weakly defined spur halfway between central spur and ventro-proximal tip of LAP; outer surface with very fine vertical striation composed of thin lamellae, very slightly overlapping distalwards, proximalwards slightly decreasing in size and fading into finely meshed stereom close to proximal edge of LAP. Four relatively large, ear-shaped spine articulations in tight notches of distal edge, interrupting vertical striation; spine articulations nearly equal-sized and equi-distant; dorsal and ventral lobes forming continuous volute; no connecting ridge between spine articulations and vertical striation; moderately wide gap between spine articulations and distal edge of LAP. Ventral edge of LAP with large, deeply concave tentacle notch.

Inner side of LAP with narrow, well-defined, prominent ridge, with very narrow, oblique central part, strongly widened dorsalwards pointing dorsal tip and short, narrow, ventro-proximalwards pointing ventral tip sharply separated from thickened ventral edge of LAP; inner side of distal edge of LAP with central, large, well-defined, horizontally elongate, prominent but not protruding spur composed of more densely meshed stereom; second, smaller and less well-defined spur close to ventro-distal edge of LAP. Inner side of tentacle notch distally bordered by short, oblique ridge. No perforations discernible on inner side of LAP.

\section{Paratype supplements and variation}

GZG.INV.78676 is a dissociated, median LAP; nearly as high as wide; dorsal edge straight; distal edge convex; ventral sixth of LAP slightly protruding; proximal edge of LAP weakly concave, with two very poorly defined, slightly prominent but not protruding spurs; vertical striation on outer surface limited to narrow band close to spine articulations, proximalwards fading into finely meshed stereom. Three spine articulations, ventralmost of which slightly smaller than remaining two; dorsal gap between spine articulations slightly larger than ventral one. Ventral edge of LAP with hardly discernible tentacle notch. Ridge on inner side of LAP well in agreement with that of holotype, ventral portion of ridge less well defined; two barely discernible spurs on inner side of distal edge. Inner side of tentacle notch large. 
GZG.INV.78677 is dissociated, distal LAP; almost twice wider than high; of rectangular outline, with straight dorsal edge and slightly convex distal edge; proximal edge weakly concave, with two almost indiscernible, weakly prominent spurs; outer surface entirely covered by finely meshed stereom, no vertical striation. Two spine articulations in tight notches of distal edge; very narrow gap between spine articulations and distal edge of LAP. Ventral edge of LAP weakly convex, with small, weakly concave tentacle notch.

Inner side with short, oblique, well-defined ridge with pointed dorso-proximal and ventro-distal tips; two almost indiscernible, very weakly prominent spurs on inner side of distal edge of LAP. Tentacle notch narrow, deeply encompassed by thickened ventral edge.

\section{Remarks}

These LAPs are unambiguously assignable to Dermocoma on account of the size, shape and position of the spine articulations, the strongly protruding ventral portion of the LAPs and the shape of the ridge on the inner side. Within this genus, the presence of up to four spine articulations and two horizontally elongate spurs on the outer proximal edge makes it incompatible with any other currently known LAP type assigned to this genus. It is thus described here as a new species.

\section{Occurrence}

Late Pliensbachian of France.

Dermocoma toarcensis (Hess, 1962) comb. nov.

Fig. 26: 7-8

Ophiacantha? toarcensis Hess, 1962: 649, figs 122-125.

"Seewen Typ IIA" - Hess 1962: 635, fig. 28.

Ophiacantha? toarcensis - Kutscher 1996: 17, pl. 3 figs 1-5. — Kutscher \& Villier 2003: 183, pl. 3 figs 5-7.

non Ophiacantha? toarcensis - Thuy 2005: 40, pl. 5 figs 1-6, pl. 6 figs 5-6.

non Ophiacantha? cf. toarcensis - Kutscher \& Hary 1991: 45, pl. 1 fig. 4.

\section{Diagnosis}

Species of Dermocoma with moderately large LAPs displaying a well-developed vertical striation on outer surface; up to three spurs on outer proximal and inner distal edges; up to six large spine articulations; ventral lobe merged with distalwards pointing tip of outer surface separating notches of spine articulations; ridge on inner side of LAPs slender, dorsal part not thickened.

\section{Material examined}

NHMB M11216, NHMB M11217 and 161 dissociated LAPs from the late Toarcian of Seewen, Switzerland, the type material of Hess (1962) termed "Seewen Typ IIA"; 17 dissociated LAPs from the late Pliensbachian of Seewen, Switzerland, the original material of Hess (1962) described as Seewen; the original material of Kutscher (1996) and Kutscher \& Villier (2003).

\section{Description}

Moderately large, dissociated LAPs, proximal ones nearly twice higher than wide, distal ones almost twice wider than high; dorsal edge straight to slightly concave as a result of a weak constriction; distal edge convex; proximal edge irregularly undulose, with up to three poorly to moderately welldefined, horizontally elongate, prominent and protruding spurs, dorsal one of which slightly smaller than remaining two; ventral quarter to fifth of LAP strongly protruding ventro-proximalwards; outer 
surface with fine, regular, vertical striation composed of slightly overlapping lamellae and replaced in proximal half of outer surface by finely meshed stereom. Six (proximal LAPs) to three (distal LAPs) large, ear-shaped spine articulations in notches of elevated distal edge; dorsal and ventral lobes of spine articulations merged into continuous volute; ventral lobe merged with distalwards pointing tips of outer surface separating notches; spine articulations proximally sharply delimited by edge of notches rather than single distalmost lamella or well-defined ridge; notches incising vertical striation of outer surface; spine articulations nearly equal sized, with slighty dorsalward increase in size of gaps separating them; gap between spine articulations and distal edge of LAP narrow. Ventral edge of LAP with small but clearly concave tentacle notch in proximal to median LAPs, straight and devoid of tentacle notch in distal LAPs.

Inner side of LAPs with large, conspicuous, sharply defined, prominent and relatively narrow ridge; ventral part of ridge pointing ventro-proximalwards, sharply separated from thickened ventral portion of LAP, oblique central part and near-vertical, slender dorsal part, with all parts connected by very gentle, rounded kinks; ridge in distal LAPs short, with thickened ventral tip and dorso-proximally pointing, slender dorsal tip; inner side of distal edge of LAP with up to three large, moderately well- to welldefined, oval, prominent spurs composed of more densely meshed stereom; inner side of tentacle notch relatively small, with coarsely meshed, horizontally slightly elongate stereom, sharply defined laterally. Small, irregular perforations in poorly defined vertical row dorsally bordering tentacle notch in proximal to median LAPs.

\section{Remarks}

A re-examination of the LAPs originally described by Hess (1962) as Ophiacantha? toarcensis from the Toarcian of Switzerland has now revealed that the species should be transferred to Dermocoma on account of the size, shape and position of the spine articulations, the strongly protruding ventral portion of the LAP and the shape of the ridge on the inner side. Within this genus, D. toarcensis is unique in combining six spine articulations and up to three spurs on the outer proximal and inner distal edges.

Subsequent records of this species from coeval or slightly younger strata by Kutscher (1996) and Kutscher \& Villier (2003) have proved to be conspecific. The Hettangian and Sinemurian records by Thuy (2005) and Kutscher \& Hary (1991), respectively, belong to different species. The former is here reinterpreted as a new species of Dermocoma, and the latter is a still unknown species which is most probably assignable to Dermocoma - it can only be formally described after re-examination of the original material and/or discovery of new finds. At the present state, this Sinemurian record is best listed as Dermocoma sp.

The LAPs from the Pliensbachian of Seewen, Switzerland, described and illustrated as "Seewen Typ IIA" by Hess (1962) almost certainly belong to Dermocoma toarcensis comb. nov. Kutscher \& Hary (1991) synonymised the LAPs termed "Seewen Typ IIA" with those of "Seewen Typ IA", here re-interpreted as Ophiotoma vadosa sp. nov. (see above), and assigned them to their new species Ophiocten? seeweni Kutscher \& Hary, 1991, which was based on dissociated LAPs from the Sinemurian of Luxembourg. The latter are, however, neither conspecific with "Seewen Typ IIA" nor with "Seewen Typ IA" (original specimens of "Seewen Typ IB and IIB" were not examined). Ophiocten? seeweni is here transferred to Dermacantha gen. nov. (see below).

\section{Occurrence}

Late Pliensbachian to Late Toarcian of Switzerland, Toarcian of France and Toarcian/Aalenian of Germany. 


\section{Dermocoma longwyensis sp. nov. urn:lsid:zoobank.org:act:2EC1952C-3BD6-4708-9BD0-6FCB36214D97}

Fig. 26: 9-11

\section{Diagnosis}

Species of Dermocoma with relatively small LAPs displaying a well-developed, slightly undulose vertical striation; no discernible spurs on outer proximal edge in proximal LAPs; up to two, large, very poorly defined spurs on proximal edge in median to distal LAPs; single moderately well-defined spur on inner distal edge of proximal LAPs, two in median and distal LAPs; up to six large spine articulations; ventral lobe connected with distalwards projecting tip of outer surface stereom separating notches; ridge on inner side long, slender, devoid of thickened dorsal part.

\section{Etymology}

Named after Longwy, the type locality.

\section{Type material}

\section{Holotype}

GZG.INV.78679.

\section{Paratypes}

GZG.INV.78680 and GZG.INV.78681.

\section{Type locality and horizon}

Piedmont near Longwy, France; Laeviuscula Zone, early Bajocian, Middle Jurassic.

\section{Additional material}

GZG.INV.78682 (91 dissociated LAPs) from the early Bajocian of Longwy; GZG.INV.78683 (29 dissociated LAPs) from the Humphriesianum Zone, early Bajocian of Cirey-lès-Nolay, France.

\section{Description}

\section{Holotype}

GZG.INV.78679 is a dissociated, small, proximal LAP; slightly more than 1.5 times higher than wide; dorsal edge slightly convex; distal edge convex; proximal edge concave, devoid of well-developed, discernible spurs; ventral fifth of LAP strongy protruding ventro-proximalwards; outer surface with moderately fine, slightly undulose vertical striation composed of slightly overlapping, irregular lamellae and replaced by finely meshed stereom on proximal half of outer surface. Six large, ear-shaped spine articulations in notches of elevated distal portion of LAP; slighty dorsalward increase in size of spine articulations; gaps separating spine articulations clearly increasing in size larger towards dorsal edge of LAP; ventral and dorsal lobes of spine articulations merged into continuous volute; ventral lobe connected with distalwards projecting tips of outer surface stereom separating notches; spine articulations sharply bordered proximally by edge of notches rather than single distalmost lamella or ridge; notches incising vertical striation; narrow gap separating spine articulations and distal edge of LAP. Ventral edge of LAP with moderately large, concave tentacle notch.

Inner side of LAP with long, well-defined, prominent, rather slender ridge; ventral part of ridge gently bent, pointing ventro-proximalwards, merged ventrally with slightly thickened ventral portion of LAP; central part of ridge straight, oblique; dorsal part largely obscured by sediment, straight and almost vertical, not widened; three parts of ridge connected with very gentle, round kinks; inner side of distal edge of LAP with single small, moderately well-defined, very weakly prominent, round spur composed of densely meshed stereom; inner side of tentacle notch moderately large, well defined laterally; shallow, 
moderately well-defined vertical furrow with few small, scattered perforations dorsally bordering tentacle notch.

\section{Paratype supplements and variation}

GZG.INV.78680 is a dissociated median LAP; slightly less than 1.5 times higher than wide; very well in agreement with holotype; single large, slightly prominent, non-protruding, very poorly defined, almost indiscernible spur in ventral half of proximal edge. Five spine articulations similar to those observed on holotype.

Ridge on inner side of LAP better preserved; dorsal part straight, almost vertical, very close to proximal edge of LAP. Few small, scattered perforations loosely arranged in vertical row dorsally bordering tentacle notch.

GZG.INV.78681 is a dissociated distal LAP; slightly wider than high; proximal edge with two large, weakly prominent, non-protruding, very poorly defined, almost indiscernible spurs; vertical striation on outer surface more regular than in holotype. Four spine articulations similar to those observed on holotype; connection between ventral lobe of spine articulations and distalwards projecting tip of outer surface stereom separating notches very thin, weak. Ventral edge of LAP with small, weakly concave tentacle notch.

Ridge on inner side of LAP with oblique, slender dorsal part pointing dorso-proximalwards; ventral part of ridge widened, nearly triangular, separated from thickened ventral portion of LAP. Single, moderately large, irregular perforation dorsally bordering tentacle notch.

\section{Remarks}

These LAPs display all distinctive features to warrant assignment to the genus Dermocoma. The presence of up to six spine articulations is a feature shared with the LAPs of Dermocoma toarcensis comb. nov. and $D$. numbergerorum sp. nov. While the former differ in having up to three, rather than two, spurs on the outer proximal and inner distal edges, the latter display two much better-defined, widely separated spurs, a generally larger size and conspicuously large, wide ventral portions.

\section{Occurrence}

Early Bajocian of France.

Dermocoma wrighti Hess, 1964

Fig. 27: 1-2

Dermocoma wrighti Hess, 1964: 78, figs 42-45, pl. 6, pl. 10 fig. 2.

p.p. "Liesberg Typ I" - Hess 1963: 1151, figs 19-21.

p.p. Dermocoma wrighti - Hess \& Holenweg 1985: 146, fig. 2.

Dermocoma wrighti - Kutscher 1987a: 62, pl. 2 fig. 2, pl. 4 fig. 1.

non Dermocoma wrighti - Hess 1972a: 36, figs 39-41, pl. 13 fig. 1.

\section{Diagnosis}

Species of Dermocoma with moderately large LAPs displaying two poorly to moderately well-defined spurs on the outer proximal edge, dorsal one of which larger, developed as swollen part of proximal edge rather than well-defined spur; outer surface with well-defined, moderately fine vertical striation; up to five large spine articulations in notches of distal portion of LAP, and with distalward increase in size; ridge on the inner side with long, near-straight, oblique dorsal portion devoid of thickened parts. 


\section{Material examined}

NHMB M11218, NHMB M11219 and 13 dissociated LAPs from the Koenigi Zone, early Callovian of Liesberg, Switzerland, the original material of Hess (1963); GZG.INV.78684 (133 dissociated LAPs) from the Humphriesianum Zone, early Bajocian of Cirey-lès-Nolay, France; GZG.INV.78685 (8 dissociated LAPs) from the Humphriesianum Zone, early Bajocian of Delkhofen, Germany; GZG. INV.78686 (3 dissociated LAPs) from the Callovian of Bauer-Wehrland, Germany, the original material of Kutscher (1987a).

\section{Description}

Moderately large, dissociated LAPs; proximal ones slightly higher than wide, distal ones slightly wider than high; dorsal edge straight to weakly concave as a result of a poorly developed constriction; distal edge convex; proximal edge concave, with two poorly to moderately well-defined spurs, dorsal one large, prominent, strongly protruding, developed as swollen part of proximal edge rather than sharply defined spur; ventral spur much smaller, less strongly protruding; ventral fifth of LAPs strongly ventro-proximalwards protruding; outer surface with well-developed, moderately fine vertical striation composed of slightly irregular, weakly overlapping lamellae, and replaced by finely meshed stereom on proximal half of outer surface. Five large, ear-shaped spine articulations in notches of elevated distal portion of LAP; ventral and dorsal lobes of spine articulations merged into continuous volute; ventral lobe connected with distalwards projecting tips of outer surface separating notches; spine articulations proximally sharply separated by edge of notches rather than single distalmost lamella or ridge; dorsalward increase in size of spine articulations and of gaps separating them; moderately wide gap between spine articulations and distal edge of LAP. Ventral edge of LAP with small, concave tentacle notch in all LAPs. Inner side of LAPs with large, conspicuous, sharply defined, prominent, slender ridge; ventral part of ridge ventro-proximalwards bent, not merged with thickened ventral portion of LAP; dorsal part of ridge much longer than ventral one, almost straight, slightly oblique devoid of thickened part; ridge in distal LAPs moderately short, strongly oblique, with dorso-proximally pointing dorsal tip, and widened ventral tip; inner side of distal edge of LAP with two moderately well-defined spurs, dorsal one of which slightly larger than ventral one; inner side of tentacle notch relatively small, well defined laterally. Shallow, poorly defined vertical furrow with irregular, scattered minute perforations dorsally bordering tentacle notch in proximal to median LAPs.

\section{Remarks}

The original description of Dermocoma wrighti, the type species of the genus, by Hess (1964) provided only limited data on LAP morphology. A careful re-examination of the type specimens has now enabled a detailed, comprehensive LAP morphological diagnosis to be worked out as a basis of comparison with other records based exclusively on dissociated LAPs. In this way it has been possible to confirm Kutscher's (1987a) observation that the dissociated LAPs from the Callovian of Switzerland described earlier by Hess (1963) as "Liesberg Typ I" were assignable to Dermocoma wrighti. The LAPs of this species are characterised by the combination of up to five spine articulations and two moderately welldefined spurs on the outer proximal and inner distal edges, the dorsal one which being larger and better defined. This combination is also found in the LAPs originally described as Ophiacantha? biformis Hess, 1975, here shown to be assignable to Dermocoma (see below). In that species, however, the spine articulations are nearly of equal size, whereas in $D$. wrighti they display a dorsalward increase in size. In addition, the ridge of $D$. wrighti is devoid of thickened parts.

\section{Occurrence}

Early Bajocian of France and Germany; early Callovian of Switzerland and Callovian of Germany. 


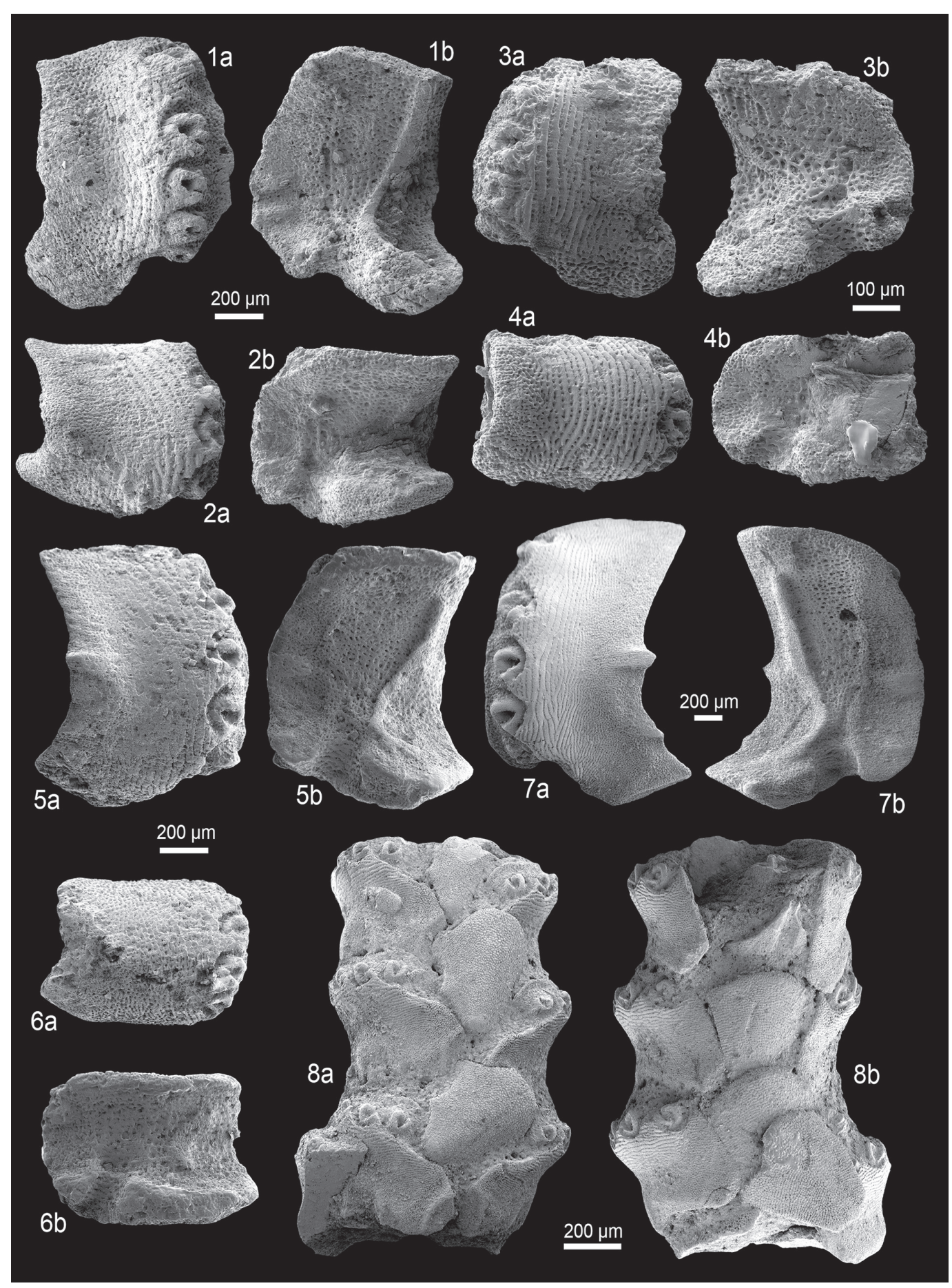

Fig. 27. Fossil lateral arm plates in external (a) and internal (b) views and articulated arm fragment of ophiacanthid brittle stars. 1-2. Dermocoma wrighti Hess, 1964 from the early Callovian (Middle Jurassic) of Liesberg, Switzerland. 1. NHMB M11218, proximal LAP. 2. NHMB M11219, distal LAP. 3-4. Dermocoma sp. 1 from the Callovian (Middle Jurassic) of Jumara, India. 3. GZG.INV.78687, proximal LAP. 4. GZG.INV.78688, distal LAP. 5-8. Dermocoma biformis (Hess, 1975) comb. nov. from the late Oxfordian (Late Jurassic) of Guldental, Switzerland (5-6) and Savigna, France (7-8). 5. NHMB M11220, proximal LAP. 6. NHMB M11221, distal LAP. 7. GZG.INV.78690, proximal LAP. 8. GZG. INV.78692, proximal arm fragment in ventral (a) and dorsal (b) views. One common scale bar for 1-2, $3-4,5-6,7$ and 8 respectively. 


\section{Dermocoma sp. 1}

Fig. 27: 3-4

\section{Material examined}

GZG.INV.78687 and GZG.INV.78688 from sample 95, lower Chari Formation, Callovian of Jumara, India; GZG.INV.78689 (dissociated LAP) from sample 24, Patcham Formation, late Bathonian of Jumara, India.

\section{Description}

GZG.INV.78687 is a dissociated, moderately large, proximal LAP; slightly higher than wide; dorsal edge fragmentary; distal edge convex; proximal edge irregularly concave, poorly preserved, no spurs discernible; ventral fifth of LAP strongly protruding ventro-proximalwards; outer surface with moderately coarse, regular vertical striation composed of very weakly overlapping lamellae replaced by finely meshed stereom on ventral portion of LAP and proximal third of outer surface. Four moderately large, equal-sized, ear-shaped spine articulations in shallow notches of slightly elevated distal edge of LAP; spine articulations proximally bordered by edge of notches; dorsal and ventral lobes of spine articulations merged into continuous volute; notches of spine articulations incising outer surface striation; very weak dorsalward increase in size of gaps separating spine articulations; probably very weak, thin connection between ventral lobe of spine articulations and distalwards projecting tip of outer surface stereom separating notches. Ventral edge of LAP with small, concave tentacle notch.

Inner side of LAP with relatively small, very slender, well-defined, slightly prominent ridge composed of ventro-proximalwards bent ventral part and nearly straight, oblique, dorso-proximalwards pointing, non-thickened dorsal part; no spurs discernible on inner side of distal edge of LAP; inner side of tentacle notch moderately small. No perforations or furrow discernible.

GZG.INV.78688 is a dissociated distal LAP; slightly less than 1.5 times wider than high; dorsal edge very weakly concave; proximal edge concave, with two small, poorly defined, prominent, weakly protruding, horizontally elongate spurs; vertical striation on almost entire outer surface. Three poorly preserved spine articulations similar to those observed in the specimen described above; weak dorsalward increase in size of spine articulations and of gaps separating them. Ventral edge of LAP gently convex; tentacle notch invisible in external view.

Inner side of LAP largely obscured by sediment; inner side of distal edge with two small, poorly defined, weakly prominent, horizontally elongate spurs; inner side of tentacle notch moderately small.

\section{Remarks}

In spite of its poor preservation, this material displays a distinctive combination of characters that warrants assignment to Dermocoma. The limited amount of material precludes a meaningful assessment at the species level. Nevertheless, it is worth recording this material since it is the first known record of Dermocoma from the Southern Hemisphere.

\section{Occurrence}

Late Bathonian to Callovian of India.

Dermocoma biformis (Hess, 1975) comb. nov.

Fig. 27: 5-8

Ophiacantha? biformis Hess, 1975a: 594, figs 10-12, pl. 1 fig. 6 [non pl. 1 fig. 5, which is not an ophiacanthid].

Ophiacantha? biformis - Hess 1975b: 608, figs 8-9. 


\section{Diagnosis}

Species of Dermocoma with very large LAPs displaying two well-defined spurs on outer proximal and inner distal edges; dorsal spur very large, prominent and strongly protruding, ventral spur smaller and less strongly protruding; fine, well-developed vertical striation on distal half of outer surface; up to five moderately large, equal-sized spine articulations in tight notches of distal portion of LAP; ridge on inner side large, relatively slender, with long, near-straight, almost vertical dorsal part slightly thickened at its centre.

\section{Material examined}

NHMB M11220, NHMB M11221 and 120 dissociated LAPs from the Günsberg Member, late Oxfordian of Guldental, Switzerland; GZG.INV.78690 and GZG.INV.78691 (137 dissociated LAPs) from sample S2a of Gale (2011) from the late Oxfordian of Savigna, France; GZG.INV.78692, GZG.INV.78693 (51 dissociated LAPs) from sample S2b of Gale (2011) from the late Oxfordian of Savigna, France; GZG. INV.78694 (36 dissociated LAPs) sample S1 of Gale (2011) from the late Oxfordian of Savigna, France; 14 dissociated LAPs from the Humeralis Member, late Oxfordian of Raedersdorf, France, original material of Hess (1975b); 33 dissociated LAPs from the Bifurcatus Zone, late Oxfordian of Guldental, Switzerland, the original material of Hess (1966); 11 dissociated LAPs from the Renggeri Member, early Oxfordian of Chapois, France, the original material of Hess (1965a).

\section{Description}

Very large, dissociated LAPs; proximal ones 1.5 times higher than wide, distal ones almost twice wider than high; dorsal edge slightly convex (proximal LAPs) to slightly concave (distal ones) as a result of a weak constriction; distal edge convex; proximal edge concave, with two spurs; dorsal spur very large, well-defined, oval, prominent and strongly protruding at least in proximal to median LAPs; ventral spur much smaller, less well-defined, weakly prominent and protruding; ventral fifth of LAPs strongly protruding ventro-proximalwards; outer surface with well-developed fine, vertical striation composed of slightly wavy, fine, weakly overlapping lamellae close to spine articulations, and replaced by very finely meshed stereom on proximal half of outer surface. Five (proximal LAPs) to three (distal ones) moderately large, ear-shaped spine articulations in relatively tight notches of the slightly elevated distal portion of the LAPs; ventral and dorsal lobes of spine articulations merged into continuous volute; ventral lobe with very weak and thin connection with distalwards projecting tips of outer surface separating notches; spine articulations proximally sharply separated by edge of notches; spine articulations nearly equal sized; dorsalward increase in size of gaps separating spine articulations; narrow gap between spine articulations and distal edge of LAP. Ventral edge of LAP with small, concave tentacle notch in all but the distalmost LAPs.

Inner side of LAPs with large, conspicuous, sharply defined, prominent, moderately slender ridge; ventral part of ridge ventro-proximalwards bent, confluent with thickened ventral portion of LAP; dorsal part of ridge longer than ventral one, almost straight, slightly oblique with weakly thickened central part; ridge in distal LAPs short, oblique, with dorso-proximalwards pointing dorsal tip, widened ventral tip, and distally bordered by small round knob; inner side of distal edge with two moderately well-defined, oval spurs composed of densely meshed stereom; dorsal spur much larger than ventral one in proximal to median LAPs; inner side of tentacle notch small, deeply incised and sharply bordered laterally. Very shallow, poorly defined vertical furrow with few, minute perforations dorsally bordering tentacle notch and distally bordered by moderately well-defined, narrow and weakly prominent ridge; no perforations or furrow discernible in distal LAPs.

Articulated arm fragments preserving median to proximal segments; ventral arm plates large, slightly longer than wide, polygonal, with straight to weakly concave distal edge, straight distalwards converging latero-distal edges; concave lateral and latero-proximal edges and a right to slightly acute proximal angle; LAPs in contact ventrally but not separating ventral arm plates; tentacle pores small, covered 
by at least one small, leaf-like tentacle scale; dorsal arm plates large, slightly longer than wide, widest distally separating LAPs, nearly trapezoid in outline, with convex distal edge, distalwards diverging, straight lateral edges and slightly convex proximal edge; dorsal arm plates with very fine transverse striation.

\section{Remarks}

Hess (1975a) originally described a set of dissociated LAPs from the Oxfordian of Switzerland as Ophiacantha? biformis, the species name being chosen to reflect the fact that median and distal LAPs display a vertical striation which the proximal ones completely lack. However, as suggested by the observations of Thuy \& Stöhr (2011), the type of ornament on the outer surface of the LAPs within one species is very unlikely to change fundamentally according to the position along the arm. Indeed, a careful re-examination of the type material has revealed that it included more than one type of LAPs and that a number of proximal LAPs, including the holotype, display the same vertical striation, although limited to a narrow band near the spine articulations, as observed on the median and distal LAPs. The original description and diagnosis of Ophiacantha? biformis are based on at least two different types of LAPs, which is a prime example of why, for new species based on dissociated LAPs, the holotype and the paratypes should always be described individually (Thuy \& Stöhr 2011).

The LAP type corresponding to the holotype of Ophiacantha? biformis can unambiguously be assigned to the genus Dermocoma on account of the shape, size and position of the spine articulations, the strongly protruding ventral portion of the LAPs and the shape of the ridge on the inner side. Closest similarities are shared with the LAPs of $D$. wrighti which, however, differ in displaying a dorsalward increase in size of the spine articulations, a slender ridge devoid of thickened parts, and a slightly less sharply defined dorsal spur on the outer proximal edge.

New finds assignable to Dermocoma biformis comb. nov. from the Oxfordian of France include articulated arm fragments which complement the morphological data based on dissociated LAPs. The additional data on arm morphology are in agreement with the assignment to Dermocoma and furthermore suggest that the dorsal arm plate illustrated by Thuy (2005) and originally assigned to Ophiacantha? toarcensis (see above), indeed, belongs to Dermocoma, most probably to $D$. faberi sp. nov.

\section{Occurrence}

Early Oxfordian of France; late Oxfordian of Switzerland and France.

Dermocoma numbergerorum sp. nov. urn:1sid:zoobank.org:act:EAD1DA00-C38B-49E3-B753-867F4C4DFA62

Fig. 28: 1-4

\section{Diagnosis}

Species of Dermocoma with large LAPs displaying a well-developed, fine vertical striation on distal half of outer surface; ventral portion of proximal LAPs very large and wide; two large, nearly equalsized, strongly protruding, moderately well-defined and widely separate spurs on proximal outer edge of proximal LAPs: up to six large, nearly equal-sized spine articulations; dorsalward increase in gaps separating spine articulations; ridge on the inner side with long, slender, near-straight and oblique dorsal part with triangular, elongate, pointed dorsal tip.

\section{Etymology}

Species named in honour of Sabine and Klaus Numberger, the best in-laws of the Phanerozoic. 


\section{Type material}

Holotype

GZG.INV.78695.

Paratypes

GZG.INV.78696, GZG.INV.78697 and GZG.INV.78698.

\section{Type locality and horizon}

Foug, France; marly pockets between coral bioherms, Transversarium Zone, middle Oxfordian, Late Jurassic.

\section{Additional material}

GZG.INV.78699 (201 dissociated LAPs).

\section{Description}

\section{Holotype}

GZG.INV.78695 is a dissociated, large, proximal LAP; 1.5 times higher than wide; dorsal edge nearly straight; distal edge slightly convex; ventral quarter of LAP very large, wide, strongly protruding ventroproximalwards; proximal edge irregularly undulose, with two large, almost equal-sized, moderately well-defined, prominent and conspicuously protruding, widely separate spurs; outer surface with very fine, regular vertical striation composed of slender, slightly overlapping lamellae, and replaced by very finely meshed stereom on the proximal two-thirds of the outer surface. Five large, nearly equal-sized, ear-shaped spine articulations in tight notches of elevated distal portion of LAP; ventral lobe merged with dorsal one into continuous volute, and connected with distalwards projecting tip of outer surface separating notch; spine articulations proximally sharply separated by edge of notch; dorsalward increase in size of gaps separating spine articulations; notches deeply incising vertical striation; moderately wide gap between spine articulations and distal edge of LAP. Ventral edge of LAP with moderately large, concave tentacle notch.

Inner side of LAP with large, sharply defined, prominent, slender ridge; ventral part of ridge gently bent ventro-proximalwards, not merged with weakly thickened ventral portion of LAP; dorsal part of ridge much longer than ventral one, nearly straight, oblique, with elongate, very slender triangular, pointed, approximately knife-shaped dorsal tip; inner side of distal edge with two moderately well-defined, widely separate, weakly prominent, oval spurs composed of more densely meshed stereom; ventral spur slightly smaller than dorsal one; inner side of tentacle notch moderately large, well defined laterally. Shallow, moderately well-defined vertical furrow dorsally bordering tentacle notch; no perforations discernible.

\section{Paratypes}

GZG.INV.78696 is a dissociated proximal LAP; very well in agreement with holotype; proximal edge and ventral portion slightly fragmentary; spurs on proximal edge as in holotype. Six spine articulations similar to those observed on holotype but less well preserved.

Inner side of LAP matching that of holotype. Vertical furrow with few small, scattered perforations.

GZG.INV.78697 is a dissociated median LAP; slightly higher than wide; proximal edge with two moderately well-developed, strongly prominent and protruding spurs; not as widely separated as in holotype, and dorsal spur slightly larger than ventral one; vertical striation on distal half rather than third of outer surface. Five spine articulations similar to those observed on holotype; dorsalward increase in size of gaps separating spine articulations stronger than in holotype; gap between spine articulations and distal edge of LAP narrower. 


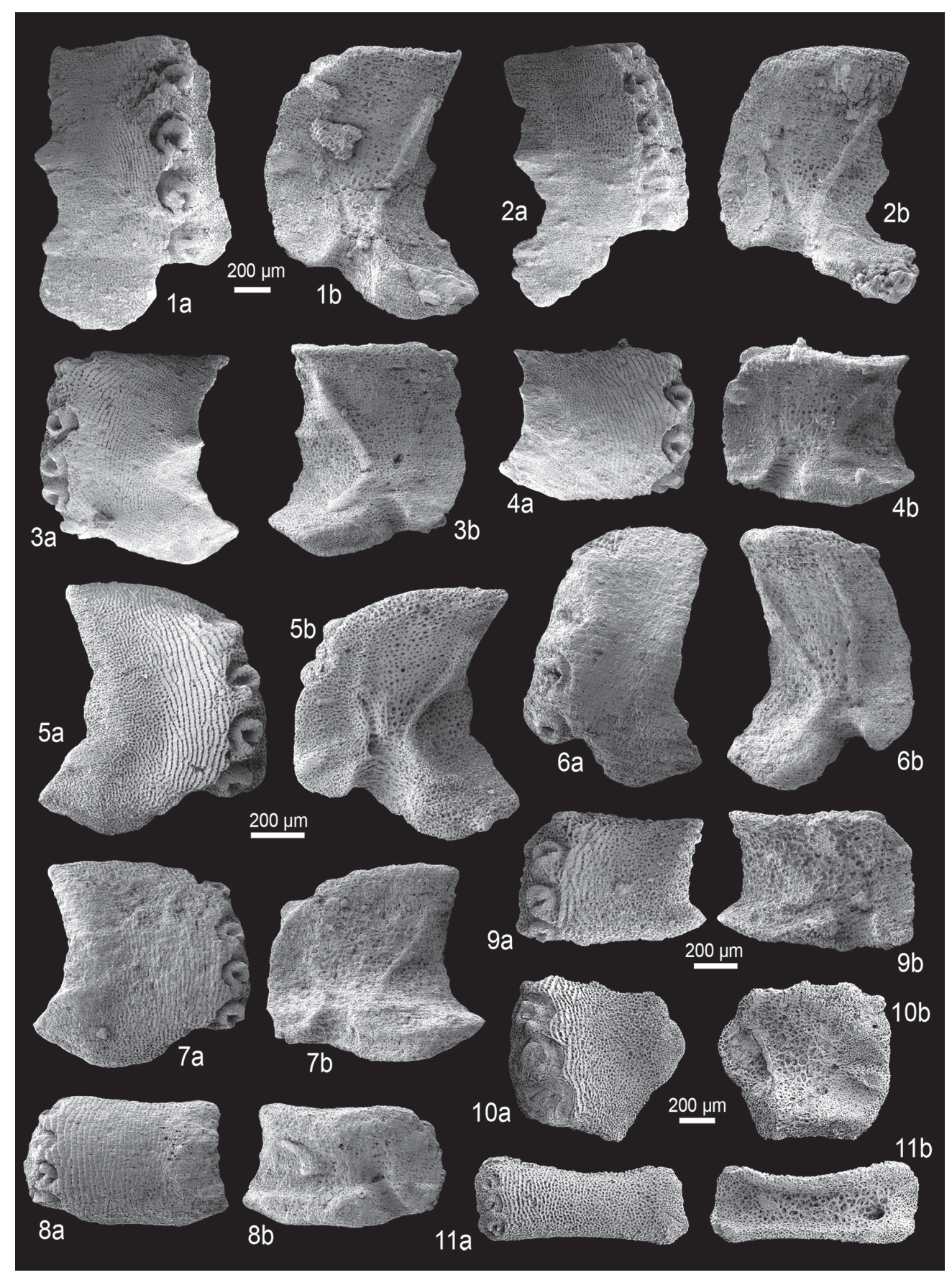

Fig. 28. Fossil lateral arm plates (LAPs) of ophiacanthid brittle stars in external (a) and internal (b) views. 1-4. Dermocoma numbergerorum sp. nov. from the middle Oxfordian (Late Jurassic) of Foug, France. 1. GZG.INV.78695 (holotype), proximal LAP. 2. GZG.INV.78696 (paratype), proximal LAP. 3. GZG.INV.78697 (paratype), median LAP. 4. GZG.INV.78698 (paratype), distal LAP. 5-8. Dermocoma simonschneideri sp. nov. from the early Kimmeridgian (Late Jurassic) of the Pointe du Chay, France (5) and the late Kimmeridgian (Late Jurassic) of Trancoso, Portugal (6-8). 5. GZG.INV.78700 (holotype), proximal LAP. 6. GZG.INV.78701 (paratype), proximal LAP. 7. GZG.INV.78702 (paratype), median LAP. 8. GZG. INV.78703 (paratype), distal LAP. 9. Dermocoma sp. nov. innom. 2 from the early Kimmeridgian (Late Jurassic) of Geisingen, Germany; GZG.INV.78705, median to distal LAP. 10-11. Dermocoma sp. nov. innom. 3 from the late Valanginian (Early Cretaceous) of the Ternberg Nappe, Austria. 10. NHMW 2012/0138/0009, proximal LAP. 11. NHMW 2012/0138/0010, distal LAP. One common scale bar per species. 
Inner side of LAP with ridge similar to that of holotype; spurs on inner side of distal LAP edge almost indiscernible. Two to three irregular, variably sized perforations dorsally bordering tentacle notch; no furrow discernible.

GZG.INV.78698 is a dissociated distal LAP; slightly wider than high; dorsal edge slightly concave as a result of a weak constriction; ventral portion of LAP weakly protruding ventro-proximalwards; spurs as in holotype; distal two-thirds of outer surface with vertical striation. Four spine articulations similar to those observed on holotype. Tentacle notch not visible in external view.

Inner side of LAP with sharply defined, slender, bent ridge; dorsal part of ridge dorso-proximally pointing, not thickened, with rounded tip; ventral part of ridge ventro-proximally pointing, with very weakly thickened ventral tip; inner side of tentacle notch relatively small, with coarsely meshed, horizontally elongate stereom, and sharply defined laterally. Very shallow, poorly defined vertical furrow dorsally bordering tentacle notch.

\section{Remarks}

Assignment of these LAPs to Dermocoma is corroborated by the strongly ventro-proximally protruding ventral portion of the LAPs, the shape and position of the spine articulations and the shape of the ridge on the inner side. Within this genus, the present LAPs are unique in combining up to six spine articulations, two well-defined, widely separate spurs on the outer proximal and inner distal edges, and a conspicuously large and wide ventral portion. They are thus described here as a new species of Dermocoma.

Dermocoma simonschneideri sp. nov. urn:1sid:zoobank.org:act:D3449C2A-A9F1-42F1-87B0-CB8E0210232A

Fig. 28: 5-8

\section{Diagnosis}

Species of Dermocoma with large LAPs displaying a very well-developed vertical striation on at least half of the outer surface; large, oval and conspicuously oblique spur on proximal edge; four spine articulations sunken in deep notches of a poorly elevated distal LAP portion; ridge on inner side very slender, with ventral tip merged with ventral portion of LAP, and dorsal tip slightly widened and merged with proximal edge of LAP.

\section{Etymology}

Species named in honour of Simon Schneider, who kindly provided the samples yielding the type material of the species.

\section{Type material}

Holotype

GZG.INV.78700.

\section{Paratypes}

GZG.INV.78701, GZG.INV.78702 and GZG.INV.78703 from the late Kimmeridgian (Late Jurassic) of Trancoso, Portugal.

\section{Type locality and horizon}

Pointe du Chay near La Rochelle, France; Achilles Subzone, Cymodoce Zone, early Kimmeridgian, Late Jurassic. 


\section{Additional material}

GZG.INV.78704 (14 dissociated LAPs) from the Amaral Formation, late Kimmeridgian of Trancoso, Portugal.

\section{Description}

\section{Holotype}

GZG.INV.78700 is a dissociated, large, proximal to median LAP; slightly higher than wide; dorsal and distal edges convex; proximal edge irregularly concave, with large, moderately well-defined, slightly prominent, non-protruding, oval and conspicuously oblique spur; ventral quarter of LAP strongly protruding ventro-proximalwards; distal half of outer surface with very well-developed, fine, regular vertical striation composed of overlapping lamellae, replaced by finely meshed stereom on proximal half of outer surface. Four relatively large, ear-shaped, nearly equal-sized spine articulations in deep notches of slightly elevated distal portion of LAP; ventral lobe merged with dorsal one into continuous volute but only weakly connected with distally projecting tip of outer surface between notches; spine articulations proximally sharply separated by edge of notches; weak dorsalward increase in size of gaps separating spine articulations; gap between spine articulations and distal edge of LAP very narrow. Ventral edge of LAP with small, weakly concave tentacle notch.

Inner side of LAP with moderately large, very slender, gently bent ridge; ventral tip pointing ventralwards, merged with ventral portion of LAP; dorsal tip pointing dorso-proximally, slightly widened and merged with proximal edge of LAP; inner side of distal edge of LAP with small, well-defined, prominent, oval and oblique spur composed of densely meshed stereom; inner side of tentacle notch relatively large, with coarsely meshed, horizontally elongate stereom; well defined laterally. Short, shallow, rather broad, irregular and slightly oblique furrow with highly variable perforations dorsally bordering tentacle notch.

\section{Paratypes}

GZG.INV.78701 is a dissociated proximal LAP; approximately 1.5 times higher than wide; very well in agreement with holotype; outer surface less well defined, vertical striation not discernible. Four spine articulations similar to those of holotype.

Inner side of LAP with ridge similar to that of holotype but slightly longer; spur on inner side of distal edge poorly defined. Short, slightly oblique furrow as in holotype but distally bordered by broad, poorly defined and weakly prominent ridge.

GZG.INV.78702 is a dissociated median LAP; slightly wider than high; very well in agreement with holotype; vertical striation slightly finer and on distal two-thirds rather distal half of outer surface. Four spine articulations slightly smaller than those observed on holotype, otherwise similar.

Ridge on inner side of LAP with more strongly widened dorsal tip; spur on inner side of distal LAP edge very poorly defined, almost indiscernible. No perforations or furrow discernible.

GZG.INV.78703 is a dissociated distal LAP; more than 1.5 times wider than high; dorsal edge slightly concave as a result of a very weak constriction; proximal edge with two moderately well-defined spurs, dorsal one of which largest; vertical striation on three-quarters of outer surface. Four spine articulations smaller than those of holotype and poorly preserved, otherwise similar. Tentacle notch invisible in external view.

Inner side of LAP with small, sharply defined ridge, with pointed, proximalwards bent dorsal tip, and widened ventral tip, not merged with ventral portion of LAP; inner side of distal edge of LAP with two poorly defined, large, oval, weakly prominent spurs; inner side of tentacle notch small, oblique, laterally well defined. Single, relatively large perforation dorsally bordering tentacle notch. 


\section{Remarks}

In spite of the limited amount of material available, these LAPs are unambiguously assignable to the genus Dermocoma on account of the highly characteristic combination of the strongly protruding ventral portion of the LAP, the nearly equal-sized spine articulations in regularly spaced notches of the weakly elevated distal portion of the LAP, and the simple ridge on the inner side devoid of sharp kinks or conspicuously widened parts. The single large, conspicuously oblique spur on the outer proximal and inner distal edges of the proximal and median LAPs is a highly distinctive feature not found in any other species assigned to Dermocoma.

\section{Occurrence}

Early Kimmeridgian of France and late Kimmeridgian of Portugal.

Dermocoma sp. nov. innom. 2

Fig. 28: 9

\section{Material examined}

GZG.INV.78705 from the Lacunosa Marls, early Kimmeridgian of Geisingen, Germany.

\section{Description}

GZG.INV.78705 is a small, dissociated median to distal LAP; slightly wider than high; dorsal edge weakly concave; distal edge convex, slightly oblique; proximal portion of LAP small, very weakly protruding ventro-proximalwards; proximal edge concave, with two very poorly defined, small, weakly prominent albeit protruding, horizontally elongate spurs; outer surface with poorly developed, irregular, vertical striation composed of slightly overlapping lamellae close to spine articulations, replaced by finely meshed stereom in proximal three-quarters of outer surface. Four large, ear-shaped spine articulations in shallow notches of very weakly elevated distal portion of LAP; strong dorsalward increase in size of spine articulations and of gaps separating them; dorsal and ventral lobes of spine articulations merged into continuous volute; row of spine articulations dorso-proximalwards receding; gap between spine articulations and distal edge of LAP narrow, widest near ventralmost spine articulation. Ventral edge of LAP nearly straight, with small, very shallow, almost indiscernible tentacle notch.

Inner side of LAP with relatively small, well-defined, prominent, oblique ridge with slender dorsoproximalwards pointing dorsal part and strongly widened, short, ventro-proximalwards pointing ventral part; inner side of distal edge of LAP with two moderately large, poorly defined, weakly prominent spurs; inner side of tentacle notch small, moderately well-defined laterally. No perforations or furrow discernible.

\section{Remarks}

In spite of the very limited amount of material available, this LAP type is clearly assignable to Dermocoma on account of the spine articulation structure, the two spurs on the outer proximal and inner distal edges, and the shape of the ridge on the inner side of the LAP. Both LAPs available are from median to even distal arm portions, which hampers a sound systematic assessment. It seems clear, however, that this LAP type is incompatible with any known species of Dermocoma on account of the oblique distal edge and similarly oblique row of spine articulations which display a strong dorsalward increase in size. In the absence of more material, in particular from proximal arm portions, the present LAP type is here treated as a new, still unnamed, species of Dermocoma. 
Dermocoma sp. nov. innom. 3

Fig. 28: 10-11

\section{Material examined}

NHMW 2012/0138/0009, NHMW 2012/0138/0010 and NHMW 2012/0138/0011 (25 dissociated LAPs) from the Verrucosum Zone, late Valanginian of the KB1-A section of Lukeneder (2004), Ternberg Nappe, Austria.

\section{Description}

Dissociated, small, fragile, fragmentary proximal to median LAPs and a single complete distal LAP; proximal ones originally as high as wide or slightly higher; median ones slightly wider than high; distal LAP more than twice wider than high; dorsal edge concave in median to distal LAPs as a result of a weak constriction; distal edge convex; proximal edge of distal LAP with two small, poorly defined, slightly prominent and protruding spurs; no spurs discernible in fragmentary proximal edge of median to distal LAPs; ventral portion of median to proximal LAP fragmentary, originally most probably protruding; outer surface with very fine, irregular, slightly wavy vertical striation composed of very slender, slightly overlapping lamellae, and replaced by finely meshed stereom on proximal three-quarters of outer surface. Three rather small, ear-shaped spine articulations in notches of weakly elevated distal portion of LAP; possibly more spine articulations in proximal LAP; weak dorsalward increase in size of spine articulations in proximal LAP; ventral lobe of spine articulations not connected with outer surface stereom and merged with dorsal lobe into continuous volute; spine articulations proximally bordered by edge of notches; gap between spine articulations and distal edge of LAP narrow. Small, weakly concave tentacle notch in median LAPs; ventral edge of distal LAP evenly concave, tentacle opening emerging at ventro-distal edge of ventralmost spine articulation.

Inner side of proximal to median LAPs with sharply defined, prominent, very slender, slightly bent, oblique ridge dorsal tip of which pointing dorso-proximalwards and ventral tip pointing ventroproximalwards; two widely separate, sharply defined, prominent knobs on inner side of distal LAP, proximal one nearly triangular, distal one minute, almost indiscernible; inner side of distal edge of LAP with up to two poorly to moderately well-defined, small, oval, slightly prominent spurs; inner side of tentacle notch not preserved in proximal LAP, moderately large, well-defined laterally and with coarsely meshed, horizontally elongate stereom in median LAP; distal LAP with large tentacle perforation in the middle of the distal third. Two small, irregular perforations loosely arranged in vertical row on inner side of proximal LAP fragment.

\section{Remarks}

This material is very limited and largely fragmentary; yet, the shape and position of the spine articulations, the spurs on the outer proximal and inner distal edges and the shape of the ridge on the inner side strongly suggest assignment to Dermocoma. The fragmentary nature precludes assignment at the species level. Nevertheless, the material is very important since it was recovered from deep shelf to upper slope sediments and thus represents the deepest occurrence of Dermocoma recorded to date.

Dermocoma sp. nov. innom. 4

Fig. 29: 1

\section{Material examined}

NHM EE 14844 from the Tardefurcata Zone, early Albian of Leighton Buzzard, Great Britain. 


\section{Description}

Dissociated, single, very large, proximal LAP; approximately twice higher than wide; dorsal and distal edges convex; ventral fifth of LAP strongly protruding ventro-proximalwards; proximal edge of LAP concave, with large central, swollen, protruding part not discernible as spur; outer surface with well-developed, regular vertical striation composed of fine, overlapping lamellae decreasing in size proximalwards; striation replaced by finely meshed stereom on proximal third of outer surface. Six moderately large, ear-shaped spine articulations in notches of weakly elevated distal portion of LAP; spine articulations equal-sized except for slightly smaller ventralmost one; weak dorsalward increase in size of gaps separating spine articulations; spine articulations proximally sharply bordered by edge of notches; ventral lobe of spine articulations with weak connection with distalwards projecting tip of outer surface stereom separating notches, and merged with dorsal lobe into continuous volute; gap between spine articulations and distal edge of LAP very narrow. Ventral edge of LAP with small, concave tentacle notch.

Inner side of LAP with moderately well-defined, prominent, very slender ridge with ventralwards pointing ventral part not merged with thickened ventral portion of LAP; dorsal part of ridge slightly bent, oblique, pointing dorso-proximalwards; ridge devoid of thickened parts and sharp kinks; inner side of distal edge with single, large, moderately well-defined, prominent, round spur; inner side of tentacle notch small, well defined laterally. Very shallow, poorly defined vertical furrow with small, scattered perforations dorsally bordering tentacle notch and distally bordered by narrow, moderately well-defined, weakly prominent ridge.

\section{Remarks}

The single LAP described here displays the distinctive combination of relatively small spine articulations in notches of the weakly elevated distal edge, with the strongly protruding ventral portion of the LAP and the simple, slender ridge on the inner side devoid of sharp kinks and thickened parts, which unambiguously places it in the genus Dermocoma. Within this genus, a number of species have up to six spine articulations but all of them display at least two spurs on the outer proximal and distal edge rather than a single, large, swollen, protruding area on the outer proximal edge and a moderately well-defined, round spur on the inner distal edge. This LAP clearly belongs to a new species, the formal description of which, however, should not be based on only a single specimen.

Genus Dermacantha gen. nov.

urn:1sid:zoobank.org:act:D73D5436-6A0A-43C1-8298-C5C4BE5D5CA3

\section{Type species}

Dermacantha leonorae sp. nov., by present designation.

\section{Other species included}

Dermacantha pattyana sp. nov., Ophiocten? seeweni Kutscher \& Hary, 1991 and Dermacantha carli sp. nov.

\section{Diagnosis}

Ophiacanthid with small to moderately large LAPs; small height/width ratio, even in proximal LAPs; relatively few (up to five) small spine articulations in notches of slightly elevated distal portion of LAP; ventral and dorsal lobes of spine articulations proximally separated by small knob; ventral portion of LAP generally strongly protruding ventro-proximalwards; up to two poorly to well-defined spurs on outer proximal and inner distal edges; inner side of LAPs with simple, slender ridge devoid of sharp kinks or strongly thickened parts; tentacle notch small. 


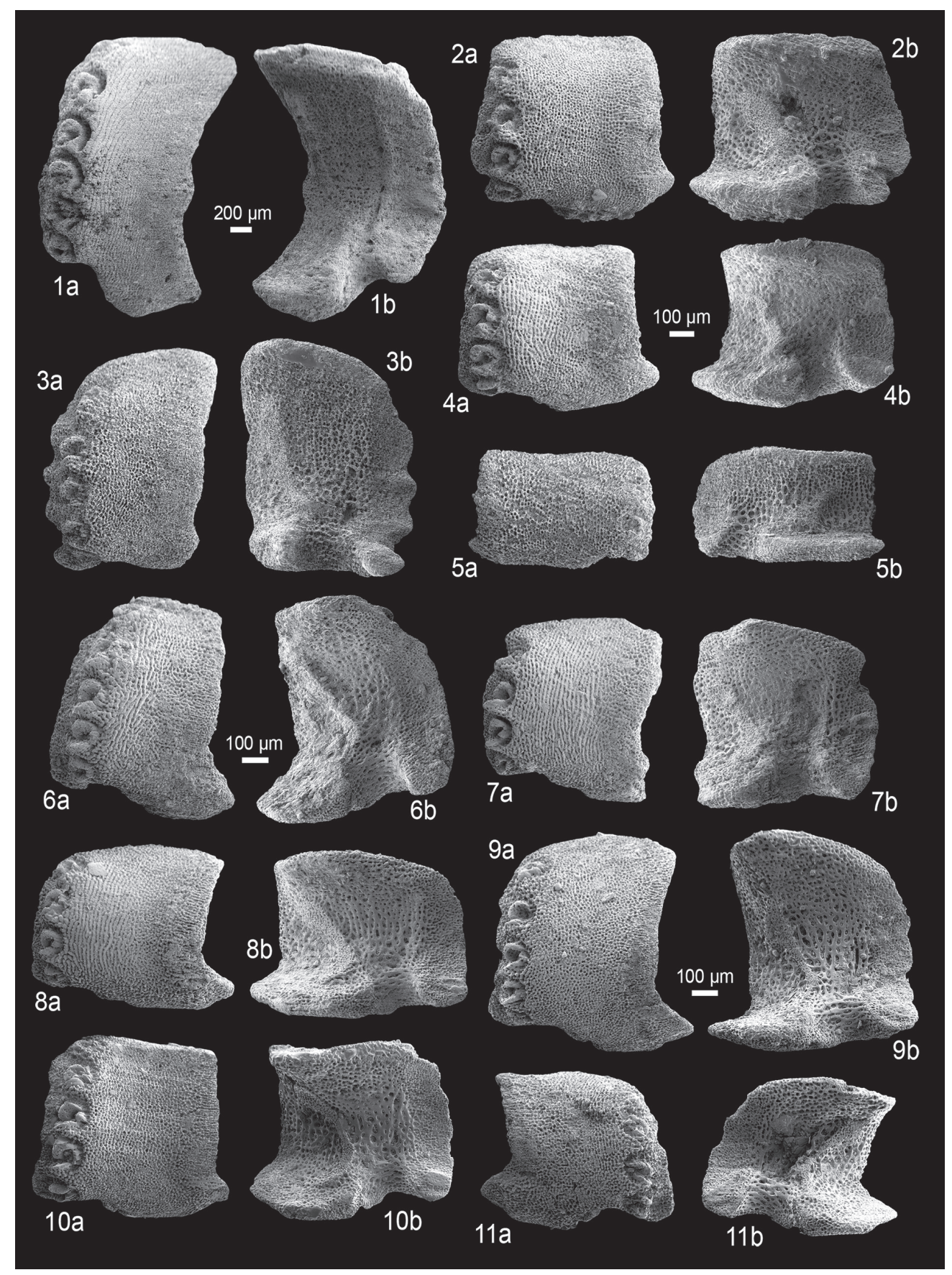

Fig. 29. Fossil lateral arm plates (LAPs) of ophiacanthid brittle stars in external (a) and internal (b) views. 1. Dermocoma sp. nov. innom. 4 from the early Albian (Early Cretaceous) of Leighton Buzzard, Great Britain; NHM EE 14844, proximal LAP. 2-5. Dermacantha pattyana gen. et sp. nov. from the Hettangian (Early Jurassic) of Fontenoille, Belgium. 2. MnhnL HE414 (holotype), proximal LAP. 3. MnhnL HE415 (paratype), proximal LAP. 4. MnhnL HE416 (paratype), median LAP. 5. MnhnL HE417 (paratype), distal LAP. 6-8. Dermacantha seeweni (Kutscher \& Hary, 1991) comb. nov. from the late Sinemurian (Early Jurassic) of Bishop's Cleeve, Great Britain. 6. GZG.INV.78706, proximal LAP. 7. GZG.INV.78707, median LAP. 8. GZG.INV.78708, distal LAP. 9-11. Dermacantha leonorae gen. et sp. nov. from the early Pliensbachian (Early Jurassic) of Blockley, Great Britain. 9. GZG.INV.78710 (holotype), proximal LAP. 10. GZG.INV.78711 (paratype), median LAP. 11. GZG.INV.78712 (paratype), distal LAP. One common scale bar per species. 


\section{Etymology}

Name composed of derma, Greek for "skin", and Acantha, a nymph in Greek mythology whose name literally translates as "thorny", in reference to the striking similarities in LAP morphology shared with Dermocoma.

\section{Remarks}

The ophiacanthid fossil record includes a number of dissociated LAP types which, at first sight, seem compatible with the LAP morphological diagnosis of Dermocoma, in particular with respect to the strongly protruding ventral portion of the LAPs, the position of the spine articulations, the presence of spurs on the outer proximal and inner distal edges and the shape of the ridge on the inner side. The spine articulation morphology, however, differs markedly. In fact, while the LAPs of Dermocoma display spine articulations with a continuous volute, those of the LAP type in question have the ventral and dorsal lobes proximally separated by one or several small knobs. This significant difference is generally combined with a smaller height/width ratio, even in proximal LAPs, and with smaller spine articulations than in Dermocoma. Since these differences co-occur consistently, Dermacantha gen. nov. is introduced here to accommodate the Dermocoma-like LAP types with small spine articulations displaying a discontinuous volute. The striking similarities in LAP morphology, however, strongly suggest that Dermocoma and Dermacantha gen. nov. share close phylogenetic ties, as suggested by the name of the new genus.

Superficial similarities are shared with the LAPs of Lapidaster gen. nov. with respect to the weakly elevated distal portion of the LAPs and the spurs on the outer proximal and inner distal edges. In Lapidaster gen. nov., however, the spine articulations are never sunken into notches of the distal LAP portion, and the tentacle notch generally is much larger.

\section{Dermacantha pattyana sp. nov. urn:lsid:zoobank.org:act:4F9EF5AE-AF42-4815-B870-EF9964CEAEC8}

Fig. 29: 2-5

\section{Diagnosis}

Species of Dermacantha gen. nov. with small LAPs displaying a very finely meshed stereom on the outer surface; trabeculae of outer surface stereom merging into very poorly developed, irregular vertical striation close to spine articulations; two very weakly defined spurs on the outer proximal and inner distal edges; up to four relatively small spine articulations; ridge on inner side relatively short and wide.

\section{Etymology}

Species named in honour of my friend and near-sister Patty Muller.

\section{Type material}

\section{Holotype}

MnhnL HE414.

\section{Paratypes}

MnhnL HE415, MnhnL HE416 and MnhnL HE417.

\section{Type locality and horizon}

Fontenoille, Belgium; level c of Delsate et al. (2002), Liasicus Zone, Hettangian, Early Jurassic.

\section{Additional material}

MnhnL HE418 (294 dissociated LAPs). 


\section{Description}

\section{Holotype}

MnhnLHE414 is a dissociated, small, proximal to median LAP; nearly as high as wide; dorsal edge straight; distal edge convex; proximal edge irregularly concave, with two large, poorly defined, horizontally elongate and weakly prominent spurs, ventral one slightly larger and more strongly protruding; ventral sixth of LAP slightly protruding ventro-proximalwards; outer surface with very finely meshed stereom; trabeculae of outer surface stereom merging into very faint, poorly developed, irregular vertical striation close to spine articulations. Four relatively small, ear-shaped spine articulations sunken individually into moderately deep notches of the non-elevated distal LAP edge; ventral and dorsal lobes thin, separated by small knob proximally; spine articulations equal-sized and equi-distant; gap between spine articulations and distal edge of LAP moderately wide, slightly narrower than the width of one spine articulation, decreasing in width ventralwards. Ventral edge of LAP with small, concave tentacle notch.

Inner side of LAP with well-defined, prominent, relatively broad, short ridge; dorsal tip of ridge slightly widened, tongue shaped, pointing dorso-proximalwards; ventral part of ridge merged with thickened ventral LAP portion; inner side of distal edge with two medium-sized, poorly defined, oval, weakly prominent spurs; inner side of ventro-distal tip of LAP thickened; inner side of tentacle notch moderately large, sharply defined laterally. No perforations or furrow discernible.

\section{Paratype supplements and variation}

MnhnL HE415 is a dissociated proximal LAP; ventral portion missing; LAP originally higher than wide; generally well in agreement with holotype; dorsal edge oblique, slightly convex; two spurs on proximal edge very weakly defined; ventro-distal tip of LAP strongly protruding ventro-distalwards, tongue shaped; trabeculae of very finely meshed stereom on outer surface not merging into vertical striation. Four spine articulations similar to those observed on holotype.

Ridge on inner side of LAP slightly narrower and longer than that of holotype, almost vertical dorsally.

MnhnL HE416 is a dissociated median LAP; slightly higher than wide; spurs on outer proximal edge very poorly defined; ventro-distal tip of LAP very slightly protruding ventro-distalwards, rounded; trabeculae of outer surface stereom more commonly merging into vertical striation than in holotype; vertical striation better developed and more widespread rather than restricted to a very narrow band near the spine articulations. Four spine articulations similar to those observed in holotype; gap between spine articulations and distal edge of LAP narrower than in holotype; ventralmost spine articulation smaller than remaining three.

Inner side of LAP similar to that of holotype.

MnhnL HE417 is a dissociated distal LAP; approximately 1.5 times wider than high; poorly preserved; dorsal edge very slightly concave; spurs on proximal edge very poorly defined, almost indiscernible; only very few trabeculae of finely meshed outer surface stereom merged into poorly developed vertical striation. Two poorly preserved spine articulations apparently similar to those observed on holotype. Ventral edge of LAP nearly straight, with small, weakly concave tentacle notch.

Inner side with small, well-defined, nearly triangular, oblique ridge, with dorso-proximally pointing dorsal tip; ventral part widest, not merged with ventral portion of LAP; spurs on inner side of distal edge of LAP almost indiscernible.

\section{Remarks}

These LAPs are unambiguously assignable to Dermacantha gen. nov. on account of the general Dermocoma-like morphology with smaller spine articulations displaying a discontinuous volute. Greatest similarities are shared with the LAPs of Dermacantha seeweni comb. nov., which, however, 
display a better-developed vertical striation on the outer surface, only one poorly defined spur, and up to five spine articulations with a conspicuously distalwards projecting ventral lobe.

\section{Occurrence}

Hettangian of Belgium.

Dermacantha seeweni (Kutscher \& Hary, 1991) comb. nov.

Fig. 29: 6-8

Ophiocten? seeweni Kutscher \& Hary, 1991: 46, pl. 1 fig. 3a-d.

non Ophiocten? seeweni - Kutscher 1996: 15, pl. 2 figs 1-5. — Kutscher \& Villier 2003: 189, pl. 5 figs 8-9, pl. 6 figs 1-2.

\section{Diagnosis}

Species of Dermacantha gen. nov. with small LAPs displaying a well-developed, very fine vertical striation on distal half of outer surface, composed of merged trabeculae of finely meshed stereom; single, very poorly defined spur on outer proximal and inner distal edges of proximal LAPs; up to five small spine articulations in notches of non-elevated distal portion of LAP; ventral and dorsal lobes of spine articulations separated by two to three small knobs; ventral lobe larger than dorsal one, projecting ventro-proximalwards.

\section{Type locality and horizon}

Bishop's Cleeve near Cheltenham, Great Britain; lowest part of the claypit, Obtusum Zone, late Sinemurian, Early Jurassic.

\section{Material examined}

GZG.INV.78706, GZG.INV.78707, GZG.INV.78708 and GZG.INV.78709 (9 dissociated LAPs) from the late Sinemurian of Bishop's Cleeve, Great Britain; the type material of Kutscher \& Hary (1991).

\section{Description}

Small, LAPs; proximal ones slightly higher than wide, distal ones slightly wider than high; dorsal edge slightly convex; distal edge convex; proximal edge irregularly undulose, with single poorly defined, almost indiscernible, weakly prominent, horizontally elongate, non-protruding spur near ventral edge in proximal to median LAPs, two very poorly defined, almost indiscernible, horizontally elongate, weakly prominent spurs in distal LAPs; ventral fifth of LAP protruding ventro-proximalwards; ventro-distal tip of LAP protruding ventralwards, rounded; outer surface with finely meshed stereom, trabeculae of which merged into fine, irregular vertical striation in distal half of outer surface; very narrow band of finely, faintly horizontally striped stereom along proximal edge of LAP. Five (proximal LAPs) to four (median to distal LAPs) moderately large, ear-shaped spine articulations in notches of non-elevated distal portion of LAP; ventral and dorsal lobes of spine articulations separated by two to three small knobs; ventral lobe larger than dorsal one, ventro-distalwards projecting; spine articulations not sharply bordered proximally, directly encompassed by finely meshed outer surface stereom; gap between spine articulations and distal edge of LAP moderately large, approximately as wide as half the width of a spine articulation; very weak dorsalward increase in size of spine articulations; dorsalmost gap between spine articulations slightly larger than remaining ones. Ventral edge of LAP with moderately large, concave tentacle notch.

Inner side of LAP with large, sharply defined, prominent, long, oblique, nearly straight, relatively narrow ridge; dorsal tip of ridge slightly widened, pointing dorso-proximalwards; ventral part of ridge bent, 
pointing ventro-proximalwards, separated from thickened ventral edge; inner side of distal edge of LAP with very weakly defined, almost indiscernible spur; inner side of tentacle notch relatively large, well defined laterally, with coarsely meshed, very slightly horizontally elongate stereom. No perforations or furrow discernible.

\section{Remarks}

The relatively small spine articulations with the discontinuous volute combined with a general Dermocoma-like morphology unquestionably place these LAPs in Dermacantha gen. nov. Within this, these LAPs are unique in displaying conspicuously distally projecting ventral lobes of the spine articulations, and are thus described here as a new species.

\section{Occurrence}

Early Sinemurian of Luxembourg and late Sinemurian of Great Britain.

Dermacantha leonorae sp. nov. urn:1sid:zoobank.org:act:95EF2CA2-C31C-415F-A639-417842B0EEC6

Fig. 29: 9-11

\section{Diagnosis}

Species of Dermacantha gen. nov. with small LAPs; proximal to median ones devoid of vertical striation on outer surface; five small spine articulations; single moderately well-defined spur near outer ventroproximal and inner ventro-distal tips of LAP; ridge on inner side very narrow but with strongly widened dorsal tip.

\section{Etymology}

Species named in hoinour of my friend and colleague Leonora Martín-Medrano, for her extraordinary hospitality and as an encouragement to her to pursue research in ophiuroid palaeontology.

\section{Type material}

\section{Holotype}

GZG.INV.78710.

Paratypes

GZG.INV.78711 and GZG.INV.78712.

\section{Type locality and horizon}

Blockley, near Cheltenham, Great Britain; shell lenses in clay matrix, Davoei Zone, early Pliensbachian, Early Jurassic.

\section{Additional material}

GZG.INV.78713 (7 dissociated LAPs).

\section{Description}

\section{Holotype}

GZG.INV.78710 is a dissociated, small, proximal LAP; slightly higher than wide; dorsal edge gently convex; distal edge convex; proximal edge concave, with single, moderately well-defined, prominent, horizontally elongate spur close to ventro-proximal tip of LAP; ventral sixth of LAP protruding ventroproximalwards; outer surface with very finely meshed stereom; no vertical striation; narrow band of very finely horizontally striated stereom along proximal edge. Five small, ear-shaped spine articulations 
in notches of non-elevated distal edge; dorsal and ventral lobes separated by small, thin knob; spine articulations proximally directly encompassed by outer surface stereom; spine articulations nearly of equal size; dorsalward increase in size of gaps separating spine articulations; gap between spine articulations and distal edge of LAP very narrow. Ventral edge of LAP with moderately large, very gently concave tentacle notch.

Inner side of LAP with moderately large, conspicuous, sharply defined, prominent, very narrow ridge; dorsal tip strongly enlarged, nearly triangular; ventral part of ridge pointing ventro-proximalwards, not merged with slightly thickened ventral portion of LAP, separated from dorsal part of ridge by gentle, rounded kink; well-defined, oval, slightly prominent knob on ventro-distal tip of LAP; inner side of tentacle notch relatively large, with coarsely meshed, horizontally elongate stereom, well defined laterally. Very short and narrow, rather deep and well-defined furrow dorsally bordering tentacle notch.

\section{Paratype supplements and variation}

GZG.INV.78711 is a dissociated median LAP; slightly wider than high; very well in agreement with holotype; dorsal edge very slightly concave; spur near ventro-proximal tip of LAP sharply defined, lenticular, strongly prominent, composed of more densely meshed stereom. Five spine articulations similar to those observed on holotype; dorsalward increase in size of gaps separating spine articulations slightly weaker; ventral and dorsal lobes of spine articulations separated by one to three very small knobs.

Inner side of LAP well in agreement with that of holotype; dorsal tip of ridge slightly less strongly widened. No furrow discernible.

GZG.INV.78712 is a dissociated distal LAP; slightly wider than high; ventro-distal tip of LAP strongly protruding ventralwards, rounded; trabeculae of outer surface stereom merging into short, poorly developed, irregular vertical striation close to spine articulations. Four spine articulations similar to those observed on holotype; dorsalmost spine articulation smallest; gap between spine articulations and distal edge of LAP moderately large, widening ventralwards. Ventral edge of LAP with large, deeply concave tentacle notch.

Inner side of LAP in agreement with that of holotype; dorsal tip of ridge slightly less strongly widened; spur on inner side of ventro-distal tip of LAP oblique. No furrow discernible.

\section{Remarks}

These LAPs are unambiguously assignable to Dermacantha gen. nov. on account of their spine articulation structure combined with the general Dermocoma-like morphology. They represent the sole LAP type within this genus which completely lacks a vertical striation on the outer surface. Closest similarities are shared with the LAPs of Dermacantha pattyana sp. nov., in particular those with reduced vertical striation on the outer surface. In the latter species, however, the ridge on the inner side is shorter and broader.

\section{Occurrence}

Early Pliensbachian of Great Britain.

Dermacantha sp. nov. innom.

Fig. 30: 1-3

\section{Material examined}

GZG.INV.78714, GZG.INV.78715, GZG.INV.78716 and GZG.INV.78717 (12 dissociated LAPs) from the Bajocian-Bathonian boundary of Touert near Chaudon, France. 


\section{Description}

GZG.INV.78714 is a dissociated, moderately large, proximal LAP; nearly as high as wide; dorsal edge slightly concave as a result of a weak constriction; distal edge almost straight; ventral sixth of LAP ventroproximalwards protruding; proximal edge slightly undulose, with large, swollen, slightly protruding central part dorsally and ventrally bordered by small, well-defined, horizontally elongate, prominent spurs; outer surface with very fine, regular, vertical striation composed of fine, very weakly overlapping lamellae replaced by finely meshed stereom on proximal third of outer surface. Four relatively small, ear-shaped spine articulations in shallow notches of slightly elevated distal portion of LAP; ventral and dorsal lobes proximally separated by small knob; very weak connection between ventral lobe of spine articulations and distalwards projecting tips of outer surface stereom separating notches; spine articulations of nearly equal size, except for slightly smaller ventralmost one; very weak distalward increase in size of spine articulations; gap between spine articulations and distal edge of LAP narrow. Ventral edge of LAP with small, weakly concave tentacle notch.

Inner side of LAP with relatively small, sharply defined, prominent, slender ridge; ventral half of ridge bent, pointing ventro-proximalwards, not merged with thickened ventral portion of LAP; dorsal half of ridge straight, oblique, with very weakly thickened dorsal tip; inner side of distal edge of LAP with two small, well-defined, prominent, oval, horizontally elongate spurs; inner side of tentacle notch small, laterally well defined. No perforations or furrow discernible.

GZG.INV.78715 is a dissociated median LAP; 1.5 times wider than high; well in agreement with holotype; vertical striation restricted to a smaller area of the outer surface. Four equal-sized spine articulations similar to those observed on holotype; gap separating spine articulations and distal edge of LAP as wide as one spine articulation.

Inner side similar to previous LAP described.

GZG.INV.78716 is a dissociated distal LAP; almost twice wider than high; vertical striation on outer surface slightly less well developed than in holotype. Three equal-sized spine articulations similar to those of holotype; distal edge of LAP slightly fragmentary, width of gap between spine articulations and distal edge of LAP not determinable.

Inner side of LAP with small, sharply defined, prominent, oblique, straight ridge; ventral tip of ridge widened.

\section{Remarks}

These LAPs, unambiguously assignable to Dermacantha gen. nov. on account of the general Dermocomalike morphology combined with a discontinuous volute of the relatively small spine articulations, bear a striking similarity to the LAPs described below as Dermacantha carli sp. nov., to such an extent that both LAP types are almost indistinguishable. Minor differences pertain to the slightly thicker ventral portion and the slightly wider ridge in proximal LAPs of the present form. In addition, the vertical striation in the proximal LAPs of $D$. carli sp. nov. is composed of slightly larger, more strongly overlapping lamellae. Yet, these differences are so small that a formal description of the present specimens as a new species appears unjustified. To make matters worse, the amount of currently available material is too limited to appreciate fully the variability of the characters on which species separation would be based on. It seems unlikely that the present material is conspecific with $D$. carli sp. nov., in particular taking into account the long stratigraphic gap (Bajocian-Kimmerdigian) and the fundamentally different depositional settings (mud bottom slope versus deep shelf sponge reef) of both occurrences. In the absence of more diagnostic material, the present specimens are here treated as a probably new, still undescribed species of Dermacantha gen. nov. 


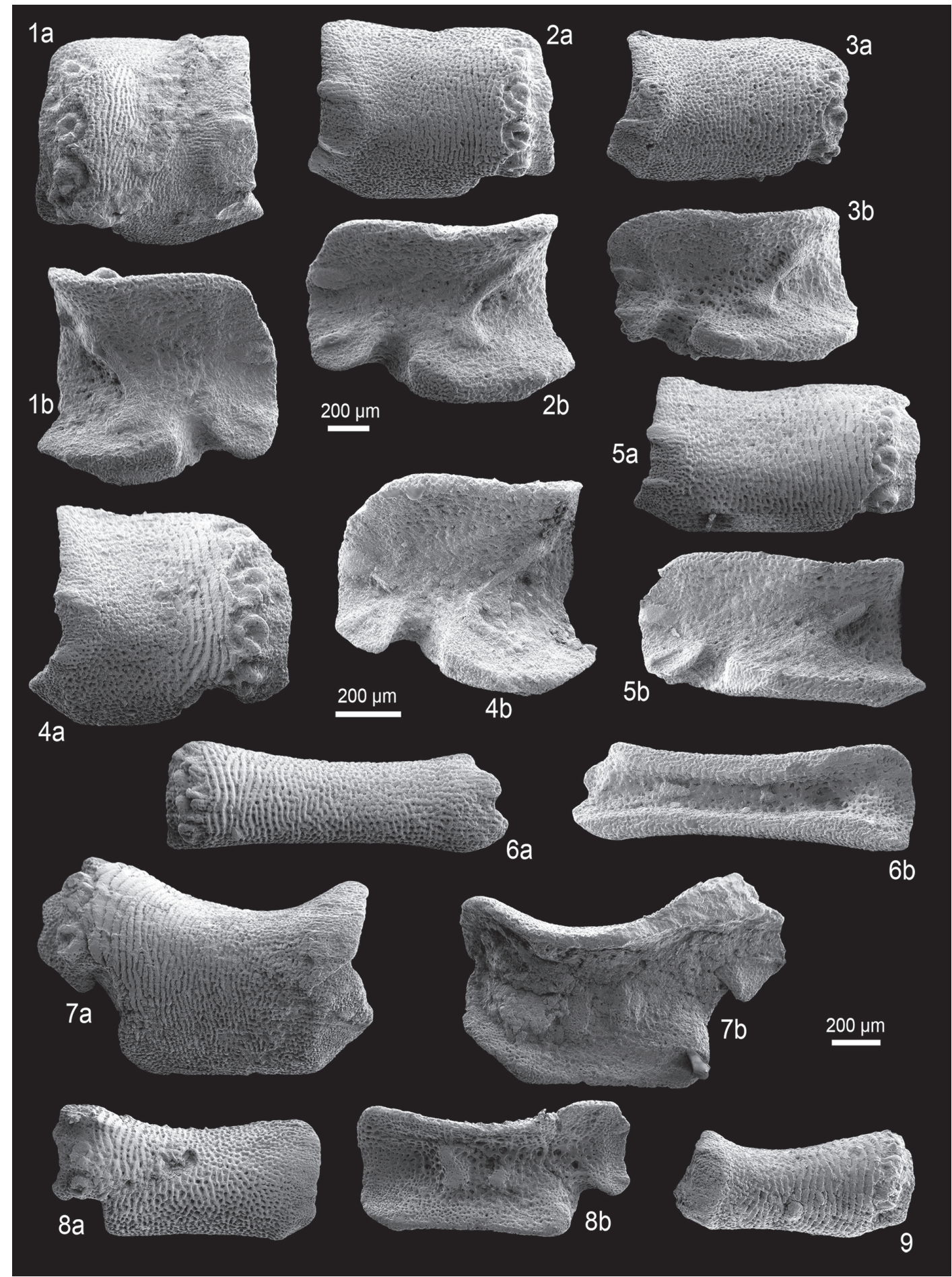

Fig. 30. Fossil lateral arm plates (LAPs) of ophiacanthid brittle stars in external (a) and internal (b) views. 1-3. Dermacantha sp. nov. innom. from the Bajocian-Bathonian boundary of Touert, France. 1. GZG.INV.78714, proximal LAP. 2. GZG.INV.78715, median LAP. 3. GZG.INV.78716, distal LAP. 4-6. Dermacantha carli gen. et sp. nov. from the late Oxfordian (Late Jurassic) of the Plettenberg, Germany. 4. GZG.INV.78718 (holotype), proximal LAP. 5. GZG.INV.78719 (paratype), median LAP. 6. GZG. INV.78720 (paratype), distal LAP. 7-9. Ishidacantha hirokoae gen. et sp. nov. from the middle Toarcian (Early Jurassic) of Le Clapier, France. 7. GZG.INV.78723 (holotype), proximal LAP. 8. GZG.INV.78724 (paratype), median LAP. 9. GZG.INV.78725 (paratype), distal LAP. One common scale bar per species. 


\section{Dermacantha carli sp. nov. urn:1sid:zoobank.org:act:3FDC618A-F737-47FC-B0BA-9AE3CD84B586}

Fig. 30: 4-6

\section{Diagnosis}

Species of Dermacantha gen. nov. with moderately large LAPs generally displaying a vert small height/ width ratio, with even proximal LAPs slightly wider than high; two small, nearly equal-sized, welldefined, proximally pointed, prominent spurs on outer proximal edge; distal quarter of outer surface with regular, well-defined vertical striation; four relatively small spine articulations with dorsal and ventral lobes separated by small knob; three dorsal spine articulations in distal LAPs with conspicuous lip-shaped distal knob; ridge on inner side small very slender, with very weakly widened, strongly oblique dorsal part.

\section{Etymology}

Species named in honour of Carl, my friend, companion, family member, for his cheerful support and all the ideas that emerged during the many outdoor walks with him.

\section{Type material}

\section{Holotype}

GZG.INV.78718.

\section{Paratypes}

GZG.INV.78719 and GZG.INV.78720.

\section{Type locality and horizon}

Plettenberg near Balingen, Germany; clay pockets between sponge associations in the lowest bed exposed in the quarry, Bimammatum Zone, late Oxfordian, Late Jurassic.

\section{Additional material}

GZG.INV.78721 (300 dissociated LAPs) from the late Oxfordian of the Plettenberg, Germany; GZG. INV.78722 (64 dissociated LAPs) from the Lacunosa Marls, early Kimmeridgian of Geisingen, Germany.

\section{Description}

\section{Holotype}

GZG.INV.78718 is a dissociated, moderately large, proximal LAP; slightly wider than high; dorsal edge slightly concave as a result of a weakly developed constriction; distal edge convex; proximal edge concave, with two small, well-defined, prominent, slightly protruding, proximally pointed spurs composed of densely meshed stereom; dorsal spur slightly larger than ventral one; ventral quarter of LAP strongly protruding ventro-proximalwards; ventro-distal tip of LAP protruding ventralwards, rounded; outer surface with narrow band of regular, vertical striation composed of rather broad, overlapping lamellae close to spine articulations, replaced by finely meshed stereom on proximal three-quarters of outer surface. Four relatively small, ear-shaped spine articulations in shallow notches of slightly elevated distal portion of LAP; ventral lobe of spine articulation separated from dorsal one proximally by small knob, and connected with distalwards projecting tip of outer surface stereom separating notches; spine articulations proximally separated by edge of notches; dorsalward increase in size of gaps separating spine articulations; ventralmost spine articulation slightly smaller than remaining, nearly equal-sized ones; notches very shallowly incising vertical striation; gap between spine articulations and distal edge of LAP almost as wide as one spine articulation. Ventral edge of LAP with moderately large, deeply concave tentacle notch. 
Inner side of LAP with relatively small, sharply defined, prominent and very slender ridge; ventral part of ridge strongly bent ventro-proximalwards, not merged with non-thickened ventral portion of LAP; dorsal part of ridge straight, strongly oblique, slightly widened dorsally; inner side of distal edge of LAP with two relatively small, well-defined, rounded, prominent spurs composed of densely meshed stereom; inner side of tentacle notch relatively small, deeply incised; sharply defined laterally. No perforations or furrows discernible.

\section{Paratype supplements and variation}

GZG.INV.78719 is a dissociated median LAP; nearly twice wider than high; ventral sixth slightly protruding ventro-proximalwards; ventro-distal tip of LAP very weakly protruding; spurs on proximal edge and outer surface ornament as in holotype. Three spine articulations similar to those observed on holotype. Ventral edge of LAP with small, weakly concave tentacle notch.

Inner side of LAP partly obscured by sediment; dorsal part of ridge exposed, as slender, straight, oblique as fine ridge observed on holotype; spurs on inner side of distal edge slightly better preserved than those of holotype.

GZG.INV.78720 is a dissociated distal LAP; more than three times wider than high; rod like; dorsal and ventral edges concave as a result of a constriction; proximal edge with two large, poorly defined, weakly prominent but very strongly protruding spurs. Four spine articulations, ventralmost similar to those observed on holotype, remaining three slightly larger and with conspicuous, lip-shaped, distal knob composed of densely meshed stereom. Tentacle opening invisible in external view, emerging on distal side of ventralmost spine articulation.

Inner side of LAP with two small, sharply defind, prominent knobs, proximal one horizontally slightly elongate, triangular, and distal one much smaller, round; inner side of distal edge of LAP with two poorly defined, prominent spurs. Large tentacle opening in the middle of the distal third of the LAP.

\section{Remarks}

These specimens display diagnostic characters that warrant inclusion in Dermacantha gen. nov., in spite of the unusually well-developed vertical striation on the outer surface and the well-defined spurs on the outer proximal and inner distal edges. On account of the latter, the LAPs in question can be unambiguously differentiated from any other currently known species of the genus. Greatest similarities are shared with an unnamed type of LAPs here assigned to Dermacantha gen. nov. from the BajocianBathonian of France. As discussed in detail above, the Middle Jurassic LAPs are almost indistinguishable from the present ones, with possible differences pertaining to minor and potentially variable details in LAP morphology. Since the above-described Late Jurassic LAPs are represented by numerous wellpreserved specimens, they are formally described as new species of Dermacantha gen. nov. The Middle Jurassic record, in contrast, is described as probably new, but remains specifically unnamed.

The presence of lip-shaped distal knobs in the three dorsal spine articulations of the distal LAP described above is intriguing. Similar knobs are known from the distal LAPs of Early Jurassic Inexpectacantha acrobatica Thuy, 2011 and of extant Ophiolycus purpureus (Düben \& Koren, 1846) and Ophiura (Ophiuroglypha) robusta (Ayres, 1854) (Thuy 2011; Thuy \& Stöhr 2011). Remarkably, in all cases the lip-shaped knobs are associated with specialised, hook-shaped spines, which suggests that distal arm segments of Dermacantha carli sp. nov. bore such spines as well.

\section{Occurrence}

Late Oxfordian to early Kimmeridgian of Germany. 


\section{Genus Ishidacantha gen. nov. urn:Isid:zoobank.org:act:0AA3C0DE-CB77-4AA9-847F-782B5B76F6CC}

\section{Type species}

Ophiopholis? trispinosa Hess, 1965, by present designation.

\section{Other species included}

Ishidacantha hirokoae sp. nov. and Ishidacantha fuersichi sp. nov.

\section{Diagnosis}

Ophiacanthid with large to moderately large LAPs displaying a very small height/width ratio, with even proximal LAPs almost twice wider than high; ventral portion of LAPs very large, wide, strongly protruding ventro-proximalwards; fine vertical striation on at least part of the outer surface; two variably well-defined, horizontally elongate and generally protruding spurs on the outer proximal and inner distal edges; three to four relatively large, ear-shaped spine articulations on elevated distal edge of LAP; inner side of LAP with two separate ridges, even in proximal LAPs; proximal ridge generally much longer than distal one; deeply incised but relatively small tentacle notches commonly developed as within-plate perforations in distal LAPs.

\section{Etymology}

Genus named in honour of my friend Yoshiaki Ishida, for his outstanding contributions to ophiuroid palaeontology and, most importantly, for his friendship and indefatigable support, and from Acantha, a nymph in Greek mythology whose name literally translates to "thorny"; gender feminine.

\section{Remarks}

The ophiacanthid fossil record inlcudes an unusual type of dissociated LAPs charactersied by a very small height/width ratio, coarsely meshed or vertically striated stereom on the outer surface, a strongly protruding, very large and wide ventral portion, three to four relatively large spine articulations, two separate ridges on the inner side, and relatively small but deeply incised tentacle notches. LAPS of this type were described by Hess (1965a) from the Oxfordian of France as Ophiopholis? trispinosa Hess, 1965. Very similar LAPs from the Toarcian/Aalenian of Germany and the Toarcian of France were described by Kutscher (1996) and Kutscher \&Villier (2003), respectively, and in both cases assigned to Sinosura brodiei (Wright, 1866), an extinct genus with probable ophioleucinid affinities (Thuy et al. 2011). Surprisingly, neither the close morphological similarities between these occurrences nor their ophiacanthid affinities have been commented on previously.

A careful, SEM-supported re-examination of this material has now confirmed the ophiacanthid affinites and enabled a reinterpretation of the material in question, along with news finds from the Toarcian of France and the Callovian of India, as a new morphologically consistent ophiacanthid LAP type. The only other ophiacanthid LAP type to display comparably small height/width ratios and two separated ridges on the inner side even in proximal LAPs is found in Geromura gen. nov. (see above). The two LAP types, however, differ fundamentally with respect to the size of the tentacle notch. In fact, while the LAPs of Geromura gen. nov. display a genuinely large tentacle notch, those of the new type in question have a deeply incised, but ultimately relatively small notch. The size of the ventral portion of the present LAPs, the oblique ventro-proximal tip and the relatively small semi-circular outline of the actual tentacle notch strongly suggest that the articulated arms were covered by large ventral plates separated by the LAPs and encompassing small tentacle pores as defined by Thuy et al. (2012). The present LAP type thus belongs to a small-pored ophiacanthid, here described as Ishidacantha gen. nov., whereas Geromura gen. nov. clearly is a large-pored genus. This implies that the striking morphological similarities, in 
fact, reflect convergent evolution, presumably as a result of paedomorphosis leading to elongated arm segments, a typically juvenile character (Stöhr 2005). At least some of the shared characters, such as the presence of two separate ridges on the inner side, might be the result of biomechanical constraints due to the small height/width ratios.

\section{Ishidacantha hirokoae sp. nov. urn:1sid:zoobank.org:act:CD39B010-D3BF-4BFA-9913-863830744D67}

Fig. 30: 7-9

p.p. Sinosura brodiei - Kutscher 1996: 10, pl. 2 figs 9-13. - Kutscher \& Villier 2003: 185, pl. 4 figs 3-6 [material incorrectly assigned to Sinosura brodiei (Wright, 1866)].

\section{Diagnosis}

Species of Ishidacantha gen. nov. with large LAPs displaying a well-developed, regular vertical striation on distal half of outer surface and composed of overlapping lamellae; two poorly developed spurs on outer proximal edge paralleled by two small, slightly better-defined spurs on inner distal edge; three moderately large, nearly equal-sized spine articulations proximally sharply delimited by distalmost lamellae; ventral and dorsal lobes of spine articulations separated by two or three small, notches; inner side of proximal LAPs with dorso-proximalwards bent, continuous proximal ridge and round distal knob; tentacle notch relatively small.

\section{Etymology}

Species named in honour of Hiroko Ishida, for her outstanding hospitality.

\section{Type material}

\section{Holotype}

GZG.INV.78723

\section{Paratype}

GZG.INV.78724 and GZG.INV.78725.

\section{Type locality and horizon}

Le Clapier, France; debris flow bed rich in skeletal detritus, middle Toarcian, Early Jurassic.

\section{Additional material}

GZG.INV.78726 (18 dissociated LAPs) from sample 1 of the middle Toarcian of Le Clapier; GZG. INV.78727 (11 dissociated LAPs) from sample 2 of the middle Toarcian of Le Clapier; the original material of Kutscher (1996) and Kutscher \& Villier (2003).

\section{Description}

\section{Holotype}

GZG.INV.78723 is a dissociated, large, proximal LAP; approximately twice wider than high; dorsal edge strongly concave as a result of a well-developed constriction; distal edge convex with a small, non-prominent protrusion; ventral half of LAP strongly protruding ventro-proximalwards, very large and wide; ventro-distal tip of LAP protruding, tongue shaped; ventro-proximal tip of LAP oblique; proximal edge of LAP with two very poorly defined, weakly prominent, very slender, non-protruding and horizontally elongate spurs; outer surface with well-developed, regular vertical striation composed of overlapping lamellae; strong proximalward decrease in size of lamellae; vertical striation replaced by finely meshed stereom on proximal half of outer surface. Three relatively small, nearly equal-sized 
and equi-distant, ear-shaped spine articulations freestanding on elevated distal portion of LAP; dorsal and ventral lobes of spine articulations separated by two or three very small notches; spine articulations proximally sharply delimited by two distalmost lamellae; gap between spine articulations and distal edge of LAP almost as wide as one spine articulation. Ventral edge of LAP nearly straight, except for extremely deeply incised, relatively small, more than semi-circular tentacle notch.

Inner side of LAP slightly obscured by sediment, with two closely spaced, but separate ridges; proximal one sharply defined, relatively broad, prominent and dorso-proximalwards bent ridge devoid of thickened parts or sharp kinks; distal ridge very short, knob like, sharply defined and moderately widely separated from proximal ridge; inner side of distal edge of LAP with small, moderately well-defined, weakly prominent, very slender, horizontally elongate. No perforations or furrow discernible.

\section{Paratype supplements and variation}

GZG.INV.78724 is a dissociated median LAP; slightly more than twice wider than high; very well in agreement wth holotype; vertical striation on outer surface slightly less well developed and regular as in holotype. Three spine articulations similar to those observed on holotype. Tentacle notch slightly not as deep as in holotype.

Inner side of LAP with two ridges similar to those of holotype but more widely separate, and proximal one shorter and with slightly widened ventral tip; two spurs on inner side of distal edge of LAP shorter than in holotype. No perforations or furrow discernible.

GZG.INV.78725 is a dissociated distal LAP; approximately 2.5 times wider than high; well in agreement with holotype; vertical striation on outer surface better developed than in holotype, replaced by finely meshed stereom only on proximal quarter of outer surface. Three spine articulations similar to those observed on holotype. Ventral edge of LAP slightly concave; tentacle opening developed as perforation emerging on ventral edge of ventralmost spine articulation.

Inner side of LAP obscured by sediment.

\section{Remarks}

These specimens appear to be identical to at least part of the LAPs described and illustrated by Kutscher (1996) and Kutscher \& Villier (2003) from the Toarcian/Aalenian of Germany and the Toarcian of France, respectively, and assigned in both cases to the ophioleucinid Sinosura brodiei (Wright, 1866). A re-examination of the type material of the latter (see Hess 1964), however, has revealed fundamental differences in LAP morphology, in particular with respect to spine articulation morphology. The LAPs in question show clear ophiacanthid affinities and, as discussed above, are here considered to belong to the same LAP type as the material described as Ophiopholis? trispinosa Hess, 1965 from the Oxfordian of France, for which Ishidacantha gen. nov. is here introduced. Within this genus, these LAPs are unique in combining three equal-sized spine articulations with a well-developed vertical striation on outer surface and two poorly defined spurs on the outer proximal edge. They are thus described here as a new species.

Kutscher (1996) and Kutscher \& Villier (2003) mentioned up to six spine articulations in their descriptions of the above-mentioned LAPs. The specimens illustrated, however, invariably show three spine articulations just like the Toarcian material of France described here. Thus, it seems probable that Kutscher (1996) and Kutscher \&Villier (2003) included more than one LAP type in their descriptions.

\section{Occurrence}

Middle Toarcian of France, Toarcian/Aalenian of Germany. 


\section{Ishidacantha fuersichi sp. nov. urn:Isid:zoobank.org:act:26105676-350E-423A-A101-8AEAC88B0FF8}

Fig. 31: 1-4

\section{Diagnosis}

Species of Ishidacantha gen. nov. with moderately large LAPs displaying a well-developed, slightly irregular vertical striation on distal third of outer surface and composed of overlapping lamellae; two well-defined, slender, horizontally strongly elongate spurs on the outer proximal and inner distal edges; spurs on the inner distal edge protruding; up to four moderately large, nearly equal-sized spine articulations proximally tightly delimited by distalmost lamellae; ventral and dorsal lobes of spine articulations separated by one to three small, notches; inner side of proximal LAPs with very large dorso-proximalwards bent, continuous proximal ridge and shorter, vertical, distal ridge; tentacle notch relatively small.

\section{Etymology}

Species named in honour of Franz T. Fürsich for his contributions on the palaeontology of the type locality and for generously providing the samples yielding the type material of the species.

\section{Type material}

\section{Holotype}

GZG.INV.78728.

\section{Paratypes}

GZG.INV.78729, GZG.INV.78730 and GZG.INV.78731.

\section{Type locality and horizon}

Jumara, Kachchh, India; sample 119, upper Chari Formation, Callovian, Middle Jurassic.

\section{Additional material}

GZG.INV.78732 (29 dissociated LAPs) from sample 117; GZG.INV.78733 (27 dissociated LAPs) from sample 119; GZG.INV.78734 (88 dissociated LAPs) from sample 121, all from the upper Chari Formation, Callovian.

\section{Description}

\section{Holotype}

GZG.INV.78728 is a dissociated, moderately large, proximal LAP; fragile; almost twice wider than high; dorsal edge slightly fragmentary, originally nearly straight; distal edge undulose, with two small, pointed, non-prominent protrusions; ventral third of LAP protruding ventro-distalwards; ventro-distal tip of LAP protruding ventralwards, rounded, slightly tongue shaped; ventro-proximal tip of LAP slightly fragmentary, originally oblique; proximal edge with two well-defined, moderately large, equalsized, horizontally strongly elongate, slender, weakly prominent and slightly protruding spurs; outer surface with well-developed, slightly irregular vertical striation composed of overlapping lamellae displaying strong proximalward decrease in size; vertical striation replaced on proximal two-thirds of outer surface by finely meshed stereom; irregular band of very finely meshed stereom along proximal edge of LAP. Four relatively small, nearly equal-sized and equi-distant, ear-shaped spine articulations on slightly elevated distal portion of LAP; dorsal and ventral lobes separated by one to three very small notches; spine articulations proximally tightly delimited by two distalmost lamellae; gap between spine articulations and distal edge of LAP almost as wide as one spine articulation. Ventral edge of LAP nearly straight except for relatively small but very deeply incised, semi-circular tentacle notch. 


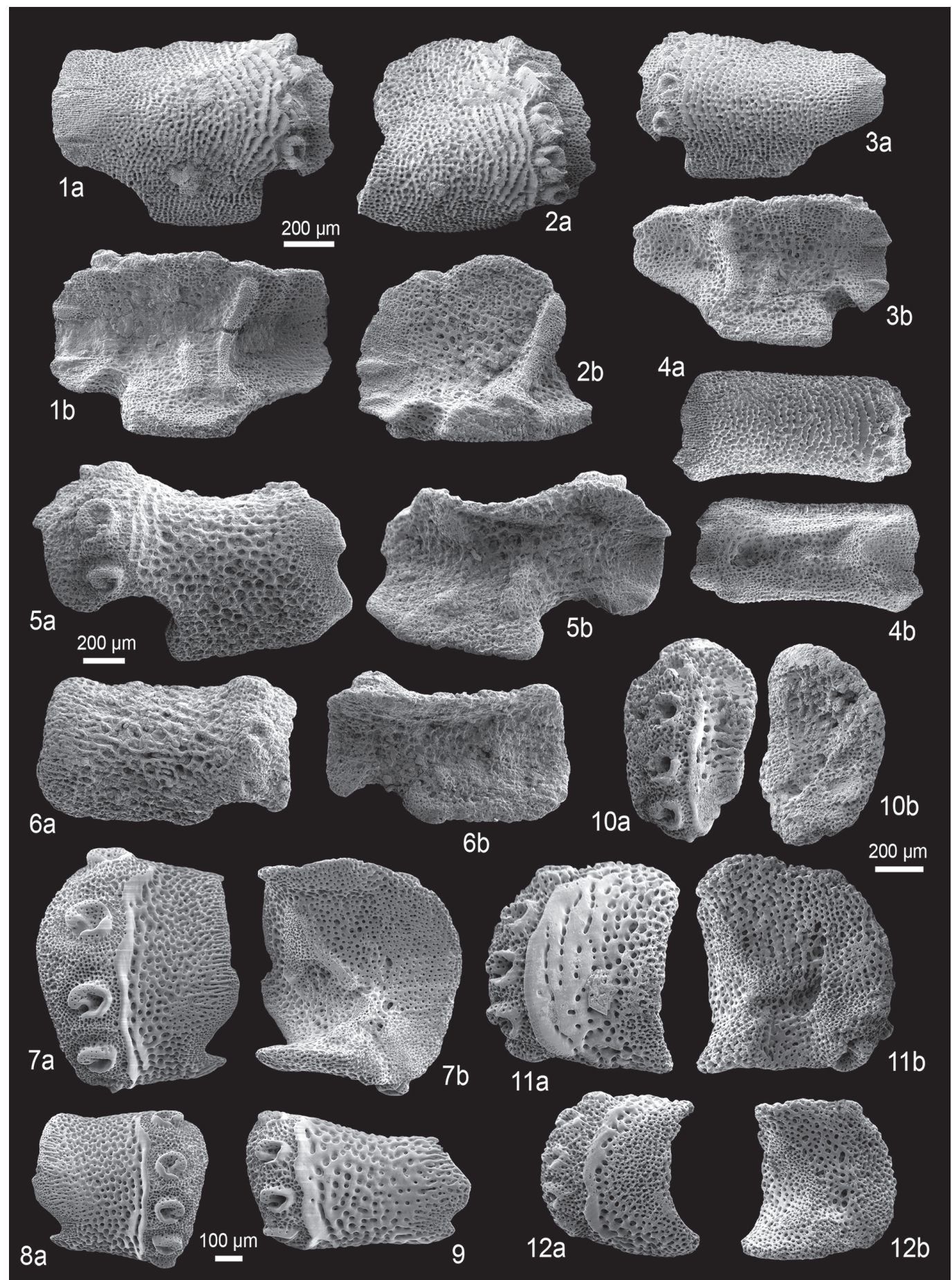

Fig. 31. Lateral arm plates (LAPs) of fossil and Recent ophiacanthid brittle stars in external (a) and internal (b) views. 1-4. Ishidacantha fuersichi gen. et sp. nov. from the Callovian (Middle Jurassic) of Jumara, India. 1. GZG.INV.78728 (holotype), proximal LAP. 2. GZG.INV.78729 (paratype), proximal LAP. 3. GZG.INV.78730 (paratype), median LAP. 4. GZG.INV.78731 (paratype), distal LAP. 5-6. Ishidacantha trispinosa (Hess, 1965) comb. nov. from the early Oxfordian (Late Jurassic) of Longecombe, France. 5. NHMB M11222, proximal LAP. 6. NHMB M11223, distal LAP. 7-9. Ophiomitrella conferta (Koehler, 1922), Recent. 7. Proximal LAP. 8. median LAP. 9. distal LAP. 10-12. Ophiomitrella? sp. 1 from the Callovian of Bauer-Wehrland, Germany. 10. GZG.INV.78735, proximal LAP. 11. GZG.INV.78736, median LAP. 12. GZG.INV.78737, distal LAP. One common scale bar per species. 
Inner side of LAP with two sharply defined, prominent, closely spaced but separate ridges; proximal ridge large, conspicuous, slender, slightly dorso-proximalwards bent with weakly widened dorsal and ventral tips; distal ridge shorter than half the length of the proximal one; nearly vertical; inner side of distal edge of LAP with two sharply defined, horizontally elongate, prominent and slightly protruding spurs. No perforations or furrow discernible.

\section{Paratype supplements and variation}

GZG.INV.78729 is a dissociated, fragmentary proximal LAP; preserved portions very well in agreement with holotype. Four spine articulations similar to those observed on holotype.

Inner side with very large, oblique, slightly bent, dorsally thickened proximal ridge with small, round knob distally bordering ventral tip of the latter; ridge and knob directly adjacent but not merged.

GZG.INV.78730 is a dissociated median LAP; twice wider than high; well in agreement with holotype; ventral quarter slightly less strongly protruding ventro-proximalwards. Three spine articulations similar to those observed on holotype.

Inner side of LAP with two ridges similar to those of holotype but slightly shorter.

GZG.INV.78731 is a dissociated distal LAP; nearly 2.5 times wider than high; dorsal edge straight; ridge on proximal edge slightly smaller and less well defined than in holotype; ventral portion of LAP not protruding. Three spine articulations similar to those observed on holotype. Ventral edge of LAP concave; tentacle opening developed as perforation emerging at ventro-proximal edge of ventralmost spine articulation.

Inner side of LAP with two sharply defined, prominent, closely spaced but separate knobs; proximal knob nearly triangular; distal knob much smaller, round; very large tentacle perforation in the middle of the distal third of the LAP.

\section{Remarks}

The unusually small height/width ratio, the large, strongly protruding ventral portion, the two protruding spurs on the outer proximal and inner distal edges and the two separate ridges on the inner side unambiguously place these LAPs in Ishidacantha gen. nov. The presence of up to four relatively small spine articulations is not found in any other LAP type assigned to this genus. The development of the ridges on the inner side in the present LAPs suggests that the distance between the ridges correlates with the position of the LAPs in the arm and thus with their height/width ratio.

\section{Occurrence}

Callovian of India.

Ishidacantha trispinosa (Hess, 1965) comb. nov.

Fig. 31: 5-6

p.p. Ophiopholis? trispinosa Hess, 1965a: 1075, figs 36-37 [non figs 16, 38-41, referable to Lapidaster etteri gen. et sp. nov.]

\section{Diagnosis}

Species of Ishidacantha gen. nov. with large LAPs displaying coarsely meshed stereom on the outer surface with a very narrow band of poorly developed vertical striation near spine articulations; two moderately well-defined, horizontally elongate spurs on outer proximal and inner distal edges in proximal to median LAPs, dorsal one of which protruding; three large spine articulations in all LAPs, with continuous volute and strong dorsalward increase in size; inner side of proximal LAPs with two round, slightly oblique knobs in vertical row connected by poorly defined, irregular, slender, weakly 
prominent vertical ridge in proximal half, and short, near-vertical ridge in distal half; tentacle notch large.

\section{Material examined}

NHMB M11222, NHMB M11223; 5 dissociated LAPs from the Renggeri Member, early Oxfordian of Longecombe, France, the type material of Hess (1965a).

\section{Description}

Large dissociated LAPs; proximal ones almost twice wider than high, distal ones slightly more than twice wider than high; dorsal edge strongly concave as a result of a well-developed constriction; distal edge convex with a conspicuous, pointed protrusion in dorsal half of distal edge, best developed in proximal LAPs; proximal edge irregularly undulose, in proximal to median LAPs with two moderately welldeveloped, prominent, protruding, horizontally elongate, ridge-like spurs, dorsal one of which larger than ventral one; spurs almost indiscernible in distal LAPs; ventro-distal tip of LAPs strongly protruding ventralwards, tongue shaped; ventro-proximal tip of LAP strongly oblique; ventral half to third of LAP strongly protruding ventro-proximalwards, large, wide; outer surface of LAPs with coarsely meshed stereom, replaced by finely meshed stereom in narrow band along proximal edge of LAP; trabeculae of coarsely meshed stereom merged into poorly developed vertical striation in very narrow band near spine articulations in proximal LAPs. Three large, ear-shaped spine articulations freestanding on strongly elevated distal portion in all LAPs; ventral and dorsal lobes of spine articulations merged into continuous volute; spine articulations not sharply bordered proximally; very strong dorsalward increase in size of spine articulations; weaker dorsalward increase in size of gaps separating spine articulations; gap between spine articulations and distal edge of LAP almost as wide as one spine articulation. Ventral edge of LAPs nearly straight, except for large, conspicuous, very deeply incised almost semi-circular tentacle notch.

Inner side of LAPs with two sharply defined, prominent ridge-like structures, proximal one separated into two, round, oblique knobs arranged in vertical row and connected by very poorly defined, narrow, weakly prominent irregular ridge; distal ridge-like structure consisting of single vertical, slightly oblique ridge in proximal to median LAPs, and of a small, round knob in distal LAPs; inner side of distal edge of proximal to median LAPs with two well-defined, prominent, horizontally elongate spurs composed of more densely meshed stereom, dorsal one of which slightly larger and protruding; spurs very poorly defined in distal LAPs; inner side of tentacle notch very large, widely encompassed by non-thickened ventral portion of LAPs. No perforations or furrow discernible.

\section{Remarks}

Hess (1965a) described Ophiopholis? trispinosa Hess, 1965 on the basis of dissociated LAPs and articulated arm fragments from the Oxfordian of France, which are here shown to belong to two different species. The smaller LAPs and the articulated arm fragments are assignable to Lapidaster gen. nov., a probably close relative of extant large-pored Ophiologimus (see above). Most of the larger LAPs, including the holotype, are here demonstrated to belong to the new small-pored ophiacanthid genus Ishidacantha gen. nov. Among the LAP types assigned to this genus, the above-mentioned ones are unique in displaying three large spine articulations with a strong dorsalward increase in size, a coarsely meshed stereom with a very poorly developed vertical striation, and a proximal ridge on the inner side separated into a ventral and a dorsal knob. Thus, they are described here as a new species which displays the highly distinctive characters of the new genus best and is therefore selected as the type species of Ishidacantha gen. nov.

\section{Occurrence}

Early Oxfordian of France. 
Genus Ophiomitrella Verrill, 1899

\section{Type species}

Ophiacantha laevipellis Lyman, 1883, by monotypy.

\section{Diagnosis}

Ophiacanthid with moderately large, ear-shaped spine articulations proximally sharply separated by a prominent, generally strongly thickened distalmost lamella or ridge; row of spine articulations extended tentacle notch very small, inconspicuous; ridge on inner side oblique, with ventro-proximalwards bent ventral part; dorsal tip of ridge widened and with ventralwards projecting extension.

\section{Remarks}

Many extant ophiacanthid lineages, in particular the small-pored ones, share highly similar LAP morphologies, as already pointed out by Thuy \& Stöhr (2011). As a result, it can be a major challenge to work out comprehensive LAP morphological diagnoses on the basis of which dissociated LAPs can be unambiguously assigned on genus level. Ophiomitrella certainly is one of the more challenging cases, being one of the genera which lack any striking, distinctive feature such as the lip-shaped ventral lobe of the spine articulations in Ophiolimna or the shape of the ridge in Ophiopristis and Ophiotreta. Although Ophiomitrella is a relatively common and diverse genus (O'Hara \& Stöhr 2006), only four extant species [O. clavigera (Ljungman, 1865), O. conferta (Koehler, 1922), O. granulosa (Lyman, 1878) and $O$. tenuis (Koehler, 1904)] of the genus were assessed with respect to the morphology of their LAPs (Fig. 31: 7-9). On the basis of this admittedly limited evidence, the LAPs of Ophiomitrella are probably best characterised by the relatively large, ear-shaped spine articulations that are proximally sharply bordered by a near-straight, prominent, well-defined and strongly thickened distalmost lamella or ridge, and the oblique ridge with a ventro-proximalwards bent ventral part and a widened dorsal tip with a ventralwards projecting extension.

It is true that this combination of characters is not among the most distinctive, considering how similar the LAPs of some species of Ophiacantha are. To make matters worse, the LAP morphology of the type species Ophiomitrella laevipellis is largely unknown, which poses problems considering that numerous species of Ophiomitrella are probably not congeneric with O. laevipellis (compare O'Hara \& Stöhr 2006). Therefore, in order not to add to the confusion but at the same time confer a maximum of taxonomic information, the diagnosis above is here taken as a reference to assign fossil dissociated LAPs to the genus Ophiomitrella, stressing, however, that the diagnosis is not among the most robust and only valid with certainty for the four extant species of the genus that have been examined personally.

Ophiomitrella? sp. 1

Fig. 31: 10-12

\section{Material examined}

GZG.INV.78735, GZG.INV.78736, GZG.INV.78737 and GZG.INV.78738 (8 dissociated LAPs) from the Callovian of Bauer-Wehrland, Germany; GZG.INV.78739 (1 dissociated LAP) from the Callovian of Althüttendorf, Germany.

\section{Description}

GZG.INV.78735 is a dissociated, small, median LAP; slightly higher than wide; dorsal edge straight; distal edge convex; proximal edge concave, devoid of spurs; distal half of outer surface with densely meshed stereom; trabeculae of densely meshed stereom merged into few, thick, irregular vertical ridges; proximal half with moderately coarsely meshed stereom. Five moderately large, nearly equal-sized, equi- 
distant, ear-shaped spine articulations freestanding on elevated distal portion of LAP; spine articulations proximally sharply bordered by near-straight, prominent, strongly thickened ridge; gap between spine articulations and distal edge of LAP very narrow; ventral and dorsal lobes of spine articulations merged into continuous volute but with very gentle kink proximally resulting in slightly oval spine articulations. Ventral edge of LAP nearly straight; tentacle notch invisible in external view. Row of spine articulations slightly protruding ventralwards.

Inner side of LAP with rather inconspicuous, well defined, prominent, oblique ridge with slightly widened, ventro-proximalwards pointing ventral tip, widened dorsal tip with ventralward projecting extension; inner side of distal edge of LAP with poorly defined, round area of slightly more densely meshed stereom; inner side of tentacle notch relatively small. Irregular row of perforations dorsally bordering tentacle notch; ventralmost perforation large, horizontally elongate, irregular.

GZG.INV.78736 is a dissociated median LAP; slightly higher than wide; well in agreement with the LAP described above; outer surface slightly less well preserved, with finely meshed stereom probably originally covered by coarsely meshed stereom. Five spine articulations similar to those observed on previous LAP; proximally bordered by slightly undulose, sharply defined, thick, prominent ridge.

Ridge on inner side of LAP similar to that of previous specimens, slightly better preserved; no area of slightly more densely meshed stereom on inner side of distal edge of LAP; inner side of tentacle notch smaller. Perforations on inner side loosely arranged in vertical row dorsally bordring tentacle notch; nearly of equal size.

GZG.INV.78737 is a dissociated proximal LAP fragment; originally clearly higher than wide; all edges broken; outer surface with coarsely and densely meshed stereom. At least five spine articulations similar to those observed on specimens described above; proximally bordered by sharply defined, prominent, broad ridge.

Inner side poorly preserved; shape of oblique, rather broad ridge not discernible; inner side of distal edge of LAP with moderately large, poorly defined, round area of slightly more densely meshed stereom. Irregular vertical row of moderately large, poorly preserved perforations.

\section{Remarks}

Although the material described above is scanty, it does display a combination of characters which is reminiscent of at least ome of the extant species of Ophiomitrella. Strong similarities are also shared with the LAPs of Ophiacantha, especially on account of the shape of the ridge on the inner side and the absence of well-developed spurs on the outer proximal edge. The unusually broad, sharply defined and straight ridge proximally bordering the spine articulations, however, is more typical of Ophiomitrella. Thus, pending a revision of the highly heterogeneous genera Ophiacantha and Ophiomitrella, the LAPs described above are here considered as a possible, indeterminate fossil record of Ophiomitrella.

Ophiomitrella? sp. 2

Fig. 32: 1

\section{Material examined}

GZG.INV.78740 (1 dissociated LAP) from sample 89, Jhurio Formation, middle Bathonian, Middle Jurassic of Jumara, India.

\section{Description}

GZG.INV.78740 is a dissociated, small, median to distal LAP; nearly as high as wide; dorsal edge very weakly concave as a result of a constriction; distal edge convex; proximal edge concave, devoid of spurs; outer surface partly obscured by sediment; probably with coarsely meshed stereom displaying irregularly thickened trabeculae. Six nearly equal-sized, equi-distant, ear-shaped spine articulations 


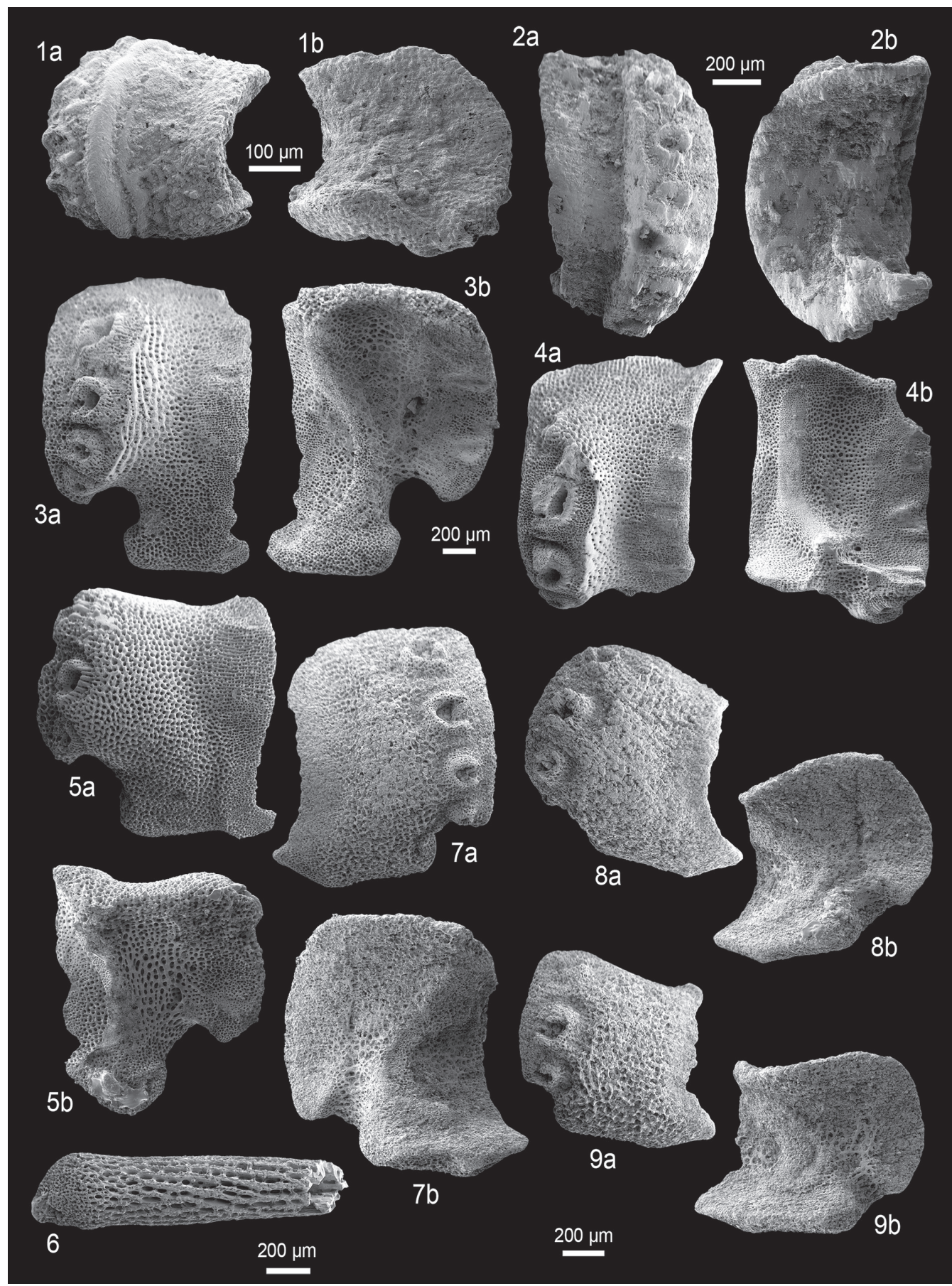

Fig. 32. Fossil skeletal plates of ophiacanthid brittle stars; lateral arm plates (LAPs) in external (a) and internal (b) views. 1. Ophiomitrella? sp. 2 from the Bathonian (Middle Jurassic) of Jumara, India; GZG. INV.78740, median to distal LAP. 2. Ophiomitrella sp. nov. from the late Maastrichtian (Late Cretaceous) of Maastricht, the Netherlands; NHMM JJ 5104, proximal LAP. 3-6. Ophiomalleus beneficarum gen. et sp. nov. from the Callovian of Bauer-Wehrland (3), Althüttendorf (4-5) and Hohensaaten (6), Germany. 3. GZG.INV.78741 (holotype), proximal to median LAP. 4. GZG.INV.78742 (paratype), proximal LAP. 5. GZG.INV.78743 (paratype), distal LAP. 6. GZG.INV.78744 (paratype), arm spine. 7-9. Ophiomalleus stevenwilsoni gen. et sp. nov. from the latest Hauterivian (Early Cretaceous) of Sarstedt, Germany. 7. GZG.INV.78748 (holotype), proximal LAP. 8. GZG.INV.78749 (paratype), median LAP. 9. GZG. INV.78750 (paratype), distal LAP. One common scale bar per species except for 6 . 
freestanding on elevated distal portion of LAP; proximally sharply bordered by exceptionally thick, straight, strongly prominent ridge; gap between spine articulations and distal edge of LAP very narrow. Ventral edge of LAP weakly convex, no tentacle notch discernible.

Inner side of LAP largely obscured by sediment; inner side of distal edge devoid of spurs; inner side of tentacle notch very small.

\section{Remarks}

The single, poorly preserved specimen described above shares greatest similarities with the median to distal LAPs of at least some of the extant species of Ophiomitrella, in particular with respect to the conspicuous, unusually thick ridge proximally bordering the spine articulations. This assignment, however, is far from robust, and the absence of better-preserved material precludes both a more secure and precise taxonomic assessment and a comparison with the above-described, slightly younger LAPs from Germany, here tentatively assigned to Ophiomitrella.

\section{Note}

The articulated specimen from the upper Maastrichtian Gronsveld Member (Maastricht Formation) of Maastricht, the Netherlands, assigned by Jagt (2000) to Ophiacantha? danica, most probably represents an undescribed species of Ophiomitrella. Corresponding dissociated LAPs (Fig. 32: 2) found in adjacent beds corroborate such an assignment. This new species of Ophiomitrella is here only mentioned as such; it will be described fully in a future study.

Genus Ophiomalleus gen. nov.

urn:1sid:zoobank.org:act:9E006789-898D-45DB-97FF-2FC9569AFF88

\section{Type species}

Ophiomalleus beneficarum sp. nov. by present designation.

\section{Other species included}

Ophiomalleus stevenwilsoni sp. nov.

\section{Diagnosis}

Ophiacanthid with very large, massive LAPs displaying a large, conspicuous, strongly protruding ventral portion; main portion of LAP generally rectangular; three to five large to very large, ear-shaped spine articulations freestanding on elevated distal portion of LAP; inner side of LAP with simple, broad ridge devoid of angular kinks or strongly widened parts; tentacle notch small but conspicuously deeply incised and generally more than semi-circular at least in proximal LAPs.

\section{Etymology}

Name composed of ophis, Greek for "snake", a commonly used prefix in ophiuroid names, and malleus, Latin for "hammer", in reference to the massive, rectangular aspect of the LAPs; gender masculine.

\section{Remarks}

Among all ophiacanthid LAP types currently known, one stands out on account of its particularly massive, rectangular general appearance. Further characters of the LAP type in question are three to four large spine articulations freestanding on the elevated distal portion of the LAP, a large and strongly protruding ventral portion, a simple ridge on the inner side devoid of angular kink and strongly widened parts, and a small but deeply incised and at least semi-circular tentacle notch. This combination of characters is highly distinctive and not found in any other currently known type of LAPs within the Ophiacanthidae. Ophiomalleus gen. nov. is thus introduced here to accommodate this LAP type. 
Closest similarities are shared with the LAPs of Ishidacantha gen. nov. on account of the large, strongly protruding ventral portion, the low number of spine articulations and the small, deeply incised, at least semi-circular, tentacle notches. In the light of the fundamentally differing ridge structures on the inner side of the LAPs, however, these similarities are superficial at most. Ophiomalleus gen. nov. clearly belongs to the small-pored ophiacanthids but any more detailed phylogenetic relationships remain elusive in the absence of articulated specimens.

Ophiomalleus beneficarum sp. nov. urn:1sid:zoobank.org:act:7B911036-1E01-4EDA-AF2C-E56F0027B8F4

Fig. 32: 3-6

Ophiacantha? constricta - Kutscher 1987a: 61, pl. 3 figs 1-2 (material incorrectly assigned to Ophiacantha? constricta Hess, 1966).

\section{Diagnosis}

Species of Ophiomalleus gen. nov. with very large LAPs displaying a poorly developed vertical striation on narrow band near spine articulations; at least six poorly defined spurs on proximal outer edge in proximal LAPs; up to five spine articulations with finely corrugated proximal edge and strong dorsalward increase in size except for often very small dorsalmost one; single, moderately broad, strongly prominent, S-shaped ridge on inner side.

\section{Etymology}

Name formed after beneficum, Latin for "charitable", in reference to the infamous malleus maleficarum, to recall that witch hunts, regrettably, did not go extinct for good in the Dark Ages.

\section{Type material}

\section{Holotype}

GZG.INV.78741.

\section{Paratype}

GZG.INV.78742, GZG.INV.78743 Althütendorf, Germany; and GZG.INV.78744 Hohensaaten, Germany; all from glacial erratic boulders, Callovian, Middle Jurassic.

\section{Type locality and horizon}

Bauer-Wehrland, Germany; glacial erratic boulders, Callovian, Middle Jurassic.

\section{Additional material}

GZG.INV.78745 (18 dissociated LAPs) from the Callovian of Bauer-Wehrland, Germany; GZG. INV.78746 (5 dissociated LAPs) from the Callovian of Althüttendorf, Germany; GZG.INV.78747 (11 dissociated LAPs) from the Callovian of Hohensaaten, Germany.

\section{Description}

\section{Holotype}

GZG.INV.78741 is a dissociated, very large, proximal to median LAP; approximately 1.5 times higher than wide; main portion of LAP of rounded rectangular outline; dorsal and distal edges gently convex; proximal edge nearly straight, with four relatively small, poorly defined, almost indiscernible, horizontally elongate spurs; ventral portion of LAP very large, conspicuously protruding ventralwards; ventro-distal tip of LAP strongly protruding ventralwards, tongue shaped; outer surface of LAP with fine, rather irregular vertical striation composed of slender, non-overlapping lamellae, and restricted to 
distal third of outer surface bordering spine articulations; moderately finely meshed stereom on ventral portion of LAP and most of the median third of the outer surface; proximal third with very finely meshed and between spurs weakly horizontally striated stereom. Four very large, ear-shaped spine articulations freestanding on strongly elevated distal portion of LAP; very strong dorsalward increase in size of spine articulations and weaker dorsalward increase in size of gaps separating them; ventral and dorsal lobes of spine articulations merged into continuous volute; proximal edge of volute finely but irregularly corrugated; ventralmost spine articulation on protruding ventro-distal tip of LAP; dorsalmost spine articulation not at dorsal edge of LAP; row of spine articulations slightly oblique; gap between spine articulations and distal edge of LAP nearly as wide as half one spine articulation. Ventral edge of LAP nearly straight, with deeply incised, relatively small, more than semi-circular tentacle notch.

Inner side of LAP with large, moderately broad, strongly prominent, nearly S-shaped ridge, with ventral tip pointing ventro-proximalwards and confluent with ventral portion of LAP, and dorsal tip pointing dorsalwards and separated from dorsal edge of LAP; inner side of distal edge of LAP with two relatively large, well-defined, slightly prominent, horizontally elongate spurs. Three irregular perforations loosely arranged in vertical row dorsally bordering tentacle notch.

\section{Paratype supplements and variation}

GZG.INV.78742 is a dissociated proximal LAP; ventral portion missing; LAP originally more than 1.5 times higher than wide; main portion of LAP nearly rectangular to trapezoid in outline; dorsal edge irregularly convex; distal edge nearly straight; proximal edge gently concave, with at least six small to moderately large, poorly defined, horizontally slightly elongate, weakly prominent, nonprotruding spurs; outer surface with moderately finely meshed stereom; trabeculae of stereom near spine articulations thickened and merged into very poorly developed, irregular vertical striation. Five spine articulations similar to those of holotype; strong dorsalward increase in size of spine articulations except for very small dorsalmost one.

Dorsal half of ridge on inner side preserved, uniformly broad, well defined, strongly prominent, composed of straight, near-vertical dorsal portion and oblique, slightly bent central part; both parts connected by round kink; at least three spurs similar to those observed on holotype. Three very small, closely spaced perforations in very short vertical row dorsally bordering tentacle notch.

GZG.INV.78743 is a dissociated distal LAP; nearly as wide as high; very well in agreement with holotype; dorsal edge concave as a result of a constriction; proximal edge with three spurs similar to those of holotype; outer surface with moderately finely meshed stereom, no vertical striation. Three spine articulations similar to those of holotype, slightly smaller, in shallow notches of elevated distal edge of LAP and with better-developed fine corrugation on proximal edge of volute. Ventral edge of LAP slightly concave, with deeply incised slightly less than semi-circular tentacle notch.

Ridge on inner side of LAP similar to that of holotype except for a shorter, near-vertical dorsal portion of the ridge.

GZG.INV.78744 is a very large, cylindrical, slightly bulgy arm spine; tip broken, exposing hollow lumen; spine with moderately coarse, irregularly longitudinal trabecular ridges beset with minute granules.

\section{Remarks}

The specimens at hand were initially described and figured as Ophiacantha? constricta Hess, 1965 by Kutscher (1987a) as a result of the misleading inclusion of more than one type of LAPs in the concept of that species. The LAP type including the holotype of O.? constricta, here transferred to Ophiogaleus gen. nov. (see above), however, fundamentally differs from the LAPs described above. The latter are here assigned to Ophiomalleus gen. nov., as discussed above. Within this genus, these LAPs are unique in displaying up to five spine articulations, a poorly developed vertical striation in median and, to a lesser extent, proximal LAPs, up to six poorly defined spurs on the outer proximal edge, and a moderately 
broad, S-shaped ridge on the inner side. Since the LAPs described above display the highly distinctive features of the new genus best it is chosen as its type species.

\title{
Occurrence
}

Callovian of Germany.

$$
\begin{aligned}
& \text { Ophiomalleus stevenwilsoni sp. nov. } \\
& \text { urn:lsid:zoobank.org:act:201BCFBC-5C34-4C2C-827A-30AF0F678279 }
\end{aligned}
$$

Fig. 32: 7-9

\section{Diagnosis}

Species of Ophiomalleus gen. nov. with large LAPs devoid of vertical striation on the outer surface and of spurs on the outer proximal and inner distal edges; up to four large, ear-shaped spine articulations not bordered proximally by a ridge; ridge on inner side of LAP very broad, with widened dorsal tip and shallow, poorly defined furrow in its centre.

\section{Etymology}

Species named in honour of British musician Steven Wilson, one of the contemporaneous masters of originality and creativity, whose music often taught me how to let ideas develop and materialise.

\section{Type material}

\author{
Holotype \\ GZG.INV.78748. \\ Paratypes \\ GZG.INV.78749 and GZG.INV.78750.
}

\section{Type locality and horizon}

Claypit Gott in Sarstedt, Germany; latest Hauterivian, Early Cretaceous.

\section{Additional material}

GZG.INV.78751 (7 dissociated LAPs).

\section{Description}

\section{Holotype}

GZG.INV.78748 is a dissociated, large, proximal LAP; slightly higher than wide; main portion of LAP nearly rectangular; dorsal and distal edges gently convex; proximal edge gently concave, devoid of spurs; ventral fifth of LAP large, strongly protruding ventro-proximalwards; outer surface with moderately finely meshed stereom, replaced by narrow and slightly sunken band of very finely meshed stereom along proximal edge. Four very large, ear-shaped spine articulations freestanding on elevated distal edge of LAP; spine articulations not bordered proximally by ridge; dorsal and ventral lobes merged into continuous volute; very strong dorsalward increase in size of spine articulations; gap between spine articulations and distal edge of LAP relatively narrow. Ventral edge of LAP with deeply incised but small tentacle notch.

Inner side of LAP with large, well-defined, prominent, broad ridge; ventral tip ventro-proximalwards bent, not merged with ventral portion of LAP; dorsal tip widened, round, dorso-proximalwards pointing; shallow, poorly defined furrow in the middle of the ridge, following its course; inner side of distal edge of LAP devoid of spurs; inner side of tentacle notch small, semi circular. Two minute perforations loosely arranged in vertical row dorsally bordering tentacle notch. 


\section{Paratype supplements and variation}

GZG.INV.78749 is a dissociated median LAP; slightly wider than high; very well in agreement with holotype; ventral sixth of LAP strongly protruding ventro-proximalwards. Four spine articulations similar to those observed on holotype.

Inner side of LAP similar to that of holotype. Shallow, poorly defined, slightly oblique furrow dorsally bordering tentacle notch.

GZG.INV.78750 is a dissociated distal LAP; slightly wider than high; dorsal edge concave as a result of a constriction. Three spine articulations similar to those observed on holotype. Tentacle less deeply incised, small.

Ridge on inner side of LAP similar to that of holotype, slightly shorter and broader; furrow in the middle of the ridge slightly better defined. No perforations discernible.

\section{Remarks}

These LAPs are unequivocally assignable to Ophiomalleus gen. nov. on account of the massive, nearrectangular aspect of the main portion, the strongly protruding ventral portion, the shape and arrangement of the spine articulations and the shape of the ridge on the inner side. Within this genus, the LAPs described above are unique in entirely lacking vertical striation on the outer surface and spurs on the outer proximal and inner distal edges.

Genus Inexpectacantha Thuy, 2011

\section{Type species}

Inexpectacantha acrobatica Thuy, 2011, by original designation.

\section{Diagnosis}

Ophiacanthid with small to moderately large LAPs of thick, massive and generally bulging aspect; outer surface devoid of conspicuous ornament; no spurs on outer proximal and inner distal edges; small, earshaped spine articulations freestanding or in shallow depressions of bulging distal portion of LAP; spine articulations commonly tilted; ventral lobe rugged to irregularly corrugate, commonly confluent with outer surface stereom; spine articulations not sharply bordered proximally and with dorsalward increase in size; short, broad, dorso-proximalwards bent, tongue-shaped ridge devoid of kinks or widened parts; tentacle notch very small, poorly defined.

\section{Remarks}

Inexpectacantha acrobatica is probably one of the best-known fossil ophiuroids. In fact, the original description was based on outstandingly well-preserved material from the Pliensbachian of France, comprising both articulated skeletons and dissociated skeletal parts, including LAPs, allowing for a morphological analysis of exceptional detail (Thuy 2011). As a result, fossil dissociated LAPs compatible with the LAP morphological diagnosis of Inexpectacantha are unambiguously identifiable and thus provide evidence for bracketing the divergence time of the genus.

The LAPs of Inexpectacantha are among the most characteristic of all ophiacanthid LAP types. In fact, the a massive, thick, round and bulging general aspect, the lack of conspicuous outer surface ornament and spurs on the outer proximal and inner distal edges, small spine articulations with dorsalward increase in size and not bordered proximally by a ridge, a large, broad, tongue-shaped ridge devoid of kinks, extensions or strongly widened parts on the inner side, and very small, poorly defined tentacle notches are a combination of characters not found in any other ophiacanthid genus. Superficial similarities are shared with the LAPs of Ophiochondrus Lyman, 1869, in which, however, the spine articulations are generally 
not oblique and not confluent with the outer surface stereom. In addition, the LAPs of Ophiochondrus are less massive, and the ridge on the inner side displays a ventro-proximalwards projecting extension.

Greatest similarities are shared with the LAPs of Ophioleviathan gen. nov.(see below), particularly with respect to the massive and thick general aspect, and the shape of the spine articulations and of the ridge on the inner side. The LAPs of Ophioleviathan gen. nov., however, are significantly larger than those of Inexpectacantha and display larger, near-vertical spine articulations in deeper notches and composed of distal and proximal rather than dorsal and ventral lobes, with a strongly thickened distal lobe. Nevertheless, as discussed below, the LAP morphologies of both genera as so similar that they most likely represent sister taxa.

Interestingly, the currently known species of Inexpectacantha fall into two groups on the basis of LAP morphology: I. ritae sp. nov. and I. lunaris (Hess, 1962), plus I. weisi sp. nov. and I. acrobatica. The two last named are characterised by generally smaller LAPs with smaller height/width ratios, spine articulations freestanding rather than in notches, a more coarsely meshed stereom on the outer surface, and lip-shaped distal knobs in the spine articulations of the distal LAPs. Most of these characters are typically indicative of a paedomorphic condition (Stöhr 2005, 2011). Indeed, the articulated specimens of Inexpectacantha acrobatica display a strikingly paedomorphic general morphology (Thuy 2011).

\section{Inexpectacantha ritae $\mathrm{sp}$. nov. urn:lsid:zoobank.org:act:7CCF96E7-E90E-4FD8-B307-1DEC45F8F82F}

Fig. 33: 1-3

Sigsbeia? lunaris - Thuy 2005: 41, pl. 4 figs 6-10 [material incorrectly assigned to Sigsbeia? lunaris (Hess, 1962)].

\section{Diagnosis}

Species of Inexpectacantha with moderately large LAPs; outer surface with finely meshed stereom, devoid of constriction, furrow or depressed area along proximal edge; up to six moderately large spine articulations in shallow notches of bulging distal portion, slightly oblique in proximal LAPs, more strongly oblique in median and distal ones; ridge on inner side LAP relatively slender, strongly bent dorso-proximalwards.

\section{Etymology}

Species named in honour of Rita Hellers, who gave me life and all the prerequisites to fill it with happiness, love and fulfilment.

\section{Type material}

\section{Holotype}

MnhnL HE419.

\section{Paratypes}

MnhnL HE420 and MnhnL HE421.

\section{Type locality and horizon}

Bourglinster, Luxembourg; sample Bou of Thuy (2005), Planorbis Zone, Hettangian, Early Jurassic.

\section{Additional material}

MnhnL HE422 (55 dissociated LAPs) from sample Bou of Thuy (2005) from the Hettangian of Bourglinster, Luxembourg; MnhnL HE423 (16 dissociated LAPs) from sample Van1 of Thuy (2005) 
from the Hettangian of Vance, Belgium; MnhnL HE254 (5 dissociated LAPs), MnhnL HE424 (20 dissociated LAPs) from sample Van2 of Thuy (2005) from the Hettangian of Vance, Belgium.

\section{Description}

\section{Holotype}

MnhnL HE419 is a dissociated, moderately large, proximal LAP; almost twice higher than wide; of massive and stout aspect; dorsal edge weakly convex, oblique; distal edge convex; proximal edge concave, devoid of spurs; no constriction or furrow along proximal edge; outer surface with moderately finely meshed stereom becoming slightly more finely meshed close to proximal edge of LAP. Six moderately large, ear-shaped, oval, horizontally slightly elongate, weakly oblique spine articulations in shallow notches of bulging distal portion of LAP; notches of three ventral spine articulations merged; spine articulations not sharply bordered proximally, edge of notches gentle; ventral lobe of spine articulations thin, rugged, confluent with stereom of notch and merged proximally with larger, thicker and more prominent dorsal lobe into continuous volute; strong dorsalward increase in size of gaps separating spine articulations; dorsalward increase in size of spine articulations very weak; gap between spine articulations and distal edge of LAP narrow. Ventral edge of LAP oblique, slightly convex; tentacle notch invisible in external view.

Inner side of LAP with large, moderately well-defined, prominent, relatively slender, dorso-proximalwards bent, tongue-shaped ridge devoid of kinks or strongly widened parts; ventral tip of ridge not merged with ventral portion of LAP; no spurs on inner side of distal edge of LAP; inner side of tentacle notch very small, poorly defined, shallow. No perforation or furrow discernible.

\section{Paratype supplements and variation}

MnhnL HE420 is a dissociated median LAP; slightly higher than wide; very well in agreement with holotype, of slightly more rounded aspect. Five spine articulations similar to those observed on holotype but more strongly oblique; weaker dorsalward increase in size of gaps separating spine articulations; two ventralmost spine articulations in very shallow notches, remaining ones freestanding. Inner side similar to that of holotype.

MnhnL HE421 is a dissociated distal LAP; slightly higher than wide. Four spine articulations similar to those of holotype but more strongly oblique, almost vertical; weaker dorsalward increase in size of gaps separating spine articulations; two ventralmost spine articulations in very shallow notches, remaining two freestanding.

Inner side similar to that of holotype.

\section{Remarks}

These LAPs from the Hettangian of Luxembourg were originally recorded by Thuy (2005), along with conspecific LAPs from the Hettangian of Belgium, and erroneously assigned to Sigsbeia? lunaris (Hess, 1962). While it is clear from the highly distinctive combination of characters that these LAPs are assignable to Inexpectacantha, the type specimens of Sigsbeia? lunaris differ from the LAPs described above in the more strongly oblique spine articulations even in proximal LAPs, the presence of a slightly depressed band along part of the proximal edge, and the much wider and less strongly bent ridge on the inner side. Evidently, these LAPs are incompatible with any currently known LAP type assignable to Inexpectacantha and are thus described here as a new species.

\section{Occurrence}

Hettangian of Luxembourg and Belgium. 


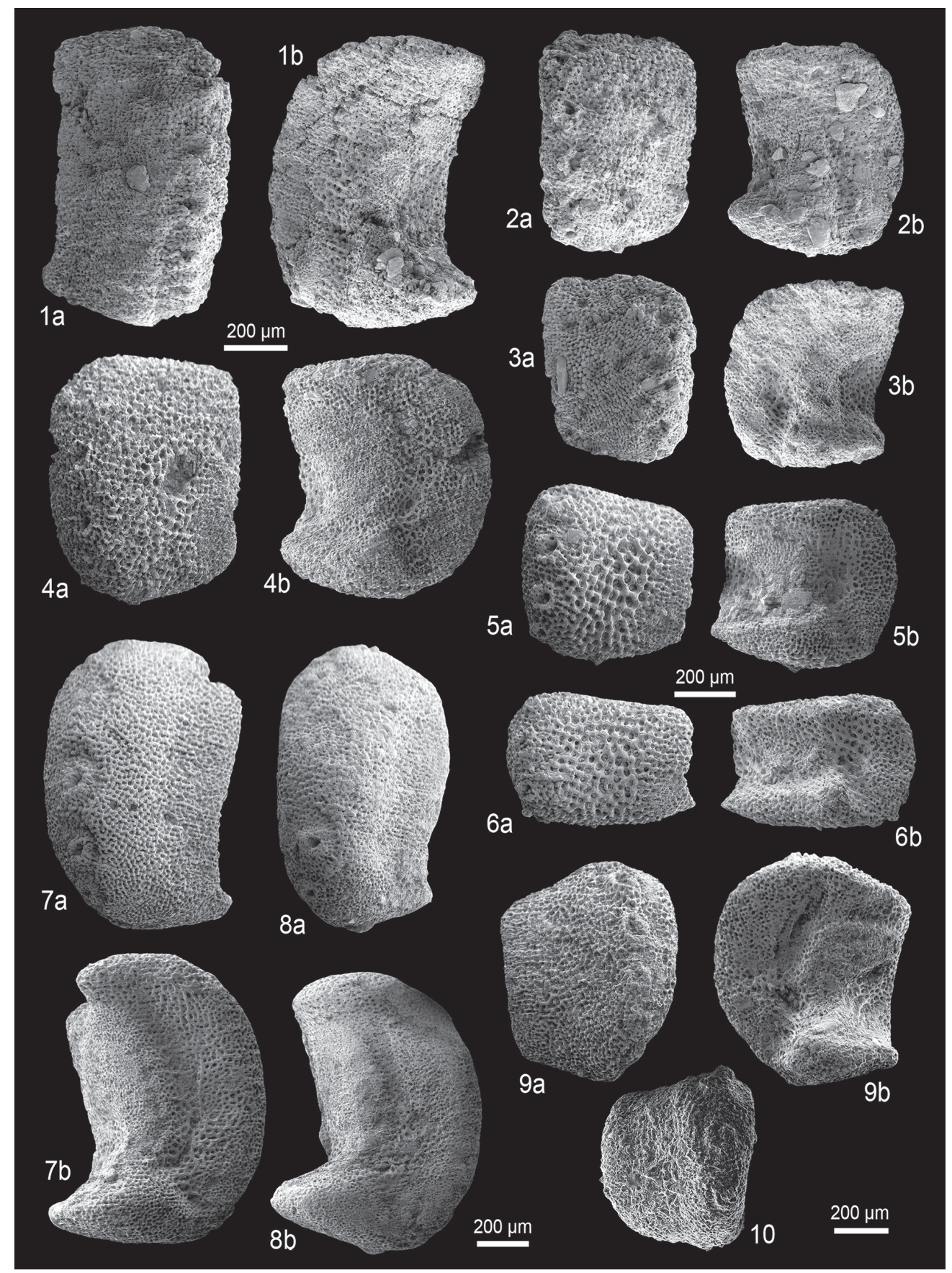

Fig. 33. Fossil lateral arm plates (LAPs) of ophiacanthid brittle stars in external (a) and internal (b) views. 1-3. Inexpectacantha ritae sp. nov. from the Hettangian (Early Jurassic) of Bourglinster, Luxembourg. 1. MnhnL HE419 (holotype), proximal LAP. 2. MnhnL HE420 (paratype), median LAP. 3. MnhnL HE421 (paratype), distal LAP. 4-6. Inexpectacantha weisi sp. nov. from the Hettangian (Early Jurassic) of Fontenoille, Belgium. 4. MnhnL HE425 (holotype), proximal LAP. 5. MnhnL HE426 (paratype), median LAP. 6. MnhnL HE427 (paratype), distal LAP. 7-8. Inexpectacantha lunaris (Hess, 1962) comb. nov. from the late Sinemurian (Early Jurassic) of Bishop's Cleeve, Great Britain. 7. GZG. INV.78752, proximal LAP. 8. GZG.INV.78753, proximal to median LAP. 9-10. Inexpectacantha acrobatica Thuy, 2011 from the early Pliensbachian (Early Jurassic) of Blockley, Great Britain (9) and the early Toarcian (Early Jurassic) of Aix-sur-Cloie, Belgium (10). 9. GZG.INV.78755, proximal LAP. 10. GZG.INV.78757, juvenile proximal LAP. One common scale bar per species. 


\section{Inexpectacantha weisi sp. nov. urn:1sid:zoobank.org:act:96A19195-86C6-4EA8-B6F2-AEDA14589A66}

Fig. 33: 4-6

Hemieuryale? n. sp. - Kutscher \& Hary 1991: 54, pl. 2 fig. 4a-d.

\section{Diagnosis}

Species of Inexpectacantha with small LAPs displaying a coarsely meshed stereom on the outer surface; no constriction and no furrow along proximal edge; spine articulations freestanding, not in depressions, oblique; single spine articulation with lip-shaped distal knob.

\section{Etymology}

Species named in honour of my friend and colleague Robert Weis for his continuous encouragement and for digging up the type locality of the species.

\section{Type material}

\section{Holotype}

MnhnL HE425.

\section{Paratypes}

MnhnL HE426 and MnhnL HE427.

\section{Type locality and horizon}

Fontenoille, Belgium; level c of Delsate et al. (2002), Liasicus Zone, Hettangian, Early Jurassic.

\section{Additional material}

MnhnL HE428 (81 dissociated LAPs) from the Hettangian of Fontenoille, Belgium; MnhnL HE429 (28 dissociated LAPs) from the Bucklandi Zone, early Sinemurian of Remerschen, Luxembourg.

\section{Description}

\section{Holotype}

MnhnL HE425 is a dissociated, small, proximal LAP; slightly higher than wide; of thick, massive and rounded aspect; dorsal edge oblique but straight; distal edge convex; proximal edge nearly straight, devoid of spurs; outer surface with moderately coarsely meshed stereom, except for poorly defined, weakly sunken area of finely meshed stereom near ventro-proximal tip of LAP; no vertical striation or other conspicuous ornament elements. Five small, ear-shaped, oblique spine articulations freestanding on bulging distal portion of LAP, not sharply separated proximally from outer surface stereom and not sunken; ventral lobe rugged, thin, merged proximally with much thicker, smoother and more prominent dorsal lobe into continuous volute; weak dorsalward increase in size of spine articulations but not in size of gaps separating them; gap between spine articulations and distal edge almost as wide as one spine articulation. Ventral edge of LAP oblique, weakly convex; tentacle notch invisible in external view.

Inner side of LAP with very large, broad, conspicuous, well-defined, prominent, strongly dorsoproximalwards bent, tongue-shaped ridge; dorsal part of ridge wider than ventral one; ventral tip of ridge not merged with ventral portion of LAP; no spur on inner side of distal edge of LAP; inner side of tentacle notch very small, shallow and poorly defined. Very poorly defined, shallow, almost indiscernible vertical furrow dorsally bordering tentacle notch; no perforations discernible. 


\section{Paratype supplements and variation}

MnhnL HE426 is a dissociated median LAP; slightly wider than high; very well in agreement with holotype; outer surface better preserved, with coarsely meshed stereom devoid of vertical striation or granules; narrow and of more finely meshed stereom along proximal edge increasing in width ventralwards. Four equi-distant spine articulations similar to those observed on holotype but better preserved; strong dorsalward increase in size of spine articulations; gap between spine articulations and distal edge of LAP narrower.

Inner side of LAP well in agreement with that of holotype.

MnhnL HE427 is a dissociated distal LAP; approximately 1.5 times wider than high; dorsal edge straight, weakly oblique; proximal edge irregularly concave. Four spine articulations similar to those observed on holotype except for ventralmost one with small, lip-shaped, strongly protruding distal knob; dorsalward increase in size of spine articulations and of gaps separating them; gap between spine articulations and distal edge of LAP narrower than in holotype. Ventral edge of LAP slightly convex.

Ridge on inner side of LAP smaller, narrower and less clearly tongue shaped than in holotype, with pointed dorsal tip and distally bordered by small, poorly defined knob.

\section{Remarks}

These LAPs are unambiguously assignable to Inexpectacantha on account of the stout, thick, rounded general aspect, the lack of outer surface ornament and spurs, the shape, size and position of the spine articulations and the shape of the ridge on the inner side. Within this genus, greatest similarities are shared with the LAPs of Inexpectacantha acrobatica, especially with respect to the freestanding spine articulations. The LAPs described above, however, lack a constriction or a furrow along the proximal edge, and display a more coarsely meshed stereom on the outer surface and fewer spine articulations. They are thus here described as a new species. The strongly prominent, lip-shaped knob on the ventralmost spine articulation in the distal LAP noted above most probably bore a hook-shaped spine similar to those known from the type material of I. acrobatica (see Thuy 2011).

Kutscher \& Hary (1991) described and illustrated dissociated LAPs from the Sinemurian of Luxembourg as "Hemieuryale? n. sp.", recognising the species as new but refraining from formally naming it on account of the limited amount of material available. The specimens in question appear to be conspecific with the LAPs described here, although only some of the original specimens of Kutscher \& Hary (1991) could be examined by myself. The material from the Pliensbachian of Great Britain described as Hemieuryale? lunaris Hess, 1962 by Hess (1964) was considered by Kutscher \& Hary (1991) to be conspecific with their unnamed LAPs. As shown below, however, Hess's (1964) original assignment was correct.

\section{Occurrence}

Hettangian of Belgium, early Sinemurian of Luxembourg.

Inexpectacantha lunaris (Hess, 1962) comb. nov.

Fig. 33: 7-8

Hemieuryale? lunaris Hess, 1962: 627, figs 29-33, 45-47.

Hemieuryale? lunaris - Hess 1964: 762, figs 4-10.

non Sigsbeia? lunaris - Kutscher 1996: 12, pl. 3 figs 6-8, pl. 4 figs 12-14. — Kutscher \& Villier 2003: 189, pl. 6 figs 7-8, pl. 7 figs 1-2. — Thuy 2005: 41, pl. 4 figs 6-10. — Hess 2006: 66, pl. 29 figs 8-9. 


\section{Diagnosis}

Species of Inexpectacantha with moderately large LAPs devoid of constriction but displaying a slightly depressed band of variable width along most of the proximal edge; outer surface with finely meshed stereom; up to six small, near-vertical spine articulations in shallow notches of bulging distal portion of LAP; ridge on inner side of LAP very broad and only slightly bent dorso-proximalwards.

\section{Material examined}

GZG.INV.78752, GZG.INV.78753 and GZG.INV.78754 (dissociated LAPs) from the Obtusum Zone, late Sinemurian of Bishop's Cleeve, Great Britain; 17 dissociated LAPs from the late Pliensbachian of Seewen, Switzerland, the type material of Hess (1962); the original material of Hess (1964).

\section{Description}

Moderately large, dissociated LAPs of thick, massive and rounded aspect; proximal LAPs nearly twice higher than wide, distal ones slightly higher than wide; dorsal edge straight to slightly convex, oblique; no constriction; distal edge convex; proximal edge straight to slightly concave, devoid of spurs; slightly depressed band of varible width, from one-fifth to one-third of the total LAP width, along most of the proximal edge, widest in the middle, not reaching dorso- and ventro-proximal tips of LAP; depressed band not sharply separated from remaining outer surface distally and without conspicuous change in stereom mesh size. Six (proximal LAPs) to four (distal LAPs) small, ear-shaped, strongly oblique to near-vertical spine articulations in shallow notches of bulging distal edge; dorsalward increase in size of spine articulations and of gaps separating them; ventral lobe of spine articulations rugged, confluent with stereom of notch, merged proximally with almost equal-sized dorsal lobe into continuous volute; gap between spine articulations and distal edge of LAP nearly as wide as one spine articulation or slightly wider; spine articulations not sharply bordered proximally, not even by edge of notches. Ventral edge of LAPs oblique, straight; tentacle notch invisible in external view.

Inner side of LAP with very large, sharply defined, prominent, conspicuously broad, tongue-shaped ridge; ventral tip of ridge not merged with ventral portion of LAP; dorsal part of ridge wider than ventral one, weakly bent dorso-proximalwards; shallow, poorly defined furrow along distal edge of ridge; no spurs on inner side of distal edge of LAP; inner side of tentacle notch very small, weakly defined, almost indiscernible in many LAPs. Shallow, poorly defined, vertical furrow dorsally bordering tentacle notch. Articulated arm fragments from the Pliensbachian of Great Britain, assignable to this species, were described in detail and illustrated by Hess (1964).

\section{Remarks}

Hess (1962) originally described dissociated LAPs from the Pliensbachian of Switzerland as Hemieuryale? lunaris, comparing them with Recent hemieuryalids such as Hemieuryale von Martens, 1867 and Sigsbeia Lyman, 1878. He later (Hess 1964) assigned dissociated LAPs and articulated arm fragments from the Pliensbachian of Great Britain to Hemieuryale? lunaris, stressing that the minor morphological differences between the Swiss type material and the British specimens could be ascribed to the better preservation of the latter.

Following these two reports, however, confusion has arisen over the concept of Hemieuryale? lunaris. First, Kutscher \& Hary (1991) described dissociated LAPs from the Sinemurian of Luxembourg which they considered to be conspecific with Hess's (1964) Brirish specimens but no with the type material from Switzerland. Then, Kutscher (1996) reported on dissociated LAPs from the Toarcian/Aalenian of Germany which he assigned to Hess's (1962) species, tentatively transferring it to the extant hemieuryalid genus Sigsbeia. Finally, Thuy (2005) recorded dissociated LAPs from the Hettangian of Belgium and Luxembourg which were assigned to Sigsbeia? lunaris. By that time, the concept of Sigsbeia? lunaris had been inflated beyond meaningful limits as far as LAP morphology is concerned, including every 
type of thick, massive, rounded LAPs with small, more or less oblique spine articulations and a broad ridge on the inner side.

A re-examination of the original material of those three papers has allowed to disentangle the different LAP types previously assigned to S.? lunaris. Hess's (1962) type material from Switzerland and the British specimens (Hess 1964) are, indeed, conspecific and differ mainly in their state of preservation. They display the highly distinctive combination of characters typical of the ophiacanthid Inexpectacantha and are thus here transferred to that genus. The LAPs of Kutscher \& Hary (1991) are here shown to be assignable to Inexpectacantha weisi sp. nov. Those of Kutscher (1996) and Kutscher \&Villier (2003), in contrast, fundamentally differ from Inexpectacantha lunaris comb. nov., in particular with respect to the spine articulation morphology. They most probably even belong to a different family. Their exact systematic position requires more detailed investigations involving comparison with Recent non-ophiacanthid genera, which is beyond the scope of the present study.

Inexpectacantha lunaris comb. nov., as defined here, is unambiguously distinguishable from its congeners in displaying small, near-vertical spine articulations in shallow notches, a slightly depressed area along most of the proximal edge, and a very broad, weakly bent ridge on the inner side. Closest similarities are shared with the LAPs of Inexpectacantha ritae sp. nov., especially on account of the larger size, the larger general height/width ratio and the position of the spine articulations. Similarities with the LAPs of Ophioleviathan gen. nov. are more superficial and mainly pertain to the near-vertical spine articulations, the broad ridge on the inner side and the very narrow, slightly depressed band along the proximal edge. The LAPs of Ophioleviathan gen. nov., however, are considerably larger and display almost overturned spine articulations in deeper notches and with much thicker, more strongly prominent dorsal lobes.

\section{Occurrence}

Late Sinemurian to early Pliensbachian of Great Britain, late Pliensbachian of Switzerland.

Inexpectacantha acrobatica Thuy, 2011

Fig. 33: 9-10

Inexpectacantha acrobatica Thuy, 2011: 217, pls 1-3, pl. 4 figs 1-6.

Inexpectacantha acrobatica - Thuy et al. 2011: 179, fig. 3f.

\section{Diagnosis}

Species of Inexpectacantha with small LAPs; relatively small height/width ratio; outer surface with moderately coarsely meshed stereom and slight constriction resulting in concave dorsal edge and shallow, poorly defined furrow parallel to proximal edge; up to six moderately large, ear-shaped, oblique spine articulations freestanding on strongly bulging distal portion of LAP; ridge on inner side of LAP moderately broad and strongly bent dorso-proximalwards; two ventralmost spine articulations of distal LAPs with conspicuous, strongly prominent, lip-shaped distal ridges originally supporting hook-shaped arm spines.

\section{Material examined}

GZG.INV.78755 and GZG.INV.78756 (dissociated LAP) from the early Pliensbachian of Blockley, Great Britain; GZG.INV.78757 and GZG.INV.78758 (70 dissociated LAPs) from the early Toarcian of Aix-sur-Cloie, Belgium; the type material of Thuy (2011). 


\section{Remarks}

The LAPs of Inexpectacantha acrobatica were described in detail and illustrated by Thuy (2011). The LAP morphological diagnosis presented above allows for an unambiguous distinction from other species of Inexpectacantha, including those known exclusively from dissociated LAPs. Two additional occurrences of the species are listed here, one of which extends the stratigraphic range into the early Toarcian.

\section{Occurrence}

Early Pliensbachian of France and Great Britain, early Toarcian of Belgium.

\section{Genus Ophioleviathan gen. nov. urn:1sid:zoobank.org:act:3AF8EB01-EA44-4C91-9614-CCFBE921662C}

\section{Type and sole known species}

Ophioleviathan watsoni sp. nov.

\section{Diagnosis}

Ophiacanthid with extremely large, thick and massive LAPs; outer surface devoid of conspicuous ornament elements; no spurs on outer proximal and inner distal edges; poorly defined, slightly depressed narrow band along the middle part of the proximal ridge in proximal LAPs; up to seven large, ear-shaped spine articulations in deep notches of strongly bulging distal portion of LAP; spine articulations vertical to slightly overturned, with rather slender, rugged distal lobe merged with much larger, thicker and more strongly prominent distal lobe into continuous volute; inner side with extremely large, wide, slightly dorso-proximalwards bent, tongue-shaped ridge devoid of kinks and widest dorsally; tentacle notch very small and poorly defined.

\section{Etymology}

Name composed of ophis, Greek for "snake", a commonly used prefix in ophiuroid names, and "Leviathan", a biblical sea monster literally translating into "coiled, twisted", referring to the genus as an unusually large ophiuroid with arms capable of considerable coiling that lived in the greater depths of the ancient Tethys Ocean; gender masculine.

\section{Remarks}

Lower Jurassic Tethyan deep-sea sediments from Austria have yielded one of the most extraordinary types of dissociated LAPs, characterised by an unusually large size, a very thick and massive aspect, and an exceptionally large ridge on the inner side. The presence of a sigmoidal fold in the spine articulations unambiguously places the LAPs in question in the family Ophiacanthidae, in spite of their highly unusual morphology. Within this family, greatest similarities are shared with the LAPs of the extinct ophiacanthid Inexpectacantha, especially on account of the massive and thick aspect, the lack of outer surface ornament and of spurs on the outer proximal and inner distal edges, the shape of the spine articulations and of the ridge on the inner side, and the very small, poorly defined tentacle notches. As a matter of fact, very similar LAPs from near-coeval, deeper-water sedimentary rocks of Switzerland, considered here to be conspecific with the LAP type in question, were described by Hess (2006) and assigned by him to Inexpectacantha lunaris comb. nov.

In spite of the striking similarities, the above-mentioned LAPs differ from those of Inexpectacantha in several aspects: they are considerably larger, thicker and display a larger height/width ratio, the spine articulations are vertical to slightly overturned and in deeper notches, the distal (dorsal) lobe of the spine articulations is much larger, thicker and more prominent than the proximal (ventral) lobe, the ridge on 
the inner side of the LAPs is much larger and wider, and the dorsal and ventral tips of the inner side protrude towards the arm midline. These differences are here considered to warrant separation at the generic level. Ophioleviathan gen. nov. is thus introduced here to accommodate the above-mentioned LAP type.

Ophioleviathan gen. nov. and Inexpectacantha are most probably sister taxa, as suggested by the highly distinctive spine articulation morphology and shape of the ridge on the inner side shared by both genera and not found in any other ophiacanthid. In terms of LAP morphology, Ophioleviathan gen. nov. is closer to the less paedomorphic group within Inexpectacantha, formed by I. ritae sp. nov. and I. lunaris comb. nov. (see above), especially on account of the larger size, the larger height/width ratio and the position of the spine articulations in notches. The LAPs of Ophioleviathan gen. nov., however, have an even less paedomorphic appearance than those of the above-mentioned group within Inexpectacantha.

\section{Ophioleviathan watsoni sp. nov. urn:Isid:zoobank.org:act:657FB229-47E4-48F1-8913-9A83DD42AB05}

Fig. 34: 1-4

Sigsbeia? lunaris - Hess 2006: 66, pl. 29 figs 8-9 [material incorrectly assigned to Sigsbeia? lunaris (Hess, 1962)].

\section{Diagnosis}

As for genus.

\section{Etymology}

Species named in honour of Paul Watson, founder of the Sea Shepherd Conservation Society, in admiring recognition of his relentless commitment to the protection of marine wildlife.

\section{Type material}

\section{Holotype}

NHMW 2012/0137/0024.

\section{Paratypes}

NHMW 2012/0137/0025, NHMW 2012/0137/0026 and NHMW 2012/0137/0027.

\section{Type locality and horizon}

Glasenbach Gorge, Austria; Hauptknollenbrekzie, late Sinemurian to early Pliensbachian, Early Jurassic.

\section{Additional material}

NHMW 2012/0137/0028 (21 dissociated LAPs) from the late Sinemurian to early Pliensbachian of the Glasenbach Gorge, Austria; original material of Hess (2006) from the late Pliensbachian of Arzo, Switzerland.

\section{Description}

\section{Holotype}

NHMW 2012/0137/0024 is a very large, dissociated proximal LAP; nearly 2.5 times higher than wide; of massive and extremely thick aspect; dorsal edge convex, oblique; distal edge evenly convex; proximal edge irregularly concave, devoid of spurs; very narrow, slightly depressed area along the central part of the proximal ridge; outer surface with finely meshed stereom, devoid of conspicuous ornament elements. Seven large, ear-shaped spine articulations in deep notches of strongly bulging distal portion of LAP; 


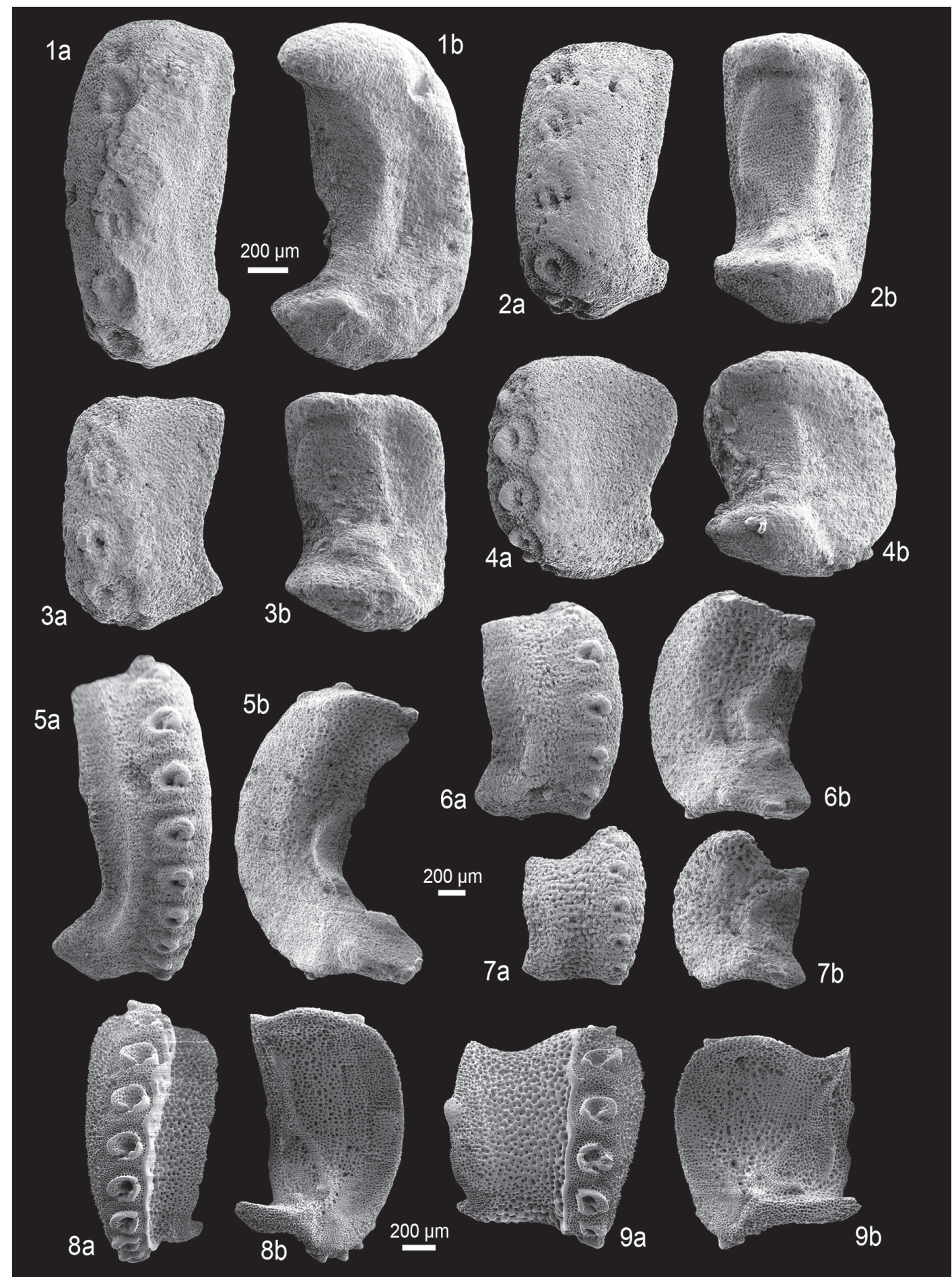

Fig. 34. Lateral arm plates (LAPs) of fossil and Recent ophiacanthid brittle stars in external (a) and internal (b) views. 1-4. Ophioleviathan watsoni gen. et sp. nov. from the late Sinemurian to early Pliensbachian (Early Jurassic) of the Glasenbach Gorge, Austria. 1. NHMW 2012/0137/0024 (holotype), proximal LAP. 2. NHMW 2012/0137/0025 (paratype), proximal LAP. 3. NHMW 2012/0137/0026 (paratype), median LAP. 4. NHMW 2012/0137/0027 (paratype), distal LAP. 5-7. Manfredura curvata (Kutscher \& Jagt, 2000) comb. nov. from the early Maastrichtian (Late Cretaceous) of Rügen, Germany. 5. GZG.INV.78759, proximal LAP. 6. GZG.INV.78760, median LAP. 7. GZG.INV.78761, distal LAP. 8-9. Ophiomitra valida Lyman, 1869, Recent. 8. Proximal LAP. 9. Median LAP. One common scale bar per species. 
spine articulations vertical or even slightly overturned, composed of distal and proximal rather than dorsal and ventral lobes; proximal lobe relatively slender, rugged and confluent with stereom of notch; dorsally merged with much larger and thicker, much more strongly prominent distal lobe into continuous, vertically elongate volute; middle spine articulations largest, with dorsalward and ventralward decrease in size; spine articulations nearly equi distant and proximally sharply bordered by edge of notches; gap between spine articulations and distal edge of LAP almost as wide as one spine articulation. Ventral edge of LAP oblique, very weakly convex.

Inner side of LAP with extremely large, broad, well-defined, prominent, slightly dorso-proximalwards bent, tongue-shaped ridge devoid of kinks; ventral tip of ridge not merged with ventral tip of LAP; dorsal part of ridge wider than ventral part; no spurs on inner side of distal edge of LAP; inner side of tentacle notch extremely small, very poorly defined, almost indiscernible; dorsal and ventral tips of LAP protruding towards midline of arm. Shallow, poorly defined, vertical furrow dorsally bordering tentacle notch; no perforations discernible.

\section{Paratype supplements and variation}

NHMW 2012/0137/0025 is a dissociated proximal LAP; approximately twice higher than wide; very well in agreement with holotype. Six spine articulations similar to those observed on holotype.

Ridge on inner side of LAP slightly better preserved than in holotype, very large, extremely wide, with much more slender ventral part not merged with ventral portion of LAP; inner side of tentacle notch very small, poorly defined. Shallow, moderately well-defined vertical furrow dorsally bordering tentacle notch, with two to three minute, irregularly spaced perforations.

NHMW 2012/0137/0026 is a dissociated median LAP; slightly higher than wide; dorsal edge oblique, straight; slightly depressed band along central part of proximal edge very weakly developed, almost indiscernible. Five spine articulations similar to those observed on holotype, less sharply defined proximally. Ventral edge of LAP straight, oblique.

Ridge on inner side of LAP similar to that of holotype but shorter, broader; inner side of tentacle notch as small and poorly defined as in holotype, oblique; dorsal and ventral tips of LAP protruding towards midline of arm. No perforations or furrow discernible.

NHMW 2012/0137/0027 is a dissociated distal LAP; nearly as high as wide, of rounded aspect; depressed area along the middle part of the proximal edge absent. Five large, spine articulations similar to those observed on holotype; distal lobe even larger, thicker, more prominent than in holotype; gap between spine articulations and distal edge of LAP narrower.

Ridge on inner side of LAP similar to that of holotype but slightly smaller, narrower and shorter. No perforations or furrow discernible.

\section{Remarks}

This LAP type is the only one currently assignable to Ophioleviathan gen. nov. Its systematic placement and affinities with other LAP types are discussed above.

\section{Occurrence}

Late Sinemurian to early Pliensbachian of Austria, late Pliensbachian of Switzerland.

Genus Manfredura gen. nov. urn:1sid:zoobank.org:act:48A7EB27-E847-4C00-A732-8D8EAC80227B

\section{Type and sole known species}

Ophiomyxa? curvata Kutscher \& Jagt, 2000. 


\section{Diagnosis}

Ophiuroid with large, conspicuously thick and strongly curved LAPs; proximal LAPs several times higher than wide; numerous non-oblique, ear-shaped spine articulations freestanding on strongly elevated distal portion of LAPs; inner side of LAP with very small, slender ridge; LAPs of neighbouring arm segments originally in contact as evidenced by strongly depressed, narrow band along most of the proximal edge.

\section{Etymology}

Genus named in honour of Manfred Kutscher, for his generous support and indefatigable, long-standing research on the echinoderms of the Rügen Chalk, which yielded the type material of the only known species of the genus; from oura, Greek for "tail", a commonly used suffix in ophiuroid names; gender feminine.

\section{Remarks}

Kutscher \& Jagt (2000) described a highly distinctive type of dissociated LAPs from the early Maastrichtian of Germany and Denmark as Ophiomyxa? curvata. A reassessment of the type material has revealed that these LAPs display large ear-shaped spine articulations with a well-developed sigmoidal fold. Along with the general morphology, the spine articulation structure precludes assignment to the Ophiomyxidae Ljungman, 1867 but rather places this LAP type in the Ophiacanthidae. Within this family, however, affinities are more problematic. Similarly curved, thick and massive LAPs devoid of outer surface ornament are found only in Ophioleviathan gen. nov. and, to a lesser extent, Inexpectacantha. The LAPs of these two, however, display fundamentally different spine articulations, and the ridge on the inner side of the LAPs is much larger. Superficial similarities are shared with the LAPs of extant Ophientrema Verrill, 1899, in particular on account of the extremely large height/width ratio, the strong curvature and the lack of outer surface ornament. However, while these two genera are characterised by a large uncalcified gap between the LAPs of neighbouring arm segments, the LAPs known as Ophiomyxa? curvata display a strongly depressed, narrow band along most of the proximal edge, suggesting that the LAPs were in contact or even slightly overlapped. In addition, the LAPs of Ophiomyxa? curvata display a much shorter, tongue-shaped ridge.

These LAPs cannot be reconciled convincingly with the LAP morphological diagnosis of any currently known ophiacanthid. It thus seems best to introduce Manfredura gen. nov. to accommodate them. The similarities in general LAP morphology, the small, poorly defined tentacle notch and the considerably smaller but similarly shaped ridge on the inner side, suggests that Manfredura gen. nov. is closest to Ophioleviathan gen. nov. and Inexpectacantha. It seems unlikely, however, that it belongs to the same lineage, considering the fundamental differences in spine articulation morphology. At the present state of knowledge, the phylogenetic position of Manfredura gen. nov. within the small-pored ophiacanthids remains elusive.

Manfredura curvata (Kutscher \& Jagt, 2000) comb. nov.

Fig. 34: 5-7

Ophiomyxa? curvata Kutscher \& Jagt, 2000: 53, pl. 31 figs 4-7.

non Ophiomyxa? cf. curvata - Štorc \& Žítt 2008: 125, fig. 4G-K.

\section{Diagnosis}

As for genus. 


\section{Material examined}

GZG.INV.78759, GZG.INV.78760, GZG.INV.78761 and 416 dissociated LAPs in the Manfred Kutscher Collection, Sassnitz, Germany, the type material of Kutscher \& Jagt (2000); GZG.INV.78762 (3 dissociated LAPs) from the early Maastrichtian of Lägerdorf-Kronsmoor, Germany.

\section{Description}

Large dissociated LAPs, of massive, thick and strongly curved aspect; proximal LAPs almost three times higher than wide, distal ones slightly higher than wide; dorsal edge straight, oblique (proximal LAPs) to strongly concave as a result of a constriction (distal LAPs); distal edge convex; proximal edge irregularly concave, with a weakly protruding, non-prominent central part; proximal to median LAPs with strongly depressed, distally well-defined band as wide as one-quarter of the total LAP width along the proximal edge except for its ventralmost part; much less well-defined, depressed band along central part of proximal edge in distal LAPs; outer surface with finely meshed stereom, devoid of conspicuous ornament elements. Ten (proximal LAPs) to seven (distal LAPs) large, ear-shaped spine articulations freestanding on strongly elevated distal portion of LAP; dorsal lobe of spine articulations larger and thicker than ventral one, merged with the latter into continuous volute; weak dorsalward incrase in size of spine articulations and of gaps separating them; gap between spine articulations and distal edge of LAP relatively narrow; spine articulations not sharply bordered proximally by ridge-like structure. Ventral edge of LAP irregularly concave; tentacle notch invisible in external view.

Inner side of LAP with very small, sharply defined, prominent, slender, dorso-proximalwards bent, tongue-shaped ridge devoid of kinks and strongly widened parts; small, well-defined, prominent, vertically elongate knobs close to the dorso-proximal and ventro-proximal tips of the proximal and median LAPs; ridge on inner side of distal LAPs larger, no knobs; no spurs on inner side of distal edge of LAPs; inner side of tentacle notch very small, shallow and poorly defined, almost indiscernible. Few, minute, inconspicuous perforations in vertical row distally bordering ventral tip of ridge.

\section{Remarks}

The LAPs of Manfredura curvata comb. nov. are highly diagnostic and cannot be confused with any other type of LAP, except for the material from the Turonian of the Czech Republic described and illustrated by Štorc \& Žítt (2008), who tentatively assigned this to Ophiomyxa? curvata. The specimens in question indeed display a striking similarity to the LAPs of $M$. curvata comb. nov. with respect to general shape, height/width ratio, shape and position of the spine articulations and size of the tentacle notch. While it seems likely that the LAPs in question are assignable to Manfredura gen. nov., they clearly belong to a different, still undescribed species. In fact, the Turonian LAPs display spine articulations with a much stronger dorsalward increase in size, a less well-developed depressed band along the proximal edge, a much more slender ridge on the inner side, and no knobs on the inner side of the dorso- and ventroproximal tips of the LAP.

\section{Occurrence}

Early Maastrichtian of Germany.

Genus Ophiocamax Lyman, 1878

\section{Type species}

Ophiocamax vitrea Lyman, 1878, by monotypy.

\section{Diagnosis}

Ophiacanthid with large to very large LAPs commonly devoid of any conspicuous outer surface ornament; single variably well-defined, protruding spur on outer proximal and inner distal edges; large 
to very large ear-shaped spine articulations freestanding on strongly elevated distal third or even half of the proximal and median LAPs, with especially the dorsal spine articulations commonly widely separated from distal edge of LAP; elevated portion of LAP commonly beset with scattered thorns or granules; dorsalmost spine articulation at some distance from dorsal edge of LAP, commonly pointing dorsalwards; dorsalmost and second dorsal spine articulations often much smaller than remaining ones; dorsal lobe of spine articulations with conspicuous central notch; ridge on inner side with strongly widened, generally short, triangular dorsal tip and evenly ventro-proximally bent ventral part; tentacle notch very small, deeply incised, well defined and generally at least semi circular.

\section{Remarks}

Ophiocamax is one of the most distinctive and homogeneous genera in the Ophiacanthidae, consistently displaying a number of characters not found in any other ophiacanthid. The same holds true for the LAPs of Ophiocamax (Fig. 35: 1-6), at least for the species examined herein with respect to their LAP morphologies, namely O. austera Verrill, 1899, O. fasciculata Lyman, 1883, O. hystrix Lyman, 1878 and the type species, $O$. vitrea. In fact, the LAPs of Ophiocamax display several highly distinctive features, including spine articulations freestanding in the middle of the strongly elevated distal third or even half of the LAPs and thus commonly widely separated from the distal edge of the LAP, dorsalwards pointing dorsalmost spine articulations well below the dorsal edge of the LAP, dorsalmost and second dorsal spine articulations which are often much smaller than the remaining ones, and a very small, welldefined and at least semi-circular tentacle notch. In addition, the dorsal lobe of the spine articulations of Ophiocamax displays a conspicuous central notch, which results in spine articulations that are seemingly composed of proximal and distal rather than dorsal and ventral lobes.

The LAPs of extant Ophiomitra Lyman, 1869 (Fig. 34: 8-9), sister to Ophiocamax, share some important characters with the LAPs of the latter, in particular the spine articulations freestanding on the strongly elevated distal third or half of the LAP, the lack of a conspicuous outer surface ornament, and the strongly widened dorsal tip of the ridge on the inner side. In contrast to the LAP of Ophiocamax, however, those of Ophiomitra display nearly equal-sized spine articulations the dorsalmost of which commonly being very close to the dorsal edge of the LAP. In addition, the dorsal lobe of the spine articulation in Ophiomitra lacks the central notch.

Thanks to the numerous highly distinctive characters, the LAPs of Ophiocamax are expected to be easily recognised in the form of dissociated fossil LAPs. Yet, only very few occurrences of dissociated LAPs and articulated arm fragments assignable to Ophiocamax are currently known from shallowwater settings, and all are from the Oxfordian. Another record from deep-sea deposits is noticeably fundamentally similar to the LAPs of extant Ophiocamax but differs in a few minor respects and is thus assigned to a new, most probably very closely related, genus, Reitneracantha gen. nov. (see below).

Ophiocamax dorotheae sp. nov. urn:1sid:zoobank.org:act:412FC94A-B8E6-48B2-915D-E719B0AD10CC

Fig. 35: 7-11

Ophiacantha? suprajurassica Hess, 1965a: 1065, 1077.

Ophiacantha? sp. or Ophiothrix? sp. - Hess 1960: 419, fig. 39.

Ophiacantha? suprajurassica - Hess 1966: 1030, 1054, figs 76-77 (material incorrectly assigned to Ophiacantha? suprajurassica Hess, 1965). 


\section{Diagnosis}

Species of Ophiocamax with large LAPs displaying large, well-defined, strongly protruding spur on the outer proximal edge paralleled by a large, non-prominent, rounded area of densely meshed stereom on the inner distal edge; up to five spine articulations, two dorsalmost of which always largest; ridge on inner side of LAP relatively short, with strongly widened dorsal tip; dorsal arm plates irregularly pentagonal to blazon-shaped, with small granules or thorns scattered on outer surface.

\section{Etymology}

Species named in honour of Dorothea Hause-Reitner for her friendship and generous assistance in scanning electron microscopy.

\section{Type material}

\section{Holotype}

GZG.INV.78763.

\section{Paratypes}

GZG.INV.78764, GZG.INV.78765, GZG.INV.78766 and GZG.INV.78767.

\section{Type locality and horizon}

Savigna, France; sample S2b of Gale (2011), Bimammatum Zone, late Oxfordian, Late Jurassic.

\section{Additional material}

GZG.INV.78768 (29 dissociated LAPs) from sample S2b of Gale (2011), GZG.INV.78769 (6 dissociated LAPs) from sample S1 of Gale (2011), GZG.INV.78770 (8 dissociated LAPs) from sample S2a of Gale (2011), all from the Bifurcatus Zone, late Oxfordian of Savigna, France; dissociated LAP from the Bifurcatus Zone, late Oxfordian of Guldental, Switzerland, the original material of Hess (1966); 26 dissociated LAPs from the Renggeri Member, early Oxfordian of Chapois, France, the original material of Hess (1965a); 2 dissociated LAPs from the Renggeri Member of Longecombe, France, the original material of Hess (1965a).

\section{Description}

\section{Holotype}

GZG.INV.78763 is a dissociated, large, proximal LAP; nearly as high as wide; dorsal edge strongly concave as a result of a well-developed constriction; distal edge strongly convex; proximal edge irregularly undulose, with a large, sharply defined, prominent and strongly protruding, oval, horizontally elongate spur composed of densely meshed stereom; weakly defined, shallow depression in ventral half of proximal edge, composed of more finely meshed stereom; outer surface with finely meshed stereom, fining towards proximal edge. Five large ear-shaped spine articulations freestanding on strongly elevated distal half of LAP; strong dorsalward increase in size of spine articulations and of gaps separating them; ventral and dorsal lobes merged into continuous volute; dorsal lobe with conspicuous central notch; gap between spine articulations and distal edge of LAP as wide as one spine articulation, strongly increasing in width dorsalwards, parallel to dorsalward increase in size of spine articulations; dorsalmost spine articulation below dorsal edge of LAP, pointing dorsalwards; spine articulations proximally sharply bordered by undulose edge of elevated distal half of LAP. Ventral edge of LAP nearly straight, with very small, weakly concave, almost indiscernible tentacle notch.

Inner side of LAP with very large, broad, sharply defined, prominent ridge with evenly bent, ventroproximally pointing ventral part, and strongly widened, near-triangular dorsal part; inner side of distal edge of LAP with large, well-defined, rounded, non-prominent spur composed of densely meshed 


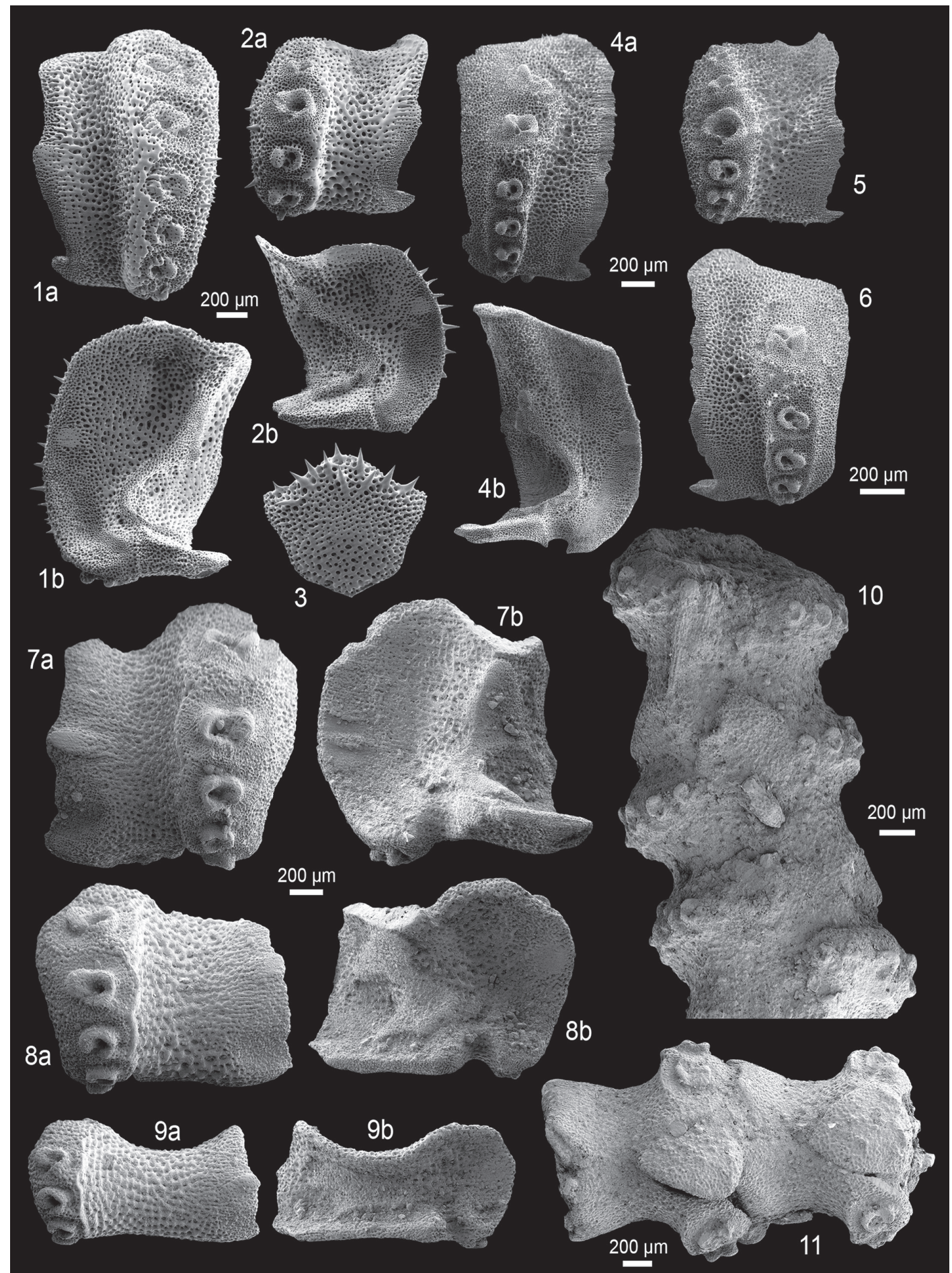

Fig. 35. Skeletal plates and arm fragments of fossil and Recent ophiacanthid brittle stars; lateral arm plates (LAPs) in external (a) and internal (b) views. 1-3. Ophiocamax vitrea Lyman, 1878, Recent. 1. Proximal LAP. 2. Median LAP. 3. Dorsal arm plate. 4-5. Ophiocamax hystrix Lyman, 1878, Recent. 4. Proximal LAP. 5. Median LAP. 6. Ophiocamax austera Verrill, 1899, Recent; proximal LAP. 7-11. Ophiocamax dorotheae sp. nov. from the late Oxfordian (Late Jurassic) of Savigna, France. 7. GZG.INV.78763 (holotype), proximal LAP. 8. GZG.INV.78764 (paratype), median LAP. 9. GZG.INV.78765 (paratype), distal LAP. 10. GZG.INV.78766 (paratype), proximal arm fragment in ventral view. 11. GZG.INV.78767 (paratype), median arm fragment in dorsal view. One common scale bar per species except for 10 and 11. 
stereom; inner side of tentacle notch very small, semi-circular, well defined laterally. No perforations or furrow discernible.

\section{Paratype supplements and variation}

GZG.INV.78764 is a dissociated median LAP; slightly wider than high; very well in agreement with holotype; dorsal edge less strongly concave; spur on proximal edge slightly smaller than in holotype. Five spine articulations similar to those of holotype; gap between spine articulations and distal edge of LAP slightly narrower. Ventral edge of LAP weakly concave, with very small, almost indiscernible tentacle notch.

Inner side of LAP with very large, well-defined, short ridge with strongly widened ventral and dorsal edges; inner side of tentacle notch very small, sharply defined, semi circular.

GZG.INV.78765 is a dissociated distal LAP; almost twice wider than high; very well in agreement with holotype; depression in ventral half of outer surface smaller and even less well defined than in holotype, almost indiscernible. Four spine articulations similar to those of holotype; dorsalmost spine articulation not pointing dorsalwards; gap between spine articulations and distal edge of LAP much narrower. Ventral edge of LAP gently concave; tentacle notch invisible in external view.

Inner side of LAP with large, poorly defined, broad, weakly prominent ridge displaying strongly widened ventral part and dorso-proximalwards pointing dorsal tip; spur on inner side of distal edge slightly less well defined; inner side of tentacle notch very small, more than semi circular.

GZG.INV.78766 is an articulated arm fragment preserving two median segments; LAPs well in agreement with dissociated ones described above; dorsal arm plates large, widely separated by LAPs, slightly longer than wide, widest distally, irregularly pentagonal to blazon shaped, with gently convex distal edge, slightly proximalwards converging lateral edges and nearly right proximal angle; outer surface of dorsal arm plates with small, scattered granules or thorns; ventral arm plates widely separated by LAPs; slighty wider than long, widest distally, with gently convex to slightly angular distal edge, short, straight lateral edges, small half-circular tentacle notches and obtuse proximal angle; few very short arm fragments preserved, originally cylindrical, with moderately coarsely meshed outer surface stereom, no further details preserved.

GZG.INV.78767 is an articulated arm fragment preserving three median to distal segments; one second ventralmost arm spine nearly completely preserved, straight, cylindrical, almost as long as one arm segment, with moderately coarsely meshed and slightly longitudinally elongate stereom.

\section{Remarks}

The highly distinctive shape and position of the spine articulations, combined with the lack of a conspicuous outer surface ornament, the distinctively shaped ridge on the inner side and the very small, well-defined, semi-circular tentacle notch unambiguously place these LAPs in the genus Ophiocamax or at least in a very closely related form (more closely related than to Ophiomitra, on account of the much closer similarities in LAP morphology). The low number of spine articulations and the very weakly ventralwards protruding row of spine articulations precludes assignment to the closely related Late Jurassic Ophiosternle crinitum (Quenstedt, 1876). The present LAPs are by far the oldest record that is assignable to Ophiocamax, predating the Miocene records from Japan (Ishida 2001) and the Grenadines (Jagt et al. in press).

The present LAPs differ in that the two dorsalmost spine articulations invariably are the largest, rather than much smaller than the remaining ones as in the LAPs of most extant species of Ophiocamax. Greatest similarities are shared with the LAPs of extant $O$. vitrea, especially on account of the shape and position of the spine articulations, the presence of a well-developed spur on the outer proximal and inner 
distal edge, and the development of the tentacle notch. In addition, the shape and outer surface ornament of the dorsal arm plates is markedly similar in $O$. vitrea and these fossil specimens. The shape of the ridge on the inner side, in contrast, is more reminiscent of that observed in the LAPs of O. austera. In the light of these minor, yet significant, morphological differences and the huge stratigraphic gap, the fossil LAPs are here described as a new species.

\section{Occurrence}

Early to late Oxfordian of France, late Oxfordian of Switzerland.

Genus Reitneracantha gen. nov. urn:1sid:zoobank.org:act:3BFFDD52-C9E7-450B-9001-E09134B80477

\section{Type, and only known, species}

Reitneracantha dissidens sp. nov.

\section{Diagnosis}

Ophiacanthid with moderately large LAPs devoid of conspicuous outer surface ornament or spurs on the outer proximal edge; up to five large to very large, ear-shaped spine articulations freestanding on the strongly elevated distal third or half of the LAP; proximal edge of the spine articulation irregularly corrugated; dorsal lobe of the spine articulations vertically elongate, much larger than ventral one; dorsalmost spine articulation invariably largest, conspicuously dorsalwards pointing, in proximal LAPs well below dorsal edge of LAP; ridge on inner side relatively short with widened dorsal tip; tentacle notch small, well defined laterally, semi circular.

\section{Etymology}

Genus named in honour of my friend and colleague Joachim Reitner, for his generous support and the delightfully shared delicacies and wines; from Acantha, a nymph in Greek mythology whose name literally translates to "thorny"; gender feminine.

\section{Remarks}

A very unusual type of dissociated LAPs was recovered from Early Jurassic deep-sea sediments of Austria. The presence of large, ear-shaped spine articulations with a sigmoidal fold, combined with the absence of a single large perforation on the inner side, clearly place these in the Ophacanthidae. Within this family, such LAPs are close to those of extant Ophiocamax. The most important similarities include the position of the spine articulations on the strongly elevated distal third or half of the LAP, the central notch in the dorsal lobe of the spine articulations, the strong dorsalward increase in size of the spine articulations, the conspicuously dorsalwards pointing dorsalmost spine articulation well below the dorsal edge of the LAP, the lack of a conspicuous outer surface ornament, the widened dorsal tip of the ridge on the inner side of the LAPs, and the very small, well-defined, semi-circular tentacle notch.

The shape of the spine articulations in these fossil LAPs, however, differs in displaying an irregularly corrugated proximal edge of the volute. In addition, the dorsal lobe of the spine articulations in the fossil LAPs is dorsally elongate and much larger than the ventral one. On account of these minor, yet significant, differences, the present LAPs are here assigned to a new genus, Reitneracantha gen. nov. However, similarities in LAP morphology are so close that Reitneracantha gen. nov. and Ophiocamax most probably share close phylogenetic ties. From an LAP morphological perspective, the phylogenetic relationships between Reitneracantha gen. nov. and Ophiocamax are probably even closer than between the latter and its extant sister taxon Ophiomitra. Thus, Reitneracantha gen. nov. and Ophiocamax are here considered to be members of the same lineage. 
Reitneracantha dissidens sp. nov.

urn:1sid:zoobank.org:act:E1A8998E-30EE-4921-B054-371C65DB6C9D

Fig. 36: 1-3

\section{Diagnosis}

As for genus.

\section{Etymology}

From dissidere, Latin for "intractable, dissenting with an established policy", in reference to the fact that this species challenges established concepts of the role of the deep-sea in macroevolutionary patterns.

\section{Type material}

\section{Holotype}

NHMW 2012/0137/0029.

\section{Paratypes}

NHMW 2012/0137/0030 and NHMW 2012/0137/0031.

\section{Type locality and horizon}

Glasenbach Gorge, Austria; Hauptknollenbrekzie, late Sinemurian to early Pliensbachian, Early Jurassic.

\section{Additional material}

NHMW 2012/0137/0032 (3 dissociated LAPs).

\section{Description}

\section{Holotype}

NHMW 2012/0137/0029 is a dissociated, moderately large, proximal LAP; dorsal edge nearly straight, oblique; distal edge convex; proximal edge nearly straight, except for small, very poorly defined, almost indiscernible, weakly prominent and protruding spur; outer surface with finely meshed stereom, devoid of conspicuous ornament. Five large, ear-shaped spine articulations freestanding on strongly elevated distal half of LAP; dorsal edge of spine articulations vertically elongated, with conspicuous central notch, much larger than ventral lobe, merged with the latter into continuous volute; very strong dorsalward increase in size of spine articulations and of gaps separating them; dorsalmost spine articulation largest, well below dorsal edge of LAP, comspicuously dorsalwards pointing; proximal edge of spine articulations irregularly corrugated; spine articulations sharply bordered proximally by edge of elevated portion, except for dorsalmost one; gap between spine articulations and distal edge of LAP as wide as one spine articulation. Ventral edge of LAP nearly straight; tentacle notch invisible in external view.

Inner side of LAP with small, sharply defined, prominent, gently bent ridge displaying a ventroproximally bent ventral part not merged with ventral portion of LAP, and a widened, angular dorsal tip; inner side of distal edge of LAP devoid of spurs; inner side of tentacle notch small, well defined laterally, semi circular. No perforations or furrow discernible.

\section{Paratype supplements and variation}

NHMW 2012/0137/0030 is a dissociated median LAP; as high as wide; of rectangular to trapezoid aspect; dorsal edge concave as a result of a constriction; distal edge nearly straight, oblique; proximal edge devoid of spurs. Four spine articulations similar to those observed on holotype; dorsalmost spine articulation much larger than remaining ones and widely separated from the latter, dorsalwards pointing, near dorsal edge of LAP. Ventral edge of LAP straight, no tentacle notch visible.

Ridge on inner side of LAP similar to that of holotype but with less strongly widened dorsal tip. 


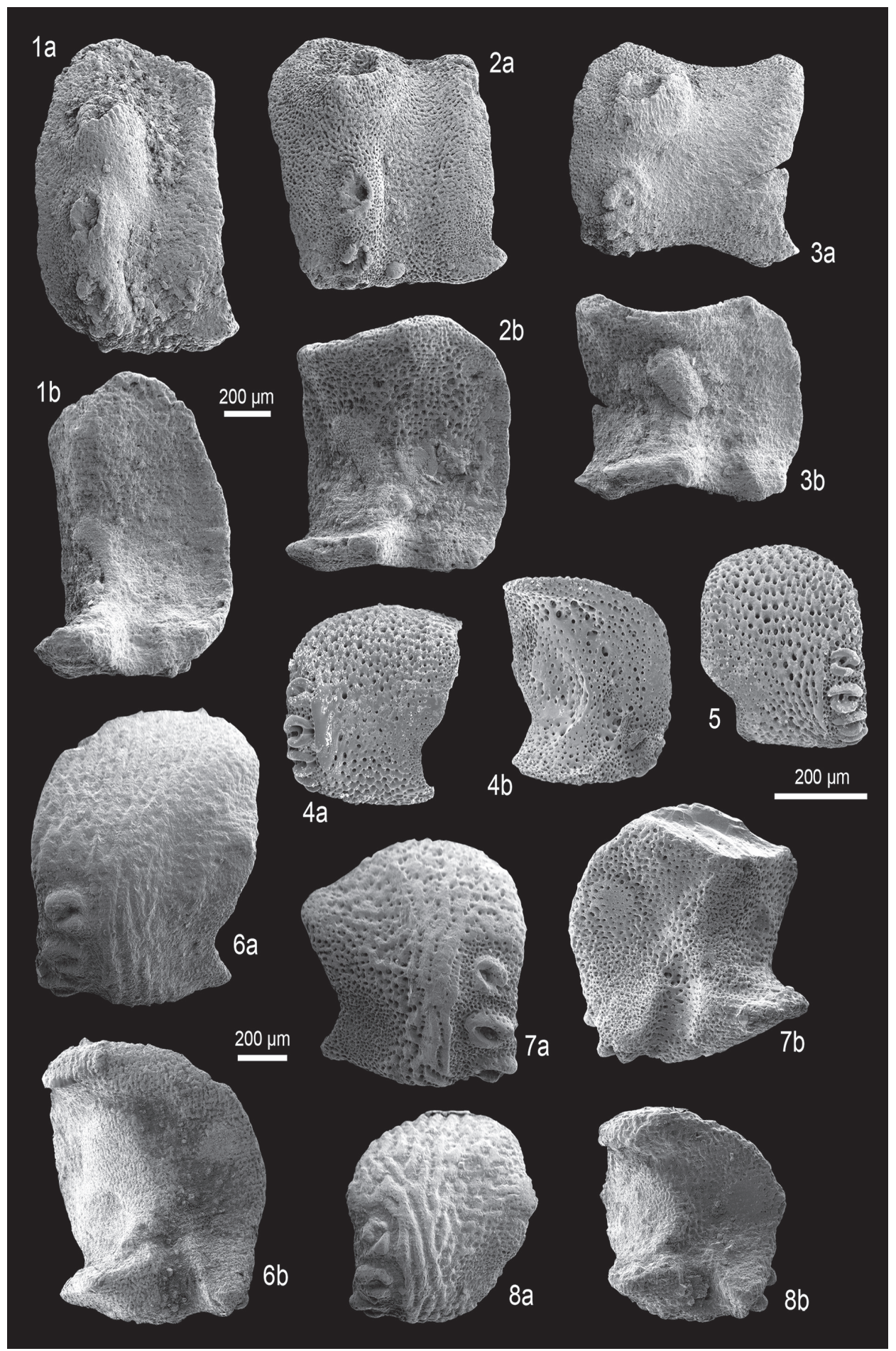

Fig. 36. Lateral arm plates (LAPs) of fossil and Recent ophiacanthid brittle stars in external (a) and internal (b) views. 1-3. Reitneracantha dissidens gen. et sp. nov. from the late Sinemurian to early Pliensbachian (Early Jurassic) of the Glasenbach Gorge, Austria. 1. NHMW 2012/0137/0029 (holotype), proximal LAP. 2. NHMW 2012/0137/0030 (paratype), median LAP. 3. NHMW 2012/0137/0031 (paratype), distal LAP. 4-5. Ophiohamus nanus O'Hara \& Stöhr, 2006, Recent. 4. Proximal to median LAP. 5. Proximal to median LAP. 6-8. Sabinacantha archetypa gen. et sp. nov. from the late Oxfordian (Late Jurassic) of the Plettenberg, Germany. 6. GZG.INV.78771 (holotype), proximal LAP. 7. GZG.INV.78772 (paratype), median LAP. 8. GZG.INV.78773 (paratype), distal LAP. One common scale bar per species. 
NHMW 2012/0137/0031 is a dissociated distal LAP; slightly wider than high; dorsal edge strongly concave as a result of a well-developed constriction; proximal edge gently concave, devoid of spurs. Four spine articulations similar to those of holotype, freestanding on slightly elevated distal third of LAP; dorsalmost spine articulation much larger than remaining ones and widely separated from the latter, pointing dorsalwards, at some distance from the dorsal edge of the LAP. Ventral edge of the LAP concave, no tentacle notch visible in external view.

Ridge on inner side of LAP similar to that of holotype but with weakly widened dorsal tip; inner side of distal edge of LAP devoid of spurs; inner side of tentacle notch moderately small, well defined laterally, semi circular.

\section{Remarks}

The taxonomic affinities of these LAPs have been discussed above.

Genus Sabinacantha gen. nov. urn:1sid:zoobank.org:act:DBFBC938-27CE-42A1-932C-F397C289B2E7

\section{Type and sole known species}

Sabinacantha archetypa sp. nov.

\section{Diagnosis}

Ophiacanthid with moderately large LAPs of thick, massive and rounded aspect; single poorly to moderately well-defined, protruding spur on outer proximal edge paralleled by large, round, weakly prominent area of more densely meshed stereom on inner side of distal LAP edge; outer surface with coarse, irregular striation; three small, ear-shaped, oval, horizontally elongate spine articulations tightly grouped on weakly elevated ventral third to half of distal edge of LAP; dorsalward decrease in size of spine articulations; inner side of LAPs with well-defined, uniformly prominent, short, broad ridge with widened, round dorsal tip; inner side of tentacle notch small.

\section{Etymology}

Genus named in honour of my friend and colleague Sabine Stöhr, who has guided me when I took my very first steps in ophiuroid research; from Acantha, a nymph in Greek mythology whose name literally translates to "thorny"; gender feminine.

\section{Remarks}

Among the most unusual LAP types of extant ophiacanthids is that of Ophiohamus nanus O'Hara \& Stöhr, 2006 (Fig. 36: 4-5). In this small-sized species, the LAPs appear atypically massive and rounded for an ophiacanthid. The most striking feature, however, are the four small, oval spine articulations with separated dorsal and ventral lobes, and grouped in the ventral half of weakly elevated distal edge. This combination of characters is highly distinctive and not found in any other currently known ophiacanthid LAP type, except for a remarkable extinct one from the Kimmeridgian of Germany, recorded herein.

These fossil LAPs are much larger and thicker that those of Ophiohamus nanus but nevertheless display the highly characteristic rounded aspect and the small, oval spine articulations with the discontinuous volute, tightly grouped in ventral half of weakly elevated distal edge. Other close similarities are seen in the shape of the ridge on the inner side, although in the fossil LAPs it is better defined and uniformly prominent. Other minor differences pertain to the presence of a single, well-developed spur on the outer proximal and inner distal edges in the fossil LAPs, and the outer surface ornament which, in the fossil LAPs, consists of a coarse, highly irregular vertical striation, generally best defined close to the spine articulations. 
These close similarities in LAP morphology strongly suggest that the fossil LAP type in question and Ophiohamus nanus share strong phylogenetic ties, most probably forming a single lineage. The fossil LAPs probably are not congeneric with the latter, on account of the minor, yet significant, differences including the size of the LAPs, the number of the spine articulations, the development of the ridge on the inner side, and the outer surface ornament. A new genus, Sabinacantha gen. nov., is thus introduced here to accommodate these Ophiohamus-like fossil LAPs.

There is, indeed, a close resemblance with the LAPs of extant Ophiochondrus convolutus Lyman, 1869, which is closely related to Ophiohamus nanus in the revised phylogenetic analysis presented herein, especially on account of the massive, rounded aspect of the LAPs, the weakly elevated distal edge of the LAPs, the small, oval, horizontally elongate spine articulations with separated dorsal and ventral lobes, the dorsalward decrease in size of the spine articulations, and even the shape of the ridge on the inner side. These astonishing similarities are perfectly in line with the observation by Thuy \& Stöhr (2011) that the closest similarities in LAPs are to be found in more closely related ophiuroid taxa.

Sabinacantha archetypa sp. nov. urn:1sid:zoobank.org:act:6CDF4231-69E4-419E-8596-AA9BDE71DC3C

Fig. 36: 6-8

\section{Diagnosis}

As for genus.

\section{Etymology}

Name formed after archetypum, Latin for "archetype" or "idol", referring to the precursor state of the species in the Sabinacantha-Ophiohamus lineage.

\section{Type material}

\section{Holotype}

GZG.INV.78771.

\section{Paratype}

GZG.INV.78772 and GZG.INV.78773.

\section{Type locality and horizon}

Plettenberg near Balingen, Germany; clay pockets between sponge associations in the lowest bed exposed in the quarry, Bimammatum Zone, late Oxfordian, Late Jurassic.

\section{Additional material}

GZG.INV.78774 (3 dissociated LAPs).

\section{Description}

\section{Holotype}

GZG.INV.78771 is a dissociated, moderately large, proximal LAP; thick, massive, rounded aspect; slightly higher than wide; dorsal edge and dorsal half of distal edge evenly convex, not separated by kink; ventral half of distal edge slightly concave; proximal edge convex, with small, moderately well-defined, rounded, prominent and very weakly protruding spur; ventro-proximal tip of LAP protruding; outer surface with coarse, irregular vertical striation composed of thick, non-overlapping lamellae replaced by moderately finely meshed stereom in proximal quarter of outer surface, with ventro-proximalward fining of stereom. Three small, ear-shaped, equi-distant, oval, horizontally slightly elongate spine 
articulations freestanding on very weakly elevated ventral third of otherwise striated distal edge of LAP; weak dorsalward decrease in size of spine articulations; dorsal and ventral lobes of spine articulations separated by small notch proximally; spine articulations sharply bordered proximally by lamella of outer surface striation. Ventral edge of LAP convex, no tentacle notch discernible.

Inner side of LAP with large, short, very broad, well-defined, uniformly prominent ridge; ventral part of ridge narrowest, pointing ventralwards, not merged with ventral portion of LAP; dorsal part of ridge strongly widened, rounded, pointing dorso-proximalwards; inner side of distal edge of LAP with moderately large, round, well-defined, very weakly prominent spur composed of densely meshed stereom; inner side of tentacle notch small, well defined laterally, slightly oblique. No perforations or furrow discernible.

\section{Paratype supplements and variation}

GZG.INV.78772 is a dissociated median LAP; nearly as high as wide; well in agreement with holotype; part of proximal edge with spur strongly protruding; spur itself poorly defined, almost indiscernible; vertical striation on outer surface less well developed and less regular than in holotype, replaced by coarsely meshed stereom on most of the outer surface except near the spine articulations and in the ventro-proximal area of finely meshed stereom. Three spine articulations similar to those observed on holotype but on weakly elevated ventral half (rather than third) of distal LAP edge.

Inner side similar to that of holotype. Group of very small, irregular perforations dorsally bordering tentacle notch.

GZG.INV.78773 is a dissociated distal LAP; slightly wider than long; spur on proximal edge of LAP moderately well defined, strongly protruding, composed of densely meshed stereom; ventro-proximal tip of LAP strongly oblique; outer surface ornament as in holotype. Three spine articulations similar to those observed on holotype but on ventral half rather than third of distal edge of LAP.

Inner side of LAP similar to that of holotype; ridge slightly shorter; spur on inner side of distal edge slightly larger, less well defined.

\section{Remarks}

These LAPs are the only ones assigned to Sabinacantha gen. nov. For a discussion of their taxonomic affinities, reference is made to the section "Remarks" of the genus.

\section{Occurrence}

Late Oxfordian of Germany.

Genus Ophiochondrus Lyman, 1869

\section{Type species}

Ophiochondrus convolutus Lyman, 1869, by monotypy.

\section{Diagnosis}

Ophiacanthid with small LAPs of massive, thick and rounded aspect; outer surface commonly with thickened trabeculae in some cases merged into a poorly developed vertical striation; generally a single, variably well-defined, protruding spur in the middle of the proximal edge, ventrally bordered by a slightly depressed area of finely meshed stereom; small, oval, horizontally slightly elongate spine articulations freestanding and evenly distributed on very weakly elevated distal portion of the LAP; dorsal and ventral lobes of spine articulations separated proximally; spine articulations of equal size or with weak dorsalward decrease in size; ridge on inner side of LAPs moderately well defined, short, 
with ventro-proximalwards projecting extension of dorsal tip; tentacle notch very small, poorly defined, almost inconspicuous.

\section{Remarks}

Ophiochondrus has traditionally been considered to be a member of the Hemieuryalidae Verrill, 1899 (e.g., Matsumoto 1917; Fell 1960; Smith et al. 1995), although the ophiacanthid affinities of the genus have repeatedly been hinted at (Mortensen 1927, 1936; O’Hara \& Stöhr 2006). Eventually, Martynov (2010) transferred Ophiochondrus to the Ophiacanthidae, along with the other former hemieuryalid Ophiomoeris Koehler, 1904, on the basis of spine articulation morphology. This transfer is corroborated by the phylogenetic anaylsis of Thuy et al. (2012) and the revised phylogeny presented herein.

Indeed, in terms of LAP morphology (Fig. 37: 1-3), Ophiochondrus is closely similar to the ophiacanthid genera Ophiolamina Stöhr \& Segonzac, 2006, Ophiohamus O'Hara \& Stöhr, 2006 and, to a lesser extent, Ophiolebes. The LAPs of Ophiochondrus can be easily differentiated from those of Ophiohamus and Ophiolamina on the basis of the shape and position of the spine articulations. Unfortunately, knowledge of the LAP morphology of Ophiomoeris is incomplete, in particular with respect to the structures on the inner side, which hampers the elaboration of a comprehensive diagnosis of LAP morphology for Ophiochondrus. However, since the LAPs of the type species of Ophiochondrus are well known, an attempt is made here to work out a diagnosis of LAP morphology for the genus. This is all the more important because the ophiacanthid fossil record includes a type of dissociated LAPs which has a lot in common with the LAPs of extant Ophiochondrus.

Ophiochondrus punctatus (Kutscher \& Jagt, 2000) comb. nov.

Fig. 37: 4-5

Ophiacantha? punctata Kutscher \& Jagt, 2000: 62-63, pl. 25 figs 3-5.

\section{Diagnosis}

Species of Ophiochondrus with small LAPs displaying a coarsely meshed stereom on the outer surface with trabecular intersections strongly thickened into slightly vertically elongate granules or knobs; small, very poorly defined, weakly prominent and protruding spur on the outer proximal edge, paralleled on the inner distal edge by a moderately well-defined, rounded area of densely meshed stereom; up to eight small, slightly oval, spine articulations, proximally bordered by thick, slightly knobby ridge; gap between spine articulations and distal edge of LAP with trabecular intersections thickened into small granules; ridge on inner side relatively small, short.

\section{Material examined}

GZG.INV.78775, GZG.INV.78776 and 260 dissociated LAPs in the Manfred Kutscher Collection in Sassnitz, Germany, the type material of Kutscher \& Jagt (2000).

\section{Description}

Small, dissociated LAPs, proximal ones slightly higher than wide, distal ones approximately 1.5 times wider than high; proximal to median LAPs of massive, thick, rounded aspect; dorsal edge straight (proximal LAPs) to concave (median and distal LAPs) as a result of a well-developed constriction; distal edge convex; proximal edge nearly straight, with small, very poorly defined, weakly prominent and very slightly protruding spur ventrally bordered by small, poorly defined, non-depressed area of slightly more finely meshed stereom; outer surface with coarsely meshed stereom slightly fining towards proximal edge; trabecular intersections of coarsely meshed stereom thickened into large, very weakly vertically elongate granules or knobs. Eight (proximal LAPs) to six (distal LAPs) small, ear-shaped, slightly oval 


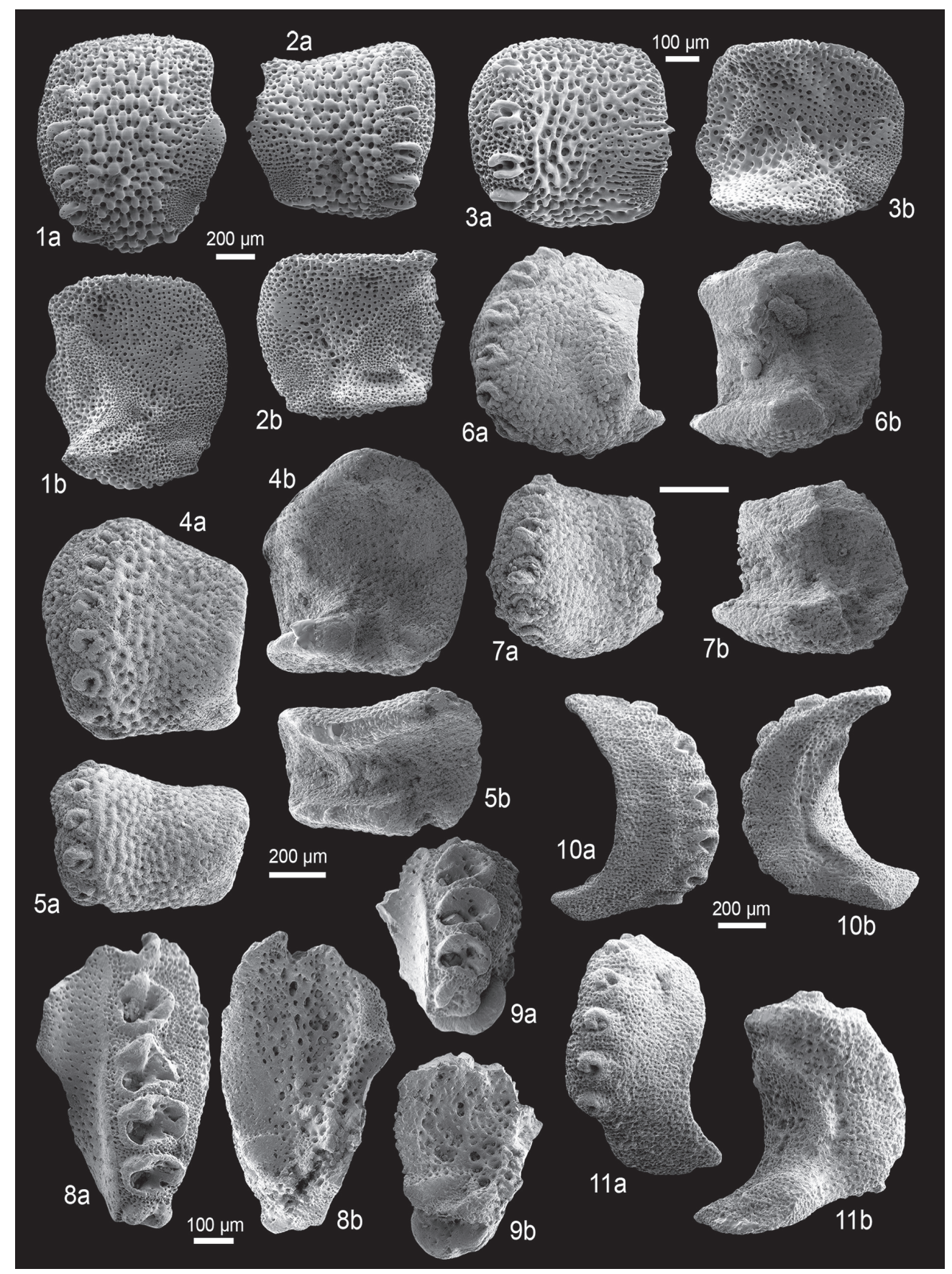

Fig. 37. Lateral arm plates (LAPs) of fossil and Recent ophiacanthid brittle stars in external (a) and internal (b) views. 1-2. Ophiochondrus convolutus Lyman, 1869, Recent. 1. Proximal LAP. 2. Median LAP. 3. Ophiochondrus stelliger Lyman, 1879, Recent; proximal LAP. 4-5. Ophiochondrus punctatus (Kutscher \& Jagt, 2000) comb. nov. from the early Maastrichtian (Early Cretaceous) of Rügen, Germany. 4. GZG.INV.78775, proximal LAP. 5. GZG.INV.78776, distal LAP. 6-7. Ophiochondrus? semirotundus (Kutscher \& Jagt, 2000) comb. nov. from the early Maastrichtian of Rügen, Germany. 6. GZG.INV.78800, proximal LAP. 7. GZG.INV.78801, median LAP. 8-9. Ophiacanthidae gen. et sp. nov. innom. from the late Oxfordian (Late Jurassic) of the Plettenberg, Germany. 8. GZG.INV.78802, proximal LAP. 9. GZG.INV.78803, median or distal LAP. 10-11. Ophiojagtus argoviensis (Hess, 1966) comb. nov. from the late Oxfordian (Late Jurassic) of Savigna, France. 10. NHMB M1124, proximal LAP. 11. NHMB M11225, proximal to median LAP. One common scale bar per species. 
spine articulations freestanding on weakly to fairly elevated distal portion of LAP; spine articulations proximally bordered by thick, well-defined, knobby ridge composed of vertically merged thickened trabeculae of coarsely meshed outer surface stereom; ventral and dorsal lobes of spine articulations separated proximally by very small notch; spine articulations nearly of equal size or with very weak dorsalward decrease in size; gap between spine articulations and distal edge of LAP at most as wide as one spine articulation, with dorsalward increase in width, with trabecular intersections of moderately finely meshed stereom thickened into small granules. Ventral edge of LAP weakly concave; tentacle notch invisible in external view.

Inner side of LAPs with relatively small, short, well-defined, prominent ridge with ventro-proximalwards bent ventral part not merged with ventral portion of LAP; dorsal tip of ridge slightly widened, with short ventro-proximalwards projecting extension; small, round knob distally bordering ridge in distal LAPs; inner side of distal edge of proximal to median LAPs with relatively small, moderately well-defined, round, very weakly protruding area of more densely meshed stereom; inner side of tentacle notch very small, shallow, moderately well defined laterally. No perforations or furrow discernible.

\section{Remarks}

Kutscher \& Jagt (2000) described this LAP type from the early Maastrichtian of Germany and Denmark in detail and tentatively assigned it to Ophiacantha using open nomenclature. They stressed, however, that this assignment was highly doubtful when the fossil LAPs were compared with those of extant species of Ophiacantha. Thanks to a systematic SEM-supported assessment of LAP morphologies in Recent ophiacanthids performed in the course of the present study, it is now possible to constrain the generic placement of these LAPs even further. Strongest similarities are shared with the LAPs of Ophiochondrus, mainly on account of the massive, thick, rounded general aspect of the LAPs, the shape, size and position of the spine articulations, the outer surface ornament, and the shape of the ridge on the inner side. It is the first fossil record of Ophiochondrus or at least of a very closely related, extinct genus.

The LAPs of Ophiochondrus punctatus comb. nov. cannot be confused with any other fossil type of LAP. Those of co-occurring Ophiochondrus? semirotundus (Kutscher \& Jagt, 2000) comb. nov. have fewer spine articulations not bordered proximally by a ridge, and large contact surfaces with the opposite LAP on the inner side. LAPs assigned to Inexpectacantha display strongly tilted spine articulations with a ventral lobe commonly merged with the outer surface stereom, and a ridge on the inner side lacking the ventro-proximalwards projecting extension.

\section{Occurrence}

Early Maastrichtian of Germany and Denmark.

Ophiochondrus? semirotundus (Kutscher \& Jagt, 2000) comb. nov.

Fig. 37: 6-7

Ophiothela? semirotunda Kutscher \& Jagt, 2000: 74-75, pl. 29 figs 11-13.

\section{Diagnosis}

Species tentatively assigned to Ophiochondrus with small, massive, rounded and thick LAPs displaying a coarsely granular outer surface; proximal edge slightly thickened, separated from the remaining outer surface by a shallow, moderately well-defined furrow; no spurs discernible on outer proximal and inner distal edges; up to six small, oval, horizontally elongate spine articulations on bulging distal portion of LAP; inner side of LAP with small, rather poorly defined ridge displaying weakly widened dorsal tip; large dorsal and ventral contact surfaces with opposite LAP facing midline of arm. 


\section{Material examined}

GZG.INV.78800, GZG.INV.78801 and 32 dissociated LAPs in the Manfred Kutscher Collection in Sassnitz, Germany, the type material of Kutscher \& Jagt (2000).

\section{Description}

Small, dissociated LAPs, proximal ones slightly higher than wide, distal ones slightly wider than high; of rounded, massive, thick aspect; dorsal edge slightly concave as a result of a constriction; distal edge convex; proximal edge nearly straight to slightly convex, with proximally protruding ventro-proximal tip; proximal edge slightly thickened, separated from remaining outer surface by shallow, moderately well-defined furrow; no spurs on proximal edge; outer surface with moderately coarsely granular stereom even between spine articulations and on thickened part of proximal edge; granules on outer surface with weak tendency to merge into short, knobby, irregular vertical ridges. Six (proximal LAPs) to five (distal LAPs) small, equal-sized and nearly equi-distant, ear-shaped, oval, horizontally elongate spine articulations freestanding on bulging distal portion of LAP; not bordered proximally by a ridge; dorsal and ventral lobes nearly horizontal, separated proximally; gap between spine articulations and distal edge of LAP as wide as half a spine articulation; row of spine articulations slightly oblique, dorsoproximalwards receding. Ventral edge of LAPs convex; tentacle notch invisible in external view.

Inner side of LAPs with small, short, poorly defined, prominent, inconspicuous ridge, with ventroproximalwards bent, slightly widened ventral part not merged with ventral portion of LAP; dorsal tip of ridge slightly widened, no extension discernible; inner side of distal edge of LAP devoid of spurs; inner side of tentacle notch very small, moderately well defined laterally, shallow; dorsal, ventral and ventro-proximal edges facing midline of arm with large, vertical contact surfaces. No perforations or furrow discernible.

\section{Occurrence}

Early Maastrichtian of Germany and Denmark.

\section{Remarks}

This LAP type from the Early Maastrichtian of Germany and Denmark was first described by Kutscher \& Jagt (2000) as Ophiothela? semirotunda. Assignment to the ophiotrichid genus Ophiothela Verrill, 1867 is untenable considering the fundamental differences in spine articulation morphology (Martynov 2010). Interestingly, Kutscher \& Jagt (2000) mentioned that their new species showed a certain resemblance to small-sized ophiacanthids, and later primarily compared it to LAP types originally assigned to hemieuryalids (here reinterpreted as species of the ophiacanthid Inexpectacantha; see above). Indeed, the presence of a sigmoidal fold in the spine articulations unambiguously places the LAPs in question in the Ophiacanthidae.

A comparison with the LAPs of Recent ophiacanthids reveals that closest similarities are shared with the LAPs of Ophiochondrus, in particular on account of the generally round, massive and stout aspect, the size, shape and position of the spine articulations, and the outer surface ornament. Significant differences, however, can be found in the structure of the inner side. In fact, these fossil LAPs display large contact surfaces with the opposite LAP, facing the midline of the arm. Such contact surfaces are commonly found in species of the ophiolepidid genus Ophiomusium Lyman, 1869 (e.g. Kutscher \& Jagt 2000), but are atypical of Ophiochondrus. This difference is very likely to warrant separation at the generic level. However, as long as the inner side of the LAPs of Ophiomoeris remains unknown, assignment to this genus cannot be ruled out. At the present state of knowledge, it thus seems best to tentatively assign the present LAPs to Ophiochondrus, stressing, however, that there are significant differences in LAP morphology between the fossil LAPs and those of Recent Ophiochondrus, in particular the type species of the genus. 
Ophiacanthidae gen. et sp. nov. innom.

Fig. 37: 8-9

\section{Material examined}

GZG.INV.78802, GZG.INV.78803 and GZG.INV.78804 (dissociated LAPs) from the Bimammatum Zone, late Oxfordian, Late Jurassic of the Plettenberg, Germany.

\section{Description}

GZG.INV.78802 is a dissociated, tiny, proximal LAP; very fragile, dorso- and ventro-proximal tips missing; originally at least twice higher than wide; distal edge convex; outer surface with finely and moderately densely meshed stereom. At least six very large, densely spaced spine articulations freestanding on elevated distal portion of LAP; shape of spine articulations very unusual, complex; dorsal lobe very large, distally encompassing several openings of variable size; sigmoidal fold well developed but very short, proximally bordering very small nerve opening; ventral lobe very slender, proximally merged with dorsal lobe; spine articulations slightly oval, horizontally elongate; middle spine articulations largest, with dorsalward and ventralward decrease in size; spine articulations proximally sharply bordered by straight, well-defined but weakly prominent edge of elevated distal portion of LAP; gap between spine articulations and distal edge of LAP generally narrow, widest near middle spine articulations. No tentacle notch discernible in external view.

Inner side of LAP with very slender, moderately well-defined, weakly prominent, oblique and nearstraight ridge with widened, vertically elongate dorsal tip composed of more finely meshed stereom; ventral tip of ridge indiscernible or poorly preserved; single, well-defined, prominent, oval spur composed of densely meshed stereom in ventral half of inner side of distal LAP edge; inner side of tentacle notch not preserved or indiscernible. No perforations or furrow discernible.

GZG.INV.78803 is a dissociated median or distal LAP, strongly broken; outer surface with very densely meshed stereom. At least four very closely spaced spine articulations similar to those observed on the proximal specimen described above, displaying dorsalward increase in size; row of spine articulations ventrally bordered by very large, oblique, lenticular, round, strongly prominent ridge-like structure composed of dense stereom.

Inner side of LAP with very slender, moderately well-defined, prominent ridge similar to the main part of the ridge observed on the previous specimen; ventral tip of ridge merged with large, well-defined, strongly prominent, oblique, elongate knob composed of densely meshed stereom; spur on inner side of distal edge of LAP much larger than in previous specimen; very large, round, lenticular, strongly prominent structure ventrally bordering row of spine articulations almost completely exposed in internal view.

\section{Remarks}

These specimens probably are among the most unusual ophiuroid LAPs ever recorded. The very weird, complex spine articulations display a sigmoidal fold, which suggests that the LAPs in question are assignable to the Ophiacanthidae. Affinities within this family, however, are purely speculative. These LAPs appear so highly derived that it is difficult, if not impossible, to deduce any phylogenetic relationships with other ophiacanthids on the basis of LAP morphology. It is even unfeasible to determine with certainty if this LAP type belongs to a large-pored or a small-pored ophiacanthid. To make matters worse, the material available is very limited and fragmentary, which hampers a proper systematic assessment of this highly intriguing LAP type.

Striking similarities in the structure of the spine articulations are shared with the LAPs of the ophiocomid Ophiopteris papillosa Lyman, 1875. It cannot be ruled out that these similarities reflect close phylogenetic 
ties, which would place the present LAP type in the Ophiocomidae Ljungman, 1867. However, most of the other characters, in particular the size and fragility of the LAPs, the shape of the ridge on the inner side, the enigmatic structure ventrally bordering the row of spine articulations and the absence of perforations on the inner side, differ fundamentally. It thus seems more probable that the similarly shaped spine articulations were acquired independently.

In the absence of more material, this LAP type cannot be formally described. It is clear, however, that it represents a new genus and species most probably assignable to the Ophiacanthidae. It is hoped that more material of this intriguing LAP type will be discovered in order to investigate its phylogenetic position and speculate on the function of the unusual spine articulation morphology and the enigmatic structure ventrally bordering the row of spine articulations.

\section{Genus Ophiojagtus gen. nov. urn:Isid:zoobank.org:act:0B5FB6EE-42F6-43D5-BC67-41AE35B82EE3}

\section{Type species}

Ophiojagtus acklesi sp. nov. by present designation.

\section{Other species included}

Hemieuryale? argoviensis Hess, 1966; Ophiojagtus irimurai sp. nov. and Ophiosmilax? alternatus Kutscher \& Jagt, 2000.

\section{Diagnosis}

Ophiacanthid with stout, thick, strongly curved LAPs generally with a large height/width ratio; outer surface devoid of ornament elements; no spurs on outer proximal and inner distal edges; ventral portion of LAPs long to extremely long, strongly protruding ventralwards and often with widened ventral tip; proximal edge commonly with proximally pointing protrudion; large, ear-shaped spine articulations composed of thick, continuous volute, freestanding on bulging distal portion of LAP and not bordered proximally by a ridge-like structure; broad, well-defined ridge on the inner side of the LAPs, generally with dorso-proximally pointing dorsal part; tentacle notch large but poorly defined and generally shallow.

\section{Etymology}

Genus named in honour of my friend and colleague John W.M. Jagt for his generous support in the course of the present project and for his outstanding contributions to ophiuroid palaeontology; gender masculine.

\section{Remarks}

The Mesozoic ophiuroid fossil record includes a highly distinctive type of dissociated LAPs characterised by a thick and massive general aspect, very long, conspicuous ventral portion, large, ear-shaped spine articulations freestanding on the bulging distal portion of the LAP and composed of a thick, continuous volute, and the absence of outer surface ornament and spurs. This combination of characters is not found in any other ophiuroid LAP type. A new genus, Ophiojagtus gen. nov., is thus introduced here to accommodate the LAP type in question.

Previous records which can be assigned to this new genus include Hemieuryale? argoviensis Hess, 1966 from the Oxfordian of Switzerland and France (Hess 1966), Ophiosmilax? alternatus Kutscher \& Jagt, 2000 from the Campanian and Maastrichtian of Germany, Denmark and Belgium (Kutscher \& Jagt 2000) and records of the latter form from the Turonian of the Czech Republic and Tunisia (Štorc 2004). Astonishingly, the striking similarities between these two species have not been noted previously. As a 
consequence, they were assigned to completely different genera belonging to unrelated families (Smith et al. 1995). On account of fundamental differences in spine articulation structure, assignment either to the Hemieuryalidae (Hemieuryale) or the Ophiomyxidae (Ophiosmilax Matsumoto, 1915) is tenable. Rather, the presence of large, ear-shaped spine articulations with a sigmoidal fold in combination with a series of small perforations on the inner side rather than a single large one near the ventral part of the ridge is suggestive of strong ophiacanthid affinities, however atypical this LAP type might appear for an ophiacanthid.

Affinities within the Ophiacanthidae, in contrast, are much more difficult to resolve. In spite of the relatively large, poorly defined tentacle notch in the LAPs of Ophiojagtus gen. nov., the tentacle pore in the context of the articulated arm was presumably small, considering the extremely long ventral portion of the LAPs. Thus, it seems probable that Ophiojagtus gen. nov. belongs to the small-pored ophiacanthids. Closest similarities seem to be shared with the LAPs of Inexpectacantha, mainly on account of the massive, thick general aspect, the position of the spine articulations, and the lack of outer surface ornament and of spurs. However, it is likely that these similarities are superficial, considering the significantly different spine articulation morphologies and ridge shapes. The LAPs of Ophiojagtus gen. nov. appear to be so highly derived that the phylogenetic relationships of the genus cannot be further explored on the basis of LAP morphology.

As already hinted at by Štorc (2004), the LAPs here assigned to Ophiojagtus gen. nov. remained morphologically conservative over considerable time intervals. Although it seems very unlikely that a single species spanned some $20 \mathrm{Ma}$, as suggested by Štorc (2004), it can be challenging, if not impossible, to differentiate stratigraphically close LAP types of Ophiojagtus gen. nov., in particular when only few LAPs are available. In the present study, a total of four LAP types of Ophiojagtus gen. nov. are characterised and identified at the species level. A few additional occurrences of the genus, including those recorded by Štorc (2004) and Štorc \& Žitt (2008), could not be assigned with certainty and are thus treated here as indeterminate records of the genus.

Ophiojagtus argoviensis (Hess, 1966) comb. nov.

Fig. 37: 10-11

Hemieuryale? argoviensis Hess, 1966: 1040, 1052, figs 24-25, 67-69.

\section{Diagnosis}

Species of Ophiojagtus gen. nov. with relatively small LAPs displaying a broad and short ventral portion accounting for approximately one-quarter of the total LAP height; proximal edge occasionally with very weak, rounded protrusion; five to six spine articulations with weak dorsalward increase in size and slightly stronger dorsalward increase in the size of the gaps separating them; ridge on the inner side relatively slender, evenly bent, with slightly widened dorsal tip and with ventral half extending well onto the ventral portion of the LAP.

\section{Material examined}

NHMB M1124, NHMB M11225 and 3 dissociated LAPs from the late Oxfordian of Savigna, France, the type material of Hess (1966); GZG.INV.78805 (1 dissociated LAP) from sample S1 of Gale (2011), GZG.INV.78806 (2 dissociated LAPs) from sample S2a of Gale (2011) and GZG.INV.78807 (4 dissociated LAPs) from sample S2b of Gale (2011), all from the Bifurcatus Zone, late Oxfordian of Savigna, France; 2 dissociated LAPs from the Bifurcatus Zone of Guldental, Switzerland, the original material of Hess (1966). 


\section{Description}

Relatively small dissociated LAPs; of thick, massive, strongly curved general aspect; more than twice higher than wide (proximal LAPs) to approximately 1.5 times higher than wide (median to distal LAPs); dorsal edge rounded; distal edge convex; proximal edge concave, generally with very weak, rounded protrusion; no spurs; ventral portion of the LAPs broad, weakly widened ventrally, relatively short, accounting for one-quarter of the total LAP height; outer surface with finely meshed stereom, devoid of conspicuous ornament elements. Five to six large, ear-shaped spine articulations freestanding on bulging distal portion of LAP and composed of a thick, continuous volute; spine articulations not sharply bordered proximally; weak dorsalward increase in size of spine articulations and slightly larger dorsalward increase in size of gaps separating them; gap between spine articulations and distal edge of LAP narrow.

Inner side of LAPs with well-defined, prominent, relatively slender, gently bent ridge; dorsal half of ridge pointing dorso-proximalwards, with slightly widened dorsal tip; ventral half of ridge extending onto most of the ventral portion of the LAP but not merged with the latter; no spurs on inner side of the distal edge of LAP; inner side of the tentacle notch moderately large, poorly defined, very shallow. Few, small, scattered perforations in shallow, moderately well-defined vertical furrow dorsally bordering tentacle notch.

\section{Remarks}

This type of LAP was originally described by Hess (1966) as Hemieuryale? lunaris on the basis of dissociated LAPs and vertebrae from the Oxfordian of Switzerland and France. A re-examination of the type material, in addition to new finds of dissociated LAPs from the Oxfordian of France, has now revealed that this LAP type displays the distinctive combination of characters unambiguously warranting assignment to Ophiojagtus gen. nov.

\section{Occurrence}

Late Oxfordian of France and Switzerland.

\section{Ophiojagtus irimurai sp. nov. urn:1sid:zoobank.org:act:F0BACE55-91F5-4744-BA63-5C078F04C4DE}

Fig. 38: 1-4

\section{Diagnosis}

Species of Ophiojagtus gen. nov. with wide, but comparatively short, ventral protrusion accounting for one-fifth to less than one-third of the total LAP height; proximal edge with weakly to very well-developed protrusion; four to seven spine articulations; weak dorsalward increase in size of spine articulations and of gaps separating them; ridge on inner side relatively slender, with weakly widened dorsal tip; ventral part of ridge extending well onto the ventral portion of the LAP; conspicuously angular kink between the ventral and dorsal parts of the ridge.

\section{Etymology}

Species named in honour of my friend and colleague Seiichi Irimura, in admiring recognition of his contributions to ophiuroid systematics.

\section{Type material}

\section{Holotype}

GZG.INV.78808. 
THUY B., Fossil record of ophiacanthid brittle stars

\author{
Paratypes \\ GZG.INV.78809, GZG.INV.78810 and GZG.INV.78811.
}

\title{
Type locality and horizon
}

Pointe du Chay near La Rochelle, France; Achilles Subzone, Cymodoce Zone, early Kimmeridgian, Late Jurassic.

\section{Additional material}

GZG.INV.78812 (3 dissociated LAPs) from the early Kimmeridgian of the Pointe du Chay, France; GZG.INV.78813 (1 dissociated LAP) from the Amaral Formation, late Kimmeridgian of Trancoso, Portugal.

\section{Description}

\section{Holotype}

GZG.INV.78808 is a dissociated, large, proximal LAP; of massive, stout and strongly curved general aspect; almost three times higher than wide; dorsal edge rounded, convex; distal edge convex; proximal edge weakly concave, devoid of spurs, with very weak, rounded protrusion; ventral portion of LAP moderately broad, widened ventrally, relatively short, accounting for one-fifth of the total LAP height; outer surface with finely meshed stereom. Seven large, nearly equal-sized, ear-shaped spine articulations freestanding on bulging distal portion of LAP and composed of thick, continuous volute; weak dorsalward increase in size of gaps separating spine articulations; gap between spine articulations and distal edge of LAP narrow.

Inner side of LAP with well-defined, prominent, rather slender ridge; dorsal part of ridge slightly bent, oblique, with weakly widened dorsal tip; ventral part of ridge slightly narrower, less well defined and less strongly prominent than dorsal one, connected with the latter by a rounded kink and extending well onto the ventral portion of the LAP; ventral tip more strongly prominent than remaining ventral part of the ridge; no spurs on inner side of LAP; inner side of tentacle notch relatively small, poorly defined and shallow. Several small perforations loosely arranged in vertical row in very shallow, poorly defined furrow dorsally bordering tentacle notch.

\section{Paratype supplements and variaton}

GZG.INV.78809 is a dissociated median LAP; approximately 1.5 times higher than wide; proximal edge with very large, conspicuous, rounded protrusion; ventral portion of LAP wide but relatively short, accounting for less than one-quarter of the total LAP height, protruding ventro-proximalwards. Four spine articulations similar to those observed on holotype; very weak dorsalward increase in size of spine articulations; stronger dorsalward increase in size of gaps separating spine articulations.

Ridge on inner side of LAP similar to that of holotype but shorter and broader; kink between dorsal and ventral part of ridge conspicuously angular; inner side of tentacle notch relatively large, moderately well defined but shallow. Broad, moderately well-defined, short vertical furrow with four small, irregular perforations distally bordering kink of ridge.

GZG.INV.78810 is a dissociated median LAP; ventral portion missing; proximal edge with large but rather weak, inconspicuous rounded protrusion. Five spine articulations similar to those of holotype; very weak dorsalward increase in size of spine articulations and of gaps separating them.

Inner side of LAP fragmentary, with only dorsal part of ridge preserved. Two small perforations in shallow, narrow, poorly defined vertical furrow.

GZG.INV.78811 is a dissociated distal LAP; slightly higher than wide; dorsal edge weakly convex; proximal edge with large but rather weak and inconspicuous rounded protrusion; ventral portion of LAP wide and moderately long, accounting for slightly less than one-third of the total LAP height, strongly 


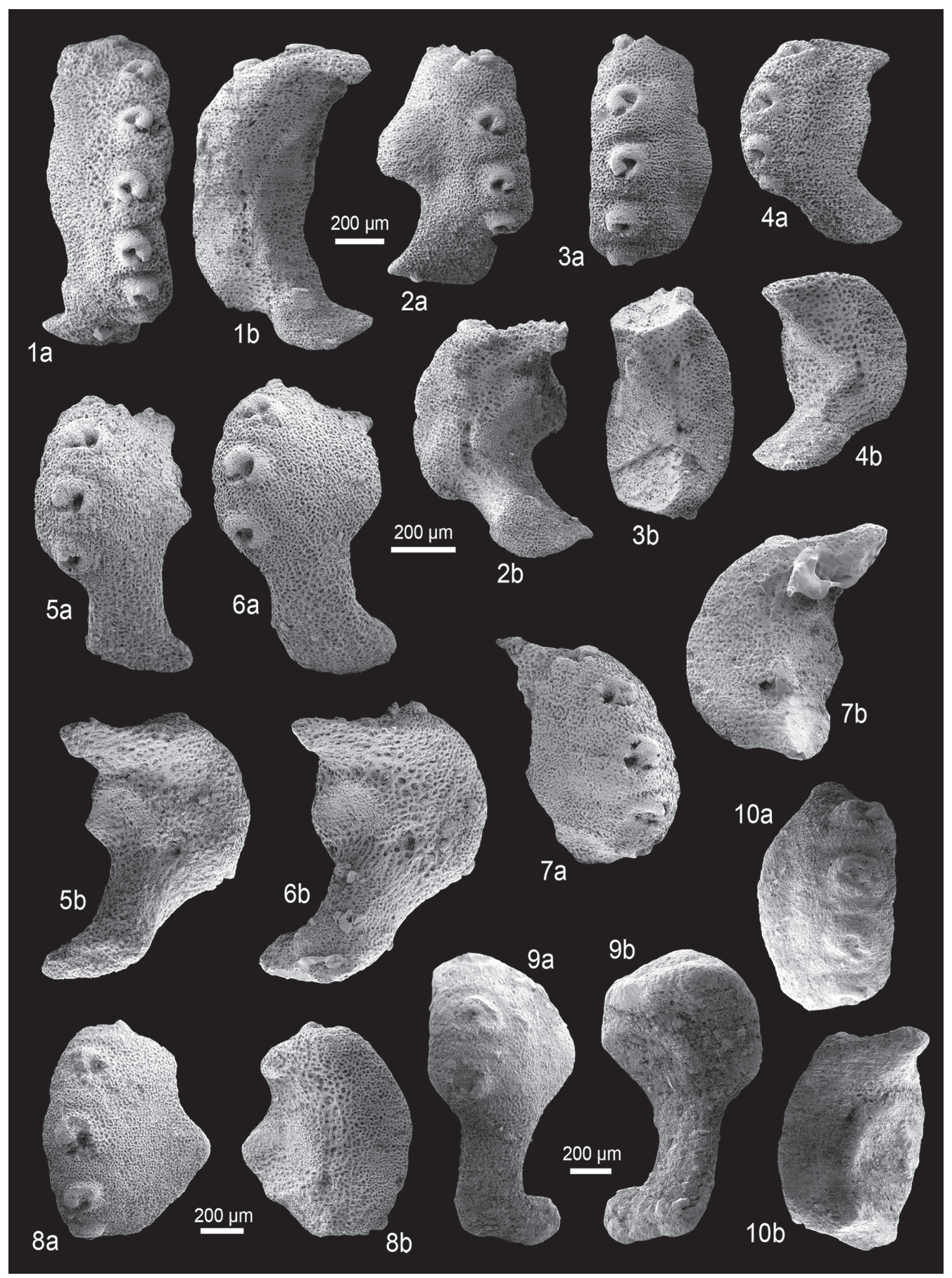

Fig. 38. Fossil lateral arm plates (LAPs) of ophiacanthid brittle stars in external (a) and internal (b) views. 1-4. Ophiojagtus irimurai gen. et sp. nov. from the early Kimmeridgian (Late Jurassic) of the Pointe du Chay, France. 1. GZG.INV.78808 (holotype), proximal LAP. 2. GZG.INV.78809 (paratype), median LAP. 3. GZG.INV.78810 (paratype), median LAP. 4. GZG.INV.78811 (paratype), distal LAP. 5-7. Ophiojagtus acklesi gen. et sp. nov. from the late Aptian (Early Cretaceous) of Wizard Way, Texas. 5. GZG.INV.78814 (holotype), proximal LAP. 6. GZG.INV.78815 (paratype), median to distal LAP. 7. GZG.INV.78816 (paratype), proximal LAP. 8. Ophiojagtus sp. 1 from the early Cenomanian (Late Cretaceous) of Waco, Texas; proximal LAP. 9-10. Ophiojagtus alternatus (Kutscher \& Jagt, 2000) comb. nov. from the early late Maastrichtian (Late Cretaceous) of Haccourt, Belgium. 9. NHMM 2012 060, proximal to median LAP. 10. NHMM 2012 061, proximal LAP. One common scale bar per species. 
protruding ventro-proximalwards. Four spine articulations similar to those observed on holotype; dorsalward increase in size of spine articulations.

Ridge on inner side of LAP similar to that of holotype but shorter and with conspicuously angular kink between dorsal and ventral parts. Several small perforations closely grouped in vertical row distally bordering kink of ridge.

\section{Remarks}

These LAPs are unambiguously assignable to Ophiojagtus gen. nov. on account of the highly distinctive general morphology, the large, protruding ventral portion, the lack of outer surface ornament, the structure and position of spine articulations and the shape of the ridge on the inner side. Among the LAP types assignable to this genus, the present ones stand out in displaying up to seven spine articulations, a relatively short ventral portion and a conspicuously angular kink between the ventral and the dorsal part of the ridge on the inner side.

\section{Occurrence}

Early Kimmeridgian of France, late Kimmeridgian of Portugal.

Ophiojagtus acklesi sp. nov. urn:1sid:zoobank.org:act:A51326C9-FAAE-4FFF-96BA-C8442F76BA0B

Fig. 38: 5-7

\section{Diagnosis}

Ophiacanthid with stout, thick, strongly curved LAPs generally with a high height/width ratio; outer surface devoid of ornamentation elements; no spurs on outer proximal and inner distal edges; ventral portion of LAPs long to extremely long, strongly protruding ventralwards and often with widened ventral tip; proximal edge commonly with proximalwards pointing protrusion; large, ear-shaped spine articulations composed of thick, continuous volute, freestanding on bulging distal portion of LAP and not bordered proximally by a ridge-like structure; broad, well defined ridge on the inner side of the LAPs, generally with dorso-proximalwards pointing dorsal part; tentacle notch large but poorly defined and generally shallow.

\section{Etymology}

Species named in honour of Texas-born actor Jensen Ackles; my wife urged me to do so.

\section{Type material}

\section{Holotype}

GZG.INV.78814.

Paratypes

GZG.INV.78815 and GZG.INV.78816.

\section{Type locality and horizon}

Wizard Way, Texas, USA; echinoid marker bed of Smith \& Rader (2009), latest Aptian, Early Cretaceous.

\section{Additional material}

GZG.INV.78817 (67 dissociated LAPs). 


\section{Description}

\section{Holotype}

GZG.INV.78814 is a dissociated, moderately large, proximal LAP; approximately twice higher than wide; of stout, massive and strongly curved aspect; dorsal edge slightly concave on account of the pointed dorso-proximal tip of the LAP strongly protruding towards arm midline; distal edge convex; proximal edge concave, with two closely spaced, pointed protrusions, ventral one of which larger; ventral portion rather narrow and very long, accounting for more than one-third of the total LAP height, with widened, conspicuously ventro-proximalwards pointing ventral tip; outer surface with finely meshed stereom, devoid of ornament elements; slightly more coarsely meshed stereom on ventral portion of LAP. Four large, nearly equi-distant, ear-shaped spine articulations freestanding on strongly bulging distal portion of LAP, and composed of a thick, continuous volute; slight dorsalward increase in size of spine articulations; gap between spine articulations and distal edge of LAP rather narrow.

Inner side of LAP with well-defined, prominent, broad but very short, oblique ridge; dorsal tip of ridge strongly widened and ventro-proximalwards extending onto inner side of protrusions of proximal edge of LAP; ridge restricted to the centre of the inner side, no part of the ridge extending onto the ventral portion of the LAP; no spurs on the inner side of the distal edge of the LAP; inner side of the tentacle notch relatively large, very poorly defined, shallow, almost indiscernible. Single small perforation between tentacle notch and ventral tip of ridge.

\section{Paratype supplements and variation}

GZG.INV.78815 is a dissociated median to distal LAP; approximately 1.5 times higher than wide; very well in agreement with holotype; ventral portion accounting for almost half of the total LAP height; single, large, well-developed, round protrusion on proximal edge. Four spine articulations similar to those observed on holotype.

Inner side of LAP very well in agreement with that of holotype; ridge slightly shorter.

GZG.INV.78816 is a dissociated proximal LAP; ventral portion missing; single large, well-developed, rounded protrusion on proximal edge. Five spine articulations similar to those of holotype but with weaker dorsalward increase in size.

Inner side similar to that of holotype.

\section{Remarks}

The highly distinctive combination of characters displayed by these LAPs unambiguously places them in the genus Ophiojagtus gen. nov. Confusion with other LAP types assigned to this genus is precluded by the presence of four to five spine articulations, in combination with a very long ventral portion and a very short ridge on the inner side not extending onto the ventral portion of the LAP but with a strongly widened dorsal tip projecting onto the inner side of the well-developed protrusion of the proximal LAP edge. Since this LAP type displays the diagnostic combination of characters of Ophiojagtus gen. nov. most clearly, it is chosen as the type species of the genus.

\section{Occurrence}

Latest Aptian of Texas.

Ophiojagtus sp. indet.

Fig. 38: 8

\section{Material examined}

GZG.INV.78818 (1 dissociated LAP) from the early Cenomanian, Late Cretaceous of Waco, Texas, USA. 


\section{Description}

GZG.INV.78818 is a dissociated, moderately large, proximal LAP; ventral portion and dorso-proximal edge missing; distal edge convex; proximal edge with very large, conspicuous, well-developed protrusion; outer surface with finely meshed stereom. Five large, ear-shaped spine articulations freestanding on strongly bulging distal portion of LAP and composed of a thick, continuous volute; dorsalward increase in the size of the spine articulations and of the gaps separating them; gap between the spine articulations and the distal edge of the LAP narrow.

Inner side of the LAP with moderately well-defined, weakly prominent, broad ridge with conspicuous, strongly widened dorsal tip extending ventro-proximalwards on inner side of protrusion of proximal LAP edge; presence of a ventral part of the ridge not determinable. Single small perforation at the ventral tip of a shallow, poorly defined vertical furrow distally bordering the ventralmost preserved part of the ridge.

\section{Remarks}

Although the single LAP described above is unambiguously assignable to Ophiojagtus gen. nov., its fragmentary nature precludes any species-level identification. The presence of five spine articulations places this LAP closest to O. acklesi sp. nov. or to the LAPs described by Štorc \& Žítt (2008) and probably erroneously assigned to O. alternatus comb. nov. (see below). However, since the ventral portion is missing, the shape of the ridge on the inner side cannot be assessed, which precludes any further conclusions on the placement of the specimen at the species level.

Ophiojagtus alternatus (Kutscher \& Jagt, 2000) comb. nov.

Fig. 38: 9-10

Ophiosmilax? alternatus Kutscher \& Jagt, 2000 in Jagt 2000: 7, pl. 1 figs 1-2.

Ophiosmilax? alternatus Kutscher \& Jagt, 2000: 47-48, pl. 31 figs 8-12, pl. 33 figs 9-11.

Ophiosmilax? n. sp. - Jagt 1999a: 199, pl. 1 figs 1-2.

Ophiosmilax? alternatus - Jagt \& Riegraf 2003: table 1.

non Ophiosmilax? alternatus - Štorc 2004: 397, figs 6-8. — Štorc \& Žítt 2008: 124, fig. 4A-F.

\section{Diagnosis}

Species of Ophiojagtus gen. nov. with moderately large LAPs displaying an extremely long ventral portion, three to four spine articulations and an evenly bent, slender ridge on the inner side extending well onto the ventral portion.

\section{Material examined}

34 dissociated LAPs in the Manfred Kutscher Collection in Sassnitz, Germany, from the early Maastrichtian of Rügen, Germany, the type material of Kutscher \& Jagt (2000); NHMM 2012 060, NHMM 2012061 and NHMM JJ 3679 (13 dissociated LAPs) from the early late Maastrichtian of Haccourt, Belgium, the original material of Jagt (2000); GZG.INV.78819 (2 dissociated LAPs) from the late Campanian of Lägerdorf-Alsen, Germany.

\section{Description}

Moderately large, dissociated LAPs of stout, massive and strongly curved aspect; proximal ones more than twice higher than wide, distal ones less than 1.5 times higher than wide; dorsal edge weakly concave as a result of the pointed dorso-proximal tip of the LAP slightly protruding towards arm midline; distal edge convex; dorsal part of proximal edge evenly convex, ventral part concave; 
ventral portion of LAP narrow, extremely long, accounting for more than half of the total LAP height in proximal LAPs to slightly less than half of the total LAP height in distal ones; outer surface with finely meshed stereom. Three to four large, ear-shaped spine articulations freestanding on strongly bulging distal portion of LAP and composed of thick, continuous volute; dorsalward increase in size of spine articulations and of gaps separating them; gap between spine articulations and distal edge of LAP narrow.

Inner side of LAP with well-defined, prominent, slender, evenly bent ridge with ventral part extending well onto the ventral portion of the LAP, and widened dorsal tip with ventro-proximalwards pointing extension; no spurs on inner side of distal edge of LAP; inner side of tentacle notch very weakly defined, almost indiscernible. Small, irregular perforations in very shallow, poorly defined vertical furrow distally bordering ridge.

\section{Remarks}

Kutscher \& Jagt (2000) first described this species on the basis of dissociated LAPs and vertebrae from the early Maastrichtian of Germany and Denmark. As noted above, the original assignment to the ophiomyxid Ophiosmilax, even if tentative, is untenable. The LAPs in question clearly belong to the new ophiacanthid genus Ophiojagtus gen. nov. Within this genus, they are unique in displaying three to four spine articulations, an extremely long ventral portion and a slender, evenly bent ridge on the inner side extending well onto the ventral portion of the LAP.

The LAPs described and illustrated as Ophiosmilax? alternatus by Štorc (2004) from the Turonian of the Czech Republic and Tunisia display much more coarsely meshed stereom on the outer surface and thus most probably belong to a different, still unnamed species of the present genus. The LAPs described by Štorc \& Žitt (2008) from the Turonian of the Czech Republic seem to display four to five, rather than three to four, spine articulations, which would challenge assignment to Ophiojagtus alternatus comb. nov. In order to clarify the exact systematic position of these Turonian occurrences of Ophiojagtus gen. nov., the original material needs to be re-examined, in particular the diagnostically important, but insufficiently described and unillustrated inner side.

\section{Occurrence}

Late Campanian of Germany, early Maastrichtian of Germany and Belgium.

\section{Acknowledgments}

For generously providing samples, I wish to thank Regina Fischer, Franz Fürsich, Andy S. Gale, Manfred Jäger, John W.M. Jagt, Andreas Kroh, Manfred Kutscher, Gero Moosleitner, Mike Reich and Simon Schneider; for permitting access to ophiuroid collections at the Naturhistorisches Museum Basel, thanks go to Walter Etter, Hans Hess, Christian Meyer and Olivier Schmidt; Manfred Kutscher, Mike Reich and Anne Mehlin Sørensen provided items of literature, for which I am grateful. I thank Andreas Kroh and Sabine Stöhr for their hospitality during my Synthesys visits to Vienna and Stockholm, respectively; Andreas Kroh for his enormous support in computing the phylogenies; Toshihiko Fujita, Yoshiaki Ishida and Dave Pawson for generous donations of Recent specimens for comparison; Wolfgang Dröse and Dorothea Hause-Reitner for assistance with scanning electron microscopy; Hans Hess for picking the La Pouza residues; Andy Gale, Steffen Kiel and Joachim Reitner for inspiring and exciting discussions; and the journal referees, John W.M. Jagt and an anonymous reviewer whose comments greatly improved an earlier version of this manuscript. The present study gained support from the European Union-funded Synthesys programme (grants AT-TAF-1307 and SE-TAF-1297) and from German Research Foundation (grant DFG RE2599/6-1). 


\section{References}

Adatte T., Arnaud-Vanneau A., Arnaud H., Blanc-Aletru M.C., Bodin S., Carrio E., Föllmi K.B., Godet A., Raddadi M.C. \& Vermeulen J. 2005. The Hauterivian -Lower Aptian sequence stratigraphy from Jura Platform to Vocontian Basin: a multidisciplinary approach. Géologie Alpine, Série spéciale "Colloques et excursions» 7: 1-181.

Adrain J.M., Westrop S.R. \& Chatterton D.E. 2000. Silurian trilobite alpha diversity and the end-Ordovician mass extinction. Paleobiology 26 (4): 625-646. http://dx.doi.org/10.1666/0094$\underline{\text { 8373(2000)026<0625:STADAT }>2.0 . \mathrm{CO} ; 2}$

Allenbach R.P. 2001. Synsedimentary tectonics in an epicontinental sea: a new interpretation of the Oxfordian basins of northern Switzerland. Eclogae geologicae Helvetiae 94: 265-287.

Aquino-Souza R., Hawkins S.J. \& Tyler P.A.2008. Early development and larval survival of Psammechinus miliaris under deep-sea temperature and pressure conditions. Journal of the Marine Biological Association of the United Kingdom 88 (3): 453-461. http://dx.doi.org/10.1017/S0025315408001148

Bachmayer F. \& Kollmann H. 1968. Eine Ophiure aus der Trias Jugoslawiens. Annalen des Naturhistorischen Museums in Wien 72: 645-648.

Baker A.N. \& Devaney D.M. 1981. New records of Ophiuroidea (Echinodermata) from southern Australia, including new species of Ophiacantha and Ophionereis. Transactions of the Royal Society of Southern Australia 105: 155-178.

Benton M.J. 1995. Diversification and extinction in the history of life. Science 268 (5207): 52-58. http:// dx.doi.org/10.1126/science. 7701342

Bernecker M. \& Weidlich O. 2005. Azooxanthellate corals in the Late Maastrichtian-Early Paleocene of the Danish basin: bryozoan and coral mounds in a boreal shelf setting. In: Freiwald A. \& Murray J. (eds) Cold-water corals and ecosystems: 3-25. Erlangen Earth Conference Series 1, Springer, Berlin. http:// dx.doi.org/10.1007/3-540-27673-4_1

Bernoulli D. \& Jenkyns H.C. 2009. Ancient oceans and continental margins of the Alpine-Mediterranean Tethys: deciphering clues from Mesozoic pelagic sediments and ophiolites. Sedimentology 56 (1): 149190. http://dx.doi.org/10.1111/j.1365-3091.2008.01017.x

Blake D.B. \& Aronson R.B. 1998. Eocene stelleroids (Echinodermata) at Seymour Island, Antarctic Peninsula. Journal of Paleontology 72 (2): 339-353.

Blake D.B. \& Reid III R. 1998. Some Albian (Cretaceous) asteroids (Echinodermata) from Texas and their paleobiological implications. Journal of Paleontology 72 (3): 512-532.

Böhm F. 1992. Mikrofazies und Ablagerungsmilieu des Lias und Dogger der Nordöstlichen Kalkalpen. Erlanger geologische Abhandlungen 121: 57-217.

Böhm F. \& Brachert T.C. 1993. Deep-water stromatolites and Frutexites Maslov from the Early and Middle Jurassic of S-Germany and Austria. Facies 28 (1): 145-168.

Böhm F., Dommergues J.-L. \& Meister C. 1995. Breccias of the Adnet Formation: indicators of a MidLiassic tectonic event in the Northern Calcareous Alps (Salzburg/Austria). Geologische Rundschau 84 (2): 272-286. http://dx.doi.org/10.1007/BF00260440

Bottjer D.J. \& Jablonski D. 1988. Paleoenvironmental patterns in the evolution of post-Paleozoic benthic marine invertebrates. Palaios 3 (6): 540-560. http://dx.doi.org/10.2307/3514444

Boulvain F., Belanger I., Delsate D., Ghysel P., Godefroit P., Laloux M., Monteyne R. \& Roche M. 2001. Triassic and Jurassic lithostratigraphic units (Belgian Lorraine). In: Bultynck P. \& Dejonghe L. (eds) Lithostratigraphic scale of Belgium. Geologica Belgica 4 (1-2): 113-119. 
Brandt A., De Broyer C., De Mesel I., Ellingsen K.E., Gooday A.J., Hilbig B., Linse K., Thomson M.R.A. \& Tyler P.A. 2007. The biodiversity of the deep Southern Ocean benthos. Philosophical Transactions of the Royal Society B 362 (1477): 39-66. http://dx.doi.org/10.1098/rstb.2006.1952

Bremer K. 1994. Branch support and tree stability. Cladistics 10 (3): 295-304. http://dx.doi. org/10.1111/j.1096-0031.1994.tb00179.x

Brey T., Dahm C., Gorny M., Klages M., Stiller M. \& Arntz W.E. 1996. Do Antarctic benthic invertebrates show an extended level of eurybathy? Antarctic Science 8 (1): 3-6. http://dx.doi.org/10.1017/ $\underline{\text { S0954102096000028 }}$

Broglio Loriga C. \& Berti Cavicchi A. 1972. Praeaplocoma hessi n. gen., n. sp., un ofiura del Werfeniano (Trias Inferiore) del Gruppo della Costabella, Dolomiti. Memorie Geopaleontologiche dell'Universita di Ferrara 2: 185-197.

Brückner A., Janussen D. \& Schneider S. 2003. Eine neue Poriferen-Fauna aus dem Septarienton (Oligozän, Rupelium) von Bad Freienwalde (NE-Deutschland) und der erste fossil erhaltene Vertreter der nicht-rigiden Hexactinelliden-Gattung Asconema. Paläontologische Zeitschrift 77 (2): 263-280.

Calzada S. \& Gutiérrez D. 1988. Ofiuras (Echinodermata) del Ladiniense catalán. Batalleria 1: 31-38.

Chen Z.Q., Shi G.R. \& Kaiho K. 2004. New ophiuroids from the Permian/Triassic boundary beds of South China. Palaeontology 47 (5): 1302-1312. http://dx.doi.org/10.1111/j.0031-0239.2004.00406.x

Clark H.L. 1911. North Pacific ophiurans in the collection of the Unites States National Museum. United States National Museum Bulletin 75, Smithsonian Institution, Washington. http://dx.doi.org/10.5962/ bhl.title. 1324

Clarke A.H.Jr. 1962. On the composition, zoogeography, origin and age of the deep-sea mollusc fauna. Deep-Sea Research 9 (7-10): 291-306. http://dx.doi.org/10.1016/0011-7471(62)90012-8

Davis R.A. 1977. Principles of oceanography. Addison-Wesley Publishing, Reading.

Delsate D. 1993. Elasmobranches du Bajocien inférieur de Longwy (Meurthe et Moselle). Cossmanniana Hors série 2: 56-58.

Delsate D., Duffin C.J. \& Weis R. 2002. A new microvertebrate fauna from the Middle Hettangian (Early Jurassic) of Fontenoille (Province of Luxembourg, south Belgium). Memoirs of the Geological Survey of Belgium 48, Royal Belgian Institute of Natural Sciences, Brussels.

Delsate D. \& Thuy B. 2005. Introduction géologique et biostratigraphique à quelques affleurements hettangiens du Luxembourg belge et grand-ducal. In: Delsate D. (ed.) Biostratigraphie et Paléontologie de l'Hettangien en Belgique et au Grand-Duché de Luxembourg: 1-25. Memoirs of the Geological Survey of Belgium 51, Royal Belgian Institute of Natural Sciences, Brussels.

Dimter A. \& Smelror M. 1990. Callovian (Middle Jurassic) marine microplankton from southwestern Germany: Biostratigraphy and paleoenvironmental interpretations. Palaeogeography, Palaeoclimatology, Palaeoecology 80 (3-4): 173-195. http://dx.doi.org/10.1016/0031-0182(90)90131-P

Donovan S.K. 2001. Evolution of the Caribbean echinoderms during the Cenozoic: moving towards a complete picture using all of the fossils. Palaeogeography, Palaeoclimatology, Palaeoecology 166 (12): 177-191. http://dx.doi.org/10.1016/S0031-0182(00)00208-X

Donovan S.K. 2003. Completeness of a fossil record: the Pleistocene echinoids of the Antilles. Lethaia $36(1): 1-7$.

Donovan S.K. \& Jakobsen S.L. 2004. An unusual crinoid-barnacle association in the type area of the Danian (Paleocene), Denmark. Lethaia 37 (4): 407-415. 
Emig C.C. \& Geistdoerfer P. 2004. The Mediterranean deep-sea fauna: historical evolution, bathymetric variations and geographical changes. Carnets de Géologie/Notebooks on Geology 2004: 1-10. http:// dx.doi.org/10.4267/2042/3230

Fatela F. \& Taborda R. 2002. Confidence limits of species proportions in microfossil assemblages. Marine Micropaleontology 45 (2): 169-174. http://dx.doi.org/10.1016/S0377-8398(02)00021-X

Fechner G.G. 1996. Septarienton und Stettiner Sand als Fazieseinheiten im Rupelium der östl. Mark Brandenburg: palynologisch-fazielle Untersuchungen bei Bad Freienwalde. In: Kohring R. (ed.) Miscellanea Palaeontologica 5: 77-119. Berliner geowissenschaftliche Abhandlungen Reihe E 18, Freie Universität Berlin, Berlin.

Feist-Burkhardt S., Götz A.E., Szulc J. (coordinators), Aigner T., Borkhataria R., Geluk M., Haas J., Hornung J., Jordan P., Kempf O., Michalík J., Nawrocki J., Reinhardt L., Ricken W., Röhling H.-G., Rüffer T., Török A. \& Zühlke R. 2008. Triassic. In: McCann T. (ed.) The Geology of Central Europe: 749-821. Geological Society, London.

Feldmann R.M. \& Woodburne M.O. (eds) 1988. Geology and paleontology of Seymour Island, Antarctic Peninsula. Geological Society of America Memoir 169, Goelogical Society of America, Boulder.

Fell H.B. 1960. Synoptic keys to the genera of Ophiuroidea. Zoology Publications from Victoria University of Wellington 26, Victoria University of Wellington, Wellington.

Feng R. 1985. New discovery of fossil ophiuroids from Guizhou and southern Sichuan, China. Acta Palaeontologica Sinica 24: 337-343.

Fernández-López S.R., Pavia G., Erba E., Guiomar M., Henriques M.H., Lanza R., Mangold C., Morton N., Olivero D. \& Tiraboschi D. 2009. The Global Boundary Stratotype Section and Point (GSSP) for base of the Bathonian Stage (Middle Jurassic), Ravin du Bès Section, SE France. Episodes 32 (4): 222248.

Forest J. 2006. The recent glypheids and their relationship with their fossil relatives (Decapoda, Reptantia). Crustaceana 79 (7): 795-820. http://dx.doi.org/10.1163/156854006778008221

Friès G. \& Parize O. 2003. Anatomy of ancient passive margin slope systems: Aptian gravity-driven deposition on the Vocontian palaeomargin, western Alps, south-east France. Sedimentology 50 (6): 1231-1270. http://dx.doi.org/10.1111/j.1365-3091.2003.00601.x

Fürsich F.T. Pandey D.K., Callomon J.H., Jaitly A.K. \& Singh I.B. 2001. Marker beds in the Jurassic of the Kachchh Basin, western India: their depositional environment and sequence-stratigraphic significance. Journal of the Palaeontological Society of India 46: 173-198.

Fürsich F.T., Oschmann W., Pandey D.L., Jaitly A.K., Singh I.B. \& Liu C. 2004. Palaeoecology of middle to lower Upper Jurassic macrofaunas of the Kachchh Basin, western India: an overview. Journal of the Palaeontological Society of India 49: 1-26.

Gage J.D. \& Tyler P.A. 1991. Deep-sea biology: a natural history of organisms at the deep-sea floor. Cambridge University Press, Cambridge. http://dx.doi.org/10.1017/CBO9781139163637

Gale A.S. 2011. Asteroidea (Echinodermata) from the Oxfordian (Late Jurassic) of Savigna, Département du Jura, France. Swiss Journal of Palaeontology 130 (1): 69-89. http://dx.doi.org/10.1007/s13358-010$\underline{0008-\mathrm{X}}$

Geister J. \& Lathuilière B. 1991. Jurassic coral reefs of the north-eastern Paris Basin (Luxembourg and Lorraine). International Symposium on Fossil Cnidaria, Münster. Excursion 3A, Guidebook.

Geyer O.F. \& Gwinner M.P. 1986. Geologie von Baden-Württemberg. Schweizerbart, Stuttgart. 
Gill G.A., Santantonio M. \& Lathuilière B. 2004. The depth of pelagic deposits in the Tethyan Jurassic and the use of corals: an example from the Apennines. Sedimentary Geology 166 (3-4): 311-334. http:// dx.doi.org/10.1016/j.sedgeo.2004.01.013

Goldberg E.E., Roy K., Lande R. \& Jablonski D. 2005. Diversity, endemism, and age distributions in macroevolutionary sources and sinks. The American Naturalist 165 (6): 623-633. http://dx.doi. org/10.1086/430012

Gordon C.M. \& Donovan S.K. 1992. Disarticulated echinoid ossicles in paleoecology and taphonomy: the last interglacial Falmouth Formation of Jamaica. Palaios 7 (2): 157-166. http://dx.doi. org $/ 10.2307 / 3514926$

Gray J.E. 1840. A synopsis of the genera and species of the class Hypostoma (Asterias Linnaeus). Annals and Magazine of Natural History 6: 175-184 and 275-290. http://dx.doi.org/10.1080/03745484009443282 and http://dx.doi.org/10.1080/037455484009443296

Guaiumi C., Nicora A., Preto N., Rigo M., Balini M., Di Stefano P., Gullo M., Levera M., Mazza M. \& Muttoni G. 2007. New biostratigraphic data around the Carnian/Norian boundary from the Pizzo Mondello section, Sicani Mountains, Sicily. New Mexico Museum of Natural History and Science Bulletin 41: 40-42.

Hagdorn H. 2011. Triassic: the crucial period of post-Palaeozoic crinoid diversification. Swiss Journal of Palaeontology 130 (1): 91-112 http://dx.doi.org/10.1007/s13358-010-0009-9

Hammer Ø., Harper D.A.T. \& Ryan P.D. 2001. PAST: Paleontological Statistics Software Package for Education and Data Analysis. Palaeontologia Electronica 4: 1-9.

Herrig E. 1996. Revision der Ostrakoden (Crustacea) der Schreibkreide (Unter-Maastrichtium) der Insel Rügen/Ostsee. Greifswalder geowissenschaftliche Beiträge 3: 21-28.

Hess H. 1960. Ophiurenreste aus dem Malm des Schweizer Juras und des Departements Haut-Rhin. Eclogae geologicae Helvetiae 53: 385-421.

Hess H. 1962. Mikropaläontologische Untersuchungen an Ophiuren II: Die Ophiuren aus dem Lias (Pliensbachien-Toarcien) von Seewen (Kt. Solothurn). Eclogae geologicae Helvetiae 55: 609-656.

Hess H. 1963. Mikropaläontologische Untersuchungen an Ophiuren III: Die Ophiuren aus dem Callovien-Ton von Liesberg (Berner Jura). Eclogae geologicae Helvetiae 56: 1141-1164.

Hess H. 1964. Die Ophiuren des englischen Jura. Eclogae geologicae Helvetiae 57: 756-801.

Hess H. 1965a. Mikropaläontologische Untersuchungen an Ophiuren IV: Die Ophiuren aus dem Renggeri-Ton (Unter-Oxford) von Chapois (Jura) und Longecombe (Ain). Eclogae geologicae Helvetiae 58: 1059-1082.

Hess H. 1965b. Trias-Ophiurien aus Deutschland, England, Italien und Spanien. Mitteilungen aus der Bayerischen Staatssammlung für Paläontologie und historische Geologie 5: 151-177.

Hess H. 1966. Mikropaläontologische Untersuchungen an Ophiuren V: Die Ophiuren aus dem Argovien (unteres Ober-Oxford) vom Guldental (Kt. Solothurn) und von Savigna (Dépt. Jura). Eclogae geologicae Helvetiae 59: 1025-1063.

Hess H. 1970a. Ein neuer Schlangenstern (Aplocoma mutata n. sp.) aus dem Hettangien von Ceilhes (Herault) und Bemerkungen über „Ophioderma“ squamosa aus dem Muschelkalk. Eclogae geologicae Helvetiae 63: 1059-1067.

Hess H. 1970b. Schlangensterne und Seesterne aus dem oberen Hauterivien „Pierre jaune“ von StBlaise bei Neuchâtel. Eclogae geologicae Helvetiae 63: 1069-1091. 
Hess H. 1972a. Eine Echinodermenfauna aus dem mittleren Dogger des Aargauer Juras. Schweizerische Paläontologische Abhandlungen 92, Birkhäuser, Basel.

Hess H. 1972b. An ophiuroid from the Triassic of Makhtesh Ramon (Negev, Israel). Eclogae geologicae Helvetiae 65: 725-729.

Hess H. 1975a. Mikropaläontologische Untersuchungen an Ophiuren VI: Die Ophiuren aus den Günsberg-Schichten (oberes Oxford) vom Guldental (Kt. Solothurn). Eclogae geologicae Helvetiae 68: 591-601.

Hess H. 1975b. Mikropaläontologische Untersuchungen an Ophiuren VII: Die Ophiuren aus den Humeralis-Schichten (Ober-Oxford) von Raedersdorf (Ht-Rhin). Eclogae geologicae Helvetiae 68: 603-612.

Hess H. 2006. Crinoids (Echinodermata) from the Lower Jurassic (Upper Pliensbachian) of Arzo, southern Switzerland. Schweizerische Paläontologische Abhandlungen 126, Birkhäuser, Basel.

Hess H. 2012. Crinoids from the Middle Jurassic (Bajocian-Lower Callovian) of Ardèche, France. Swiss Journal of Palaeontology 131 (2): 211-253. http://dx.doi.org/10.1007/s13358-012-0044-9

Hess H., Ausich W.I., Brett C.E. \& Simms M.J. 1999. Fossil crinoids. Cambridge University Press, Cambridge.

Hess H. \& Gale A.S. 2010. Crinoids from the Shenley Limestone (Albian) of Leighton Buzzard, Bedfordshire, UK. Journal of Systematic Palaeontology 8 (3): 427-447. http://dx.doi.org/10.1080/1477 $\underline{2019.2010 .484942}$

Hess H. \& Holenweg H. 1985. Die Begleitfauna auf den Seelilienbänken im mittleren Dogger des Schweizer Juras. Tätigkeitsberichte Naturforschende Gesellschaft Baselland 33: 141-177.

Hessler R.R. \& Sanders H.L. 1967. Faunal diversity in the deep-sea. Deep-Sea Research 14 (1): 65-78. http://dx.doi.org/10.1016/0011-7471(67)90029-0

Hofmann K. 1996. Die mikro-endolithischen Spurenfossilien der borealen Oberkreide NordwestEuropas. Geologisches Jahrbuch Reihe A 136, German Geological Survey BGR, Hannover.

Horne D.J. 1999. Ocean circulation modes of the Phanerozoic: implications for the antiquity of deep-sea benthonic invertebrates. Crustaceana 72 (8): 999-1018. http://dx.doi.org/10.1163/156854099503906

Huber B.T., Norris R.D. \& MacLeod K.G. 2002. Deep-sea paleotemperature record of extreme warmth during the Cretaceous. Geology30(2): 123-126.http://dx.doi.org/10.1130/0091-7613(2002)030<0123:DS PROE $>2.0 . \mathrm{CO} ; 2$

Huber B.T. \& Leckie R.M. 2011. Planktic foraminiferal species turnover across deep-sea AptianAlbian boundary sections. Journal of Foraminiferal Research 41 (1): 53-95. http://dx.doi.org/10.2113/ gsjfr.41.1.53

Insalaco E., Hallam A. \& Rosen B. 1997. Oxfordian (Upper Jurassic) coral reefs in western Europe: reef types and conceptual depositional model. Sedimentology 44 (4): 707-734. http://dx.doi. org/10.1046/j.1365-3091.1997.d01-44.x

Ishida Y. 2001. Cenozoic ophiuroids from Japan; particularly those conspecific with extant species. In: J.-P. Féral \& B. David (eds) Echinoderm Research 2001: 53-59. Swets \& Zeitlinger, Lisse.

Ishida Y., Koike H. \& Narita K. 2009. Ophiacantha (Echinodermata: Ophiuroidea) from the middle Miocene Bessho Formation at Azumino City, Nagano Prefecture, central Japan. Research Report of the Shinshushinmachi Fossil Museum 12: 1-6. 
Ishida Y., Yoshii S. \& Thuy B. 2011. Aplocoma sp. (Echinodermata, Ophiuroidea) from the Middle Triassic Yakuno Group of Kyoto, central Japan. Paleontological Research 15 (1): 31-36. http://dx.doi. org/10.2517/1342-8144-15.1.031

Jablonski D. 2005. Evolutionary innovations in the fossil record: the intersection of ecology, development and macroevolution. Journal of Experimental Zoology (Mol Dev Evol) 304B (6): 504-519. http://dx.doi. org/10.1002/jez.b.21075

Jablonski D., Sepkoski J.J., Bottjer D.J. \& Sheehan P.M. 1983. Onshore-offshore patterns in the evolution of Phanerozoic shelf communities. Science 222 (4628): 1123-1125. http://dx.doi.org/10.1126/ science.222.4628.1123

Jacobs D.K. \& Lindberg D.R. 1998. Oxygen and evolutionary patterns in the sea: onshore/offshore trends and recent recruitment of deep-sea faunas. Proceedings of the National Academy of Sciences USA 95 (16): 9396-9401. http://dx.doi.org/10.1073/pnas.95.16.9396

Jagt J.W.M. 1999a. Ophiuroid diversity in the type area of the Maastrichtian Stage. Geologie en Mijnbouw 78 (2): 197-206.

Jagt J.W.M. 1999b. Late Cretaceous-Early Palaeogene echinoderms and the K/T boundary in the southeast Netherlands and northeast Belgium - Part 1: Introduction and stratigraphy. Part 2: Crinoids. Scripta Geologica 116: 1-57, 59-255.

Jagt J.W.M. 2000. Late Cretaceous-Early Palaeogene echinoderms and the K/T boundary in the southeast Netherlands and nordeast Belgium - Part 3: Ophiuroids. With a chapter on Early Maastrichtian ophiuroids from Rügen (northeast Germany) and Møn (Denmark) by Manfred Kutscher \& John W.M. Jagt. Scripta Geologica 121: 1-179.

Jagt J.W.M. \& Odin G.S. 2001. Campanian-Maastrichtian ophiuroids (Echinodermata) from Tercis les Bains (Landes, France). In: Odin G.S. (ed.) The Campanian-Maastrichtian Stage Boundary. Characterisation at Tercis les Bains (France) and correlation with Europe and other continents : 414-420. Developments in Palaeontology and Stratigraphy 19, Elsevier, Amsterdam. http://dx.doi. org/10.1016/S0920-5446(01)80043-1

Jagt J.W.M. \& Riegraf W. 2003. Late cretaceous [sic] ophiuroids from the Münsterland Basin (Germany): preliminary observations. In: Féral J.-P. \& David B. (eds) Echinoderm Research 2001: 61-63. Swets \& Zeitlinger, Lisse.

Jagt J.W.M. \& Jagt-Yazykova E.A. 2012. Stratigraphy of the type Maastrichtian - a synthesis. In: Jagt J.W.M., Donovan S.K. \& Jagt-Yazykova E.A. (eds) Fossils of the type Maastrichtian (Part 1). Scripta Geologica, Special Issue 8: 5-32.

Jagt J.W.M., Thuy B., Donovan S.K., Stöhr S., Portell R.W., Pickerill R.K., Harper D.A.T., Lindsay W. \& Jackson T.A. In press. A starfish bed in the Middle Miocene Grand Bay Formation of Carriacou, The Grenadines (West Indies). Geological Magazine.

Jangoux M. \& Lawrence J.M. (eds) 1982. Echinoderm nutrition. A.A. Balkema Publishers, Rotterdam.

Kashiyama Y. \& Oji T. 2004. Low-diversity shallow marine benthic fauna from the Smithian of northeast Japan: paleoecologic and paleobiogeographic implications. Paleontological Research 8 (3): 199-218. http://dx.doi.org/10.2517/prpsj.8.199

Kerr T.J.V. \& Twitchett R.J. 2004. Experimental decay and disarticulation of Ophiura texturata: implications for the fossil record of ophiuroids. In: Heinzeller T. \& Nebelsick J.H. (eds.) Echinoderms: Proceedings of the Eleventh International Echinoderm Conference (Munich, 2003): 439-445. Taylor and Francis Group, London. 
Koehler R. 1922. Ophiurans of the Philippine Seas and adjacent waters. Smithsonian Institution United States National Museum Bulletin 100, Smithsonian Institution, Washington: http://dx.doi.org/10.5962/ bhl.title.32917

Kozur H. 1972. Die Bedeutung triassischer Ostracoden für stratigraphische und paläoökologische Untersuchungen. Mitteilungen der Gesellschaft der Geologie- und Bergbaustudenten 21: 623-660.

Krebs C.J. 1989. Ecological methodology, Harper \& Row, New York.

Kristan-Tollmann E. \& Gramann F. 1992. Paleontological evidence for the Triassic age of rocks dredged from the northern Exmouth Plateau (Tethyan foraminifers, echinoderms and ostracodes). In: Rad U. von, Haq B.U. et al. (eds) Proceedings of the Ocean Drilling Program, Scientific Results 122: 463-474. College Station, Texas. http://dx.doi.org/10.2973/odp.proc.sr.122.186.1992

Kristan-Tollmann E., Tollmann A. \& Hamedani A. 1979. Beiträge zur Kenntnis der Trias von Persien. Mitteilungen der Österreichischen Geologischen Gesellschaft 70: 119-186.

Kroh A. 2007. Climate changes in the Early to Middle Miocene of the Central Paratethys and the origin of its echinoderm fauna. Palaeogeography, Palaeoclimatology, Palaeoecology 253 (1-2): 169-207. http://dx.doi.org/10.1016/j.palaeo.2007.03.039

Kroh A. \& Harzhauser M. 1999. An echinoderm fauna from the Lower Miocene of Austria: paleoecology and implications for Central Paratethys paleobiogeography. Annalen des Naturhistorischen Museums in Wien A 101: 145-191.

Kucera M. 2007. Planktonic foraminifera as tracers of past oceanic environments. In: HillaireMarcel C. \& de Vernal A. (eds) Developments in marine geology, Volume 1, Proxies in Late Cenozoic paleoceanography: 213-262. Elsevier, Amsterdam. http://dx.doi.org/10.1016/S1572-5480(07)01011-1

Kühn O. 1952. Unsere palaeontologische Kenntnis vom österreichischen Jungtertiär. Verhandlungen der Geologischen Bundesanstalt Sonderheft C: 114-126.

Kummel B. \& Teichert C. 1970. Stratigraphy and paleontology of the Permian-Triassic boundary beds, Salt Range and Trans Indus ranges, West Pakistan. In: Kummel B. \& Teichert C. (eds) Stratigraphic boundary problems: Permian and Triassic of West Pakistan: 1-110. Department of Geology, University of Kansas, Lawrence.

Kutscher M. 1987a. Die Echinodermen der Callovien-Geschiebe. Der Geschiebesammler 21: 50-104.

Kutscher M. 1987b. Aspidura streichani sp. n. - eine neue Ophiuren-Art aus dem Muschelkalk von Rüdersdorf. Zeitschrift für geologische Wissenschaften 15: 703-707.

Kutscher M. 1996. Echinodermata aus dem Ober-Toarcium und Aalenium Deutschlands II. Ophiuroidea. Stuttgarter Beiträge zur Naturkunde Serie B 242: 1-33.

Kutscher M. 2000. Schlangensterne (Ophiuroidea) aus dem Oberen Muschelkalk von Atzendorf bei Magdeburg. Der Aufschluss 51: 301-304.

Kutscher M. \& Hary A. 1991. Echinodermen im Unteren Lias (Bucklandi- und Semicostatum-Zone) zwischen Ellange und Elvange (SE-Luxemburg). Neues Jahrbuch für Geologie und Paläontologie, Abhandlungen 182: 37-72.

Kutscher M. \& Jagt J.W.M. 2000. Early Maastrichtian ophiuroids from Rügen (northeast Germany) and Møn (Denmark). In: Jagt J.W.M. 2000. Late Cretaceous-Early Palaeogene echinoderms and the $\mathrm{K} / \mathrm{T}$ boundary in the southeast Netherlands and the northeast Belgium - Part 3: Ophiuroids. Scripta Geologica 121: 45-107. 
Kutscher M. \& Villier L. 2003. Ophiuroid remains from the Toarcian of Sainte-Verge (Deux-Sèvres, France): paleobiological perspectives. Geobios 36 (2): 179-194. http://dx.doi.org/10.1016/S0016$\underline{6995(03) 00005-6}$

Kutzbach J.E. \& Guetter P.J. 1990. Simulated circulation of an idealized ocean for Pangaean time. Paleoceanography 5 (3): 299-317. http://dx.doi.org/10.1029/PA005i003p00299

Lathuilière B. 2000. Coraux constructeurs du Bajocien inférieur de France. 1ère partie. Geobios 33 (1): 51-72. http://dx.doi.org/10.1016/S0016-6995(00)80149-7

Lauridsen B.W., Bjerager M. \& Surlyk F. 2012. The middle Danian Fakse Formation - new lithostratigraphic unit and a rare taphonomic window into the Danian of Denmark. Bulletin of the Geological Society of Denmark 60 : 47-60.

Lindner A., Cairns S.D. \& Cunningham C.W. 2008. From offshore to onshore: multiple origins of shallow-water corals from deep-sea ancestors. PLOS ONE 3(6): e2429. http://dx.doi.org/10.1371/ journal.pone.0002429

Loriol P. de. 1872. Description géologique et paléontologique des étages jurassiques supérieurs de la Haute-Marne. Mémoires de la Société Linnéenne de Normandie 16, Savy, Paris.

Lucius M. 1948. Das Gutland. Erläuterungen zur geologischen Spezialkarte Luxemburgs. Publications du Service géologique du Luxembourg 5, Luxembourg-

Lukeneder A. 2004. The Olcostephanus Level: an Upper Valanginian ammonoid mass-occurrence (Lower Cretaceous, Northern Calcareous Alps, Austria). Acta Geologica Polonica 54 (1): 23-33.

Lukeneder A. 2011. Barremian ammonoids from Serre de Bleyton (Drôme, SE France). Annalen des Naturhistorischen Museums in Wien A 112: 613-626.

Madsen F.J. 1961. On the zoogeography and origin of the abyssal fauna. Galathea Reports 4: 177-218.

Martens E. von. 1867. Über eine neue zwischen den Ophiuren und Euryalen die Mitte haltende Gattung von Seesternen, Hemieuryale. Sitzungsberichte der preussischen Akademie der Wissenschaften, physikalisch-mathematische Klasse 1867: 481-486.

Martynov A. 2010. Reassessment of the classification of the Ophiuroidea (Echinodermata), based on morphological characters. I. General character evaluation and delineation of the families Ophiomyxidae and Ophiacanthidae. Zootaxa 2697: 1-154.

Martynov A. \& Litvinova N.M. 2008. Deep-water Ophiuroidea of the northern Atlantic with descriptions of three new species and taxonomic remarks on certain genera and species. Marine Biology Research 4 (1-2): 76-111. http://dx.doi.org/10.1080/17451000701840066

Matsumoto H. 1917. A monograph of Japanese Ophiuroidea, arranged according to a new classification. Journal of the College Science, Imperial University Tokyo 38: 1-408.

McClain C.R. \& Mincks Hardy S. 2010. The dynamics of biogeographic ranges in the deep sea. Proceedings of the Royal Society B 277 (1700): 3533-3546. http://dx.doi.org/10.1098/rspb.2010.1057

McClintock J.B. 1994. Trophic biology of Antarctic shallow-water echinoderms. Marine Ecology Progress Series 111: 191-202. http://dx.doi.org/10.3354/meps111191

McClintock J.B., Baker B.J., Baumiller T. \& Messing C.G. 1999. Lack of chemical defense in two species of stalked crinoids: support for the predation hypothesis for Mesozoic bathymetric restriction. Journal of Experimental Marine Biology and Ecology 232 (1): 1-7. http://dx.doi.org/10.1016/S00220981(98)00003-3 
Menzies R.J., George R.Y. \& Rowe G.T. 1973. Abyssal environment and ecology of the world oceans. New York, Wiley-Interscience.

Merle D. (ed.) 2008. Stratotype Lutétien. Patrimoine géologique 1, Muséum national d'Histoire naturelle, Paris; Biotope, Mèze; BRGM, Orléans.

Metaxas A. \& Giffin B. 2004. Dense beds of the ophiuroid Ophiacantha abyssicola on the continental slope off Nova Scotia, Canada. Deep-Sea Research I 51 (10): 1307-1317. http://dx.doi.org/10.1016/j. dsr.2004.06.001

Miglietta M.P., Faucci A. \& Santini F. 2011. Speciation in the sea: overview of the Symposium and Discussion of Future Directions. Integrative and Comparative Biology 51 (3): 449-455. http://dx.doi. org/10.1093/icb/icr024

Miller K.J., Rowden A.A., Williams A. \& Häussermann V. 2011. Out of their depth? Isolated deep populations of the cosmopolitan coral Desmophyllum dianthus may be highly vulnerable to environmental change. PLoS ONE 6 (5): e19004. http://dx.doi.org/10.1371/journal.pone.0019004

Mortensen T. 1927 [1977]. Handbook of the echinoderms of the British Isles. Backhuys, Rotterdam. http://dx.doi.org/10.5962/bhl.title.6841

Mortensen T. 1936. Echinoidea and Ophiuroidea. Discovery Reports 12: 199-348.

Moseley H.N. 1880. Deep-sea dredging and life in the deep sea. Nature 21 (545): 543-547. http://dx.doi. $\underline{\operatorname{org} / 10.1038 / 021543 \mathrm{a} 0}$

Moura C.J., Cunha M.R., Porteiro F.M., Yesson C. \& Rogers A.D. 2012. Evolution of Nemertesia hydroids (Cnidaria: Hydrozoa, Plumulariidae) from the shallow and deep waters of the NE Atlantic and Western Mediterranean. Zoologica Scripta 41 (1): 79-96. http://dx.doi.org/10.1111/j.1463-6409.2011.00503.x

Murray J.W. \& Wright C.A. 1974. Palaeogene Foraminiferida and palaeoecology: Hampshire and Paris Basins, and the English Channel. Special Papers in Palaeontology 14, Palaeontological Association, London:

Mutterlose J. 1997. Gott clay-pit near Sarstedt. In: Mutterlose J., Wippich M.G.E. \& Geisen M. (eds) Cretaceous depositional environments of NW Germany: 63-76. Bochumer Geologische und geotechnische Arbeiten 46, Institut für Geologie der Ruhr-Universität Bochum, Bochum.

Nebelsick J.H. 1992. Echinoid distribution by fragment identification in the northern Bay of Safaga, Red Sea, Egypt. Palaios 7 (3): 316-328. http://dx.doi.org/10.2307/3514976

Nebelsick J.H. 1996. Biodiversity of shallow-water Red Sea echinoids: implications for the fossil record. Journal of the Marine Biological Association of the United Kingdom 76 (1): 185-194. http:// dx.doi.org/10.1017/S0025315400029118

Norris R.D., Kroon D., Klaus A. et al. 1998. Proceedings of the Ocean Drilling Program, Initial Reports 171B. College Station, TX (Ocean Drilling Program).

O’Hara T.D. \& Stöhr S. 2006. Deep water Ophiuroidea (Echinodermata) of New Caledonia: Ophiacanthidae and Hemieuryalidae. In: Richer de Forges B. \& Justine J.-L. (eds) Tropical DeepSea Benthos 24: 33-141. Mémoires du Muséum national d'Histoire naturelle 193, Muséum national d'Histoire naturelle, Paris.

Ogg J., Ogg G. \& Gradstein F.M. 2008. The concise geologic time scale. Cambridge University Press, Cambridge.

Oji T. 1996. Is predation intensity reduced with increasing depth? Evidence from the West Atlantic stalked crinoid Endoxocrinus parrae (Gervais) and implications for the Mesozoic marine revolution. Paleobiology 22 (3): 339-351. 
Olivier N., Hantzpergue P., Gaillard C., Pittet B., Leinfelder R.R., Schmid D.U. \& Werner W. 2003. Microbialite morphology, structure and growth: a model of the Upper Jurassic reefs of the Chay Peninsula (western France). Palaeogeography, Palaeoclimatology, Palaeoecology 193 (3-4): 383-404. http://dx.doi.org/10.1016/S0031-0182(03)00236-0

Olivier N., Pittet B. \& Mattioli E. 2004. Palaeoenvironmental control on sponge-microbialite reefs and contemporaneous deep-shelf marl-limestone deposition (Late Oxfordian, southern Germany). Palaeogeography, Palaeoclimatology, Palaeoecology 212 (3-4): 233-263. http://dx.doi.org/10.1016/j. palaeo.2004.06.003

Orbigny A.D. d' 1850. Prodrome du paléontologie stratigraphique universelle des animaux mollusques et rayonnés faisant suite au cours élémentaire de paléontologie et de géologie stratigraphique. Masson, Paris.

Paterson G.L.J. 1985. The deep-sea Ophiuroidea of the North Atlantic Ocean. Bulletin of the British Museum (Natural History), Zoology Series 49, British Museum, London.

Peckmann J., Kiel S., Sandy M.R., Taylor D.G. \& Goedert J.L. 2011. Mass occurrences of the brachiopod Halorella in Late Triassic methane-seep deposits, eastern Oregon. Journal of Geology 119 (2): 207-220. http://dx.doi.org/10.1086/658199

Pflaumann U., Duprat J., Pujol C. \& Labeyrie L. 1996. SIMMAX: a modern analog technique to deduce Atlantic sea surface temperatures from planktonic foraminifera in deep-sea sediments. Paleoceanography 11 (1): 15-35. http://dx.doi.org/10.1029/95PA01743

Pieńkowski G., Schudack M.E., Bosák P., Enay R., Feldman-Olszewska A., Golonka J., Gutowski J., Herngreen G.F.W., Jordan P., Krobicki M., Lathuilière B., Leinfelder R.R., Michalik J., Mönnig E., Noe-Nygaard N., Pálfy J., Pint A., Rasser M.W., Reisdorf A.G., Schmid D.U., Schweigert G., Surlyk F., Wetzel A. \& Wong T.E. 2008. Jurassic. In: McCann T. (ed.) The geology of central Europe 2: Mesozoic and Cenozoic: 823-922. The Geological Society, London.

Radwański A. 2002. Triassic brittlestar beds of Poland: a case of Aspiduriella ludeni (v. Hagenow, 1846) and Arenorbis squamosus (E. Picard, 1858). Acta Geologica Polonica 52 (4): 395-410.

Rasmussen H.W. 1952. Cretaceous Ophiuroidea from Germany, Sweden, Spain and New Jersey. Meddelelser fra Dansk Geologisk Forening 12 (1951): 47-57.

Rasmussen H.W. 1972. Lower Tertiary Crinoidea, Asteroidea and Ophiuroidea from northern Europe and Greenland. Biologiske Skrifter 19, Det kongelige Danske Videnskabernes Selskab, Copenhagen-

Reich M. \& Frenzel P. 2002. Die Fauna und Flora der Rügener Schreibkreide (Maastrichtium, Ostsee). Archiv fur Geschiebekunde 3 (2/4): 73-284.

Reisdorf A.G., Wetzel A., Schlatter R. \& Jordan P. 2011. The Staffelegg Formation: a new stratigraphic scheme for the Early Jurassic of northern Switzerland. Swiss Journal of Geosciences 104 (1): 97-146. http://dx.doi.org/10.1007/s00015-011-0057-1

Rex M.A. \& Etter R.J. 2010. Deep-sea biodiversity: pattern and scale. Harvard University Press, Cambridge.

Ricklefs R.E. \& Schluter D. 1993. Species diversity: regional and historical influences. In: Ricklefs R.E. \& Schluter D. (eds) Species diversity in ecological communities: 350-363. University of Chicago Press, Chicago.

Rogers A.D. 2000. The role of the oceanic oxygen minima in generating biodiversity in the deep sea. Deep-Sea Research II 47 (1-2): 119-148. http://dx.doi.org/10.1016/S0967-0645(99)00107-1 
Rögl F. Córić S., Harzhauser M., Jimenez-Moreno G., Kroh A., Schultz O., Wessely G. \& Zorn I. 2008. The Middle Miocene Badenian stratotype at Baden-Sooss (Lower Austria). Geologica Carpathica 59 (5): 367-374.

Ropolo P., Moullade M., Gonnet R., Conte G. \& Tronchetti G. 2006. The Deshayesitidae Stoyanov, 1949 (Ammonoidea) of the Aptian historical stratotype region at Cassis-La Bédoule (SE France). Carnets de Géologie/Notebooks on Geology 2006/01: 1-46. http://dx.doi.org/10.4267/2042/4744

Runnegar B. 1969. A Lower Triassic ammonoid fauna from south-east Queensland. Journal of Paleontology 43: 818-828.

Russo F. 2005. Biofacies evolution in the Triassic platforms of the Dolomites, Italy. Annali dell'Università degli Studi di Ferrara, Museologia Scientifica e Naturalistica, volume speciale 2005: 33-45.

Salamon M. 2004. High-density populations of the Triassic ophiuroid Aspiduriella ludeni (Hagenow) in the Holy Cross Mountains (central Poland). Freiberger Forschungshefte 12: 1-7.

Sanders H.L. 1968. Marine benthic diversity: a comparative study. The American Naturalist 102 (925): 243-282. http://dx.doi.org/10.1086/282541

Schmid D.U., Leinefelder R.R. \& Nose M. 2001. Growth dynamics and ecology of Upper Jurassic mounds, with comparisons to Mid-Palaeozoic mounds. Sedimentary Geology 145 (3-4): 343-376. http:// dx.doi.org/10.1016/S0037-0738(01)00157-9

Schneider S., Fürsich F.T. \& Werner W. 2009. Sr-isotope stratigraphy of the Upper Jurassic of central Portugal (Lusitanian Basin) based on oyster shells. International Journal of Earth Sciences 98 (8): 1949-1970. http://dx.doi.org/10.1007/s00531-008-0359-3

Schönfeld J. 1990. Zur Stratigraphie und Ökologie benthischer Foraminiferen im SchreibkreideRichtprofil von Lägerdorf/Holstein. Geologisches Jahrbuch A 117, German Geological Survey BGR, Hannover. 1-151.

Schulz M.-G., Ernst H. \& Weitschat W. 1984. Stratigraphie und Fauna der Ober-Kreide (Coniac Maastricht) von Lägerdorf und Kroonsmoor (Holstein). In: Degens E.T. Exkursionsführer Erdgeschichte des Nordsee- und Ostseeraumes: 483-517. Geologisch-Paläontologisches Institut der Universität Hamburg, Hamburg.

Simms M.J., Chidlaw N., Morton N. \& Page K.N. 2004. British Lower Jurassic stratigraphy. Geological Conservation Review Series 30, Joint Nature Conservation Committee, Peterborough.

Scotese C.R. 1991. Jurassic and Cretaceous plate tectonic reconstructions. Palaeogeography, Palaeoclimatology, Palaeoecology 87 (1-4): 493-501. http://dx.doi.org/10.1016/0031-0182(91)90145-H

Smith A.B. 2011. Gymnodiadema and the Jurassic roots of the Arbacioida (stirodont echinoids). Swiss Journal of Palaeontology 130 (1): 155-171. http://dx.doi.org/10.1007/s13358-010-0014-z

Smith A.B., Paterson G.L.J. \& Lafay B. 1995. Ophiuroid phylogeny and higher taxonomy: morphological, molecular and palaeontological perspectives. Zoological Journal of the Linnean Society 114 (2): 213243. http://dx.doi.org/10.1111/j.1096-3642.1995.tb00117c.x

Smith A.B. \& Rader W.I. 2009. Echinoid diversity, preservation potential and sequence stratigraphical cycles in the Glen Rose Formation (early Albian, Early Cretaceous), Texas, USA. Palaeobiodiversity and Palaeoenvironments 89 (1-2): 7-52. http://dx.doi.org/10.1007/s12549-009-0002-8

Smith A.G., Smith D.G., \& Funnell B.M. 1994. Atlas of Mesozoic and Cenozoic Coastlines. Cambridge University Press, Cambridge. 
Smith A.B. \& Stockley B. 2005. The geological history of deep-sea colonization by echinoids: roles of surface productivity and deep-water ventilation. Proceedings of the Royal Society B 272 (1565): 865869. http://dx.doi.org/10.1098/rspb.2004.2996

Stöhr S. 2005. Who's who among baby brittle stars (Echinodermata, Ophiuroidea): postmetamorphic development of some North Atlantic forms. Zoological Journal of the Linnean Society 143 (4): 543-576. http://dx.doi.org/10.1111/j.1096-3642.2005.00155.x

Stöhr S. 2011. New records and new species of Ophiuroidea (Echinodermata) from Lifou, Loyalty Islands, New Caledonia. Zootaxa 3089: 1-50.

Stöhr S. \& O’Hara T.D. 2007. World Ophiuroidea database. Available from http://www.marinespecies. org/ophiuroidea [accessed on 14 Jun. 2012].

Stöhr S., O’Hara T.D. \& Thuy B. 2012. Global diversity of brittle stars (Echinodermata: Ophiuroidea). PLoS One 7(3): e31940. http://dx.doi.org/10.1371/journal.pone.0031940

Štorc R. 2004. The Late Cretaceous brittle star Ophiosmilax? alternatus from Europe and northern Africa. Geobios 37 (3): 395-401. http://dx.doi.org/10.1016/j.geobios.2003.01.010

Štorc R. \& Žítt J. 2008. Late Turonian ophiuroids (Echinodermata) from the Bohemian Cretaceous Basin, Czech Republic. Bulletin of Geosciences 83 (2): 123-140. http://dx.doi.org/10.3140/bull. geosci.2008.02.123

Stöver B.C. \& Müller K. 2010. TreeGraph 2: combining and visualizing evidence from different phylogenetic analyses. BMC Bioinformatics 11 (1): 1-7. http://dx.doi.org/10.1186/1471-2105-11-7

Strugnell J.M., Rogers A.D., Prodöhl P.A., Collins M. \& Allcock A.L. 2008. The thermohaline expressway: the Southern Ocean as a centre of origin for deep-sea octopuses. Cladistics 24 (6): 853 860. http://dx.doi.org/10.1111/j.1096-0031.2008.00234.x

Summesberger H. 1997. Postconference Excursion 2. The Cretaceous of the Grünbach - Neue Welt Basin. In: Kollmann H.A. \& Hubmann B. (eds) Climates: past, present and future: 77-89. Second European Palaeontological Congress, Excursion Guides, Vienna.

Surlyk F. \& Sørensen A.M. 2010. An early Campanian rocky shore at Ivö Klack, southern Sweden. Cretaceous Research 31 (6): 567-576. http://dx.doi.org/10.1016/j.cretres.2010.07.006

Swofford D. L. 2005. PAUP*. Phylogenetic analysis using parsimony (*and other methods). Version 4.0b10. Sinauer Associates, Sunderland.

Thuy B. 2005. Les Ophiures de l'Hettangien inférieur de Vance (B), Bereldange/Bridel et Bourglinster (L). In : Delsate D. (éd.) Biostratigraphie et Paléontologie de l'Hettangien en Belgique et au GrandDuché de Luxembourg: 33-57. Memoirs of the Geological Survey of Belgium 51, Royal Belgian Institute of Natural Sciences, Brussels.

Thuy B. 2011. Exceptionally well-preserved brittle stars from the Pliensbachian (Early Jurassic) of the French Ardennes. Palaeontology 54 (1): 215-233. http://dx.doi.org/10.1111/j.1475-4983.2010.00981.x

Thuy B., Gale A.S. \& Reich M. 2011. A new echinoderm Lagerstätte from the Pliensbachian (Early Jurassic) of the French Ardennes. Swiss Journal of Palaeontology 130 (1): 173-185. http://dx.doi. org/10.1007/s13358-010-0015-y

Thuy B., Ishida Y., Doi E. \& Kroh A. 2012. New ophiacanthid brittle stars (Echinodermata: Ophiuroidea) from the Upper Triassic of Japan: first insights into the origin and evolution of an extant deep-sea group. Journal of Systematic Palaeontology.

Thuy B. \& Kroh A. 2011. Barremian ophiuroids from the Serre de Bleyton (Drôme, SE France). Annalen des Naturhistorischen Museums in Wien A 113: 777-807. 
THUY B., Fossil record of ophiacanthid brittle stars

Thuy B. \& Meyer C.A. 2013. The pitfalls of extrapolating present-day depth ranges to fossil communities: new insights from brittle stars (Echinodermata: Ophiuroidea) from the Middle Jurassic of Switzerland. Swiss Journal of Palaeontology 132 (1): 5-21. http://dx.doi.org/10.1007/s13358-012-0048-5

Thuy B. \& Schulz H. In Press. The oldest representative of a modern deep-sea ophiacanthid brittle-star clade from Jurassic shallow-water coral reef sediments. Acta Palaeontologica Polonica http://dx.doi. org/10.4202/app.2011.0192

Thuy B. \& Stöhr S. 2011. Lateral arm plate morphology in brittle stars (Echinodermata: Ophiuroidea): new perspectives for ophiuroid micropalaeontology and classification. Zootaxa 3013: 1-47.

Tipper J.C. 1979. Rarefaction and rarefiction - the use and abuse of a method in paleoecology. Paleobiology 5: 423-434.

Twitchett R.J., Feinberg J.M., O’Connor D.D., Alvarez W. \& McCollum L. 2005. Early Triassic ophiuroids: their paleoecology, taphonomy and distribution. Palaios 20 (3): 213-223.

Twitchett R.J. \& Oji T. 2005. The Early Triassic recovery of echinoderms. Comptes Rendus Palevol 4 (6-7): 531-542. http://dx.doi.org/10.1016/j.crpv.2005.02.006

Tyler P.A. 1980. Deep-sea ophiuroids. Oceanography and Marine Biology Annual Review 18: 125-153.

Tyler P.A. \& Young C.M. 1998. Temperature and pressure tolerances in dispersal stages of the genus Echinus (Echinodermata: Echinoidea): prerequisites for deep-sea invasion and speciation. Deep-Sea Research II 45 (1-3): 253-277. http://dx.doi.org/10.1016/S0967-0645(97)00091-X

Vermeij G.J. 1977. The Mesozoic Marine Revolution; evidence from snails, predators and grazers. Paleobiology 3 (3): 245-258.

Vermeij G.J. 1987. Evolution and escalation: an ecological history of life. Princeton University Press, Princeton.

Vermeij G.J. 1995. Economics, volcanos, and Phanerozoic revolutions. Paleobiology 21 (2): 125-152.

Vörös A. (ed.) 2003. The Pelsonian Substage on the Balaton Highland (Middle Triassic, Hungary). Geologica Hungarica, Series Palaeontologica 55: 1-50.

Vörös A. 2005. The smooth brachiopods of the Mediterranean Jurassic: refugees or invaders? Palaeogeography, Palaeoclimatology, Palaeoecology 223 (3-4): 222-242. http://dx.doi.org/10.1016/j. palaeo.2005.04.006

Vortisch W. 1970. Die Geologie des Glasenbachtales südlich von Salzburg. Geologica et Palaeontologica 4: 147-166.

Wendt J., Wu X. \& Reinhardt W. 1989. Deep-water hexactinellid sponge mounds from the Upper Triassic of northern Sichuan (China). Palaeogeography, Palaeoclimatology, Palaeoecology 76 (1-2): 17-29. http://dx.doi.org/10.1016/0031-0182(89)90100-4

Wiese F., Čech S., Ekrt B., Košt'ak M., Mazuch M. \& Voigt S. 2004. The Upper Turonian of the Bohemian Cretaceous Basin (Czech Republic) exemplified by the Úpohlavy working quarry: integrated stratigraphy and palaeoceanography of a gateway to the Tethys. Cretaceous Research 25 (3): 329-352. http://dx.doi.org/10.1016/j.cretres.2004.01.003

Wilmsen M. 2005. Stratigraphy and biofacies of the Lower Aptian of Cuchía (Cantabria, northern Spain). Journal of Iberian Geology 31: 253-275.

Wilson G.D.F. 1999. Some of the deep-sea fauna is ancient. Crustaceana 72 (8): 1019-1030. http:// dx.doi.org/10.1163/156854099503915 
Wolf T. 1960. The hadal community, an introduction. Deep-Sea Research 6: 95-124. http://dx.doi. org/10.1016/0146-6313(59)90063-2

Yang Z. 1960. On the discovery of a Scythian ophiuroid from Kueichou, China. Acta Palaeontologica Sinica 8: 159-163.

Young J.R., Gale A.S., Knight R.I. \& Smith A.B. 2010. Fossils of the Gault Clay. Field Guide to Fossils 12, Palaeontological Association, London.

Young C.M., Tyler P.A. \& Fenaux L. 1997. Potential for deep sea invasion by Mediterranean shallow water echinoids: pressure and temperature as stage-specific dispersal barriers. Marine Ecology Progress Series 154: 197-209. http://dx.doi.org/10.3354/meps154197

Zágoršek K. \& Kroh A. 2003. Cretaceous Bryozoa from Scharrergraben (Santonian, Gosau Group, Eastern Alps). Geologica Carpathica 54 (6): 1-13.

Zapfe H. 1967. Beiträge zur Paläontologie der nordalpinen Riffe. Die Fauna der Zlambach-Mergel der Fischerwiese bei Aussee, Steiermark. Annalen des Naturhistorischen Museums in Wien 71: 413-480.

Zatoń M., Salamon M.A., Boczarowski A. \& Sitek S. 2008. Taphonomy of dense ophiuroid accumulations from the Middle Triassic of Poland. Lethaia 41 (1): 47-58. http://dx.doi.org/10.1111/ j.1502-3931.2007.00041.x

Zenkevitch L.A. \& Birstein J.A. 1960. On the problem of the antiquity of the deep-sea fauna. Deep-Sea Research 7 (1): 10-23. http://dx.doi.org/10.1016/0146-6313(60)90003-4

Zonneveld J.-P. 2001. Middle Triassic biostromes from the Liard Formation, British Columbia, Canada: oldest examples from the Mesozoic of NW Pangea. Sedimentary Geology 145 (3-4): 317-341. http:// dx.doi.org/10.1016/S0037-0738(01)00154-3

Manuscript received: 1 November 2012

Manuscript accepted: 20 March 2013

Published on: 2 July 2013

Topic editor: Christian de Muizon

Desk editor: Charlotte Thionois

Printed versions of all papers are also deposited in the libraries of the institutes that are members of the EJT consortium: Muséum National d'Histoire Naturelle, Paris, France; National Botanic Garden of Belgium, Meise, Belgium; Royal Museum for Central Africa, Tervuren, Belgium; Natural History Museum, London, United Kingdom; Royal Belgian Institute of Natural Sciences, Brussels, Belgium; Natural History Museum of Denmark, Copenhagen, Denmark. 
Appendix 1. Faunal list for the assemblages studied with corresponding counts of lateral arm plates or articulated individual (art.). Note that previously published assemblages which lack ophiacanthids or for which no significant taxonomic changes or new counts are proposed have been omitted. Records marked with an asterisk (*) are not described in the present study.

\begin{tabular}{|c|c|c|}
\hline \multicolumn{3}{|c|}{ SHALLOW-WATER ASSEMBLAGES } \\
\hline Locality & Taxon & LAP count \\
\hline Baden & non-ophiacanthids & 111 \\
\hline Rauchstallbrunngraben & non-ophiacanthids & 208 \\
\hline \multirow[t]{2}{*}{ Mannersdorf } & Ophiotreta sp. nov. innom 2 & 4 \\
\hline & non-ophiacanthids & 467 \\
\hline Wiesfleck & non-ophiacanthids & 549 \\
\hline \multirow[t]{2}{*}{ Stotzing 1} & Ophiotreta sp. nov. innom 2 & 1 \\
\hline & non-ophiacanthids & 103 \\
\hline Stotzing 3 & non-ophiacanthids & 86 \\
\hline Obernalb & non-ophiacanthids & 214 \\
\hline \multirow[t]{2}{*}{ Grignon } & Ophiotreta hedone sp. nov. & 122 \\
\hline & non-ophiacanthids & 604 \\
\hline Eben Emael & non-ophiacanthids & 393 \\
\hline \multirow[t]{2}{*}{ Maastricht } & Ophiomitrella sp. nov. innom. $1^{*}$ & 1 (art) \\
\hline & non-ophiacanthids & 31 (art) \\
\hline \multirow[t]{9}{*}{ Rügen } & Ophiologimus rugosus comb. nov. & 50 \\
\hline & Ophiotreta striata comb. nov. & 216 \\
\hline & Ophiogaleus danicus comb. nov. & 332 \\
\hline & Manfredura curvata comb. nov. & 416 \\
\hline & Ophiochondrus punctatus comb. nov. & 260 \\
\hline & Ophiochondrus? semirotundus comb. nov. & 32 \\
\hline & Ophiojagtus alternatus comb. nov. & 34 \\
\hline & Ophiacanthidae gen. et sp. $1^{*}$ & 3 \\
\hline & non-ophiacanthids & 13479 \\
\hline \multirow[t]{4}{*}{ Lägerdorf-Kronsmoor } & Ophiotreta striata comb. nov. & 2 \\
\hline & Ophiogaleus danicus comb. nov. & 16 \\
\hline & Manfredura curvata comb. nov. & 3 \\
\hline & non-ophiacanthids & 1689 \\
\hline \multirow[t]{2}{*}{ Haccourt (Maastr.) } & Ophiojagtus alternatus comb. nov. & 15 \\
\hline & non-ophiacanthids & 953 \\
\hline Aachen & non-ophiacanthids & 690 \\
\hline \multirow[t]{2}{*}{ Haccourt (Camp.) } & Ophiologimus rugosus comb. nov. & 1 \\
\hline & non-ophiacanthids & 256 \\
\hline \multirow[t]{3}{*}{ Lägerdorf-Alsen } & Ophiacantha reginae sp. nov. & 4 \\
\hline & Ophiojagtus alternatus comb. nov. & 2 \\
\hline & non-ophiacanthids & 584 \\
\hline Ivö Klack & non-ophiacanthids & 426 \\
\hline Piesting & non-ophiacanthids & 239 \\
\hline \multirow[t]{2}{*}{ Waco } & Ophiojagtus sp. 1 & 1 \\
\hline & non-ophiacanthids & 432 \\
\hline Saginaw & non-ophiacanthids & 392 \\
\hline Folkestone (level 6) & non-ophiacanthids & 206 \\
\hline \multirow[t]{3}{*}{ Folkestone (level 2) } & Lapidaster mathcore sp. nov. & 8 \\
\hline & Ophiacantha sp. nov. innom. 3 & 4 \\
\hline & non-ophiacanthids & 96 \\
\hline \multirow[t]{2}{*}{ Leighton Buzzard } & Dermocoma sp. nov. innom. 4 & 1 \\
\hline & non-ophiacanthids & 198 \\
\hline \multirow[t]{2}{*}{ Wizard Way } & Ophiojagtus acklesi sp. nov. & 70 \\
\hline & non-ophiacanthids & 380 \\
\hline \multirow[t]{2}{*}{ Cuchía } & Ophiojagtus sp. $2^{*}$ & 2 \\
\hline & non-ophiacanthids & 171 \\
\hline
\end{tabular}


European Journal of Taxonomy 48: 1-242 (2013)

\begin{tabular}{|c|c|c|}
\hline \multirow[t]{3}{*}{ Sarstedt } & Ophiacantha jaegeri sp. nov. & 9 \\
\hline & Ophiomalleus stevenwilsoni sp. nov. & 10 \\
\hline & non-ophiacanthids & 335 \\
\hline \multirow[t]{5}{*}{ Trancoso } & Ophiolimna lisae sp. nov. & 81 \\
\hline & Krohcoma ampla sp. nov. & 14 \\
\hline & Dermocoma simonschneideri sp. nov. & 17 \\
\hline & Ophiojagtus irimurai sp. nov. & 1 \\
\hline & non-ophiacanthids & 246 \\
\hline \multirow[t]{6}{*}{ Geisingen } & Lapidaster mastodon sp. nov. & 2 \\
\hline & Lapidaster sp. nov. innom. 2 & 1 \\
\hline & Ophiogaleus sp. & 3 \\
\hline & Dermocoma sp. nov. innom. 2 & 1 \\
\hline & Dermacantha carli sp. nov. & 64 \\
\hline & non-ophiacanthids & 824 \\
\hline \multirow[t]{7}{*}{ Pointe du Chay } & Ophiotoma charlottae sp. nov. & 6 \\
\hline & Ophiolimna lisae sp. nov. & 1 \\
\hline & Krohcoma ampla sp. nov. & 3 \\
\hline & Alternacantha dilionessa sp. nov. & 532 \\
\hline & Dermocoma simonschneideri sp. nov. & 1 \\
\hline & Ophiojagtus irimurai sp. nov. & 7 \\
\hline & non-ophiacanthids & 330 \\
\hline \multirow[t]{7}{*}{ Plettenberg } & Lapidaster mastodon sp. nov. & 197 \\
\hline & Ophiotreta stefaniae sp. nov. & 57 \\
\hline & Ophiogaleus sp. & 3 \\
\hline & Dermacantha carli sp. nov. & 303 \\
\hline & Sabinacantha archetypa sp. nov. & 6 \\
\hline & Ophiacanthidae gen. et sp. nov innom. & 3 \\
\hline & non-ophiacanthids & 846 \\
\hline \multirow[t]{2}{*}{ Guldental (Hess 1975a) } & Dermocoma biformis comb. nov. & 122 \\
\hline & non-ophiacanthids & 562 \\
\hline \multirow[t]{2}{*}{ Raedersdorf } & Dermocoma biformis comb. nov. & 14 \\
\hline & non-ophiacanthids & 1962 \\
\hline \multirow[t]{6}{*}{ Savigna (S1) } & Ophiogaleus constrictus comb. nov. & 7 \\
\hline & Alternacantha schwermannorum sp. nov. & 47 \\
\hline & Dermocoma biformis comb. nov. & 36 \\
\hline & Ophiocamax dorotheae sp. nov. & 6 \\
\hline & Ophiojagtus argoviensis comb. nov. & 1 \\
\hline & non-ophiacanthids & 124 \\
\hline \multirow[t]{6}{*}{ Savigna (S2a) } & Ophiogaleus constrictus comb. nov. & 16 \\
\hline & Alternacantha schwermannorum sp. nov. & 105 \\
\hline & Dermocoma biformis comb. nov. & 138 \\
\hline & Ophiocamax dorotheae sp. nov. & 8 \\
\hline & Ophiojagtus argoviensis comb. nov. & 2 \\
\hline & non-ophiacanthids & 781 \\
\hline \multirow[t]{6}{*}{ Savigna (S2b) } & Ophiogaleus constrictus comb. nov. & 90 \\
\hline & Alternacantha schwermannorum sp. nov. & 182 \\
\hline & Dermocoma biformis comb. nov. & 63 \\
\hline & Ophiocamax dorotheae sp. nov. & 42 \\
\hline & Ophiojagtus argoviensis comb. nov. & 4 \\
\hline & non-ophiacanthids & 782 \\
\hline \multirow[t]{4}{*}{ Guldental (Hess 1966) } & Ophiogaleus constrictus comb. nov. & 22 \\
\hline & Dermocoma biformis comb. nov. & 33 \\
\hline & Ophiocamax dorotheae sp. nov. & 1 \\
\hline & Ophiojagtus argoviensis comb. nov. & 2 \\
\hline \multirow[t]{2}{*}{ Foug } & Dermocoma numbergerorum sp. nov. & 205 \\
\hline & non-ophiacanthids & 163 \\
\hline Chapois & Lapidaster etteri sp. nov. & 7 \\
\hline
\end{tabular}


THUY B., Fossil record of ophiacanthid brittle stars

\begin{tabular}{|c|c|c|}
\hline & Ophiogaleus constrictus comb. nov. & 4 \\
\hline & Dermocoma biformis comb. nov. & 11 \\
\hline & Ophiocamax dorotheae sp. nov. & 26 \\
\hline & non-ophiacanthids & 316 \\
\hline \multirow[t]{4}{*}{ Longecombe } & Lapidaster etteri sp. nov. & 307 \\
\hline & Ishidacantha trispinosa comb. nov. & 8 \\
\hline & Ophiocamax dorotheae sp. nov. & 2 \\
\hline & non-ophiacanthids & 221 \\
\hline \multirow[t]{3}{*}{ Jumara (117) } & Lapidaster varuna sp. nov. & 81 \\
\hline & Ishidacantha fuersichi $\mathrm{sp}$. nov. & 30 \\
\hline & non-ophiacanthids & 91 \\
\hline \multirow[t]{3}{*}{ Jumara (119) } & Lapidaster varuna sp. nov. & 14 \\
\hline & Ishidacantha fuersichi sp. nov. & 28 \\
\hline & non-ophiacanthids & 3 \\
\hline \multirow[t]{4}{*}{ Jumara (121) } & Lapidaster varuna sp. nov. & 12 \\
\hline & Ophiogaleus sp. nov. innom. 2 & 1 \\
\hline & Ishidacantha fuersichi $\mathrm{sp}$. nov. & 89 \\
\hline & non-ophiacanthids & 57 \\
\hline \multirow[t]{4}{*}{ Jumara (95) } & Ophiogaleus sp. nov. innom. 2 & 22 \\
\hline & Hanshessia sp. & 3 \\
\hline & Alternacantha sp. nov. innom. 2 & 2 \\
\hline & Dermocoma sp. 1 & 2 \\
\hline \multirow[t]{4}{*}{ Jumara (31) } & Ophiolimna malagasica sp. nov. & 6 \\
\hline & Ophiogaleus sp. nov. 2 & 1 \\
\hline & Ophiacanthidae gen. et sp. $2^{*}$ & 8 \\
\hline & non-ophiacanthids & 10 \\
\hline \multirow[t]{3}{*}{ Althüttendorf } & Ophiomitrella? sp. nov. 1 & 1 \\
\hline & Ophiomalleus beneficarum sp. nov. & 7 \\
\hline & non-ophiacanthids & 311 \\
\hline \multirow[t]{5}{*}{ Bauer-Wehrland } & Hanshessia sp. nov. innom. 2 & 1 \\
\hline & Dermocoma wrighti Hess, 1964 & 3 \\
\hline & Ophiomitrella? sp. 1 & 11 \\
\hline & Ophiomalleus beneficarum sp. nov. & 19 \\
\hline & non-ophiacanthids & 1331 \\
\hline \multirow[t]{2}{*}{ Hohensaaten } & Ophiomalleus beneficarum sp. nov. & 12 \\
\hline & non-ophiacanthids & 435 \\
\hline \multirow[t]{2}{*}{ Liesberg } & Dermocoma wrighti Hess, 1964 & \\
\hline & non-ophiacanthids & 2492 \\
\hline \multirow[t]{4}{*}{ Jumara (24) } & Ophiolimna malagasica sp. nov. & 8 \\
\hline & Krohcoma sp. nov. innom. & 3 \\
\hline & Dermocoma sp. 1 & 1 \\
\hline & non-ophiacanthids & 111 \\
\hline \multirow[t]{2}{*}{ Jumara (15) } & Ophiolimna malagasica sp. nov & 13 \\
\hline & non-ophiacanthids & 86 \\
\hline \multirow[t]{5}{*}{ Jumara (89) } & Ophiolimna malagasica sp. nov. & 9 \\
\hline & Ophiomitrella? sp. 2 & 1 \\
\hline & Ophiacanthidae gen. et sp. $3 *$ & 4 \\
\hline & Ophiacanthidae gen. et sp. $2 *$ & 5 \\
\hline & non-ophiacanthids & 196 \\
\hline \multirow[t]{5}{*}{ La Pouza } & Lapidaster sp.* & 3 \\
\hline & Ophiogaleus stans sp. nov. & 6 \\
\hline & Hanshessia sp. nov. innom. 2 & 5 \\
\hline & Dermocoma sp. 3* & 3 \\
\hline & non-ophiacanthids & 95 \\
\hline \multirow[t]{2}{*}{ Delkhofen } & Dermocoma wrighti Hess, 1964 & 8 \\
\hline & non-ophiacanthids & 242 \\
\hline Cirey-les-Nolay & Alternacantha occulta Thuy \& Meyer, 2013 & 23 \\
\hline
\end{tabular}


European Journal of Taxonomy 48: 1-242 (2013)

\begin{tabular}{|c|c|c|}
\hline & Dermocoma longwyensis sp. nov. & 29 \\
\hline & Dermocoma wrighti Hess, 1964 & 133 \\
\hline & non-ophiacanthids & 22 \\
\hline \multirow[t]{3}{*}{ Longwy } & Alternacantha occulta Thuy \& Meyer, 2013 & 50 \\
\hline & Dermocoma longwyensis sp. nov. & 94 \\
\hline & non-ophiacanthids & 266 \\
\hline \multirow[t]{3}{*}{ Seewen (Toarc.) } & Lapidaster sp. nov. innom. 1 & 1 \\
\hline & Dermocoma toarcensis comb. nov. & 163 \\
\hline & non-ophiacanthids & 258 \\
\hline \multirow[t]{4}{*}{ Le Clapier 1} & Lapidaster fasciatus comb. nov. & 16 \\
\hline & Alternacantha sp. nov. innom. 1 & 1 \\
\hline & Ishidacantha hirokoae sp. nov. & 21 \\
\hline & non-ophiacanthids & 420 \\
\hline \multirow{3}{*}{ Le Clapier 2} & Lapidaster fasciatus comb. nov. & 8 \\
\hline & Ishidacantha hirokoae sp. nov. & 11 \\
\hline & non-ophiacanthids & 126 \\
\hline \multirow[t]{3}{*}{ Aix-sur-Cloie } & Dermocoma sp. 2* & 12 \\
\hline & Inexpectacantha acrobatica Thuy, 2011 & 71 \\
\hline & non-ophiacanthids & 132 \\
\hline \multirow[t]{5}{*}{ Seewen (Pliensb.) } & Ophiotoma vadosa sp. nov. & 175 \\
\hline & Ophiogaleus dorecki comb. nov. & 37 \\
\hline & Dermocoma toarcensis comb. nov. & 17 \\
\hline & Inexpectacantha lunaris comb. nov. & 17 \\
\hline & non-ophiacanthids & 1069 \\
\hline \multirow[t]{3}{*}{ Amellago } & Alternacantha? sp. & 3 \\
\hline & Ophiacanthidae gen. et sp. $4^{*}$ & 2 \\
\hline & non-ophiacanthids & 119 \\
\hline \multirow[t]{2}{*}{ Feuguerolles } & Dermocoma potti sp. nov. & 66 \\
\hline & non-ophiacanthids & 124 \\
\hline \multirow[t]{5}{*}{ Blockley } & Lapidaster hystricarboris comb. nov. & 44 \\
\hline & Ophiotoma vadosa comb. nov. & 23 \\
\hline & Dermacantha leonorae comb. nov. & 10 \\
\hline & Inexpectacantha acrobatica Thuy, 2011 & 2 \\
\hline & non-ophiacanthids & 561 \\
\hline \multirow[t]{2}{*}{ Sedan } & Inexpectacantha acrobatica Thuy, 2011 & 210 \\
\hline & non-ophiacanthids & 683 \\
\hline \multirow[t]{2}{*}{ Sedan } & Inexpectacantha acrobatica Thuy, 2011 & 78 (art) \\
\hline & non-ophiacanthids & 210 (art) \\
\hline \multirow[t]{3}{*}{ Bishop's Cleeve } & Dermacantha seeweni comb. nov. & 9 \\
\hline & Inexpectacantha lunaris comb. nov. & 3 \\
\hline & non-ophiacanthids & 167 \\
\hline \multirow[t]{3}{*}{ Remerschen } & Dermocoma sp. nov. innom. $6^{*}$ & 84 \\
\hline & Inexpectacantha weisi sp. nov. & 28 \\
\hline & non-ophiacanthids & 242 \\
\hline \multirow[t]{4}{*}{ Fontenoille } & Dermocoma faberi sp. nov. & 457 \\
\hline & Dermacantha pattyana sp. nov. & 298 \\
\hline & Inexpectacantha weisi $\mathrm{sp}$. nov. & 84 \\
\hline & non-ophiacanthids & 1616 \\
\hline \multirow[t]{3}{*}{ Vance (Van1) } & Dermocoma faberi sp. nov. & 392 \\
\hline & Inexpectacantha ritae $\mathrm{sp}$. nov. & 16 \\
\hline & non-ophiacanthids & 732 \\
\hline \multirow[t]{3}{*}{ Vance (Van2) } & Dermocoma faberi sp. nov. & 239 \\
\hline & Inexpectacantha ritae sp. nov. & 25 \\
\hline & non-ophiacanthids & 519 \\
\hline \multirow[t]{3}{*}{ Fischerwiese } & Dermocoma subtilirugosa comb. nov. & 5 \\
\hline & Dermocoma sp. nov. innom. 1 & 1 \\
\hline & non-ophiacanthids & 232 \\
\hline
\end{tabular}


THUY B., Fossil record of ophiacanthid brittle stars

\begin{tabular}{|l|l|c|}
\hline Jushui (C30) & Eolaxoporus hagdorni sp. nov. & 38 \\
\hline & non-ophiacanthids & 1689 \\
\hline Jushui (C36) & Eolaxoporus hagdorni sp. nov. & 11 \\
\hline & non-ophiacanthids & 316 \\
\hline Jushui (C33) & Eolaxoporus hagdorni sp. nov. & 1 \\
\hline & non-ophiacanthids & 340 \\
\hline Alpe di Specie & non-ophiacanthids & 249 \\
\hline Romerlo & non-ophiacanthids & 120 \\
\hline Milieres & Eolaxoporus sp. nov. innom. & 1 \\
\hline & non-ophiacanthids & 284 \\
\hline Oberscheffach & Eolaxoporus sp. & 1 \\
\hline & non-ophiacanthids & 245 \\
\hline Schillingstadt & non-ophiacanthids & 278 \\
\hline Górazdze & non-ophiacanthids & 253 \\
\hline Strzelce Opolski & non-ophiacanthids & 282 \\
\hline Felsöörs & Europacantha paciphila sp. nov. & 8 \\
\hline & non-ophiacanthids & 509 \\
\hline Recoaro & non-ophiacanthids & 296 \\
\hline Sóly & non-ophiacanthids & 292 \\
\hline Kitakami Mountains & non-ophiacanthids & 383 \\
\hline
\end{tabular}

\begin{tabular}{|c|c|c|}
\hline \multicolumn{3}{|c|}{ DEEP-SEE ASSEMBLAGES } \\
\hline Locality & Taxon & LAP count \\
\hline \multirow[t]{3}{*}{ Bad Freienwalde } & Ophiacantha steffenschneideri sp. nov. & 713 \\
\hline & Ophiacanthidae gen. et sp. $5^{*}$ & 1 \\
\hline & non-ophiacanthids & 385 \\
\hline Fakse & Ophiotreta dendrophyllicola sp. nov. & 177 \\
\hline \multirow[t]{9}{*}{ Blake Nose } & Ophiologimus martynovi sp. nov. & 48 \\
\hline & Ophiologimus aiodipius sp. nov. & 36 \\
\hline & Ophiotoma incredibilis sp. nov. & 29 \\
\hline & Ophiolimna kucerai sp. nov. & 756 \\
\hline & Ophiacantha sp. nov. innom. 1 & 2 \\
\hline & Ophiacantha sp. nov. innom 2 & 1 \\
\hline & Ophiotreta sp. nov. innom. $3^{*}$ & 4 \\
\hline & Ophiacanthidae gen. et sp. $6^{*}$ & 103 \\
\hline & non-ophiacanthids & 1051 \\
\hline \multirow[t]{2}{*}{ Carniol } & Lapidaster coreytaylori sp. nov. & 54 \\
\hline & non-ophiacanthids & 7 \\
\hline \multirow[t]{4}{*}{ Ternberg } & Lapidaster lukenederi sp. nov. & 91 \\
\hline & Geromura teckliformis sp. nov. & 126 \\
\hline & Dermocoma sp. nov. innom. 3 & 27 \\
\hline & non-ophiacanthids & 36 \\
\hline \multirow[t]{4}{*}{ Touert } & Lapidaster wolfii & 3 \\
\hline & Geromura touertensis sp. nov. & 3 \\
\hline & Dermacantha sp. nov. innom. & 15 \\
\hline & non-ophiacanthids & 31 \\
\hline \multirow[t]{11}{*}{ Glasenbach Gorge } & Eolaxoporus imminens sp. nov. & 9 \\
\hline & Lapidaster caeloscopus sp. nov. & 14 \\
\hline & Ophiotoma sp. nov. innom. & 1 \\
\hline & Ophiolimna tiamatia sp. nov. & 56 \\
\hline & Krohcoma mira sp. nov. & 13 \\
\hline & Ophiogaleus sp. nov. innom. 1 & 15 \\
\hline & Hanshessia sp. nov. innom 1 & 6 \\
\hline & Ophioleviathan watsoni sp. nov. & 25 \\
\hline & Reitneracantha dissidens sp. nov. & 6 \\
\hline & Ophiacanthidae gen. et sp. $7^{*}$ & 69 \\
\hline & non-ophiacanthids & 263 \\
\hline
\end{tabular}


Appendix 2. Matrix for phylogenetic analysis

\begin{tabular}{|c|c|c|c|c|c|c|c|c|c|c|c|c|c|c|c|c|c|c|c|c|c|c|c|c|c|c|c|}
\hline & ఏ & 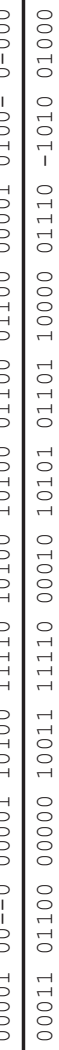 & $\begin{array}{l}7 \\
0 \\
1 \\
0 \\
0 \\
0 \\
0 \\
0 \\
0 \\
0 \\
-1 \\
0 \\
0 \\
0 \\
0 \\
0 \\
0 \\
0 \\
0 \\
0 \\
0 \\
0 \\
0 \\
0 \\
0 \\
0 \\
0 \\
0 \\
0 \\
0 \\
0 \\
0 \\
0 \\
0 \\
0 \\
0 \\
0 \\
0 \\
0\end{array}$ & 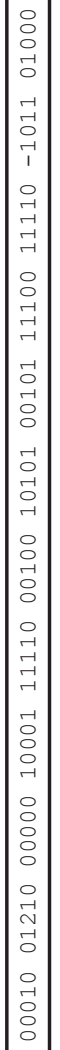 & $\begin{array}{l}\overrightarrow{0} \\
\text { ने } \\
0\end{array}$ & 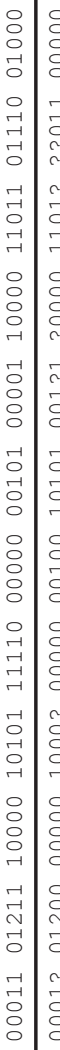 & 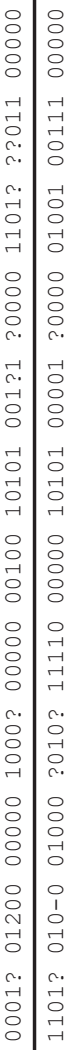 & 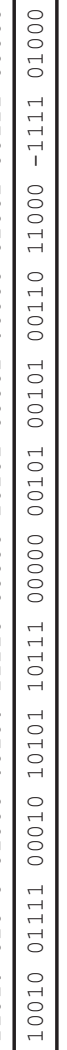 & 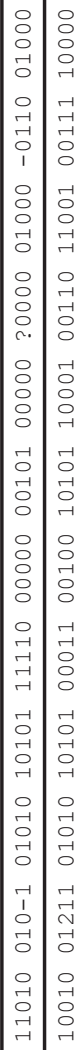 & 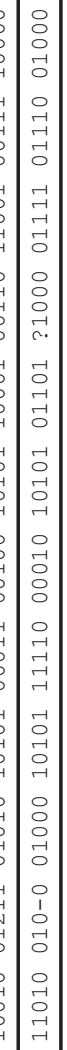 & 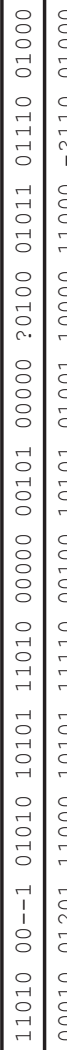 & 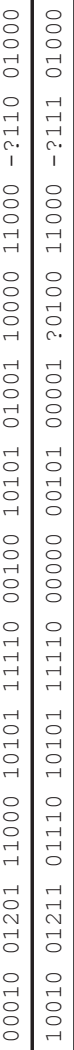 & 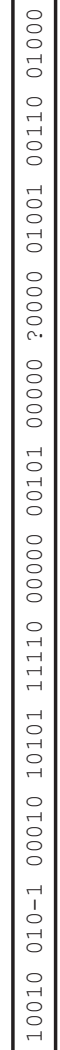 & 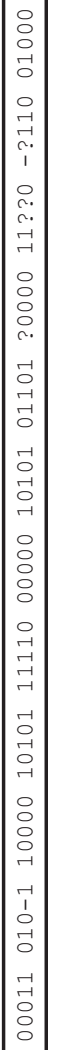 & 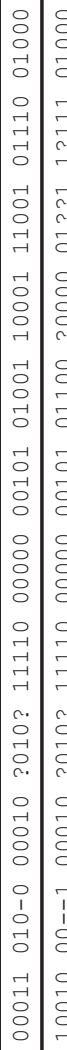 & 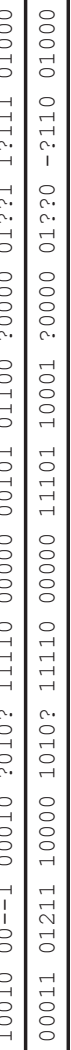 & 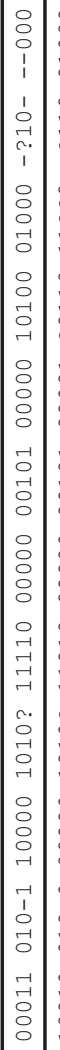 & 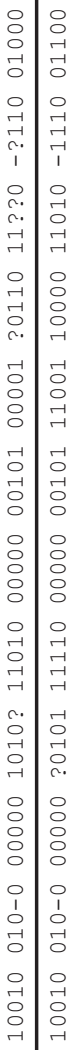 & 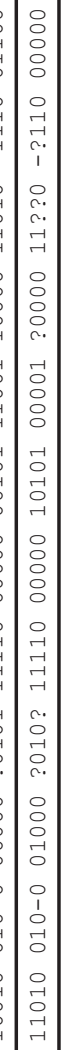 & 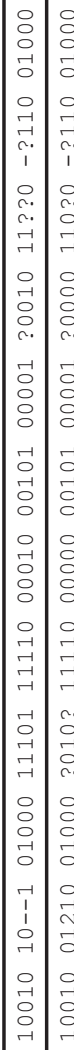 & 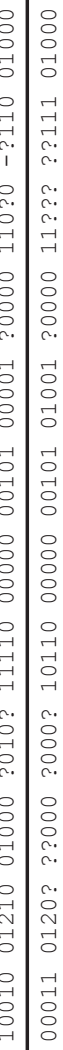 & 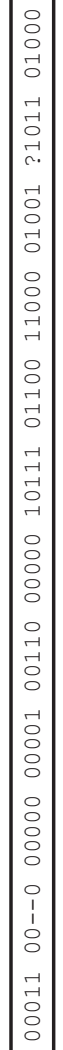 & 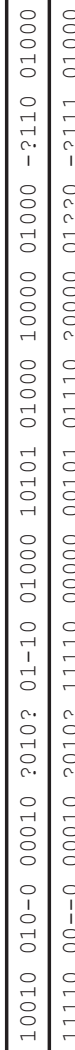 & 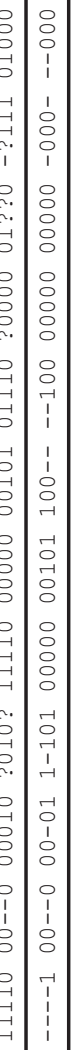 & 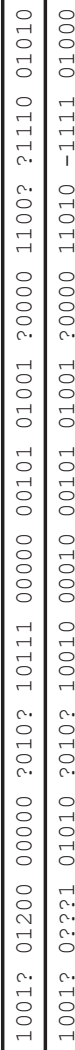 & 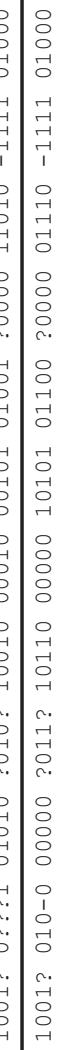 & \\
\hline & & & & 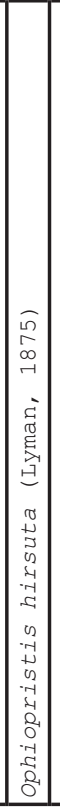 & & 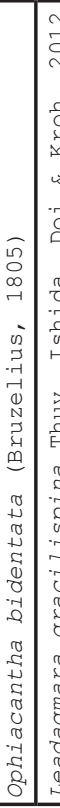 & 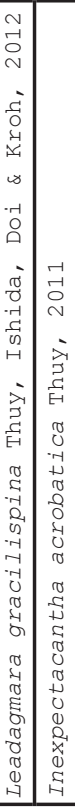 & 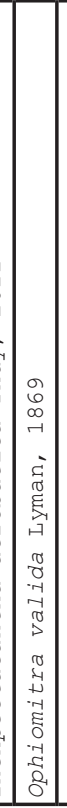 & $\begin{array}{l}4 \\
4 \\
0 \\
0 \\
0 \\
0\end{array}$ & $\frac{\pi}{2}$ & 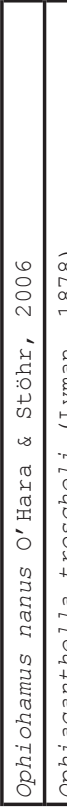 & 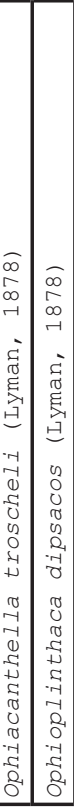 & 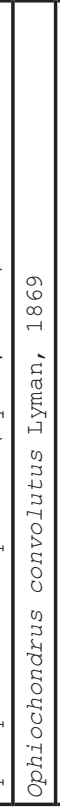 & 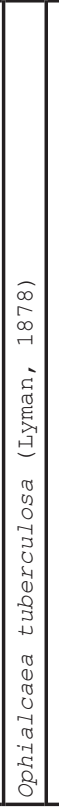 & 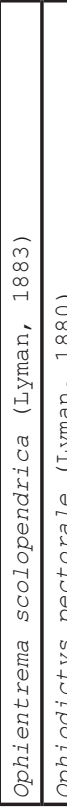 & 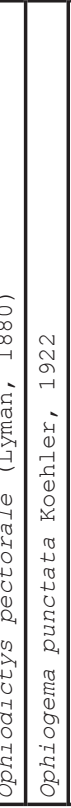 & $\left.\right|_{\substack{\infty \\
\sim}}$ & 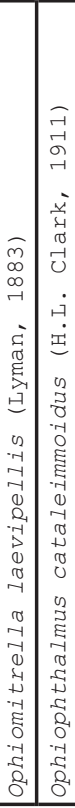 & 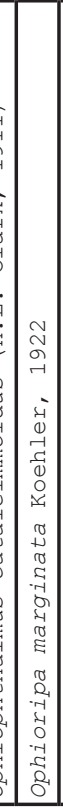 & 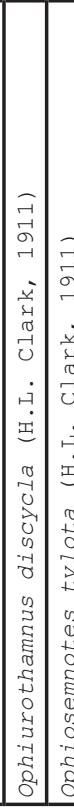 & 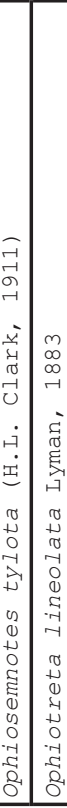 & 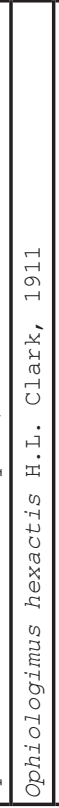 & 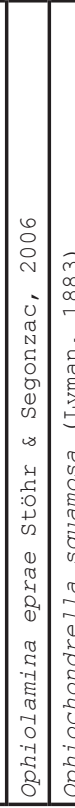 & $\begin{array}{l}\widehat{c} \\
0 \\
0\end{array}$ & 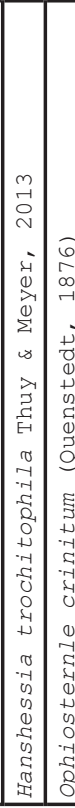 & I & \\
\hline
\end{tabular}

